Journal of

Composites Science

Multifunctional

Composites

Printed Edition of the Special Issue Published in Journal of Composites Science 
Multifunctional Composites 



\section{Multifunctional Composites}

Editor

Phuong Nguyen-Tri

MDPI • Basel • Beijing • Wuhan • Barcelona $\bullet$ Belgrade $\bullet$ Manchester $\bullet$ Tokyo $\bullet$ Cluj $\bullet$ Tianjin

\section{MDPI}


Editor

Phuong Nguyen-Tri

University of Quebec in

Trois-Rivieres (UQTR)

Canada

Editorial Office

MDPI

St. Alban-Anlage 66

4052 Basel, Switzerland

This is a reprint of articles from the Special Issue published online in the open access journal Journal of Composites Science (ISSN 2504-477X) (available at: https://www.mdpi.com/journal/jcs/ special_issues/multifunctional_composites).

For citation purposes, cite each article independently as indicated on the article page online and as indicated below:

LastName, A.A.; LastName, B.B.; LastName, C.C. Article Title. Journal Name Year, Volume Number, Page Range.

ISBN 978-3-0365-0492-6 (Hbk)

ISBN 978-3-0365-0493-3 (PDF)

(C) 2021 by the authors. Articles in this book are Open Access and distributed under the Creative Commons Attribution (CC BY) license, which allows users to download, copy and build upon published articles, as long as the author and publisher are properly credited, which ensures maximum dissemination and a wider impact of our publications.

The book as a whole is distributed by MDPI under the terms and conditions of the Creative Commons license CC BY-NC-ND. 


\section{Contents}

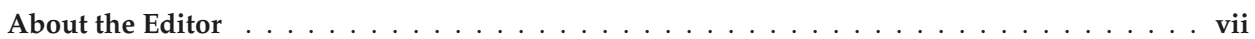

\section{Phuong Nguyen-Tri}

Editorial for the Special Issue: Multifunctional Composites in the Journal of Composites Science Reprinted from: J. Compos. Sci. 2021, 5, 15, doi:10.3390/jcs5010015 . . . . . . . . . . . . . . . 1

Alena Smirnova, Georgii Konoplev, Nikolay Mukhin, Oksana Stepanova and Ulrike Steinmann

Milk as a Complex Multiphase Polydisperse System: Approaches for the Quantitative and Qualitative Analysis

Reprinted from: J. Compos. Sci. 2020, 4, 151, doi:10.3390/jcs4040151 . . . . . . . . . . . . . .

\section{Dung Nguyen Trong, Van Cao Long and Ştefan Ţălu}

The Structure and Crystallizing Process of NiAu Alloy: A Molecular Dynamics

Simulation Method

Reprinted from: J. Compos. Sci. 2021, 5, 18, doi:10.3390/jcs5010018 . . . . . . . . . . . . . . . 35

Ghaidaa Alharaty and Hosahalli S. Ramaswamy

The Effect of Sodium Alginate-Calcium Chloride Coating on the Quality Parameters and Shelf Life of Strawberry Cut Fruits

Reprinted from: J. Compos. Sci. 2020, 4, 123, doi:10.3390/jcs4030123 . . . . . . . . . . . . . .

Dexu Kong and Lee D. Wilson

Uptake of Methylene Blue from Aqueous Solution by Pectin-Chitosan Binary Composites

Reprinted from: J. Compos. Sci. 2020, 4, 95, doi:10.3390/jcs4030095 . . . . . . . . . . . . . . . 65

Arash Afshar and Roy Wood

Development of Weather-Resistant 3D Printed Structures by Multi-Material

Additive Manufacturing

Reprinted from: J. Compos. Sci. 2020, 4, 94, doi:10.3390/jcs4030094 _ . . . . . . . . . . . . . . 77

Imran Abbas, Yanxiang Wang, Hassan Elahi, Muhammad Ali Siddiqui, Mudaser Ullah and Faisal Qayyum

Effect of $\mathrm{MoSi}_{2}-\mathrm{Si}_{3} \mathrm{~N}_{4} / \mathrm{SiC}$ Multi-Layer Coating on the Oxidation Resistance of Carbon/Carbon Composites above $1770 \mathrm{~K}$

Reprinted from: J. Compos. Sci. 2020, 4, 86, doi:10.3390/jcs4030086 . . . . . . . . . . . . . . 8

Van Khoi Nguyen, Thanh Tung Nguyen, Thu Ha Pham Thi and Thu Trang Pham

Effects of Pulp Fiber and Epoxidized Tung Oil Content on the Properties of Biocomposites Based on Polylactic Acid

Reprinted from: J. Compos. Sci. 2020, 4, 56, doi:10.3390/jcs4020056 .

Thien Vuong Nguyen, Tuan Anh Nguyen and Thi Hau Nguyen

The Synergistic Effects of $\mathrm{Sio}_{2}$ Nanoparticles and Organic Photostabilizers for Enhanced Weathering Resistance of Acrylic Polyurethane Coating

Reprinted from: J. Compos. Sci. 2020, 4, 23, doi:10.3390/jcs4010023 . . . . . . . . . . . . . . . 113

Mahmoud Moradi, Mojtaba Karami Moghadam, Mahmoud Shamsborhan and

Mahdi Bodaghi

The Synergic Effects of FDM 3D Printing Parameters on Mechanical Behaviors of Bronze Poly Lactic Acid Composites

Reprinted from: J. Compos. Sci. 2020, 4, 17, doi:10.3390/jcs4010017 . . . . . . . . . . . . . . . 125 
Vu Van Tham, Tran Huu Quoc and Tran Minh Tu

Free Vibration Analysis of Laminated Functionally Graded Carbon Nanotube-Reinforced Composite Doubly Curved Shallow Shell Panels Using a New Four-Variable Refined Theory

Reprinted from: J. Compos. Sci. 2019, 3, 104, doi:10.3390/jcs3040104 . . . . . . . . . . . . . . . . . 141

Yohannes Teklemariam Gaim, Gebrekidan Mebrahtu Tesfamariam,

Gebretinsae Yeabyo Nigussie and Mengstu Etay Ashebir

Synthesis, Characterization and Photocatalytic Activity of $\mathrm{N}$-doped $\mathrm{Cu}_{2} \mathrm{O} / \mathrm{ZnO}$

Nanocomposite on Degradation of Methyl Red

Reprinted from: J. Compos. Sci. 2019, 3,93, doi:10.3390/jcs3040093 . . . . . . . . . . . . . . . . . 163

Abdullah Al Mamun Sakib, Shah Md. Masum, Jan Hoinkis, Rafiqul Islam and

Md. Ashraful Islam Molla

Synthesis of $\mathrm{CuO} / \mathrm{ZnO}$ Nanocomposites and Their Application in Photodegradation of Toxic

Textile Dye

Reprinted from: J. Compos. Sci. 2019, 3, 91, doi:10.3390/jcs3030091 . . . . . . . . . . . . . . . . . 177 


\section{About the Editor}

Phuong Nguyen-Tri is Professor at the Department of Chemistry, Biochemistry and Physics, Université du Québec à Trois-Rivières in Trois-Rivières, Quebec, Canada. He is the founder of the Laboratory of Advanced Materials for Energy and Environment at the Université du Québec à Trois-Rivières. He holds an M.Sc. degree from École Nationale Supérieure de Chimie de Mulhouse, France, and a Ph.D. degree in Material Sciences from the Conservatoire National des Arts et Métiers in Paris, France in 2009. His main research interests are in nanomaterials, hybrid nanoparticles, smart coatings, polymer crystallization, and polymer blends and composites. Dr. Nguyen-Tri has edited 14 books (including 10 books by Elsevier). He has served as Editor of several issues of ISI-indexed journals. Dr. Nguyen-Tri is Topic Editor of Polymers, Editor of AIMS Materials Science, Editorial Board Member for journals including RSEM, Journal of Composites Science, PLOS One (PLOS), Frontiers in Chemical Engineering, Nanostructures and Nano-Objects (Elsevier), and SN Applied Science (Nature-Springer). He is Guest Editor for various journals including Progress in Organic Coatings (Elsevier), Environmental Science and Pollution Research (Nature-Springer), and Energy Sources, Part A (Taylor \& Francis). 



\title{
Editorial \\ Editorial for the Special Issue: Multifunctional Composites in the Journal of Composites Science
}

\author{
Phuong Nguyen-Tri
}

check for

updates

Citation: Nguyen-Tri, P. Editorial for the Special Issue: Multifunctional Composites in the Journal of Composites Science. J. Compos. Sci. 2021, 5, 15. https://doi.org/ $10.3390 /$ jcs5010015

Received: 4 January 2021

Accepted: 6 January 2021

Published: 7 January 2021

Publisher's Note: MDPI stays neutral with regard to jurisdictional clai$\mathrm{ms}$ in published maps and institutional affiliations.

Copyright: ( 2021 by the author. Licensee MDPI, Basel, Switzerland. This article is an open access article distributed under the terms and conditions of the Creative Commons Attribution (CC BY) license (https:// creativecommons.org/licenses/by/ $4.0 /)$.
Department of Chemistry, Biochemistry and Physics, Université du Québec à Trois-Rivieres, Local 3170, CIPP, 3351, boul. des Forges, C.P. 500, Trois-Rivières, QC G9A 5H7, Canada; Phuong.Nguyen-Tri@uqtr.ca

With the progress in nanotechnology and production methods, composite materials are becoming lighter, cheaper, more durable, and more versatile. At present, great progress has been made in the design, preparation, and characterization of composite materials, making them smarter and more versatile [1-3]. By creating new properties using suitable fillers and matrixes [3-5], the functional composites can meet the most difficult demands of users, especially in high-tech industries. Advanced composites reinforced by highperformance carbon fibers and nanofillers are popular in the automotive and aerospace industries thanks to their significant advantages, such as high specific strength to weight ratio and non-corrosion properties. In addition to the improvement of the mechanical performance, composite materials today are designed to provide new functions dealing with antibacterial, self-cleaning, self-healing, super-hard, and solar reflective activities for desired end-use applications [6-9]. On the other hand, composite materials can contribute to reducing environmental issues by providing renewable energy technologies in conjunction with multifunctional, lightweight energy storage systems with high performance and noncorrosive properties. They are also used to prepare a new generation of batteries and directly contribute to $\mathrm{H}_{2}$ production or $\mathrm{CO}_{2}$ reduction in fuels and chemicals.

In this Special Issue, we have collected a total of 12 excellent articles reporting on recent developments dealing with preparative methods, design, properties, structure, and characterization methods, as well as promising applications of multifunctional composites from internationally recognized researchers worldwide. These papers come from a total of 44 authors from 14 different countries, including the USA (2), the UK (1), Canada (4), Germany (4), China (3), Italy (1), Pakistan (1), Vietnam (11), Iran (3), Ethiopia (4), Bangladesh (4), Russia (4), Romania (1) and Poland (2). These articles cover potential applications in various areas, such as anticorrosion, photocatalyst, absorbers, superhydrophobic, selfcleaning, antifouling/antibacterial, renewable energy, energy storage systems, construction, electronics, and modeling and simulating processes involving the design and preparation of functional and multifunctional composites.

Various multifunctional materials based on biodegradable polymers are reported in this collection. Kong D. et al. reported on the preparation of composites that contain chitosan and pectin biopolymers with tunable adsorption properties. Binary biopolymer composites were prepared at variable pectin-chitosan composition in a solvent directed synthesis, dimethyl sulfoxide (DMSO) versus water [10], while Nguyen et al. published an article on the preparation of biodegradable composites based on polylactide acid reinforced by pulp fiber (PF) and epoxidized tung-oil (ETO). The effect of these components on mechanical properties are deeply discussed [11]. In another article, the influence of layer thickness (LT), infill percentage (IP), and extruder temperature (ET) on the maximum failure load, thickness, and build time of bronze polylactic acid (Br-PLA) composites 3Dprinted by the fused deposition modeling (FDM) was investigated via an optimization method [12].

Some articles reported on the recent developments in smart coatings in terms of their mechanical properties, while the oxidative and weather resistance of come smart composite 
coatings are also reported [13-16]. Regarding the applications of multifunctional composites to the environmental field, $\mathrm{N}$-doped $\mathrm{Cu}_{2} \mathrm{O} / \mathrm{ZnO}$ nanocomposite on the degradation of methyl red is reported by Raim et al. [17], while the phototodegradation of $\mathrm{CuO} / \mathrm{ZnO}$ to textile dyes is also investigated [18]. Computer simulation has also been used to predict the behavior of composite materials at the nanoscale [19]. A critical review on the complex multiphase polydisperse system is also reported in this collection [20].

The guest editor would like to thank the Editor in chief of the Journal of composites Science for accepting his proposal related to this Special Issue. Many thanks to the assistant editors for their kind help during the review process and for all steps relating to the production of the selected articles. I hope the high-quality articles published in this SI may provide helpful information to students, engineers, and researchers working on multifunctional composites.

\section{References}

1. Nguyen-Tri, P.; Tran, H.N.; Plamondon, C.O.; Tuduri, L.; Vo, D.-V.N.; Nanda, S.; Mishra, A.; Chao, H.-P.; Bajpai, A.K. Recent progress in the preparation, properties and applications of superhydrophobic nano-based coatings and surfaces: A review. Progr. Organ. Coat. 2019, 132, 235-256. [CrossRef]

2. Nguyen-Tri, P.; Nguyen, T.A.; Carriere, P.; Ngo Xuan, C. Nanocomposite Coatings: Preparation, Characterization, Properties, and Applications. Int. J. Corros. 2018, 2018, 4749501. [CrossRef]

3. Nguyen-Tri, P.; Sollogoub, C.; Guinault, A. Relationship between fiber chemical treatment and properties of recycled pp/bamboo fiber composites. J. Reinf. Plast. Compos. 2010, 29, 3244-3256. [CrossRef]

4. Tri, P.N.; Domenek, S.; Guinault, A.; Sollogoub, C. Crystallization behavior of poly(lactide)/poly( $\beta$-hydroxybutyrate)/talc composites. J. Appl. Polym. Sci. 2013, 129, 3355-3365. [CrossRef]

5. Azizi, S.; David, E.; Fréchette, M.F.; Nguyen-Tri, P.; Ouellet-Plamondon, C.M. Electrical and thermal phenomena in low-density polyethylene/carbon black composites near the percolation threshold. J. Appl. Polym. Sci. 2019, 136, 47043. [CrossRef]

6. Nguyen-Tri, P.; Altiparmak, F.; Nguyen, N.; Tuduri, L.; Ouellet-Plamondon, C.M.; Prud'homme, R.E. Robust Superhydrophobic Cotton Fibers Prepared by Simple Dip-Coating Approach Using Chemical and Plasma-Etching Pretreatments. ACS Omeg. 2019, 4, 7829-7837. [CrossRef]

7. Tri, P.N.; Prud'homme, R.E. Nanoscale Lamellar Assembly and Segregation Mechanism of Poly(3-hydroxybutyrate)/Poly(ethylene glycol) Blends. Macromolecules 2018, 51, 181-188. [CrossRef]

8. Nguyen-Tri, P.; Gilbert, V. Non-isothermal Crystallization Kinetics of Short Bamboo Fiber-reinforced Recycled Polypropylene Composites. J. Reinf. Plast. Compos. 2010, 29, 2576-2591. [CrossRef]

9. Azizi, S.; Ouellet-Plamondon, C.M.; Nguyen-Tri, P.; Fréchette, M.; David, E. Electrical, thermal and rheological properties of low-density polyethylene/ethylene vinyl acetate/graphene-like composite. Compos. Part B Eng. 2019, 177, 107288. [CrossRef]

10. Kong, D.; Wilson, L.D. Uptake of Methylene Blue from Aqueous Solution by Pectin-Chitosan Binary Composites. J. Compos. Sci. 2020, 4, 95. [CrossRef]

11. Nguyen, V.K.; Nguyen, T.T.; Pham Thi, T.H.; Pham, T.T. Effects of Pulp Fiber and Epoxidized Tung Oil Content on the Properties of Biocomposites Based on Polylactic Acid. J. Compos. Sci. 2020, 4, 56. [CrossRef]

12. Moradi, M.; Karami Moghadam, M.; Shamsborhan, M.; Bodaghi, M. The Synergic Effects of FDM 3D Printing Parameters on Mechanical Behaviors of Bronze Poly Lactic Acid Composites. J. Compos. Sci. 2020, 4, 17. [CrossRef]

13. Nguyen, T.V.; Nguyen, T.A.; Nguyen, T.H. The Synergistic Effects of Sio2 Nanoparticles and Organic Photostabilizers for Enhanced Weathering Resistance of Acrylic Polyurethane Coating. J. Compos. Sci. 2020, 4, 23. [CrossRef]

14. Alharaty, G.; Ramaswamy, H.S. The Effect of Sodium Alginate-Calcium Chloride Coating on the Quality Parameters and Shelf Life of Strawberry Cut Fruits. J. Compos. Sci. 2020, 4, 123. [CrossRef]

15. Abbas, I.; Wang, Y.; Elahi, H.; Siddiqui, M.A.; Ullah, M.; Qayyum, F. Effect of $\mathrm{MoSi}_{2}-\mathrm{Si}_{3} \mathrm{~N}_{4} / \mathrm{SiC}$ Multi-Layer Coating on the Oxidation Resistance of Carbon/Carbon Composites above 1770 K. J. Compos. Sci. 2020, 4, 86. [CrossRef]

16. Afshar, A.; Wood, R. Development of Weather-Resistant 3D Printed Structures by Multi-Material Additive Manufacturing. J. Compos. Sci. 2020, 4, 94. [CrossRef]

17. Gaim, Y.T.; Tesfamariam, G.M.; Nigussie, G.Y.; Ashebir, M.E. Synthesis, Characterization and Photocatalytic Activity of N-doped Cu2O/ZnO Nanocomposite on Degradation of Methyl Red. J. Compos. Sci. 2019, 3, 93. [CrossRef]

18. Sakib, A.A.M.; Masum, S.M.; Hoinkis, J.; Islam, R.; Molla, M.A.I. Synthesis of CuO/ZnO Nanocomposites and Their Application in Photodegradation of Toxic Textile Dye. J. Compos. Sci. 2019, 3, 91. [CrossRef]

19. Van Tham, V.; Huu Quoc, T.; Minh Tu, T. Free Vibration Analysis of Laminated Functionally Graded Carbon Nanotube-Reinforced Composite Doubly Curved Shallow Shell Panels Using a New Four-Variable Refined Theory. J. Compos. Sci. 2019, 3, 104. [CrossRef]

20. Smirnova, A.; Konoplev, G.; Mukhin, N.; Stepanova, O.; Steinmann, U. Milk as a Complex Multiphase Polydisperse System: Approaches for the Quantitative and Qualitative Analysis. J. Compos. Sci. 2020, 4, 151. [CrossRef] 


\title{
Milk as a Complex Multiphase Polydisperse System: Approaches for the Quantitative and Qualitative Analysis
}

\author{
Alena Smirnova ${ }^{1,2, *}$, Georgii Konoplev ${ }^{3}$, Nikolay Mukhin ${ }^{3,4, *}$, Oksana Stepanova ${ }^{3}$ and \\ Ulrike Steinmann ${ }^{5}$ \\ 1 State Institution "Ustyuzhenskaya Regional Station of Preventing and Monitoring Animal Diseases", \\ 162800 Vologda Region, Russia \\ 2 Institute of Experimental Medicine of the North-West Branch of the Russian Academy of Medical Sciences, \\ 197376 Saint Petersburg, Russia \\ 3 Department of Photonics, Saint Petersburg Electrotechnical University "LETI", \\ 197376 Saint Petersburg, Russia; gakonoplev@mail.ru (G.K.); oksana_lopatenko@mail.ru (O.S.) \\ 4 Institute for Micro and Sensor Systems, Otto von Guericke University of Magdeburg, \\ 39106 Magdeburg, Germany \\ 5 Institute for Automation Engineering, Otto von Guericke University of Magdeburg, \\ 39106 Magdeburg, Germany; ulrike.steinmann@ovgu.de \\ * Correspondence: alena.smirnova.e93@gmail.com (A.S.); mukhin.nikolay.v@gmail.com or \\ nikolay.mukhin@ovgu.de (N.M.)
}

Received: 10 September 2020; Accepted: 12 October 2020; Published: 15 October 2020

\begin{abstract}
Milk is a product that requires quality control at all stages of production: from the dairy farm, processing at the dairy plant to finished products. Milk is a complex multiphase polydisperse system, whose components not only determine the quality and price of raw milk, but also reflect the physiological state of the herd. Today's production volumes and rates require simple, fast, cost-effective, and accurate analytical methods, and most manufacturers want to move away from methods that use reagents that increase analysis time and move to rapid analysis methods. The review presents methods for the rapid determination of the main components of milk, examines their advantages and disadvantages. Optical spectroscopy is a fast, non-destructive, precise, and reliable tool for determination of the main constituents and common adulterants in milk. While mid-infrared spectroscopy is a well-established off-line laboratory technique for the routine quality control of milk, near-infrared technologies provide relatively low-cost and robust solutions suitable for on-site and in-line applications on milking farms and dairy production facilities. Other techniques, discussed in this review, including Raman spectroscopy, atomic spectroscopy, molecular fluorescence spectroscopy, are also used for milk analysis but much less extensively. Acoustic methods are also suitable for non-destructive on-line analysis of milk. Acoustic characterization can provide information on fat content, particle size distribution of fat and proteins, changes in the biophysical properties of milk over time, the content of specific proteins and pollutants. The basic principles of ultrasonic techniques, including transmission, pulse-echo, interferometer, and microbalance approaches, are briefly described and milk parameters measured with their help, including frequency ranges and measurement accuracy, are given.
\end{abstract}

Keywords: milk composition; multiphase polydisperse system; near-infrared spectroscopy; mid-infrared spectroscopy; Raman spectroscopy; milk optical and acoustical properties; milk spectral analysis; speed of sound; attenuation; ultrasonic techniques 


\section{Introduction}

Milk is one of the most common foods. Dairy products are important dietary sources of calcium because of its high content, high absorption rate, availability, and relatively low cost. They contain more protein, calcium, potassium, magnesium, zinc, and phosphorus per calorie than any other popularly food found in our diet [1]. Regular consumption of milk improves enamel in children, promotes better absorption of vitamins, and prevents dehydration of the body. According to research by the Annals of Internal Medicine, dairy consumption reduces acidity throughout the body. But when using milk, it should be borne in mind that some people may have lactose intolerance and may have problems digesting milk because of the lactose contained in it [2-4]. The dynamics of growth in the production and consumption of dairy products is observed annually [4].

The safety and quality of raw milk is now a key competitive factor in the industry. The main reason for the low quality of milk is the lack of effective organization of technological processes. Optimization of quality control of dairy products remains a pressing issue. Gradually, along with traditional methods of analysis, which take a long time, require chemical reagents and preliminary sample preparation, express analyzers are being introduced more and more. Now the market for equipment for the analysis of milk and dairy products is represented by very diverse new models. Such equipment can perform analysis on several indicators in a short time.

All express analyzers are united by the fact that working with them is not difficult for a non-professional, they do not require additional reagents for operation, they are capable of operating at least $8 \mathrm{~h}$, they can be transported and calibrated according to their samples. But despite all the advantages of modern analyzers, there are issues that have not yet been resolved. The most common and interesting devices for further modernization work on the basis of optical, spectroscopic, and ultrasonic methods of analysis.

Optical spectroscopy is among the most widely used methods for the routine quality control of milk and dairy products since it provides fast, simple, and reliable analytical procedures with minimal sample preparation.

Mid-infrared (MIR) spectroscopy has been successfully used for the quantitative determination of the principal milk constituents (protein, fat, lactose) for decades and became some kind of a gold standard; apart from improving accuracy and reliability, the recent developments in this area were aimed at the detection of milk adulteration, the problem which is extremely acute worldwide. Fourier transform infrared (FTIR) spectrometers with attenuated total reflection (ATR) accessories are largely used for the MIR spectral analysis of milk. While there is an obvious market demand for on-site and in-line applications, the high cost of FTIR spectral equipment and the intrinsic limitations of ATR measurements hamper the implementation of MIR spectroscopy outside off-line, laboratory conditions.

Near-infrared (NIR) spectroscopy provides relatively low-cost and robust solutions suitable for in-line applications on milking farms and dairy production facilities, including devices incorporated in milking robots and industrial processing equipment. Because of the significant advances in chemometrics NIR technologies of milk analysis have now achieved the level of accuracy and reliability only slightly inferior to MIR spectroscopy.

Different aspects of milk spectral analysis are discussed in this section of the review: optical properties of milk in a wide spectral range $(0.2-25 \mu \mathrm{m})$, various analytical techniques, the spectral equipment. The emphasis was made on the methods, which are widely employed for routine milk quality control, namely MIR and NIR molecular absorption spectroscopy (spectrophotometry). Spectroscopic techniques, which are not so extensively used, including ultraviolet (UV) absorption spectroscopy, Raman spectroscopy, atomic spectroscopy, and molecular fluorescent spectroscopy are also briefly described.

The following are acoustic methods that are suitable for non-destructive analysis of milk. This article discusses the acoustic properties of milk and acoustic methods for measuring the speed of sound, attenuation, density. Questions about how the acoustic properties of milk are related to its ingredients are discussed. It is discussed how acoustic characterization can provide information on fat 
content, particle size distribution of fat and proteins, and the kinetics of changes in the biophysical properties of milk over time, the content of specific proteins and pollutants.

The basic principles of ultrasonic measuring techniques, including transmission, pulse-echo, interferometer, and microbalance approaches, are briefly described and examples of milk parameters measured with their help, including frequency ranges and measurement accuracy, are given.

\section{Milk as a Complex Multyphase Polydisperse System: Urgent Tasks}

\subsection{Milk Industry and Actual Problems}

It is known that milk and dairy products belong to the group of products of daily consumption and accompany a person throughout his life; many studies have been done and published on the effect of milk on human health [4-8]. The world market is mainly represented by such types of milk as cow, buffalo, goat, sheep, and camel. The dynamics of the annual increase in milk yield is shown in Figure 1a.

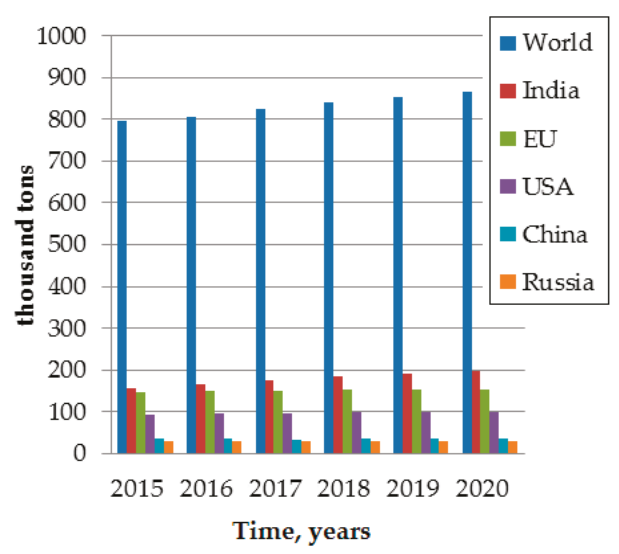

(a)

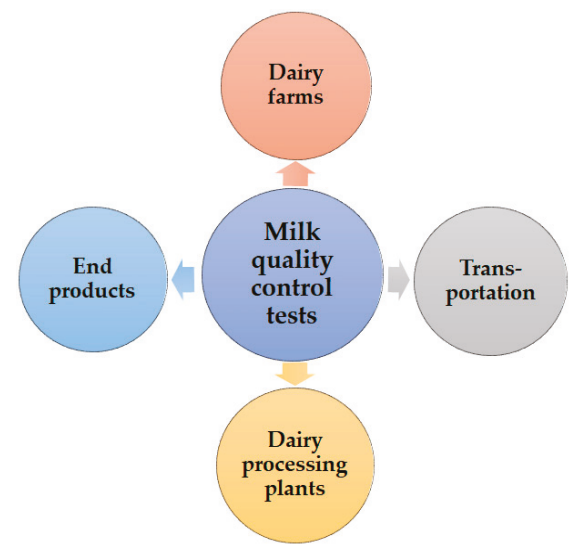

(b)

Figure 1. Production of all types of milk according OECD-FAO Agricultural Outlook [9] (a) and relevance of milk tests $(\mathbf{b})$.

The annual consumption of dairy products in Russia reaches $16 \%$ of all types of food [7]. In the conditions of the current deficiency of animal protein, it is imperative to include dairy products in the diet. According to the Ministry of Health, the rate of consumption of milk and dairy products per person in Russia is $325 \mathrm{~kg}$ per year [7]. However, according to Rosstat reports, Russians receive less than $30 \%$. So in 2018, Russians consumed less than $230 \mathrm{~kg}$ of dairy products, and in 2019-229 kg. In China, according to the «Dietary Guidelines for Chinese Residents», the daily consumption of milk and dairy products should be $300 \mathrm{~g}$ per day or $109.5 \mathrm{~kg}$ per year. But according to IFCN, the average is only $31 \mathrm{~kg}$ per capita per year (or $85 \mathrm{~g}$ per day). The low level of consumption of dairy products is due to cultural and historical features. In India, the recommended rate is the same as in China, $109.5 \mathrm{~kg}$ per year, while the real consumption exceeds the nominal and averages $131 \mathrm{~kg}$ per year. European countries have a high level of consumption of dairy products. The average is $306 \mathrm{~kg}$ per year. According to the recommendations of the German Society for Healthy Nutrition (DGE, Deutsche Gesellschaft für Ernährung), it is recommended to consume 200-250 g of milk and low-fat dairy products daily, 2 slices of low-fat cheese (50-60 g), i.e., about $91-113 \mathrm{~kg}$ of milk per per capita year. According to the «2015-2020 Dietary Guidelines for Americans» [6], developed in the United States and used as a guide in some countries, the recommended level of dairy consumption for children aged 9-18 and adults is about 3 "cup-equivalents," that is about $1137.7 \mathrm{~g}$ per day or $415 \mathrm{~kg}$ per year. 
The real indicator of consumption of milk and dairy products in 2015 in the United States was $269 \mathrm{~kg}$ per capita per year. According to The DairyNews, citing Dairy Repoter, Switzerland also does not consume enough dairy products. Thus, the annual consumption of milk per inhabitant has decreased over 20 years from 79 to $53.3 \mathrm{~kg}$.

In general, an important problem in the world remains the lack of raw milk and the deficit in both total volume and quality. The reasons for this situation are multifaceted-there is a decrease in the total livestock population, production of low-quality products, insufficient breeding work, outdated methods of keeping and feeding animals, outdated and worn out equipment, a shortage of personnel (both highly qualified and working personnel), unpopularity of the profession, low prices for raw milk, low investment attractiveness (the dairy industry is traditionally an industry with a low payback level), long payback periods.

Currently, an urgent problem in dairy farming is to ensure the quality and safety of raw milk as the main raw material for dairy products. Quality management should be considered as a purposeful process of coordinated actions in the system of the dairy complex of the agro-industrial complex to establish, ensure, and maintain the required quality level of marketable products that meets the requirements of customers and processing enterprises. Quality is the fundamental factor that makes up competitiveness. This also applies to agricultural producers, whose products must compete successfully in a free market economy. Competent assessment of raw milk allows to prevent and reduce losses, increase sales income.

Milk has a short shelf life. Its quality directly depends on the fulfillment of conditions at all stages of production: from collection at the farm level, transportation, acceptance, and processing at the dairy. Therefore, sampling and analysis must be carried out throughout the milk processing line. Modern industrial processing based on high-tech processes makes high demands on the quality of milk used as raw material for the production of a wide range of dairy products (Figure 1b).

Some large producers make their requirements for raw materials, which are often quite strict in terms of protein, fat, and somatic cells content, while reducing the purchase prices for milk of a lower grade. The solution to improve the quality and reduce the cost of equipment can be new efficient and inexpensive technologies that would allow assessing the quality of milk produced. The problems faced by the agricultural producer are the ingress of low-quality raw milk into the general flow (milk pipeline, cooling tanker). For example, milk from cows with mastitis (open or closed form), contamination of raw materials with microorganisms from an insufficiently treated udder of a cow, poor-quality disinfection of dairy equipment, etc. In this case, the raw material becomes either unsuitable for further use and processing, or its grade decreases, and as a consequence, the purchase price decreases. Dairies cannot produce a quality product from such raw materials, and farms suffer significant losses.

Another important question is the composition of milk. Its chemical composition not only determines its nutritional and biological value, but also affects the technological processing, yield, and quality of finished products [10,11]. The content of individual components in milk is not constant; it changes depending on the stage of lactation, breed, and health status of animals [12], quality of feed, season, age, individual characteristics, conditions of maintenance, milking technique, etc. [13,14]. During processing and production of products, milk is subjected to mechanical, thermal, and chemical treatments that change its characteristics, which affects the technological processes and properties of the final product $[10,11,15]$. If the raw milk does not meet the necessary requirements, then the final product will be of inadequate quality. Therefore, it is very important that already at the farm level it is possible to determine the composition of milk from each group of cows. This will allow adjusting the ration of the dairy herd and culling the livestock in time.

\subsection{Milk Composition and Main Parameters}

The main indicators that characterize the quality of milk are: chemical composition, degree of purity, organoleptic, biochemical, physical and mechanical properties, as well as the presence of toxic and neutralizing substances in it. 
Milk contains more than a hundred organic (fat, proteins, carbohydrates, enzymes, vitamins, hormones) and inorganic (water, mineral salts, pigments, gases) substances [16]. Milk consists of water and food substances distributed in it-fats, proteins, carbohydrates, enzymes, vitamins, minerals, gases [17] (Figure 2).

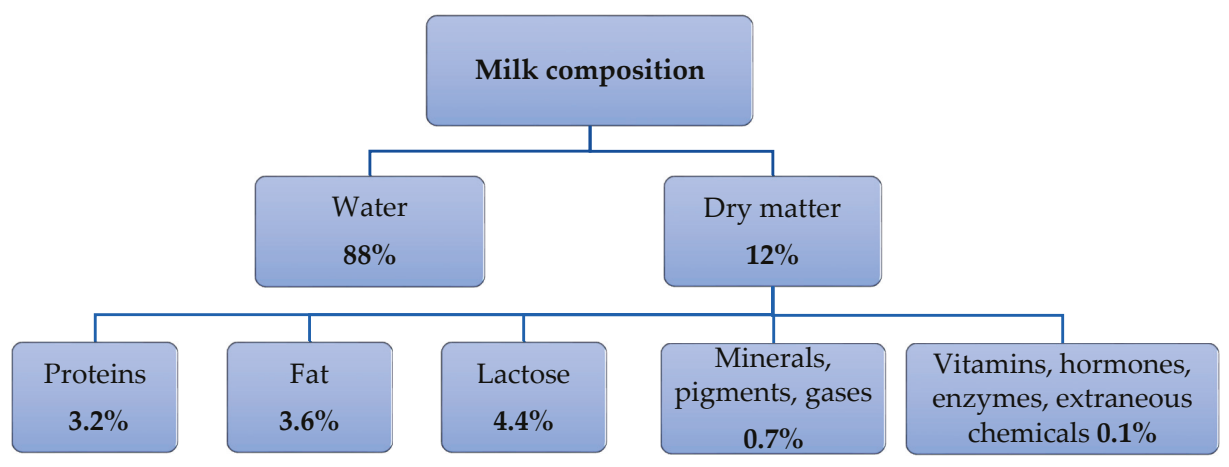

Figure 2. Milk composition.

In terms of physical composition, milk is a complex polydisperse system containing many interconnected structural formations.

These structures include an emulsion dispersed system of fat globules, the structural system is colloidal, it consists of protein particles $0.2-1$ microns in size. The composition of milk also includes a fractional system-true solutions of scattered molecules and atoms.

In milk quality control, samples are checked for acidity, antibiotic content, added water, fat, and protein. These analytical tests and methods are determined by international standards.

\subsubsection{Milk Fat}

Milk fat is the most variable in composition and concentration component of milk [18], its content in cow's milk ranges from 2.8 to $6.3 \%$. Milk sold to the consumer is standardized with a range of different fat content choices. It is a source of energy and essential fatty acids (linoleic, arachidonic), fat-soluble vitamins (A, D, E, K). Until recently, the economic value of milk was based precisely on the fat content of milk.

Milk fat is an ester of a trihydric alcohol of glycerol and fatty acids. Triacylglycerols (triglycerides) represent $97-98 \%$ of the total lipids in the milks. It also contains accompanying fat-like substances, or natural impurities [19]. These include phospholipids (the presence of hydrophilic and hydrophobic parts in their molecules contributes to the formation of emulsions that are stable in water), glycolipids (are biologically active components, preventing the production of enterotoxins in the body by certain types of bacteria), sterols (part of the membranes of fat globules), fat-soluble pigments (karotin, etc., determine the color of milk), fat-soluble vitamins. Despite the insignificant amount of impurities, some of them significantly affect the nutritional value of milk fat [20].

Fat in milk is a dispersed system of fat globules and is an oil-in-water emulsion, the properties of which have a marked effect on many properties of milk, such as color, taste and viscosity. The globules in bovine milk range in diameter a mean of $\sim 3.5 \mu \mathrm{m}$ (from $\sim 0.1$ to $\sim 20 \mu \mathrm{m}$ ). The size distribution of fat globules in milk may be determined by light microscopy, light scattering (Malvern Mastersizer), or electronic counting devices (the Coulter counter) [21,22].

\subsubsection{Milk Proteins}

The content of milk protein is an important component of milk, both a source of good nutrition (contains 18 amino acids, including 9 essential amino acids) and a factor in determining the price of 
milk [23]. The protein in milk ranges from 2.9 to $4 \%$. The proteins in milk can be fractionated into two defined groups: casein and serum protein. The ratio of casein to whey proteins consists is 80:20. Casein is in the form of relatively large colloidal particles-micelles and contains four fractions $(\alpha \mathrm{S} 1, \alpha \mathrm{S} 2$, $\beta$, and $\mathrm{k}$-caseins) and their fragments. Whey proteins are heterogeneous and include globular proteins that differ in structure and properties- $\beta$-lactoglobulin, $\alpha$-lactoglobulin, immunoglobulins, lactoferrin, and serum albumin. The third group can be distinguished, these include proteins of the shells of fat globules, which make up only about $1 \%$ of all milk proteins. The milk proteins contain the nine essential amino acids required by humans, making it an important human food $[24,25]$.

\subsubsection{Lactose}

Lactose (milk sugar) is a ready source of energy, participates in the formation of the nervous system, skin, bone, and cartilage tissue in childhood and prevent bone loss in the elderly [26].

The lactose content in milk of cows is 3.6-5.6 (4.7\% on average). Lactose is a disaccharide built from D-glucose and D-galactose residues linked by a 1.4-glycosidic bond. Lactose is 5-6 times less sweet than sucrose and less soluble in water. In milk, milk sugar is in two forms: $\alpha$ and $\beta$. At $20^{\circ} \mathrm{C}$ contains $40 \% \alpha$-lactose and $60 \% \beta$-lactose. Both forms can transform one into another, the rate of transition from one form to another depends on the temperature. When milk is heated to a temperature above $100{ }^{\circ} \mathrm{C}$ (especially during sterilization and high-temperature processing), milk sugar is partially converted into lactulose. Lactulose differs from milk sugar in that it contains fructose instead of glucose. Lactulose is readily soluble in water, $1.5-2$ times sweeter than lactose. At high heating temperatures $\left(160-180{ }^{\circ} \mathrm{C}\right)$, milk sugar caramelizes, and the lactose solution turns brown.

\subsubsection{Minerals, Vitamins, Urea, Enzymes, Hormones, and Other Ingredients}

Mineral substances in milk contain from 0.6 to $0.8 \%$. The main macronutrients include: calcium, magnesium, potassium, sodium; microelements: copper, iron, zinc, cobalt, manganese, iodine, etc. Milk contains almost all vital vitamins. They are represented by fat-soluble (A, D, E, K) and water-soluble (B1, B2, B3, PP, B6, B9, B12, C, H) vitamins. Another important component of milk is urea. Monitoring the level of urea in milk and blood allows to adjust the feeding diet in a timely manner, as well as improve the quality of milk and dairy products. Urea is also added to improve the thermal stability of milk and to increase the total nitrogen content (milk protein), which is a type of adulteration. Milk also contains more than 20 native enzymes, hormones (prolactin, oxytocin, somatotropin, thyroxin), pigments (carotenoids that determine the color of milk), gases such as nitrogen, oxygen, carbon dioxide, ammonia (they get into milk from blood, air during milking, pipeline transport), etc.

Thus, the composition of milk is complex and unstable, and the absence of one of the substances or a deviation of its quantity from the norm usually indicates a sick state of the animal, an inadequacy of the diet (feed) or falsification of milk.

\subsubsection{Falsification}

On the list of the most counterfeited foods in the world, milk follows immediately after olive oil; over the past 30 years, milk has featured in $24 \%$ of all incidents [27]. Since the composition and properties of milk fluctuate (Table 1) under the influence of various factors, this in practice makes it possible to falsify milk in different ways.

The methods of falsification have practically not changed in recent years. At the moment, two large groups of counterfeit can be distinguished-the falsification of the composition (mainly raw materials) and the falsification of quality. The most common counterfeit is dilution with water [28], milk whey (Table 2), the addition of nitrogen-containing substances, milk substitutes, preservatives $[18,22,29]$. 
Table 1. Average chemical composition of cow's milk and range of fluctuations in the norm.

\begin{tabular}{lcc}
\hline \multicolumn{1}{c}{ Components } & Average Content, $\%$ & Oscillation Limits \\
\hline Water & 87.5 & $84-89$ \\
Dry matter & 12.5 & $11-16$ \\
Including: & & \\
Fat & 3.8 & $2.5-6.8$ \\
Protein & 3.3 & $2.7-5.0$ \\
Lactose & 4.7 & $3.6-5.6$ \\
Ash & 0.7 & $0.6-0.9$ \\
\hline
\end{tabular}

Table 2. Comparison of the chemical and physical properties of whole and falsified milk.

\begin{tabular}{cccc}
\hline Parameters & Diluted with Water & Whole Milk & Skimmed Milk \\
\hline $\begin{array}{c}\text { organoleptic } \\
\text { characteristics }\end{array}$ & $\begin{array}{c}\text { weakened taste and odor, } \\
\text { decreased viscosity } \\
\text { (wateriness), bluish color }\end{array}$ & $\begin{array}{c}\text { specific smell, no foreign } \\
\text { impurities, color from } \\
\text { white to light cream }\end{array}$ & $\begin{array}{c}\text { taste is significantly } \\
\text { reduced, a bluish tint, } \\
\text { wateriness is acquired }\end{array}$ \\
\hline density, $\mathrm{kg} / \mathrm{m}^{3}$ & $<1027$ & $1027-1032$ & $1030-1035$ \\
\hline viscosity at $20{ }^{\circ} \mathrm{C}, \mathrm{mPa} \cdot \mathrm{s}$ & 1.2 & 2.127 & 1.79 \\
\hline acidity, To & $<16$ & $16-21$ & without changes \\
\hline dry residue, $\%$ & $<10$ & 12.2 & changes slightly \\
\hline fat, $\%$ & $<3.2$ & 3.6 & $<2.8$ \\
\hline protein, $\%$ & $<2.5$ & $2.8-3.2$ & without changes
\end{tabular}

The most important components of milk, fats and proteins are objects of falsification. The mass fraction of protein is determined by the official standard methods of Kjeldahl and Lowry [30,31]. For example, the Kjeldahl method calculates the mass fraction of all nitrogenous compounds, then multiplying by a factor of 6.38 to find the mass fraction of total protein in milk. Some of these compounds are normal products of the animal's body and are present in milk normally. But other nitrogen may also be present in the milk-for example, mineral nitrogen compounds that get into the milk with feed, the content of which sometimes exceeds in the feed, or intentionally introduces nitrogen-containing substances to increase the protein content in the milk. According to the Kjeldahl method, the content of any nitrogen will be calculated as milk protein.

When milk fat is falsified, it is replaced with cheaper plant analogues. Such substitutes can be of high quality, characterized by the presence of both hydrogenated and non-hydrogenated fats, and a low level of trans isomers. The most common chemical methods for measuring fat content are the Gerber method [32] and the Rose-Gottlieb method [33]. At the same time, the analyzes last 1.5-2 h, they are sensitive to foreign impurities used in the preparation of samples, chemical reagents are required, which in many cases are harmful to laboratory workers. Receiving milk requires simple, safe, and quick methods.

\subsection{Commercial Milk Analyzers}

Dairy farming and working conditions are changing at a fast pace. Dairy farms today use modern automation tools, embrace digital technologies, and implement intelligent solutions for profitable and efficient milk production. The market for equipment for the analysis of milk and dairy products is very diverse and is constantly being replenished with various new models, both from manufacturers that have been working in this field for a long time, and from manufacturers previously not present on the market. All equipment can be conditionally divided into two groups: which operates on the basis of direct methods of analysis (extraction, weighing, etc.) and equipment that uses indirect methods of obtaining data on the composition of the sample. 
The first group includes any devices that determine the mass, temperature, and equipment designed to conduct the actual chemical analysis with varying degrees of automation. For example, "Kjeldahl devices", which are represented by a wide variety of models in a wide price range, but, accordingly, with the same wide range of capabilities.

The second group includes instruments using instrumental analysis methods. This is a large number of various devices using spectroscopy in different ranges [34-36], devices using ultrasonic vibrations [37,38], measuring the optical activity of the sample, as well as "combined devices", in which two methods can be applied at once, or preliminary sample preparation (for example, precipitation or "binding" of any component of the sample), followed by analysis of the sample thus obtained by a standard method (for example, optical spectroscopy).

About 10 years ago, the study of milk and dairy products was only possible under laboratory conditions, and was based on chemical or physicochemical methods. Since these are direct methods, they are considered the most reliable, but such an analysis is a laborious, long-term (analysis could take up to $15 \mathrm{~h}$ ) process that requires experience and specialized knowledge from personnel, high-purity chemicals. This leads to an increase in the cost of the examination of raw materials, in addition, the accuracy of the results may decrease because of imperfect reagents, the human factor-laboratory assistant errors and subjective assessment of the results. Often a situation arises when the indicators of the device used, calibrated according to the manufacturer's data, differ from the indicators obtained by reference methods, for example, the Gerber method for determining fat. The difference can be significant, say $0.3 \%$ fat. With the apparent simplicity of the method, forgetting about its intricacies can lead to systematic errors in the analysis. For example, the temperature regime is not maintained, the isomeric composition of the isoamyl alcohol used is not monitored. This leads to discrepancies between the readings of the milk analyzer and the results obtained from the chemical analysis data precisely because the control analysis method (Gerber's method) was performed incorrectly.

In addition, the modern pace of life and production constantly requires an increase in the speed of all stages of production. Owing to new technologies, quality analysis is carried out much faster and does not depend so much on the qualifications of employees. Therefore, now more and more often give preference to analyzers that use indirect methods of data collection.

Despite all the advantages of modern analyzers, there are areas that still need to be refined. Equipment for agricultural producers must meet a number of requirements. First, it should be inexpensive and competitive. So the average cost for present analyzers ranges from $340 €$ to $22,660 €$ and more, depending on the modernization (Table 3). Second, it should be easy to use. If we talk about the analysis of milk quality directly on farms, then the best option is the ability to adapt to any milk pipeline, without making significant changes to the structure of the milk pipeline and without breaking the vacuum regime. Third, the analyzer must take into account the heterogeneity of the milk flow in the milk pipe. Milk is a complex polydisperse system. Milk sugar (lactose) is dissolved in a dispersed medium (water: $85-89 \%$ ) of milk, the size of its molecules is $1-1.5 \mathrm{~nm}$. Milk salts are in the form of colloidal particles, protein substances form colloidal solutions. Milk fat is in a warm state in the form of an emulsion, in a cold state-in the form of a suspension. The process of milk movement through the pipeline of the milking installation is unsteady, from laminar to turbulent modes. It is also necessary to take into account the heterogeneity of the milk-air flows because of the mechanical effect on the milk, leading to foaming. This complicates the determination of milk quality parameters. Fourth, the analyzer must carry out tests as quickly as possible. The best option is to work in real time, directly in the stream. There is currently no automatic counter-sensor for linear installations. Non-independent manufacturers (De Laval, GEA PHARM Technologies, etc.) offer mobile milking machines for use. They have small dimensions and do not interfere with the measured flow. However, they have a significant cost and high error (up to $10-12 \%$, with the maximum allowable rate not exceeding $5 \%$ ). Thus, at the moment there are no analyzers that could meet all modern requirements. 


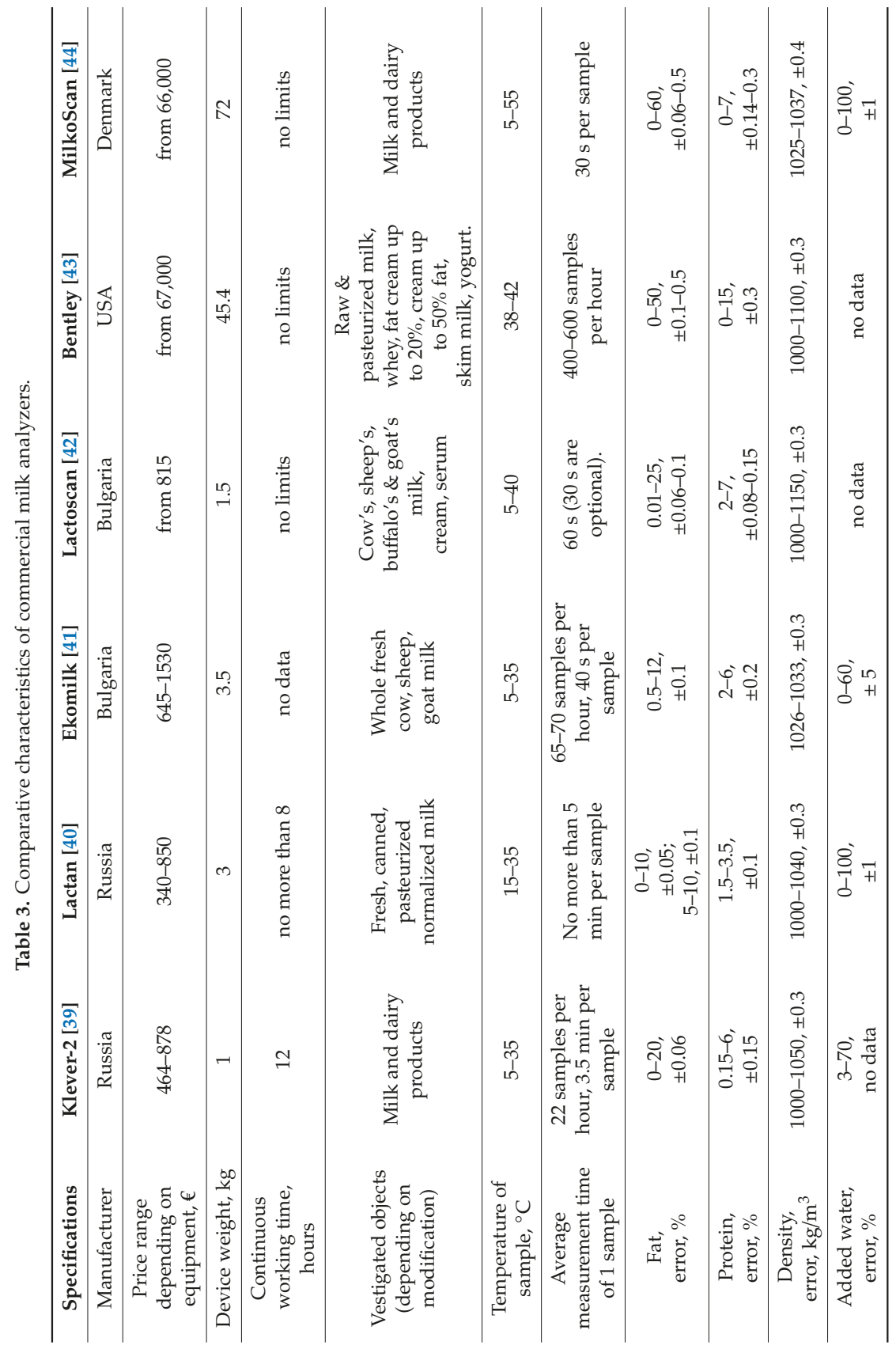




\section{Optical Spectroscopic Approaches and Techniques for Milk Analysis}

\subsection{Optical Properties of Milk in a Wide Spectral Range}

Attenuation of optical radiation propagating through a medium is a consequence of two fundamental physical phenomena of light-matter interaction-absorption and scattering; according to the Beer-Lambert law the intensity of radiation $I_{\lambda}$ decreases exponentially [45]:

$$
I_{\lambda}=I_{0 \lambda} \exp \left[-\mu_{\mathrm{e}} \cdot d\right]=I_{0 \lambda} \exp \left[-\left(\mu_{\mathrm{a}}+\mu_{\mathrm{es}}\right) \cdot d\right],
$$

where $I_{0 \lambda}$ is the intensity of incident radiation; $\mu_{\mathrm{a}}$ is the bulk absorption coefficient; $\mu_{\mathrm{s}}$ is the bulk scattering coefficient; $\mu_{\mathrm{e}}=\mu_{\mathrm{a}}+\mu_{\mathrm{s}}$ is the extinction coefficient, which includes both absorption and scattering; $d$ is the thickness of an optical layer. The absorption and scattering coefficients $\mu_{\mathrm{a}}$ and $\mu_{\mathrm{s}}$, along with the refractive index $\mathrm{n}$ and the scattering anisotropy factor $g$ [46] are referred to as bulk optical properties of a medium [47]. For highly turbid media, where multiple scattering events take place on the optical path, more sophisticated mathematical description of radiative transfer than the classical Beer-Lambert law may be needed [48,49].

For the purpose of optical radiation transfer analysis, milk can be represented as a three-phase inhomogeneous composite liquid medium consisting of the serum, the fat globules, and the casein micelles [50]. The serum (or whey) is an aqueous solution of whey proteins, lactose, vitamins, electrolytes, and other water-soluble components of milk. The fat globules are spherical lipid droplets, which form a stable emulsion in the serum, the size of the droplets in raw milk lies in the wide range from a few hundred nanometers up to $10 \mu \mathrm{m}$ [51], but it can be sufficiently reduced and uniformed in the process of homogenization [52]. The casein micelles are solid spherical formations dispersed in the serum; they are formed of the insoluble casein proteins which represented up to $80 \%$ of all proteins in milk. These micelles vary in sizes from $50 \mathrm{~nm}$ to $680 \mathrm{~nm}$ (the mean diameter is about $200 \mathrm{~nm}$ ) which are smaller than the diameter of fat globules [50].

The milk serum may be slightly opaque, but elastic scattering of photons occurs mainly on the fat globules and casein micelles. Taking into account that the sizes of these spherical particles $\mathrm{P}$ are comparable with the wavelengths of radiation $\lambda$ in a considerable part of the optical region $0.1 \lambda<\mathrm{P}<\lambda$, the Mie theory should be applied to analyze elastic light scattering in milk [51]. It is a highly turbid medium because the fraction of the scattering particles is very substantial: the concentration of fat in raw milk can achieve $8 \%$, casein content can be as high as 3\% [50]. In molecular absorption spectroscopy (spectrophotometry) the main challenges when dealing with such samples are distinguishing and separating absorption and scattering effects in the experimental data (usually reflectance and transmittance spectra), and subsequent recovering of the bulk optical properties [47]. For raw milk, this task is even more complicated because the distribution of scattering particle by size is not known beforehand and depends on many factors [51].

Alongside with the fat globules and casein micelles, somatic cells (primarily leucocytes with the diameter of $8.5-10 \mu \mathrm{m}$, which should be considered as an additional type of scattering particles) are always present in relatively small amounts even in normal milk. In case of inflammation (cow mastitis) the concentration of these cells is elevated; in the process of milk quality assessment it is necessary to control that it is below a certain threshold. This can be done by optical methods because somatic cells influence milk scattering properties [53].

In the Table 4 the wavelengths (wavenumbers) of the characteristic absorption of several important milk constituents are summarized; the strongest absorption bands, which are often used for quantitative spectral analysis, were selected in a wide spectral range $(0.2-25 \mu \mathrm{m})$. 
Table 4. The wavelengths/wavenumbers of the main milk constituents' characteristic absorption in a wide spectral range.

\begin{tabular}{|c|c|c|c|c|}
\hline $\begin{array}{l}\text { Spectral } \\
\text { Region }\end{array}$ & $\begin{array}{l}\text { Wavelength } \\
\text { Interval }\end{array}$ & $\begin{array}{c}\text { Milk } \\
\text { Constituents }\end{array}$ & $\begin{array}{c}\text { Absorption } \\
\text { Wavelengths/Wavenumbers }\end{array}$ & Reference \\
\hline $\begin{array}{l}\text { Ultraviolet and } \\
\text { visible }\end{array}$ & $0.2-0.7 \mu \mathrm{m}$ & $\begin{array}{l}\begin{array}{l}\text { proteins } \\
\text { fat }\end{array} \\
\beta \text {-carotene } \\
\text { riboflavin }\end{array}$ & $\begin{array}{c}280 \mathrm{~nm} \\
205,230,270 \mathrm{~nm} \\
435 \mathrm{~nm}, 480 \mathrm{~nm} \\
449 \mathrm{~nm}\end{array}$ & $\begin{array}{c}{[53-56]} \\
{[57]} \\
{[58]}\end{array}$ \\
\hline Near infrared & $0.7-2.5 \mu \mathrm{m}$ & $\begin{array}{c}\text { water } \\
\text { whey protein } \\
\text { fat }\end{array}$ & $\begin{array}{c}970,1200,1450,1940, \\
1953,1984 \mathrm{~nm} \\
1731,1774,2056,2060, \\
2167,2180 \mathrm{~nm} \\
1220,1720,1730,1740-1770, \\
1780,2076,2270 \\
2310,2340,2386 \mathrm{~nm} \\
1450,1680,1720,1730,1780, \\
1820,1980,2100,2310, \\
2340,2790 \mathrm{~nm} \\
1450,1820,2100,2340 \mathrm{~nm}\end{array}$ & $\begin{array}{c}{[60,61]} \\
{[60]}\end{array}$ \\
\hline Middle infrared & $\begin{array}{c}2.5-25 \mu \mathrm{m} \\
\left(4000-400 \mathrm{~cm}^{-1}\right)\end{array}$ & $\begin{array}{c}\text { water } \\
\text { fat } \\
\text { proteins } \\
\text { lactose }\end{array}$ & $\begin{array}{c}1640,3300 \mathrm{~cm}^{-1} \\
1175,1470,1754,2857 \mathrm{~cm}^{-1} \\
1240,1600-1700 \\
1550-1570 \mathrm{~cm}^{-1} \\
1052,1080,1157 \mathrm{~cm}^{-1}\end{array}$ & $\begin{array}{c}{[62]} \\
{[63]} \\
{[62,63]} \\
{[63]}\end{array}$ \\
\hline
\end{tabular}

The diagram in the Figure 3 shows the most practically significant optical spectroscopic techniques for milk analysis; molecular absorption spectroscopy (spectrophotometry) is dominant among them for the purpose of the qualitative determination of the main milk constituents and some adulterants in routine milk testing.

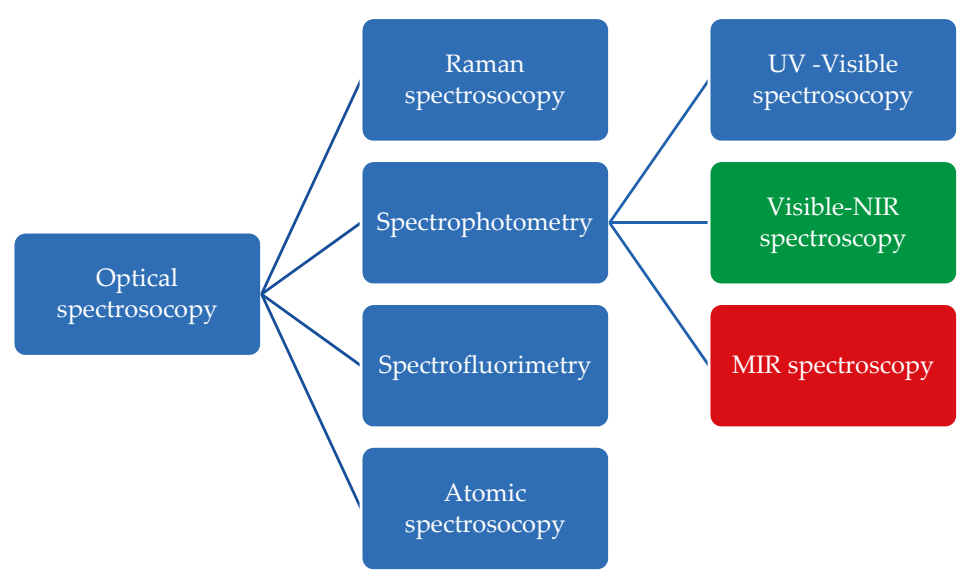

Figure 3. Optical spectroscopic techniques for milk quantitative and qualitative analysis.

Despite similarity in the background physical principles, analytical approaches, methods, and equipment for the spectral analysis of milk strongly differ in different spectral regions (UV, visible, NIR, MIR) and should be discussed separately. 


\subsection{UV-Visible Spectroscopy}

In the UV and the short-wavelength part of the visible region (below $500 \mathrm{~nm}$ ) characteristic electronic absorption of the whey proteins, fats, and some vitamins could be detected in diluted milk samples, while water is virtually transparent up to $900 \mathrm{~nm}$. This region is not often used for milk spectrophotometric analysis because of very intensive light scattering on the casein micelles and the necessity of sample dilution and pretreatment; the rare examples include the methods for determination of casein [54] and fat [56]. Some scattering-based techniques for fat and protein spectroscopic determination [64-67] exploit the longer wavelengths part of the visible spectrum often along with the short-wavelengths part of the NIR region (below $1100 \mathrm{~nm}$ ). The chief advantage of this approach is the possibility to develop cheap, portable, and easy-to-use analytical devices with CCD or CMOS silicon photodetectors.

\subsection{MIR Spectroscopy}

The MIR region is the most relevant for the spectral analysis of milk, since strong characteristic absorption bands associated with fundamental vibrational and rotational stretching modes of the main milk constituents molecules, including proteins, saccharides, fats, etc., are manifested in this part of the optical spectrum. At the same time background scattering on the milk particles is not so prominent because the ratio of the fat globules and casein micelles sizes to the working wavelengths is much lower than in the NIR region. Analytical methods based on MIR spectroscopy have been used for the laboratory testing of milk since sixties [68] and are well established now [69]. Novel approaches are constantly developing $[50,69,70]$ because this technique gives the most precise and detailed information about sample chemical composition; some examples of the most remarkable applications of MIR spectroscopy for the analysis of milk are summarized in the Table 5.

Because milk is an extremely complicated multicomponent scattering medium the straightforward determination of the constituents' concentrations from the intensity (or area) of the characteristic absorption peaks in spectra according to the classical Beer-Lambert law is impossible in most cases. Therefore, various multivariate chemometrics algorithms for spectral calibration and data analysis are applied: Partial Least Square Regression (PLS) and Discriminant Analysis (PLS-DA), Principal Component Regression (PCR), Principal Component Analysis (PCA), Artificial Neural Networks (ANN), Soft Independent Modeling of Class Analogy (SIMCA), Multivariate curve resolution alternating least square (MCR-ALS), etc. [71,72].

It is very important to mention that MIR spectroscopy is an immensely powerful tool not only for the quantitative determination of the basic milk constituents or residual amounts of antibiotics and disinfectants (see Table 5), but also widely used for detecting milk adulteration, when original proteins and fats are replaced with vegetables products, or foreign, often dangerous substances (sucrose, starch, urea, melamine, formalin, etc.) are deliberately and illegally added to milk and other dairy products by fraudsters to extend the shelf life or falsely increase the claimed protein and fat content. 


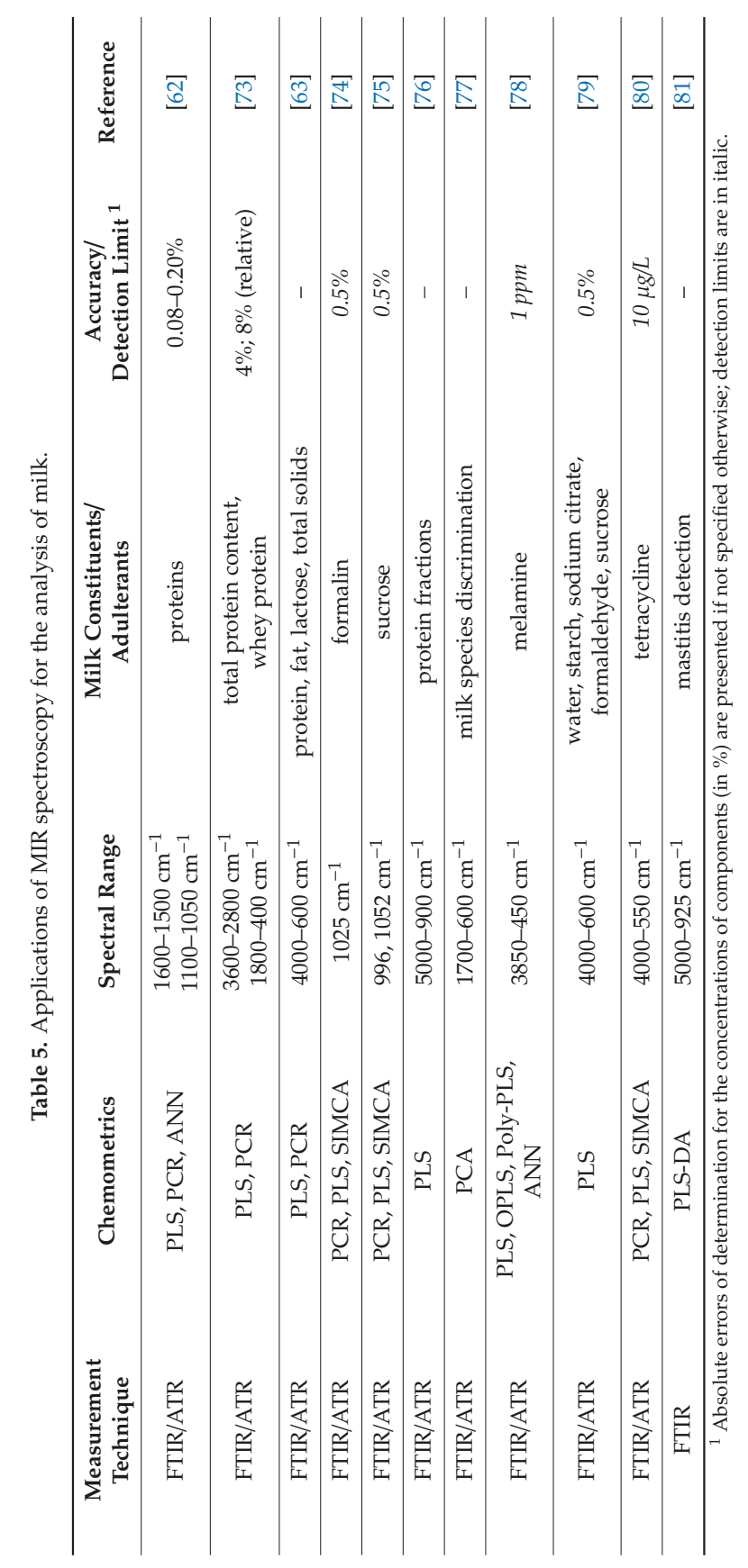


Fourier transform infrared (FTIR) spectrometers are usually used for the analysis of milk and dairy products in the MIR region; highly specialized platforms are available on the market, for example MilkoScan ${ }^{\circledR}$ series by FOSS (Hillerød, Denmark). The main obstacle for wider implementation of this technique is strong MIR water absorption [82]; so very thin optical cuvettes or, which is more preferable, attenuated total internal reflectance (ATR) accessories have to be used [62]. The main element of an ATR accessory is an optically dense IR crystal with a high refractive index which is simultaneously transparent in a working spectral range (Figure 4). An incident IR beam travels through the crystal and undergoes multiple total internal reflections. The surface of the crystal is in direct contact with a liquid medium where an evanescent electromagnetic wave propagates along the border. In regions of the spectrum where the liquid absorbs electromagnetic energy of the evanescent wave the IR beam in the crustal is attenuated.

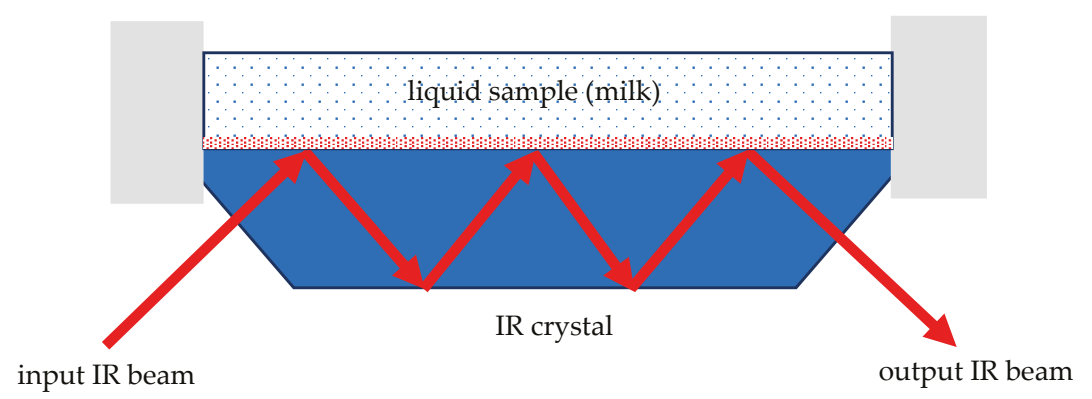

Figure 4. Measuring MIR absorption spectra using ATR setup.

Because the penetration depth of the evanescent wave is limited to a few micrometers, IR radiation interacts with the liquid sample in a very thin near-surface layer. As a consequence, the spectra are very sensitive to the presence of fat globules or fat biofilms in the boundary layer that forms at the interface between the milk and the crystal which serves both as radiation waveguide and sensing element [83]. In combination with such factors as high-cost spectral equipment, complicated maintenance, cleaning, calibration, and sample preparation procedures, this fundamental limitation makes FTIR/ATR spectroscopy almost exclusively off-line, laboratory technique not suitable for real-time in-line monitoring in milking machines on farms or milk processing equipment on production facilities [65].

\subsection{Near-Infrared (NIR) and Visible Spectroscopy}

In the NIR range characteristic absorption bands corresponding to the overtones and combination vibrations of proteins, lactose, fat, and water molecules are manifested (see Table 6), but these bands are weaker than in the MIR region and harder to distinguish on the background of highly intensive light scattering on the milk particles—the fat globules and casein micelles. The NIR spectra of the bulk scattering coefficient and the scattering anisotropy factor strongly depend on the particle size distribution which can vary in each sample of milk [50]. It means that samples with equal fat and protein content, but different particle size distributions have different spectral transmittance and reflectance, which makes extracting information about sample composition from the spectral data a complicated task, especially for raw, unhomogenized milk [65].

From the other side, weaker than in MIR, water absorption, especially in the visible and the short-wavelength part of the NIR region allows using longer optical path flow-through cuvettes (up to $10 \mathrm{~mm}$ ) suitable for in-line measurements. Another advantage of NIR techniques is the possibility to employ more affordable and robust multichannel detectors-based spectral instruments with no moving parts. Despite some lack of sensitivity and selectivity, less reliable and more specific calibration compared to MIR spectroscopy, NIR techniques are now leading in milk analysis. 
Different approaches and measuring schemes (Figures 5 and 6) are used for the registration of the NIR spectra of milk, including collimated transmission (CT) [84], diffuse transmission (DT) [64], diffuse reflection (DR) [85], backscattering (BS) [86].

Table 6 summarizes the applications of NIR technologies for the quantitative and qualitative determination of the main milk constituents (crude protein, casein, fat, lactose), comatic cells count, and common adulterants reported in the selected papers.

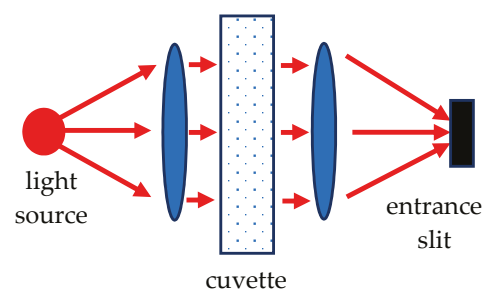

(a)

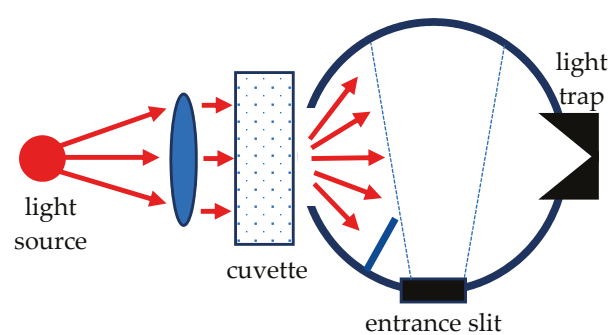

(b)

Figure 5. Measuring collimated transmission (a) and diffuse transmission (b).

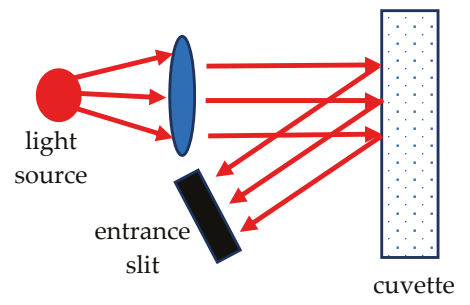

(a)

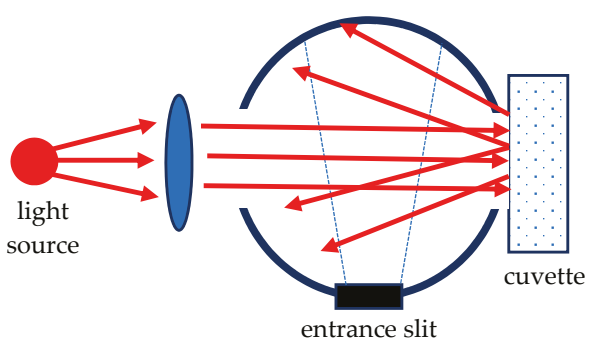

(b)

Figure 6. Measuring backscattering (a) and diffuse reflection (b). 


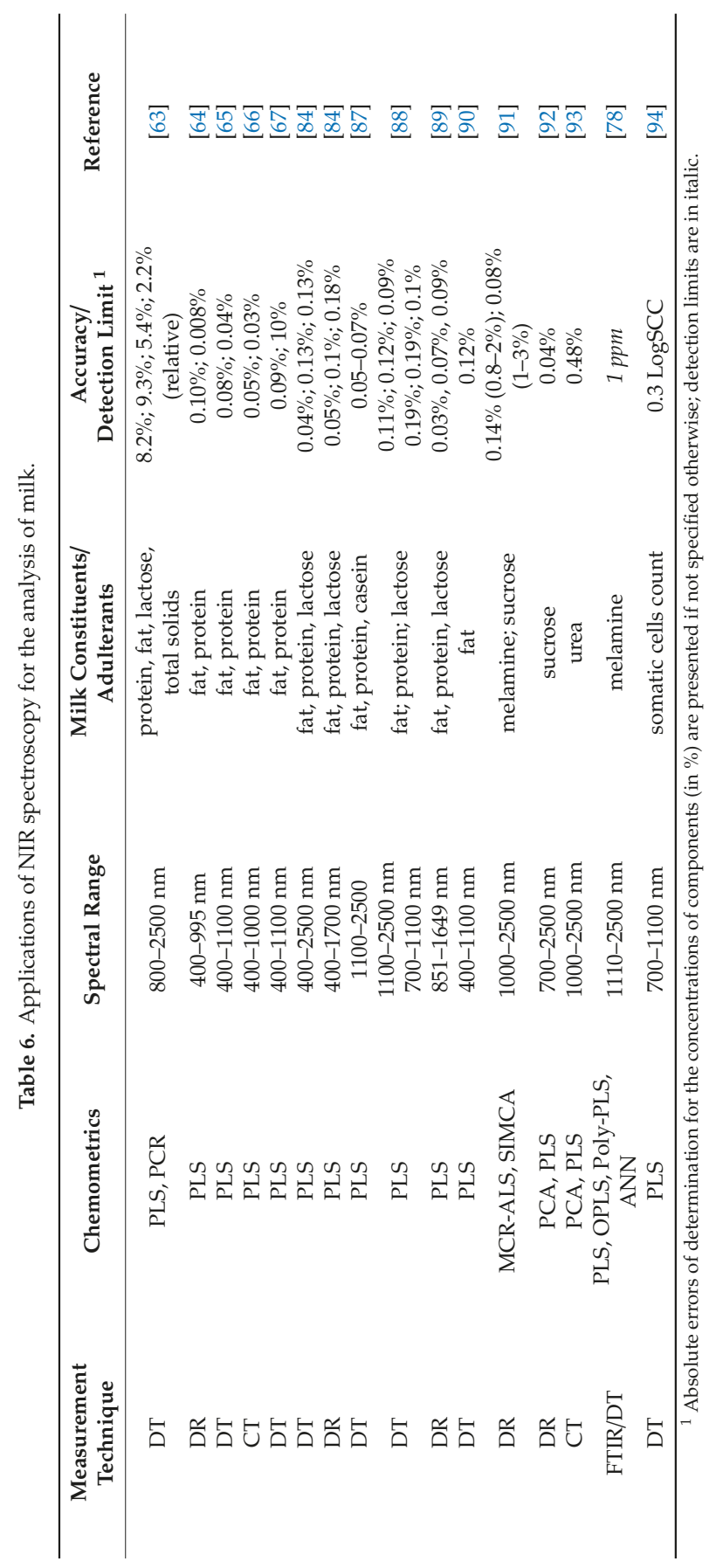


In contrast to the off-line milk analyzers based on FTIR spectrometers working in the MIR spectral region, NIR technology allows developing portable devices for fast on-farm milk quality control [95] and analytical solutions for in-line applications in milking robots [96] and automated milking systems [97]. Authors claim that such devices can determine the concentrations of three major milk constituents (fat, protein, and lactose) and somatic cells count with accuracy which is quite acceptable for practical use.

\subsection{Atomic Spectroscopy, Raman Spectrosocopy, Fluorescent Spectrosocopy}

Besides the above-mentioned spectrophotometric methods based on measuring molecular absorption and elastic scattering of optical radiation, spectroscopic techniques that utilize different optical phenomena are also used for milk analysis and quality control, though not so often.

In analytical chemistry, atomic spectroscopy is considered to be the most widespread method for elemental analysis; when applied to milk and dairy products it is mainly used for the determination of macroelements (Ca, $\mathrm{P}, \mathrm{Mg}, \mathrm{K}$ ) and microelements ( $\mathrm{P}, \mathrm{Fe}, \mathrm{Zn}, \mathrm{Se}, \mathrm{Al}, \mathrm{Cd}, \mathrm{Cu}, \mathrm{S})$, including toxic heavy metals $(\mathrm{Cd}, \mathrm{Pb})$. Various techniques are employed: atomic absorption spectroscopy with prior atomization [98], inductively coupled plasma atomic emission spectrophotometry [99,100].

Raman spectroscopy has long been used for the quality control and the quantitative analysis of powdered milk and baby formula and to screen samples adulterated with whey and melamine. It is a very capable and convenient method, because Raman spectra can be collected extremely fast, without any special sample preparation, and even from samples in glass and polymer packaging [101]. The main obstacle for the application of Raman analysis for liquid milk and other dairy products with high humidity is a weak signal from the main milk constituents on the background of very intensive water bands. Despite this problem modern chemometrics approaches have been successfully used for extracting from the Raman spectra of milk information about the concentrations of fat, proteins, lactose, antibiotics, and adulterants (melamine) [102]. Raman spectroscopy are even considered as a perspective on-line analytical method [103].

Molecular fluorescence spectroscopy is one of the most sensitive and highly selective spectroscopic methods, which can detect extremely low amount of chemical substances. In milk industry it is used for the determination of vitamins, fatty acids [104], residual amounts of antibiotics [105], and identification of different milk species in dairy products [106].

\subsection{Prospects for the Further Development of Optical Methods and New Devices for Milk Analysis}

The main leading trend in the optical spectroscopy of milk and dairy products is developing affordable, portable, on-site or in-line devices, which can be used outside of a laboratory or even incorporated in milking robots or processing equipment, for the monitoring of milk quality in real-time, either on milking-farms or production facilities. The most promising results so far have been achieved in the NIR technologies, even with conventional spectral equipment, mainly because of the implementation of sophisticated chemometrics algorithms such as artificial neural networks.

The other acute problem in milk analysis is the detection of as many known adulterants as possible. Despite constant improving of the calibration and prediction algorithms it is not always possible even by FTIR spectroscopy because of the inherent limitations of optical spectroscopic techniques [107]. Combination of several different approaches, for example spectrophotometry and acoustic analysis, may be a solution here.

\section{Ultrasound Approaches and Techniques for Milk Analysis}

Ultrasound techniques are well-developed instruments used for non-destructive, accurate, and non-invasive measurements [108,109]. In the dairy industry, ultrasound is widely used both for non-destructive monitoring of the quality and parameters of milk [37,110-118], and in the ultrasonic processing of dairy products $[110,119,120]$. In the first case, low-intensity ultrasound (less than $1 \mathrm{~W} / \mathrm{cm}^{2}$ ) is used at frequencies above $100 \mathrm{kHz}$, which is a non-destructive instrument for milk characterization. 
In the second case, high-intensity ultrasound (above $10 \mathrm{~W} / \mathrm{cm}^{2}$ ) is mostly used in the $20-100 \mathrm{kHz}$ frequency range, which is destructive for milk sample: it modifies the properties of milk and is used for the ultrasound treatment at different stages of dairy products processing. In this review, we are interested only in methods of low-power non-destructive ultrasonic characterization of milk.

Ultrasound spectrometry offers the ability to characterize dairy products excluding special preparation or disruption of the liquid sample. In addition, ultrasound methods are of interest for monitoring processes in real time.

\subsection{Acoustic Properties of Milk}

Acoustic measurement techniques can provide data about protein [121] and fat [113] content, physiochemical changes of milk with time [122], size distribution of air and fat droplets [123], content of contaminants [112].

When an acoustic wave propagates through a liquid sample, its amplitude decreases, and the phase changes because of the interaction with liquid medium and its dispersed filler. The decline in ultrasound intensity is commonly called attenuation. The phase links to the velocity of propagation of sound through a sample. The variations of sound velocity and attenuation are governed by the physicochemical features of liquid medium and its ingredients. By measuring changes in these acoustic parameters, specific information about the properties of a liquid sample can be accessed. Thus, the thermo-acoustic, physical, and chemical properties of milk can be obtained by measuring ultrasound speed and attenuation. These measurements can be carried out by such methods as transmission, pulse-echo and interferometer techniques (Figure 7). An alternative microbalance approach to acoustic measurements allows access to viscosity and density of milk via measuring of additional mass load of resonant sensor. The analysis and interpretation of acoustic measurements can be done in two steps. The first step is purely phenomenological and involves determination of the ultrasound parameters (speed of sound and attenuation, or viscosity and density) of milk sample. The second step requires the use of model to describe the real milk as a complex multiphase polydisperse system. By solving inverse problems on the basis of appropriate models, it is possible to determine the content of various ingredients in milk and their size information. Such calculations can be done using models of ultrasound attenuation [123] and velocity [124] in dispersed liquids and emulsions.

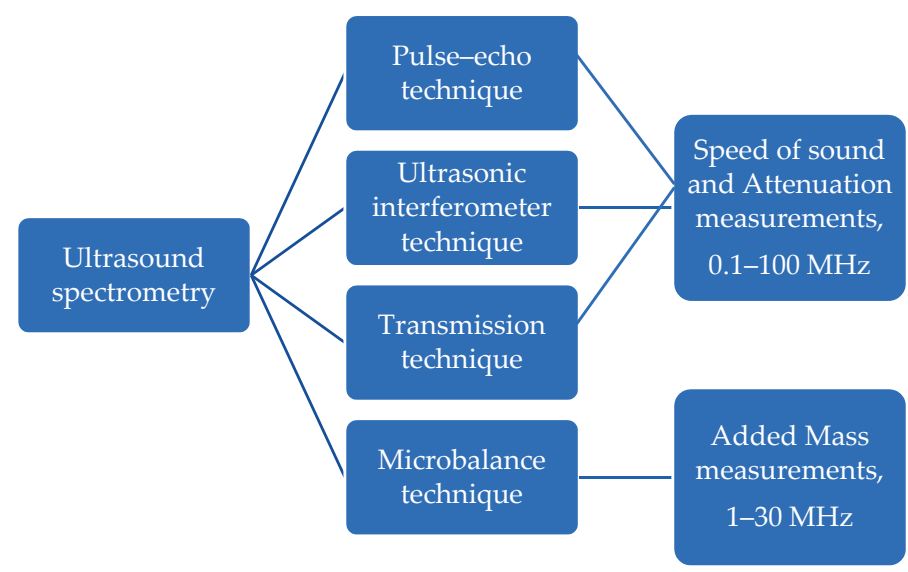

Figure 7. Ultrasound techniques for milk quantitative and qualitative analysis.

The speed of sound can provide some specific information about the composition of a liquid. Speed of sound is a collective value. The simplest mixing rule for sound velocity has been proposed 
by [125] and fits well with experimental data in liquid mixtures. Molecule interactions gives to excess Gibb's energy to an ideal mixture, and this affects in an excess compressibility and an excess volume [126]. The speed of sound contains information about the nature of interactions between molecules, because it depends on changes in the shape of molecules and on the type of interaction potentials between the components of liquid mixture [127]. The speed of sound in suspensions and emulsions was studied in detail in [124]. The sound velocity is very sensitive to milk chemistry content and temperature. It is the most suitable parameter for studying milk features on a molecular scale, that is, with characteristic dimensions in angstroms. The speed of sound changes from 1000 to $2000 \mathrm{~m} / \mathrm{s}$ for a variety of dairy products. For dilute milk, it is about $1500 \mathrm{~m} / \mathrm{s}$, close to water sound velocity at room temperature.

Attenuation of ultrasound propagating through a heterogeneous system is the sum of scattering and absorption. Particle scattering redirects energy of ultrasound wave out of the propagation line. Absorption converts ultrasonic energy into heat because of the interaction effects between the ultrasonic wave and particles and medium. The propagation of acoustic waves through the milk medium is mainly of a thermodynamic character. Big droplets can serve as scattering centers. Submicron particles in milk only absorb ultrasound. Absorption in milk can be divided into so-called internal attenuation and thermal attenuation. The first is measured directly. The second is associated with differences in thermo-mechanical properties between particles and a liquid medium, whereby the particles and liquid expand in ultrasonic field in different ways, creating a temperature gradient at the particle-liquid interface, as a result of which the ultrasonic energy at this interface is converted into heat $[123,128]$. Thermal part of attenuation in a liquid medium depends on thermal conductivity, thermal expansion, and heat capacity. The total value of the thermal part of attenuation of the multiphase polydisperse liquid depends on these three thermo-mechanical parameters for each component as well as the particle distribution by sizes [123]. Ultrasound attenuation is not good enough to reflect changes in chemical, ionic, and molecular milk composition, but it is sensitive to particles present in milk. Attenuation perceives changes in nanometre-micrometre size level and is suitable for characterizing liquid features associated with inhomogeneity and phase composition of a disperse liquid system [113,123]. Milk can be modelled as a liquid composition of spherical fat droplets of approximately spherical shape in an aqueous solution of proteins and sugars $[123,124,129]$. Knowing the corresponding physical properties of the constituent milk ingredients, fat particles size distribution in milk can be determined from measurements of attenuation [123]. Attenuation in milk can vary very widely depending on the frequency. In water the attenuation rises with frequency up to $0.2 \mathrm{~dB} / \mathrm{cm}$ per $\mathrm{MHz}$ at $100 \mathrm{MHz}$. In milk, depending on the fat content, the attenuation can vary from 0.4 to $0.7 \mathrm{~dB} / \mathrm{cm}$ per $\mathrm{MHz}$ for $100 \mathrm{MHz}$ and from 0.1 to $0.4 \mathrm{~dB} / \mathrm{cm}$ per $\mathrm{MHz}$ for $2 \mathrm{MHz}$. For comparison, for butter and margarine, the attenuation increases from 2 to $7 \mathrm{~dB} / \mathrm{cm}$ per $\mathrm{MHz}$ as the frequency increases from $2 \mathrm{MHz}$ to $100 \mathrm{MHz}$ [113].

Milk density is close to the density of water. Normal milk density ranges from 1027 to $1032 \mathrm{~kg} / \mathrm{m}^{3}$, with an average of $1030 \mathrm{~kg} / \mathrm{m}^{3}$. The density of milk is higher if it contains more sugar, proteins, and minerals, and lower, with an increase in fat [130]. Density can reflect falsification: decreases with water addition and increases with skimming or diluted with skim milk. For example, a density of $1028 \mathrm{~kg} / \mathrm{m}^{3}$ indicates natural milk, $1027 \mathrm{~kg} / \mathrm{m}^{3}$ means suspicious milk, $1027 \mathrm{~kg} / \mathrm{m}^{3}$ and below indicates falsified milk with water, more than $1031 \mathrm{~kg} / \mathrm{m}^{3}$ means suspicion of dilution backwards. The addition of water to milk causes a decrease in density of approximately $3 \mathrm{~kg} / \mathrm{m}^{3}$ for every $10 \%$ water added. It is characteristic that if the fat is removed from the milk and the same amount of water is added, then the density does not change, and such falsification can only be detected by determining the amount of fat in the milk [22].

Viscosity of milk is understood as the internal friction of liquid layers during their relative movement, which depends on the adhesion forces between the molecules. The viscosity of milk is influenced by emulsified (fats) and colloid-soluble particles (casein), the state of whey proteins, technological modes of milk processing, causing changes in the state of aggregation of its components, etc. [131]. The viscosity of milk and dairy products strongly depends not only on the 
composition, but also on the temperature [132]. An increase in temperature leads to an increase in the speed of Brownian motion (random motion [133]) of solution molecules, a weakening of the interaction forces between them, and as a consequence, a decrease in viscosity. However, if the temperature exceeds the coagulation point of whey proteins, the viscosity of these products begins to increase again. This is due to a decrease in the degree of dispersion of whey proteins caused by their thermal denaturation and aggregation [134]. Typical values of milk viscosity are given in Table 2.

Techniques for measuring the above acoustic properties of milk are briefly discussed below.

\subsection{Transmission Technique}

Figure 8a shows in a simplified way the idea of the transmission measurement method. To the left and to the right of the cuvette with the liquid sample, two piezoelectric transducers are located at the same level, opposite to each other. The first acts as a transmitter, and the second as a receiver of an ultrasound waves. The transmitter sends an ultrasonic wave with a certain frequency and amplitude into the liquid-filled cuvette, and the receiver gets a signal weakened in intensity and changed in phase as a result of the wave propagation through the liquid sample and the interaction between ultrasound wave and liquid medium and its dispersed filler. A piezoelectric receiver converts this ultrasonic signal into an electrical one, which is then compared with the input signal. The result of such a comparison makes it possible to determine the values of speed of sound and attenuation in a liquid sample, according to the equations [108,135]:

$$
V=x / t ; A_{\text {out }}=A_{\text {in }} \exp (-\alpha x),
$$

where $V$ is the speed of sound; $\alpha$ is attenuation; $x$ is the traveling distance; $t$ is the traveling time of the wave; $A_{\text {in }}$ and $A_{\text {out }}$ are the amplitudes of ultrasound wave at the beginning and at the end of the traveling distance. For the transmission approach (Figure 8a) $x=L$.

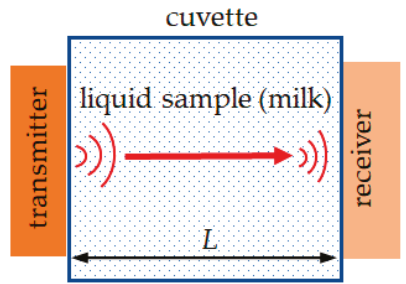

(a)

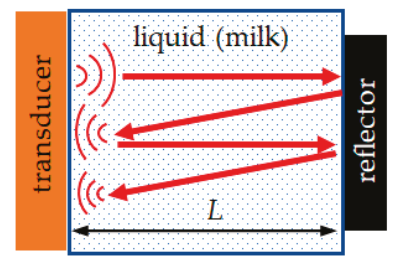

(b)

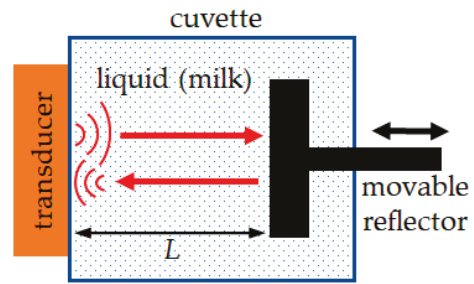

(c)

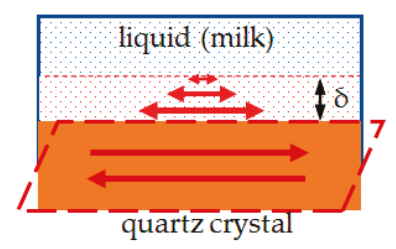

(d)

Figure 8. Ultrasound measuring approaches: simplified illustrations of transmission (a), pulse-echo (b), interferometer (c) and quartz crystal microbalance (d) techniques.

Sound velocity and attenuation measurements can be made over a wide frequency range, typically for milk in the 1 to $100 \mathrm{MHz}$ range.

The most informative frequency range for detecting fat in milk is from 40 to $50 \mathrm{MHz}$ [113]. Relatively big particles, such as air droplets in milk, can be detected by measuring the attenuation 
spectrum at low frequencies up to $10 \mathrm{MHz}$. Small particles down to $5 \mathrm{~nm}$ can be detected by studying and interpretation of the attenuation spectra in the higher frequency part of the spectrum up to $100 \mathrm{MHz}$ [123]. For a sufficiently accurate control of the fat particle size distribution in milk, an attenuation measurement accuracy of level about $0.01 \mathrm{~dB} / \mathrm{cm}$ per $\mathrm{MHz}$ is required [113].

The accuracy of sound velocity measurements is limited by the accuracy of temperature control. A $1{ }^{\circ} \mathrm{C}$ change in temperature leads to a change in the velocity of sound in water by $2.4 \mathrm{~m} / \mathrm{s}$, while maintaining a uniform temperature of the liquid sample with an accuracy less than $0.01{ }^{\circ} \mathrm{C}$ is impossible.

The transmission method has been used by various researchers to determine the water content, fat content [113], particle size distribution [123], and various chemical compounds [113], melamine [114], microorganisms [136] in milk.

\subsection{Pulse-Echo Technique}

In a pulse-echo method [110,137], the only one piezoelectric transducer is used (see Figure 8b). It is both a transmitter and a receiver of the ultrasonic signals. On the opposite side of the cuvette with a liquid sample, there is a reflector. The wall of the cuvette can act as a reflector, while for good reflection it is important to reach a high acoustic contrast and low acoustic losses at the liquid-wall interface. The pulsed ultrasound wave is directed from the transducer to the opposite wall of the cuvette, reflected from it, and returns to the transducer with weakened intensity. The wave partially reflected from the transducer travels the same path again and returns to the transducer as a second echo. Knowing the travel time of the wave and the distance, it is possible to calculate the speed of sound and attenuation based on Equation (2), only in this case, unlike the transmission method, the travel distance $x$ is equal to $2 L$ for the first echo and $4 L$ for the second one. Also, when using Equation (2) to calculate attenuation, it is necessary to take into account multiple reflections and the respective reflection coefficients at the interfaces.

Pulse-echo technique has been used to determine the water content, carbohydrates, and total fat content, fat globular, and casein micelles sizes distribution in milk [110,124,137].

\subsection{Ultrasonic Interferometer Technique}

At first glance, the ultrasonic interferometer technique is very close to the previous approach, but in reality, it has differences both in the method of collecting raw data, in the approach to their analysis, and in sensitivity to changes in the speed of sound and attenuation. An ultrasonic interferometer uses a single transducer that serves both transmitter and receiver roles. On the opposite side there is a movable reflector (Figure 8c) that allows profiling the distance at which standing acoustic waves are generated in the liquid sample because of the interference of the incident and reflected waves. When the distance between transducer and reflector changes, the intensity oscillations are measured, corresponding to the maxima and minima of the ultrasonic wave along its propagation path with a step of the half wavelength. Description of devices, principles of use, and improvements of the ultrasonic interferometer technique can be found in [138-140]. Furthermore, some devices of the ultrasonic interferometer include optical diffraction, which allows expanding its analytical capabilities [141]. Examples of using an ultrasonic interferometer for milk analysis are given in [111,142].

\subsection{Microbalance Technique}

Acoustic resonant sensor principles are broadly used as biochemical sensors. They are typically understood to convert a surface mass change into a frequency change of a resonant device. They are therefore often called microbalance with the quartz crystal microbalance (QCM) being its most prominent sensor. However, a resonance sensor is far more than a mass balance. Shear bulk acoustic resonators are commonly used for biosensing because of low in-liquid radiation losses. This allows to keep relatively high quality factor of the resonant sensor even while interfacing viscous liquids. QCM is a recognized technology that is used to detect interactions at the surface [143]. Excited at a 
shear bulk vibration mode, its resonant frequency shifts in accordance with interface loading. For milk characterization, QCM is commonly used to detect proteins [121,144,145].

The QCM measurements are based on a frequency shift $(\Delta f)$ detection from the fundamental resonant frequency $\left(f_{0}\right)$ of quartz resonator when it is loaded by a small additional mass $(\Delta m)$ per area of electrode $(A)$, according to the equation:

$$
\Delta f=-K \cdot f_{0}^{2}(\Delta m / A)
$$

where $K$ is a constant and depends on the properties of quartz crystal and its cut.

Small mass and high Q-factor of the resonator give access to a mass detection limit $\Delta m / m_{\text {res }}$ of $10^{-6}$ to $10^{-9}$ with $\Delta m$ and $m_{\text {res }}$ being the added mass and resonator mass per unit area, respectively.

When a quartz crystal sensor is in direct contact with a liquid, the shear wave penetrates into it to a small depth and the frequency shift is determined by the acoustic properties of the near-surface liquid with the thickness of $\delta=(\eta / \pi \rho f)^{1 / 2}$ (Figure $8 \mathrm{~d}$ ), where $\eta$ and $\rho$ are the liquid viscosity and density. For reliable separate measurements of liquid sample viscosity and density, in [143] a method for comparing the results of measuring a liquid using smooth and corrugated electrodes of QCM was proposed. The respective frequency shifts for a smooth- $\left(\Delta f_{1}\right)$ and corrugated-surface $\left(\Delta f_{2}\right) \mathrm{QCM}$ liquid sensors are given as [143]:

$$
\Delta f_{1}=-c_{1} \sqrt{\rho \eta} ; \quad \Delta f_{2}=-c_{1} \sqrt{\rho \eta}-c_{2} h \rho,
$$

where $c_{1}$ and $c_{2}$ are constants, $h$ is the depth of the grooves on the corrugated surface of QCM electrode.

Some modern QCM biosensors use a sensitive or recognition layer to enhance sensitivity and selectivity for specific ingredients in liquid sample. Such QCM biosensors with specially prepared sensitized surfaces have been used to detect specific proteins in milk [144,145].

Table 7 summarizes information about ultrasonic measurements of milk by various research groups.

\subsection{Prospects for the Further Development of Ultrasound Methods and New Devices for Milk Analysis}

New promising directions for the development of milk characterization can become microfluidic concepts, phononic crystals concepts, and a combination of acoustic and optical approaches in one device.

Microfluidic technologies may be of interest for separating milk ingredients using acoustophoresis and other methods. Pre-separation of particles based on their differences in size and other physical properties allows for more accurate analysis at a later stage. Up to now, various microfluidic devices have been developed to separate and characterize suspensions and emulsions [112,129]. The acoustofluidic separation can become a powerful instrument for accurate milk analysis.

Improving existing and developing new microfluidic sensor devices involves the use of phononic crystals with liquid-filled cavities [146-148]. Phononic crystals can manipulate and tailor elastic and acoustic wave propagation, can create dynamically resonant metastructures. Phononic crystal designs can be scaled to meet given real object dimensions. Resonance frequency and bandwidth are highly sensitive to geometric and material parameters, specifically speed of sound and sound attenuation. High resolution requires high-Q resonators. Fabrication of phononic crystal and resonant sensor structures with high Q-factor is a challenging but realistic task. Recent studies [146-148] show that the use of phononic crystals can improve the resolution and isolation of responses from liquid resonances. The unique combination of the properties and concepts of phononic crystals, resonant sensors, ultrasonic measurement, and acoustofluidic methods can lead us to a new generation of high-sensitive and high-resolutive liquid sensor devices. 


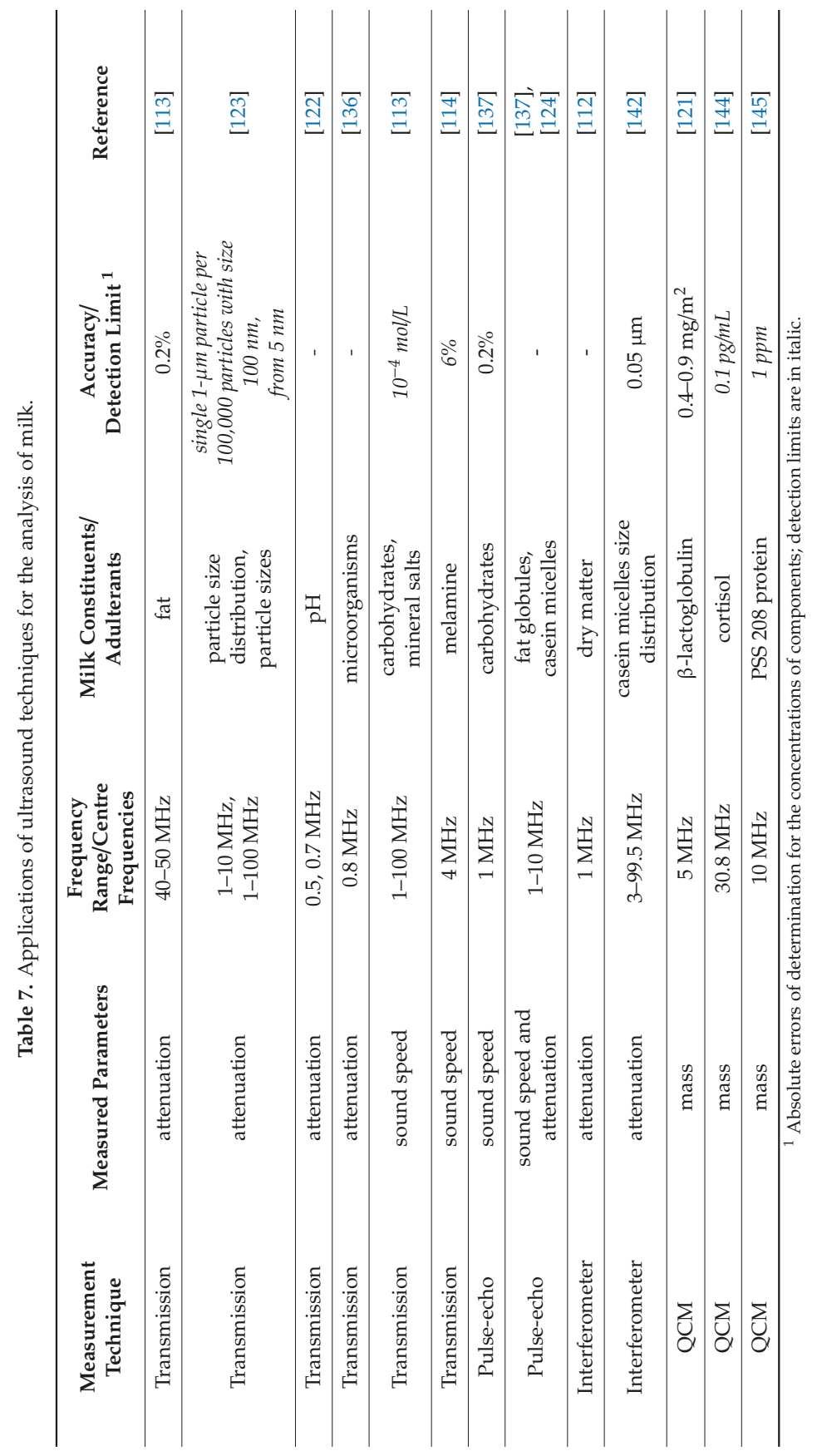


The development of liquid sensor devices that combine the advantages of optical and acoustic methods are carried out both on the basis of traditional methods (like ultrasonic interferometer include optical diffraction [141]) and using promising phononic-photonic crystals approaches [149].

\section{Conclusions}

The use of rapid methods for the analysis of the composition and falsification of dairy products has significant advantages over traditional chemical methods. These advantages include: high productivity and degree of automation, speed of measurements, minimal sample preparation, as well as the ability to determine a large number of parameters from the data of one experiment. But to create optimal analyzers for modern manufacturers, it is still necessary to solve such issues as the possibility of introducing the sensor into the milk pipeline, where it will have to take into account the complex polydisperse composition of milk and the heterogeneity of the flow. The analysis should be carried out in the shortest possible time, preferably in real time, and most importantly for manufacturers, it should be inexpensive.

Optical spectroscopy is an extremely powerful and versatile tool for the quantitative and qualitative analysis of milk composition. Not only the concentrations of the principal milk constituents (fat, protein, lactose) but somatic cells count, common adulterants, residual amounts of antibiotics and disinfectants, amino acid composition, and even milk species could be estimated by optical spectroscopic techniques.

Recent advances in chemometrics made possible more widespread use of NIR spectroscopy which allows developing and implementing spectral equipment for on-site or in-line monitoring of milk quality in real-time.

Optical methods are capable of detecting many types of milk adulteration, but not all of them; using optical spectroscopy in combination with other approaches, for example acoustic methods may greatly improve the analytical possibilities of this technique.

Ultrasound techniques are well-developed instruments used for non-destructive, accurate, and non-invasive measurements. Ultrasound spectrometry offers the ability to characterize dairy products excluding special preparation or disruption of the liquid sample. In addition, ultrasound methods are of interest for monitoring processes in real time.

Acoustic measurement techniques can provide data about protein and fat content, size distribution of air and fat droplets, physiochemical changes of milk with time, content of contaminants.

New promising directions for the development of milk characterization can become microfluidic concepts, phononic crystals concepts and a combination of acoustofluidic and optical approaches in one device.

Author Contributions: Section 2 was written by A.S.; Section 3 was prepared by G.K. and O.S.; Section 4 was written by N.M. and U.S. Final editing of manuscript was made by A.S. and N.M. All authors have read and agreed to the published version of the manuscript.

Funding: This research received no external funding.

Conflicts of Interest: The authors declare no conflict of interest.

\section{References}

1. Caroli, A.; Poli, A.; Ricotta, D.; Banfi, G.; Cocchi, D. Invited review: Dairy intake and bone health: A viewpoint from the state of the art. J. Dairy Sci. 2011, 94, 5249-5262. [CrossRef] [PubMed]

2. Rozenberg, S.; Body, J.-J.; Bruyère, O.; Bergmann, P.; Brandi, M.L.; Cooper, C.; Devogelaer, J.-P.; Gielen, E.; Goemaere, S.; Kaufman, J.-M.; et al. Effects of dairy products consumption on health: Benefits and beliefs-A commentary from the belgian bone club and the european society for clinical and economic aspects of Osteoporosis, Osteoarthritis and Musculoskeletal Diseases. Calcif. Tissue Int. 2016, 98, 1-17. [CrossRef] [PubMed]

3. Van Lieshout, G.A.A.; Lambers, T.T.; Bragt, M.C.E.; Hettinga, K.A. How processing may affect milk protein digestion and overall physiological outcomes: A systematic review. Crit. Rev. Food Sci. Nutr. 2020, 60, 2422-2445. [CrossRef] [PubMed] 
4. Willett, W.C.; Ludwig, D.S. Milk and Health. N. Engl. J. Med. 2020, 382, 644-654. [CrossRef] [PubMed]

5. Neumann, C.; Harris, D.M.; Rogers, L.M. Contribution of animal source foods in improving diet quality and function in children in the developing world. Nutr. Res. 2002, 22, 193-220. [CrossRef]

6. U.S. Department of Health and Human Services; U.S. Department of Agriculture. 2015-2020 Dietary Guidelines for Americans. 8th Edition. December 2015. Available online: https://health.gov/our-work/foodand-nutrition/2015-2020-dietary-guidelines/ (accessed on 30 January 2020).

7. Order of the Ministry of Health of the Russian Federation of August 19, 2016 No. 614 "On Approval of Recommendations on Rational Norms of Food Consumption that Meet Modern Requirements for Healthy Nutrition". Available online: https://static-2.rosminzdrav.ru (accessed on 7 May 2020).

8. Jenkins, T.C.; McGuire, M.A. Major Advances in Nutrition: Impact on Milk Composition. J. Dairy Sci. 2006, 89, 1302-1310. [CrossRef]

9. OECD-FAO Agricultural Development Forecast 2020-2029, for Commodities OECD-FAO Agricultural Outlook 2020-2029. Available online: https://stats.oecd.org/viewhtml.aspx?QueryId=98960\&vh=0000\&vf= $0 \& l \& i l=\& l a n g=$ en\# (accessed on 2 September 2020).

10. Dumuta, A.; Giurgiulescu, L.; Mihaly-Cozmuta, L.; Vosgan, Z. Physical and Chemical Charateristics of Milk. Variation due to Microwave Radiation. Croat. Chem. Acta 2011, 84, 429-433. [CrossRef]

11. Vaskova, H.; Buckova, M. Spectroscopic Measurement and Analysis of Fat in Mi. In Proceedings of the 26th International DAAAM Symposium 2016; Katalinic, B., Ed.; DAAAM International Vienna: Vienna, Austria, 2016; pp. 365-370, ISBN 9783902734075.

12. Bansal, B.K.; Hamann, J.; Grabowskit, N.T.; Singh, K.B. Variation in the composition of selected milk fraction samples from healthy and mastitic quarters, and its significance for mastitis diagnosis. J. Dairy Res. 2005, 72, 144-152. [CrossRef]

13. Mansbridge, R.J.; Blake, J.S. Nutritional factors affecting the fatty acid composition of bovine milk. Br. J. Nutr. 1997, 78 (Suppl. 1), S37-S47. [CrossRef]

14. Santiago, B.M.; da Silva, F.F.; Silva, R.R.; Costa, E.G.L.; Porto Junior, A.F.; Costa, E.N.; de Souza, D.D. Effect of different roughages sources on performance, milk composition, fatty acid profile, and milk cholesterol content of feedlot feed crossbred cows (Holstein $\times$ Zebu). Trop. Anim. Health Prod. 2019, 51, 599-604. [CrossRef]

15. Pereira, R.; Vicente, A. Novel Technologies for Milk Processing. In Engineering Aspects of Milk and Dairy Products; Coimbra, J., Teixeira, J., Eds.; CRC Press: Boca Raton, FL, USA, 2009; pp. 155-174, ISBN 978-1-4200-9022-2.

16. Jensen, R.G. Handbook of Milk Composition; Academic Press: San Diego, CA, USA, 1995; ISBN 9780080533117.

17. Pereira, P.C. Milk nutritional composition and its role in human health. Nutrition 2014, 30, 619-627. [CrossRef]

18. Poonia, A.; Jha, A.; Sharma, R.; Singh, H.B.; Rai, A.K.; Sharma, N. Detection of adulteration in milk: A review. Int. J. Dairy Technol. 2017, 70, 23-42. [CrossRef]

19. Bauman, D.E.; Griinari, J.M. Nutritional regulation of milk fat synthesis. Annu. Rev. Nutr. 2003, 23, $203-227$. [CrossRef] [PubMed]

20. Palmquist, D.L. Milk Fat: Origin of Fatty Acids and Influence of Nutritional Factors Thereon. In Advanced Dairy Chemistry Volume 2 Lipids; Fox, P.F., McSweeney, P.L.H., Eds.; Springer: Boston, MA, USA, 2006; pp. 43-92, ISBN 978-0-387-26364-9.

21. Keenan, T.W.; Mather, I.H. Intracellular origin of milk fat globules and the nature of the milk fat globule membrane. In Advanced Dairy Chemistry Volume 2 Lipids; Fox, P.F., McSweeney, P.L.H., Eds.; Springer: Boston, MA, USA, 2006; pp. 137-171, ISBN 978-0-387-26364-9.

22. Azad, T.; Ahmed, S. Common milk adulteration and their detection techniques. Food Contam. 2016, 3. [CrossRef]

23. Kala, R.; Samková, E.; Hanuš, O.; Pecová, L.; Sekmokas, K.; Riaukienè, D. Milk Protein Analysis: An Overview of the Methods-Development and Application. Acta Univ. Agric. Silv. Mendel. Brun. 2019, 67, 345-359. [CrossRef]

24. Bhat, M.Y.; Dar, T.A.; Singh, L.R. Casein Proteins: Structural and Functional Aspects. In Milk Proteins-From Structure to Biological Properties and Health Aspects; Gigli, I., Ed.; InTech: London, UK, 2016; ISBN 978-953-51-2536-5.

25. Walstra, P.; Walstra, P.; Wouters, J.T.M.; Geurts, T.J. Dairy Science and Technology; CRC Press: Boca Raton, FL, USA, 2005; ISBN 9780429116148.

26. Rizzoli, R. Dairy products, yogurts, and bone health. Am. J. Clin. Nutr. 2014, 99, 1256S-1262S. [CrossRef] 
27. Evershed, R.; Temple, N. Sorting the Beeffrom the Bull. The Science of Food Fraud Forensics/Richard Evershed E Nicola Temple; Bloomsbury Sigma: London, UK, 2016; ISBN 9781472911339.

28. Dave, A.; Banwari, D.; Srivastava, S.; Sadistap, S. Optical sensing system for detecting water adulteration in milk. In Proceedings of the Global Humanitarian Technology Conference (GHTC), Seattle, WA, USA, 13-16 October 2016; pp. 634-639, ISBN 978-1-5090-2432-2.

29. Fox, P.F.; Uniacke-Lowe, T.; McSweeney, P.L.H.; O'Mahony, J.A. Water in Milk and Dairy Products. In Dairy Chemistry and Biochemistry; Fox, P.F., Uniacke-Lowe, T., McSweeney, P.L.H., O'Mahony, J.A., Eds.; Springer International Publishing: Cham, Switzerland, 2015; pp. 299-320, ISBN 978-3-319-14891-5.

30. Inácio, M.R.C.; de Moura, M.F.V.; de Lima, K.M.G. Classification and determination of total protein in milk powder using near infrared reflectance spectrometry and the successive projections algorithm for variable selection. Vib. Spectrosc. 2011, 57, 342-345. [CrossRef]

31. Olson, B.J.S.C.; Markwell, J. Assays for determination of protein concentration. Curr. Protoc. Protein Sci. 2007, 38, A.3A.1-A.3A.29. [CrossRef]

32. ISO. IDF 105:2008 Milk-Determination of Fat Content-Gerber Butyrometers. Available online: https: //www.iso.org/standard/51018.html (accessed on 2 September 2020).

33. Xin, Q.; Ling, H.Z.; Long, T.J.; Zhu, Y. The rapid determination of fat and protein content in fresh raw milk using the laser light scattering technology. Opt. Lasers Eng. 2006, 44, 858-869. [CrossRef]

34. Agranovich, D.; Ben Ishai, P.; Katz, G.; Bezman, D.; Feldman, Y. Dielectric spectroscopy study of water dynamics in frozen bovine milk. Colloids Surf. B Biointerfaces 2016, 141, 390-396. [CrossRef] [PubMed]

35. Huang, H.; Yu, H.; Xu, H.; Ying, Y. Near infrared spectroscopy for on/in-line monitoring of quality in foods and beverages: A review. J. Food Eng. 2008, 87, 303-313. [CrossRef]

36. ISO (International Organization for Standardization). Whole Milk_Determination of Milk Fat, Protein and Lactose Content-Guidance on the Operation of Mid-Infrared Instruments; International Standard ISO 9622:2000/IDF 141C:2000; International Dairy Federation: Brussels, Belgium, 2000.

37. Priev, D.; Ponomarev, V.; Priev, A. Acoustic radiation forces in monitoring of milk composition. J. Acoust. Soc. Am. 2008, 123, 3789. [CrossRef]

38. Manske, G.A.; Rigo, E.; Gomes, F.J.; Schogor, A.L.B. Infrared or ultrasonic milk analysis can affect its results? Cienc. Rural 2019, 49. [CrossRef]

39. Operation Manual for Klever-2. Available online: https://www.kleverltd.ru (accessed on 8 August 2020)

40. Manual for the Operation of Lactan. Available online: https://sibagropribor.ru/ (accessed on 8 August 2020).

41. Ekomilk Operation Manual. Available online: http://ekomilk.ru/ (accessed on 8 August 2020).

42. Lactoscan Operation Manual. Available online: https://www.milkotronic.com/downloads.html (accessed on 8 August 2020).

43. Operation Manual for Bentley. Available online: http://www.bentleyplemtech.ru/ (accessed on 8 August 2020).

44. Zhu, Z.; Guo, W. Recent developments on rapid detection of main constituents in milk: A review. Crit. Rev. Food Sci. Nutr. 2020, 1-13. [CrossRef] [PubMed]

45. Mäntele, W.; Deniz, E. UV-VIS absorption spectroscopy: Lambert-Beer reloaded. Spectrochim. Acta Part A Mol. Biomol. Spectrosc. 2017, 173, 965-968. [CrossRef]

46. Gupta, K.; Shenoy, M.R. Method to determine the anisotropy parameter g of a turbid medium. Appl. Opt. 2018, 57, 7559-7563. [CrossRef]

47. Aernouts, B.; Van Beers, R.; Watté, R.; Huybrechts, T.; Lammertyn, J.; Saeys, W. Visible and near-infrared bulk optical properties of raw milk. J. Dairy Sci. 2015, 98, 6727-6738. [CrossRef]

48. Steponavičius, R.; Thennadil, S.N. Full correction of scattering effects by using the radiative transfer theory for improved quantitative analysis of absorbing species in suspensions. Appl. Spectrosc. 2013, 67, 526-535. [CrossRef]

49. Regnima, G.O.; Koffi, T.; Bagui, O.; Kouacou, A.; Kristensson, E.; Zoueu, J.; Berrocal, E. Quantitative measurements of turbid liquids via structured laser illumination planar imaging where absorption spectrophotometry fails. Appl. Opt. 2017, 56, 3929-3938. [CrossRef]

50. Stocker, S.; Foschum, F.; Krauter, P.; Bergmann, F.; Hohmann, A.; Happ, C.S.; Kienle, A. Broadband Optical Properties of Milk. Appl. Spectrosc. 2017, 71, 951-962. [CrossRef]

51. Michalski, M.-C.; Briard, V.; Michel, F. Optical parameters of milk fat globules for laser light scattering measurements. Lait 2001, 81, 787-796. [CrossRef] 
52. Aernouts, B.; van Beers, R.; Watté, R.; Huybrechts, T.; Jordens, J.; Vermeulen, D.; Gerven, T.V.; Lammertyn, J.; Saeys, W. Effect of ultrasonic homogenization on the Vis/NIR bulk optical properties of milk. Colloids Surf. B Biointerfaces 2015, 126, 510-519. [CrossRef]

53. Tsenkova, R.; Atanassova, S.; Kawano, S.; Toyoda, K. Somatic cell count determination in cow's milk by near-infrared spectroscopy: A new diagnostic tool. J. Anim. Sci. 2001, 79, 2550-2557. [CrossRef] [PubMed]

54. Stefanescu, R.; Brebu, S.; Matei, M.; Risca, I.M.; Surleva, A.; Drochioiu, G. Contribution to casein determination by UV spectrophotometry. Acta Chem. Iasi. 2017, 25, 112-126. [CrossRef]

55. McCarthy, O.J. Physical and Physico-Chemical Properties of Milk. In Encyclopedia of Dairy Sciences; Elsevier: Amsterdam, The Netherlands, 2002; Volume 3, pp. 467-477, ISBN 9780123744029.

56. Xiong, S.; Adhikari, B.; Chen, X.D.; Che, L. Determination of ultra-low milk fat content using dual-wavelength ultraviolet spectroscopy. J. Dairy Sci. 2016, 99, 9652-9658. [CrossRef]

57. Miller, E.S.; Mackinney, G.; Zscheile, F.P. Absorption spectra of alpha and beta carotenes and lycopene. Plant Physiol. 1935, 10, 375-381. [CrossRef]

58. Koziol, J. Studies on flavins in organic solvents-i. Spectral characteristics of riboflavin, riboflavin tetrabutyrate and lumichrome. Photochem. Photobiol. 1966, 5, 41-54. [CrossRef]

59. Wójcicki, K. Applying NIR spectroscopy to evaluate quality of whey protein supplements available on the polish market. Żywność Naukatechnologia Jakość 2018, 25, 59-70. [CrossRef]

60. Brandão, M.C.M.P.; Carmo, A.P.; Bell, M.J.V.; Anjos, V.C. Characterization of milk by infrared spectroscopy. Rev. Inst. Latic. Cândid. 2010, 65, 30-33.

61. Holroyd, S.E. The Use of near Infrared Spectroscopy on Milk and Milk Products. J. Near Infrared Spectrosc. 2013, 21, 311-322. [CrossRef]

62. Etzion, Y.; Linker, R.; Cogan, U.; Shmulevich, I. Determination of Protein Concentration in Raw Milk by Mid-Infrared Fourier Transform Infrared/Attenuated Total Reflectance Spectroscopy. J. Dairy Sci. 2004, 87, 2779-2788. [CrossRef]

63. Mohamed, H.; Nagy, P.; Agbaba, J.; Kamal-Eldin, A. Use of near and mid infra-red spectroscopy for analysis of protein, fat, lactose and total solids in raw cow and camel milk. Food Chem. 2020, 334, 127436. [CrossRef] [PubMed]

64. Bogomolov, A.; Belikova, V.; Galyanin, V.; Melenteva, A.; Meyer, H. Reference-free spectroscopic determination of fat and protein in milk in the visible and near infrared region below $1000 \mathrm{~nm}$ using spatially resolved diffuse reflectance fiber probe. Talanta 2017, 167, 563-572. [CrossRef] [PubMed]

65. Bogomolov, A.; Melenteva, A. Scatter-based quantitative spectroscopic analysis of milk fat and total protein in the region 400-1100 $\mathrm{nm}$ in the presence of fat globule size variability. Chemom. Intell. Lab. Syst. 2013, 126, 129-139. [CrossRef]

66. Bogomolov, A.; Dietrich, S.; Boldrini, B.; Kessler, R.W. Quantitative determination of fat and total protein in milk based on visible light scatter. Food Chem. 2012, 134, 412-418. [CrossRef]

67. Melenteva, A.; Galyanin, V.; Savenkova, E.; Bogomolov, A. Building global models for fat and total protein content in raw milk based on historical spectroscopic data in the visible and short-wave near infrared range. Food Chem. 2016, 203, 190-198. [CrossRef]

68. Goulden, J. Analysis of milk by infra-red absorption. J. Dairy Res. 1964, 3, 273-284. [CrossRef]

69. de Marchi, M.; Penasa, M.; Zidi, A.; Manuelian, C.L. Invited review: Use of infrared technologies for the assessment of dairy products-Applications and perspectives. J. Dairy Sci. 2018, 101, 10589-10604. [CrossRef]

70. Pereira, C.; Luiz, L.C.; Bell, M.J.V.; Anjos, V. Near and Mid Infrared Spectroscopy to Assess Milk Products Quality: A Review of Recent Applications. J. Dairy Res. Technol. 2020, 3, 100014. [CrossRef]

71. Balabin, R.M.; Safieva, R.Z.; Lomakina, E.I. Comparison of linear and nonlinear calibration models based on near infrared (NIR) spectroscopy data for gasoline properties prediction. Chemom. Intell. Lab. Syst. 2007, 88, 183-188. [CrossRef]

72. Balabin, R.M.; Safieva, R.Z.; Lomakina, E.I. Wavelet neural network (WNN) approach for calibration model building based on gasoline near infrared (NIR) spectra. Chemom. Intell. Lab. Syst. 2008, 93, 58-62. [CrossRef]

73. Andrade, J.; Guimarães Pereira, C.; de Almeida, J.C., Jr.; Viana, C.C.; de Oliveira Neves, L.N.; da Silva, P.H.; Bell, M.J.; dos Anjos, V.D. FTIR-ATR determination of protein content to evaluate whey protein concentrate adulteration. LWT 2019, 99, 166-172. [CrossRef] 
74. Balan, B.; Dhaulaniya, A.S.; Jamwal, R.; Sodhi, K.K.; Kelly, S.D.; Cannavan, A.; Singh, D.K. Application of Attenuated Total Reflectance-Fourier Transform Infrared (ATR-FTIR) spectroscopy coupled with chemometrics for detection and quantification of formalin in cow milk. Vib. Spectrosc. 2020, 107, 103033. [CrossRef]

75. Balan, B.; Dhaulaniya, A.S.; Jamwal, R.; Yadav, A.; Kelly, S.; Cannavan, A.; Singh, D.K. Rapid detection and quantification of sucrose adulteration in cow milk using Attenuated total reflectance-Fourier transform infrared spectroscopy coupled with multivariate analysis. Spectrochim. Acta A Mol. Biomol. Spectrosc. 2020, 240, 118628. [CrossRef]

76. Franzoi, M.; Niero, G.; Visentin, G.; Penasa, M.; Cassandro, M.; de Marchi, M. Variation of Detailed Protein Composition of Cow Milk Predicted from a Large Database of Mid-Infrared Spectra. Animals 2019, 9, 176. [CrossRef]

77. Cirak, O.; Icyer, N.; Durak, M. Rapid detection of adulteration of milks from different species using Fourier Transform Infrared Spectroscopy (FTIR). J. Dairy Res. 2018, 85, 222-225. [CrossRef] [PubMed]

78. Balabin, R.M.; Smirnov, S.V. Melamine detection by mid- and near-infrared (MIR/NIR) spectroscopy: A quick and sensitive method for dairy products analysis including liquid milk, infant formula, and milk powder. Talanta 2011, 85, 562-568. [CrossRef] [PubMed]

79. Botelho, B.G.; Reis, N.; Oliveira, L.S.; Sena, M.M. Development and analytical validation of a screening method for simultaneous detection of five adulterants in raw milk using mid-infrared spectroscopy and PLS-DA. Food Chem. 2015, 181, 31-37. [CrossRef]

80. Casarrubias-Torres, L.M.; Meza-Márquez, O.G.; Osorio-Revilla, G.; Gallardo-Velazquez, T. Mid-infrared spectroscopy and multivariate analysis for determination of tetracycline residues in cow's milk. Acta Vet. Brno 2018, 87, 181-188. [CrossRef]

81. Rienesl, L.; Khayatzadeh, N.; Köck, A.; Dale, L.; Werner, A.; Grelet, C.; Gengler, N.; Auer, F.J.; Egger-Danner, C.; Massart, X.; et al. Mastitis detection from milk mid-infrared (MIR) spectroscopy in dairy cows. Acta Univ. Agric. Silv. Mendel. Brun. 2019, 67, 1221-1226. [CrossRef]

82. Libnau, F.O.; Kvalheim, O.M.; Christy, A.A.; Toft, J. Spectra of water in the near- and mid-infrared region. Vib. Spectrosc. 1994, 7, 243-254. [CrossRef]

83. Linker, R.; Etzion, Y. Potential and limitation of mid-infrared attenuated total reflectance spectroscopy for real time analysis of raw milk in milking lines. J. Dairy Res. 2009, 76, 42-48. [CrossRef] [PubMed]

84. Aernouts, B.; Polshin, E.; Lammertyn, J.; Saeys, W. Visible and near-infrared spectroscopic analysis of raw milk for cow health monitoring: Reflectance or transmittance? J. Dairy Sci. 2011, 94, 5315-5329. [CrossRef] [PubMed]

85. Melfsen, A.; Holstermann, M.; Haeussermann, A.; Molkentin, J.; Susenbeth, A.; Hartung, E. Accuracy and application of milk fatty acid estimation with diffuse reflectance near-infrared spectroscopy. J. Dairy Res. 2018, 85, 212-221. [CrossRef]

86. Katsumata, T.; Aizawa, H.; Komuro, S.; Ito, S.; Matsumoto, T. Quantitative analysis of fat and protein concentrations of milk based on fibre-optic evaluation of back scattering intensity. Int. Dairy J. 2020, 109, 104743. [CrossRef]

87. Laporte, M.; Paquin, P. Near-infrared analysis of fat, protein, and casein in cow's milk. J. Agric. Food Chem. 1999, 47, 2600-2605. [CrossRef]

88. Tsenkova, R.; Atanassova, S.; Toyoda, K.; Ozaki, Y.; Itoh, K.; Fearn, T. Near-Infrared Spectroscopy for Dairy Management: Measurement of Unhomogenized Milk Composition. J. Dairy Sci. 1999, 82, 2344-2351. [CrossRef]

89. Melfsen, A.; Hartung, E.; Haeussermann, A. Accuracy of milk composition analysis with near infrared spectroscopy in diffuse reflection mode. Biosyst. Eng. 2012, 112, 210-217. [CrossRef]

90. Surkova, A.; Belikova, V.; Kirsanov, D.; Legin, A.; Bogomolov, A. Towards an optical multisensor system for dairy: Global calibration for fat analysis in homogenized milk. Microchem. J. 2019, 149, 104012. [CrossRef]

91. Mazivila, S.J.; Páscoa, R.N.M.J.; Castro, R.C.; Ribeiro, D.S.M.; Santos, J.L.M. Detection of melamine and sucrose as adulterants in milk powder using near-infrared spectroscopy with DD-SIMCA as one-class classifier and MCR-ALS as a means to provide pure profiles of milk and of both adulterants with forensic evidence: A short communication. Talanta 2020, 216, 120937. [CrossRef]

92. Kamboj, U.; Kaushal, N.; Jabeen, S. Near Infrared Spectroscopy as an efficient tool for the Qualitative and Quantitative Determination of Sugar Adulteration in Milk. J. Phys. Conf. Ser. 2020, 1531, 012024. [CrossRef] 
93. Mabood, F.; Ali, L.; Boque, R.; Abbas, G.; Jabeen, F.; Haq, Q.M.; Hussain, J.; Hamaed, A.M.; Naureen, Z.; Al-Nabhani, M.; et al. Robust Fourier transformed infrared spectroscopy coupled with multivariate methods for detection and quantification of urea adulteration in fresh milk samples. Food Sci. Nutr. 2019, 1-10. [CrossRef]

94. Tsenkova, R.; Meilina, H.; Kuroki, S.; Burns, D.H. Near infrared spectroscopy using short wavelengths and leave-one-cow-out cross-validation for quantification of somatic cells in milk. J. Near Infrared Spectrosc. 2009, 17, 345-351. [CrossRef]

95. Yang, B.; Zhu, Z.; Gao, M.; Yan, X.; Zhu, X.; Guo, W. A portable detector on main compositions of raw and homogenized milk. Comput. Electron. Agric. 2020, 177, 105668. [CrossRef]

96. Kawasaki, M.; Kawamura, S.; Tsukahara, M.; Morita, S.; Komiya, M.; Natsuga, M. Near-infrared spectroscopic sensing system for on-line milk quality assessment in a milking robot. Comput. Electron. Agric. 2008, 63, 22-27. [CrossRef]

97. Diaz-Olivares, J.A.; Adriaens, I.; Stevens, E.; Saeys, W.; Aernouts, B. Online Milk Composition Analysis with an On-farm Near-Infrared Sensor. Available Online: https://www.biorxiv.org/content/10.1101/2020.06.02. 129742v1.full.pdf (accessed on 15 October 2020).

98. Aleixo, P.C.; Nóbrega, J.A. Direct determination of iron and selenium in bovine milk by graphite furnace atomic absorption spectrometry. Food Chem. 2003, 83, 457-462. [CrossRef]

99. Birghila, S.; Dobrinas, S.; Stanciu, G.; Soceanu, A. Determination of major and minor elements in milk through ICP-AES. Environ. Eng. Manag. J. 2008, 7, 805-808. [CrossRef]

100. Asfaw, A.; Wibetoe, G. Simultaneous determination of hydride (Se) and non-hydride-forming (Ca, Mg, K, P, $\mathrm{S}$ and $\mathrm{Zn}$ ) elements in various beverages (beer, coffee, and milk), with minimum sample preparation, by ICP-AES and use of a dual-mode sample-introduction system. Anal. Bioanal. Chem. 2005, 382, 173-179. [CrossRef]

101. Mazurek, S.; Szostak, R.; Czaja, T.; Zachwieja, A. Analysis of milk by FT-Raman spectroscopy. Talanta 2015, 138, 285-289. [CrossRef]

102. He, H.; Sun, D.-W.; Pu, H.; Chen, L.; Lin, L. Applications of Raman spectroscopic techniques for quality and safety evaluation of milk: A review of recent developments. Crit. Rev. Food Sci. Nutr. 2019, 595, 770-793. [CrossRef]

103. Reiner, J.; Protte, K.; Hinrichs, J. Investigation of the Applicability of Raman Spectroscopy as Online Process Control during Consumer Milk Production. Chem. Eng. 2020, 4, 45. [CrossRef]

104. Soulat, J.; Andueza, D.; Graulet, B.; Girard, C.L.; Labonne, C.; Aït-Kaddour, A.; Martin, B.; Ferlay, A. Comparison of the potential abilities of three spectroscopy methods: Near-infrared, mid-infrared, and molecular fluorescence, to predict carotenoid, vitamin and fatty acid contents in cow milk. Foods 2020, 9, 592. [CrossRef]

105. Ntakatsane, M.; Chen, P.; Liu, J.; Mosebi, P.; Xu, L.; Matebesi, P.; Wang, Y. Multi-dimensional fluorescence spectroscopy coupled with chemometrics in rapid antibiotic detection and discrimination. J. Food Meas. Charact. 2020, 14, 1892-1900. [CrossRef]

106. Genis, D.O.; Bilge, G.; Sezer, B.; Durna, S.; Boyaci, I.H. Identification of cow, buffalo, goat and ewe milk species in fermented dairy products using synchronous fluorescence spectroscopy. Food Chem. 2019, 284, 60-66. [CrossRef] [PubMed]

107. Yang, Y.; Hettinga, K.A.; Erasmus, S.W.; Pustjens, A.M.; van Ruth, S.M. Opportunities for fraudsters: When would profitable milk adulterations go unnoticed by common, standardized FTIR measurements? Food Res. Int. 2020, 136, 109543. [CrossRef]

108. Villa-Arango, S.; Torres, R.; Kyriacou, P.A.; Lucklum, R. Acoustic spectrometer: Resonant sensing platform for measuring volumetric properties of liquid samples. In Proceedings of the VII Latin American Congress on Biomedical Engineering CLAIB 2016, Bucaramanga, Santander, Colombia, 26-28 October 2016; Torres, I., Bustamante, J., Sierra, D.A., Eds.; Springer: Singapore, 2017; pp. 70-73, ISBN 978-981-10-4085-6.

109. Szabo, T.L. Diagnostic Ultrasound Imaging. Inside out/Thomas L. Szabo; Elsevier Academic Press: Amsterdam, The Netherlands; Oxford, UK, 2004; ISBN 0-12-680145-2.

110. Mohammadi, V.; Ghasemi-Varnamkhasti, M.; Ebrahimi, R.; Abbasvali, M. Ultrasonic techniques for the milk production industry. Measurement 2014, 58, 93-102. [CrossRef]

111. Ali, M.-H.; Ahmad, A. Attenuation of ultrasound in reconstituted milk. Int. J. Sci. Environ. Technol. 2017, 6, 1828-1832. 
112. Adami, A.; Mortari, A.; Morganti, E.; Lorenzelli, L. Microfluidic Sample Preparation Methods for the Analysis of Milk Contaminants. J. Sens. 2016, 2016, 1-9. [CrossRef]

113. Dukhin, A.S.; Goetz, P.J.; Travers, B. Use of ultrasound for characterizing dairy products. J. Dairy Sci. 2005, 88, 1320-1334. [CrossRef]

114. Elvira, L.; Rodríguez, J.; Lynnworth, L.C. Sound speed and density characterization of milk adulterated with melamine. J. Acoust. Soc. Am. 2009, 125, EL177-EL182. [CrossRef]

115. Halachmi, I.; Guarino, M.; Bewley, J.; Pastell, M. Smart Animal Agriculture: Application of Real-Time Sensors to Improve Animal Well-Being and Production. Annu. Rev. Anim. Biosci. 2019, 7, 403-425. [CrossRef] [PubMed]

116. Mohammadi, V.; Ghasemi-Varnamkhasti, M.; González, L.A. Analytical measurements of ultrasound propagation in dairy products: A review. Trends Food Sci. Technol. 2017, 61, 38-48. [CrossRef]

117. McClements, D.J. Ultrasonic characterization of foods and drinks: Principles, methods, and applications. Crit. Rev. Food Sci. Nutr. 1997, 37, 1-46. [CrossRef]

118. De Luca, M.; Santonico, M.; Pennazza, G.; Iarossi, S. Ultrasound based sensor for fat detection in fresh milk. In Sensors; Baldini, F., D'Amico, A., Di Natale, C., Siciliano, P., Seeber, R., de Stefano, L., Bizzarri, R., Andò, B., Eds.; Springer: New York, NY, USA, 2014; pp. 499-502, ISBN 978-1-4614-3859-5.

119. Munir, M.; Nadeem, M.; Qureshi, T.M.; Leong, T.S.H.; Gamlath, C.J.; Martin, G.J.O.; Ashokkumar, M. Effects of high pressure, microwave and ultrasound processing on proteins and enzyme activity in dairy systems-A review. Innov. Food Sci. Emerg. Technol. 2019, 57, 102192. [CrossRef]

120. Paniwnyk, L. Applications of ultrasound in processing of liquid foods: A review. Ultrason. Sonochem. 2017, 38, 794-806. [CrossRef] [PubMed]

121. Murray, B.S.; Deshaires, C. Monitoring protein fouling of metal surfaces via a quartz crystal microbalance. J. Colloid Interface Sci. 2000, 227, 32-41. [CrossRef] [PubMed]

122. Gan, T.H.; Pallav, P.; Hutchins, D.A. Non-contact ultrasonic quality measurements of food products. J. Food Eng. 2006, 77, 239-247. [CrossRef]

123. Dukhin, A.S.; Goetz, P.J. Ultrasound for Characterizing Colloids. Particle Sizing, Zeta Potential, Rheology; Elsevier: Amsterdam, The Netherlands, 2002.

124. McClements, D.J. Ultrasonic characterisation of emulsions and suspensions. Adv. Colloid Interface Sci. 1991, 37, 33-72. [CrossRef]

125. Natta, G.; Baccaredda, M. Sulla velocita di propagazione degli ultrasuoni nelle miscele ideali. Atti Accad. Naz. Lincei-Rend. Sc. Fis. Mat. Nat. 1948, 4, 360-366.

126. Rowlinson, J.S.; Swinton, F. Liquids and Liquid Mixtures, 3rd ed.; Butterworth Scientific: Oxford, UK, 1982.

127. Flory, P.J. Statistical Thermodynamics of Liquid Mixtures. J. Am. Chem. Soc. 1965, 87, 1833-1838. [CrossRef]

128. Hahn, P.; Dual, J. A numerically efficient damping model for acoustic resonances in microfluidic cavities. Phys. Fluids 2015, 27, 62005. [CrossRef]

129. Trujillo, F.J.; Juliano, P.; Barbosa-Cánovas, G.; Knoerzer, K. Separation of suspensions and emulsions via ultrasonic standing waves-A review. Ultrason. Sonochem. 2014, 21, 2151-2164. [CrossRef] [PubMed]

130. Fox, P.F.; Uniacke-Lowe, T.; McSweeney, P.L.H.; O’Mahony, J.A. Physical Properties of Milk. In Dairy Chemistry and Biochemistry; Fox, P.F., Uniacke-Lowe, T., McSweeney, P.L.H., O’Mahony, J.A., Eds.; Springer International Publishing: Cham, Switzerland, 2015; pp. 321-343, ISBN 978-3-319-14891-5.

131. McCarthy, O.J.; Singh, H. Physico-chemical Properties of Milk. In Advanced Dairy Chemistry; McSweeney, P., Fox, P.F., Eds.; Springer: New York, NY, USA, 2009; pp. 691-758, ISBN 978-0-387-84864-8.

132. Singh, H.; McCarthy, O.J.; Lucey, J.A. Physico-Chemical Properties of Milk. In Advanced Dairy Chemistry Volume 3; Fox, P.F., Ed.; Springer: Boston, MA, USA, 1997; pp. 469-518, ISBN 978-1-4757-4411-8.

133. Russel, W.B. Brownian motion of small particles suspended in liquids. Annu. Rev. Fluid Mech. 1981, 13, 425-455. [CrossRef]

134. Caprita, R.; Caprita, A.; Benscik, I.; Cretescu, I. The Influence of Milk Protein Content on the Surface Tension and Viscosity. Acta Vet. Scand. 2003, 44, P86. [CrossRef]

135. Vives, A.A. Piezoelectric Transducers and Applications; Springer: Berlin/Heidelberg, Germany, 2008; ISBN 978-3-540-77507-2.

136. Elvira, L.; Sampedro, L.; de Espinosa, F.M.; Matesanz, J.; Gómez-Ullate, Y.; Resa, P.; Echevarría, F.J.; Iglesias, J.R. Eight-channel ultrasonic device for non-invasive quality evaluation in packed milk. Ultrasonics 2006, 45, 92-99. [CrossRef] 
137. McClements, D.J. Advances in the application of ultrasound in food analysis and processing. Trends Food Sci. Technol. 1995, 6, 293-299. [CrossRef]

138. Saxena, I.; Pathak, R.N.; Kumar, V.; Devi, R. Introduction of ultrasonic interferometer and experimental techniques for determination of ultrasonic velocity, density, viscosity and various thermodynamic parameters. Int. J. Appl. Res. 2015, 1, 562-569. [CrossRef]

139. Kucera, D.M.; Ketterson, J.B. Variable path cryogenic acoustic interferometer. Rev. Sci. Instrum. 1998, 69, 4156-4159. [CrossRef]

140. Sharma, S.; Mishra, U.K.; Yadav, S.; Dubey, P.K. Improved ultrasonic interferometer technique for propagation velocity and attenuation measurement in liquids. Rev. Sci. Instrum. 2019, 90, 45107. [CrossRef] [PubMed]

141. Inoue, N.; Hirai, M.; Hasegawa, T.; Matsuzawa, K. A new ultrasonic interferometer for velocity measurement in liquids using optical diffraction. J. Phys. D Appl. Phys. 1986, 19, 1439-1447. [CrossRef]

142. Gülseren, I.; Alexander, M.; Corredig, M. Probing the colloidal properties of skim milk using acoustic and electroacoustic spectroscopy. Effect of concentration, heating and acidification. J. Colloid Interface Sci. 2010, 351, 493-500. [CrossRef] [PubMed]

143. Martin, S.J.; Wessendorf, K.O.; Gebert, C.T.; Frye, G.C.; Cernosek, R.W.; Casaus, L.; Mitchell, M.A. Measuring liquid properties with smooth- and textured-surface resonators. In Proceedings of the Annual Frequency Control Symposium, Salt Lake City, UT, USA, 2 June 1993; pp. 603-608. [CrossRef]

144. Ito, T.; Aoki, N.; Tsuchiya, A.; Kaneko, S.; Akiyama, K.; Uetake, K.; Suzuki, K. Detection of Stress Hormone in the Milk for Animal Welfare Using QCM Method. J. Sens. 2017, 2017, 1-7. [CrossRef]

145. Sakti, S.P.; Chabibah, N.; Ayu, S.P.; Padaga, M.C.; Aulanni'am, A.A. Development of QCM Biosensor with specific cow milk protein antibody for candidate milk adulteration detection. J. Sens. 2016, 2016, 1-7. [CrossRef]

146. Mukhin, N.; Kutia, M.; Oseev, A.; Palis, S.; Steinmann, U.; Lucklum, R. Narrow band solid-liquid composite arrangements: Alternative solutions for phononic crystal-based liquid sensors. Sensors 2019, 19, 3743. [CrossRef] [PubMed]

147. Mukhin, N.; Lucklum, R. QCM based sensor for detecting volumetric properties of liquids. Curr. Appl. Phys. 2019, 19, 679-682. [CrossRef]

148. Oseev, A.; Lucklum, R.; Zubtsov, M.; Schmidt, M.-P.; Mukhin, N.V.; Hirsch, S. SAW-Based Phononic Crystal Microfluidic Sensor-Microscale Realization of Velocimetry Approaches for Integrated Analytical Platform Applications. Sensors 2017, 17, 2187. [CrossRef] [PubMed]

149. Lucklum, R.; Zubtsov, M.; Oseev, A. Phoxonic crystals-A new platform for chemical and biochemical sensors. Anal. Bioanal. Chem. 2013, 405, 6497-6509. [CrossRef]

Publisher's Note: MDPI stays neutral with regard to jurisdictional claims in published maps and institutional affiliations.

(C) 2020 by the authors. Licensee MDPI, Basel, Switzerland. This article is an open access article distributed under the terms and conditions of the Creative Commons Attribution (CC BY) license (http://creativecommons.org/licenses/by/4.0/). 



\title{
The Structure and Crystallizing Process of NiAu Alloy: A Molecular Dynamics Simulation Method
}

\author{
Dung Nguyen Trong ${ }^{1, *}$, Van Cao Long ${ }^{1}$ and Ştefan Ţălu ${ }^{2}$ \\ 1 Institute of Physics, University of Zielona Góra, 65-516 Zielona Góra, Poland; caolongvanuz@gmail.com \\ 2 The Directorate of Research, Development and Innovation Management, Technical University of Cluj-Napoca, \\ 15 Constantin Daicoviciu St., Cluj-Napoca, 400020 Cluj County, Romania; stefan_ta@yahoo.com \\ * Correspondence: dungntsphn@gmail.com
}

check for

updates

Citation: Nguyen Trong, D.; Cao Long, V.; Țălu, Ş. The Structure and Crystallizing Process of NiAu Alloy: A Molecular Dynamics Simulation Method. J. Compos. Sci. 2021, 5, 18. https://doi.org/10.3390/jcs5010018

Received: 16 December 2020

Accepted: 3 January 2021

Published: 7 January 2021

Publisher's Note: MDPI stays neutral with regard to jurisdictional clai$\mathrm{ms}$ in published maps and institutional affiliations.

Copyright: (ㅇ 2021 by the authors. Licensee MDPI, Basel, Switzerland. This article is an open access article distributed under the terms and conditions of the Creative Commons Attribution (CC BY) license (https:// creativecommons.org/licenses/by/ $4.0 /)$.

\begin{abstract}
This paper studies the influence of factors such as heating rate, atomic number, temperature, and annealing time on the structure and the crystallization process of NiAu alloy. Increasing the heating rate leads to the moving process from the crystalline state to the amorphous state; increasing the temperature $(\mathrm{T})$ also leads to a changing process into the liquid state; when the atomic number $(\mathrm{N})$, and $\mathrm{t}$ increase, it leads to an increased crystalline process. As a result, the dependence between size (l) and atomic number $(\mathrm{N})$, the total energy of the system $\left(\mathrm{E}_{\mathrm{tot}}\right)$ with $\mathrm{N}$ as $1 \sim \mathrm{N}^{-1 / 3}$, and $-\mathrm{E}_{\text {tot }}$ always creates a linear function of $\mathrm{N}$, glass temperature $\left(\mathrm{T}_{\mathrm{g}}\right)$ of the NiAu alloy, which is $\mathrm{T}_{\mathrm{g}}=600 \mathrm{~K}$. During the study, the number of the structural units was determined by the Common Neighborhood Analysis (CNA) method, radial distribution function (RDF), size (l), and $\mathrm{E}_{\text {tot. }}$. The result shows that the influencing factors to the structure of NiAu alloy are considerable.
\end{abstract}

Keywords: annealing time; crystallize process; molecular dynamics; NiAu alloy; structure

\section{Introduction}

Today, the alloys PtAu [1], PdAu [2], NiAu [3] are receiving great attention from theoretical and experimental scientists $[4,5]$ because they have many special properties compared to pure materials [6,7]. In particular, NiAu alloy is synthesized by two metals, $\mathrm{Ni}$ and $\mathrm{Au}$, and applied in many fields of science, technology, and life such as magnetism [8-10], photocatalyst [11,12], DNA markers [13,14], or cancer treatment [15] as the agent in cell separation [16,17], and biological processing $[18,19]$ which increase contrast and biological agents [20]. The properties of alloys such as ionization, optics, and magnetism [21] depend on the shape and the concentration of doping [22].

There are a lot of methods to research and manufacture NiAu alloy, such as experimental, theoretical, and simulated. The experimental method includes mechanical grinding [23], electric arc [24], deposition [25,26], electrochemical [27], hydrothermal [28], Sol-Gel [29], mechanics [30], micro-emulsion [31], and colloidal solution [32].

These methods can change the size and shape of the alloy in normal conditions and do not require an environment of pressure $(\mathrm{P})$ and high temperature $(\mathrm{T})$ [33]. Theoretical methods include initial principles, Ab initio model [34], and methods of Molecular Dynamics (MD) simulation [35-37] combined with different interaction potentials such as Finnis-Sinclair (FS) [38], and Sutton-Chen (SC) [39,40]. In particular, the method of MD simulation is considered as the most preeminent method today with low research costs, capable of researching at the atomic level and providing a huge amount of information o the structure and explaining relevant physical mechanisms [41,42].

The result of research of $\mathrm{Ni}, \mathrm{Au}$ metal and NiAu alloy in the liquid state, crystalline state, an amorphous state [43-45] shows that at the temperature (T), $\mathrm{T}=300 \mathrm{~K}$, pure $\mathrm{Ni}$, Au metals do not change the structure transition process when being combined to form NiAl alloy; their electronic mobility is in ranges from $5 \%$ to $99 \%$ depending on the impurity concentration [46] that leads to the crystallize processes, and the structural 
transitions occurring quickly [47]. They use NiAu alloys as catalysts for clean water [48-50] by using $\mathrm{Au}$ atoms in combination with $\mathrm{Ni}$ atoms to ionize water atoms. However, to meet below phase diagram, the study and synthesis of NiAu alloy [51] are being performed by electrolysis, the results showing an irregularly distributed shape and a medium particle size, which is $25 \mathrm{~nm}$ [52].

Recently, researchers have proposed a method using low temperature $[53,54]$ and reduction as a way to synthesize NiAu alloy [55]. Vasquez et al. [56] also used this method to synthesize $\mathrm{Au}_{3} \mathrm{Fe}, \mathrm{Au}_{3} \mathrm{Co}$, and $\mathrm{Au}_{3} \mathrm{Ni}$ alloys. With this one, the shape and size of $\mathrm{NiAu}$ alloy are better controlled, and it has carried out more research in recent years [57-61]. With these obtained results [3], at high pressure [62,63] and Morse potential interaction, we can measure accurately the elastic modulus of AuNi. Lecadre et al. [64] studied the scattering and diffusion mechanism in $\mathrm{Au}-\mathrm{Ni}$ alloys with $\mathrm{Au}_{3} \mathrm{Ni}$ and $\mathrm{Au}_{3} \mathrm{Ni}_{2}$ ratios. Berendsen et al. [65] have identified the transition temperature $\left(T_{m}\right)$ of NiAu ranges from $T_{m}=1100 \mathrm{~K}$ to $\mathrm{T}_{\mathrm{m}}=1300 \mathrm{~K}$ with $\mathrm{Au}$ impurity concentration of 58\% [66]. Combined with our recent results as $\mathrm{Al}$ [67], $\mathrm{FeNi}[68], \mathrm{AlNi}$ [69], $\mathrm{Ni}_{1-x} \mathrm{Fe}_{x}$ [70], $\mathrm{Ni}_{1-x} \mathrm{Cu}_{x}$ [71], $\mathrm{Ni}$ [72,73], these results show that the transition temperature $\left(\mathrm{T}_{\mathrm{m}}\right)$ of Ni material; $\mathrm{T}_{\mathrm{m}}$ is always proportional with atom number $(\mathrm{N}), \mathrm{N}^{-1 / 3}[74,75]$, and the electronic structure of $\mathrm{AuCu}$ [76] and $\mathrm{AgAu}$ [77]. The phase transition of Ni material can be determined by stress or temperature [78-81], and the bonding length of Ni-Ni determined by the experimental method is $r=2.43 \AA$ [82], while the simulation method of Dung, N.T is $r=2.45 \AA$ [73], and P.H. Kien is $r=2.52 \AA$ [72]. Meanwhile, $\mathrm{Ni}$ and $\mathrm{Au}$ both have significant differences in atomic radius ( $\mathrm{R})$ sizes such as: $\mathrm{Ni}$ is $\mathrm{R}=1.245 \AA$, $\mathrm{Au}$ is $\mathrm{R}=1.44 \AA$, and surface energy (E) of $\mathrm{Ni}$ is $\mathrm{E}=149 \mathrm{meV}^{-2}, \mathrm{Au}$ is $\mathrm{E}=96.8 \mathrm{meVA}^{-2}$ [83], which lead to the diffusion of Au atoms in the crust and Ni atoms in the core layer [84]. So, what processes were happened to NiAu alloy when there was a change in heating rate, atomic number, and temperature? To answer this question, we focus on studying the factors that affect the structure and crystallization process of $\mathrm{NiAu}$ alloys.

\section{Method of Calculation}

Initially, the ratio between NiAu alloy and Ni:Au is 1:1, as in $2048 \mathrm{NiAu}$ atoms, there are $1024 \mathrm{Ni}$ atoms, $1024 \mathrm{Au}$ atoms $\left(\mathrm{NiAu}_{2048}\right), 2916$ atoms $\left(\mathrm{NiAu}_{2916}\right), 4000$ atoms $\left(\mathrm{NiAu}_{4000}\right), 5324$ atoms $\left(\mathrm{NiAu}_{5324}\right), 6912$ atoms $\left(\mathrm{NiAu}_{6912}\right)$; all samples are studied by molecular dynamics (MD) simulation method [85-95] with embedded Sutton-Chen (SC) interaction [39,96-99] and boundary conditions recirculating with the Equation (1):

$$
E_{\text {tot }}=\sum_{i=1}^{N} \frac{1}{2} \sum_{j=1, j \neq i}^{N} \Phi\left(r_{i j}\right)+F\left(\rho_{i}\right), \Phi\left(r_{i j}\right)=\varepsilon\left(\frac{a}{r_{i j}}\right)^{n}, F\left(\rho_{i}\right)=-\varepsilon C \sum_{i=1}^{N} \sqrt{\rho_{i}}, \rho_{i}=\sum_{j=1, j \neq i}^{N} \rho\left(r_{i j}\right), \rho\left(r_{i j}\right)=\left(\frac{a}{r_{i j}}\right)^{n}
$$

The parameters of the NiAu alloy (Table 1) are shown below.

Table 1. Parameters of NiAu alloy.

\begin{tabular}{cccccc}
\hline Alloy & $\varepsilon\left(\times \mathbf{1 0}^{-\mathbf{2}} \mathbf{e V}\right)$ & $\mathbf{a}(\mathbf{A})$ & $\mathbf{n}$ & $\mathbf{m}$ & $\mathbf{C}$ \\
\hline $\mathrm{Ni}$ & 1.5707 & 3.52 & 9 & 6 & 39.432 \\
$\mathrm{Au}$ & 1.2793 & 4.08 & 10 & 8 & 34.408 \\
$\mathrm{NiAu}$ & 1.4175 & 3.80 & 9.5 & 7.0 & 36.834 \\
\hline
\end{tabular}

The parameters of the alloy are determined by the mathematical Formula (2):

$$
\varepsilon_{\mathrm{NiAu}}=\sqrt{\varepsilon_{\mathrm{Ni}} \cdot \varepsilon_{\mathrm{Au}}} ; \mathrm{a}_{\mathrm{NiAu}}=\frac{\left(\mathrm{a}_{\mathrm{Ni}}+\mathrm{a}_{\mathrm{Au}}\right)}{2} ; \mathrm{n}_{\mathrm{NiAu}}=\frac{\left(\mathrm{n}_{\mathrm{Ni}}+\mathrm{n}_{\mathrm{Au}}\right)}{2} ; \mathrm{m}_{\mathrm{NiAu}}=\frac{\left(\mathrm{m}_{\mathrm{Ni}}+\mathrm{m}_{\mathrm{Au}}\right)}{2} ; \mathrm{C}_{\mathrm{NiAu}}=\sqrt{\mathrm{C}_{\mathrm{Ni}} \cdot \mathrm{C}_{\mathrm{Au}}}
$$


At all samples, there is an increase in temperature $(\mathrm{T})$ from $\mathrm{T}=0.0 \mathrm{~K}$ to $\mathrm{T}=2000 \mathrm{~K}$ to $\mathrm{NiAu}$ alloy at the liquid state. From the liquid state, the temperature of the samples was reduced from $\mathrm{T}=2000 \mathrm{~K}$ to $\mathrm{T}=300 \mathrm{~K}$ to change from a liquid state to a crystalline one. After getting NiAu alloy, NiAu 6912 alloys are run MD with a heating speed of $4 \times 10^{11} \mathrm{~K} / \mathrm{s}$, $4 \times 10^{12} \mathrm{~K} / \mathrm{s}, 4 \times 10^{13} \mathrm{~K} / \mathrm{s}, 4 \times 10^{14} \mathrm{~K} / \mathrm{s}$ at $(\mathrm{T}), \mathrm{T}=300 \mathrm{~K}$. After determining the heating speed of $4 \times 10^{12} \mathrm{~K} / \mathrm{s}$ to be appropriate, the effects of $\mathrm{NiAu}_{2048}, \mathrm{NiAu}_{2916}, \mathrm{NiAu}_{4000}$, $\mathrm{NiAu}_{5324}, \mathrm{NiAu}_{6912}$ at $\mathrm{T}=300 \mathrm{~K} ; \mathrm{NiAu}_{6912}$ at $\mathrm{T}=300 \mathrm{~K}, 400 \mathrm{~K}, 500 \mathrm{~K}, 600 \mathrm{~K}, 700 \mathrm{~K}, 900 \mathrm{~K}$, $1100 \mathrm{~K}$ are studied. All given samples are structurally studied through shape, size (l) as (3),

$$
\rho=\frac{\mathrm{N}}{\mathrm{V}} \rightarrow 1=\sqrt[3]{\frac{\mathrm{N}}{\rho}}=\sqrt[3]{\frac{\left(\mathrm{m}_{\mathrm{Ni}} \cdot \mathrm{n}_{\mathrm{Ni}}+\mathrm{m}_{\mathrm{Au}} \cdot \mathrm{n}_{\mathrm{Au}}\right)}{\rho}}
$$

radial distribution function (RDF) as (4):

$$
\mathrm{g}(\mathrm{r})=\frac{\mathrm{V}}{\mathrm{N}^{2}}\left\langle\frac{\sum_{\mathrm{i}} \mathrm{n}_{\mathrm{i}}(\mathrm{r})}{4 \pi \mathrm{r}^{2} \Delta \mathrm{r}}\right\rangle
$$

In it: $1, \rho, r, N, n_{i}(r), V, g(r)$ is the size, density, radial distance, the number of atoms, the coordinates, the volume, the probability of finding an atom in the distance from $r$ to $r+$ $\Delta r$. To determine the number of structural units, are applied the Common Neighborhood Analysis (CNA) method [100-103]. The crystallizing process is carried out based on the laws of Nosé el [104] and Hoover el [105] and uses the techniques of particle size analysis, atomic composition, and configuration [106].

\section{Results and Discussion}

\subsection{Effect of Heating Rate}

The factors that affect the heating rate $4 \times 10^{12} \mathrm{~K} / \mathrm{s}, 2 \times 10^{13} \mathrm{~K} / \mathrm{s}, 4 \times 10^{13} \mathrm{~K} / \mathrm{s}$, $2 \times 10^{14} \mathrm{~K} / \mathrm{s}$, and $4 \times 10^{14} \mathrm{~K} / \mathrm{s}$ on the structural characteristics and crystallization process of $\mathrm{NiAu}_{5324}$ alloy at temperature $(\mathrm{T}), \mathrm{T}=300 \mathrm{~K}$, are shown in Figure 1.

a)

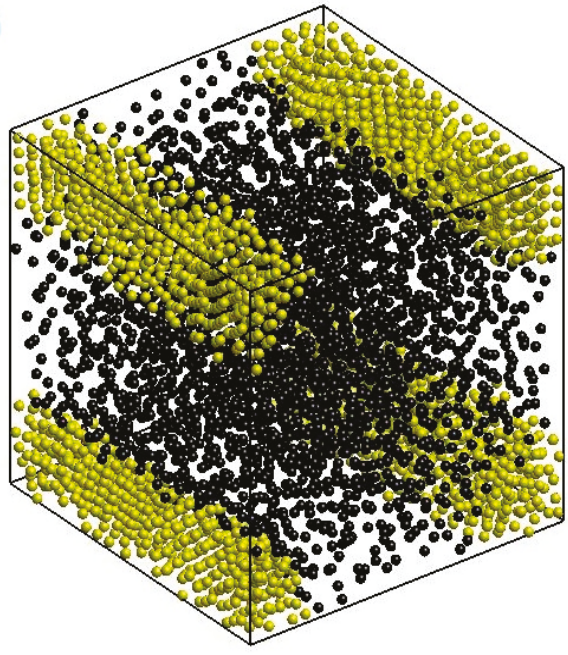

b)

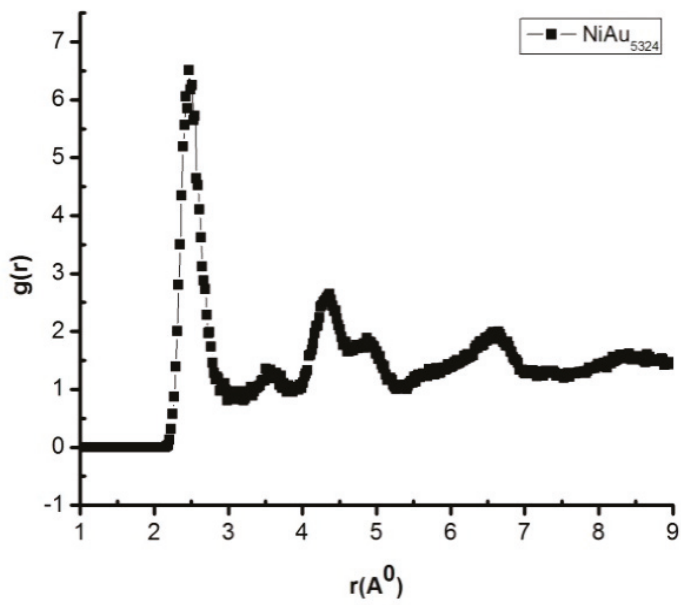

Figure 1. The shape (a), $\mathrm{g}(\mathrm{r})$ of $\mathrm{NiAu}_{5324}$ alloy (b) at $\mathrm{T}=300 \mathrm{~K}$, and heating rate $4 \times 10^{12} \mathrm{~K} / \mathrm{s}$. 
The result shows that when $\mathrm{NiAu}_{5324}$ alloy at $\mathrm{T}=300 \mathrm{~K}$ with the heating rate of $4 \times 10^{12} \mathrm{~K} / \mathrm{s}$, it has a cube shape, made by two atoms: Ni shown in black and Au in yellow (Figure 1a), and has structural features such as $\mathrm{r}$ of radial distribution function $(\mathrm{RDF})=2.47 \AA$; the height of RDF is $\mathrm{g}(\mathrm{r})=6.51$, size $(\mathrm{l}), 1=10.16 \mathrm{~nm}, \mathrm{E}_{\text {tot }}=-446.09 \mathrm{eV}$ (Figure $1 \mathrm{~b}$ ). That increasing heating rate from $4 \times 10^{12} \mathrm{~K} / \mathrm{s}$ to $2 \times 10^{13} \mathrm{~K} / \mathrm{s}, 4 \times 10^{13} \mathrm{~K} / \mathrm{s}$, $2 \times 10^{14} \mathrm{~K} / \mathrm{s}$, and $4 \times 10^{14} \mathrm{~K} / \mathrm{s}$ leads to $\mathrm{r}$ decreases from $\mathrm{r}=2.47 \AA$ to $\mathrm{r}=2.43 \AA$ and $\mathrm{g}(\mathrm{r})$ decreases from $\mathrm{g}(\mathrm{r})=6.51$ to $\mathrm{g}(\mathrm{r})=6.05, \mathrm{l}$ negligibly changes from $\mathrm{l}=9.71 \mathrm{~nm}$ to $\mathrm{l}=10.76 \mathrm{~nm}$, and $\mathrm{E}_{\text {tot }}$ negligibly changes from $\mathrm{E}_{\text {tot }}=-440.25 \mathrm{eV}$ to $\mathrm{E}_{\text {tot }}=-447.18 \mathrm{eV}$ (Table 2). These results show that increasing the heating rate leads to $\mathrm{NiAu}_{5324}$ alloy change, the state from crystalline to amorphous. To study the process of structural transition, the CNA method was used and the results are shown in Figure 2.

Table 2. The structural features such as $\mathrm{r}, \mathrm{g}(\mathrm{r})$ of the radial distribution function, $\mathrm{l}$, and $\mathrm{E}_{\text {tot }}$ with $\mathrm{t}$ different heating rates.

\begin{tabular}{cccccc}
\hline Heating Rates (K/s) & $4 \times 10^{12}$ & $2 \times 10^{13}$ & $4 \times 10^{13}$ & $2 \times 10^{14}$ & $4 \times 10^{14}$ \\
$\mathbf{r}(\mathbf{A})$ & 2.47 & 2.47 & 2.45 & 2.45 & 2.43 \\
$\mathbf{g}(\mathbf{r})$ & 6.51 & 6.08 & 5.43 & 4.87 & 6.05 \\
$\mathbf{1}(\mathbf{n m})$ & 10.16 & 10.35 & 10.05 & 9.71 & 10.76 \\
$\mathbf{E}_{\text {tot }}(\mathbf{e V})$ & -446.09 & -446.84 & -447.18 & -447.15 & -440.25 \\
\hline
\end{tabular}

a)

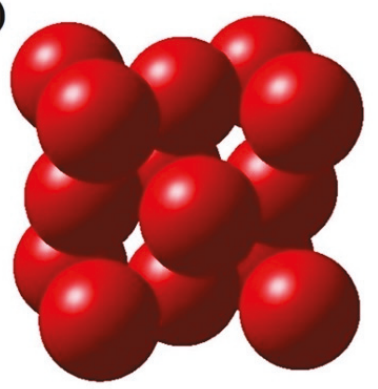

b)

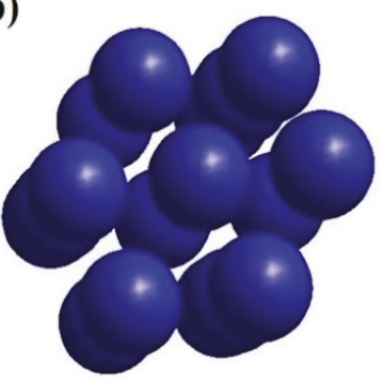

c)

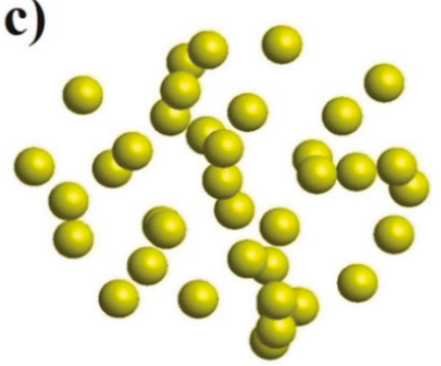

Figure 2. The structural unit number shape includes FCC structure (a), HCP structure (b), Amor structure (c) of NiAu alloy.

The result shows that $\mathrm{NiAu}_{5324}$ alloy at the heating rate of $4 \times 10^{12} \mathrm{~K} / \mathrm{s}$ has structural shapes (Figure 3a) corresponding with 03 links Ni-Ni, Au-Au: Ni- Ni is r $=2.47 \AA$, Ni-Au is $r=2.47 \AA$, Au-Au is $r=3.17 \AA$ (Figure $3 b$ ), and expresses through structural unit number FCC (Figure 2a), HCP (Figure 2b), Amor (Figure 2c). The obtained results are consistent with the results of Ni-Ni by experimental methods $r=2.43 \AA$ [82], and $R=1.245 \AA$, with the simulation method $r=2.45 \AA$ [73], $r=2.52 \AA$ [72], for Au-Au, only X-ray diffraction results in an atomic radius value $\mathrm{R}=1.44 \AA[83,84]$. Increasing heating rate from $4 \times 10^{12} \mathrm{~K} / \mathrm{s}$ to $2 \times 10^{13} \mathrm{~K} / \mathrm{s}, 4 \times 10^{13} \mathrm{~K} / \mathrm{s}, 2 \times 10^{14} \mathrm{~K} / \mathrm{s}$, and $4 \times 10^{14} \mathrm{~K} / \mathrm{s}$ leads to $\mathrm{r}$ of link Ni-Ni, Ni-Au, Au-Au change values. Besides, when Ni-Ni changes from $r=2.47 \AA$ to $r=2.41 \AA, \mathrm{Ni}-\mathrm{Au}$ decreases from $r=2.47 \AA$ to $r=2.43 \AA$, Au-Au decreases from $r=3.17 \AA$ to $r=3.09 \AA$, corresponding to the change of $\mathrm{g}(\mathrm{r})$ and structural unit number FCC, HCP, Amor; as FCC decreases from 802 to 0.0 FCC, HCP decreases from $811 \mathrm{HCP}$ to $13 \mathrm{HCP}$, Amor increases from 3711 Amor to 5311 Amor (Table 3). That confirms that there is an increase in the heating rate when the crystallization process decreases. 

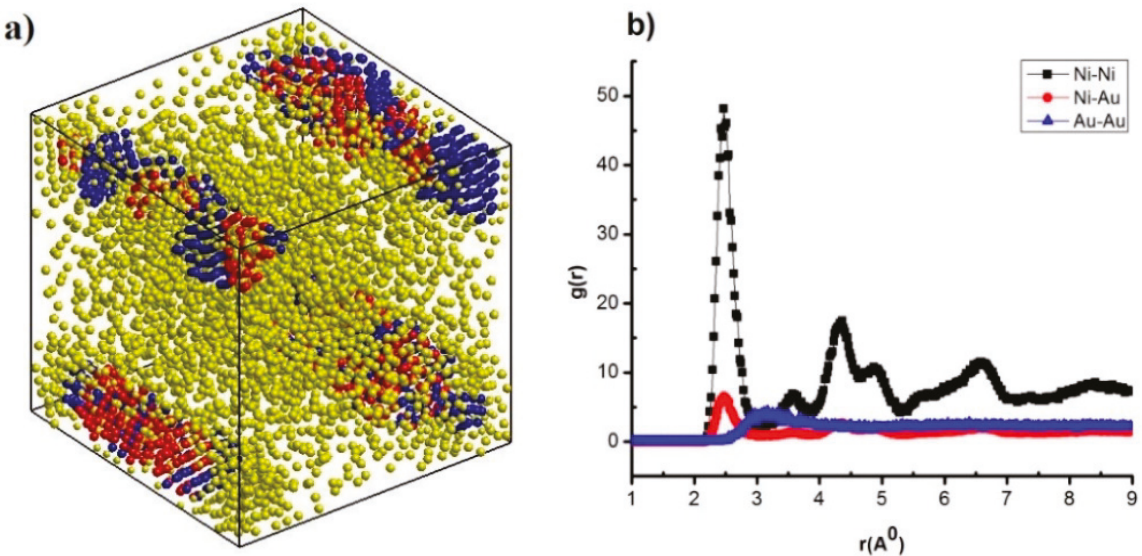

Figure 3. The structural shape (a), radial distribution function (b) of $\mathrm{NiAu}_{5324}$ alloy at heating rates of $4 \times 10^{12} \mathrm{~K} / \mathrm{s}$.

Table 3. The structural features such as links Ni-Ni, Ni-Au, Au-Au include $\mathrm{r}$ and $\mathrm{g}(\mathrm{r})$ with a different atomic number (N).

\begin{tabular}{|c|c|c|c|c|c|c|c|c|c|}
\hline \multirow{2}{*}{$\mathrm{NiAu}_{5324}$ Alloy } & \multicolumn{3}{|c|}{$\mathbf{r}\left(\mathrm{A}^{0}\right)$} & \multicolumn{3}{|c|}{$g(r)$} & \multicolumn{3}{|c|}{ Structural Unit Number } \\
\hline & $\mathbf{r}_{\mathrm{Ni}-\mathrm{Ni}}$ & $\mathbf{r}_{\mathrm{Ni}-\mathrm{Au}}$ & $\mathbf{r}_{\mathrm{Au}-\mathrm{Au}}$ & $\mathrm{g}_{\mathrm{Ni}-\mathrm{Ni}}$ & $\mathrm{g}_{\mathrm{Ni}-\mathrm{Au}}$ & $\mathrm{g}_{\mathrm{Au}-\mathrm{Au}}$ & FCC & HCP & Amor \\
\hline $4 \times 10^{12}$ & 2.47 & 2.47 & 3.17 & 48.11 & 6.51 & 4.41 & 802 & 811 & 3711 \\
\hline $2 \times 10^{13}$ & 2.45 & 2.47 & 3.11 & 44.98 & 6.08 & 4.35 & 111 & 139 & 5074 \\
\hline $4 \times 10^{13}$ & 2.41 & 2.45 & 3.11 & 39.84 & 5.43 & 4.75 & 58 & 115 & 5151 \\
\hline $2 \times 10^{14}$ & 2.45 & 2.45 & 3.11 & 33.60 & 4.87 & 5.17 & 0 & 26 & 5298 \\
\hline $4 \times 10^{14}$ & 2.45 & 2.43 & 3.09 & 42.15 & 6.05 & 5.70 & 0 & 13 & 5311 \\
\hline $\begin{array}{l}\text { Results simulation } \\
\text { experiment }\end{array}$ & $\begin{array}{l}2.45[73] \\
2.52[72] \\
2.43[82]\end{array}$ & & $\begin{array}{c}2.88 \\
{[83,84]}\end{array}$ & & & & & & \\
\hline
\end{tabular}

\subsection{Effect of Atomic Number}

Similarly, with the influence of atomic numbers $\mathrm{NiAu}_{2048}, \mathrm{NiAu}_{2916}, \mathrm{NiAu}_{4000}, \mathrm{NiAu}_{5324}$, and $\mathrm{NiAu}_{6912}$ on structural characteristics, results are shown in Figure 4.
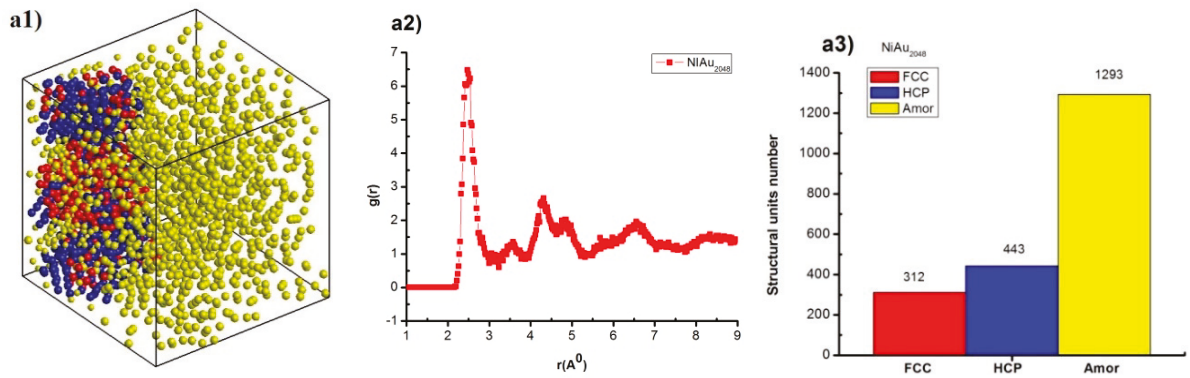

Figure 4. Cont. 

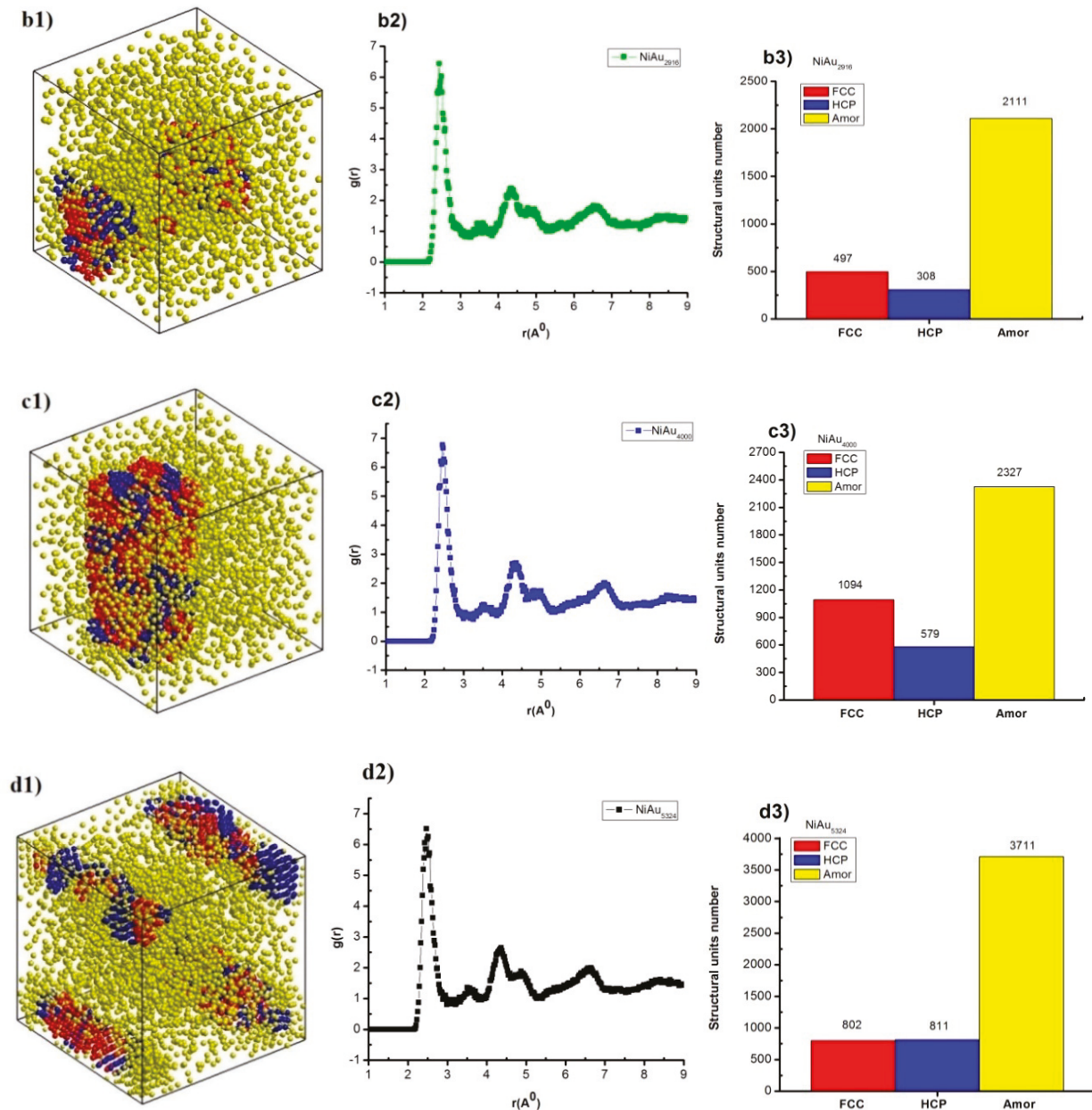

d2)
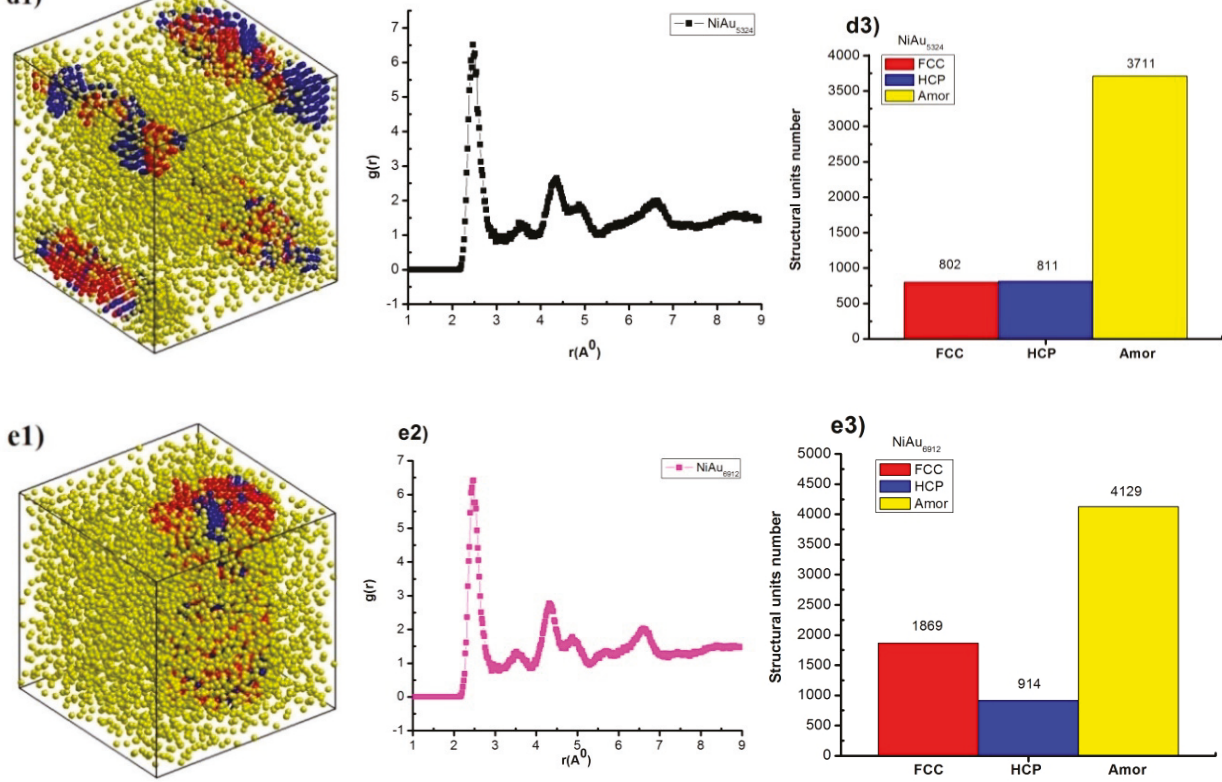

Figure 4. The structural shape (a1,b1,c1,d1,e1), radial distribution function (RDF) (a2,b2,c2,d2,e2), structural unit number $(\mathrm{a} 3, \mathrm{~b} 3, \mathrm{c3}, \mathrm{d} 3, \mathrm{e} 3)$ of NiAu alloy with different $\mathrm{N}$. 
The results indicate that $\mathrm{NiAu}_{2048}$ alloy at $\mathrm{T}=300 \mathrm{~K}$ has structural shape and $\mathrm{l}=7.34 \mathrm{~nm}$, $\mathrm{E}_{\mathrm{tot}}=-173.85 \mathrm{eV}$ (Figure 4(a1)), together with the radial distribution function, has $\mathrm{r}=2.49 \AA$, $\mathrm{g}(\mathrm{r})=6.47$ (Figure $4(\mathrm{a} 2))$, and the structural unit numbers are 312 FCC, 443 HCP, 1293

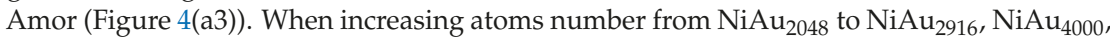
$\mathrm{NiAu}_{5324}, \mathrm{NiAu}_{6912}$, then structural shape changes, size (l) increases from $1=7.34 \mathrm{~nm}$ to $\mathrm{l}=10.89 \mathrm{~nm}, \mathrm{E}_{\text {tot }}$ decreases from $\mathrm{E}_{\text {tot }}=-173.85 \mathrm{eV}$ to $\mathrm{E}_{\text {tot }}=-580.35 \mathrm{eV}$ (Figure 4(b1,c1,d1,e1)); $\mathrm{r}$ changes from $\mathrm{r}=2.49 \AA$ to $\mathrm{r}=2.45 \AA, \mathrm{g}(\mathrm{r})$ changes from $\mathrm{g}(\mathrm{r})=6.43$ to $\mathrm{g}(\mathrm{r})=6.77$ (Figure 4(b2,c2,d2,e2)); and the structural unit number change corresponding to FCC about from 312 FCC to 1869 FCC, HCP about from 308 HCP to 914 HCP, Amor increases from 1293 Amor to 4129 Amor (Figure 4(b3,c3,d3,e3)). The given result indicates that increasing $\mathrm{N}$ leads to 1 increase and $\mathrm{E}_{\text {tot }}$ decrease. As a result, there is a relationship between $1, \mathrm{~N}$, and $\mathrm{E}_{\mathrm{tot}}, \mathrm{N}$. To confirm the defining relationships between size, atom number, and between $\mathrm{E}_{\text {tot }}$, atom number of NiAu alloy, the results are shown in Figure 5.
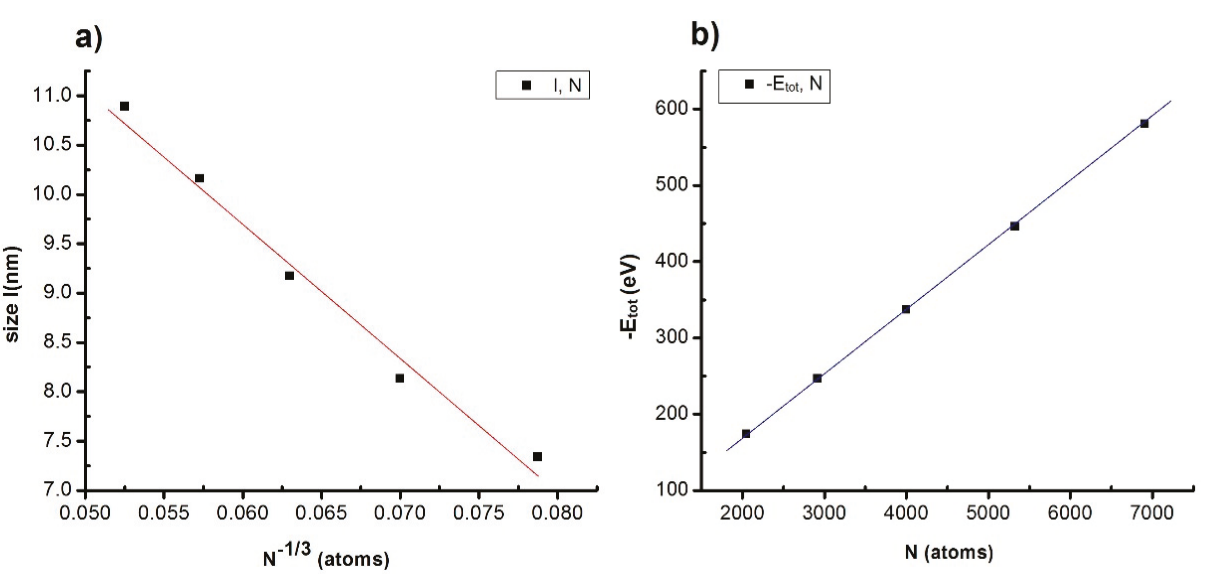

Figure 5. The relationship between characteristic quantities such as structures as dependence between $1, N(\mathbf{a}) ;-E_{\text {tot }}, N(\mathbf{b})$ of the NiAu alloy with different $\mathrm{N}$.

The given result shows that increasing $\mathrm{N}$ leads to 1 increase, and satisfy the formula: $1=18.021-138.153 \mathrm{~N}^{-1 / 3}$, corresponding to $1 \sim \mathrm{N}^{-1 / 3}$ (Figure $5 \mathrm{a}$ ) and $-\mathrm{E}_{\text {tot }}$ proportional to $\mathrm{N}$ (Figure $5 \mathrm{~b}$ ). The results are consistent with the results of crystallizing process temperature $\left(\mathrm{T}_{\mathrm{m}}\right)$ proportional with $\mathrm{N}^{-1 / 3}[74,75]$ and size $(\mathrm{l}$ or $\mathrm{D})$ proportional with $\mathrm{N}^{-1 / 3}$ [67-73]. This proves that increasing atom number leads to crystalline atoms number FCC, HCP increase, Amor decrease, size increase, the total energy of system decrease; and the relationship with $1 \sim N^{-1 / 3}$ is an important result for future experimental implementation.

\subsection{Influence of Temperature}

The research results of the effect of temperature, $\mathrm{T}=300 \mathrm{~K}, 400 \mathrm{~K}, 500 \mathrm{~K}, 600 \mathrm{~K}, 700 \mathrm{~K}$, $900 \mathrm{~K}, 1100 \mathrm{~K} 1300 \mathrm{~K}$, and $1500 \mathrm{~K}$, on the structural characteristics are shown in Figure 6. 

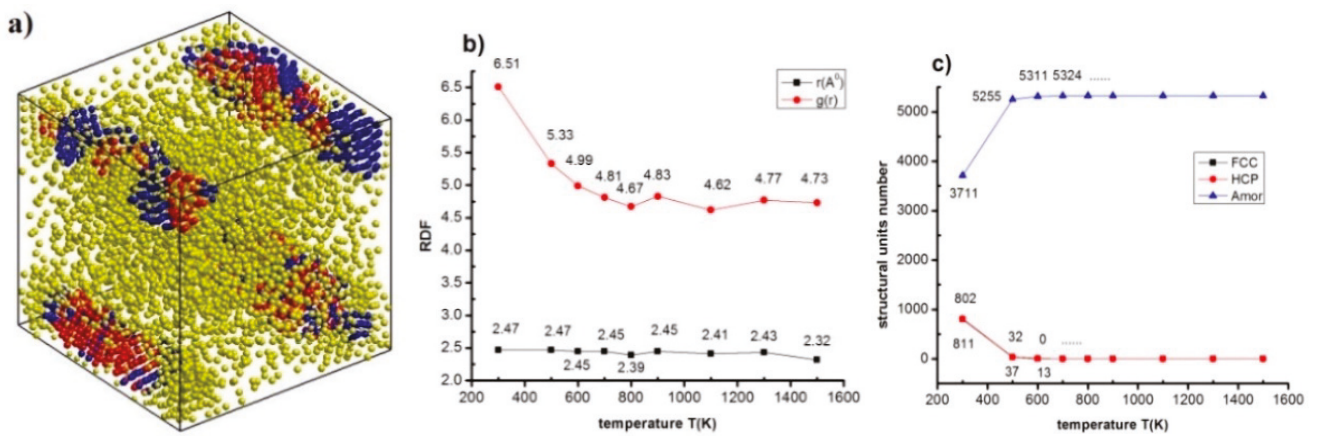

Figure 6. The structural characteristics as structural shape (a) of $\mathrm{NiAu}_{5324}$ alloy at $\mathrm{T}=300 \mathrm{~K}$; RDF (b) and structural unit number (c) at different $\mathrm{T}$.

The results indicate at $\mathrm{T}=300 \mathrm{~K}, \mathrm{NiAu}_{5324}$ alloy has structural shape, $\mathrm{r}=2.47 \AA$, $\mathrm{g}(\mathrm{r})=6.51,802 \mathrm{FCC}, 811 \mathrm{HCP}, 3711$ Amor (Figure 6a). When increasing $\mathrm{T}$ from $\mathrm{T}=300 \mathrm{~K}$ to $\mathrm{T}=1500 \mathrm{~K}, \mathrm{r}$ decreases from $\mathrm{r}=2.47 \AA$ to $\mathrm{r}=2.32 \AA, \mathrm{g}(\mathrm{r})$ changes from $\mathrm{g}(\mathrm{r})=6.51$ to $\mathrm{g}(\mathrm{r})=4.62$ (Figure $6 \mathrm{~b}$ ), FCC decreases rapidly from 802 FCC to 0.0 FCC, HCP decreases dramatically from $811 \mathrm{HCP}$ to $0.0 \mathrm{HCP}$, Amor increases from $3711 \mathrm{HCP}$ to $5324 \mathrm{HCP}$, at $\mathrm{T}=700 \mathrm{~K}$ Amor state maximum increases (Figure 6c). This proves that with $\mathrm{T}<700 \mathrm{~K}$, $\mathrm{NiAu}$ alloy is in the crystalline state, $\mathrm{T}>700 \mathrm{~K}$, and NiAu alloy is in the liquid state, thereby, this is a crystallizing process between the crystallization and liquid states of $\mathrm{NiAu}$ alloy. The results of phase transition from crystalline state to a liquid state by type 1 phase transition theory, for each value of temperature $(\mathrm{T})$, will correspond to a total energy value of the system $\left(\mathrm{E}_{\text {tot }}\right)$. To confirm that, a study of the relationship between $\mathrm{T}$ and $\mathrm{E}_{\text {tot }}$ was carried out and the obtained results are shown in Figure 7.

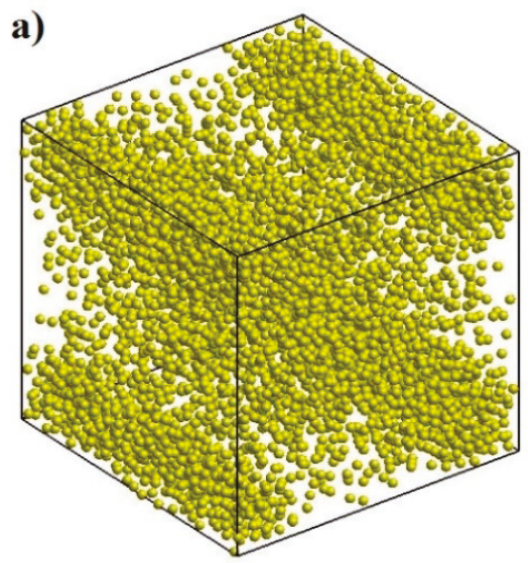

b)

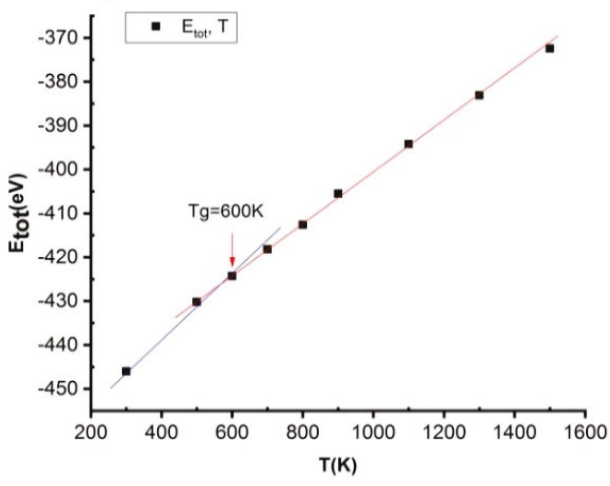

Figure 7. The structural shape of $\mathrm{NiAu}_{5324}$ alloy at temperatures $700 \mathrm{~K}(\mathbf{a})$, phase transition (b) of NiAu 5324 alloy at different temperatures.

Increasing T from T $=300 \mathrm{~K}$ to $\mathrm{T}=400 \mathrm{~K}, 500 \mathrm{~K}, 600 \mathrm{~K}, 700 \mathrm{~K}, 900 \mathrm{~K}, 1100 \mathrm{~K}, 1300 \mathrm{~K}$, and $1500 \mathrm{~K}$ leads to $l$ insignificant change range $\mathrm{l}=7.34 \mathrm{~nm}$ to $\mathrm{l}=7.35 \mathrm{~nm}$ and $\mathrm{E}_{\text {tot }}$ increase from $\mathrm{E}_{\mathrm{tot}}=-446.0 \mathrm{eV}$ to $\mathrm{E}_{\mathrm{tot}}=-430.2 \mathrm{eV},-424.3 \mathrm{eV},-418.2 \mathrm{eV},-415.6 \mathrm{eV},-405.5 \mathrm{eV}$, $-394.2 \mathrm{eV},-383.1 \mathrm{eV}$, and $-372.4 \mathrm{eV}$. In it, the structural shape of NiAu alloy at $\mathrm{T}=700 \mathrm{~K}$ (Figure 7a) and an interrupting point at $\mathrm{T}=600 \mathrm{~K}$ then corresponds with $\mathrm{E}_{\text {tot }}=-418.2 \mathrm{eV}$ observed at glass temperature $\left(T_{g}\right), T_{g}=600 \mathrm{~K}$ (Figure $7 \mathrm{~b}$ ). The results obtained show that, 
with $\mathrm{T}<600 \mathrm{~K}, \mathrm{NiAu}_{5324}$ alloy exists in the crystalline state and $\mathrm{T}>600 \mathrm{~K}$ is in a liquid state, this result is completely consistent with the results obtained in on and are considered as the basis for future empirical research.

\subsection{Influence of Annealing Time}

The crystallization process of $\mathrm{NiAu}_{5324}$ alloy is carried out after the tempering period and shown in Figure 8, Table 4.

a)

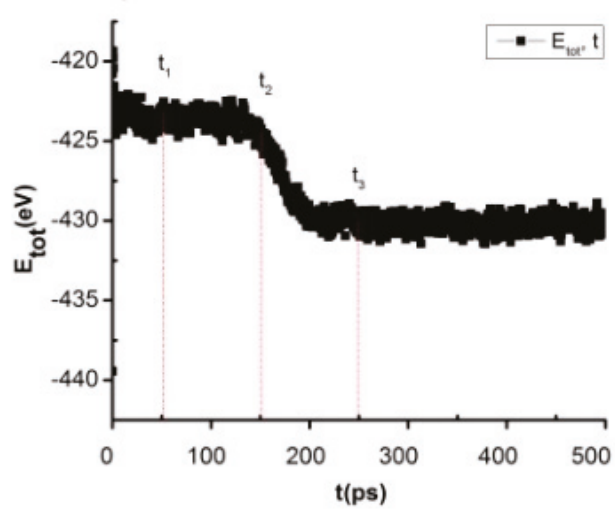

b)

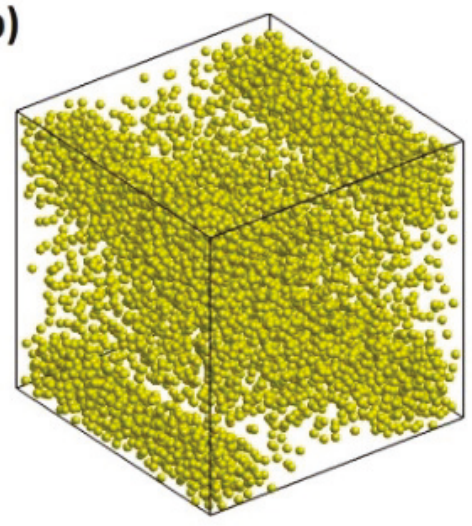

c)

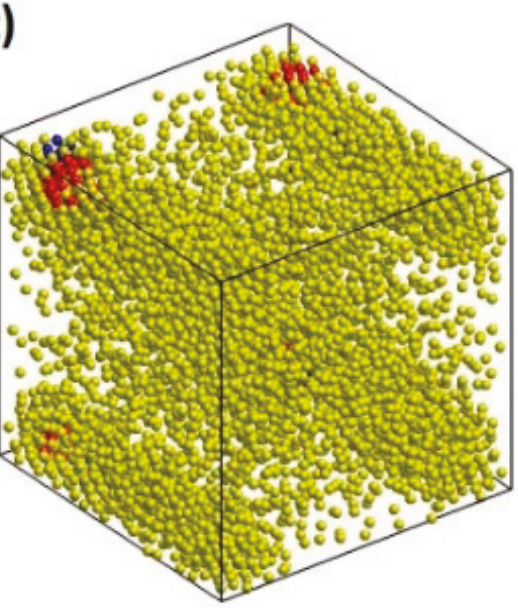

d)

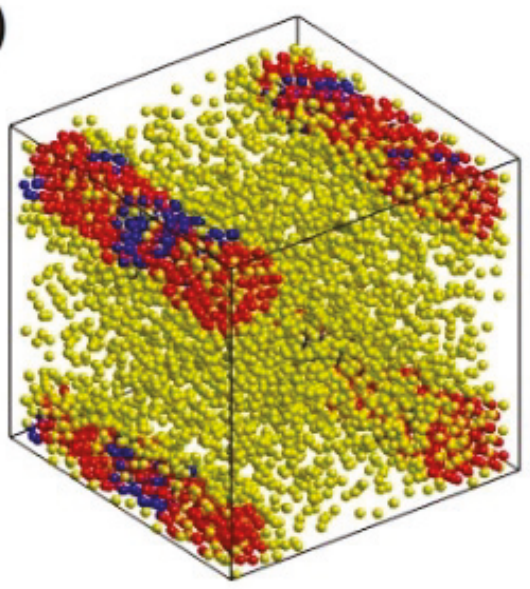

Figure 8. The crystallization process of $\mathrm{NiAu}_{5324}$ alloy after different annealing time (a), the shape of $\mathrm{NiAu}$ alloy at $\mathrm{t}_{1}=50 \mathrm{ps}$ $(\mathbf{b}), \mathrm{t}_{2}=150 \mathrm{ps}(\mathbf{c}), \mathrm{t}_{3}=250 \mathrm{ps}(\mathbf{d})$.

Table 4. The structural characteristics and number of structural units of $\mathrm{NiAu}_{5324}$ alloy after different annealing times.

\begin{tabular}{cccc}
\hline $\mathbf{t}(\mathbf{p s})$ & $\mathbf{5 0}$ & $\mathbf{1 5 0}$ & $\mathbf{2 5 0}$ \\
\hline $\mathrm{r}(\AA)$ & 2.45 & 2.49 & 2.47 \\
$\mathrm{~g}(\mathrm{r})$ & 5.26 & 5.08 & 5.88 \\
$\mathrm{FCC}$ & 0.0 & 58 & 1463 \\
$\mathrm{HCP}$ & 0.0 & 9 & 368 \\
Amor & 5324 & 5257 & 3493 \\
\hline
\end{tabular}


The result shows that after incubation period, $t=50$ ps, 150 ps, 250 ps, $E_{\text {tot }}$ decreases from $E_{\text {tot }}=-425 \mathrm{eV}$ to $E_{\text {tot }}=-430 \mathrm{eV}$ (Figure $8 \mathrm{a}$ ), the structural shape at $t_{1}=50 \mathrm{ps}$ (Figure $8 \mathrm{~b}$ ), $\mathrm{t}_{2}=150 \mathrm{ps}$ (Figure $8 \mathrm{c}$ ), $\mathrm{t}_{3}=250 \mathrm{ps}$ (Figure $8 \mathrm{~d}$ ) corresponding with the link length, the height of the RDF Ni-Au varies greatly from $r=2.45 \AA$ to $r=2.49 \AA, g(r)=5.26$ to $g(r)=5.88$ and structural unit number FCC increases from 0.0 FCC to 1463 FCC, HCP increases from $0.0 \mathrm{HCP}$ to $368 \mathrm{HCP}$, and Amor decreases from 5324 Amor to 3493 Amor (Table 4). The results obtained show that NiAu5324 alloy at $\mathrm{Tg}=600 \mathrm{~K}$ after the annealing time $t=250 \mathrm{ps}$, the crystallization process increases, proving that NiAu5324 alloy is easy to crystallize at the temperature $\mathrm{Tg}$ and results obtained are consistent with the results of the previous alloys such as AlNi [69], $\mathrm{NiCu}[71], \mathrm{FeNi}[68,70]$.

When increasing heating rate, the temperature leads to $r, g(r)$ decreases, $1, E_{\text {tot }}$ increase, FCC, HCP decrease and Amor increase and vice versa with increasing atomic number and the incubation time at $T_{g}=600 \mathrm{~K}$. This is a very useful result for the process of implementing experimental results in the future.

\section{Conclusions}

After studying the effect of factors on the structure and crystallize process, we got the following results: The relationship between size (l) and atomic number $(\mathrm{N})$ is determined according to the formula is $1 \sim \mathrm{N}^{-1 / 3}$; the total energy of the system $\left(-\mathrm{E}_{\text {tot }}\right)$ always depends on $\mathrm{N}$ by function, the result is consistent with results [67-75] when the glass temperature $\left(\mathrm{T}_{\mathrm{g}}\right), \mathrm{T}_{\mathrm{g}}=600 \mathrm{~K}$. With $\mathrm{NiAu}_{5324}$, when increasing the heating rate from $4 \times 10^{12} \mathrm{~K} / \mathrm{s}$ to $2 \times 10^{13} \mathrm{~K} / \mathrm{s}, 4 \times 10^{13} \mathrm{~K} / \mathrm{s}, 2 \times 10^{14} \mathrm{~K} / \mathrm{s}$, and $4 \times 10^{14} \mathrm{~K} / \mathrm{s}$ leads to $\mathrm{r}$ decrease from $\mathrm{r}=2.47 \AA$ to $\mathrm{r}=2.43 \AA$, and $\mathrm{g}(\mathrm{r})$ decrease from $\mathrm{g}(\mathrm{r})=6.51$ to $\mathrm{g}(\mathrm{r})=6.05$, corresponding to the change of $\mathrm{g}(\mathrm{r})$ and structural unit number. FCC, HCP, Amor FCC decreases from 802 FCC to 0.0 FCC, $\mathrm{HCP}$ decreases from $811 \mathrm{HCP}$ to $13 \mathrm{HCP}$, Amor increases from 3711 Amor to 5311 Amor. When increasing atom number from $\mathrm{NiAu}_{2048}$ to $\mathrm{NiAu}_{2916}, \mathrm{NiAu}_{4000}, \mathrm{NiAu}_{5324}, \mathrm{NiAu}_{6912}$, first peak position ( $r$ ) of RDF changes values from $r=2.49 \AA$ to $r=2.45 \AA, g(r)$ changes from $\mathrm{g}(\mathrm{r})=6.43$ to $\mathrm{g}(\mathrm{r})=6.77$, the structural unit number changes corresponding to FCC increases from 312 FCC to 1869 FCC, HCP increases from 308 HCP to 914 HCP, Amor increases from 1293 Amor to 4129 Amor. Similarly, with $\mathrm{NiAu}_{5324}$ when increasing $\mathrm{T}$ from $\mathrm{T}=300 \mathrm{~K}$ to $\mathrm{T}=1500 \mathrm{~K}, \mathrm{r}$ decreases from $\mathrm{r}=2.47 \AA$ to $\mathrm{r}=2.32 \AA, \mathrm{g}(\mathrm{r})$ changes in the range from $\mathrm{g}(\mathrm{r})=6.51$ to $\mathrm{g}(\mathrm{r})=4.62$, FCC decreases rapidly from 802 FCC to $0.0 \mathrm{FCC}, \mathrm{HCP}$ decreases rapidly from $811 \mathrm{HCP}$ to $0.0 \mathrm{HCP}$, Amor increases from $3711 \mathrm{HCP}$ to $5324 \mathrm{HCP}$, Amor state maximum increases. When increasing in annealing times at $\mathrm{T}_{\mathrm{g}}=600 \mathrm{~K}$ leads to the structural unit number FCC, HCP increases, Amor decreases. It indicates that the heating rate increase leads to the $\mathrm{NiAu}$ alloy change from crystallizing state to the amorphous state; increasing atomic number, annealing times leads to crystallization process increase; increasing temperature leads to process change from a crystallization state to a liquid state. This is a very essential factor and a basis for future empirical research.

Author Contributions: D.N.T.: conceptualization, methodology, validation, investigation, writingoriginal draft preparation. V.C.L.: data curation. S..T.: writing-review and editing. All authors have read and agreed to the published version of the manuscript.

Funding: This research received no external funding.

Data Availability Statement: The data that support the findings of this study are available from the corresponding author upon reasonable request.

Conflicts of Interest: The authors declare no conflict of interest.

\section{References}

1. Liu, H.B.; Pal, U.; Ascencio, J.A. Thermodynamic stability and melting mechanism of bimetallic Au-Pt nanoparticles. J. Phys. Chem. C 2008, 112, 19173-19177. [CrossRef]

2. Mejía-Rosales, S.J.; Fernández-Navarro, C.; Pérez-Tijerina, E.; Montejano-Carrizales, J.M.; José-Yacamán, M. Two-Stage Melting of Au-Pd Nanoparticles. J. Phys. Chem. B 2006, 110, 12884-12889. [CrossRef] [PubMed] 
3. Davoodi, J.; Katouzi, F. High pressure molecular dynamics simulation of Au-x\%Ni alloys. J. Appl. Phys. 2014, 115, 094905. [CrossRef]

4. Link, S.; Wang, Z.L.; El-Sayed, M.A. Alloy formation of gold-silver nanoparticles and the dependence of the plasmon ab-sorption on their composition. J. Phys. Chem. B 1999, 103, 3529-3533. [CrossRef]

5. Wu, M.-L.; Chen, D.-H.; Huang, T.-C. Synthesis of Au/Pd bimetallic nanoparticles in reverse micelles. Langmuir 2001, 17, 3877-3883. [CrossRef]

6. Lee, C.C.; Chen, D.H. Large-scale synthesis of $\mathrm{Ni}-\mathrm{Ag}$ core-shell nanoparticles with magnetic, optical and antioxidation properties. Nanotechnology 2006, 17, 3094-3099. [CrossRef]

7. De, G.; Rao, C.N.R. Au-Pt alloy nanocrystals incorporated in silica films. J. Mater. Chem. 2005, 15, 891-894. [CrossRef]

8. Duan, S.; Wang, R. Bimetallic nanostructures with magnetic and noble metals and their physicochemical applications. Prog. Nat. Sci. Mater. Int. 2013, 23, 113-126. [CrossRef]

9. Ziaei-azad, H.; Yin, C.X.; Shen, J.; Hu, Y.; Karpuzov, D.; Semagina, N. Size- and structure-controlled mono- and bimetallic Ir-Pd nanoparticles in selective ring opening of indan. J. Catal. 2013, 300, 113-124. [CrossRef]

10. Brullot, W.; Valev, V.K.; Verbiest, T. Magnetic-plasmonic nanoparticles for the life sciences: Calculated optical properties of hybrid structures. Nanomed. Nanotechnol. Biol. Med. 2012, 8, 559-568. [CrossRef]

11. Wang, X.; Sun, S.; Huong, Z.; Zhong, H.; Zhong, S. Preparation and catalytic activity of PVP-protected Au/Ni bimetallic nanoparticles for hydrogen generation from hydrolysis of basic $\mathrm{NaBH}_{4}$ solution. Int. J. Hydrogen Energy 2014, 39, 905-916. [CrossRef]

12. Chen, D.H.; Liao, M.H. Preparation and characterization of YADH-bound magnetic nanoparticles. J. Mol. Catal. B-Enzym. 2002, 16, 283-291. [CrossRef]

13. Stoeva, S.I.; Huo, F.; Lee, J.-S.; Mirkin, C.A. Three-layer composite magnetic nanoparticle probes for DNA. J. Am. Chem. Soc. 2005, 127, 15362-15363. [CrossRef]

14. Weizmann, Y.; Patolsky, F.; Katz, E.; Willner, I. Amplified DNA sensing and immunosensing by the rotation of functional magnetic particles. J. Am. Chem. Soc. 2003, 125, 3452-3454. [CrossRef] [PubMed]

15. Weizmann, Y.; Patolsky, F.; Katz, E.; Willner, I. Amplified telomerase analysis by using rotating magnetic particles: The rapid and sensitive detection of cancer cells. ChemBioChem 2004, 5, 943-948. [CrossRef] [PubMed]

16. $\mathrm{Gu}, \mathrm{H} . ; \mathrm{Xu}, \mathrm{K} . ; \mathrm{Xu}, \mathrm{C} . ; \mathrm{Xu}, \mathrm{B}$. Biofunctional magnetic nanoparticles for protein separation and pathogen detection. Chem. Commun. 2006, 941-949. [CrossRef] [PubMed]

17. Lee, W.; Kim, M.G.; Choi, J.; Park, J.-I.; Ko, S.J.; Oh, S.J.; Cheon, J. Redox-transmetalation process as a generalized synthetic strategy for core-shell magnetic nanoparticles. J. Am. Chem. Soc. 2005, 127, 16090-16097. [CrossRef] [PubMed]

18. Alikhani, S.; Tajalli, H.; Koushki, E. Third order optical nonlinearity and diffraction pattern of Ni nanoparticles prepared by laser ablation. Opt. Commun. 2013, 286, 318-321. [CrossRef]

19. Mafune, F.; Okamoto, T.; Ito, M. Surfactant-free small Ni nanoparticles trapped on silica nanoparticles prepared by pulsed laser ablation in liquid. Chem. Phys. Lett. 2014, 591, 193-196. [CrossRef]

20. Perez, J.M.; Simeone, F.J.; Saeki, Y.; Josephson, L.; Weissleder, R. Viral-induced self-assembly of magnetic nanoparticles allows the detection of viral particles in biological media. J. Am. Chem. Soc. 2003, 125, 10192-10193. [CrossRef]

21. Parks, E.K.; Kerns, K.P.; Riley, S.J. The structure of nickel-iron clusters probed by adsorption of molecular nitrogen. Chem. Phys. 2000, 262, 151-167. [CrossRef]

22. Chiang, I.C.; Chen, Y.T.; Chen, D.H. Synthesis of NiAu colloidal nanocrystals with kinetically tunable properties. J. Alloys Compd. 2009, 468, 237-245. [CrossRef]

23. Ban, I.; Stergar, J.; Drofenik, M.; Ferk, G.; Makovec, D. Synthesis of copper-nickel nanoparticles prepared by mechanical mill-ing for use in magnetic hyperthermia. J. Magn. Magn. Mater. 2011, 323, 2254-2258. [CrossRef]

24. Song, A.J.; Ma, M.Z.; Zhang, W.G.; Zong, H.T.; Liang, S.X.; Hao, Q.H.; Zhou, R.Z.; Jing, Q.; Liu, R.P. Preparation and growth of $\mathrm{Ni}-\mathrm{Cu}$ alloy nanoparticles prepared by arc plasma evaporation. Mater. Lett. 2010, 64, 1229-1231. [CrossRef]

25. Sarac, U.; Baykul, M.C. Morphological and microstructural properties of two-phase Ni-Cu films electrodeposited at different electrolyte temperatures. J. Alloys Compd. 2013, 552, 195-201. [CrossRef]

26. Alper, M.; Kockar, H.; Safak, M.; Baykul, M.C. Comparison of Ni-Cu alloy films electrodeposited at low and high pH levels. J. Alloys Compd. 2008, 453, 15-19. [CrossRef]

27. Qiu, R.; Zhang, X.L.; Qiao, R.; Li, Y.; Kim, Y.I.; Kang, Y.S. CuNi dendritic material: Synthesis, mechanism discussion, and application as glucose sensor. Chem. Mater. 2007, 19, 4174-4180. [CrossRef]

28. Mohamed Saeed, G.H.; Radiman, S.; Gasaymeh, S.S.; Lim, H.N.; Huang, N.M. Mild hydrothermal synthesis of Ni-Cu nanoparticles. J. Nanomater. 2010, 2010, 184137. [CrossRef]

29. Pramanik, S.; Pal, S.; Bysakh, G.D. Cu-Ni alloy nanoparticles embedded $\mathrm{SiO}_{2}$ films: Synthesis and structure. J. Nanopart. Res. 2011, 13, 321-329. [CrossRef]

30. Durivault, L.; Brylev, O.; Reyter, D.; Sarrazin, M.; Bélanger, D.; Roué, L. Cu-Ni materials prepared by mechanical milling: Their properties and electrocatalytic activity towards nitrate reduction in alkaline medium. J. Alloys Compd. 2007, 432, 323-332. [CrossRef]

31. Feng, J.; Zhang, C.H.P. Preparation of Cu-Ni alloy nanocrystallites in water-in-oil microemulsions. J. Colloid Interface Sci. 2006, 293, 414-420. [CrossRef] [PubMed] 
32. Yan, Z.; Chrisey, D.B. Pulsed laser ablation in liquid for micro-/nanostructure generation. J. Photochem. Photobiol. C Photochem. Rev. 2012, 13, 204-223. [CrossRef]

33. Sukhov, I.A.; Shafeev, G.A.; Voronov, V.V.; Sygletou, M.; Stratakis, E.; Fotakis, C. Generation of nanoparticles of bronze and brass by laser ablation in liquid. Appl. Surf. Sci. 2014, 302, 79-82. [CrossRef]

34. Caprion, D.; Schober, H.R. Computer simulation of liquid and amorphous selenium. J. Non-Cryst. Solids 2003, 326-327, 369-373. [CrossRef]

35. Marqués, L.A.; Pelaz, L.; Aboy, M.; Lopez, P.; Barbolla, J. Atomistic modeling of dopant implantation and annealing in Si: Damage evolution, dopant diffusion and activation. Comput. Mater. Sci. 2005, 33, 92-105.

36. Shao, Y.; Clapp, P.C.; Rifkin, J.A. Molecular dynamics simulation of martensitic transformations in NiAI. Metall. Mater. Trans. A 1996, 27, 1477-1489. [CrossRef]

37. Erkoc, S. Empirical many-body potential energy functions used in computer simulations of condensed matter properties. Phys. Rep. 1997, 278, 79-105. [CrossRef]

38. Finnis, M.W.; Sinclair, J.E. A simple empirical N-body potential for transition metals. Philos. Mag. A 1984, 50, 45-55. [CrossRef]

39. Sutton, A.P.; Chen, J. Long-range Finnis-Sinclair potentials. Philos. Mag. Lett. 1990, 61, 139-146. [CrossRef]

40. Rapallo, A.; Olmos-Asar, J.A.; Oviedo, O.A.; Ludueña, M.; Ferrando, R.; Mariscal, M.M. Thermal properties of Co/Au nanoalloys and comparison of different computer simulation techniques. J. Phys. Chem. C 2012, 116, 17210-17218. [CrossRef]

41. Barnard, A.S. Modelling of nanoparticles: Approaches to morphology and evolution. Rep. Prog. Phys. 2010, 73, 086502. [CrossRef]

42. Jiang, S.; Zhang, Y.W.; Gan, Y.; Chen, Z.; Peng, H. Molecular dynamics study of neck growth in laser sintering of hollow silver nanoparticles with different heating rates. J. Phys. D Appl. Phys. 2013, 46, 335302. [CrossRef]

43. Shim, J.H.; Lee, S.C.; Lee, B.J.; Suh, J.Y.; Cho, Y.W. Molecular dynamics simulation of the crystallization of a liquid gold nanoparticle. J. Cryst. Growth 2003, 250, 558-564. [CrossRef]

44. Chen, K.; Sha, X.; Zhang, X.; Li, Y. Rapid solidification of Cu 25at.\% Ni alloy: Molecular dynamics simulations using embedded atom method. Mater. Sci. Eng. A 1996, 214, 139-145.

45. Brown, T.M.; Adams, J.B. EAM calculations of the thermodynamics of amorphous copper. J. Non-Cryst. Solids 1995, 180, 275-284. [CrossRef]

46. Hultgren, R.; Orr, R.L.; Anderson, P.D.; Kelley, K.K. Selected Values of Thermodynamic Properties of Metals and Alloys; John Wiley \& Sons Inc.: New York, NY, USA, 1963.

47. Yuan, G.; Louis, C.; Delannoy, L.; Keane, M.A. Silica- and titania-supported Ni-Au: Application in catalytic hydrodechlorination. J. Catal. 2007, 247, 256-268. [CrossRef]

48. Triantafyllopoulos, N.C.; Neophytides, S.G. Dissociative adsorption of $\mathrm{CH}_{4}$ on NiAu/YSZ: The nature of adsorbed carbonaceous species and the inhibition of graphitic C formation. J. Catal. 2006, 239, 187-199. [CrossRef]

49. Chin, Y.H.; King, D.L.; Roh, H.S.; Wang, Y.; Heald, S.M. Structure and reactivity investigations on supported bimetallic Au-Ni catalysts used for hydrocarbon steam reforming. J. Catal. 2006, 244, 153-162. [CrossRef]

50. Lv, H.; Xi, Z.; Chen, Z.Z.; Guo, S.; Yu, Y.; Zhu, W.; Li, Q.; Zhang, X.; Pan, M.; Lu, G.; et al. A New Core/Shell NiAu/Au Nanoparticle Catalyst with Pt-like Activity for Hydrogen Evolution Reaction. J. Am. Chem. Soc. 2015, 137, 5859-5862. [CrossRef]

51. Wang, J.H.; Lu, X.G.; Sundman, B.; Su, X.P. Thermodynamic assessment of the Au-Ni system. Calphad 2005, $29,263-268$. [CrossRef]

52. Lu, D.L.; Domen, K.; Tanaka, K. Electrodeposited Au-Fe, Au-Ni, and Au-Co alloy nanoparticles from aqueous electrolytes. Langmuir 2002, 18, 3226-3232. [CrossRef]

53. Schaak, R.E.; Sra, A.K.; Leonard, B.M.; Cable, R.E.; Bauer, J.C.; Han, Y.F.; Means, J.; Teizer, W.; Vasquez, Y.; Funck, E.S. Metallurgy in a beaker: nanoparticle toolkit for the rapid low-temperature solution synthesis of functional multimetallic solid-state materials. J. Am. Chem. Soc. 2005, 127, 3506-3515. [CrossRef] [PubMed]

54. Leonard, B.M.; Bhuvanesh, N.S.P.; Schaak, R.E. Low-temperature polyol synthesis of $\mathrm{AuCuSn}_{2}$ and $\mathrm{AuNiSn}_{2}$ : Using solution chemistry to access ternary intermetallic compounds as nanocrystals. J. Am. Chem. Soc. 2005, 127, 7326-7327. [CrossRef] [PubMed]

55. Zhou, S.H.; Yin, H.F.; Schwartz, V.; Wu, Z.L.; Mullins, D.R.; Eichhorn, B.; Overbury, S.H.; Dai, S. In situ phase separation of NiAu bulk nanoparticles for preparing highly active $\mathrm{Au} / \mathrm{NiO} \mathrm{CO}$ oxidation catalysts. Chem. Phys. Chem. 2008, 9, 2475-2479. [CrossRef] [PubMed]

56. Vasquez, Y.; Luo, Z.P.; Schaak, R.E. Low-temperature solution synthesis of the non-equilibrium ordered intermetallic compounds $\mathrm{Au}_{3} \mathrm{Fe}, \mathrm{Au}_{3} \mathrm{Co}$, and $\mathrm{Au}_{3} \mathrm{Ni}$ as nanocrystals. J. Am. Chem. Soc. 2008, 130, 11866-11867. [CrossRef] [PubMed]

57. Haruta, M.; Date, M. Advances in the catalysis of Au nanoparticles. Appl. Catal. A 2001, 222, 427-437. [CrossRef]

58. Choudhary, T.V.; Goodman, D.W. Oxidation catalysis by supported gold nano-clusters. Top. Catal. 2002, 21, 25-34. [CrossRef]

59. Bond, G.C.; Louis, C.; Thompson, D.T. Catalysis by Gold; Imperial College Press: London, UK, 2006.

60. Kung, M.C.; Davis, R.J.; Kung, H.H. Understanding Au-catalyzed low-temperature co oxidation. J. Phys. Chem. C 2007, 111, 11767-11775. [CrossRef]

61. Corti, C.W.; Holliday, R.J.; Thompson, D.T. Progress towards the commercial application of gold catalysts. Top. Catal. 2007, 44, 331-343. [CrossRef] 
62. Haile, J.M. Molecular Dynamics Simulation: Elementary Methods; John Wiley \& Sons: New York, NY, USA, 1992.

63. Kart, H.H.; Tomak, M.; Uludogan, M.; Cagin, T. Thermodynamical and mechanical properties of Pd-Ag alloys. Comput. Mater. Sci. 2005, 32, 107-117. [CrossRef]

64. Lecadre, F.; Maroun, F.; Braems, I.; Berthier, F.; Goyhenex, C.; Allongue, P. AuNi alloy monolayer films electrodeposited on Au (111): An in situ STM study. Surf. Sci. 2013, 607, 25-32. [CrossRef]

65. Berendsen, H.J.C.; Postma, J.P.M.; van Gunsteren, W.F.; DiNola, A.; Haak, J.R. Molecular dynamics with coupling to an external bath. J. Chem. Phys. 1984, 81, 3684-3690. [CrossRef]

66. Li, B.; Xing, G.; Wang, H.; Wang, R. Tailoring characteristic thermal stability of Ni-Au binary nanocrystals via structure and composition engineering: Theoretical insights into structural evolution and atomic in-ter-diffusion. AIP Adv. 2014, 4, 117132. [CrossRef]

67. Quoc, T.T.; Trong, D.N. Molecular dynamics factors affecting on the structure, crystallize process of Al bulk. Phys. B Condens. Matter 2019, 570, 116-121. [CrossRef]

68. Nguyen-Trong, D.; Pham-Huu, K.; Nguyen-Tri, P. Simulation on the factors affecting the crystallization process of FeNi alloy by Molecular Dynamics. ACS Omega 2019, 4, 14605-14612. [CrossRef]

69. Dung, N.-T.; Phuong, N.-T. Factors affecting the structure, crystallize process and crystallization process of AlNi nanoparticles. J. Alloys Compd. 2020, 812, 152133.

70. Dung, N.T. Influence of impurity concentration, atomic number, temperature and tempering time on microstructure and phase transformation of $\mathrm{Ni}_{1-\mathrm{x}} \mathrm{Fe}_{\mathrm{x}}(\mathrm{x}=0.1,0.3,0.5)$ nanoparticles. Mod. Phys. Lett. B 2018, 32, 1850204. [CrossRef]

71. Tuan, T.Q.; Dung, N.T. Effect of heating rate, impurity concentration of $\mathrm{Cu}$, atomic number, temperatures, time annealing temperature on the structure, crystallization temperature and crystallization process of $\mathrm{Ni}_{1-\mathrm{x}} \mathrm{Cu}_{\mathrm{x}}$ bulk; $\mathrm{x}=0: 1,0.3,0.5,0.7$. Int. J. Mod. Phys. B 2018, 32, 1830009. [CrossRef]

72. Kien, P.H. Study of structural transition of nickel metal under temperature. Phase Transit. 2017, 90, 732-741.

73. Nguyen, T.D.; Nguyen, C.C.; Tran, V.H. Molecular dynamics study of microscopic structures, crystallize processs and dynamic crystallization in Ni nanoparticles. RSC Adv. 2017, 7, 25406-25413. [CrossRef]

74. Qi, Y.; Çagin, T.; Johnson, W.L.; Goddard, W.A., III. Melting and crystallization in Ni nanoclusters: The mesoscale regime. J. Chem. Phys. 2001, 115, 385-394. [CrossRef]

75. Zhang, Y.; Wang, L.; Wang, W. Thermodynamic, dynamic and structural relaxation in supercooled liquid and glassy Ni below the critical temperature. J. Phys. Condens. Matter 2007, 19, 196106. [CrossRef]

76. Nguyen-Trong, D.; Nguyen-Chinh, C.; Duong-Quo, V. Study on the effect of doping on lattice constant and elec-tronic structure of bulk AuCu by the density functional theory. J. Multiscale Model. 2020, 11, 2030001. [CrossRef]

77. Long, V.C.; Quoc, V.D.; Trong, D.N. Ab initio calculations on the structural and electronic properties of AgAu alloys. ACS Omega 2020, 5, 31391-31397. [CrossRef]

78. Levitas, V.I.; Roy, A.M.; Preston, D.L. Multiple twinning and variant-variant transformations in martensite: Phase-field approach. Phys. Rev. B 2013, 88, 054113. [CrossRef]

79. Levitas, V.I.; Roy, A.M. Multiphase phase field theory for temperature- and stress-induced phase transformations. Phys. Rev. B 2015, 91, 174109. [CrossRef]

80. Levitas, V.I.; Roy, A.M. Multiphase phase field theory for temperature-induced phase transformations: Formulation and application to interfacial phases. Acta Mater. 2016, 105, 244-257. [CrossRef]

81. Roy, A.M. Effects of interfacial stress in phase field approach for martensitic phase transformation in NiAl shape memory alloys. Appl. Phys. A 2020, 126, 576. [CrossRef]

82. Ichikawa, T. Electron diffraction study of the local atomic arrangement in amorphous Iron and Nickel films. Phys. Status Solidi (a) 1973, 19, 707-716. [CrossRef]

83. Ferrando, R.; Jellinek, J.; Johnston, R.L. Nanoalloys: from theory to applications of alloy clusters and nanoparticles. Chem. Rev. 2008, 108, 845-910. [CrossRef] [PubMed]

84. Kim, H.Y.; Kim, H.G.; Ryu, J.H.; Lee, H.M. Preferential segregation of Pd atoms in the Ag-Pd bimetallic cluster: Density functional theory and molecular dynamics simulation. Phys. Rev. B 2007, 75, 212105. [CrossRef]

85. Chiang, I.C.; Chen, D.H. Synthesis of monodisperse FeAu nanoparticles with tunable magnetic and optical properties. Adv. Funct. Mater. 2007, 17, 1311-1316. [CrossRef]

86. dos Santos, V.; Kuhnen, C.A. Electronic structure and magnetic properties of Ni/Au and Ni/Cu bilayers. Thin Solid Films 1999, 350, 258-263. [CrossRef]

87. Togasaki, N.; Okinaka, Y.; Homma, T.; Osaka, T. Preparation and characterization of electroplated amorphous gold-nickel alloy film for electrical contact applications. Electrochim. Acta 2005, 51, 882-887. [CrossRef]

88. Molenbroek, A.M.; Nørskov, J.K.; Clausen, B.S. Structure and reactivity of Ni-Au nanoparticle catalysts. J. Phys. Chem. B 2001, 105, 5450-5458. [CrossRef]

89. Antoniak, C.; Gruner, M.E.; Spasova, M.; Trunova, A.V.; Roemer, F.M.; Warland, A.; Krumme, B.; Fauth, K.; Sun, S.; Entel, P.; et al. A guideline for atomistic design and understanding of ultrahard nanomagnets. Nat. Commun. 2011, 2, 528. [CrossRef]

90. Sun, S.H.; Murray, C.B.; Weller, D.; Folks, L.; Moser, A. Monodisperse FePt nanoparticles and ferromagnetic FePt nanocrystal superlattices. Science 2000, 287, 1989-1992. [CrossRef] 
91. Gao, Y.; Shao, N.; Pei, Y.; Zeng, X.C. Icosahedral crown gold nanocluster $\mathrm{Au}_{43} \mathrm{Cu}_{12}$ with high catalytic activity. Nano Lett. 2010, 10, 1055-1062. [CrossRef]

92. Sun, Q.; Ren, Z.; Wang, R.; Wang, N.; Cao, X. Platinum catalyzed growth of NiPt hollow spheres with an ultrathin shell. J. Mater. Chem. 2011, 21, 1925-1930. [CrossRef]

93. Wang, R.M.; Zhang, H.Z.; Farle, M.; Kisielowski, C. Structural stability of icosahedral FePt nanoparticles. Nanoscale 2009, 1, 276-279. [CrossRef]

94. Wang, R.M.; Dmitrieva, O.; Farle, M.; Dumpich, G.; Acet, M.; Mejia-Rosales, S.; Perez-Tijerina, E.; Yacaman, M.J.; Kisielowski, C. FePt icosahedra with magnetic cores and catalytic shells. J. Phys. Chem. C 2009, 113, 4395-4400. [CrossRef]

95. Green, I.X.; Tang, W.J.; Neurock, M.; Yates, J.T. Spectroscopic observation of dual catalytic sites during oxidation of CO on a $\mathrm{Au} / \mathrm{TiO}_{2}$ catalyst. Science 2011, 333, 736-739. [CrossRef] [PubMed]

96. Rafii-Tabar, H.; Sutton, A.P. Long-range Finnis-Sinclair potentials for f.c.c. metallic alloys. Philos. Mag. Lett. 1991, 63, 217-224. [CrossRef]

97. Kimura, Y.; Qi, Y.; Cagin, T.; Goddard, W.A. The quantum Sutton-Chen many-body potential for properties of fcc metals. Phys. Rev. 1998. to be submitted.

98. Doye, J.P.K.; Wales, D.J. Global minima for transition metal clusters described by Sutton-Chen potentials. New J. Chem. 1998, 22, 733-744. [CrossRef]

99. Qi, Y.; Cagin, T.; Kimura, Y.; Goddard, W.A. Molecular-dynamics simulations of glass formation and crystallization in binary liquid metals: Cu-Ag and Cu-Ni. Phys. Rev. B 1999, 59, 3527. [CrossRef]

100. Sankaranarayanan, S.K.R.S.; Bhethanabotla, V.R.; Joseph, B. Molecular dynamics simulation study of the melting of Pd-Pt nanoclusters. Phys. Rev. B 2005, 71, 195415. [CrossRef]

101. Tsuzuki, H.; Branicio, P.S.; Rino, J.P. Structural characterization of deformed crystals by analysis of common atomic neighborhood. Comput. Phys. Commun. 2007, 177, 518-523. [CrossRef]

102. Honeycutt, J.D.; Andersen, H.C. Molecular dynamics study of melting and freezing of small lennard-jones clusters. J. Phys. Chem. 1987, 91, 4950-4963. [CrossRef]

103. Radhi, A.; Behdinan, K. Identification of crystal structures in atomistic simulation by predominant common neighborhood analysis. Comput. Mater. Sci. 2017, 126, 182-190. [CrossRef]

104. Nose, S. A unified formulation of the constant temperature molecular dynamics methods. J. Chem. Phys. 1984, 81, 511-519. [CrossRef]

105. Hoover, W.G. Canonical dynamics: Equilibrium phase-space distributions. Phys. Rev. A 1985, 31, 1695-1697. [CrossRef] [PubMed]

106. Xu, Y.H.; Wang, J.P. Direct Gas-phase synthesis of heterostructured nanoparticles through phase separation and surface segregation. Adv. Mater. 2008, 20, 994-999. [CrossRef] 


\title{
The Effect of Sodium Alginate-Calcium Chloride Coating on the Quality Parameters and Shelf Life of Strawberry Cut Fruits
}

\author{
Ghaidaa Alharaty and Hosahalli S. Ramaswamy * \\ Department of Food Science and Agricultural Chemistry, Macdonald Campus of McGill University, \\ 21111 Lakeshore Road, Ste Anne de Bellevue, QC H9X 3V9, Canada; ghaidaa.alharaty@mail.mcgill.ca \\ * Correspondence: hosahalli.ramaswamy@mcgill.ca; Tel.: +1-514-398-7919
}

Received: 30 July 2020; Accepted: 18 August 2020; Published: 21 August 2020

\begin{abstract}
Strawberry fruits have a short shelf life after harvesting due the physiological factors that enhances ripening such as respiration and transpiration. Sensory properties including color, texture, odor, and flavor are the main factors that makes fresh produce appealing to consumers, and they change very rapidly upon harvest. For this reason, quality preservation is essential during post-harvest handling and storage of strawberry fruits. Quality deterioration rates are higher in strawberry fruit cuts due to the mechanical damage and the loss of their natural protective barriers, resulting in an increase in moisture loss, respiration rates, and the deterioration of their sensory properties. The effect of a sodium alginate-calcium chloride edible coating on quality preservation and shelf life extension of strawberry cut fruits stored at $4{ }^{\circ} \mathrm{C}$ was studied. Control samples had mold growth initiated after one week of storage at $4{ }^{\circ} \mathrm{C}$, while the coated fruit samples had a mold free shelf life extension for up to 15 days. The sodium alginate-calcium chloride edible coating was effective in reducing respiration and transpiration rates and delayed the increase of the $\mathrm{pH}$ and soluble solid content. Furthermore, the coating delayed surface mold growth for up to 15 days and preserved the sensory properties of the cut fruits such as color and texture.
\end{abstract}

Keywords: strawberry; edible coating; cut fruits; post-harvest; storage; quality

\section{Introduction}

Different methods have been used to reduce food losses and extend the shelf life of fresh fruits and vegetables including conventional refrigerated storage, modified atmosphere packaging (MAP), and controlled atmosphere storage [1]. Active packaging is also a method that has been used to reduce post-harvest losses, and it consists of using synthetic packages with variable active functions such as oxygen scavengers, carbon dioxide absorbents, and ethylene absorbents. Moreover, edible film and coating is a preservation method that has become very popular in the last few decades due its effectiveness in the extension of the post-harvest shelf life of the fresh produce [2].

An edible coating is a thin layer of adhesive material that must be applied on the surface of the food product in a liquid form by brushing, spraying, or complete immersion, forming a protective coating that can be consumed together with the food product, while an edible film is a self-standing material that can be used to wrap the food products or cover them. Edible films and coatings extend the shelf life of fresh produce and protect them from the external environmental damages in addition to the physical, chemical, and biological changes [3]. Research studies have shown that edible films can act as natural barriers against moisture loss, gas exchange, lipids, and flavor compounds losses [4]. Additionally, edible coatings create an internal atmosphere when applied on the surface of the fresh produce, which reduces the respiration and transpiration rates and delays quality deterioration and ripening [5]. 
Research is focused today on developing eco-friendly and biodegradable food packaging to replace synthetic packaging materials [6]. In the past several decades, scientists have been able to identify different types of natural polymers that can be used in the production of edible films and coatings. These polymers can be derived from multiple sources such as plants, animals, and microorganisms and are divided into three different categories. The hydrocolloid category including proteins and polysaccharides; the lipid category; and composites [3]. Composites are made of a combination of hydrocolloids and lipids to produce edible films and coatings with shared advantages from two different categories [5]. The thermo-physical and mechanical spectral properties of these special composite materials have also been extensively studied to determine their suitability for different applications with the desired adhesive, water vapor and gas permeability control respiration, and transpiration rates of perishable produce $[7,8]$.

Polysaccharides are polymers of monosaccharides connected to each other by glycocidic bonds and used in the production of edible films and coatings. Polysaccharides are suitable for use in the coating of fruits and vegetables due to their effective gas barriers. Their selective permeability to $\mathrm{O}_{2}$ and $\mathrm{CO}_{2}$ gases allows for the creation of a modified atmosphere. Other advantages are their low cost and their high availability since they are mainly found in plants and seaweeds. However, polysaccharides are hydrophilic with a high-water vapor permeability [9]. Cellulose derivatives, starches, alginates, pectin, chitosan, pullulan, and carrageenan are the most commonly used polysaccharides in the production of edible films and coatings [3].

Pullulan is a water soluble microbial exopolysaccharide obtained from the yeast-like fungus Aureobasidium pullulans and can be used in the production of thin, colorless, odorless, and tasteless edible films [6]. Moreover, alginates are polysaccharides naturally produced by brown marine algae or seaweeds such as Laminaria hyperborean and Macrocystis pyrifera. Alginates can also be produced by some bacteria such as Azotobacter vinelandii, which were first discovered in 1881. Alginates are considered as generally recognized as safe (GRAS) by the U.S. Food and Drug Administration (FDA) and were used as thickening agents and stabilizers. In addition, they are an approved food additive by the European Commission (EC). Water soluble sodium alginate is commonly used in the making of edible films and coatings and should be mixed with divalent ions to reduce its water solubility. The addition of divalent ions such as calcium allows for the formation of divalent salt bridges due to the binding of calcium ions between two chains, which provides rigid and dense gels [10].

According to the Food and Agriculture Organization report (FAO, 2011), over 4.5 million tons of strawberries were harvested each year around the world, mainly in Spain, Egypt, the USA, and Mexico [11]. Several studies have focused on strawberry fruits due to their high perishability. The effect of a chitosan-based edible coating on the shelf life extension of strawberry cut fruits was reported [12]. Additionally, the effect of a gellan-based edible coating on the quality parameters of strawberry cut fruits was studied. Their soft texture makes them more susceptible to mechanical damage and quality loss during post-harvest storage [13].

With the increased interest in ready to eat and nutritious snacks, cut fruits have become more popular and widely available in supermarkets, cafeterias, airline catering, universities, and schools [10]. Cut fruits and vegetables are wounded tissues with a shorter shelf life than the intact fruits due to the induced mechanical damages. The internal tissues in cut fruits are exposed to the external environment, which increases respiration and transpiration rates, oxidative browning, and microbial growth [14].

Minimally processed fruits and vegetables usually show uneven responses to edible coatings due to the differences in their tissue structures, surface texture, turgidity, and metabolic activity. However, a successful adhesion of the coating solution on the fruit surfaces can extend their shelf life and provide a fresh-like appearance [15].

Several studies have been carried out to evaluate the best coating composition to extend the shelf life of cut fruits. A whey protein-calcium caseinate-based edible coating has been credited with a beneficial effect in preventing oxidative browning in apple and potato cuts. However, whey proteins have low mechanical properties, which makes them not very suitable for use on the surfaces of fresh 
fruit and vegetables [14]. It has also been reported that a methyl cellulose and sodium alginate-based edible coating extended the shelf life of peaches stored at $15^{\circ} \mathrm{C}$, up to 21 and 24 days compared with 15 days in the control samples. This edible coating reduced the respiration and transpiration rates and delayed the increase in total soluble solids content $[7,8]$. It was also reported that the chitosan-based edible coating significantly reduced the weight loss of fresh strawberries and red raspberries during storage at $2{ }^{\circ} \mathrm{C}$ and $88 \%$ relative humidity (RH) compared to the control [16]. The sodium alginate composites provide some additional advantages because of their ability to complex with calcium chloride [17]. Calcium chloride has been widely used as a texture firming agent for fruits and vegetables for a long time since it can form complexes with low methoxyl pectin present in the produce tissue, thereby facilitating texture firming $[18,19]$. A similar benefit can potentially be realized with the combination of sodium alginate-calcium chloride combinations [17].

The objective of this study was to evaluate the effect of a sodium alginate-calcium chloride-based edible coating on the quality parameters and the shelf life extension of cut strawberry fruits stored for two weeks at $4{ }^{\circ} \mathrm{C}$ was evaluated. The available information of edible coating for cut fruits is very scanty.

\section{Materials and Methods}

\subsection{Sample Preparation}

Four kg of strawberry fruits were purchased fresh from the market and chosen based on similar degrees of maturity and stored at $4{ }^{\circ} \mathrm{C}$ overnight until use the next day. Strawberries were washed with tap water to remove the external impurities and cut into 1-cm thicknesses along their longitudinal axis. Cut fruits were drained for $10 \mathrm{~min}$ after washing and before coating.

\subsection{Coating Solution Preparation}

Calcium chloride salt was used in the study due to its effect as a firming agent and high-water solubility. Distilled water was used to prepare the coating solutions of $2 \%(w / w)$ sodium alginate (Sigma, Oakville, ON, Canada) and 2\% (w/w) calcium chloride (Sigma, Oakville, ON, Canada). To prepare the sodium alginate coating solution, sodium alginate powder was added to distilled water and the beaker was placed on a magnetic stirring rod at $300 \mathrm{rpm}$ with no heat until the sodium alginate powder was completely dissolved at room temperature. To prepare the calcium chloride solution, calcium chloride salts were added in a volumetric flask with distilled water and shaken to completely dissolve the salt.

\subsection{Control Sample Preparation}

For the preparation of control samples, two $\mathrm{kg}$ of strawberry fruits were only washed with tap water, cut into $1 \mathrm{~cm}$ thicknesses, drained for $10 \mathrm{~min}$ at room temperature, and stored in plastic containers at $4{ }^{\circ} \mathrm{C}$. Fruit samples were covered with polyvinyl chloride stretch film (PVC films) [20].

\subsection{Sample Coating}

Sodium alginate and calcium chloride solutions were poured in to the plastic containers and the strawberry cut fruits were placed in a fabric mesh and dipped completely into the sodium alginate solution for $5 \mathrm{~min}$, removed, and drained for $1 \mathrm{~min}$ in a plastic mesh, dipped again this time in the calcium chloride solution for $5 \mathrm{~min}$, removed, drained, and left on filter paper for $10 \mathrm{~min}$ at room temperature $\left(22^{\circ} \mathrm{C}\right)$ to remove the surface excess of the coating solution. Two kg of strawberry cut fruits were coated with the sodium alginate-calcium chloride-based edible coating [21].

\subsection{Sample Storage}

Coated and control samples were stored in plastic containers (each container contained six to seven fruit samples) and covered with polyvinyl chloride stretch film (PVC film). Small four to five holes were made in the PVC film (1-2 mm each) to maintain the atmospheric composition of air within 
the container (Figure 1). Plastic containers were stored in the refrigerator at $4{ }^{\circ} \mathrm{C}$ for two weeks and tests were done on both the control and coated samples every three days (days $0,3,6,9,12$, and 15) with quality monitoring on a daily basis [20].

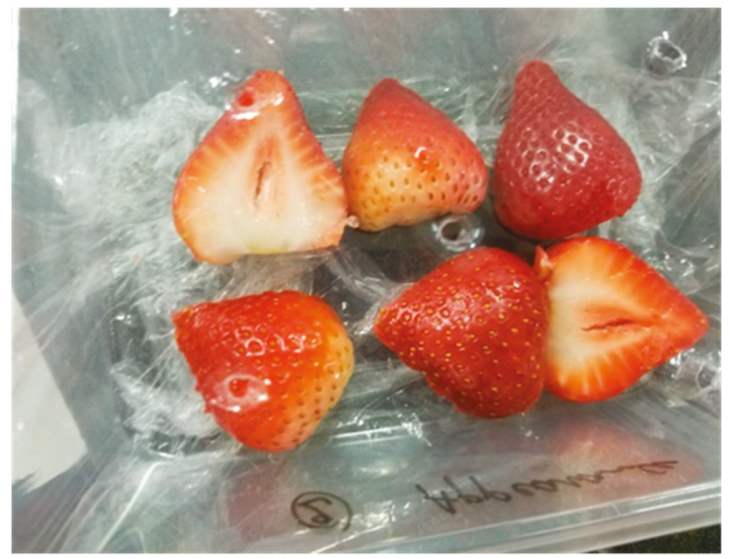

Figure 1. Sample storage in plastic containers covered with polyvinyl chloride (PVC) films.

\subsection{Respiration Rate}

Control and coated strawberry cut fruits (150 g) were placed for $2 \mathrm{~h}$ in an airtight Plexi-glass chamber $(18 \mathrm{~cm} \times 12 \mathrm{~cm} \times 27 \mathrm{~cm})$ at room temperature $\left(22{ }^{\circ} \mathrm{C}\right)$. The glass chamber was connected to a $\mathrm{CO}_{2}$ sensor (ACR Systems Inc, St-Laurent, QC, Canada) that transferred the results to a data acquisition system (Smart Reader plus 7). The $\mathrm{CO}_{2}$ concentration was collected every 1 min over a $2 \mathrm{~h}$ period. Respiration rates were obtained from the regression slope of $\mathrm{CO}_{2}$ concentration versus time and evaluated as $\mathrm{mL} \mathrm{CO} \mathrm{kg}^{-1} \mathrm{~h}^{-1}[7,8]$.

\subsection{Transpiration/Weight Loss}

Weight loss was measured by periodically weighing fruit samples using a digital balance (Denver instrument, APX-323, NY, USA). The difference between the initial weight on day 0, and the final weight measured every three days was considered as the weight loss and expressed as a percentage of the initial weight. The test was done in triplicate every three days during storage using $200 \mathrm{~g}$ of uncoated fruit samples and $200 \mathrm{~g}$ of coated fruit samples stored in multiple plastic containers (six to seven fruit samples per container) [22].

\subsection{Color}

The color characteristics of strawberry cut fruits were measured using a calorimeter, a tristimulus Minolta Chroma Meter (Minolta Corp, Ramsey, NJ, USA), to determine the L value (lightness), a * (green-red chromaticity), and b* (yellow-blue chromaticity), Chroma, and Hue angle. The calorimeter was calibrated using a white standard. Readings were done at room temperature on five to six samples of the control and coated samples $[7,8]$.

\subsection{Texture}

Seven to ten samples from each lot (control and coated) were subjected to a puncture test using a Texture Analyzer (Model TA XT Plus, Texture Technologies Corporation, Scarsdale, NY, USA/Stable Micro Systems, Godalming, Surrey, UK) fitted with a $25 \mathrm{~mm}$ diameter round tipped puncture probe with a speed of $10 \mathrm{~mm} / \mathrm{s}$. The force deformation and firmness of the fruit samples were measured based on the force-deformation curve. Measurements are in Newton (N) [7]. 


\subsection{0. $\mathrm{pH}$}

The $\mathrm{pH}$ was measured with a standard calibrated $\mathrm{pH}$ meter (Brinkman Co., Mississauga, ON, Canada). $\mathrm{pH}$ measurements were made by blending for $1 \mathrm{~min}$ and $50 \mathrm{~g}$ of the strawberry cut fruits with $150 \mathrm{~mL}$ of distilled water. A pH meter calibration was done with variable standard solutions at $\mathrm{pH} 7$ and 10 .

\subsection{Titratable Acidity}

Titratable acidity (TA) was measured using the Association of Official Analytical Chemists (AOAC) titrimetric method for fruits [23] by titrating $10 \mathrm{~mL}$ of strawberry juice with $0.1 \mathrm{~mol} / \mathrm{L} \mathrm{NaOH}$ using phenolphthalein as an indicator. The tests were done in triplicate on coated and uncoated samples. The results are expressed in citric acid (\%).

$$
\text { Titratable acidity }(\%)=\frac{\mathrm{V}(\mathrm{NaOH})(0.1)(0.064)}{\mathrm{m}} \times 100
$$

where $\mathrm{V}_{(\mathrm{NaOH})}$ is the $\mathrm{mL}$ of $\mathrm{NaOH}$ used during titration; $(0.1)$ is the molarity of the $\mathrm{NaOH}$ solution used; (0.064) is the conversion factor for citric acid, which is the main acid in strawberries; and (m) is the mass of the strawberry samples used during the test [24].

\subsection{Total Soluble Solids (TSS)}

Total soluble solids (TSS) were measured using a hand refractometer (ATAGO N1, Kirkland, DC, USA) and expressed in ${ }^{\circ}$ Brix scale. Tests were done in triplicate for both the coated and control samples [22].

\subsection{Total Aerobic Count of Microorganisms}

Total aerobic counts of microorganisms were analyzed using the plate count method. Ten grams of different control and coated samples were transferred to a blender with $90 \mathrm{~mL}$ of saline peptone water $(0.1 \mathrm{~g}$ peptone $/ 100 \mathrm{~mL}$ water). After blending, a serial dilution was done and pour-plated onto plate count agar (PCA). Plates were incubated for five days at $25{ }^{\circ} \mathrm{C}$ for counting of total aerobic microorganisms. Colony count was expressed as Log CFU/g of strawberries. Tests were done every three days in triplicate on both the control and coated samples [25].

\subsection{Appearance}

The appearance of samples was evaluated based on the color and surface mold growth. Three plastic containers of control samples and three plastic containers of coated samples (each container containing six to seven fruit samples) were stored at $4{ }^{\circ} \mathrm{C}$ and used to evaluate the appearance of the control and coated strawberry cut fruits during the experiment.

\subsection{Statistical Analysis}

A statistical analysis system (Analysis ToolPak in Excel) was used to conduct one-way Analysis of Variance (ANOVA) at 95\% level of confidence and 5\% level of significance. The significance level used was $(p<0.05)$. Tukey's method was used to indicate the significant difference between the control and coated samples during storage as well as between the different storage times for both the control and coated. The effect of the edible coating on $\mathrm{pH}$, moisture loss, respiration, TSS, titratable acidity, firmness, color, and microbiological count on strawberry cut fruits was evaluated $[7,8]$. 


\section{Results and Discussion}

\subsection{Transpiration/Weight Loss}

The transpiration rates (expressed as percentage moisture loss) measured for fruit samples stored at $4{ }^{\circ} \mathrm{C}$ are shown in Figure 2a. Weight loss was measured every three days during storage in triplicate using $200 \mathrm{~g}$ of the control samples and $200 \mathrm{~g}$ of the coated samples stored in multiple plastic containers. During the 15 days of the experiment, overall, the moisture loss percentages in the coated samples were significantly lower $(p<0.05)$ than in the control samples. The weight loss in the control samples after three days of storage was $5.2 \%$, slightly higher than $4.0 \%$ in the coated samples. Transpiration rates increased in both the control and coated samples during the experiment. On the final day 15, moisture loss in the control samples reached $13 \%$ while in the coated samples, it was $11 \%$. Differences between the coated and uncoated samples were clear from day 3 onward. Moisture loss was reduced due to the water vapor barrier formed by the sodium alginate-calcium chloride edible coating on the fruit's surface (Figure 2a).

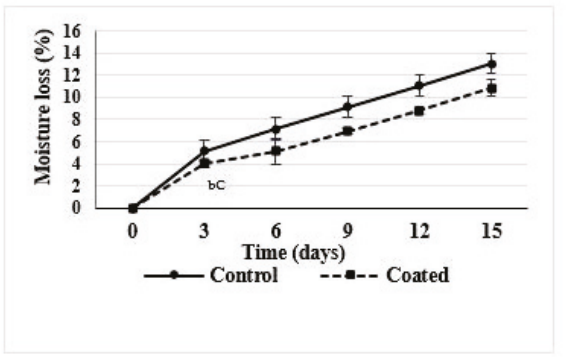

(a)

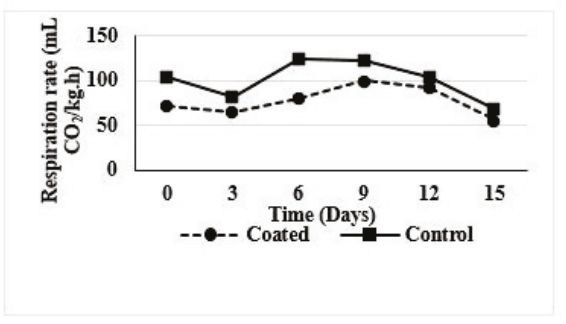

(b)

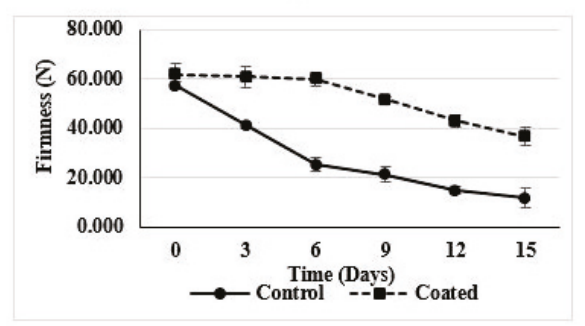

(c)

Figure 2. Moisture loss (\%) (a), respiration rate (b), and firmness of control and sodium alginate-calcium chloride coated samples during storage $(\mathbf{c})$. Different lowercase letters indicate a significant difference due to storage time $(p<0.05)$. Different uppercase letters indicate a significant difference among the control and coated samples $(p<0.05)$. 
One-way ANOVA statistical analysis showed that there was a significant difference in moisture loss among the control samples and among the coated samples during storage $(p<0.05)$. A clear significant difference in moisture loss between the control and coated samples was observed starting from day 6 up to day $15(p<0.05)$. Moisture loss was significant with respect to time for both the coated and uncoated cut fruits. Moisture loss is also related to quality loss and the reduction in weight and volume (shrinkage or shriveling) of the fresh produce. It was also reported that the reduction of moisture loss in coated fruits during storage played an important role in the shelf life extension of the strawberry cut fruits. Formation of a layer of the alginate film obviously helped to reduce the moisture loss from the fruit by acting as a barrier [10].

\subsection{Respiration Rate}

The respiration rates of the control and coated samples were measured over the period of storage. The amounts of $\mathrm{CO}_{2}$ produced were measured every minute for $2 \mathrm{~h}$ using $150 \mathrm{~g}$ of both the control and coated strawberry cut fruits. The results were taken during the first hour until the saturation of $\mathrm{CO}_{2}$ [24]. Based on this methodology, the respiration rates measured $\left(\mathrm{mL} \mathrm{CO}_{2} \mathrm{~kg}^{-1} \mathrm{~h}^{-1}\right)$ in the control samples were higher than the respiration rates in coated fruit samples over the whole period of the experiment starting from day zero. The sodium alginate-calcium chloride edible coating played an effective role in decreasing the respiration rates in the coated samples by reducing the amounts of $\mathrm{CO}_{2}$ produced. On day zero, the respiration rate in the control samples was $104 \mathrm{~mL} \mathrm{CO}_{2} \mathrm{~kg}^{-1} \mathrm{~h}^{-1}$, while it was $71.6 \mathrm{~mL} \mathrm{CO}_{2} \mathrm{~kg}^{-1} \mathrm{~h}^{-1}$ in the coated samples. Previous studies showed that on day zero, the respiration rates in both the control and coated samples should be high due to the mechanical damage. The respiration rates decreased in the control samples on day 3 to $81.3 \mathrm{~mL} \mathrm{CO}_{2} \mathrm{~kg}^{-1} \mathrm{~h}^{-1}$, while in the coated samples, it decreased to $64.7 \mathrm{~mL} \mathrm{CO}_{2} \mathrm{~kg}^{-1} \mathrm{~h}^{-1}$. On day 6, the respiration rates in the control samples increased to $123.7 \mathrm{~mL} \mathrm{CO}_{2} \mathrm{~kg}^{-1} \mathrm{~h}^{-1}$ and stayed stable until day 9, before it decreased to $68.5 \mathrm{~mL} \mathrm{CO}_{2} \mathrm{~kg}^{-1} \mathrm{~h}^{-1}$ on day 15. In the coated samples, the respiration rate increased to $99.6 \mathrm{CO}_{2} \mathrm{~kg}^{-1} \mathrm{~h}^{-1}$ on day 9, before it decreased to $55.5 \mathrm{~mL} \mathrm{CO}_{2} \mathrm{~kg}^{-1} \mathrm{~h}^{-1}$ on day 15 (Figure $2 \mathrm{~b}$ ). The sodium alginate-calcium chloride coating reduced the respiration rates in strawberry cut fruits.

One-way ANOVA statistical analysis showed no significant overall difference between the control and coated samples $(p>0.05)$ (because of the consideration of the variation over the entire range rather than a direct one to one comparison). However, the differences were significant in the beginning and between six and 12 days of storage. Other studies have shown that calcium dips can be effective in reducing respiration rates in addition to extending the shelf life of cut fruits. A decrease in the respiration rates in cut cantaloupe dipped in a calcium salt solution and stored $4{ }^{\circ} \mathrm{C}$ was reported. This reduction is facilitated by the reduced oxygen and carbon dioxide permeability by the coating. This will not only result in reducing the oxygen tension within the fruit because of the lower infusion of oxygen into the tissue, but at the same time, reduced removal of the $\mathrm{CO}_{2}$ produced will thereby promote a higher concentration of $\mathrm{CO}_{2}$ within the tissue and the consequence of both will be a reduced respiration rate [26].

\subsection{Texture}

The firmness of the strawberry cut fruits was measured using seven to 10 samples of the control and coated samples, the results of which are shown in Figure 2c. Firmness of coated strawberry cut fruits decreased during the 15 days of storage at $4{ }^{\circ} \mathrm{C}$. However, the coated samples showed better results than the control samples. A beneficial effect in the firmness retention was observed in coated samples during the 15 days of the experiment. Since day zero, the texture of the coated samples showed higher values than the control samples due to the added calcium chloride, which acts as firming agents as well as the lowered respiration and transpiration rates. The firmness of the control samples decreased from $57.3 \mathrm{~N}$ on day zero to $41.2 \mathrm{~N}$ on day 3 , while in the coated samples, the firmness was almost stable during the first six days of storage. On day 6, the firmness in the control samples showed a dramatic decrease and declined to $11.8 \mathrm{~N}$ at the end of the experiment on day 15 . In the coated 
samples, firmness declined only to $36.6 \mathrm{~N}$ on day 15, thus remained firm. Additionally, after 12 days of storage, it was difficult to perform the texture analysis on the control samples due to their extremely soft texture, while coated samples were still in good condition. The results showed the positive effect of the sodium alginate-calcium chloride edible coating on the texture of strawberry cut fruits, since a good texture was maintained over the whole period of the experiment. Values observed in coated fruits were three times higher than in the control samples (Figure 2c).

One-way ANOVA statistical analysis showed a significant difference in the firmness among the control samples after day 0 (i.e., from day 3 to 15$)(p<0.05)$. However, with the coated samples, no significant decline in texture was observed until day 9 . Furthermore, a significant difference in the firmness between the control and sodium alginate-calcium chloride coated samples was observed starting from day 3 up to day $15(p<0.05)$.

Fruit softening during maturation is caused by the biochemical changes in the cell turgidity and the cell wall compositions. The changes are shown by a degradation of the middle lamella of the cortical parenchyma cells, and a decrease in the pectin content [24]. The addition of calcium chloride salts was reported to play an effective role in maintaining the firmness of the coated samples during storage, acting as firming agents [9].

\subsection{Total Soluble Solids}

Total soluble solids ( ${ }^{\circ}$ Brix) is used as an indicator of fruit maturity and is measured in fruits to study their maturation rates. Based on different studies, the total soluble solids content (TSS) in fruits increased during storage. The edible coating could reduce the TSS content by delaying the fruits ripening [27]. During the 15 days of storage, the TSS in the control samples was higher than in the coated samples, which suggests that sugars are synthesized at a slower rate due to the sodium alginate-calcium chloride coating. On day zero, the values of TSS were 7.7 in the control samples and 7.6 in the coated samples. TSS in the control samples increased to 8.3 on day 6 , while in the coated samples, the TSS remained almost stable from day 0 until day 6 with a value of 7.6. The edible coating reduced the rates of carbohydrate breakdown and delayed fruit maturation (Figure 3a). The decrease in the TSS content at the end of the experiment is an important indicator of fruit maturation since it can indicate fruits over ripening [28]. One-way ANOVA statistical analysis showed an overall significant difference between the control and sodium alginate-calcium chloride coated samples during the experiment $(p<0.05)$. However, no significant difference was observed among the control samples or among the coated samples during storage $(p>0.05)$. The increase in TSS is related, first, to moisture loss and the increase in the soluble solid concentration. Moreover, it is related to the breakdown of complex carbohydrates into soluble solids due to the respiration and ripening of fruits. Starch is degraded rapidly into sugars such as sucrose, glucose, and fructose due to the activity of amylases, starch phosphorylase and 1,6-glucosidase enzymes [27].

\section{5. $p H$}

A significant increase in the $\mathrm{pH}$ of the control samples over the period of storage was observed. The $\mathrm{pH}$ of the control sample was higher than in the coated sample during the 15 days of the experiment. On day zero, the $\mathrm{pH}$ of the control and coated samples was 3.6. The $\mathrm{pH}$ of the control samples gradually increased and reached 3.8 on day 12 , while in the coated sample, the $\mathrm{pH}$ was almost stable from day zero until day 12 . The sodium alginate-calcium chloride edible coating reduced the $\mathrm{pH}$ of the coated samples in comparison with the control samples. Additionally, it delayed the increase in the $\mathrm{pH}$ values during storage (Figure $3 \mathrm{~b}$ ). One-way ANOVA statistical analysis showed a significant difference between the control and sodium alginate-calcium chloride coated samples during the 15 days of storage, especially day 3 onward $(p<0.05)$. The $\mathrm{pH}$ of the coated fruits remained higher than in the control samples throughout the study. A delay in the increase of the $\mathrm{pH}$ of strawberries coated with carboxyl methyl cellulose (CMC) was reported [22]. It has also been reported that the sodium 
alginate-based edible coating delayed the increase in the $\mathrm{pH}$ of the fruit samples, which delayed fruit ripening and mold growth by maintaining the acidity of the fruits [27].

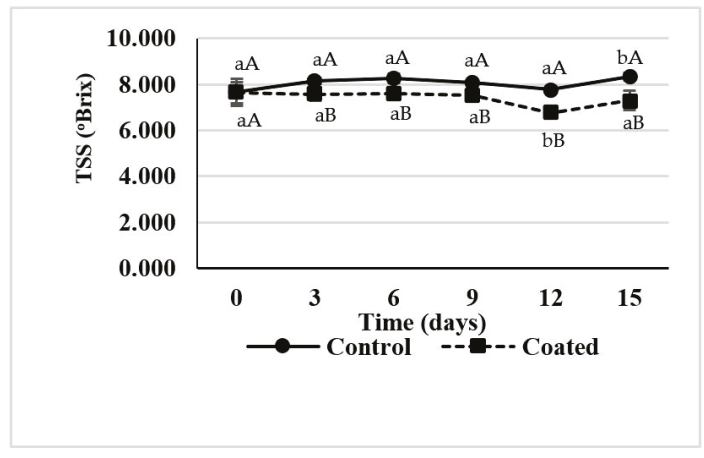

(a)

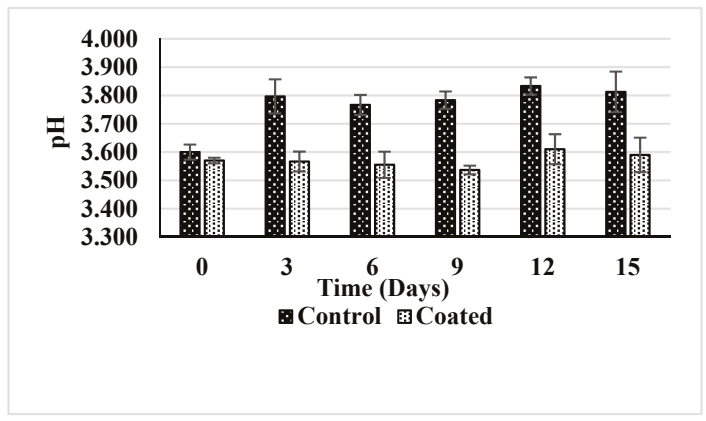

(b)

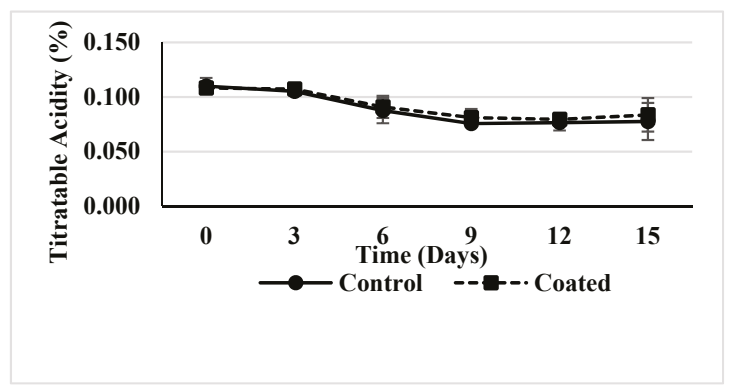

(c)

Figure 3. Changes in total soluble solids (TSS) (a), $\mathrm{pH}$ change (b), and titratable acidity of the control and coated samples during storage (c). Different lowercase letters indicate a significant difference due to storage time $(p<0.05)$. Different uppercase letters indicate a significant difference among the control and coated samples $(p<0.05)$.

\subsection{Titratable Acidity}

Titratable acidity (TA) was measured and expressed in citric acid (\%). Based on the test results, the coated fruits had a higher citric acid (\%) than the uncoated samples. On day zero, the titratable acidity was the same in both the control and coated samples. The acidity decreased at a slightly lower rate in the coated samples during the 15 days of storage. On day 6, a significant decrease in TA was observed 
in the control samples and the value reached $0.088 \%$, while in the coated samples, it decreased to $0.091 \%$. On day 9 , the TA decreased in the coated samples to $0.081 \%$ and stayed steady up to day 15 . Additionally, in the control samples, TA declined on day 9 to $0.076 \%$ and stayed steady thereafter until day 15 with a value of $0.078 \%$ (Figure 3c). Coated fruits had a higher TA (\%) during the 15 days of the experiment. The sodium alginate-calcium chloride edible coating minimized the reduction of fruit acidity compared to the control. However, one-way ANOVA statistical analysis did not show a significant difference in TA (\%) between the control and coated samples $(p>0.05)$.

Titratable acidity is related to the organic acid content in strawberries. Acidity decreases at the late stages of fruit ripening due to the use of organic acids during respiration. Coating of strawberries with CMC and hydroxypropyl methylcellulose (HPMC) showed a delay in the decrease in TA (\%) in strawberries. The edible coating reduced the loss of ascorbic acid during the 16 days of storage by reducing oxygen diffusion and respiration rates, which caused ascorbic acid retention [22]. Slower rates of decreased acidity were also observed in pectin coated cherry tomatoes stored at different temperatures [27]. Moreover, methyl cellulose coated peaches showed a delayed reduction in the titratable acidity $[7,8]$.

\subsection{Color}

The color of strawberry cut fruits was affected by the sodium alginate-calcium chloride edible coating and storage time. The color parameters L value, a * value, and Chroma were evaluated as the other parameters of $b^{*}$ value and hue angle did not show any differences between the control and coated samples.

\subsection{Value}

The decrease in L value is an indicator of surface darkening [14]. On day zero, both the control and coated samples had similar values. The $\mathrm{L}$ value in the control samples showed a dramatic decrease starting from day 3 and declined from 31.6 on day zero to 20.8 on day 15 . In the coated samples, the L value was almost stable until day 6 . The $\mathrm{L}$ value decreased on day 9 and reached 26.7 on day 15 . The $\mathrm{L}$ value was higher in the coated samples than in the control samples during the whole period of the experiment, which indicates that the sodium alginate-calcium chloride coating prevented oxidative enzymatic browning (Table 1). One-way ANOVA statistical analysis showed a significant difference in the $\mathrm{L}$ value between the control and sodium alginate-calcium chloride coated samples $(p<0.05)$ as well as a gradual decrease with storage time, while it reduced more rapidly in the control samples.

Table 1. Color parameters $L$ value, $a *$ value, and $C$ value of the control and coated samples during storage.

\begin{tabular}{|c|c|c|c|c|c|c|c|}
\hline & Samples & Day 0 & Day 3 & Day 6 & Day 9 & Day 12 & Day 15 \\
\hline \multirow{2}{*}{$\mathrm{L}$ values } & Control & $31.6 \pm 1.1^{\mathrm{a}, \mathrm{A}}$ & $26.9 \pm 0.8^{b, B}$ & $25.6 \pm 1.6^{b, C}$ & $24.0 \pm 1.5^{c, C}$ & $22.5 \pm 1.5^{\mathrm{c}, \mathrm{D}}$ & $20.8 \pm 2.8^{\mathrm{d}, \mathrm{E}}$ \\
\hline & Coated & $31.3 \pm 1.0^{\mathrm{a}, \mathrm{A}}$ & $30.8 \pm 0.8^{\mathrm{a}, \mathrm{C}}$ & $30.6 \pm 0.2^{\mathrm{a}, \mathrm{D}}$ & $29.9 \pm 1.4^{b, D}$ & $27.1 \pm 0.3^{b, E}$ & $26.7 \pm 0.5^{b, F}$ \\
\hline \multirow{2}{*}{$a *$ values } & Control & $32.4 \pm 0.2^{a, A}$ & $31.2 \pm 0.9^{\mathrm{a}, \mathrm{A}}$ & $30.3 \pm 2.6^{b, A}$ & $29.3 \pm 0.8^{c, A}$ & $27.4 \pm 1.9^{\mathrm{d}, \mathrm{B}}$ & $26.4 \pm 2.6^{e, C}$ \\
\hline & Coated & $32.6 \pm 1.3^{\mathrm{a}, \mathrm{A}}$ & $31.3 \pm 0.7^{\mathrm{b}, \mathrm{A}}$ & $29.3 \pm 2.0^{\mathrm{c}, \mathrm{A}}$ & $29.0 \pm 2.0^{\mathrm{c}, \mathrm{A}}$ & $30.0 \pm 2.1^{b, B}$ & $32.0 \pm 0.6^{\mathrm{a}, \mathrm{D}}$ \\
\hline \multirow{2}{*}{$C$ values } & Control & $37.8 \pm 0.4^{\mathrm{a}, \mathrm{A}}$ & $35.7 \pm 1.0^{\mathrm{b}, \mathrm{A}}$ & $34.8 \pm 3.8^{\mathrm{b}, \mathrm{A}}$ & $33.7 \pm 1.0^{\mathrm{b}, \mathrm{A}}$ & $31.9 \pm 3.4^{\mathrm{c}, \mathrm{A}}$ & $29.9 \pm 3.7^{\mathrm{c}, \mathrm{B}}$ \\
\hline & Coated & $38.3 \pm 1.1^{\mathrm{a}, \mathrm{A}}$ & $34.0 \pm 1.1^{\mathrm{b}, \mathrm{A}}$ & $35.1 \pm 3.9^{\mathrm{b}, \mathrm{A}}$ & $33.9 \pm 2.1^{b, A}$ & $34.6 \pm 2.6^{b, A}$ & $36.2 \pm 1.3^{b, c}$ \\
\hline
\end{tabular}

Different lowercase letters within a row indicate a significant difference due to storage time $(p<0.05)$. Different uppercase letters indicate a significant difference among the control and coated samples $(p<0.05)$.

It has been reported that the $\mathrm{L}$ value decreased in the uncoated cherry tomatoes, pectin coated cherry tomatoes, and alginate coated cherry tomatoes stored at different temperatures $\left(4^{\circ} \mathrm{C}\right.$ and $\left.12{ }^{\circ} \mathrm{C}\right)$. However, the $\mathrm{L}$ value was higher in the coated samples than in the control samples over the 21 days of storage [27]. 


\section{9. $a *$ Value}

The $\mathrm{a}$ *value indicates the green/red components. On day zero, a * value was almost the same in the control and coated samples with values of 32.4 and 32.6, respectively. In the control samples, the $\mathrm{a} *$ value slowly decreased during storage and reached 26.4 on day $15(p<0.05)$. The decrease in the $\mathrm{a}$ *value in the control samples might be a response to surface darkening and the formation of a red-brownish color. Additionally, the surface mold growth negatively affected the redness of the fruit samples. The changes in a value in the sodium alginate-calcium chloride coated samples was not significant $(p>0.05)$ and almost remained steady during the 15 days of the experiment (Table 1$)$. However, one-way ANOVA statistical analysis did not show a significant overall difference in the a * value between the control and sodium alginate-calcium chloride coated samples during storage $(p>0.05)$.

It has been reported that the a ${ }^{*}$ value increased slightly in the sodium alginate coated cherry tomatoes and pectin coated cherry tomatoes stored at $4{ }^{\circ} \mathrm{C}$ and $12{ }^{\circ} \mathrm{C}$. In the control samples, the a * value was higher due to the increased redness of the cherry tomatoes during the 21 days of storage [27].

\subsection{Value}

The $C$ value, which is the Chroma of the color, was also measured. The $C$ value in the coated samples slightly decreased from 38.3 on day zero to 33.9 on day 9 and increased again on day 12 to finally reach 36.2 on day 15 . In the control samples, the $C$ value gradually decreased from 37.8 on day zero to 29.9 on day 15 . The $C$ value was lower in the control samples during the whole experiment. The difference between the control and coated samples was mainly observed on days 12 and day 15 due to the fruit maturation, surface browning, and mold growth in the control samples (Table 1). However, as with a * values, one-way ANOVA statistical analysis did not show a significant overall difference in the $C$ values between the control and sodium alginate-calcium chloride coated samples $(p>0.05)$.

A decrease in the Chroma of the uncoated strawberries stored for 8 days at $1{ }^{\circ} \mathrm{C}$ was reported. During storage, the color of the fruits became less vivid and was caused by the development of a red-brownish color in the fully ripe strawberries [29]. The edible coating maintained the Chroma of the color during storage of strawberry fruits [22].

\subsection{Total Aerobic Count of Microorganisms}

A plate count analysis was performed every three days on the control and sodium alginate-calcium chloride coated samples. On day zero, almost similar values were observed in the control and coated samples. After only three days of storage, the number of yeasts and molds in the control samples increased to $5.9 \log \mathrm{CFU} / \mathrm{g}$, while in the coated samples, it increased to $5.1 \log \mathrm{CFU} / \mathrm{g}$. On day 6, minor mold growth was observed in the control samples and the values increased to $6.15 \log \mathrm{CFU} / \mathrm{g}$ and reached $6.25 \log \mathrm{CFU} / \mathrm{g}$ on day 9 . After 12 and 15 days of storage, the number of colonies of aerobic microorganisms in the control sample was too large to count $(>300$ colonies on the least diluted agar plate) using the plate count analysis method; hence, only the total aerobic count of microorganisms for coated samples were shown on day 12 and day 15 (Figure 4).

In the coated samples, the total aerobic count of microorganisms slightly increased to $5.5 \mathrm{log}$ $\mathrm{CFU} / \mathrm{g}$ on day 6 and reached $5.9 \log \mathrm{CFU} / \mathrm{g}$ on day 12. On day 15, minor mold growth was observed on the surface of the coated samples and the total aerobic count of microorganisms increased to 6.1 log $\mathrm{CFU} / \mathrm{g}$ (Figure 4). One-way ANOVA statistical analysis showed a significant increase in total aerobic counts among the control samples starting from day 0 until day 9 (stopped at this stage due to spoilage) and among the sodium alginate-calcium chloride coated samples starting from day 0 until day 15 $(p<0.05)$, although quantitatively slightly less than the coated ones. 


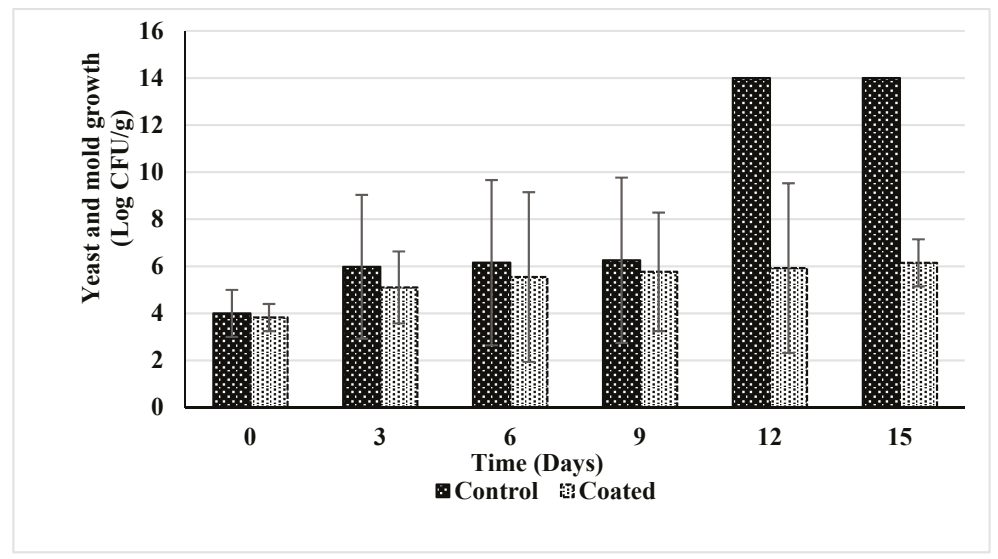

Figure 4. Total aerobic microorganisms count (Log CFU/g) in the control and sodium alginate-calcium chloride coated samples during storage. Error bars are indicated with the points and significance detailed in the text. Different lowercase letters indicate a significant difference due to storage time $(p<0.05)$. Different uppercase letters indicate a significant difference among the control and coated samples $(p<0.05)$. TLC: Too Large to Count.

It has been reported that a chitosan-based edible coating reduced the decay and surface mold growth in strawberry fruits and raspberries stored at $2{ }^{\circ} \mathrm{C}$ and $88 \% \mathrm{RH}$. Mold growth appeared on the surface of the control samples only after five days of storage, while in the coated samples, the mold growth was delayed [16].

\subsection{Appearance}

Minor mold growth was apparent on the surface of the control samples on day 6, while in the coated samples, mold growth was observed only on day 15 . Control samples stored at $4{ }^{\circ} \mathrm{C}$ had an acceptable visual quality during the first six days of storage before the beginning of decay and mold growth. On day zero, both the control and coated strawberry cut fruits showed similar appearances with a bright red color (Figure 5a). After six days of storage, the color of the control samples became darker with a minor appearance of mold growth on the surface. The color of the coated samples became a bit darker after six days with no mold growth (Figure 5b). After nine days of storage, control samples showed some browning, tissue softening, and mold growth while the coated samples showed no darkening and no mold growth (Figure 5c). After 12 days of storage, the control samples had mold growth, very soft texture, and browning, while the coated samples showed no mold growth and a slight darkening in color (Figure 5d). On day 15, the control samples were completely grey with mold growth, and extremely soft with a watery texture. The coated samples showed minor mold growth on the surface of some samples with tissue softening and color darkening (Figure 5e).

The addition of calcium chloride salts helped in enhancing the texture of strawberry cut fruits since they act as firming agents. Additionally, it helps in reducing mold growth, physiological disorders, and oxidative browning [30]. CMC, with the incorporation of probiotic Lactobacillus plantarum, was also used to coat strawberries stored at $4{ }^{\circ} \mathrm{C}$ for 15 days. A delay in mold surface growth was observed in the coated strawberries [31]. In another study, the chitosan coating reduced mold and yeast growth in fresh cut papaya and reduced mesophilic plate counts [15]. 


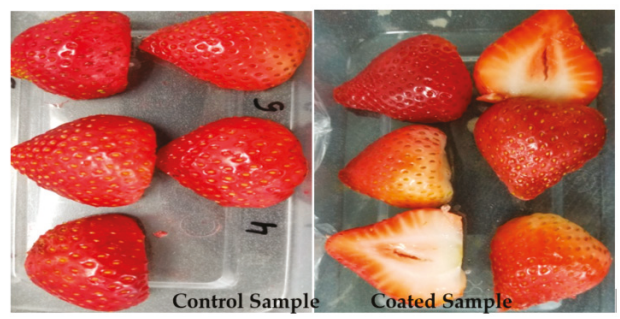

(a)

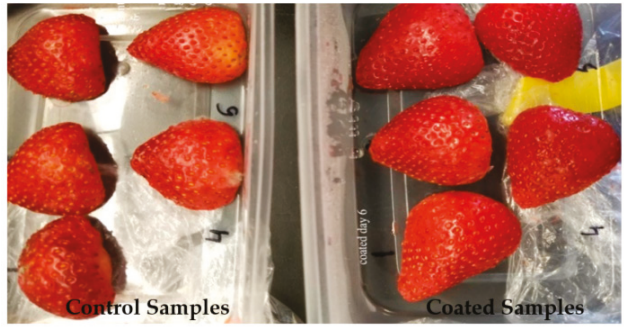

(b)

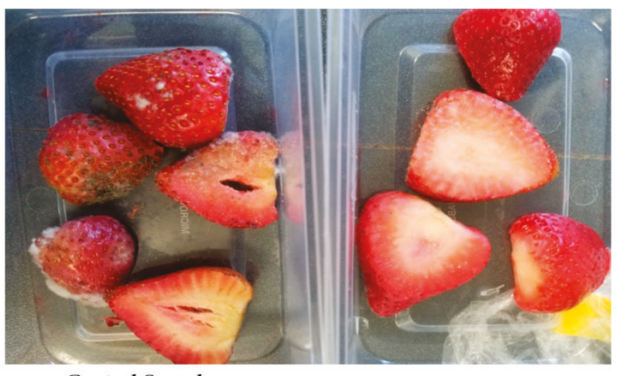

Control Samples Coated Samples

(c)

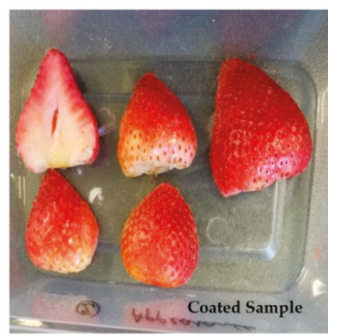

(d)

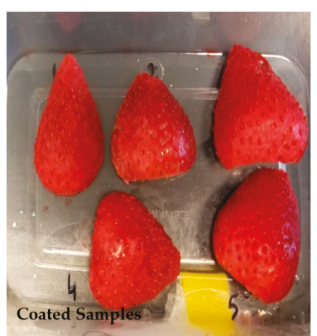

(e)

Figure 5. Side by side appearance of the control and coated fruits at day zero (a) and after storage for six (b) and nine (c) days, and only for coated fruits after storage for 12 (d) and 15 (e) days (extensive mold grown on control samples, not shown). 


\section{Conclusions}

The results demonstrated that the sodium alginate-calcium chloride edible coating extended the shelf life of strawberry cut fruits stored at $4{ }^{\circ} \mathrm{C}$ for up to 15 days. The edible coating reduced the transpiration and respiration rates, acting as a protective barrier, which caused the reduction of mold growth and preserved the sensory properties of the cut strawberries. Additionally, the sodium alginate-calcium chloride edible coating delayed the increase in TSS content and the $\mathrm{pH}$ of the cut fruits through citric acid retention. The use of a sodium alginate-based edible coating on cut fruits help both consumers and producers reduce food losses and save money.

Author Contributions: Conceptualization, G.A. and H.S.R.; Methodology, G.A.; Software, G.A.; Validation, G.A.; Formal analysis, G.A. and H.S.R.; Investigation, G.A.; Resources, H.S.R.; Data curation, G.A. and H.S.R.; Writing—original draft preparation, G.A.; Writing—review and editing, G.A. and H.S.R.; Visualization, G.A. and H.S.R.; Supervision, H.S.R.; Project administration, H.S.R.; Funding acquisition, H.S.R. All authors have read and agreed to the published version of the manuscript.

Funding: This research received no external funding.

Acknowledgments: This research was partly supported by the Natural Sciences and Engineering Research Council (NSERC) Discovery Grants Program.

Conflicts of Interest: The authors declare no conflict of interest.

\section{References}

1. Ramaswamy, H.S. Post-Harvest Technologies of Fruits \& Vegetables; DEStech Publications Inc.: Lancaster, PA, USA, 2015.

2. Siddiqui, M.W.; Rahman, S.; Wani, A.A. Innovative Packaging of Fruits and Vegetables: Strategies for Safety and Quality Maintenance. Available online: http://public.ebookcentral.proquest.com/choice/publicfullrecord. aspx?p=5400699 (accessed on 19 August 2020).

3. Sabina, G.; Emine Aytunga Arik, K.; Małgorzata, G.; Karolina, K.N. Novel materials in the preparation of edible films and coatings-A review. Coatings 2020, 10, 674. [CrossRef]

4. Mahfoudhi, N.; Hamdi, S. Use of almond gum and gum arabic as novel edible coating to delay postharvest ripening and to maintain sweet cherry (Prunus avium) quality during storage. J. Food Process. Preserv. 2015, 39, 1499-1508. [CrossRef]

5. Singh, B.; Singh, S. Advances in Post-Harvest Technologies of Vegetable Crops. Available online: https: //www.taylorfrancis.com/books/e/9781315161020 (accessed on 19 August 2020).

6. Karolina, K.; Katarzyna, P.; Małgorzata, G. Pullulan-Biopolymer with potential for use as food packaging. Int. J. Food Eng. 2019, 15, 20190030. [CrossRef]

7. Maftoonazad, N.; Ramaswamy, H.S. Postharvest shelf-life extension of avocados using methyl cellulose-based coating. LWT-Food Sci. Technol. 2005, 38, 617-624. [CrossRef]

8. Maftoonazad, N.; Ramaswamy, H.S.; Marcotte, M. Shelf-Life extension of peaches through sodium alginate and methyl cellulose edible coatings. Int. J. Food Sci. Technol. 2008, 43, 951-957. [CrossRef]

9. Vargas, M.; Pastor, C.; Chiralt, A.; McClements, D.J.; González-Martínez, C. Recent advances in edible coatings for fresh and minimally processed fruits. Crit. Rev. Food Sci. Nutr. 2008, 48, 496-511. [CrossRef] [PubMed]

10. Senturk Parreidt, T.; Muller, K.; Schmid, M. Alginate-Based edible films and coatings for food packaging applications. Foods 2018, 7, 170. [CrossRef]

11. Food and Agriculture Organization. FAOSTAT Strawberries Crops (Production). Available online: http: //www.fao.org/faostat/en/\#home (accessed on 19 August 2020).

12. Campaniello, D.; Bevilacqua, A.; Sinigaglia, M.; Corbo, M.R. Chitosan: Antimicrobial activity and potential applications for preserving minimally processed strawberries. Food Microbiol. 2008, 25, 992-1000. [CrossRef]

13. Tomadoni, B.; Moreira, M.R.; Pereda, M.; Ponce, A.G. Gellan-based coatings incorporated with natural antimicrobials in fresh-cut strawberries: Microbiological and sensory evaluation through refrigerated storage. LWT-Food Sci. Technol. 2018, 97, 384-389. [CrossRef]

14. Yousuf, B.; Qadri, O.S.; Srivastava, A.K. Recent developments in shelf-life extension of fresh-cut fruits and vegetables by application of different edible coatings: A review. LWT 2018, 89, 198-209. [CrossRef] 
15. González-Aguilar, G.A.; Valenzuela-Soto, E.; Lizardi-Mendoza, J.; Goycoolea, F.; Martínez-Téllez, M.A.; Villegas-Ochoa, M.A.; Ayala-Zavala, J.F. Effect of chitosan coating in preventing deterioration and preserving the quality of fresh-cut papaya 'Maradol'. J. Sci. Food Agric. 2009, 89, 15-23. [CrossRef]

16. Han, C.; Zhao, Y.; Leonard, S.W.; Traber, M.G. Edible coatings to improve storability and enhance nutritional value of fresh and frozen strawberries (Fragaria ananassa) and raspberries (Rubus ideaus). Postharvest Biol. Technol. 2004, 33, 67-78. [CrossRef]

17. Marcotte, M.; Taherian, A.R.; Ramaswamy, H.S. Physical properties of reconstituted carrot/alginate particles suitable for aseptic processing. J. Food Process Eng. 2000, 23, 463-480. [CrossRef]

18. Izumi, H.; Watada, A.E. Calcium treatments affect storage quality of shredded carrots. J. Food Sci. 1994, 59, 106-109. [CrossRef]

19. Alonso, J.; Canet, W.; Rodriguez, T. Thermal and calcium pretreatment affects texture, pectinesterase and pectic substances of frozen sweet cherries. J. Food Sci. 1997, 62, 511-515. [CrossRef]

20. Garcia, L.C.; Pereira, L.M.; de Luca Sarantópoulos, C.I.G.; Hubinger, M.D. Effect of antimicrobial starch edible coating on shelf-life of fresh strawberries. Packag. Technol. Sci. 2012, 25, 413-425. [CrossRef]

21. Gamboa-Santos, J.; Campañone, L.A. Application of osmotic dehydration and microwave drying to strawberries coated with edible films. Dry. Technol. 2018, 1-11. [CrossRef]

22. Gol, N.B.; Patel, P.R.; Rao, T.V.R. Improvement of quality and shelf-life of strawberries with edible coatings enriched with chitosan. Postharvest Biol. Technol. 2013, 85, 185-195. [CrossRef]

23. AOAC-Association of Offical Analytical Chemists. Official Method of Analysis, Titrimetric Method for Fruits; AOAC: Rockville, MD, USA, 1990.

24. Velickova, E.; Winkelhausen, E.; Kuzmanova, S.; Alves, V.D.; Moldão-Martins, M. Impact of chitosan-beeswax edible coatings on the quality of fresh strawberries (Fragaria ananassa cv Camarosa) under commercial storage conditions. LWT Food Sci. Technol. 2013, 52, 80-92. [CrossRef]

25. Moreira, M.R.; Cassani, L.; Martín-Belloso, O.; Soliva-Fortuny, R. Effects of polysaccharide-based edible coatings enriched with dietary fiber on quality attributes of fresh-cut apples. J. Food Sci. Technol. 2015, 52, 7795-7805. [CrossRef]

26. Lamikanra, O.; Watson, M.A. Effect of Calcium Treatment Temperature on Fresh-cut Cantaloupe Melon during Storage. J. Food Sci. 2004, 69, C468-C472. [CrossRef]

27. Narayanapurapu, P. Effect of Composite Edible Coatings and Abiotic Stress on Post Harvest Quality of Fruits; McGill University Libraries: Montreal, QC, Canada, 2012.

28. Yan, J.; Luo, Z.; Ban, Z.; Lu, H.; Li, D.; Yang, D.; Li, L. The effect of the layer-by-layer (LBL) edible coating on strawberry quality and metabolites during storage. Postharvest Biol. Technol. 2019, 147, 29-38. [CrossRef]

29. Collins, J.K.; Perkins, V.P. Postharvest Changes in Strawberry Fruit Stored Under Simulated Retail Display Conditions. J. Food Qual. 1993, 16, 133-143. [CrossRef]

30. Soazo, M.; Pérez, L.M.; Rubiolo, A.C.; Verdini, R.A. Prefreezing application of whey protein-based edible coating to maintain quality attributes of strawberries. Int. J. Food Sci. Technol. 2015, 50, 605-611. [CrossRef]

31. Khodaei, D.; Hamidi-Esfahani, Z. Influence of bioactive edible coatings loaded with Lactobacillus plantarum on physicochemical properties of fresh strawberries. Postharvest Biol. Technol. 2019, 156, 110944. [CrossRef]

(C) 2020 by the authors. Licensee MDPI, Basel, Switzerland. This article is an open access article distributed under the terms and conditions of the Creative Commons Attribution (CC BY) license (http://creativecommons.org/licenses/by/4.0/). 



\title{
Uptake of Methylene Blue from Aqueous Solution by Pectin-Chitosan Binary Composites
}

\author{
Dexu Kong ${ }^{1,2}$ and Lee D. Wilson ${ }^{2, *}$ \\ 1 Saskatchewan Research Council, 125-15 Innovation Boulevard, Saskatoon, SK S7N 2X8, Canada; \\ dek593@mail.usask.ca \\ 2 Department of Chemistry, University of Saskatchewan, 110 Science Place, Saskatoon, SK S7N 5C9, Canada \\ * Correspondence: lee.wilson@usask.ca; Tel.: +1-306-966-2961; Fax: +1-306-966-4730
}

Received: 23 June 2020; Accepted: 15 July 2020; Published: 18 July 2020

\begin{abstract}
To address the need to develop improved hybrid biopolymer composites, we report on the preparation of composites that contain chitosan and pectin biopolymers with tunable adsorption properties. Binary biopolymer composites were prepared at variable pectin-chitosan composition in a solvent directed synthesis, dimethyl sulfoxide (DMSO) versus water. The materials were characterized using complementary methods (infrared spectroscopy, thermal gravimetric analysis, $\mathrm{pH}$ at the point-of-zero charge, and dye-based adsorption isotherms). Pectin and chitosan composites prepared in DMSO yielded a covalent biopolymer framework (CBF), whereas a polyelectrolyte complex (PEC) was formed in water. The materials characterization provided support that cross-linking occurs between amine groups of chitosan and the $-\mathrm{COOH}$ groups of pectin. CBF-based composites had a greater uptake of methylene blue (MB) dye over the PEC-based composites. Composites prepared in DMSO were inferred to have secondary adsorption sites for enhanced MB uptake, as evidenced by a monolayer uptake capacity that exceeded the pectin-chitosan PECs by 1.5 -fold. This work provides insight on the role of solvent-dependent cross-linking of pectin and chitosan biopolymers. Sonication-assisted reactions in DMSO favor CBFs, while cross-linking in water yields PECs. Herein, composites with tunable structures and variable physicochemical properties are demonstrated by their unique dye adsorption properties in aqueous media.
\end{abstract}

Keywords: composites; chitosan-pectin; adsorption; polyelectrolyte complex; covalent biopolymer framework

\section{Introduction}

Methylene blue is a cationic dye with high water solubility that has many diverse applications which includes the dyeing of paper, cotton, wool, and hair [1]. The occurrence of synthetic dyes in industrial effluent has led to global environmental concern due to the inadvertent release into aquatic environments and the impacts of such contaminants on ecosystems and human health. Exposure to lethal doses of cationic dyes such as methylene blue may lead to vomiting, cyanosis, jaundice, shock, and tissue necrosis in humans [2]. To address the removal of synthetic dyes from industrial wastewater, conventional methods such as electrochemical, coagulation, flocculation, chemical oxidation, solvent extraction, and adsorption have been reported [3-5]. Among these methods, adsorption is a popular choice for contaminant removal due to its simplicity of operation, cost-effectiveness, and availability of commercial adsorbents such as zeolites and activated carbon. Whereas the efficiency of adsorption processes is often limited by the physicochemical properties of the adsorbent and its regeneration capability, there is continued interest that exists in the development of biomaterial adsorbents derived from renewable sources such as cellulose and chitosan. Chitosan is a natural product derived from chitin upon deacetylation via alkaline hydrolysis, where the resulting copolymer contains glucosamine and acetylated glucosamine co-monomer units. The solubility of chitosan and its chemical reactivity 
scale as the degree of deacetylation reaches $60 \%$ or more [1]. The synthetic versatility of chitosan is evidenced by its various modified forms upon surface functionalization, cross-linking, and composite formation. As well, the physical modification of native chitosan through the alteration of its morphology in the form of nanomaterials, beads, and fibers can also lead to changes in the textural and adsorption properties toward ionic species. Raw chitosan and its derivatives are promising biopolymers for cation-anion adsorbate binding due to its unique adsorption properties $[1,6,7]$.

The continued interest in the development of biopolymer-based sorbents provides an opportunity to develop sustainable adsorbent technology [8]. A previous study by Sabzevari et al. on the preparation of chitosan composites that contain graphene oxide (GO) displayed unique adsorption with methylene blue, as compared with pristine chitosan. Whereas GO is an arene base fragment with polar functional groups $(-\mathrm{OH},-\mathrm{COOH})$ due to the controlled oxidation of graphite, pectin contains $\alpha-(1-4)$ linked D-galacturonic acid units and $\alpha-(1-2)$ linked L-rhamnopyranose residues. In comparison to GO, pectin is a suitable precursor for the preparation of cross-linked chitosan-based composites $[9,10]$ due to its relatively low $p K_{a}\left(p K_{a}=2.9-3.2\right)$. The galacturonic acid (GalA) groups of pectin can react with methanol in an acidic environment to form methyl esters, where the majority of these GalA units are present as methyl esters in their native form. The degree of substitution (DS) of methyl ester formation is used to classify pectin polymers, where such biopolymers with a high methyl ester content (DS $>50 \%$ ) are referred to as HM pectins [11].

Since chitosan contains glucosamine and $\mathrm{N}$-acetyl glucosamine units linked through a (1-4) linkage, the biopolymer can exist in its cationic form upon protonation at acidic $\mathrm{pH}$ below its $\mathrm{pK}_{\mathrm{a}}$. The protonated amine groups of chitosan are considered as the active sites to attract anion species through electrostatic interactions. As well, the amine groups can also undergo reaction with carboxylic acids to form hybrid composite materials [9,12]. Chitosan-based composites that contain pectin may undergo covalent or ionic bonding, as shown by the formation of a polyelectrolyte complex (PEC) or amide linkages between chitosan and pectin to yield a covalent biopolymer framework (CBF), as conceptually illustrated in Scheme 1.

In this study, various pectin-chitosan composite adsorbents were prepared and their physicochemical properties were characterized using infrared (IR) spectroscopy and other complementary methods. The dye adsorption properties of the composites were studied using methylene blue $(\mathrm{MB})$, which is a model cationic dye that can provide insight on the nature of composites formed between pectin and chitosan (cf. Scheme 1). The overall goal of this study was to synthesize and characterize novel hybrid biopolymer adsorbents derived from chitosan and pectin, where the following objectives were addressed: (1) to synthesize pectin-chitosan composites at variable composition ratios using two different solvents (DMSO versus water), (2) to characterize the structure and physicochemical properties of the composites using complementary methods, and (3) to characterize the equilibrium adsorption properties of the biopolymer composites using methylene blue as a dye probe. This research addresses the knowledge gap concerning the structure-adsorption properties of pectin and chitosan composites according to the mode of preparation. 
<smiles>CO[C@H]1O[C@H](CO)[C@@H](O[C@@H]2O[C@H](CO)[C@@H](O[C@@H]3O[C@H](CO)[C@@H](C)[C@H](O)[C@H]3N)C(O)[C@H]2NC(C)=O)[C@H](O)[C]1N</smiles>

Chitosan

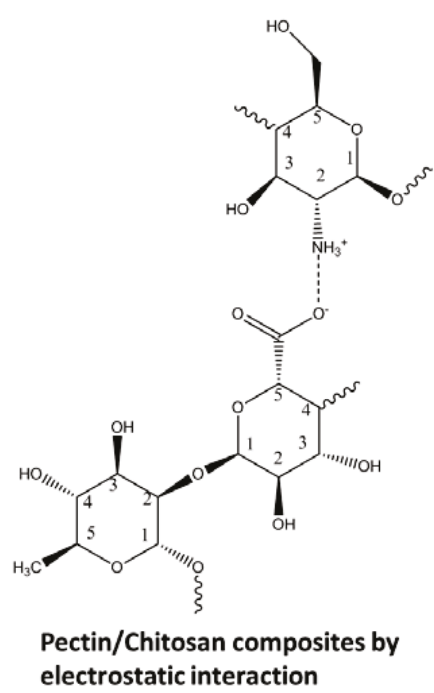

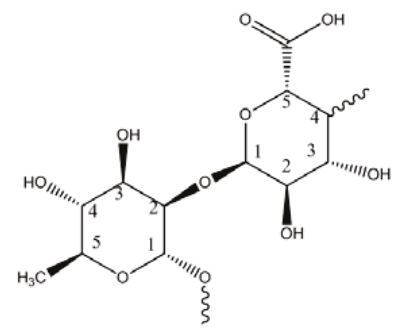

Pectin

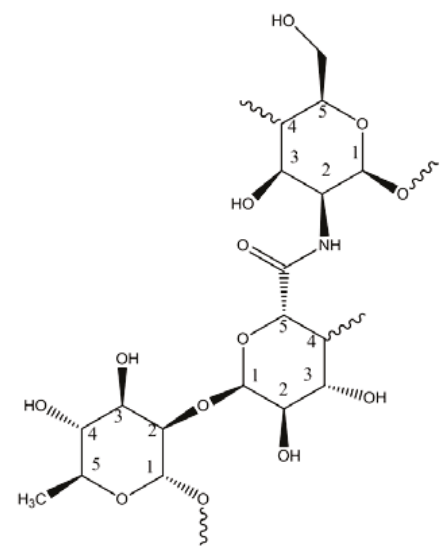

Pectin/Chitosan composites by covalent interaction

Scheme 1. Formation of pectin-chitosan composites through a polyelectrolyte complex (PEC) or a covalent biopolymer framework (CBF).

\section{Materials and Methods}

\subsection{Materials and Equipment}

Chitosan (Mwt. approximately 50,000-190,000 g/mol) with an average deacetylation of 75-85\%, dimethyl sulfoxide (>99.7\%, DMSO), methylene blue (MB), and pectin from citrus peel galacturonic acid $\geq 74.0 \%$ (dry basis) were obtained from Sigma-Aldrich (Edmonton, AB, Canada). Ultrasonic homogenizer (Fisherbrand ${ }^{\mathrm{TM}}$ Model 505) is from Fisher Scientific (Edmonton, AB, Canada).

\subsection{Synthesis of Pectin and Chitosan Composites}

\subsubsection{Pectin-Chitosan Polyelectrolyte Complexes in Water: PC15 W, PC11 W, PC51 W}

To prepare the 1:5 pectin/chitosan composite (PC15 W), the 2 wt \% chitosan solution was prepared by dissolving chitosan (ca. $2 \mathrm{~g}$ ) into $98 \mathrm{~g}$ of acetic acid ( $2 \mathrm{wt} \%$ ), and the pectin solution was prepared by dissolving of pectin (ca. $1.37 \mathrm{~g}$ ) into $68.6 \mathrm{~g}$ of deionized water to make a $2 \mathrm{wt} \%$ solution. In a $150 \mathrm{~mL}$ beaker, $50 \mathrm{~g}$ of the $2 \mathrm{wt} \%$ chitosan solution was mixed with $10 \mathrm{~g}$ of the pectin $2 \mathrm{wt} \%$ solution at $23{ }^{\circ} \mathrm{C}$ with a magnetic stirrer at $1000 \mathrm{rpm}$ overnight. The mixture was neutralized with $1 \mathrm{M} \mathrm{NaOH}(a q) 12 \mathrm{~h}$ after the mixing step until $\mathrm{pH} 7$ to yield a suspension of pectin-chitosan particles. The pectin-chitosan composite precipitate was filtered by a vacuum pump with Whatman 42 ashless filter paper and 
washed with deionized water, where the filtrate reached a low conductivity $(35 \mu \mathrm{S} / \mathrm{cm})$. The final products were air-dried for $48 \mathrm{~h}$. Procedures for making PC11 W and PC51 W were similar to the previous procedures to obtain the PC15 W products, except the relative amount of pectin and chitosan was varied to achieve the different weight ratios accordingly.

2.2.2. Sonication-Assisted Synthesis of Pectin-Chitosan Composites in DMSO: PC15 S DMSO, PC11 S DMSO, and PC51 S DMSO

To prepare PC15 S DMSO, pectin (ca. $1.5 \mathrm{~g}$ ) and chitosan (ca. $7.5 \mathrm{~g}$ ) were dispersed in DMSO $(200 \mathrm{~mL})$. The pectin and chitosan mixture in DMSO was sonicated for $10 \mathrm{~min}$. After cooling, the brown-dark pectin/chitosan composites were filtered and dried in the fume hood at $23^{\circ} \mathrm{C}$. The preparation of the PC11 S DMSO and PC51 S DMSO composites were similar to the above except that pectin (ca. $2 \mathrm{~g}$ and $7.5 \mathrm{~g}$ ) and chitosan (ca. $2 \mathrm{~g}$ and $1.5 \mathrm{~g}$ ) were suspended in DMSO (200 mL).

\subsection{Characterization of Composite Materials}

The characterization of the composites involved the use of several complementary methods: $\mathrm{pH}$ at the point-of-zero charge $\left(\mathrm{pH}_{\mathrm{pzc}}\right)$, Fourier Transform Infrared (FTIR) spectroscopy, ultraviolet-visible (UV-vis) spectrophotometry, and thermal gravimetric analysis (TGA).

\subsection{1. $\mathrm{pH}$ at the Point-of-Zero Charge $\left(\mathrm{pH}_{\mathrm{pzc}}\right)$}

The relative surface charge of the sample was determined by estimation of the $\mathrm{pH}_{\mathrm{pzc}}$ using an adapted method reported previously [13]. First, $0.01 \mathrm{M} \mathrm{NaCl}$ aqueous solution $(20 \mathrm{~mL})$ was transferred into each of nine 7-dram glass vials. The solution $\mathrm{pH}$ of each vial was adjusted by the addition of $\mathrm{NaOH} / \mathrm{HCl}$ to obtain $\mathrm{pH}$ values that ranged from $\mathrm{pH} 2.0$ to 13.0 . The sample materials (ca. $0.5 \mathrm{~g}$ ) were added to each solution and allowed to equilibrate for $48 \mathrm{~h}$ before the final $\mathrm{pH}$ was measured. A graph of final $\mathrm{pH}$ versus initial $\mathrm{pH}$ was plotted where the intersection point was recorded as the $\mathrm{pH}$ for the point-of-zero charge $\left(\mathrm{pH}_{\mathrm{pzc}}\right)$ for each material.

\subsubsection{FTIR Spectroscopy}

Fourier transform infrared (FTIR) spectra of powdered samples were obtained as 1 wt \% solid samples mixed with $\mathrm{KBr}$ and analyzed in diffuse reflectance mode using a BIO-RAD FTS-40 spectrophotometer. Multiple $(n=64)$ scans were obtained with a $4 \mathrm{~cm}^{-1}$ resolution that was corrected against a background spectrum of spectroscopic grade $\mathrm{KBr}$ over a defined spectral range $\left(400-4000 \mathrm{~cm}^{-1}\right)$.

\subsubsection{Thermal Gravimetric Analysis (TGA)}

TGA profiles were obtained using open aluminum pans with a TA Q50 (New Castle, DE) instrument. The heating rate $\left(5^{\circ} \mathrm{C} \mathrm{min}-1\right)$ profile was monitored from 30 to $500{ }^{\circ} \mathrm{C}$ using a $\mathrm{N}_{2}$ purge gas environment.

\subsubsection{Dye Adsorption Studies}

The adsorption properties of the samples were evaluated using methylene blue (MB) in batch mode. Stock aqueous solutions of $\mathrm{MB}(0.2-10 \mathrm{mM})$ were prepared at $\mathrm{pH} 6$ under ambient conditions. For each different set of 3-dram glass vials, adsorbents (ca. $10 \mathrm{mg}$ ) were added along with the MB solution $(10 \mathrm{~mL})$ at variable dye concentration $(0.2-10 \mathrm{mM})$. The vials were sealed with parafilm and mixed in a horizontal shaker for $24 \mathrm{~h}$ at $130 \mathrm{rpm}$. After mixing for $24 \mathrm{~h}$, the system reached equilibrium and the samples were centrifuged, where the supernatant containing MB was analyzed using UV-vis spectrophotometry. The optical absorbance of MB was determined using a Shimadzu UV-vis spectrophotometer (Bio-RAD FTS-40 IR spectrophotometer, Bio-Rad Laboratories, Inc., Philadelphia, PA, USA) at the maximum absorbance $\left(\lambda_{\max }=662 \mathrm{~nm}\right)$ to yield a calibration curve across a concentration 
range of dye (0.1-10 mM) [14]. The dye adsorption properties of the samples were evaluated by measuring the concentration of unbound $\mathrm{MB}$ in the supernatant phase.

Adsorption of Methylene Blue (MB)

The molar absorptivity of methylene blue $(\varepsilon-\mathrm{MB})$ was estimated by the Beer-Lambert law using linear calibration plots and compared against literature values. UV-Vis spectroscopy can be used to determine residual levels of $\mathrm{MB}$ in solution after the adsorption process from the experimental value of $\varepsilon$-мB. Adsorption was carried out for all composites at ambient conditions, where the uptake of dye by the composites was determined from the difference between the initial dye concentration $\left(C_{o}\right)$ and the residual dye concentration $\left(C_{e}\right)$, as described by Equation (1).

$$
Q_{e}=\frac{\left(C_{e}-C_{o}\right) \times V}{m}
$$

$C_{o}(\mathrm{mmol})$ and $C_{e}(\mathrm{mmol})$ are defined above, where $V(\mathrm{~L})$ is the volume of dye solution, $\mathrm{m}$ is the mass of the adsorbent $(\mathrm{g})$, and $\mathrm{Q}_{\mathrm{e}}$ is the dye uptake by per mass of adsorbent $(\mathrm{mmol} / \mathrm{g})$ at equilibrium.

\section{Adsorption Isotherms}

Adsorption isotherms were obtained by plotting $Q_{e}$ versus $C_{e}(c f$. Equation (1)) and were analyzed by fitting to a suitable isotherm model (cf. Equations (2)-(4)). The Langmuir model (Equation (2)) accounts for monolayer adsorption onto a homogeneous surface.

$$
Q_{e}=\frac{Q_{m} K_{L} C_{e}}{1+K_{L} C_{e}}
$$

$Q_{e}$ and $C_{e}$ are defined as in Equation (1), whereas $Q_{m}$ is the maximum monolayer adsorption capacity of the dye per unit mass of adsorbent $(\mathrm{mmol} / \mathrm{g})$, and $K_{L}(\mathrm{~L} / \mathrm{mmol})$ is the Langmuir equilibrium adsorption constant. By comparison, the Freundlich model (Equation (3)) describes the possibility of multilayer adsorption onto a heterogeneous adsorbent surface.

$$
Q_{e}=K_{f} C_{e}^{\frac{1}{n_{f}}}
$$

$\mathrm{K}_{\mathrm{f}}$ is the Freundlich adsorption capacity constant and $\mathrm{n}_{\mathrm{f}}$ denotes the intensity of adsorption. The Sips adsorption model (Equation (4)) accounts for both Langmuir (when $n_{s}=1$ ) and Freundlich behavior (when $n_{S} \neq 1$ ) under certain limiting conditions. The maximum monolayer adsorption capacity $\left(Q_{m}, \mathrm{mmol} / \mathrm{g}\right)$ of the adsorbent can also be estimated. $K_{s}(\mathrm{~L} / \mathrm{mmol})$ is the Sips equilibrium adsorption constant, and $\mathrm{n}_{\mathrm{s}}$ denotes the Sips heterogeneity parameter

$$
Q_{e}=\frac{Q_{m} K_{s} C_{e}^{n_{s}}}{1+K_{L} C_{e}^{n_{s}}}
$$

Surface Area Estimated from MB Adsorption

The dye sorption method provides an independent estimate of the adsorbent surface area (SA; $\mathrm{m}^{2} / \mathrm{g}$ ), according to the following equation [15]:

$$
S A=\frac{A_{m} Q_{m} L}{Y}
$$

where $A_{m}$ represents the cross-sectional area occupied by MB ( $A_{m}$, for a "coplanar" orientation is $8.72 \times 10^{-19} \mathrm{~m}^{2} / \mathrm{mol}$, where the dimensions of the dye are $\left.1.43 \mathrm{~nm} \times 0.61 \mathrm{~nm}\right), Q_{m}$ is the monolayer adsorption capacity per unit mass of sorbent, $L$ is Avogadro's number $\left(\mathrm{mol}^{-1}\right)$, and $Y$ is the coverage factor $(Y=2.0$ for $\mathrm{MB})[16]$. 


\section{Results and Discussion}

As noted above, several pectin-chitosan adsorbent materials were prepared herein according to variable synthetic conditions using adapted methods reported by other groups [17,18]. The characterization of the materials and selected physicochemical properties rely on various complementary methods: $\mathrm{pH}$ analysis, TGA, IR spectroscopy, and dye adsorption properties in aqueous media using methylene blue (MB). The results for the structural and physicochemical characterization of the composite materials are outlined in the sections below.

\subsection{PZC Analysis}

The point-of-zero charge (PZC) is the $\mathrm{pH}$ where the net surface charge of the adsorbent is zero [13]. The PZC value becomes an important parameter for interpreting interactions that occur at material surfaces, especially for charged adsorbate species when the dominant adsorption mechanism is driven by electrostatic interactions. At $\mathrm{pH}>\mathrm{PZC}$, the surface of the adsorbent shows a negative surface charge due to the adsorption of $\mathrm{OH}^{-}$ions or deprotonation of hydrogen ions. For conditions where $\mathrm{pH}<\mathrm{PZC}$, the adsorbent surface shows a positive surface charge due to the adsorption of hydrogen ions from solution [19]. In Figure 1, the PZC results show the pectin-chitosan composite that was prepared in water with a net charge of zero near $\mathrm{pH}$ 4.7. Since pectin is soluble in water at all $\mathrm{pH}$ values [20], an estimate of its $\mathrm{pK}_{\mathrm{a}}$ can be inferred according to the reported value for galacturonic acid $\left(p K_{a}=3.24\right)$. An estimate of the PZC value for chitosan (ca. 6.5) has been reported [21], where changes in the PZC value upon the formation of pectin-chitosan composites reveals a unique material that differs relative to the biopolymer precursors. The reduced PZC value of the pectin-chitosan composite is within the range of an independent estimate (PZC $=4.4)$ [22]. On the other hand, the pectin-chitosan composites prepared in DMSO with sonication show a net charge of zero near $\mathrm{pH} 3.8$. The lower PZC value for composites prepared in DMSO may reflect the greater contribution of the pectin fraction, according to the lower $p K_{a}$ value estimated for galacturonic acid. This implies that the level of pectin grafting onto chitosan is higher and/or there are fewer available amine groups of chitosan to buffer the hydrogen ions dissociated from pectin. In the case of a dominant electrostatic interaction, the adsorption mechanism for pectin-chitosan $\mathrm{CBF}$ composites with a lower PZC value have greater Coulombic attraction to cation species (MB). This is in contrast to composites with a higher PZC value that possess a reduced surface charge.
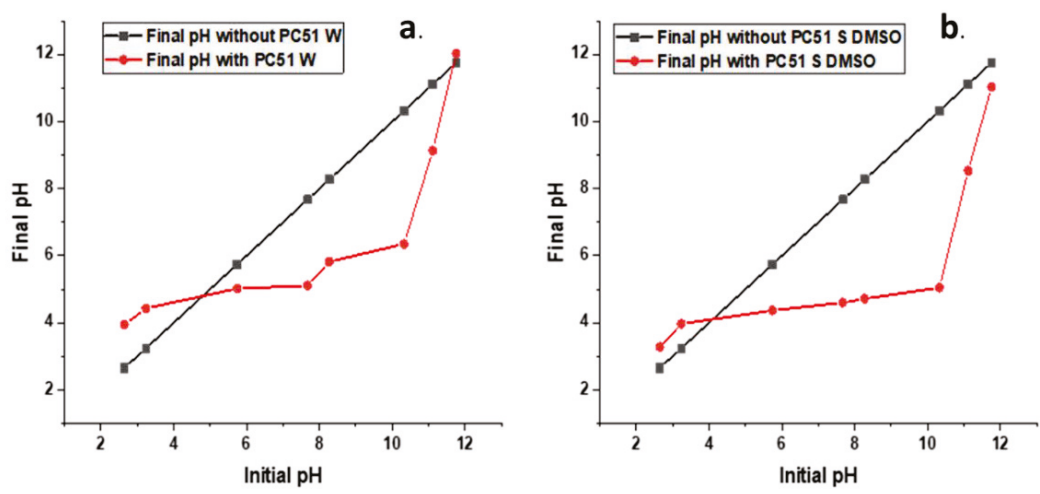

Figure 1. Point-of-zero charge (PZC) results of pectin and chitosan composites: (a) water-based synthesis; (b) dimethyl sulfoxide-based synthesis.

\subsection{TGA Results of Pectin and the Pectin-Chitosan Composites}

The TGA results reveal that pectin decomposes at $236{ }^{\circ} \mathrm{C}$, which is in agreement with the results reported by Cao [23], where the main thermal event was attributed to scission of the saccharide 
rings. Pal and Kaityar reported the synthesis of a lactic acid oligomer-grafted chitosan that undergoes decomposition at a lower onset temperature (ca. $200{ }^{\circ} \mathrm{C}$ ) relative to that of pristine chitosan (ca. $200{ }^{\circ} \mathrm{C}$ ) [24]. By comparison, the pectin-chitosan composite (PC11 S DMSO) prepared under sonication-assisted synthesis in DMSO reveals a higher decomposition temperature in Figure 2, as compared with the composites prepared in water (PC11 W and PC51 W). The greater decomposition temperature of the composites formed under sonication in DMSO (PC51 S DMSO, PC11 S DMSO, and PC15 S DMSO) provides support of the different bonding that results from water- versus DMSO-based composite syntheses. Materials prepared in water are anticipated to favor the formation of PECs due to the higher dielectric constant of aqueous media. Composites synthesized in DMSO are more likely to form CBFs due to amide bond formation between pectin and chitosan biopolymers. The FTIR results in Figure 3a for DMSO-based preparations provide confirmation of secondary amine features (two bands ca. $2900 \mathrm{~cm}^{-1}$ ) that provide support for amide bond formation [25]. By contrast, pectin and chitosan composites prepared in water reveal a prominent thermal event at $220-230{ }^{\circ} \mathrm{C}$ that indicates the formation of PECs by electrostatic interactions. The TGA results for the PEC and CBF materials are in agreement with independent results from the preparation of related composites [12,26,27].

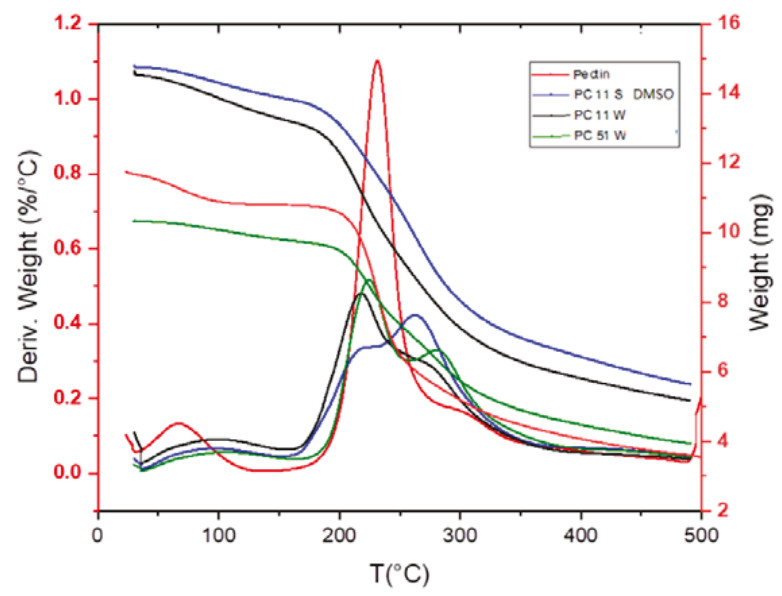

Figure 2. Thermal gravimetric analysis (TGA) results of pectin and pectin-chitosan composites.
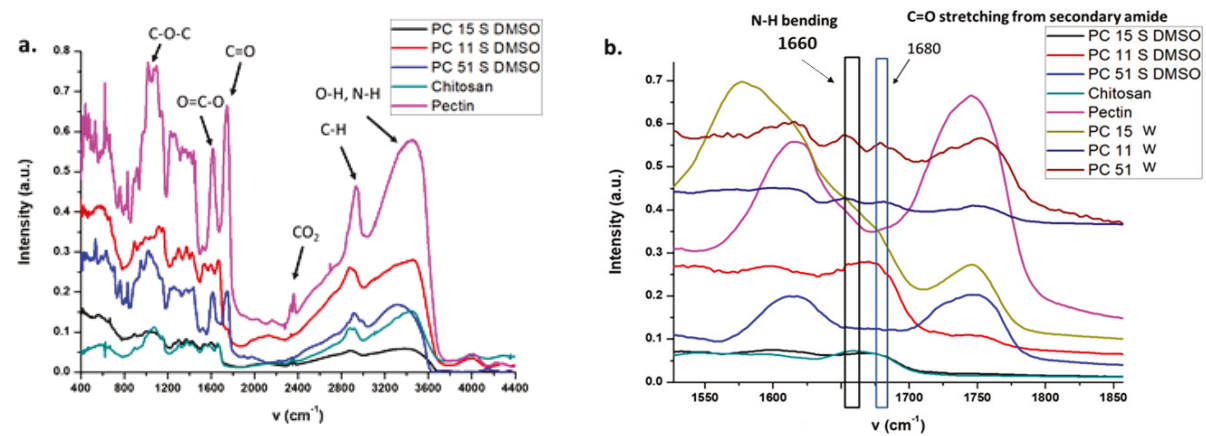

Figure 3. (a) Infrared (IR) spectra of pectin, chitosan, and their composites prepared in DMSO under assisted sonication, and (b) IR spectra of pectin, chitosan, and composites prepared in water and DMSO solvents. 


\subsection{FTIR Spectral Results}

In Figure $3 \mathrm{a}$, pectin reveals a strong intensity stretching band $(\mathrm{C}=\mathrm{O})$ from non-ionized carboxy groups $\left(-\mathrm{COOH}\right.$ and $\left.-\mathrm{COOCH}_{3}\right)$ of galacturonic acid at $1750 \mathrm{~cm}^{-1}$, and lower intensity bands for the symmetric and anti-symmetric carboxylate $\left(-\mathrm{COO}^{-}\right)$vibration at 1442 and $1673 \mathrm{~cm}^{-1}$, which concur with spectral results for pectin from other reports [28,29]. The broad IR band at $1600 \mathrm{~cm}^{-1}$ for the chitosan spectrum relates to the $\mathrm{N}-\mathrm{H}$ bending of a primary amine group of the glucosamine units. The shift of this $\mathrm{N}-\mathrm{H}$ band to $1660 \mathrm{~cm}^{-1}$ for the pectin-chitosan composite indicates a change in the chemical environment of this group upon interaction with pectin. The IR shift results are consistent with the reported results of such pectin-chitosan PECs [12,26,28]. Various reported studies of pectin-chitosan composites indicate the formation of PECs in water [18,30], which are supported by the IR results for composites prepared in water in Figure 3b. In Figure 3b, the IR bands for the pectin polymer at $2924 \mathrm{~cm}^{-1}$ indicate C-H stretching vibrations, and IR signatures between $950 \mathrm{~cm}^{-1}$ and $1200 \mathrm{~cm}^{-1}$ relate to the IR absorption of the pyranose ring of pectin [31]. The $\mathrm{C}=\mathrm{O}$ stretching band of galacturonic acid from the pectin-chitosan composites (prepared in DMSO) appear at $1750 \mathrm{~cm}^{-1}$ and relate to non-ionized carboxy groups (-COOH and $\left.-\mathrm{COOCH}_{3}\right)$. The bands at $1442 \mathrm{~cm}^{-1}$ and $1637 \mathrm{~cm}^{-1}$ are assigned to the symmetric and anti-symmetric vibration of carboxylate (-COO${ }^{-}$) groups [31]. By comparison, the carboxylate band intensity increased, whereas the band intensity of non-ionized carboxy groups decreased, according to the formation of PECs between chitosan and pectin [31] A comparison of the IR signatures of pectin-chitosan systems in water (PECs) with composites prepared in DMSO through sonication reveal an increased intensity in the $\mathrm{C}=\mathrm{O}$ stretching from a secondary amide that provide support for amide bond formation between pectin and chitosan $[24,26,27,29,32]$. Notwithstanding the difference in solvent properties, a rationale for the product distribution between the water and DMSO synthesis can be attributed to the modes of energy employed. Sonication-assisted synthesis differs from conventional heating and stirring, since ultrasonic waves can create vapor cavities around the surface of dispersed solids due to heating and subsequent pressure gradients due to cavitation effects. The resulting temperature and pressure gradients adjacent to the reactant surface can facilitate the amide bond formation [33]. Udoetok et al. [27] reported enhanced cross-linking effects at ambient temperature conditions in the case of epichlorohydrin cross-linked cellulose. The formation of amide linkages between pectin and chitosan is further supported by the increased signature of amide II band (N-H) bending of $\mathrm{NH}_{2}$ from chitosan at $1595 \mathrm{~cm}^{-1}$ for DMSO-based composites. The IR results provided herein are also supported by other reported studies of amide bond formation for related chitosan composite materials [9,24,26,27,29].

\subsection{Sorption Isotherm Results}

Dye adsorption isotherm results have been shown to provide insight on structurally similar systems due to the sensitivity of dye probe to its chemical environment, especially dyes with large molar absorptivity values. The change in dye adsorption reveals the variable surface accessibility of active sites on the adsorbent material due to differences in morphology and the number of active adsorption sites [34]. The trend in dye adsorption for MB with the various composites prepared in water and DMSO are shown in Figure 4, along with a comparison with results for pristine pectin. In all cases, the isotherm profiles show a nonlinear increase in dye uptake with increasing MB concentration. In the case of composites, the dye adsorption capacity increases as the pectin content increases, where the composites prepared in DMSO show notably greater uptake versus the composites prepared in water. The observed trend parallels the greater negative surface charge of composites prepared in DMSO versus the products prepared in water, which are in agreement with the offset in PZC values for each synthetic preparation. The uptake of $\mathrm{MB}$ by pectin and pectin-chitosan composites in aqueous solution were analyzed by several adsorption isotherms. According to Figure 4, the best-fit isotherm results for the adsorption profiles of pectin and pectin-chitosan composites with MB dye were obtained using the Sips model. Table 1 shows the Sips isotherm parameters, where $\mathrm{K}_{\mathrm{s}}$ is the Sips adsorption constant that relates to the adsorption energy, $Q_{m}$ is the monolayer adsorption capacity of $M B$, and $n_{\mathrm{s}}$ indicates the 
adsorbent surface heterogeneity [6]. The $Q_{m}$ values for the composites reveal an incremental uptake of MB as the weight fraction of pectin increased. The values of $Q_{m}(\mathrm{mmol} / \mathrm{g})$ listed in Table 1 reveal that pectin has the greatest $\mathrm{MB}$ uptake capacity, which concurs with its abundant $-\mathrm{OH}$ and $-\mathrm{COOH}$ active sites. As well, pectin is very soluble in water with highly accessible carboxylate groups since $\mathrm{pH}>p K_{a}$, which is in contrast to heterogeneous adsorbents that are water-insoluble with lesser surface accessibility [35]. The formation of pectin-chitosan composites with covalent amide bonding show promising dye uptake performance such as PC51 S DMSO, since such CBF-based systems are more amenable to phase separation and recovery after the dye adsorption process. Insoluble composites are contrasted with pristine pectin, in spite of the relatively high adsorption capacity of pectin. In the case of PECs prepared in water such as PC51 W, lower dye uptake is observed relative to PC51 S DMSO. The enhanced adsorption of MB by the PC51 S DMSO system can be attributed to its relatively high pectin content and the branched structure of this CBF-based adsorbent. The covalent framework likely contributes to potential cooperative effects between the biopolymer subunits to afford secondary adsorption sites for $\mathrm{MB}$ along the chitosan backbone. The primary adsorption sites are attributed to the carboxylate groups of pectin due to the key role of electrostatic interactions with $\mathrm{MB}$. The prominent role of the carboxylate sites is evidenced by the unitary exponential term $\left(n_{s} \approx 1\right)$ for the composites in Table 1, irrespective of the composition of the biopolymer composite. Hence, the use of MB as a dye probe enables elucidation of the active adsorption sites $(-\mathrm{COOH},-\mathrm{OH}$, and $-\mathrm{NHR})$ for pectin and the pectin-chitosan composites.

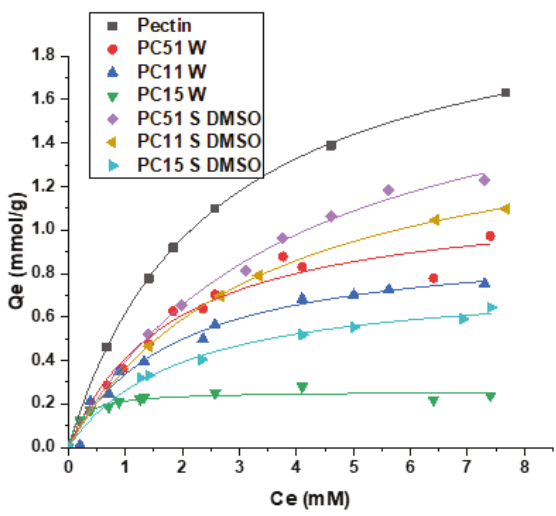

Figure 4. Methylene blue (MB) dye uptake isotherms for pectin and pectin-chitosan composites, where the solid lines represent best-fit results by the Sips isotherm model.

Table 1. Sips model fitting parameters for methylene blue (MB) dye uptake by pectin and pectin-chitosan composite adsorbents.

\begin{tabular}{|c|c|c|c|c|c|}
\hline Sample Name & $K_{s}\left(\mathrm{M}^{-1}\right)$ & $Q_{m}(\mathrm{mmol} / \mathrm{g})$ & $n_{s}$ & Adjusted $\mathbf{R}^{2}$ & $\mathrm{SA}\left(\mathrm{m}^{2} / \mathrm{g}\right)^{1}$ \\
\hline Pectin & $0.50 \pm 0.015$ & $2.2 \pm 0.012$ & 0.99 & 0.99 & 170 \\
\hline PC51 W & $0.54 \pm 0.10$ & $1.2 \pm 0.089$ & 1.3 & 0.96 & 92 \\
\hline PC11 W & $0.54 \pm 0.081$ & $0.96 \pm 0.051$ & 1.0 & 0.97 & 75 \\
\hline PC15 W & $0.69 \pm 0.093$ & $0.26 \pm 0.011$ & 1.1 & 0.96 & 20 \\
\hline PC51 S DMSO & $0.36 \pm 0.071$ & $1.9 \pm 0.10$ & 1.1 & 0.97 & 146 \\
\hline PC11 S DMSO & $0.45 \pm 0.023$ & $1.6 \pm 0.011$ & 1.0 & 0.97 & 123 \\
\hline PC15 S DMSO & $0.50 \pm 0.0 .53$ & $0.78 \pm 0.028$ & 0.84 & 0.97 & 60 \\
\hline
\end{tabular}




\section{Conclusions}

The preparation of a composite with a covalent biopolymer framework (CBF) was achieved by the formation of amide linkages between pectin and chitosan using a sonication-assisted synthesis in DMSO. By contrast, the use of water as a solvent with conventional heating yielded pectin-chitosan polyelectrolyte complexes (PECs). Characterization of the covalent and ionic types of pectin-chitosan composites was supported by TGA results that revealed a more thermally stable cross-linked composite with a covalent framework (PC11 S DMSO) over the pectin-chitosan polyelectrolyte complex (PC11 W) prepared in water. The IR intensity changes for the secondary amine groups of chitosan before and after composite formation provided support for the two types of composites (CBFs and PECs). Amide-based CBFs prevail in DMSO, while PECs are favored in water-based reactions. The MB uptake capacity for the pectin-chitosan CBFs exceed that of the PECs due to the key role of the carboxylate anions of pectin. The greater dye uptake capacity of pectin highlights the prominent role of the carboxylate anion site accessibility in the CBF composites versus the PEC-based materials. The formation of an amide-based covalent network results in greater pectin incorporation onto chitosan with secondary adsorption sites along the chitosan backbone. The use of a solvent to bias the formation of CBFs versus PECs in the case of pectin-chitosan composites will contribute to the rational design of materials with improved properties for diverse adsorption-based applications. This includes solid phase extraction and recovery processes due to enhanced phase separation and the removal efficiency of waterborne species that possess positive electrostatic potential.

Author Contributions: Conceptualization, L.D.W.; methodology, L.D.W. and D.K.; software, D.K.; validation, L.D.W. and D.K.; formal analysis, D.K.; investigation, L.D.W. and D.K.; resources, L.D.W.; data curation, L.D.W.; writing - original draft preparation, D.K.; writing — review and editing, L.D.W. and D.K.; visualization, D.K.; supervision, L.D.W.; project administration, L.D.W.; funding acquisition, L.D.W. All authors have read and agreed to the published version of the manuscript.

Funding: Lee D. Wilson acknowledges the support granted by the Government of Canada through the Natural Sciences and Engineering Research Council of Canada (Discovery Grant Number: RGPIN 2016-06197).

Acknowledgments: The authors acknowledge the support provided by the Saskatchewan Research Council and the University of Saskatchewan.

Conflicts of Interest: The authors declare no conflict of interest.

\section{References}

1. Guo, R.; Wilson, L.D. Synthetically engineered chitosan-based materials and their sorption properties with methylene blue in aqueous solution. J. Colloid Interface Sci. 2012, 388, 225-234. [CrossRef] [PubMed]

2. Kumar, K.V.; Ramamurthi, V.; Sivanesan, S. Modeling the mechanism involved during the sorption of methylene blue onto fly ash. J. Colloid Interface Sci. 2005, 284, 14-21. [CrossRef] [PubMed]

3. Forgacs, E.; Cserháti, T.; Oros, G. Removal of synthetic dyes from wastewaters: A review. Environ. Int. 2004, 30, 953-971. [CrossRef] [PubMed]

4. Tünay, O.; Kabdasli, I.; Eremektar, G.; Orhon, D. Color removal from textile wastewaters. Water Sci. Technol. 1996, 34, 9-16.

5. Zhang, L.; Zeng, Y.; Cheng, Z. Removal of heavy metal ions using chitosan and modified chitosan: A review. J. Mol. Liq. 2016, 214, 175-191. [CrossRef]

6. Mahaninia, M.H.; Wilson, L.D. Cross-linked chitosan beads for phosphate removal from aqueous solution. J. Appl. Polym. Sci. 2015, 133, 42949. [CrossRef]

7. Kumar, S.; Krishnakumar, B.; Sobral, A.J.; Koh, J. Bio-based (chitosan/PVA/ZnO) nanocomposites film: Thermally stable and photoluminescence material for removal of organic dye. Carbohydr. Polym. 2019, 205, 559-564. [CrossRef]

8. Baroncini, E.A.; Yadav, S.K.; Palmese, G.R.; Stanzione, I.J.F. Recent advances in bio-based epoxy resins and bio-based epoxy curing agents. J. Appl. Polym. Sci. 2016, 133, 44103-44122. [CrossRef]

9. Sabzevari, M.; Cree, D.E.; Wilson, L.D. Graphene Oxide-Chitosan Composite Material for Treatment of a Model Dye Effluent. ACS Omega 2018, 3, 13045-13054. [CrossRef] 
10. Birch, N.P.; Schiffman, J.D. Characterization of Self-Assembled Polyelectrolyte Complex Nanoparticles Formed from Chitosan and Pectin. Langmuir 2014, 30, 3441-3447. [CrossRef]

11. Ventura, I.; Peled, H. Small-angle X-ray scatting study on pectin-chitosan mixed solutions and thermoreversible gels. Carbohydr. Polym. 2015, 123, 122-129. [CrossRef]

12. Wu, L.; Wang, H.; Zhu, X.; Hou, Y.; Liu, W.; Yang, G.; Jiang., A. Pectin-chitosan complex: Preparation and application in colon-specific capsule. Int. J. Agric. Biol. Eng. 2015, 8, 151-160.

13. Udoetok, I.A.; Dimmick, R.M.; Wilson, L.D.; Headley, J.V. Adsorption properties of cross-linked cellulose-epichlorohydrin polymers in aqueous solution. Carbohydr. Polym. 2016, 136, 329-340. [CrossRef]

14. Dolatkhah, A.; Wilson, L.D. Magnetite/Polymer Brush Nanocomposites with Switchable Uptake Behavior Toward Methylene Blue. ACS Appl. Mater. Interfaces 2016, 8, 5595-5607. [CrossRef] [PubMed]

15. Mohamed, M.H.; Wilson, L.D.; Headley, J.V. Design and characterization of novel $\beta$-cyclodextrin based copolymer materials. Carbohydr. Res. 2011, 346, 219-229. [CrossRef]

16. Pelekani, C.; Snoeyink, V.L. Competitive adsorption between atrazine and methylene blue on activated carbon: The importance of pore size distribution. Carbon 2000, 38, 1423-1436. [CrossRef]

17. Delmar, K.; Bianco-Peled, H. The dramatic effect of small $\mathrm{pH}$ changes on the properties of chitosan hydrogels crosslinked with genipin. Carbohydr. Polym. 2015, 127, 28-37. [CrossRef] [PubMed]

18. Neufeld, L.; Bianco-Peled, H. Pectin-chitosan physical hydrogels as potential drug delivery vehicles. Int. J. Boil. Macromol. 2017, 101, 852-861. [CrossRef]

19. Hubbe, M.A.; Beck, K.R.; O'Neal, W.G.; Sharma, Y.C. Cellulosic substrates for removal of pollutants from aqueous systems: A Review. 2. Dyes. BioResources 2012, 7, 5951-5962. [CrossRef]

20. Zhao, X.J.; Zhou, Z. Synthesis and Applications of Pectin-based Nanomaterials. Curr. Nanosci. 2015, 12, 103-109. [CrossRef]

21. Neto, J.D.O.M.; Milagres, J.L.; Pessoa, K.D.; Alvarenga, E.S.; Bellato, C.R. Preparation and evaluation of chitosan beads immobilized with Iron(III) for the removal of As(III) and As(V) from water. J. Braz. Chem. Soc. 2013, 24, 121-132. [CrossRef]

22. Igberase, E.; Osifo, P.; Ofomaja, A. Chromium (VI) ion adsorption by grafted cross-linked chitosan beads in aqueous solution-A mathematical and statistical modelling study. Environ. Technol. 2017, 38, 1-30. [CrossRef] [PubMed]

23. Liu, Y.; Sun, Y.; Ding, G.; Geng, Q.; Zhu, J.; Guo, M.; Duan, Y.; Wang, B.; Cao, Y. Synthesis, Characterization, and Application of Microbe-Triggered Controlled-Release Kasugamycin-Pectin Conjugate. J. Agric. Food Chem. 2015, 63, 4263-4268. [CrossRef]

24. Pal, A.K.; Katiyar, V. Nanoamphiphilic Chitosan Dispersed Poly(lactic acid) Bionanocomposite Films with Improved Thermal, Mechanical, and Gas Barrier Properties. Biomacromolecules 2016, 17, 2603-2618. [CrossRef] [PubMed]

25. Wade, L.G., Jr. Organic Chemistry, 6th ed.; Pearson Prentice Hall Inc.: Upper Saddle River, NJ, USA, 2006; Chapter 12.

26. Chen, H.; Yang, W.; Chen, H.; Liu, L.; Gao, F.; Yang, X.; Jiang, Q.; Zhang, Q.; Wang, Y. Surface modification of Mitoxantrone-loaded PLGA nanospheres with chitosan. Colloids Surfaces B: Biointerfaces 2009, 73, 212-218. [CrossRef] [PubMed]

27. Demarger-André, S.; Domard, A. Chitosan carboxylic acid salts in solution and in the solid state. Carbohydr. Polym. 1994, 23, 211-219. [CrossRef]

28. Marudova, M.; MacDougall, A.J.; Ring, S.G. Pectin-chitosan interactions and gel formation. Carbohydr. Res. 2004, 339, 1933-1939. [CrossRef]

29. Chetouani, A.; Follain, N.; Marais, S.; Rihouey, C.; Elkolli, M.; Bounekhel, M.; Benachour, D.; Le Cerf, D. Physicochemical properties and biological activities of novel blend films using oxidized pectin/chitosan. Int. J. Boil. Macromol. 2017, 97, 348-356. [CrossRef]

30. Rampino, A.; Borgogna, M.; Bellich, B.; Blasi, P.; Virgilio, F.; Cesàro, A. Chitosan-pectin hybrid nanoparticles prepared by coating and blending techniques. Eur. J. Pharm. Sci. 2016, 84, 37-45. [CrossRef]

31. Li, F.T.; Yang, H.; Zhao, Y.; Xu, R. Novel modified pectin for heavy metal adsorption. Chin. Chem. Lett. 2007, 18, 325-328. [CrossRef]

32. Bernabe, P.; Peniche, C.; Argüelles-Monal, W. Swelling behavior of chitosan/pectin polyelectrolyte complex membranes. Effect of thermal cross-linking. Polym. Bull. 2005, 55, 367-375. [CrossRef] 
33. Ogutu, F.O.; Mu, T.; Elahi, R.; Zhang, M.; Sun, H.-N. Ultrasonic Modification of Selected PolysaccharidesReview. J. Food Process. Technol. 2015, 6, 1000446. [CrossRef]

34. Kong, D.; Wilson, L.D. Synthesis and characterization of cellulose-goethite composites and their adsorption properties with roxarsone. Carbohydr. Polym. 2017, 169, 282-294. [CrossRef] [PubMed]

35. Yu, L.-L.; Jiang, L.-N.; Wang, S.-Y.; Sun, M.-M.; Li, D.-Q.; Du, G.-M. Pectin microgel particles as high adsorption rate material for methylene blue: Performance, equilibrium, kinetic, mechanism and regeneration studies. Int. J. Boil. Macromol. 2018, 112, 383-389. [CrossRef] [PubMed]

(C) 2020 by the authors. Licensee MDPI, Basel, Switzerland. This article is an open access article distributed under the terms and conditions of the Creative Commons Attribution (CC BY) license (http://creativecommons.org/licenses/by/4.0/). 


\title{
Development of Weather-Resistant 3D Printed Structures by Multi-Material Additive Manufacturing
}

\author{
Arash Afshar * and Roy Wood \\ School of Engineering, Mercer University, Macon, GA 31207, USA; Roy.Andrew.Wood@live.mercer.edu \\ * Correspondence: afshar_a@mercer.edu; Tel.: +1-478-301-2421
}

Received: 11 June 2020; Accepted: 16 July 2020; Published: 18 July 2020

\begin{abstract}
Additive manufacturing, or 3D printing, has had a big impact on the manufacturing world through its low cost, material recyclability, and fabrication of intricate geometries with a high resolution. Three-dimensionally printed polymer structures in aerospace, marine, construction, and automotive industries are usually intended for service in outdoor environments. During long-term exposures to harsh environmental conditions, the mechanical properties of these structures can be degraded significantly. Developing coating systems for 3D printed parts that protect the structural surface against environmental effects and provide desired surface properties is crucial for the long-term integrity of these structures. In this study, a novel method was presented to create 3D printed structures coated with a weather-resistant material in a single manufacturing operation using multi-material additive manufacturing. One group of specimens was 3D printed from acrylonitrile-butadiene-styrene (ABS) material and the other group was printed from ABS and acrylic-styrene-acrylonitrile (ASA) as a substrate and coating material, respectively. The uncoated ABS specimens suffered significant degradation in the mechanical properties, particularly in the failure strain and toughness, during exposure to UV radiation, moisture, and high temperature. However, the ASA coating preserved the mechanical properties and structural integrity of ABS 3D printed structures in aggressive environments.
\end{abstract}

Keywords: 3D printed coating; multi-material additive manufacturing; environmental exposure; ABS; ASA

\section{Introduction}

Additive manufacturing (AM) has numerous applications, ranging from medicinal delivery to aerospace, automotive systems, construction, biodegradable solutions, and ever-expanding technologies as a platform for innovative designs [1-4]. Three-dimensional printing technology found its way into different industries through a variety of techniques such as powder bed fusion, inkjet printing, direct energy deposition, and laminated object manufacturing [5,6]. Given the expanding range of processes, the scope of solutions has likewise expanded, from the 3D printing of shape-memory materials in the development of aerospace deployable equipment in solar panels and antennas [3], and thermoplastic equipment that can be printed on board the international space station, to manufacturing of biodegradable scaffolds for organ growth, and direct printing of organs and tissues [7]. The process has been adopted as one of the industrial requirements for technology and scientific research. The most common method of 3D printing is fused deposition modeling (FDM). In this technique, a thermoplastic material, typically in the form of continuous filaments, is heated and then extruded through a nozzle into several layers to form the final object as it is being cooled down [8-13].

Polymer matrix 3D printed structures, like other types of polymer-based structure, are susceptible to environmental exposure, such as ultraviolet (UV) radiation, moisture, or heat. The diffusion of moisture into the structural components can damage the material as a result of the change in the 
mechanical properties of the polymer or replacing or weakening matrix-reinforcement interfacial bonds through irreversible hydrolysis and plasticization $[14,15]$. Ultraviolet photons from sunlight exposure initiate photo-oxidative reactions (i.e., chains scission and chain crosslinking) which deteriorate polymer materials by altering their chemical structures. Chain scission reduces the molecular weight of the polymer, which in turn degrades its strength and heat resistance. Chain cross-linking enhances the brittleness of the polymer, leading to the surface microcracking [16-19]. The synergistic environmental exposures can be more detrimental than individual exposures acting alone. For instance, in outdoor environments, moisture diffuses into polymer materials and occupies positions among the polymer molecules that results in the swelling of polymers. The moisture-induced damage will be exacerbated by microcracking formation during UV exposure, which facilitates the moisture diffusion into polymers. Moisture also dissolves and removes products of photo-oxidative reactions and exposes a fresh surface for further degradation by UV radiation [20-22]. The adverse effect of moisture increases at elevated temperatures as a result of an increase in the rate of water absorption into polymer-based structures $[23,24]$.

Nowadays, 3D printers can create multi-material objects with desired properties in specific locations. By the advancement of AM processes, the creation of multifunctional parts becomes feasible, which has never been possible through traditional, single-material manufacturing methods. This unique AM feature is possible through layer-by-layer placement of material in the specific areas, which enables the manufacturer to control structural properties at exact locations and tailor them for specific applications [25-27]. Multi-material additive manufacturing can produce coatings with certain properties on the surface of 3D printed structures, and it is a great replacement for conventional ways of painting structures, such as brushing and air-spraying, or recently developed methods for metallization of structural surface that are more costly and time-consuming [28]. The compatibility between 3D printing materials as well as the printing parameters such as nozzles' temperatures and printing speed are important factors in creating a strong adhesion between 3D printed layers with distinct material properties using multi-material additive manufacturing methods $[5,25]$.

ABS, or acrylonitrile-butadiene-styrene, has seen the largest commercial usage in the additive manufacturing industry due to its rigidity and high mechanical performance. ABS can be used to create objects with intricate designs, structures with moving parts, and structures that are aimed for further plastic forming, without the risk of breakage. However, it has been reported that the mechanical properties of 3D printed ABS structures can diminish significantly during exposure to harsh environmental conditions [28-30]. ASA, or acrylic-styrene-acrylonitrile, is a weather-resistant thermoplastic material with a high performance in outdoor environmental conditions, including UV radiation, moisture, and high temperatures. It offers easy printing, good dimensional stability, and an excellent layer to layer adhesion.

In this paper, the surfaces of ABS 3D printed structures were coated by weather-resistant ASA using a multi-material additive manufacturing technique to enhance the durability of the structure in aggressive environments. The current study offers insights for the design, coating, and maintenance of 3D printed polymer structures exposed to outdoor environmental conditions.

\section{Experimental Methods and Materials}

A Raise3D Pro2 dual extruder 3D printer (Raise3D, Irvine, CA, USA) was employed to produce samples from eSUN ABS and FilamentOne ASA PRO SELECT filaments using the FDM method. Three-dimensionally printed specimens had dimensions according to the ASTM D790 standard of $127 \mathrm{~mm}$ (length) $\times 12.7 \mathrm{~mm}$ (width) $\times 3.2 \mathrm{~mm}$ (thickness). Nozzles with a size of $0.4 \mathrm{~mm}$ were used for 3D printing of specimens and nozzles' temperatures were established to be $205{ }^{\circ} \mathrm{C}$ for ABS and $22{ }^{\circ} \mathrm{C}$ for ASA extrusion. The bed temperature and the infill density were set to $100{ }^{\circ} \mathrm{C}$ and $100 \%$, respectively. The bed temperature is the temperature of the platform where the object is $3 \mathrm{D}$ printed. The infill density determines the distance between adjacent deposited filaments within the shell of the printed structure and an infill density of $100 \%$ results in no air gaps between adjacent filaments. 
The shell is the outer wall of the printed object that outlines the desired shape of the printed structure and provides an anchor for the infill deposition. The print pattern was set to alternating angles (i.e., periodic $-45^{\circ} / 45^{\circ}$ ) of layer deposition with solid edges to create identical mechanical properties in longitudinal and transverse directions of specimens, as illustrated in Figure 1. The pattern was printed with an inner shell speed of $70 \mathrm{~mm} / \mathrm{s}$, outer shell speed of $25 \mathrm{~mm} / \mathrm{s}$, and infill speed of $80 \mathrm{~mm} / \mathrm{s}$. The layer height for the deposition of ABS and ASA filaments was set to 0.3 and $0.125 \mathrm{~mm}$, respectively. The layer height is the thickness of the deposited filament per pass. In ASA-coated ABS specimens, ASA coating with a thickness of $0.25 \mathrm{~mm}$ that consists of 2 layers was deposited on both sides of specimens. One of the advantages of AM compared to traditional manufacturing techniques is the ability to combine dissimilar materials in one continuous process, which eliminates the requirement of using intermediate adhesives for bonding two distinctive materials. The thickness of ASA coating was taken into consideration during 3D printing in order to manufacture uncoated and ASA-coated ABS specimens with the same thickness.

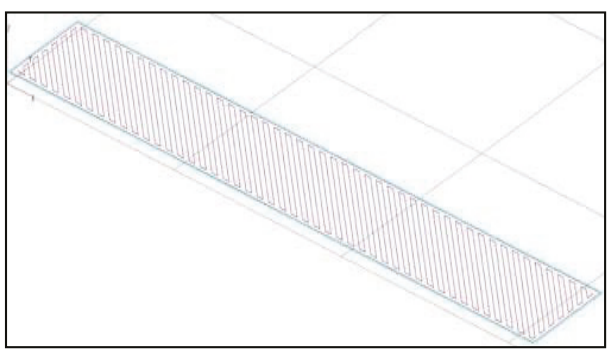

(a)

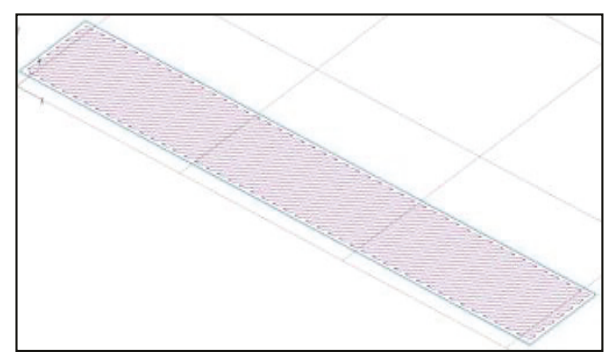

(b)

Figure 1. Deposition of the (a) first and (b) second layers during 3D printing of specimens to create a pattern of alternating $-45^{\circ} / 45^{\circ}$ angles.

To simulate the effects of outdoor environmental conditions on 3D printed polymer structures, ABS samples with or without an ASA coating layer were aged in a controlled environmental chamber. Exposure to UV radiation and moisture was conducted by using a UV radiation/condensation (Q-Lab QUV/basic) accelerated weathering tester. In the environmental chamber, the specimens were exposed to UV radiation and moisture cycles. UV radiation was generated with $340 \mathrm{~nm}$ wavelength UVA lights set at $0.89 \mathrm{~W} / \mathrm{m}^{2}$ intensity and $60{ }^{\circ} \mathrm{C}$ chamber temperature. The condensation was produced by condensing vapor on specimens in the environmental chamber with $100 \%$ humidity and a temperature of $50{ }^{\circ} \mathrm{C}$. To follow the ASTM G154 standard and create a synergistic exposure to both UV radiation and moisture, specimens were cyclically exposed to $8 \mathrm{~h}$ of UV radiation followed by $4 \mathrm{~h}$ condensation.

The LEO 1530 Scanning Electron Microscope (Zeiss, White Plains, NY, USA) and VHX 6000 Keyence Digital Microscope (Keyence, Itasca, IL, USA) were used to characterize the surface morphology of specimens during environmental exposure. A $5 \mathrm{~nm}$ gold layer was deposited on samples via a Quorum sputter coater before SEM analysis and scanning electron microscopy was carried out with the beam accelerating voltage of $5 \mathrm{kV}$. The resistance of ASA coating to separation from the ABS substrate before and after environmental aging was assessed according to ISO 2409 standard. The flexural properties of specimens during environmental exposure were evaluated using the three-point bending test carried out by using Mark-10 testing equipment after 0, 300, 600, and $1200 \mathrm{~h}$ of environmental aging. The span length of $51.2 \mathrm{~mm}$ (span to depth ratio of 16:1) and the crosshead rate of $1.37 \mathrm{~mm} / \mathrm{min}$ were used to produce a strain rate of $0.01 \mathrm{~mm} / \mathrm{mm} / \mathrm{min}$ in specimens based on the ASTM D790 standard. Six specimens per each condition were used to ensure the reproducibility of results. 


\section{Results and Discussion}

\subsection{Surface Analysis}

During service, 3D printed polymer structures are typically exposed to aggressive environmental conditions that may lead to the initiation and propagation of surface damage and eventually failure of the entire structure under loading conditions. Therefore, investigation of the surface microstructure of $3 \mathrm{D}$ printed parts is necessary to evaluate their performance in outdoor environments.

The digital microscopy images of the surface of uncoated ABS samples before and after $1200 \mathrm{~h}$ of exposure to UV radiation and moisture are given in Figure $2 \mathrm{a}, \mathrm{b}$. The yellowing of the surface areas due to UV radiation and the creation of surface microcracks can be observed in Figure $2 \mathrm{~b}$. The cyclic temperature variation inside the environmental chamber produces thermal stresses in the specimens, which facilitates the creation and propagation of microcracks on the UV-exposed surfaces. Figure 3a,b present the surface microscopy images of ASA-coated ABS specimens before and after environmental aging. It can be observed that the ASA coating provides good protection for the underlying ABS specimen and no microcracking was observed on the specimen's surface.

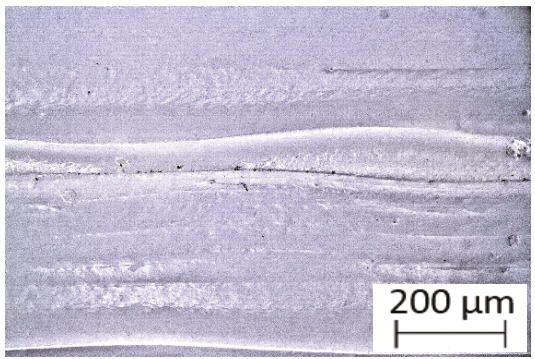

(a)

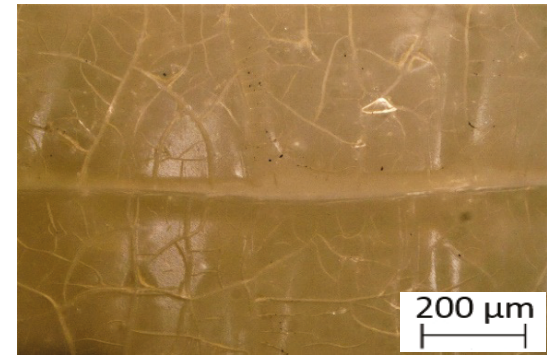

(b)

Figure 2. Digital microscopy images of the surface of uncoated acrylonitrile-butadiene-styrene (ABS) specimen (a) before and (b) after $1200 \mathrm{~h}$ of exposure to UV radiation and moisture.

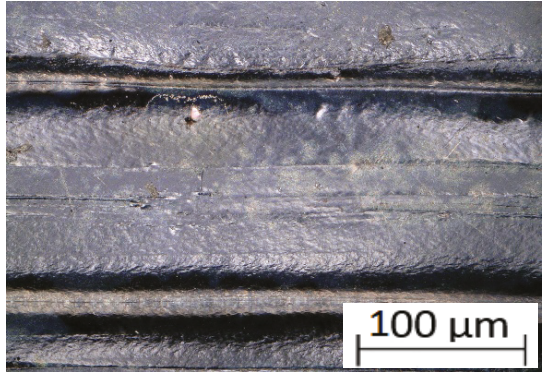

(a)

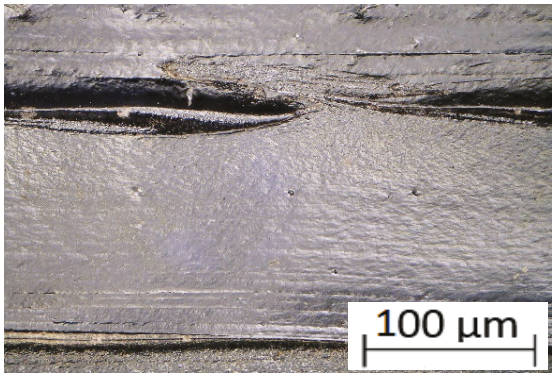

(b)

Figure 3. Digital microscopy images of the surface of acrylic-styrene-acrylonitrile (ASA)-coated ABS specimen (a) before and (b) after $1200 \mathrm{~h}$ of exposure to UV radiation and moisture.

To better assess the damage in the specimens after environmental aging, scanning electron microscopy (SEM) images of the surface area of uncoated and ASA-coated ABS samples before and after environmental exposure are presented in Figures 4 and 5. It can be seen that an extensive propagation of microcracking occurred on the surface of the uncoated specimen after $1200 \mathrm{~h}$ of environmental aging. The UV-induced microcracks and a high-temperature environment facilitate the 
ingression of moisture into 3D printed polymer structures that can have detrimental effects on the long-term durability of structures.

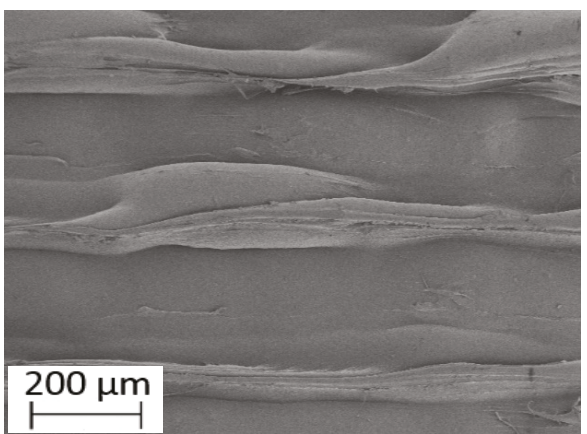

(a)

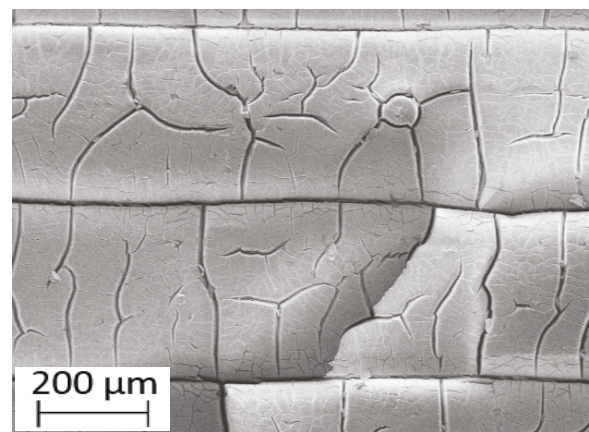

(b)

Figure 4. SEM images of the surface of uncoated ABS specimen (a) before and (b) after $1200 \mathrm{~h}$ of exposure to UV radiation and moisture.

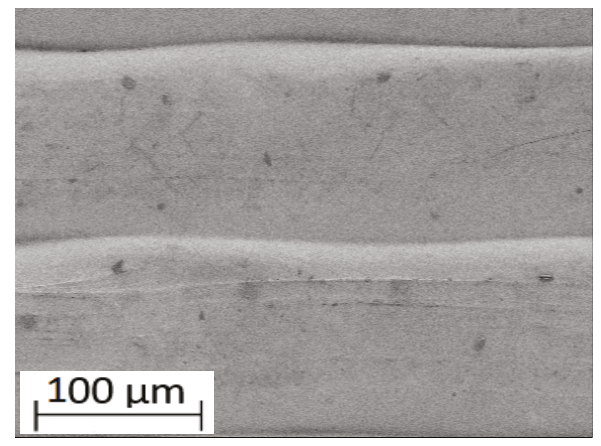

(a)

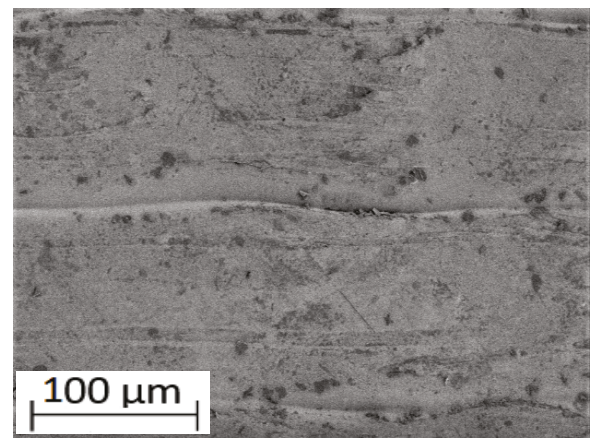

(b)

Figure 5. SEM images of the surface of ASA-coated ABS specimen (a) before and (b) after $1200 \mathrm{~h}$ of exposure to UV radiation and moisture.

The environmental exposure has no noticeable effects on the surface microstructure of ASAcoated ABS specimens, as illustrated in Figure 5b. No observable microcracks were generated on the structural surface and the ASA-coated ABS specimen retained its structural integrity throughout the exposure.

A robust interfacial adhesion between the coating and the substrate is essential for the durability of 3D printed structures created by multi-material additive manufacturing. The strength of the adhesion bond between the ASA coating and ABS substrate before and after $1200 \mathrm{~h}$ of environmental aging was examined according to ISO 2409 standard. The adhesion test was performed on ASA-coated ABS 3D printed samples with dimensions of $60 \mathrm{~mm}$ (length) $\times 60 \mathrm{~mm}$ (width) $\times 3.2 \mathrm{~mm}$ (thickness). Since the thickness of the ASA coating is $0.25 \mathrm{~mm}$, six cuts with $3 \mathrm{~mm}$ spacing were created along the length and width directions following the standard.

No separation of ASA coating was observed after the removal of adhesive tape from the surface of both environmentally aged and unexposed specimens. The adhesion of ASA coating to the ABS substrate was classified as grade 0 based on the ISO 2409 standard, demonstrating the highest level of resistance of the coating to the separation from the substrate that remained unaffected during the environmental aging. 


\subsection{Flexural Response}

Out-of-plane loading is one of the main forces that acts on the structural components in outdoor environments. This requires a thorough investigation of the flexural response of 3D printed polymer structures under the bending load. Figure 6a shows that the flexural modulus of ABS specimens with or without ASA coating was relatively unchanged during the environmental exposure. This can be attributed to the fact that modulus is a bulk material property, while the environmental effect is primarily a surface phenomenon. The embrittlement of polymers on the surface area due to UV radiation can cause a slight increase in the modulus of specimens, as illustrated in Figure $6 a$.

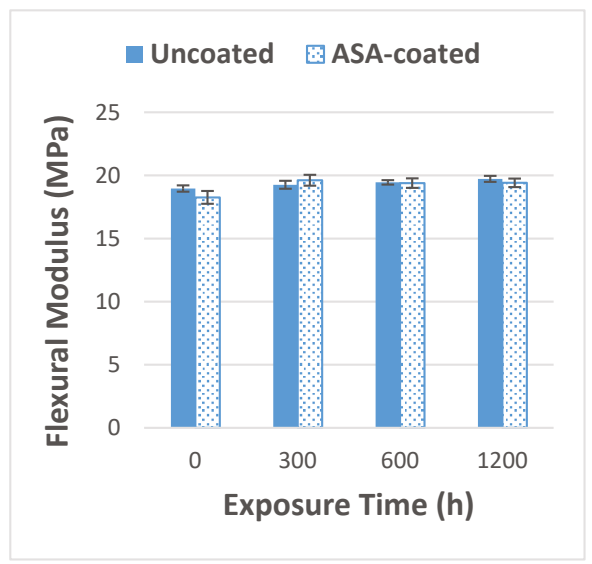

(a)

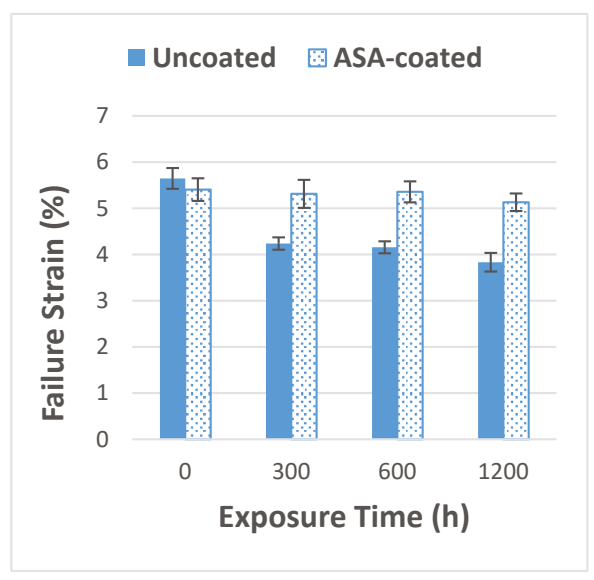

(c)

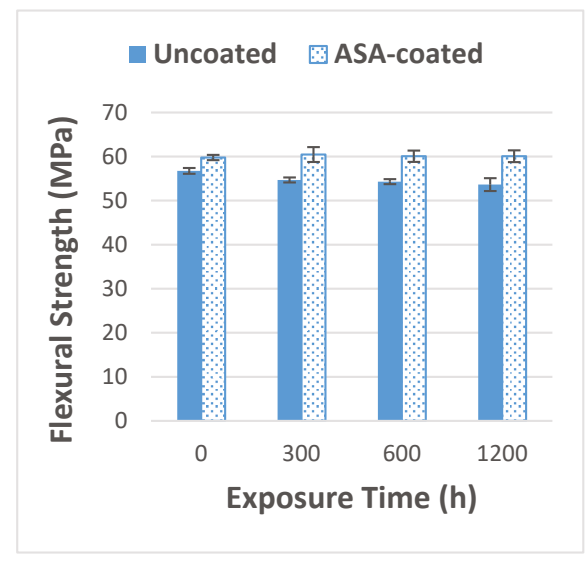

(b)

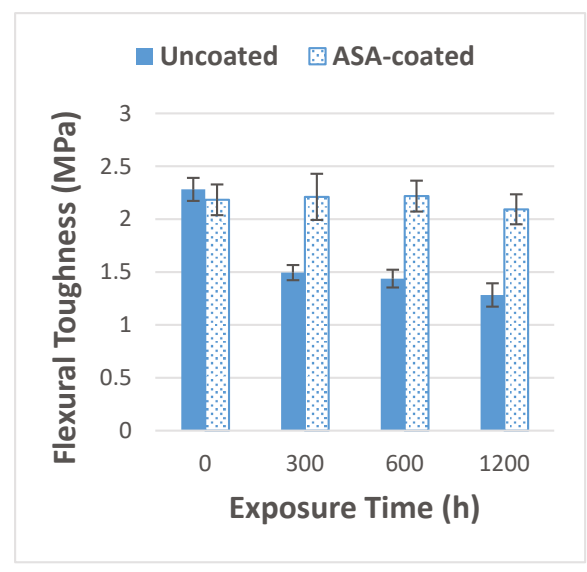

(d)

Figure 6. Flexural properties of uncoated and ASA-coated 3D printed ABS samples during exposure to UV radiation and moisture. (a) Flexural modulus; (b) flexural strength; (c) failure strain; (d) flexural toughness.

Figure $6 \mathrm{~b}$ demonstrates that uncoated ABS specimens lost $5.5 \%$ of their flexural strength throughout the exposure, while no noticeable changes in the flexural strength of ASA-coated ABS specimens were observed. The failure strain of specimens over the exposure time is given in Figure $6 \mathrm{c}$. The failure strain of uncoated specimens decreased significantly during exposure to UV radiation and moisture 
with a maximum reduction of $32.1 \%$ after $1200 \mathrm{~h}$ of environmental aging. However, the ductility of ASA-coated specimens showed a slight reduction throughout the exposure, with a maximum decrease of $5.1 \%$. This can be attributed to the extensive propagation of microcracks on the surface areas of uncoated ABS specimens that can significantly impair the elongation in the outer layers which are subjected to maximum tensile stresses.

Flexural toughness was measured as the integral of the area under the stress-strain curves of samples during the three-point bending test. Figure $6 \mathrm{~d}$ shows that the flexural toughness is the most susceptible mechanical properties of uncoated 3D printed ABS specimens to the environmental aging with a maximum reduction of $43.8 \%$ after $1200 \mathrm{~h}$ of exposure to UV radiation and moisture. The ASA-coated ABS specimens could significantly preserve their flexural toughness after $1200 \mathrm{~h}$ of environmental exposure with a retention of $95.9 \%$ of the initial flexural toughness. Figure 7 presents the average stress-strain curves of uncoated and ASA-coated ABS specimens after 0, 300, 600, and $1200 \mathrm{~h}$ of environmental exposure that are obtained from the flexural test. It can be observed that both uncoated and ASA-coated ABS specimens show ductile failure before and after environmental aging. The significant reduction in the flexural toughness of uncoated specimens was a result of a decrease in both flexural strength and ductility of specimens that largely reduced the area under the stress-strain curves, as observed in Figure 7.

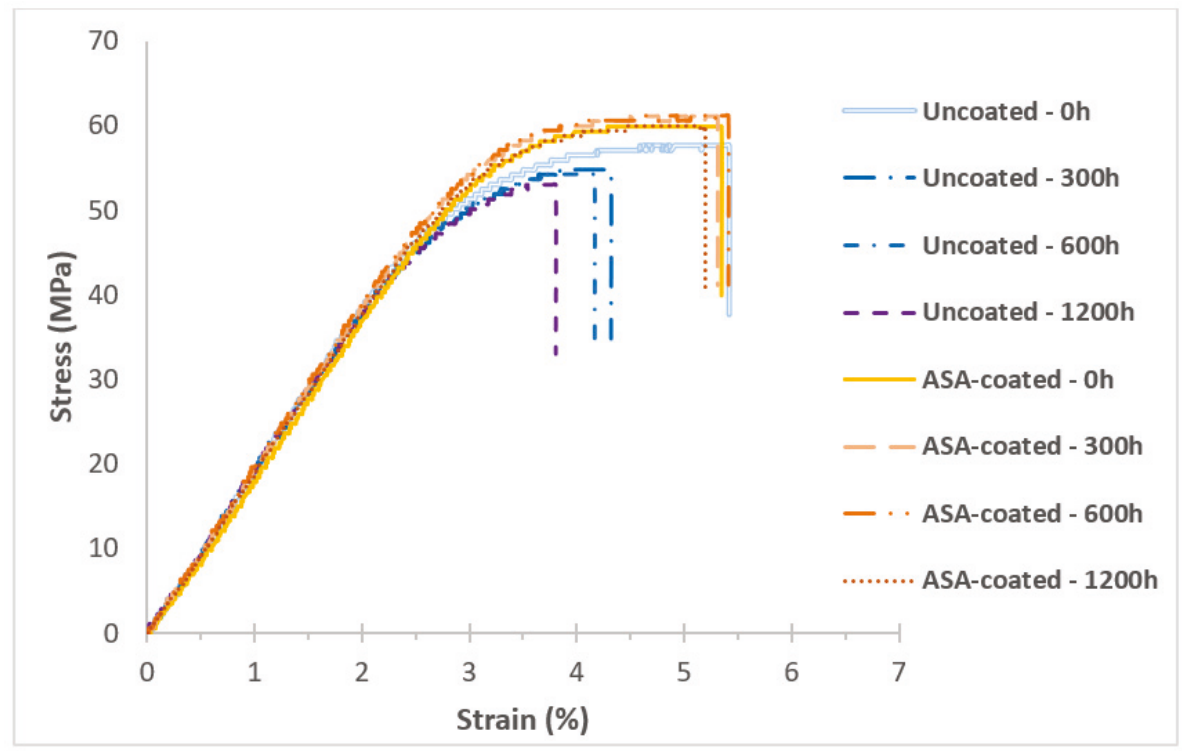

Figure 7. The average stress-strain curves of uncoated and ASA-coated 3D printed ABS specimens after $0,300,600$, and $1200 \mathrm{~h}$ of environmental exposure to UV radiation and moisture.

\section{Conclusions}

Developing coating systems for 3D printed polymer structures that protect the structural surface against aggressive environmental conditions is critical for the long-term durability of the structures. In this study, multi-material 3D printing was used to deposit an ASA coating on the surface of ABS structures to protect the structure against UV radiation, moisture, and heat. The uncoated ABS samples suffered significant degradation in the mechanical properties, particularly in the failure strain and toughness, during environmental aging. However, ASA-coated ABS specimens largely retained their initial mechanical properties throughout the environmental exposure. 
Author Contributions: Data curation and Investigation, R.W.; Conceptualization and Writing-original draft, A.A. All authors have read and agreed to the published version of the manuscript.

Funding: This research received no external funding.

Acknowledgments: The authors would like to thank Provost Office at Mercer University for the SEED grant and the support of this work.

Conflicts of Interest: The authors declare no conflict of interest.

\section{References}

1. Dey, A.; Yodo, N. A Systematic Survey of FDM Process Parameter Optimization and Their Influence on Part Characteristics. J. Manuf. Mater. Process. 2019, 3, 64. [CrossRef]

2. Ahn, S.-H.; Montero, M.; Odell, D.; Roundy, S.; Wright, P.K. Anisotropic material properties of fused deposition modeling ABS. Rapid Prototyp. J. 2002, 8, 248-257. [CrossRef]

3. Mitchell, A.; Lafont, U.; Hołyńska, M.; Semprimoschnig, C.J.A.M. Additive manufacturing-A review of 4D printing and future applications. Addit. Manuf. 2018, 24, 606-626. [CrossRef]

4. Perez, A.R.T.; Roberson, D.A.; Wicker, R.B. Fracture Surface Analysis of 3D-Printed Tensile Specimens of Novel ABS-Based Materials. J. Fail. Anal. Prev. 2014, 14, 343-353. [CrossRef]

5. Ngo, T.; Kashani, A.; Imbalzano, G.; Nguyen, Q.T.; Hui, D. Additive manufacturing (3D printing): A review of materials, methods, applications and challenges. Compos. Part B Eng. 2018, 143, 172-196. [CrossRef]

6. Conner, B.P.; Manogharan, G.P.; Martof, A.N.; Rodomsky, L.M.; Rodomsky, C.M.; Jordan, D.C.; Limperos, J.W. Making sense of 3-D printing: Creating a map of additive manufacturing products and services. Addit. Manuf. 2014, 1, 64-76. [CrossRef]

7. Yan, Q.; Dong, H.-H.; Su, J.; Han, J.; Song, B.; Wei, Q.; Shi, Y. A Review of 3D Printing Technology for Medical Applications. Engineering 2018, 4, 729-742. [CrossRef]

8. Ning, F.; Cong, W.; Qiu, J.; Wei, J.; Wang, S. Additive manufacturing of carbon fiber reinforced thermoplastic composites using fused deposition modeling. Compos. Part B Eng. 2015, 80, 369-378. [CrossRef]

9. Christiyan, K.J.; Chandrasekhar, U.; Venkateswarlu, K. A study on the influence of process parameters on the Mechanical Properties of 3D printed ABS composite. IOP Conf. Ser. Mater. Sci. Eng. 2016, 114, 012109. [CrossRef]

10. Sanatgar, R.H.; Campagne, C.; Nierstrasz, V. Investigation of the adhesion properties of direct 3D printing of polymers and nanocomposites on textiles: Effect of FDM printing process parameters. Appl. Surf. Sci. 2017, 403, 551-563. [CrossRef]

11. Huang, B.; Singamneni, S. Raster angle mechanics in fused deposition modelling. J. Compos. Mater. 2014, 49, 363-383. [CrossRef]

12. Ning, F.; Cong, W.; Hu, Y.; Wang, H. Additive manufacturing of carbon fiber-reinforced plastic composites using fused deposition modeling: Effects of process parameters on tensile properties. J. Compos. Mater. 2016, 51, 451-462. [CrossRef]

13. Wei, X.; Li, D.; Jiang, W.; Gu, Z.; Wang, X.; Zhang, Z.; Sun, Z. 3D Printable Graphene Composite. Sci. Rep. 2015, 5, 11181. [CrossRef] [PubMed]

14. Loos, A.C.; Springer, G.S. Moisture Absorption of Graphite-Epoxy Composites Immersed in Liquids and in Humid Air. J. Compos. Mater. 1979, 13, 131-147. [CrossRef]

15. Wright, W. The effect of diffusion of water into epoxy resins and their carbon-fibre reinforced composites. Composites 1981, 12, 201-205. [CrossRef]

16. Yousif, E.; Haddad, R. Photodegradation and photostabilization of polymers, especially polystyrene. SpringerPlus 2013, 2, 1-32. [CrossRef] [PubMed]

17. Signor, A.W.; VanLandingham, M.R.; Chin, J.W. Effects of ultraviolet radiation exposure on vinyl ester resins: Characterization of chemical, physical and mechanical damage. Polym. Degrad. Stab. 2003, 79, 359-368. [CrossRef]

18. Rånby, B. Photodegradation and photo-oxidation of synthetic polymers. J. Anal. Appl. Pyrolysis 1989, 15, 237-247. [CrossRef]

19. Afshar, A.; Mihut, D.; Baqersad, J.; Hill, S. Study of metallic thin films on epoxy matrix as protective barrier to ultraviolet radiation. Surf. Coat. Technol. 2019, 367, 41-48. [CrossRef] 
20. Afshar, A.; Liao, H.-T.; Chiang, F.-P.; Korach, C.S. Time-dependent changes in mechanical properties of carbon fiber vinyl ester composites exposed to marine environments. Compos. Struct. 2016, 144, 80-85. [CrossRef]

21. Afshar, A.; AlKhader, M.; Korach, C.S.; Chiang, F.-P. Effect of long-term exposure to marine environments on the flexural properties of carbon fiber vinylester composites. Compos. Struct. 2015, 126, 72-77. [CrossRef]

22. Afshar, A.; Mihut, D.; Chen, P. Effects of environmental exposures on carbon fiber epoxy composites protected by metallic thin films. J. Compos. Mater. 2019, 54, 167-177. [CrossRef]

23. Ray, B.C. Temperature effect during humid ageing on interfaces of glass and carbon fibers reinforced epoxy composites. J. Colloid Interface Sci. 2006, 298, 111-117. [CrossRef] [PubMed]

24. Eftekhari, M.; Fatemi, A. Tensile behavior of thermoplastic composites including temperature, moisture, and hygrothermal effects. Polym. Test. 2016, 51, 151-164. [CrossRef]

25. Bandyopadhyay, A.; Heer, B. Additive manufacturing of multi-material structures. Mater. Sci. Eng. R Rep. 2018, 129, 1-16. [CrossRef]

26. Huang, S.H.; Liu, P.; Mokasdar, A.; Hou, L. Additive manufacturing and its societal impact: A literature review. Int. J. Adv. Manuf. Technol. 2012, 67, 1191-1203. [CrossRef]

27. Tibbits, S. 4D Printing: Multi-Material Shape Change. Arch. Des. 2014, 84, 116-121. [CrossRef]

28. Afshar, A.; Mihut, D. Enhancing durability of 3D printed polymer structures by metallization. J. Mater. Sci. Technol. 2020, 53, 185-191. [CrossRef]

29. Santos, R.M.; Botelho, G.; Machado, A.V. Artificial and natural weathering of ABS. J. Appl. Polym. Sci. 2010, 116, 2005-2014. [CrossRef]

30. Perez, J.M.; Vilas, J.L.; Laza, J.M.; Arnaiz, S.; Mijangos, F.; Bilbao, E.; León, L.M. Effect of Reprocessing and Accelerated Weathering on ABS Properties. J. Polym. Environ. 2009, 18, 71-78. [CrossRef]

(C) 2020 by the authors. Licensee MDPI, Basel, Switzerland. This article is an open access article distributed under the terms and conditions of the Creative Commons Attribution (CC BY) license (http://creativecommons.org/licenses/by/4.0/). 



\title{
Effect of $\mathrm{MoSi}_{2}-\mathrm{Si}_{3} \mathrm{~N}_{4} / \mathrm{SiC}$ Multi-Layer Coating on the Oxidation Resistance of Carbon/Carbon Composites above $1770 \mathrm{~K}$
}

\author{
Imran Abbas ${ }^{1}$, Yanxiang Wang ${ }^{1}$, Hassan Elahi ${ }^{2, *}$, Muhammad Ali Siddiqui ${ }^{3}$, Mudaser Ullah ${ }^{4}$ \\ and Faisal Qayyum ${ }^{5}$ \\ 1 Carbon Fiber Engineering Research Center, Faculty of Materials Science, Shandong University, \\ Jinan 250061, China; engr.imran514@outlook.com (I.A.); wyx079@sdu.edu.cn (Y.W.) \\ 2 Department of Mechanical and Aerospace Engineering, Sapienza University of Rome, 00184 Rome, Italy \\ 3 Institute of Metal Research, Chinese academy of sciences, 72 Wenhua Road, Shenyang 110016, China; \\ mueatali@yahoo.com \\ 4 Department of Mechanical Engineering, CET, University of Sargodha, Sargodha 40100, Pakistan; \\ mudaser_me150@yahoo.com \\ 5 Institutfür Metallformung, Technische Universität Bergakademie Freiberg, D-09599 Freiberg, Germany; \\ faisal.qayyum@student.tu-freiberg.de \\ * Correspondence: hassan.elahi@uniroma1.it
}

Received: 25 May 2020; Accepted: 30 June 2020; Published: 3 July 2020

\begin{abstract}
To improve the oxidation resistance of carbon/carbon composites at high temperatures $(>1770 \mathrm{~K})$, they were coated with $\mathrm{MoSi}_{2}-\mathrm{Si}_{3} \mathrm{~N}_{4} / \mathrm{SiC}$. The slurry and pack cementation methods were adopted to deposit the inner $\mathrm{SiC}$ layer and outer $\mathrm{MoSi}_{2}-\mathrm{Si}_{3} \mathrm{~N}_{4}$ layer. The phase composition, microstructure, and elemental distributions in the coating were analyzed using SEM, XRD, EDS, and Raman spectroscopy. Oxidation tests show that the deposited multi-layer coating can protect the carbon/carbon matrix from oxidation at high temperatures $(>1770 \mathrm{~K}$ ) for $150 \mathrm{~h}$ and that the coating can withstand 40 thermal cycles between 1773 and $300 \mathrm{~K}$. It is observed that $\mathrm{Si}_{3} \mathrm{~N}_{4}$ assists in the formation of a dense $\mathrm{SiO}_{2}$ layer at a high temperature, which plays a vital role in increasing the thermal cyclic and oxidation resistance of the coating itself. The weight loss of coated carbon/carbon composite is attributed to the formation of micro-cracks and diffusion of $\mathrm{SiO}_{2}, \mathrm{MoO}_{3}$, and $\mathrm{N}_{2}$ out of the material at high temperatures.
\end{abstract}

Keywords: carbon/carbon composites; multi-phase coatings; oxidation resistance; thermal cycling

\section{Introduction}

For aggressive service environments in the nuclear and aerospace industry, carbon/carbon composites are candidate structural materials due to their attractive properties such as a high strength-to-weight ratio, thermal cyclic oxidation resistance, strength retention, and a low thermal expansion coefficient [1-5]. However, these composites exhibit limitations such as susceptibility to oxidation beyond $773 \mathrm{~K}$ and strength loss upon exposure to high temperatures. This makes them highly unfavorable for specific high-temperature applications [6-8]. It was shown by previous researchers that carbon/carbon composites could be protected against oxidation at high temperatures by the application of anti-oxidizing coatings [9].

In multi-layered coatings, $\mathrm{MoSi}_{2}$ is used as an outer layer, while $\mathrm{SiC}$ forms the inner buffer layer. The peripheral multi-layer coating containing $\mathrm{MoSi}_{2}$ exhibits a superior oxidation-resistant capability for carbon/carbon composites at $1500-1600^{\circ} \mathrm{C}[10]$. However, due to the mismatch of the thermal expansion coefficient between the $\mathrm{SiC}$ bonding layer and the $\mathrm{MoSi}_{2}$ outer coating, micro-cracks in the $\mathrm{MoSi}_{2}$ appear at extended high-temperature (i.e., $800-1000{ }^{\circ} \mathrm{C}$ ) exposure [11-14]. Therefore, 
the protective temperature range of coatings containing $\mathrm{MoSi}_{2}$ is constricted; this limits the structural and high-temperature applications of such materials. The coefficient of thermal expansion (CTE) of $\mathrm{MoSi}_{2}\left(\sim 8.1 \times 10^{-6} / \mathrm{K}\right)$ is higher than that of carbon/carbon composites $\left(\sim 1.0 \times 10^{-6} / \mathrm{K}\right)$. Therefore, the mismatch between the CTEs of the outer $\mathrm{MoSi}_{2}$ layer and the inner $\mathrm{SiC}$-coated carbon/carbon matrix causes the degradation of the coating under thermal cycling and ultimately lowers the coating durability $[15,16]$.

$\mathrm{MoSi}_{2}$ coating at a temperature range of $400-600{ }^{\circ} \mathrm{C}$ efficiently reacts with oxygen to form $\mathrm{MoO}_{3}$ and $\mathrm{SiO}_{2}$. These oxides result in the considerable volume expansion of the $\mathrm{MoSi}_{2}$ matrix, which results in the disintegration of bulk $\mathrm{MoSi}_{2}$ into powders and causes catastrophic failure of the coating [17]. This is called the "pest phenomenon" and is another primary reason for coating failure. In addition, $\mathrm{MoSi}_{2}$ is a low toughness material which limits its industrial application even at ambient temperature [18].

Earlier reports have suggested that the addition of $\mathrm{Si}_{3} \mathrm{~N}_{4}$ to $\mathrm{MoSi}_{2}$ can minimize the coefficient of thermal expansion (CTE) mismatch between the outer $\mathrm{MoSi}_{2}$ and inner $\mathrm{SiC}$ coatings. $\mathrm{Si}_{3} \mathrm{~N}_{4}$ exhibits high flexural strength and excellent compatibility with $\mathrm{MoSi}_{2}$ and $\mathrm{SiC}$ due to better mixing with these compounds. It also exhibits a reasonable resistance to creep, isothermal oxidation, and cyclic thermal oxidation [19]. The $\mathrm{MoSi}_{2}-\mathrm{Si}_{3} \mathrm{~N}_{4}$ coating exhibits excellent oxidation resistance with minute weight loss. At high temperature, $\mathrm{MoSi}_{2}-\mathrm{Si}_{3} \mathrm{~N}_{4}$ forms a dense glassy $\mathrm{SiO}_{2}$ film on the coating surface. Owing to its low oxygen-diffusion coefficient, the $\mathrm{SiO}_{2}$ film serves as an oxygen diffusion barrier and efficiently protects carbon/carbon composites from oxidation at $1773 \mathrm{~K}[20,21]$. Due to good fluidity at high temperatures, $\mathrm{SiO}_{2}$ can seal all the micro-cracks formed during the volatilization of $\mathrm{MoO}_{3}, \mathrm{CO}_{2}$, and $\mathrm{N}_{2}$ [22]. Furthermore, the addition of $\mathrm{Si}_{3} \mathrm{~N}_{4}$ provides better refractory and some oxidation-resistant properties, which decrease the possibility of pest disintegration of $\mathrm{MoSi}_{2}$. Huang et al. [23] prepared a $\mathrm{MoSi}_{2} / \mathrm{Si}_{3} \mathrm{~N}_{4}$ coating on Mo substrate and described the effect of the $\mathrm{Si}_{3} \mathrm{~N}_{4}$ content on the microstructure and antioxidant properties of multi-layer coatings.

In this study, coatings composed of a $\mathrm{SiC}$ bonding layer and a $\mathrm{MoSi}_{2}-\mathrm{Si}_{3} \mathrm{~N}_{4}$ outer layer were prepared by a simple and low-cost slurry method. The phase composition, microstructure, and oxidation resistance of the above multi-layer coatings at $1773 \mathrm{~K}$ in the air were investigated in detail.

\section{Experimental Procedure}

\subsection{Coating Preparation}

Small specimens $\left(10 \times 10 \times 10 \mathrm{~mm}^{3}\right)$ of carbon/carbon composite (Shandong Weiji Carbon Technology Co. Ltd., Jinan, China) with a density of $1.79 \mathrm{~g} / \mathrm{cm}^{3}$ used as substrates were cut from thin bulk sheet. The carbon/carbon composite used in this study was carbon fiber-strengthened graphite. The surface area of the samples was increased by abrading them with commercially available rough $\mathrm{SiC}$ papers. To remove any remaining debris and moisture, the samples were cleaned ultrasonically with distilled water and dried in an oven at $100{ }^{\circ} \mathrm{C}$ for $2 \mathrm{~h}$.

The powder compositions used were $\mathrm{Si} 75 \mathrm{wt} \%$, graphite $20 \mathrm{wt} \%$, and $\mathrm{Al}_{2} \mathrm{O}_{3} 5 \mathrm{wt} \%$ respectively. All the powders used were lab-grade and had a purity $\geq 99 \%$ with particle size ranging between $1-10 \mu \mathrm{m}$. $\mathrm{SiC}$ inner coatings were applied to the specimens by the pack-cementation method. The carbon/carbon composites and pack mixtures were put in a graphite crucible and heated at $1873 \mathrm{~K}$ for $2 \mathrm{~h}$ in an argon atmosphere to form the SiC coating. After the completion of inner coating, the SiC-coated specimens were cleaned ultrasonically and dried in an oven at $100{ }^{\circ} \mathrm{C}$ for $2 \mathrm{~h}$.

The liquid slurry mixture method was adopted for applying the outer coating of $\mathrm{MoSi}_{2}-\mathrm{Si}_{3} \mathrm{~N}_{4}$ over the already applied inner $\mathrm{SiC}$ coating. High-purity $\mathrm{MoSi}_{2}$ and $\mathrm{Si}_{3} \mathrm{~N}_{4}$ powders supplied by Turnnano Ltd., Henan, China) were used. The $\mathrm{MoSi}_{2}$ and $\mathrm{Si}_{3} \mathrm{~N}_{4}$ powders were mixed in $10 \mathrm{~mL}$ aqueous solution of H-PSO, and a homogenous slurry solution was prepared. The SiC-coated carbon/carbon specimens were put in a slurry mixture of $\mathrm{MoSi}_{2}$ and $\mathrm{Si}_{3} \mathrm{~N}_{4}$. The as-coated specimens were put in a 
graphite crucible and heated up to $2073 \mathrm{~K}$ for two hours in the nitrogen atmosphere to apply the outer $\mathrm{MoSi}_{2}-\mathrm{Si}_{3} \mathrm{~N}_{4}$ coating on the samples.

The slurry method was preferred over others due to its compositional flexibility, ease of processing, and low cost. Also, it is known that the coating deposited via the slurry method exhibits reasonable resistance to oxidation and thermal cyclic oxidation [11]. The $\mathrm{MoSi}_{2}-\mathrm{SiC}$ and $\mathrm{MoSi}_{2}-\mathrm{Si}_{3} \mathrm{~N}_{4} / \mathrm{SiC}$ coatings were prepared using a similar approach to elucidate the effect of $\mathrm{Si}_{3} \mathrm{~N}_{4}$ addition on the oxidation resistance of the multi-layer coatings.

\subsection{Oxidation Test}

Isothermal oxidation tests on the $\mathrm{MoSi}_{2}-\mathrm{Si}_{3} \mathrm{~N}_{4} / \mathrm{SiC}$ multi-layer coated carbon/carbon specimens were performed in a corundum tube furnace at $1773 \mathrm{~K}$ for $150 \mathrm{~h}$. After every $10 \mathrm{~h}$ to a maximum time of $150 \mathrm{~h}$, the samples were taken out of the furnace directly and cooled to room temperature in air. The weight loss of each specimen at room temperature was measured with an electronic balance with a sensitivity of $\pm 0.1 \mathrm{mg}$. The percentage weight loss (wt \%) was calculated using Equation (1), where $m_{0}$ and $m_{1}$ are the weights of specimens before and after the oxidation test, respectively.

$$
\mathrm{wt} \%=\frac{m_{0}-m_{1}}{m_{0}} \times 100 \%
$$

The thermal cyclic oxidation resistance of the $\mathrm{MoSi}_{2}-\mathrm{Si}_{3} \mathrm{~N}_{4} / \mathrm{SiC}$ multi-layer coating was investigated by conducting a test between $1773 \mathrm{~K}$ and room temperature. In this test, the coated carbon/carbon specimens were heated at $1773 \mathrm{~K}$ for $10 \mathrm{~min}$, removed from the furnace, and air-cooled to room temperature for each cycle. The testing was carried out in 40 cycles.

\subsection{Characterization of the Coatings}

The morphology of the $\mathrm{MoSi}_{2}-\mathrm{Si}_{3} \mathrm{~N}_{4} / \mathrm{SiC}$ multi-layer coating before and after the oxidation test was analyzed using a scanning electron microscope (SEM), equipped with an energy dispersive spectroscope (EDS). Raman spectroscopy (LabRam-1B, 633nm line of the He-Ne laser) was used to identify the chemical composition and phase transformation. An X-ray diffraction (XRD) technique was used for the crystallographic characterization of the coating before and after the oxidation test.

To analyze the elemental distribution along with the depth of the coated samples, they were sectioned using a power cutter and were then ground and polished to prepare the surface perpendicular to the top coating surface. These samples were then analyzed using the same characterization techniques stated earlier in this section.

\section{Results and Discussion}

\subsection{Microstructure of Coating before the Oxidation Test}

The XRD pattern of the as-coated inner SiC layer is shown in Figure 1a. Three significant peaks at $2 \theta \approx 35.6^{\circ}, 60.0^{\circ}$, and $71.7^{\circ}$ correspond to the (111), (220), and (311) crystalline planes of $\beta$-SiC, indicating the formation of the $\beta$-SiC crystalline plane during the pack cementation process. The low-intensity peak at $2 \theta \approx 33.6^{\circ}$ indicates the existence of stacking faults (SF) in the $\beta$-SiC coating. The stacking faults might be induced due to the thermal stresses produced in the coating process [24]. 


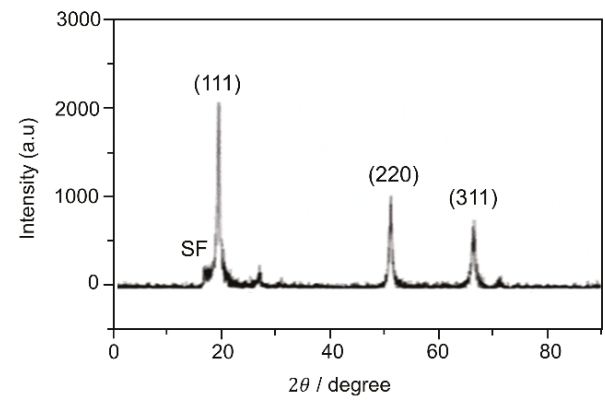

(a)

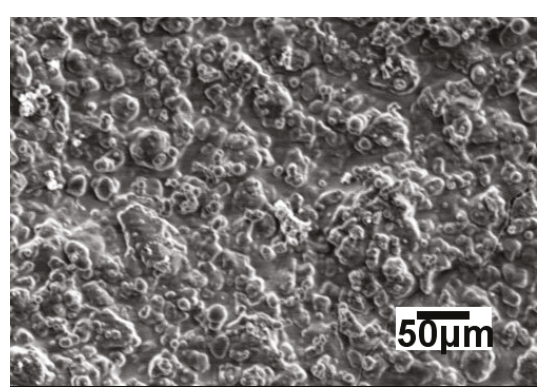

(b)

Figure 1. Structure of the inner SiC coating: (a) XRD pattern; (b) surface SEM image.

Figure $1 \mathrm{~b}$ shows the surface microstructure of the as-coated inner SiC layer. Figure 2 shows the XRD analysis of the as-coated specimen, i.e., the $\mathrm{MoSi}_{2}-\mathrm{Si}_{3} \mathrm{~N}_{4} / \mathrm{SiC}$-coated carbon/carbon specimen before the oxidation test. $\mathrm{MoSi}_{2}, \mathrm{Si}_{3} \mathrm{~N}_{4}$, and $\mathrm{SiC}$ phases are apparent. The more vigorous peak intensity of the $\mathrm{MoSi}_{2}$ phase in Figure 2 indicates that it is relatively more abundant in the slurry.

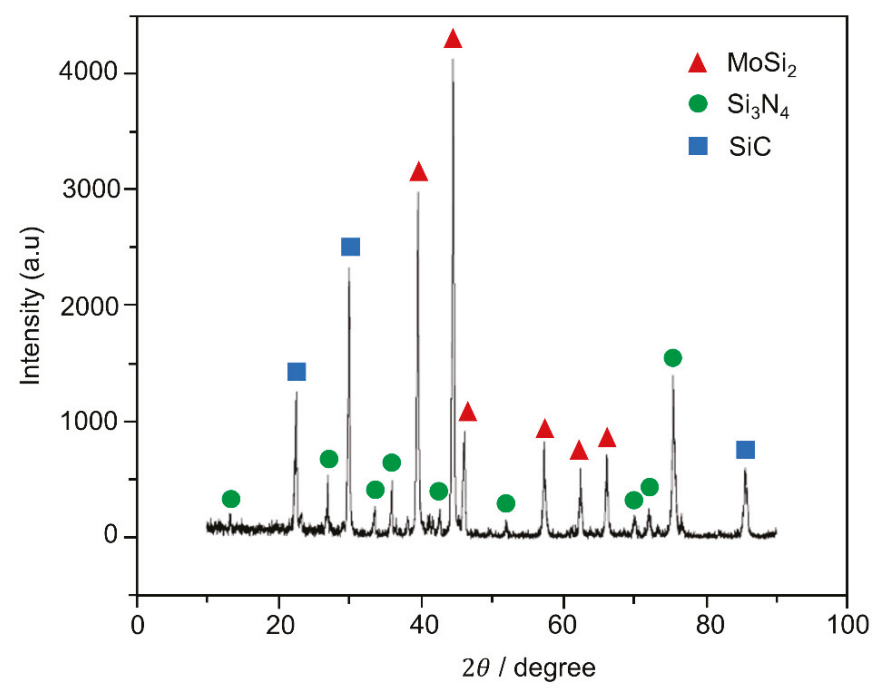

Figure 2. XRD pattern of $\mathrm{MoSi}_{2}-\mathrm{Si}_{3} \mathrm{~N}_{4} / \mathrm{SiC}$ coated carbon/carbon specimen before the oxidation test.

Figure 3 a shows the surface microstructure of the as-coated $\mathrm{MoSi}_{2}-\mathrm{Si}_{3} \mathrm{~N}_{4}$ outer layer before the oxidation test. The surface of the coating has no micro-cracks, indicating that the as-prepared coating is dense and homogeneous. In Figure 3b, the EDS pattern of the area marked with the red square in Figure 3a clearly shows that the smooth area of the as-coated $\mathrm{MoSi}_{2}-\mathrm{Si}_{3} \mathrm{~N}_{4}$ is composed of the elements Si, N, and Mo. 

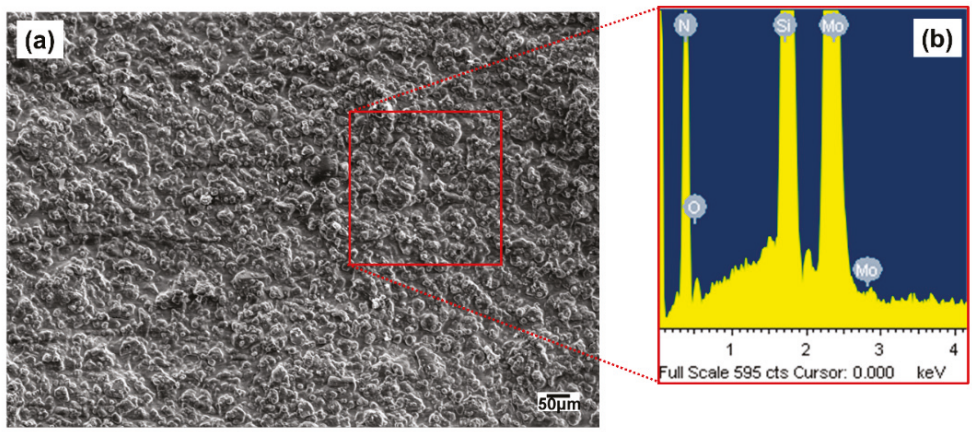

Figure 3. Surface of the as-coated $\mathrm{MoSi}_{2}-\mathrm{Si}_{3} \mathrm{~N}_{4}$ outer layer: (a) SEM image; (b) EDS pattern corresponding to the marked red square in Figure $3 \mathrm{a}$.

Figure 4 shows an overlay of element line scanning over the SEM image of the cross-section of $\mathrm{MoSi}_{2}-\mathrm{Si}_{3} \mathrm{~N}_{4} / \mathrm{SiC}$ coated $\mathrm{C} / \mathrm{C}$ composite before the oxidation test. The multi-layer coating has an average thickness of $195 \pm 3 \mu \mathrm{m}$. It can be observed from the line scan that the as-prepared coating is composed of a $\mathrm{MoSi}_{2}-\mathrm{Si}_{3} \mathrm{~N}_{4}$ outer layer, $\mathrm{SiC}$ inner layer, and $\mathrm{SiC}$ transition layer, of thicknesses $40 \pm 5$, $61 \pm 2$, and $93 \pm 2 \mu \mathrm{m}$, respectively. The SiC transition layer, formed possibly due to the infiltration of $\mathrm{Si}$ into the carbon/carbon substrate at high temperature, increases the oxidation and thermal cyclic oxidation resistance of the coating. The lack of voids between the outer and inner coating layers in Figure 4 indicate two things:

1. An increase in the interfacial bonding strength of the coating [25];

2. A reduction in the thermal mismatch of the expansion between the coatings and the $\mathrm{C} / \mathrm{C}$ substrate.

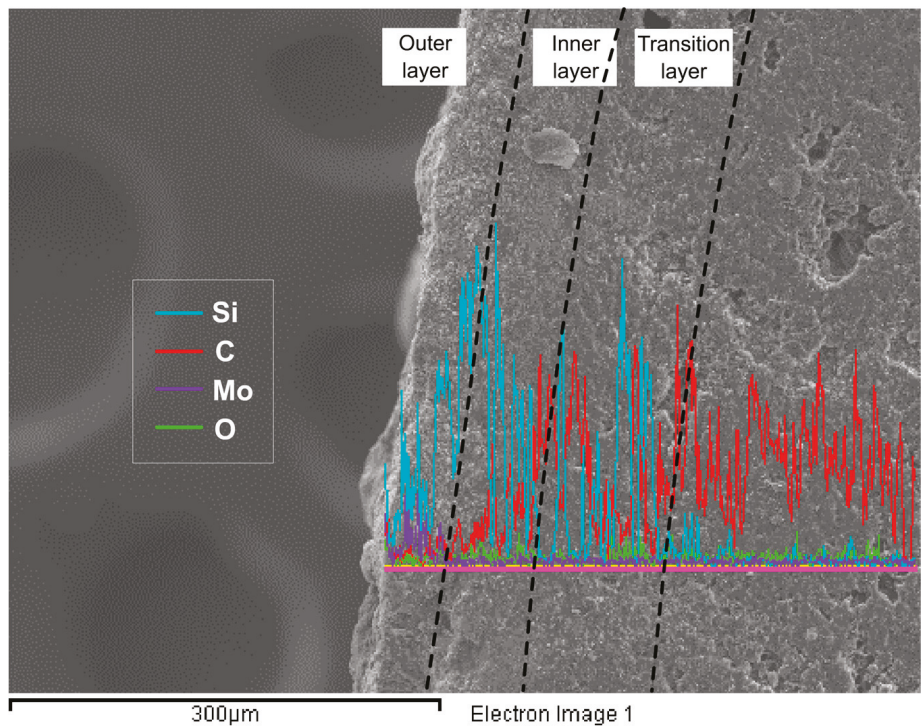

Figure 4. Line scans of the cross-section of $\mathrm{C} / \mathrm{C}$ composite coated with $\mathrm{MoSi}_{2}-\mathrm{Si}_{3} \mathrm{~N}_{4} / \mathrm{SiC}_{\text {. }}$

\subsection{Microstructure of Coating Post-Oxidation Test: Oxidation Resistance Evaluation}

Figure 5 shows the $\mathrm{XRD}$ spectrum of the $\mathrm{MoSi}_{2}-\mathrm{Si}_{3} \mathrm{~N}_{4} / \mathrm{SiC}$ coating after the oxidation test at $1773 \mathrm{~K}$. It is clear that the oxidation test resulted in the formation of several new phases. The $\mathrm{MoSi}_{2}$ phase of 
the $\mathrm{MoSi}_{2}-\mathrm{Si}_{3} \mathrm{~N}_{4} / \mathrm{SiC}$ coating has undergone complete transformation, producing some new phases, $\mathrm{SiO}_{2}, \mathrm{Mo}_{5} \mathrm{Si}_{3}$, and $\mathrm{MoO}_{3}$. The appearance of large fractions of Si-based new phases indicates that $\mathrm{MoSi}_{2}$ is completely oxidized. The partial oxidation of $\mathrm{Si}_{3} \mathrm{~N}_{4}$ at oxidation temperature has resulted in the formation of the $\mathrm{Si}_{2} \mathrm{~N}_{2} \mathrm{O}$ phase that is in accordance with the XRD pattern [26]. The possible reactions are as follows.

$$
\begin{gathered}
\mathrm{SiC}(\mathrm{s})+2 \mathrm{O}_{2}(\mathrm{~g}) \rightarrow \mathrm{SiO}_{2}+\mathrm{CO}_{2}(\mathrm{~g}) \\
5 \mathrm{MoSi}_{2}(\mathrm{~s})+7 \mathrm{O}_{2}(\mathrm{~g}) \rightarrow \mathrm{Mo}_{5} \mathrm{Si}_{3}(\mathrm{~s})+7 \mathrm{SiO}_{2}(\mathrm{~s}) \\
2 \mathrm{Mo}_{5} \mathrm{Si}_{3}(\mathrm{~s})+21 \mathrm{O}_{2}(\mathrm{~g}) \rightarrow 10 \mathrm{MoO}_{3}(\mathrm{~g})+6 \mathrm{SiO}_{2}(\mathrm{~s}) \\
2 \mathrm{MoSi}_{2}(\mathrm{~s})+7 \mathrm{O}_{2}(\mathrm{~g}) \rightarrow 4 \mathrm{SiO}_{2}(\mathrm{~s})+2 \mathrm{MoO}_{3}(\mathrm{~g}) \\
\mathrm{Si}_{3} \mathrm{~N}_{4}(\mathrm{~s})+3 \mathrm{O}_{2}(\mathrm{~g}) \rightarrow 3 \mathrm{SiO}_{2}(\mathrm{~s})+2 \mathrm{~N}_{2}(\mathrm{~g}) \\
\mathrm{Si}_{3} \mathrm{~N}_{4}(\mathrm{~s})+\mathrm{SiO}_{2}(\mathrm{~s}) \rightarrow 2 \mathrm{Si}_{2} \mathrm{~N}_{2} \mathrm{O}(\mathrm{s})
\end{gathered}
$$

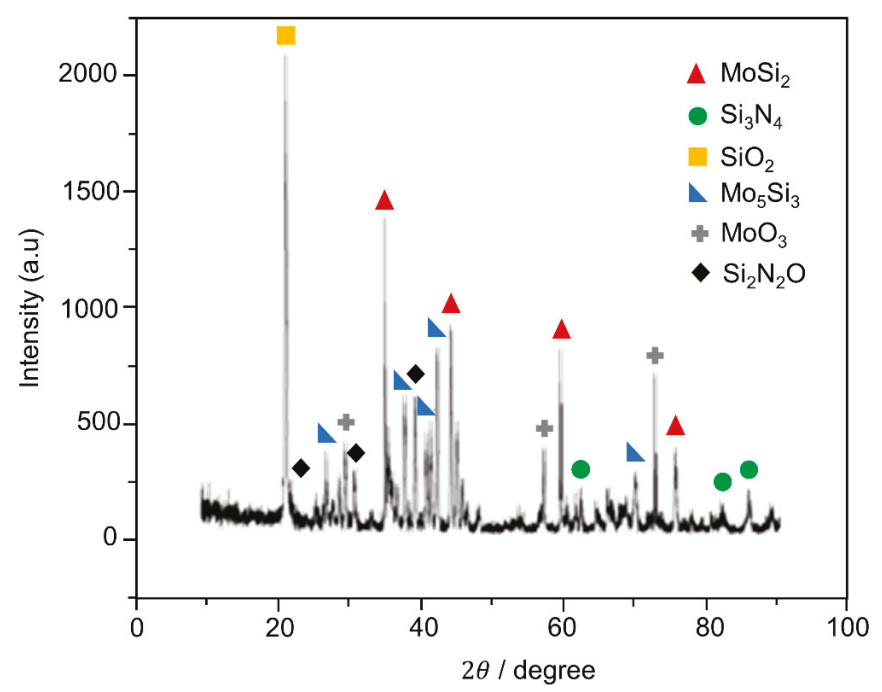

Figure 5. XRD pattern of $\mathrm{MoSi}_{2}-\mathrm{Si}_{3} \mathrm{~N}_{4} / \mathrm{SiC}$-coated C/C composites after oxidation at $1773 \mathrm{~K}$.

$\mathrm{Mo}_{5} \mathrm{Si}_{3}$ and $\mathrm{SiO}_{2}$ play an important role in increasing the oxidation resistance of the coating. The $\mathrm{Mo}_{5} \mathrm{Si}_{3}$ phase increases the coating flexural strength and the coating-substrate compatibility and enhances the creep strength [27]. The $\mathrm{SiO}_{2}$ phase, owing to its inherent low viscosity, good fluidity and low oxygen permeability, serves as a barrier against oxygen attack. In Figure 6, the Raman spectroscopy result also confirms the formation of $\mathrm{SiO}_{2}$ in the $\mathrm{MoSi}_{2}-\mathrm{Si}_{3} \mathrm{~N}_{4}$ coating after oxidation at $1773 \mathrm{~K}$. It can be found that the peak with wave number of 228 and $414 \mathrm{~cm}^{-1}$ is the crystallite while the wave number of $1034 \mathrm{~cm}^{-1}$ is the amorphous silica, which is accordance with the XRD result. 


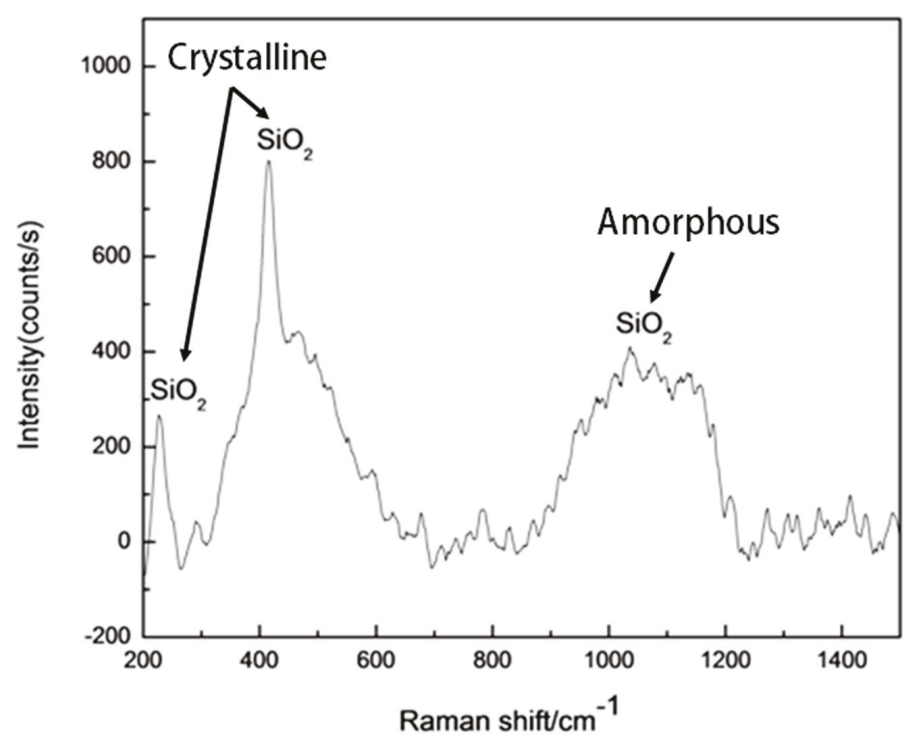

Figure 6. Raman spectrum of the $\mathrm{MoSi}_{2}-\mathrm{Si}_{3} \mathrm{~N}_{4} / \mathrm{SiC}$ coating after oxidation at $1773 \mathrm{~K}$ for $150 \mathrm{~h}$ [26].

The effect of $\mathrm{Si}_{3} \mathrm{~N}_{4}$ on the oxidation resistance of the multi-layer coating was investigated from the microstructure analysis and weight loss of the coatings constituting the $\mathrm{MoSi}_{2}$ and $\mathrm{MoSi}_{2}-\mathrm{Si}_{3} \mathrm{~N}_{4}$ outer layers. Figure 7a shows the microstructure of the $\mathrm{MoSi}_{2}$ surface of the $\mathrm{MoSi}_{2} / \mathrm{SiC}$ multi-layer coating after the oxidation test. The incomplete formation of silica $\left(\mathrm{SiO}_{2}\right)$ was due to the non-uniform agglomeration of $\mathrm{MoSi}_{2}$ particles in the brushing process [28]. These particles degraded the surface of the coating and gradually reduced its oxidation resistance. As a result, some deep cracks occurred and propagated through the randomly deposited $\mathrm{MoSi}_{2}$.

Figure $\mathrm{7b}$ shows the SEM micrograph of the cross-section of $\mathrm{MoSi}_{2} / \mathrm{SiC}$ multi-layer-coated carbon/carbon composites. The cross-section is rough, porous, and oxidized. This is because of the large CTE difference between $\mathrm{SiC}$ and $\mathrm{MoSi}_{2}$, leading to the incomplete formation of $\mathrm{SiO}_{2}$ and pore/cavity formation $[25,29]$. These pores provide the diffusion channel for oxygen that penetrates the substrate and causes the failure of the coating. It is also noteworthy that the infiltration of oxygen via the cavities would reduce the thickness of the coating. Therefore, the porous morphology of the $\mathrm{MoSi}_{2} / \mathrm{SiC}$ coating is detrimental for its oxidation resistance.

Figure $7 \mathrm{c}$ shows the microstructure of the outer surface of the $\mathrm{MoSi}_{2}-\mathrm{Si}_{3} \mathrm{~N}_{4} / \mathrm{SiC}$ coating after the oxidation test at $1773 \mathrm{~K}$. A dense glassy $\mathrm{SiO}_{2}$ layer on the surface is evident, which prevents the carbon/carbon matrix from oxygen penetration and protects the coating from oxidation. This makes the $\mathrm{MoSi}_{2}-\mathrm{Si}_{3} \mathrm{~N}_{4} / \mathrm{SiC}$ coating oxidation-resistant and an ideal choice for high-temperature applications.

In Figure 7d, the cross-sectional morphology of the post-oxidation tested $\mathrm{MoSi}_{2}-\mathrm{Si}_{3} \mathrm{~N}_{4} / \mathrm{SiC}$ coating exhibits excellent compatibility between the coating and the substrate, which is responsible for the high bonding and flexural strengths of the coating in high-temperature environments [30,31]. Furthermore, the absence of voids/holes at the coating-substrate interface indicates that the coating is resistant to high-temperature rupture. In addition, $\mathrm{Si}_{3} \mathrm{~N}_{4}$ forms a suitable combination with $\mathrm{MoSi}_{2}$ in the slurry, which helps to minimize the CTE difference between the outer $\mathrm{MoSi}_{2}-\mathrm{Si}_{3} \mathrm{~N}_{4}$ layer and the inner $\mathrm{SiC}$-coated carbon/carbon substrate. Therefore, $\mathrm{Si}_{3} \mathrm{~N}_{4}$ plays a vital role in increasing the oxidation protective ability of outer coatings at high temperatures [32]. The formation of microdefects (i.e., microcracks and micropores) is due to the volatilization of $\mathrm{MoO}_{3}$. From experimental observations, these pores are far from detrimental to the coating and can be cured by the glassy $\mathrm{SiO}_{2}$ layer at high temperatures. 

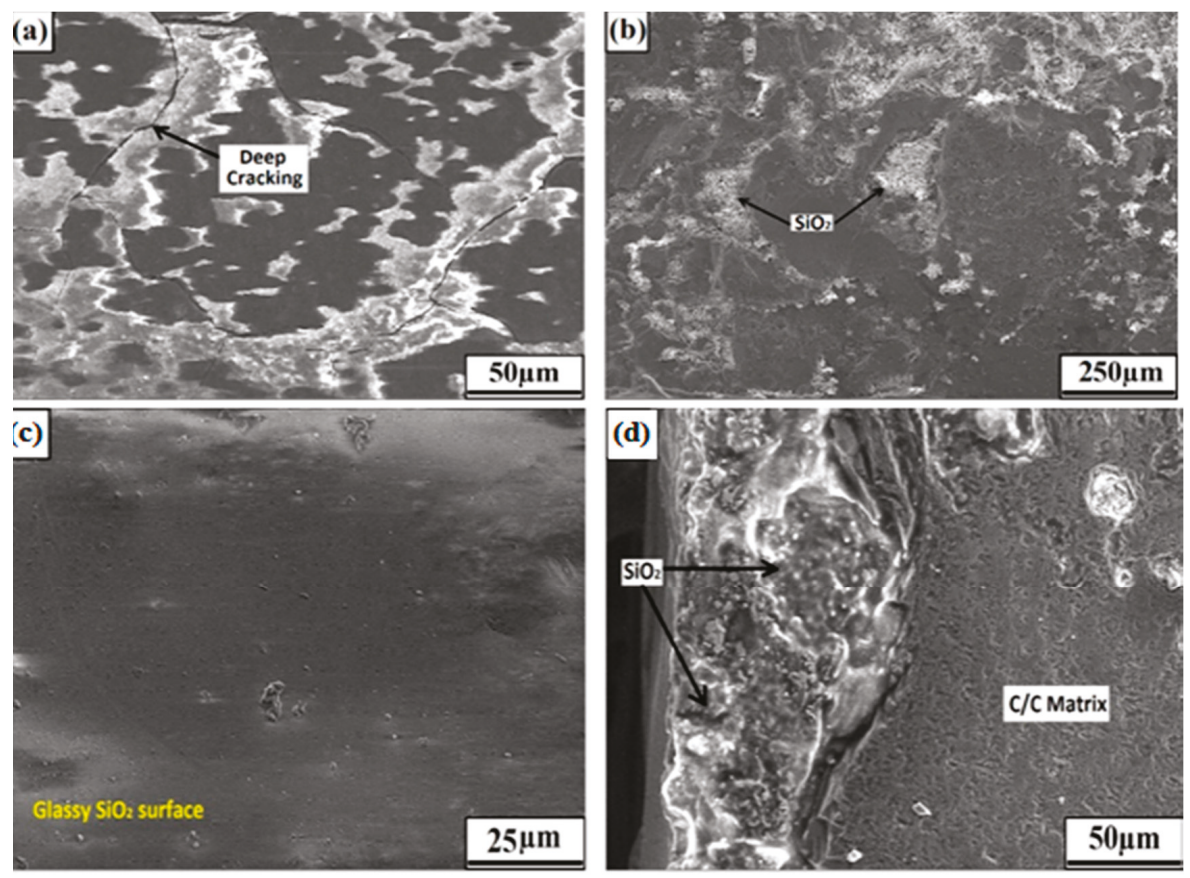

Figure 7. SEM image of $\mathrm{MoSi}_{2} / \mathrm{SiC}$ coating after oxidation at $1773 \mathrm{~K}$ : (a) surface, (b) cross-section; SEM image of $\mathrm{MoSi}_{2}-\mathrm{Si}_{3} \mathrm{~N}_{4} / \mathrm{SiC}$ coating after oxidation at $1773 \mathrm{~K}$ : (c) surface, (d) cross-section.

Figure 8 shows a comparison of weight losses for the two coatings, with and without $\mathrm{Si}_{3} \mathrm{~N}_{4}$, after the oxidation test at $1773 \mathrm{~K}$. The $\mathrm{MoSi}_{2}-\mathrm{Si}_{3} \mathrm{~N}_{4} / \mathrm{SiC}$ coating experienced a weight loss of $0.9 \%$ after $150 \mathrm{~h}$ of oxidation treatment while the $\mathrm{MoSi}_{2} / \mathrm{SiC}$ coating suffered a relatively high weight loss of $4.0 \%$ even after $90 \mathrm{~h}$ of oxidation.

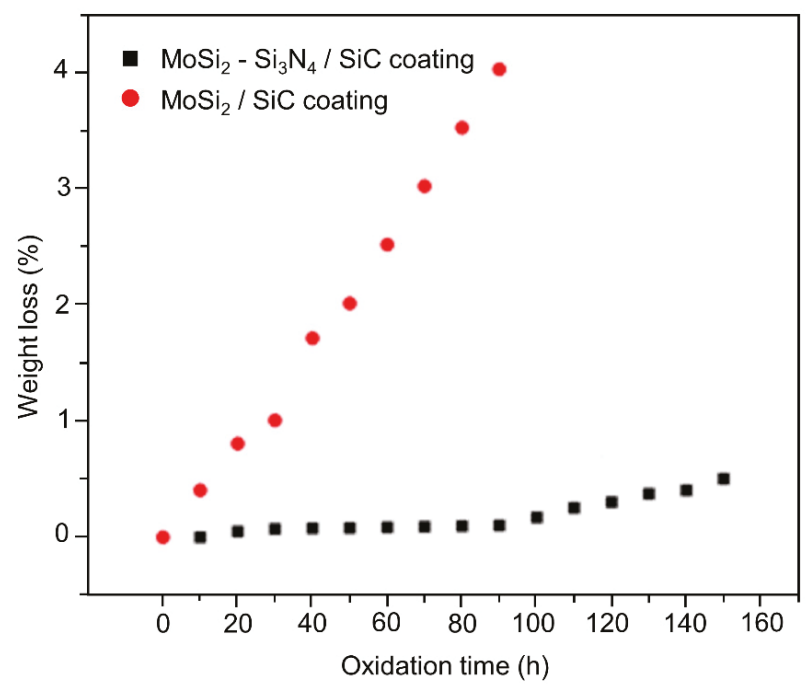

Figure 8. Isothermal oxidation curves of $\mathrm{MoSi}_{2}-\mathrm{Si}_{3} \mathrm{~N}_{4} / \mathrm{SiC}$-coated $\mathrm{C} / \mathrm{C}$ composites in the air at $1773 \mathrm{~K}$. 
The absence of $\mathrm{Si}_{3} \mathrm{~N}_{4}$ in the $\mathrm{MoSi}_{2} / \mathrm{SiC}$ coatings causes the pest disintegration of $\mathrm{MoSi}_{2}$ which results in the coating's degradation at high temperatures. The increasing weight loss with oxidation time is due to the insufficient amount of $\mathrm{SiO}_{2}$ that results in the formation of large cracks on the surface of the coating. This severely affects the coating surface and allows oxygen access to the $\mathrm{C} / \mathrm{C}$ composites, causing gaseous byproducts. At high temperatures, these gaseous byproducts quickly evaporate to cause the sudden weight loss of the coating. This de-gasification produces some micro-cracks and deep cavities in the coating surface, which are the principal contributors to weight reduction.

The lower weight loss in the $\mathrm{MoSi}_{2}-\mathrm{Si}_{3} \mathrm{~N}_{4} / \mathrm{SiC}$ coating indicates that the addition of $\mathrm{Si}_{3} \mathrm{~N}_{4}$ is beneficial for the coating's integrity at high temperatures. Additionally, the absence of debonding or spallation at $1773 \mathrm{~K}$ indicates that the $\mathrm{Si}_{3} \mathrm{~N}_{4}$ in the coating yields better coating-substrate compatibility at high temperatures. This suggests that the $\mathrm{MoSi}_{2}-\mathrm{Si}_{3} \mathrm{~N}_{4}$ coating is more resistant to high-temperature oxidation.

\subsection{Thermal Cyclic Oxidation Resistance of the Coating at $1773 \mathrm{~K}$}

Figure 9a shows the SEM image of the $\mathrm{MoSi}_{2}-\mathrm{Si}_{3} \mathrm{~N}_{4} / \mathrm{SiC}$ coating surface after the thermal cyclic oxidation test. It can be observed that whiskers are formed throughout the surface. The exposure of $\mathrm{Si}_{3} \mathrm{~N}_{4}$ coatings to high temperatures can foster the formation of $\mathrm{Si}_{2} \mathrm{~N}_{2} \mathrm{O}$ whiskers [33]. These whiskers play an essential role in increasing the oxidation resistance of the coating [34]. The cross-sectional view of the multi-layer coating in Figure $9 \mathrm{~b}$ shows small pores, mainly caused by the rapid cooling from $1773 \mathrm{~K}$ to room temperature. These pores can be sealed by the formation of $\mathrm{Si}_{3} \mathrm{~N}_{4}$ whiskers in the subsequent thermal cyclic oxidation process, which further protects the coating from high-temperature oxidation [35].
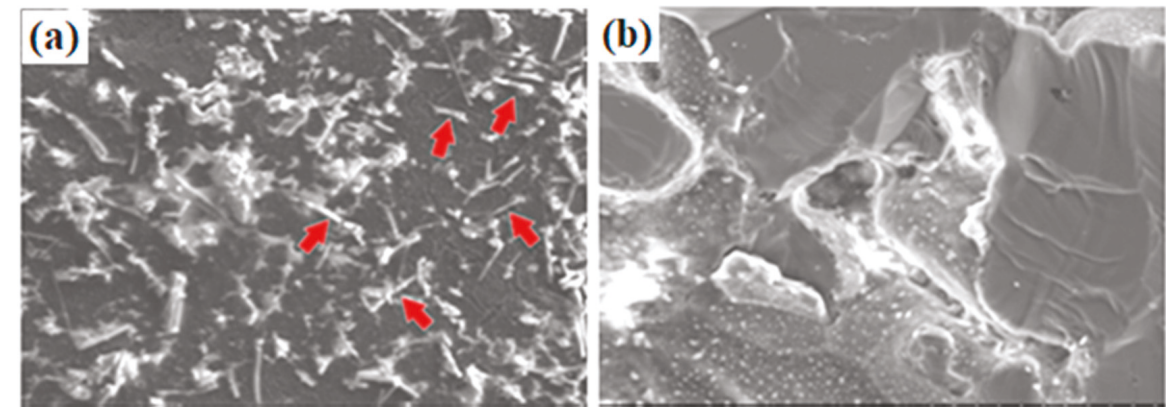

Figure 9. (a) Surface SEM image, where red arrows represent whiskers; (b) cross-section of multi-layer coatings after thermal cyclic oxidation test between $1773 \mathrm{~K}$ and room temperature 40 times.

Figure 10 shows the weight loss curve of the $\mathrm{MoSi}_{2}-\mathrm{Si}_{3} \mathrm{~N}_{4} / \mathrm{SiC}$-coated $\mathrm{C} / \mathrm{C}$ specimen during its repeated thermal cycling between $1773 \mathrm{~K}$ and room temperature. It can be observed that the weight loss of the coated specimen was only $0.05 \%$ after 40 thermal cycles. During the thermal cycling, the coating remained intact, and no oxidation or spallation was found. This indicates that the coating exhibits excellent oxidation and thermal cyclic oxidation resistance, which can be attributed to the filling of micro cracks under oxidizing environments by abundant glassy oxides. 


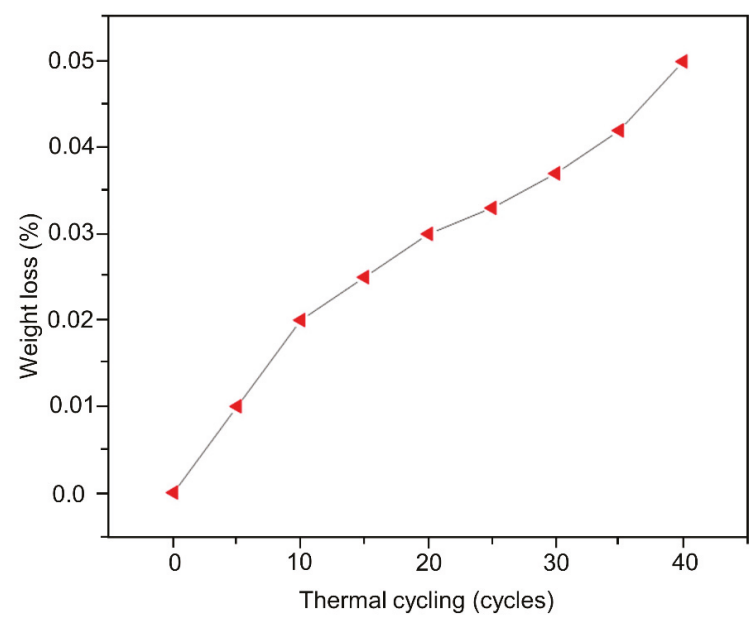

Figure 10. Thermal cycling oxidation curves of the $\mathrm{MoSi}_{2}-\mathrm{Si}_{3} \mathrm{~N}_{4} / \mathrm{SiC}$ coating between $1773 \mathrm{~K}$ and room temperature.

\section{Conclusions}

The effect of $\mathrm{Si}_{3} \mathrm{~N}_{4}$ addition in $\mathrm{MoSi}_{2} / \mathrm{SiC}$ coating on the oxidation and thermal cyclic oxidation resistance at $1773 \mathrm{~K}$ was investigated. The $0.5 \%$ weight loss in the $\mathrm{MoSi}_{2}-\mathrm{Si}_{3} \mathrm{~N}_{4} / \mathrm{SiC}$ coating after its oxidation for $150 \mathrm{~h}$ in comparison to the $4.0 \%$ weight loss in the $\mathrm{MoSi}_{2} / \mathrm{SiC}$ coating after $90 \mathrm{~h}$ proves that the coating with $\mathrm{Si}_{3} \mathrm{~N}_{4}$ has a better high-temperature oxidation resistance. The negligible weight loss after 40 thermal cycles between $1773 \mathrm{~K}$ and room temperature proves that the $\mathrm{MoSi}_{2}-\mathrm{Si}_{3} \mathrm{~N}_{4} / \mathrm{SiC}$ coating has an excellent thermal cyclic oxidation resistance. The presence of $\mathrm{Si}_{3} \mathrm{~N}_{4}$ results in a complete transformation of $\mathrm{MoSi}_{2}$ to $\mathrm{SiO}_{2}$, which results in a dense glassy $\mathrm{SiO}_{2}$ film. The $\mathrm{SiO}_{2}$ film improves the coating's resistance to high-temperature oxidation by preventing gas diffusion into the coating, thus shielding the $\mathrm{C} / \mathrm{C}$ substrate from byproduct-forming gases and delaying the generation of micro cracks. The addition of $\mathrm{Si}_{3} \mathrm{~N}_{4}$ to the multi-layer coating is found to be beneficial for both coating integrity and coating-substrate compatibility.

Author Contributions: Conceptualization, I.A. and Y.W.; Methodology, I.A.; Software, H.E.; Validation, M.A.S., M.U., and I.A.; Formal analysis, F.Q.; Investigation, I.A.; Resources, M.A.S. and M.U.; Data curation, I.A., F.Q; Writing — original draft preparation, I.A., F.Q., and H.E.; Writing - review and editing, all co-authors; Visualization, I.A.; Supervision, Y.W.; Project administration, Y.W.; Funding acquisition, Y.W. All authors have read and agreed to the published version of the manuscript.

Funding: This work was supported by the National Natural Science Foundation of China (51573087) and the Natural Science Foundation in Shandong Province (ZR2014EZ001, ZR2011EMM002).

Acknowledgments: The authors acknowledge the support of the National Natural Science Foundation of China and the German Academic Exchange Service (DAAD). The authors also acknowledge the support of technical staff for assisting in preparing samples and analyzing them.

Conflicts of Interest: The authors do not have any conflict of interest.

\section{References}

1. Krenkel, W.; Berndt, F. C/C-SiC composites for space applications and advanced friction systems. Mater. Sci. Eng. A 2005, 412, 177-181. [CrossRef]

2. Katoh, Y.; Snead, L.L.; Henager, C.H., Jr.; Hasegawa, A.; Kohyama, A.; Riccardi, B.; Hegeman, H. Current status and critical issues for development of SiC composites for fusion applications. J. Nucl. Mater. 2007, 367, 659-671. [CrossRef] 
3. Kim, B.G.; Dong, S.; Park, S.D. Effects of thermal processing on thermal expansion coefficient of a 50 vol.\% SiCp/Al composite. Mater. Chem. Phys. 2001, 72, 42-47. [CrossRef]

4. Van der Berg, N.; Malherbe, J.B.; Botha, A.; Friedland, E. Thermal etching of SiC. Appl. Surf. Sci. 2012, 258, 5561-5566. [CrossRef]

5. Gasch, M.; Ellerby, D.; Irby, E.; Beckman, S.; Gusman, M.; Johnson, S. Processing, properties and arc jet oxidation of hafnium diboride/silicon carbide ultra high temperature ceramics. J. Mater. Sci. 2004, 39, 5925-5937. [CrossRef]

6. Kim, Y.-W.; Chun, Y.-S.; Nishimura, T.; Mitomo, M.; Lee, Y.-H. High-temperature strength of silicon carbide ceramics sintered with rare-earth oxide and aluminum nitride. Acta Mater. 2007, 55, 727-736. [CrossRef]

7. Fu, Q.-G.; Li, H.-J.; Shi, X.-H.; Li, K.-Z.; Sun, G.-D. Silicon carbide coating to protect carbon/carbon composites against oxidation. Scr. Mater. 2005, 52, 923-927. [CrossRef]

8. Zhang, Y.; Li, H.; Qiang, X.; Li, K. Oxidation protective C/SiC/Si-SiC multilayer coating for carbon/carbon composites applying at 1873 K. J. Mater. Sci. Technol. 2010, 26, 1139-1142. [CrossRef]

9. Chu, Y.; Li, H.; Fu, Q.; Wang, H.; Hou, X.; Zou, X.; Shang, G. Oxidation protection of C/C composites with a multilayer coating of $\mathrm{SiC}$ and $\mathrm{Si}+\mathrm{SiC}+\mathrm{SiC}$ nanowires. Carbon 2012, 50, 1280-1288. [CrossRef]

10. Tian, X.; Guo, X.; Sun, Z.; Qu, J.; Wang, L. Oxidation resistance comparison of $\mathrm{MoSi}_{2}$ and B-modified $\mathrm{MoSi}_{2}$ coatings on pure Mo prepared through pack cementation. Mater. Corros. 2015, 66, 681-687. [CrossRef]

11. Zhang, Y.-L.; Li, H.-J.; Qiang, X.-F.; Li, K.-Z.; Zhang, S.-Y.C/SiC/MoSi 2 -Si multilayer coatings for carbon/carbon composites for protection against oxidation. Corros. Sci. 2011, 53, 3840-3844. [CrossRef]

12. Fu, Q.; Shan, Y.; Cao, C.; Li, H.; Li, K. Oxidation and erosion resistant property of $\mathrm{SiC} / \mathrm{Si}-\mathrm{Mo}-\mathrm{Cr} / \mathrm{MoSi}{ }_{2}$ multi-layer coated C/C composites. Ceram. Int. 2015, 41, 4101-4107. [CrossRef]

13. Feng, T.; Li, H.-J.; Fu, Q.-G.; Shen, X.-T.; Wu, H. Microstructure and oxidation of multi-layer $\mathrm{MoSi}_{2}-\mathrm{CrSi}_{2}-\mathrm{Si}$ coatings for $\mathrm{SiC}$ coated carbon/carbon composites. Corros. Sci. 2010, 52, 3011-3017. [CrossRef]

14. Friedrich, C.; Gadow, R.; Speicher, M. Protective multilayer coatings for carbon-carbon composites. Surf. Coat. Technol. 2002, 151, 405-411. [CrossRef]

15. Wu, H.; Li, H.-J.; Ma, C.; Fu, Q.-G.; Wang, Y.-J.; Wei, J.-f.; Tao, J. MoSi 2 -based oxidation protective coatings for $\mathrm{SiC}$-coated carbon/carbon composites prepared by supersonic plasma spraying. J. Eur. Ceram. Soc. 2010, 30, 3267-3270. [CrossRef]

16. Shi, X.; Wang, C.; Lin, H.; Huo, C.; Jin, X.; Shi, G.; Dong, K. Oxidation resistance of a La-Mo-Si-O-C coating prepared by supersonic atmosphere plasma spraying on the surface of SiC-coated C/C composites. Surf. Coat. Technol. 2016, 300, 10-18. [CrossRef]

17. Li, H.-J.; Xue, H.; Wang, Y.-J.; Fu, Q.-G.; Yao, D.-J. A MoSi ${ }_{2}-\mathrm{SiC}-\mathrm{Si}$ oxidation protective coating for carbon/carbon composites. Surf. Coat. Technol. 2007, 201, 9444-9447. [CrossRef]

18. Fu, Q.; Zou, X.; Chu, Y.; Li, H.; Zou, J.; Gu, C. A multilayer MoSi ${ }_{2}-\mathrm{SiC}-\mathrm{B}$ coating to protect SiC-coated carbon/carbon composites against oxidation. Vacuum 2012, 86, 1960-1963. [CrossRef]

19. Feng, T.; Li, H.; Shi, X.; Yang, X.; Wang, S.; He, Z. Multi-layer CVD-SiC/MoSi $2-\mathrm{CrSi}_{2}-\mathrm{Si} / \mathrm{B}-$ modified SiC oxidation protective coating for carbon/carbon composites. Vacuum 2013, 96, 52-58. [CrossRef]

20. Zhang, H.; Lv, J.; Zhuang, S.; Chen, Y.; Gu, S. Effect of $\mathrm{WSi}_{2}$ and $\mathrm{Si}_{3} \mathrm{~N}_{4}$ contents on the thermal expansion behaviors of (Mo, W) $\mathrm{Si}_{2}-\mathrm{Si}_{3} \mathrm{~N}_{4}$ composites. Ceram. Int. 2017, 43, 2847-2852. [CrossRef]

21. Li, L.; Li, H.; Shen, Q.; Lin, H.; Feng, T.; Yao, X.; Fu, Q. Oxidation behavior and microstructure evolution of $\mathrm{SiC}-\mathrm{ZrB}_{2}-\mathrm{ZrC}$ coating for C/C composites at $1673 \mathrm{~K}$. Ceram. Int. 2016, 42, 13041-13046. [CrossRef]

22. He, Z.; Li, H.; Shi, X.; Fu, Q.; Wu, H. Microstructure and oxidation resistance of SiC-MoSi 2 multi-phase coating for SiC coated C/C composites. Prog. Nat. Sci. Mater. Int. 2014, 24, 247-252. [CrossRef]

23. Huang, Y.; Lin, J.; Zhang, $\mathrm{H}$. Effect of $\mathrm{Si}_{3} \mathrm{~N}_{4}$ content on microstructures and antioxidant properties of $\mathrm{MoSi}_{2} / \mathrm{Si}_{3} \mathrm{~N}_{4}$ composite coatings on Mo substrate. Ceram. Int. 2015, 41, 13903-13907. [CrossRef]

24. Hu, M.; Li, K.; Wang, J. Effect of $\mathrm{Cr}$ content on the microstructure and thermal properties of $\mathrm{ZrSi}_{2}-\mathrm{CrSi}_{2}-\mathrm{SiC}$ multiphase coating for the SiC coated C/C composites. Ceram. Int. 2016, 42, 19357-19364. [CrossRef]

25. Srivastava, A.; Tripathi, P.; Nayak, M.; Lodha, G.; Nandedkar, R. Formation of $\mathrm{Mo}_{5} \mathrm{Si}_{3}$ phase in Mo/Si multilayers. J. Appl. Phys. 2002, 92, 5119-5126. [CrossRef]

26. Fabrizi, A.; Cecchini, R.; Kiryukhantsev-Korneev, P.V.; Sheveyko, A.N.; Spigarelli, S.; Cabibbo, M. Comparative investigation of oxidation resistance and thermal stability of nano-structured Ti-B-N and Ti-Si-B-N coatings. J. Prot. Met. Phys. Chem. Surf. 2017, 53, 452-459. [CrossRef] 
27. Jianhui, Y.; Hongmei, X.U.; Houan, Z.; Siwen, T. MoSi 2 oxidation resistance coatings for $\mathrm{Mo}_{5} \mathrm{Si}_{3} / \mathrm{MoSi}_{2}$ composites. Rare Met. 2009, 28, 418-422.

28. Fu, Q.-G.; Jing, J.-Y.; Tan, B.-Y.; Yuan, R.-M.; Zhuang, L.; Li, L. Nanowire-toughened transition layer to improve the oxidation resistance of $\mathrm{SiC}-\mathrm{MoSi}_{2}-\mathrm{ZrB}_{2}$ coating for C/C composites. Corros. Sci. 2016, 111, 259-266. [CrossRef]

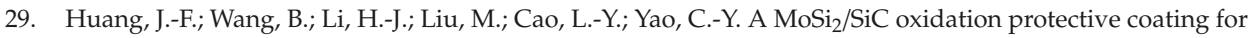
carbon/carbon composites. Corros. Sci. 2011, 53, 834-839. [CrossRef]

30. Iizuka, T.; Kita, H. Tribological behavior of $\mathrm{Mo}_{5} \mathrm{Si}_{3}$ particle reinforced $\mathrm{Si}_{3} \mathrm{~N}_{4}$ matrix composites. Wear 2005, 258, 877-889. [CrossRef]

31. Zhang, J.; Fu, Q.; Qu, J. Enhanced bonding strength and thermal cycling performance of $\mathrm{MoSi}_{2}-\mathrm{CrSi}_{2}-\mathrm{SiC}_{-} \mathrm{Si}$ coating for carbon/carbon composites by surface modification via blasting treatment. Ceram. Int. 2016, 42, 14021-14027. [CrossRef]

32. Yoon, J.-K.; Lee, K.-H.; Kim, G.-H.; Han, J.-H.; Doh, J.-M.; Hong, K.-T. Low-temperature cyclic oxidation behavior of $\mathrm{MoSi}_{2} / \mathrm{SiC}$ nanocomposite coating formed on Mo substrate. Mater. Trans. 2004, 45, 2435-2442. [CrossRef]

33. De la Pena, J.; Pech-Canul, M. Microstructure and kinetics of formation of $\mathrm{Si}_{2} \mathrm{~N}_{2} \mathrm{O}$ and $\mathrm{Si}_{3} \mathrm{~N}_{4}$ into $\mathrm{Si}$ porous preforms by chemical vapor infiltration (CVI). Ceram. Int. 2007, 33, 1349-1356. [CrossRef]

34. ZhongLiu, W.; Peng, X.; Zhuan, L.; XiaoYu, Y.; Yang, L. Thermal cycling behavior and oxidation resistance of $\mathrm{SiC}$ whisker-toughened-mullite/SiC coated carbon/carbon composites in burner rig tests. Corros. Sci. 2016, 106, 179-187. [CrossRef]

35. Lai, Z.; Meng, S.; Zhu, J.; Jeon, J. Microstructure of a Mo-Si-CN multi-layered anti-oxidation coating on carbon/carbon composites by fused slurry. Rare Met. 2009, 28, 460-464. [CrossRef]

(C) 2020 by the authors. Licensee MDPI, Basel, Switzerland. This article is an open access article distributed under the terms and conditions of the Creative Commons Attribution (CC BY) license (http://creativecommons.org/licenses/by/4.0/). 


\title{
Article \\ Effects of Pulp Fiber and Epoxidized Tung Oil Content on the Properties of Biocomposites Based on Polylactic Acid
}

\author{
Van Khoi Nguyen *, Thanh Tung Nguyen *, Thu Ha Pham Thi and Thu Trang Pham \\ Institute of Chemistry, VAST, 18 Hoang Quoc Viet, Cau Giay, Ha Noi 122300, Vietnam; \\ haptt6@gmail.com (T.H.P.T.); thutrang90vhh@gmail.com (T.T.P.) \\ * Correspondence: khoinguyen56@gmail.com (V.K.N.); nttung@ich.vast.vn (T.T.N.); \\ Tel.: +84-904141011 (V.K.N.); +84-901333885 (T.T.N.)
}

Received: 13 April 2020; Accepted: 15 May 2020; Published: 19 May 2020

\begin{abstract}
Recently, various environmental-friendly materials have been investigated and developed, especially composites of polylactic acid (PLA) and plant fibers. This paper investigates the effects of pulp fiber (PF) and epoxidized Tung oil (ETO) content on the properties of biocomposites, based on polylactic acid. The bleached pulp fiber reinforced PLA (PLA/PF) composites with 10-50 wt $\%$ fiber contents and $0-15 \%$ epoxidized Tung oil contents (with a certain number of fiber) were prepared in an internal mixer (Plastograph ${ }^{\circledR} \mathrm{EC}$ ) at $150{ }^{\circ} \mathrm{C}$. The mechanical properties of PLA/PF composites were improved significantly. The pulp fiber reinforced PLA composites, with the fiber content of $30 \mathrm{wt} \%$, were found to have the highest mechanical properties. The tensile and flexural properties of PLA/Tung oil-soaked-pulp fiber composites were higher than those of PLA/Tung oil unsoaked pulp fiber composites. In addition, the degradation temperature of PLA-based composites decreased after adding more pulp fiber. The pulp fibers were well-dispersed in the PLA matrix with the content up to $30 \mathrm{wt} \%$. The interaction between pulp fiber and PLA matrix improved by the addition of epoxidized Tung oil. Epoxidized Tung oil also improved tensile and flexural strength of composite materials when it was added with a number of below $10 \%$ of fiber.
\end{abstract}

Keywords: poly (lactic acid); pulp fiber; natural fiber reinforced composites; epoxidized Tung oil

\section{Introduction}

Over the last few decades, the natural fiber, reinforced polymer composites, have rapidly grown and are now widely used in the academic and industrial applications due to the advantages of natural fibers, such as low density, lightweight, renewability, high specific strength, enhanced energy recovery, good thermal properties, non-toxicity, low cost and biodegradability [1]. The natural fiber reinforced composites are used in various applications, such as transportation, building and construction materials, packaging, consumer products, etc. due to their environmentally-friendly properties [2]. Natural fibers, which are commonly used as reinforcement for polymer composites, include abaca, jute, kenaf, coir, cotton, bamboo, flax, hemp, ramie, sisal, banana, etc. [3,4]. Despite the advantages, natural fibers, used as reinforcement agents, also have some disadvantages, such as high moisture absorbtion, poor wettability, and incompatibility with polymeric matrices [1]. Recently, chemical treatment methods have been used to improve the compatibility between natural fibers and polymer matrix, such as alkaline treatment, coupling agents (silanes, acetylation, graft copolymerization), bleaching, enzyme, etc. This increases the interaction between fibers and polymer matrix, as well as improves the mechanical properties of the composites.

One of the most widely investigated polymers to replace petroleum-based polymers is PLA because of its favorable properties, namely good mechanical properties, biocompatibility, biodegradability, 
and especially the use of the same technological equipment as what used for conventional fiber reinforced composite materials. In addition, PLA can be made from renewable resources, for example, maize, sugarbeet, rice, etc. In the recent years, many studies concentrate on the performance of PLA with different natural fibers, such as flax fiber [5-7], jute [8,9], kenaf [10-12], abaca fiber [13] and hemp [14]. Pulp fibers are also a good option for reinforcement composites because of their availability, uniform quality and cheaper price than agro fibers. Zhaozhe Y. et al. found that the tensile and flexural modulus of the PLA composites with wood fiber and pulp fiber were greater than those of pure PLA, and pulp fiber improved the properties of the composites better than wood fiber [15]. Kirsi Immoen et al. fabricated PLA composite with softwwood kraft pulp using epoxidized linseed oil (ELO) as a plasticizer and a platicizer-coupling agent. The results showed that ELO improved, not only the interaction between pulp fiber and PLA, but also the tensile strength of composites by using at 5-8\% content of ELO [16]. Heidi Peltola et al. found that epoxidized linseed oil, not only promotes the adhesion of PLA wood pulp, but also reduces fiber loss during melting processing [17]. Research also showed that unbleached fibers had a stronger reinforcement effect than bleached fibers.

However, hydrophilic cellulose fibers are difficult to disperse equally and to interact with the PLA matrix. A commonly used method to increase the interaction between fiber and polymer is adding plasticizers, especially vegetable oil-based plasticizers because of its availability, biodegradability, and low cost. Among vegetable oils, Tung oil is widely used in the industry, especially in the field of paints and plastics due to its high heat resistance, water resistance and salinity tolerance. Moreover, as one of oil with the highest iodine index [18], Tung oil promises good results when used as a plasticizer for PLA/pulp fiber composites. The aim of this study is to study the effects of pulp fiber and epoxidized Tung oil content on the properties of biocomposites, based on polylactic acid.

\section{Materials and Methods}

\subsection{Materials}

Poly (lactic acid) (PLA) resin produced by SMBEST Pvt. Ltd. (Busan, Korea) was used as the matrix material. Its density was $1.2-1.31 \mathrm{~g} / \mathrm{cm}^{3}$, and its melt flow index (MFI) was below $5 \mathrm{~g} / 10 \mathrm{~min}$ at $5 \mathrm{~kg} / 190^{\circ} \mathrm{C}$. In terms of the reinforcement materials, bleached pulp fibers were initially supplied by An Hoa Paper Joint Stock Company (Tuyen Quang, Viet Nam) then cut to the size of 3-4 mm. The properties of bleached pulp fibers were listed in Table 1.

Table 1. The properties of bleached pulp fibers.

\begin{tabular}{cc}
\hline Properties & Value \\
\hline$\alpha$-cellulose, $\%$ & $96.7 \pm 0.5$ \\
\hline Lignin, $\%$ & $0.27 \pm 0.08$ \\
\hline Viscosity, $\mathrm{ml} / \mathrm{g}$ & 655 \\
\hline Ash, $\%$ & $0.28 \pm 0.05$ \\
\hline
\end{tabular}

Tung oil was supplied by Vietnam Tung oil company limited (Ha Noi, Viet Nam). The properties of Tung oil were listed in Table 2. Amberlite ${ }^{\circledR}$ IRC120 H, hydrogen form $15 \mathrm{wt} \%$ to oil (Sigma), $\mathrm{H}_{2} \mathrm{O}_{2}$ (Sigma) and acetic acid (Sigma) were used to modified Tung oil. 
Table 2. The properties of Tung oil.

\begin{tabular}{cc}
\hline Properties & Value \\
\hline Density $\left(\right.$ at $\left.20{ }^{\circ} \mathrm{C}\right)$ & $0.920-0.945$ \\
\hline Acid value & 1.4 \\
\hline Iodine value & $149.5-170.6$ \\
\hline Saponification value & $193.4-196.7$ \\
\hline
\end{tabular}

To prepare epoxidized Tung oil, Tung oil was stirred in a flask and heated to $55^{\circ} \mathrm{C}$ in the presence of Amberlite ${ }^{\circledR}$ IRC120 Has the catalyst with a uniform agitation under the constant stirring speed of $1600 \mathrm{rpm}$. A mixture of $\mathrm{H}_{2} \mathrm{O}_{2}$ and acetic acid was dropwise added into the mixture of Tung oil and Amberlite ${ }^{\circledR}$ IRC120 at a constant rate for $2 \mathrm{~h}$. The reaction time was $5 \mathrm{~h}$ and the ratio of Tung oil/acid acetic $/ \mathrm{H}_{2} \mathrm{O}_{2}$ was 1.0/0.5/0.5. At the end of the reaction, the mixture was cooled and centrifuged at least $5 \mathrm{~min}$ under the rotation speed of $2000 \mathrm{rpm}$. The oil phase, separated from the aqueous phase and the catalyst, was washed with distilled water until acid free, and evaporated for at least $1 \mathrm{~h}$ under the vacuum of about $40 \mathrm{mbar}$ at $60^{\circ} \mathrm{C}$ [19]. Epoxy value was determined by titration method according to TY-6-10-722-72. Epoxy value of epoxidized Tung oil was $6.8 \%$.

\subsection{Composite Preparation}

The PLA resin and pulp fibers were dried at $80{ }^{\circ} \mathrm{C}$ for $5 \mathrm{~h}$ under vacuum. PLA/pulp fiber composites were manufactured according to two methods (Figure 1): (1) Pulp fiber (NPF), epoxidized Tung oil and PLA were mixed directly; (2) epoxidized Tung oil soaked pulp fibers (SPF) were mixed with PLA (Sce. To soak the pulp fibers with epoxidized Tung oil, epoxidized Tung oil was dissolved in methyl ethyl ketone (ratio of $1 / 20$ ) and sprayed onto the pulp. After that, the mixtures were dried in an oven at $80^{\circ} \mathrm{C}$ for $5 \mathrm{~h}$ for the reaction between Tung oil and pulp fiber to take place.

Method 1:

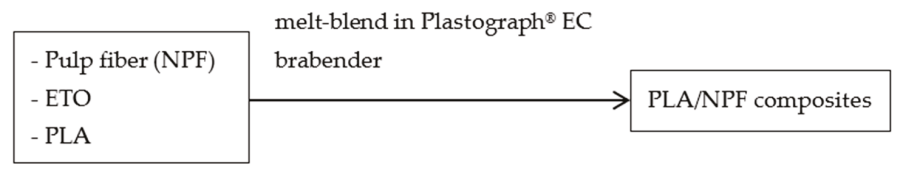

Method 2:

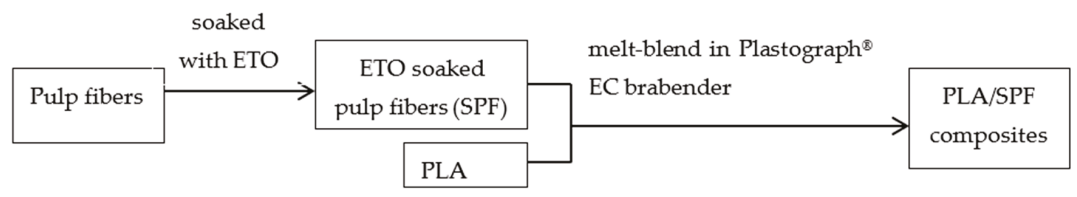

Figure 1. Two fabricating methods for Poly (lactic acid) (PLA)/pulp fiber (PF) composites.

The separated pulp fibers and epoxidized Tung oil or epoxidized Tung oil-soaked pulp fibers were melt-blended with PLA resin in an internal mixer model Plastograph ${ }^{\circledR}$ EC (Duisburg, Germany) at $150{ }^{\circ} \mathrm{C}$ with a rotor speed of $50 \mathrm{rpm}$ for $6 \mathrm{~min}$. The pulp fiber/PLA composites were compressed and moulded into 3-mm-thick plates on a GoTech hot press at $170{ }^{\circ} \mathrm{C}$ at a pressure of 50 psi for 5 min. Moulded samples were cut into specimens according to ASTM D638 and ISO 178 to determine tensile properties and flexural properties respectively. To study the effect of pulp fiber contents on the properties of composite, the pulp fibers were adding into PLA with different fiber contents $(0 \%, 10 \%$, $20 \%, 30 \%, 40 \%$ and $50 \%$ ) in the presence of epoxidized Tung oil (in amount of $10 \%$ of fiber). To study the effect of pulp fiber contents on the properties of composite, the used epoxidized Tung oil contents were $0 \%, 5 \%, 7.5 \%, 10 \%, 15 \%$, respectively. 


\subsection{Characterization of Composites}

\subsubsection{Mechanical Properties}

Tensile test was determined by ASTM D638 at a crosshead speed of $50 \mathrm{~mm} / \mathrm{min}$ by using Instron 5980 Testing Machine (Illinois Tool Works Inc., Norwood, MA, USA). Flexural test was carried out on Instron 3382 (American) according to ISO 187. All the test samples were stabilized at a room temperature for $24 \mathrm{~h}$ before testing. An average value of five tests was reported.

\subsubsection{Scanning Electron Microscope (SEM)}

The fracture surface morphology of the pulp fiber reinforced PLA composites was investigated by using a scanning electron microscope SEM (JEOL 6490, Tokyo, Japan) at $15 \mathrm{kV}$. The fracture surface of the samples was coated with platinum before examination.

\subsubsection{Fourier Transfer Infrared Spectra (FTIR)}

The IR spectra of composites was analysed with a Fourier transform infra-red (FTIR) spectrometer (Nicolet Impact model 410, Nicolet, Madison, WI, USA). The equipment was operated with a resolution of $4 \mathrm{~cm}^{-1}$ and scanning range from 4000 to $500 \mathrm{~cm}^{-1}$.

\subsubsection{Thermogravimetry Analysis (TGA)}

Thermogravimetry analysis was carried out at $10^{\circ} \mathrm{C} / \mathrm{min}$ heating rate in the air, from room temperature to $550{ }^{\circ} \mathrm{C}$ on a thermogravimetry analysis system TGA209F1 (Netzch, Selb, Germany).

\subsubsection{Differential Scanning Calorimetry (DSC)}

Differential scanning calorimetry analysis was conducted using NETZSCH DSC 204F1 Phoneix (Netzsch, Selb, Germany). The sample was heated at a rate of $10^{\circ} \mathrm{C} / \mathrm{min}$ from rt to $200{ }^{\circ} \mathrm{C}$, followed by cooling at $10^{\circ} \mathrm{C} / \mathrm{min}$ to $\mathrm{rt}$.

\section{Results and Discussions}

\subsection{Effect of Pulp Fiber Contents}

\subsubsection{Mechanical Properties of Composites}

In this study, the samples were prepared with different pulp fiber contents (ranging from $0 \%$ to $50 \%$ ), and the epoxidized Tung oil was fixed at 10\% of fiber. The mechanical properties of neat PLA and PLA/PF composites were presented in Table 3.

Table 3. Effect of pulp fiber contents on the mechanical properties of PLA/PF composites.

\begin{tabular}{ccccccc}
\hline $\begin{array}{c}\text { Composite } \\
\text { Fabrication } \\
\text { Method }\end{array}$ & $\begin{array}{c}\text { Pulp Fiber } \\
\text { Contents } \\
\mathbf{( \% )}\end{array}$ & $\begin{array}{c}\text { Tensile } \\
\text { Strength } \\
\mathbf{( M P a )}\end{array}$ & $\begin{array}{c}\text { Tensile Modulus } \\
\mathbf{( M P a )}\end{array}$ & $\begin{array}{c}\text { Elongation } \\
\text { at Break (\%) }\end{array}$ & $\begin{array}{c}\text { Flexural } \\
\text { Strength } \\
\text { (MPa) }\end{array}$ & $\begin{array}{c}\text { Flexural } \\
\text { Modulus } \\
\mathbf{( G P a )}\end{array}$ \\
\hline & 0 & $40.67 \pm 1.87$ & $2187.64 \pm 95.37$ & $11.70 \pm 0.41$ & $95.0 \pm 4.65$ & $2.91 \pm 0.12$ \\
\hline & 10 & $45.74 \pm 2.03$ & $2209.94 \pm 86.22$ & $11.63 \pm 0.53$ & $101.2 \pm 4.91$ & $3.14 \pm 0.09$ \\
\cline { 2 - 7 } & 20 & $51.62 \pm 1.94$ & $2482.22 \pm 101.05$ & $5.11 \pm 0.30$ & $103.6 \pm 5.02$ & $3.86 \pm 0.23$ \\
\cline { 2 - 7 } Method 1 & 30 & $56.61 \pm 2.11$ & $2809.67 \pm 90.43$ & $5.24 \pm 0.28$ & $109.5 \pm 6.36$ & $4.54 \pm 0.17$ \\
\cline { 2 - 7 } & 40 & $52.84 \pm 1.21$ & $3060.97 \pm 98.12$ & $2.54 \pm 0.20$ & $104.9 \pm 4.23$ & $5.09 \pm 0.20$ \\
\cline { 2 - 7 } & 50 & $42.87 \pm 1.53$ & $3542.66 \pm 88.96$ & $2.14 \pm 0.23$ & $103.3 \pm 5.64$ & $5.93 \pm 0.34$ \\
\hline
\end{tabular}


Table 3. Cont.

\begin{tabular}{ccccccc}
\hline $\begin{array}{c}\text { Composite } \\
\text { Fabrication } \\
\text { Method }\end{array}$ & $\begin{array}{c}\text { Pulp Fiber } \\
\text { Contents } \\
(\%)\end{array}$ & $\begin{array}{c}\text { Tensile } \\
\text { Strength } \\
\mathbf{( M P a )}\end{array}$ & $\begin{array}{c}\text { Tensile Modulus } \\
\mathbf{( M P a )}\end{array}$ & $\begin{array}{c}\text { Elongation } \\
\text { at Break (\%) }\end{array}$ & $\begin{array}{c}\text { Flexural } \\
\text { Strength } \\
\text { (MPa) }\end{array}$ & $\begin{array}{c}\text { Flexural } \\
\text { Modulus } \\
(\mathbf{G P a})\end{array}$ \\
\hline & 10 & $46.34 \pm 2.24$ & $2316.46 \pm 102.68$ & $11.71 \pm 0.39$ & $102.2 \pm 6.15$ & $3.21 \pm 0.25$ \\
\cline { 2 - 7 } & 20 & $52.88 \pm 1.96$ & $2502.19 \pm 93.14$ & $5.26 \pm 0.25$ & $105.0 \pm 5.28$ & $4.02 \pm 0.29$ \\
\cline { 2 - 7 } Method 2 & 30 & $59.32 \pm 2.35$ & $3043.54 \pm 96.52$ & $5.13 \pm 0.31$ & $114.7 \pm 3.67$ & $4.97 \pm 0.18$ \\
\cline { 2 - 7 } & 40 & $55.45 \pm 2.41$ & $3390.27 \pm 99.45$ & $2.64 \pm 0.18$ & $108.8 \pm 4.82$ & $5.85 \pm 0.10$ \\
\hline & 50 & $50.28 \pm 2.07$ & $3751.38 \pm 92.47$ & $2.23 \pm 0.24$ & $106.5 \pm 5.26$ & $6.18 \pm 0.32$ \\
\hline
\end{tabular}

It can be seen that the tensile strength of neat PLA is lower than that of PLA/PF composites. The tensile strength of PLA/PF composites increased significantly by increasing the percentage of pulp fiber content up to $30 \mathrm{wt} \%$ and then decreased by further addition of pulp fiber. When the pulp fiber contents were from 10 to $30 \%$, the tensile strength of the composites increased from $45.74 \mathrm{MPa}$ to $56.61 \mathrm{MPa}$ (for PLA/NPF composites) and to 59.32 (for PLA/SPF composites). The increase of tensile modulus of PLA/PF composites was in proportion to the increase of pulp fiber content. These revealed that the addition of pulp fibers into PLA matrix provided effective reinforcement. This was because the stress was expected to transfer from the matrix to the strong fiber. Huda M. S. et al. suggested the better the alignment of the fibers, the higher the strength value [20]. However, when the pulp fiber was added to more than $30 \%$, the tensile properties of composite decreased. This might be due to the poor dispersion of fiber into the PLA matrix at higher pulp content. This result was consistent with the results of Jin Qian et al. for-cotton fiber/PLA composites [21]. However, Zhaozhe Yang et al. found that the tensile strength of both PLA/pulp fiber and PLA/wood fiber composites decreased with the increase of fiber content [15]. The results also showed that the tensile strength and modulus of composites, with untreated or soaked pulp fibers, were not significantly different with a fiber content of less than $30 \%$, but those of composites, containing soaked pulp fibers, were higher than those of composites containing untreated pulp fibers. This might be due to the fact that epoxidized Tung oil-treated pulp fibers were more evenly dispersed in PLA matrix, and Tung oil improved the interaction between PLA matrix and pulp fiber. The chemical interaction mechanism among epoxidized vegetable oil, PLA and natural fiber was proposed by Buong Woei Chieng et al. [22] (Figure 2) and Omid Nabinejad et al. [23] (Figure 3).

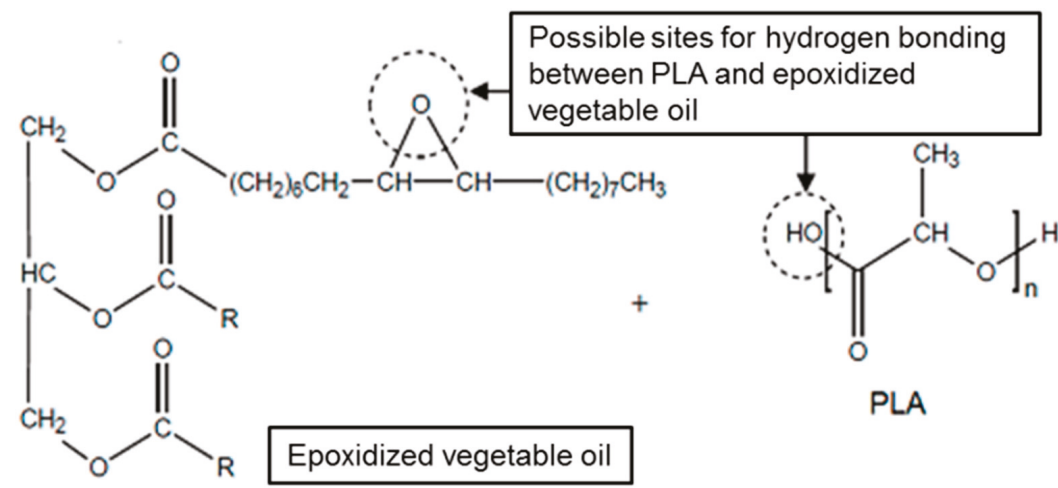

Figure 2. Suggested chemical interactions between epoxidized vegetable oil and PLA by Buong Woei Chieng et al. [22]. 


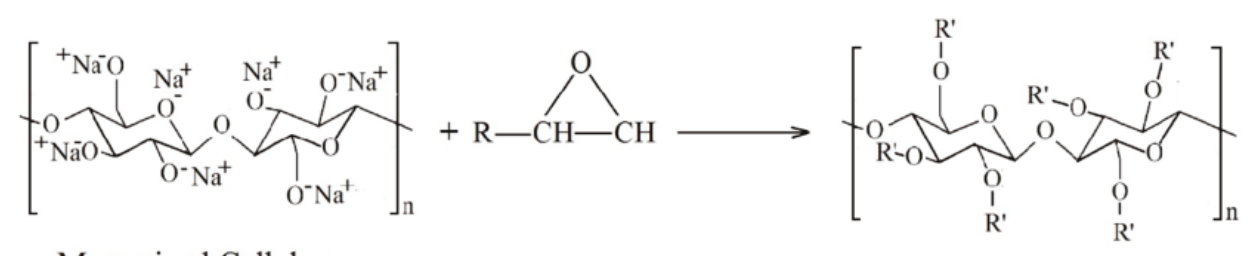

Mercerized Cellulose

Where $\mathrm{R}^{\prime}$ is $\begin{gathered}\mathrm{H} \\ \begin{array}{l}1 \\ -\mathrm{C} \\ -1\end{array}-\mathrm{C} \\ \mathrm{H}\end{gathered}$

Figure 3. Suggested chemical interactions between epoxidized vegetable oil and mercerized natural fiber by Omid Nabinejad et al. [23].

Elongation at the break of the PLA/PF composites was also tested and shown in Table 3. The elongation at break of composites decreased as the fiber content in the composites increased.

According to the results, the flexural modulus of the composites increased significantly by increasing the pulp fiber content, while the flexural strength of the composite had non-significant change. However, both the flexural strength and flexural modulus of the composites were higher than that of the neat PLA. This could be explained that the addition of pulp fiber promoted the nucleation and crystallization of PLA matrix, so that the flexural modulus of the composites improved. This indicated that the pulp fiber acted as a rigid filler, which increased the stiffness of the composites. Similarly to the tensile properties, the flexural strength and modulus of PLA/SPF composites were slightly higher than that of PLA/NPF composites. When the content of pulp fiber was $30 \%$, the flexural strength of PLA/NPF and PLA/SPF composites reached 109.5 and 114.7 Mpa respectively, which increased by $15.3 \%$ and $20.7 \%$ compared with the pure PLA. This result was consistent with the results of Buket Okutan Baba and Ugur Özmen for chicken feather/PLA composites [24].

\subsubsection{Morphology Observation}

Figure 4 showed the fractured surfaces morphologies of PLA/NPF composites. As can be seen in Figure 4, there was a difference in the adhesion between NPF fiber and PLA matrix. At the lower fiber content, the voids between PLA matrix and NPF fiber were invisible. The composite containing $30 \%$ of pulp fiber began to show voids between PLA matrix and NPF fiber. When the fiber content exceeded $30 \%$, the fiber breakages and the voids can be observed more clearly. The NPF fibers were pulled out from the PLA matrix, and the surface of PF fiber was not wrapped by PLA matrix. This suggested a poor adhesion between NPF fiber and PLA matrix.

Figure 5 showed that when treating pulp fiber with epoxidized Tung oil, the bonds between fibers and the PLA improved more significantly, compared to the untreated fibers. Even at $10 \%$ of fiber content, it was difficult to distinguish pulp fibers and PLA because the pulp fibers was covered by PLA. At 40 and $50 \%$ of fiber content, the gaps and holes between the SPF and PLA matrix can be observed. 


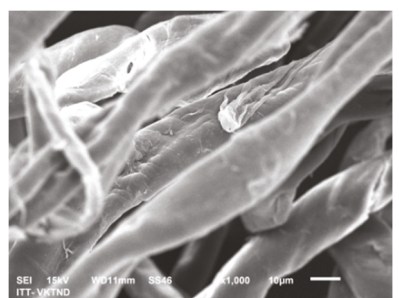

Pulp fiber

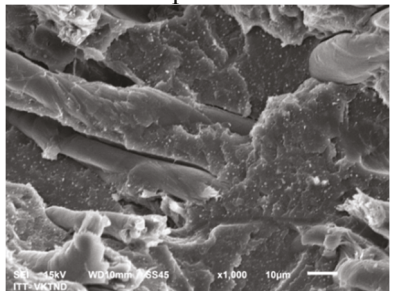

$20 \% \mathrm{NPF}$

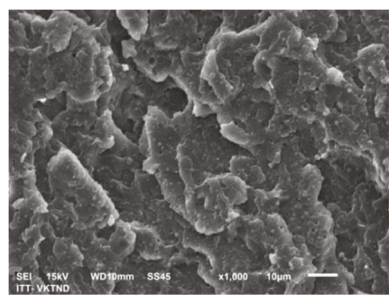

Neat PLA

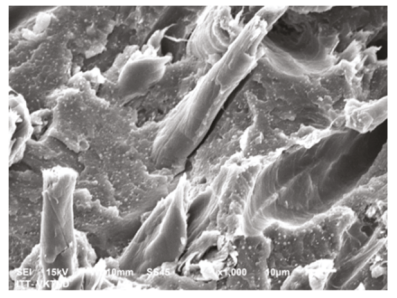

$30 \%$ NPF

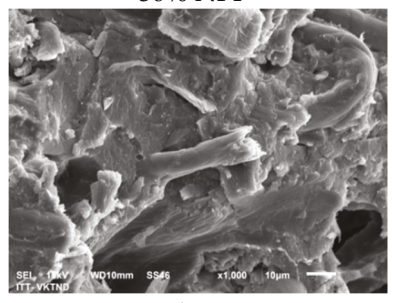

$50 \%$ NPF

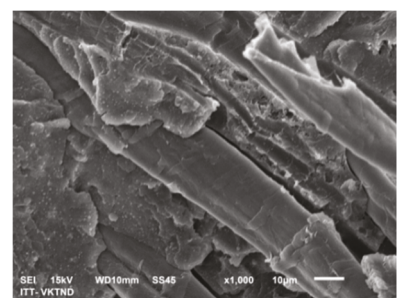

$10 \% \mathrm{NPF}$

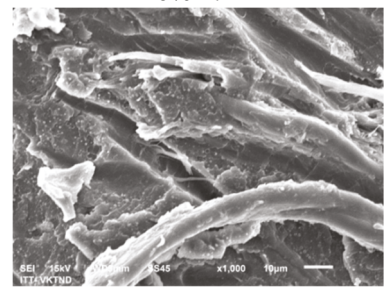

$40 \% \mathrm{NPF}$

Figure 4. SEM images of fractured surface of PLA/NPF composites with different NPF contents.

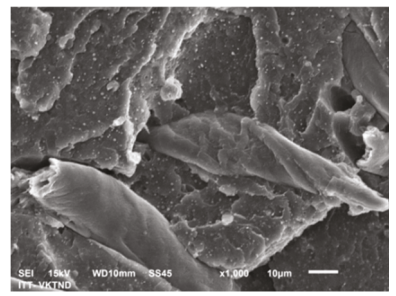

$10 \% \mathrm{SPF}$

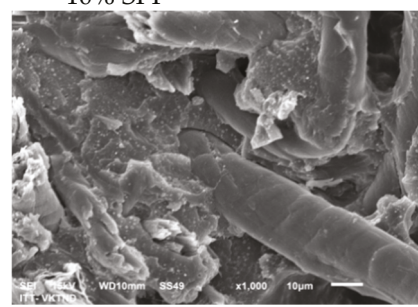

$40 \% \mathrm{SPF}$

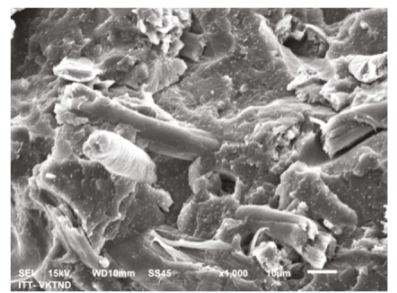

$20 \% \mathrm{SPF}$

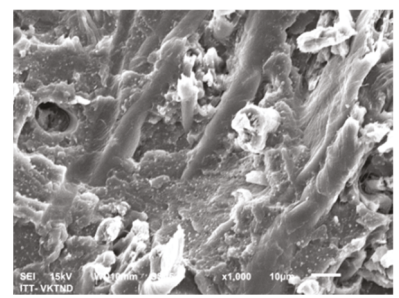

$30 \% \mathrm{SPF}$

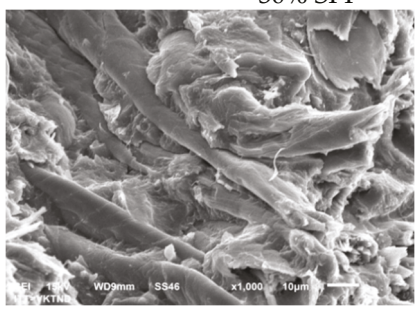

$50 \%$ SPF

Figure 5. SEM images of fractured surface of PLA/SPF composites with different SPF contents.

3.1.3. Fourier Transfer Infrared Spectra

The FTIR spectra of pulp fiber, ETO, PLA, PLA/SPF composites with 10, 30 and 50\% SPF were presented in Figure 6. 


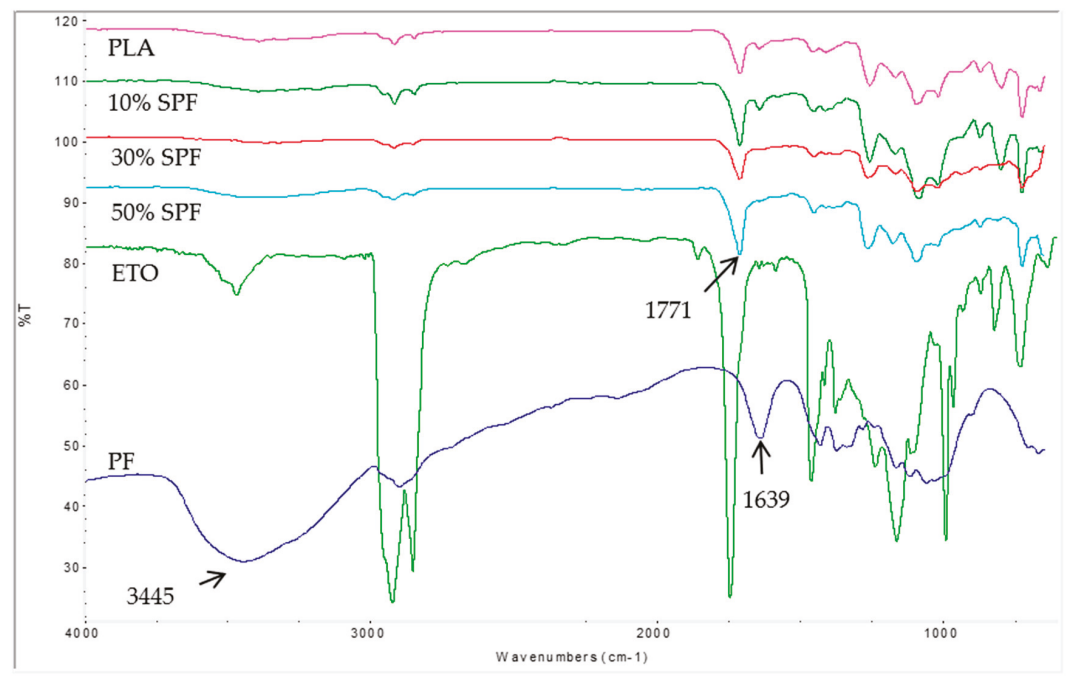

Figure 6. The FTIR spectra of pulp fiber, ETO, PLA, PLA/SPF composites with $10 \%$ SPF, 30 SPF and $50 \%$ SPF.

In IR spectrum of ETO, the peak at $1642 \mathrm{~cm}^{-1}$ which was assigned for $\mathrm{C}=\mathrm{C}$ disappeared. Instead there was appearance of a peak at $824 \mathrm{~cm}^{-1}$ which was assigned for C-O in epoxy ring [25]. This indicated that epoxidation of Tung oil had occurred. The IR spectrum of the pulp fiber appeared as a peak at $3445 \mathrm{~cm}^{-1}$, which was assigned for $\mathrm{O}-\mathrm{H}$ stretching vibration. This peak of PLA/SPF composites increased by increasing SPF content. A peak at $1771 \mathrm{~cm}^{-1}$, which was assigned for $\mathrm{C}=\mathrm{O}$ group in PLA and ETO [16], also increased by increasing SPF content. This might be due to the increase of SPF content means that the ETO content in the composite also increased, so the concentration of $\mathrm{C}=\mathrm{O}$ group increased.

\subsubsection{Differential Scanning Calorimetry}

The thermal properties of the composites with different SPF fiber contents were investigated by Differential Scanning Calorimetry (DSC). The DSC results for PLA, PLA/SPF composite were listed in Table 4.

Table 4. Differential Scanning Calorimetry (DSC) results of PLA/SPF composites.

\begin{tabular}{cccc}
\hline Soaked Pulp Fiber Contents $(\%)$ & $\mathrm{T}_{\mathrm{g}}\left({ }^{\circ} \mathrm{C}\right)$ & $\mathrm{T}_{\mathrm{m}}\left({ }^{\circ} \mathrm{C}\right)$ & $\mathrm{T}_{\mathrm{c}}\left({ }^{\circ} \mathrm{C}\right)$ \\
\hline 0 & 56.2 & 148.1 & 86.4 \\
\hline 10 & 56.2 & 147.7 & 88.8 \\
\hline 20 & 54.8 & 146.5 & - \\
\hline 30 & 55.0 & 146.8 & - \\
\hline 40 & 53.5 & 146.9 & - \\
\hline 50 & 50.6 & 150.3 & - \\
\hline
\end{tabular}

The results showed that when the fiber content was 10-30\%, the glass transition $\left(\mathrm{T}_{\mathrm{g}}\right)$ temperature of PLA in the composite was almost insignificantly as compared to that of neat PLA. This indicated that there was no restriction on the mobility of the PLA chains when adding pulp fiber. Espinach et al. [26] also observed the same phenomenon when adding $20-25 \%$ of bleached kraft soft wood 
to PLA matrix. However, when the fiber content exceeded 30\%, the glass transition temperature of composites decreased.

The melting temperature ( $\mathrm{T}_{\mathrm{m}}$ ) of PLA in the composite, containing $10 \%$ fiber, was quite similar to that of neat PLA, but the crystallization temperature $\left(\mathrm{T}_{\mathrm{C}}\right)$ increased slightly. Meanwhile, at the fiber content of $20-50 \%$, the melting temperature of PLA decreased, compared to the composite, containing $10 \%$ of fiber and had no differences among samples. In addition, the crystallization temperature of these samples was not observed, and this change in crystallinity reduced the melting temperature of the composites.

\subsubsection{Thermogravimetry Analysis}

The thermal stability of PLA/SPF composites was investigated by thermogravimetry analysis method, and the results are shown in Figure 7. Data analysis from the thermal analysis curves of these composites was listed in Table 5.

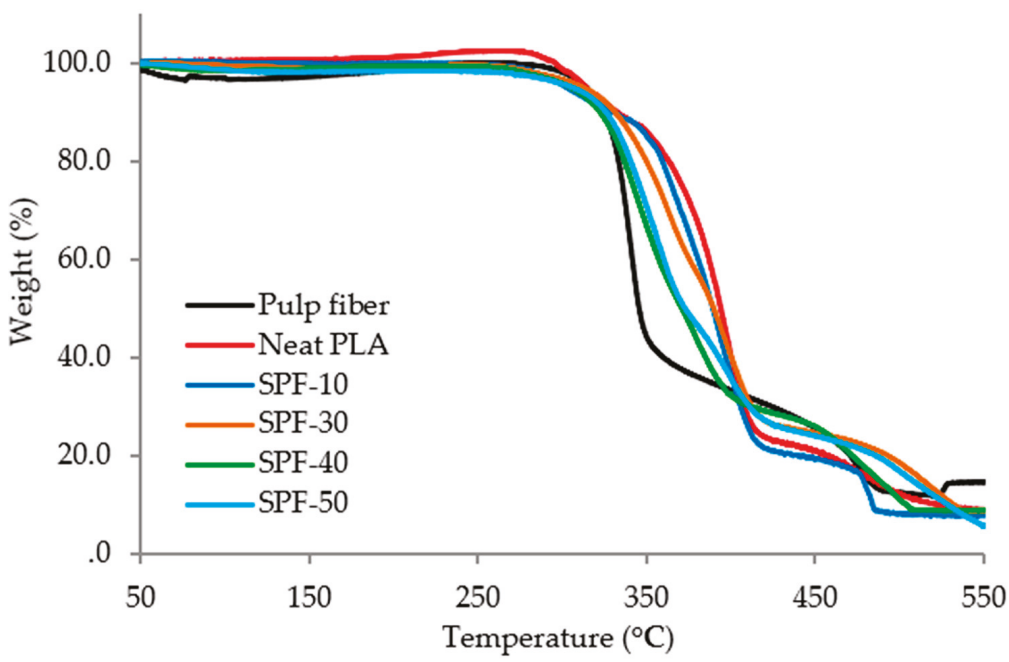

Figure 7. TGA curves of pulp fiber, PLA and PLA/SPF composites.

Table 5. Thermal analysis value of PLA and PLA/SPF composites.

\begin{tabular}{ccccc}
\hline Soaked Pulp Fiber Contents $(\%)$ & $\mathrm{T}_{\mathbf{5}}\left({ }^{\circ} \mathbf{C}\right)$ & $\mathrm{T}_{\mathbf{2 5}}\left({ }^{\circ} \mathbf{C}\right)$ & $\mathrm{T}_{\mathbf{5 0}}\left({ }^{\circ} \mathbf{C}\right)$ & Weight Loss at $\mathbf{4 5 0}{ }^{\circ} \mathbf{C}(\%)$ \\
\hline SPF & 314.6 & 335.9 & 346.3 & 74.37 \\
\hline 0 & 313.9 & 371.2 & 394.0 & 78.98 \\
\hline 10 & 302.8 & 365.0 & 389.3 & 80.61 \\
\hline 20 & 310.5 & 360.9 & 393.2 & 77.29 \\
\hline 30 & 312.7 & 356.9 & 390.0 & 75.39 \\
\hline 40 & 305.1 & 342.0 & 370.8 & 74.02 \\
\hline 50 & 306.1 & 346.0 & 372.9 & 79.68 \\
\hline
\end{tabular}

The pulp fiber decomposition process can be divided into 3 stages. The first stage was the process of losing moisture at about $100{ }^{\circ} \mathrm{C}$ with about a $3 \%$ of weight loss. The second stage takes place at about $280-410^{\circ} \mathrm{C}$ with a mass loss of $63.6 \%$. This weight-loss stage was due to the decomposition of the main components of the fibers which took place mainly in amorphous regions [27]. This stage can be the polymerization of hemicellulose [28] and the random cleavage of glycoside bonds in cellulose [29]. 
The results showed that TGA curves of PLA/SPF composites exhibited multiple steps. The decomposition stage takes place at about $300-410{ }^{\circ} \mathrm{C}$ due to the decomposition of the PLA polymer chains and the main components of pulp fibers. The stage at $410-480{ }^{\circ} \mathrm{C}$ is due to carbon burning. The results in Table 5 also indicated that the degradation temperature of composites was lower than that of neat PLA. The degradation temperature of PLA-based composites decreased by increasing the SPF fiber content. It might be due to the degradation temperature of SPF fiber was lower than that of neat PLA.

\subsection{Effect of Epoxidized Tung Oil Contents}

\subsubsection{Mechanical Properties of Composites}

In this study, the sample was prepared according to method 2 with different epoxidized Tung oil contents $(0-15 \%)$, but the ratio of PLA/pulp fiber was fixed at 70/30. Physical properties such as tensile strength, flexural strength of PLA/SPF composites were measured to evaluated effect of epoxidized Tung oil. Results of the mechanical tests were presented in Table 6.

Table 6. Mechanical properties of PLA/SPF composites with different percentages of epoxidized Tung oil.

\begin{tabular}{cccccc}
\hline $\begin{array}{c}\text { Epoxidized Tung Oil } \\
\text { Contents (\%) }\end{array}$ & $\begin{array}{c}\text { Tensile } \\
\text { Strength } \\
\mathbf{( M P a )}\end{array}$ & $\begin{array}{c}\text { Tensile Modulus } \\
\mathbf{( M P a )}\end{array}$ & $\begin{array}{c}\text { Elongation at } \\
\text { Break (\%) }\end{array}$ & $\begin{array}{c}\text { Flexural } \\
\text { Strength } \\
\mathbf{( M P a )}\end{array}$ & $\begin{array}{c}\text { Flexural } \\
\text { Modulus } \\
\mathbf{( G P a )}\end{array}$ \\
\hline 0 & $48.05 \pm 1.85$ & $2403.11 \pm 105.42$ & $2.19 \pm 0.08$ & $98.3 \pm 4.88$ & $2.93 \pm 0.12$ \\
\hline 5 & $50.52 \pm 2.09$ & $3219.22 \pm 96.23$ & $2.56 \pm 0.23$ & $102.1 \pm 5.03$ & $3.17 \pm 0.15$ \\
\hline 7.5 & $52.28 \pm 2.14$ & $3094.93 \pm 101.45$ & $3.71 \pm 0.40$ & $103.2 \pm 3.94$ & $3.34 \pm 0.09$ \\
\hline 10 & $59.32 \pm 2.35$ & $3043.54 \pm 96.52$ & $5.13 \pm 0.31$ & $114.7 \pm 3.67$ & $4.97 \pm 0.18$ \\
\hline 15 & $54.03 \pm 2.28$ & $2667.19 \pm 95.16$ & $5.45 \pm 0.30$ & $105.8 \pm 4.52$ & $4.19 \pm 0.16$ \\
\hline
\end{tabular}

The results showed that the mechanical properties of the composites with ETO, used as a plasticizer, were higher than those without ETO. The tensile strength increased from 50.52 to $59.32 \mathrm{MPa}$, elongation at break increased from 2.56 to $5.13 \%$, the flexural strength increased from 98.3 to $114.7 \mathrm{MPa}$ and flexural modulus increased from 3.17 to $4.97 \mathrm{GPa}$ when the ETO content increased from 5 to $10 \%$, but the tensile modulus decreased from 3219.22 to $3043.54 \mathrm{MPa}$. This indicated that the ETO improved the mechanical properties of the composites, due to the fact that the ETO also acted as a plasticizer for PLA, so it increased the flexibility of matrix and reduced its free surface energy. This had also been proved by several other authors [30]. However, when the content of the ETO in fiber exceeded 15\%, both strength and modulus reduced because it made the material softer. This phenomenon was also observed by Kirsi when using $12 \%$ of epoxidized linseed oil as a plasticizer for PLA/bleached softwood kraft pulp composites [26].

\subsubsection{Morphology Observation}

The fracture surface morphology of the ETO soaked pulp fiber reinforced PLA composites with different epoxidized Tung oil contents were presented in Figure 8. 


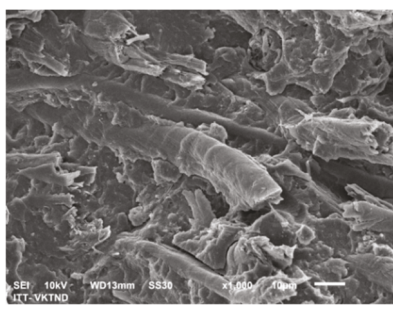

ETO-0

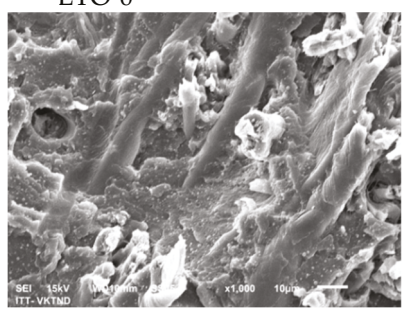

ETO-10

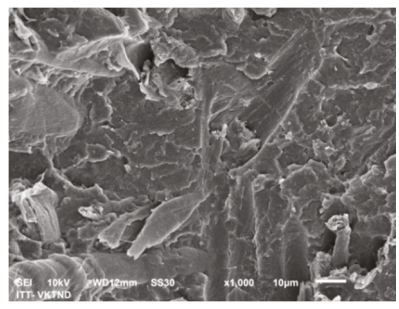

ETO-5

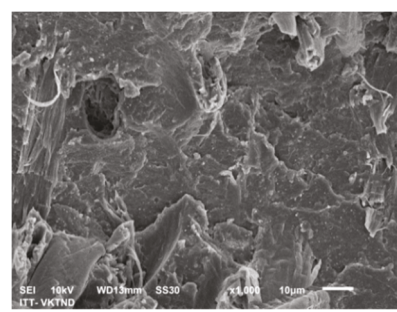

ETO-7.5

Figure 8. SEM picture of PLA/SPF composites with different contents of ETO.

The results showed that the composite without ETO can experience clear gaps between fiber and PLA. There was less phase separation between fiber and PLA when ETO was added to the number of fiber of $5-7.5 \%$. When the number of fiber in ETO content was $10 \%$, it was found that the pulp fibers showed more tight connections with PLA matrix. However, with ETO content with 15\% of fiber, it seemed that the links between the pulp fiber and PLA were weakened, and there were gaps between the two surfaces.

\section{Conclusions}

This research suggested that pulp fiber could be successfully used as a reinforcement in PLA-based composites. The tensile properties of PLA/PF composites firstly increased after adding the fiber, and then decreased when the content of fiber was over $30 \%$. With the addition of PF fiber, the flexural modulus of PLA-based composites increased, but the flexural strength of them experienced no change. An improvement in the mechanical properties was possibly caused by PF reinforcement, as well as the efficient stress transfer between the PLA matrix and fiber. The PLA-based composite with 30\% SPF fiber had the optimal mechanical properties; the tensile strength, tensile modulus, flexural strength and flexural modulus of this composite increased by $45.86 \%, 39.12 \%, 20.74 \%$, and $70.79 \%$, respectively, when compared with those of the neat PLA. In addition, the thermal stability of the PLA/PF composites decreased by the increase of the PF fiber.

The interaction between pulp fibers and PLA matrix improved, as the ETO content increased. The tensile and flexural strength of the composite increased by adding ETO with the percentage of $5-10 \%$ content. The mechanical properties of composites reduced when the ETO content was high (in amount of $15 \%$ of fiber) because ETO acted as a plasticizer for PLA.

Author Contributions: Conceptualization: T.T.N. and T.H.P.T.; data curation: T.T.P.; formal analysis: T.T.N. and T.T.P.; investigation: T.T.N. and T.T.P.; methodology: T.T.N. and T.H.P.T.; project administration: V.K.N.; software: T.H.P.T. and T.T.P.; writing—original draft: T.H.P.T. and T.T.P.; writing—review and editing: V.K.N. and T.T.P. All authors have read and agreed to the published version of the manuscript.

Funding: This research received no external funding.

Conflicts of Interest: The authors declare no conflict of interest. 


\section{References}

1. Naudu, A.L.; Ramana Rao, P.S.V. A review on chemical behaviour of natural fiber composites. Int. J. Chem. Sci. 2016, 14, 2223-2238.

2. Karim, M.A.A.; Zaman, I.; Rozlan, S.A.M.; Berhanuddin, N.I.C.; Manshoor, B.; Mustapha, M.S.; Khalid, A.; Chan, S.W. Structural characterization and mechanical properties of polypropylene reinforced natural fibers. J. Phys. Conf. Ser. 2017, 94, 012035. [CrossRef]

3. Michael, A.F.; Huo, S.; Ulven, C.A. Natural fiber reinforced composites. Polym. Rev. 2012, 52, 259-320.

4. Rohit, K.; Dixit, S. Areview-Future aspect of natural fiber reinforced composite. Polym. Renew. Resour. 2016, 7, 43-60.

5. Bax, B.; Müssig, J. Impact and tensile properties of PLA/Cordenka and PLA/flax composites. Comp. Sci. Technol. 2008, 68, 1601-1607. [CrossRef]

6. Duigou, A.L.; Davies, P.; Baley, C. Macroscopic analysis of interfacial properties of flax/PLLA biocomposites. Compos. Sci. Technol. 2010, 70, 1612-1620. [CrossRef]

7. Kumar, R.; Yakubu, M.K.; Anandjiwala, R.D. Biodegradation of flax fiber reinforced poly lactic acid. Express. Polym. Lett. 2010, 4, 423-430. [CrossRef]

8. Plackett, D. Biodegradable composites based on L-polylactide and jute fibers. Comp. Sci. Technol. 2003, 63, 1287. [CrossRef]

9. Hu, R.H.; Jang, M.H.; Kim, Y.J.; Piao, Y.J.; Lim, J.K. Fully Degradable Jute Fiber Reinforced Polylactide Composites Applicable to Car Interior Panel. Adv. Mater. Res. 2010, 123, 1151-1154. [CrossRef]

10. Graupner, N.; Herrmann, A.S.; Müssig, J. Natural and man-made cellulose fibre-reinforced poly(lactic acid) (PLA) composites: An overview about mechanical characteristics and application areas. Compos. Pt A Appl. Sci. Manuf. 2009, 40, 810-821. [CrossRef]

11. Tholibona, D.; Tharazia, I.; Sulonga, A.B.; Muhamada, N.; Ismaila, N.F.; Radzia, M.K.F.M.; Radzuand, N.A.M.; Hui, D. Kenaf Fiber Composites: A Review on Synthetic and Biodegradable Polymer Matrix. J. Kejuruteraan. 2019, 31, 65-76.

12. Tharazi, I.; Muhamad, N.; Ismail, N.F.; Radzi, M.K.F.M.; Razak, Z. Effects of Fiber Content and Processing Parameters on Tensile Properties of Unidirectional Long Kenaf Fiber Reinforced PolylacticAcid Composite. J. Mech. Eng. 2017, 3, 65-76.

13. Bledzki, A.K.; Jaszkiewicz, A.; Scherzer, D. Mechanical properties of PLA composites with man-made cellulose and abaca fibres. Compos. Pt A Appl. Sci. Manuf. 2009, 40, 404-412. [CrossRef]

14. Masirek, R.; Kulinski, Z.; Chionna, D.; Piorkowska, E.; Pracella, M. Composites of Poly(L-lactide) with Hemp Fibers: Morphology and Thermal and Mechanical Properties. J. Appl. Polym. Sci. 2007, 105, 255-268. [CrossRef]

15. Yang, Z.; Feng, X.; Bi, Y.; Zhou, Z.; Yue, J.; Xu, M. Bleached extruder chemi-mechanical pulp fiber-PLA composites: Comparison of mechanical, thermal, and rheological properties with those of wood flour-PLA bio-composites. J. Appl. Polym. Sci. 2016, 133, 44241. [CrossRef]

16. Immonen, K.; Anttila, U.; Wikström, L. Coupling of PLA and bleached softwood kraft pulp (BSKP) for enhanced properties of biocomposites. J. Compos. Mater. 2019, 32, 328-341. [CrossRef]

17. Peltola, H.; Immonen, K.; Johansson, L.-S.; Virkajärvi, J.; Sandquist, D. Influence of pulp bleaching and compatibilizer selection on performance of pulp fiber reinforced PLA biocomposites. J. Appl. Polym. Sci. 2019, 136, 47955. [CrossRef]

18. Gardner, H.A.; Sward, G.G. Part 2: Raw materials, Chapter 2.1. Drying oils. In Paint Testing Manual: Physical and Chemical Examination of Paints, Varnishes, Lacquers, and Colors, 3rd ed.; Sward, G.G., Ed.; American Society for Testing and Materials: West Conshohocken, PA, USA, 1972; pp. 53-70.

19. Aniket, E.K.; Disha, G.; Preeti, S.Z.; Manoj, B.M. Recent Advances in Epoxidation of Vegetable oils. Int. J. Emerg. Technol. Innova. Res. 2017, 4, 171-175.

20. Hajba, S.; Tábi, T. Development of natural fibre reinforced poly (lactic acid) biocomposites. In Proceedings of the ECCM16-16th European Conference on Composite Materials, Seville, Spain, 22-26 June 2014.

21. Qian, J.; Yu, M.; Ge, Z.; Xu, M.; Zhang, H.; Yang, G.; Shao, H. Preparation and properties of cotton fiber/poly (lactic acid) composites. Mater. Sci. Forum. 2014, 789, 100-105. [CrossRef] 
22. Chieng, B.W.; Ibrahim, N.A.; Then, Y.Y.; Loo, Y.Y. Epoxidized Vegetable Oils Plasticized Poly(lactic acid) Biocomposites: Mechanical, Thermal and Morphology Properties. Molecules 2014, 19, 16024-16038. [CrossRef] [PubMed]

23. Nabinejad, O.; Sujan, D.; Rahman, M.E.; Davies, I.J. Effect of filler load on the curing behavior and mechanical and thermal performance of wood flour filled thermoset composites. J. Clean. Prod. 2017, 164, 1145-1156. [CrossRef]

24. Baba, B.O.; Özmen, U. Preparation and mechanical characterization of chicken feather/PLA composites. Polym. Compos. 2017, 38, 837-845. [CrossRef]

25. Chang, B.P.; Thakur, S.; Mohanty, A.K.; Misra, M. Novel sustainable biobased flame retardant from functionalized vegetable oil for enhanced fame retardancy of engineering plastic. Sci. Rep. 2019, 9, 15971. [CrossRef] [PubMed]

26. Espinach, F.X.; Boufi, S.; Delgado-Aguilar, M.; Julián, F.; Mutjé, P.; Méndez, J.A. Composites from poly(lactic acid) and bleached chemical fibres: Thermal properties. Compos. Part B Engine 2018, 134, 169-176. [CrossRef]

27. Jonoobi, M.; Niska, K.O.; Harun, J.; Misra, M. Chemical composition, crystallinity, and thermal degradation of bleached and unbleached kenaf bast (Hibiscus cannabinus) pulp and nanofibers. Bioresource 2009, 4, 626-639.

28. Kim, H.S.; Kim, S.; Kim, H.J.; Yang, H.S. Thermal properties of bio-flour-filled polyolefin composites with different compatibilizing agent type and content. Thermochim. Acta 2006, 451, 181-188. [CrossRef]

29. Poletto, M.; Zattera, A.J.; Forte, M.M.; Santana, R.M. Thermal decomposition of wood: Influence of wood components and cellulose crystallite size. Bioresour. Technol. 2012, 109, 148-153. [CrossRef]

30. Menčík, P.; Přikryl, R.; Stehnová, I.; Melčová, V.; Kontárová, S.; Figalla, S.; Alexy, P.; Bočkaj, J. Effect of selected commercial plasticizers on mechanical, thermal, and morphological properties of poly(3-hydroxybutyrate)/poly(lactic acid)/plasticizer biodegradable blends for three-dimensional (3d) print. Materials 2018, 11, 1893. [CrossRef]

(C) 2020 by the authors. Licensee MDPI, Basel, Switzerland. This article is an open access article distributed under the terms and conditions of the Creative Commons Attribution (CC BY) license (http://creativecommons.org/licenses/by/4.0/). 



\title{
The Synergistic Effects of $\mathrm{Sio}_{2}$ Nanoparticles and Organic Photostabilizers for Enhanced Weathering Resistance of Acrylic Polyurethane Coating
}

\author{
Thien Vuong Nguyen ${ }^{1,2, *}$, Tuan Anh Nguyen ${ }^{1}$ and Thi Hau Nguyen ${ }^{3}$ \\ 1 Institute for Tropical Technology, VAST, 18 Hoang Quoc Viet, Cau Giay, Hanoi 122300, Vietnam; \\ ntanh2007@gmail.com \\ 2 Graduate University of Science and Technology, VAST, 18 Hoang Quoc Viet, Cau Giay, \\ Hanoi 122300, Vietnam \\ 3 High School of Education Sciences-University of Education, Viet Nam National University, Kieu Mai street, \\ Bac Tu Liem, Hanoi 143510, Vietnam; haunguyen47@gmail.com \\ * Correspondence: vuongvast@gmail.com
}

Received: 28 January 2020; Accepted: 24 February 2020; Published: 26 February 2020

\begin{abstract}
This study aims to evaluate the synergical effects of $\mathrm{SiO}_{2}$ nanoparticles (nano- $\mathrm{SiO}_{2}$ ) and organic photostabilizers (Tinuvin 384 (T384) and Tinuvin 292 (T292)) on the weathering resistance of acrylic polyurethane coating. Data obtained from infrared (IR), field emission scanning electron microscopy (FESEM), and weight loss of coatings (before and after aging test), suggest that the $\mathrm{SiO}_{2}$ nanoparticles play a dual role, as both reinforcer and $\mathrm{UV}$ absorber, thus improving effectively both the mechanical properties and the weathering resistance of polyurethane acrylic coatings. The nanocomposite coating containing $2 \mathrm{wt} \%$ nano-SiO${ }_{2}, 2 \mathrm{wt} \% \mathrm{~T} 384$, and $1 \mathrm{wt} \% \mathrm{~T} 292$ exhibits excellent weathering and abrasion resistances, offering a durable outdoor application.
\end{abstract}

Keywords: acrylic polyurethane coating; nanocomposite; nano- $\mathrm{SiO}_{2}$; mechanical properties; weathering resistance

\section{Introduction}

Having many advantages over other conventional polymer coatings, such as good adhesion, transparency, high gloss, and weathering resistance, acrylic polyurethane coating is used widely as a protective and decorative coating for metal structures, interior and exterior wood, and automotive paint $[1,2]$. Two-component acrylic polyurethane paint can be cured at room temperature through the step-growth polymerization of isocyanate groups with hydroxyl groups in the acrylic polyol resin forming crosslinked urethane.

In order to improve the weathering resistance of the outdoor coatings, in addition to selecting the main components such as resins and pigments with high weathering durability, organic and inorganic light stabilizing additives are usually added to the paint formulation [3-7]. Previous published works showed that organic light stabilizers (such as Tinuvin 384, Tinuvin 1130, Tinuvin 292) exhibited an excellent light stabilizing efficiency. Adding these additives at appropriate content could increase the weathering durability of the polymer coatings by 2-3 times [3]. Besides, as reported in literature, some metal oxides $\left(\mathrm{TiO}_{2}, \mathrm{ZnO}, \mathrm{ZrO}_{2}\right)$ can absorb ultraviolet (UV) rays, therefore having an ability to protect the polymer substrates from harmful UV light [4-9].

During UV absorption, an electron from the valence band jumps onto the conduction band, leaving a positively charged hole. These electrons and positively charged holes move onto the particle surface, where they recombine to each other or react with oxygen and water to form ${ }^{\bullet} \mathrm{OH}$ activated free radicals [4]. These free radicals can be the agent promoting the degradation of polymers. Thus, 
metal oxides exhibit the dual effects: (i) Blocking UV rays, and (ii) causing photo-catalytic degradation of the polymer (depending on their content, sizes, structure, and surface modifications) [5].

Currently, the addition of inorganic particles/nanoparticles (at appropriate content) into the polymer substrate can enhance its property [10-16]. Nano- $\mathrm{SiO}_{2}$ is the most used among the common inorganic nanoparticles. For example, by adding nano- $\mathrm{SiO}_{2}$ into the coating formulation, the mechanical, thermal, [2,17] weathering resistance [18,19], and anticorrosion properties [20,21] of the organic coatings were significantly improved. Nano- $\mathrm{SiO}_{2}$ is also used for both super hydrophobic coatings [22-25] or hydrophilic coatings [26].

In our previous work [3], acrylic polyurethane coating with photostabilizers exhibited the lifespan over 12 years under the marine weathering condition (natural exposure). On the other side, as reported in literature, nano- $\mathrm{SiO}_{2}$ has only been considered as a reinforcer (nanofiller) for polymer matrix. In this study, the combination of nano- $\mathrm{SiO}_{2}$ and organic light stabilizers (Tinuvin 384, Tinuvin 292) are expected to enhance simultaneously the abrasion resistance and weathering durability of coatings. We will try to explore the role of nano- $\mathrm{SiO}_{2}$ in this expected enhancement.

\section{Experimental}

\subsection{Materials}

The acrylic polyol solution (HSU 1168) obtained from A\&P Industrial Resins Company (Taiwan) contained $65 \mathrm{wt} \%$ solid, in which the content of hydroxyl groups was $4.3 \mathrm{wt} \%$. The curing agent was polyisocyanate N-75 (75 wt \%, Germany) in which the weight percentage of isocyanate groups was $17 \%$. The organic UV absorber, benzotriazole-UV (2-(2-hydroxy-3-tert-butyl-5-propionic acid isooctyl ester)-2H-benzotriazol, or Tinuvin 384 and the light stabilizer HALS, bis (1, 2, 2, 6, 6-pentamethyl-4-piperid502) sebacate or Tinuvin 292, were provided by Ciba (Switzerland). The chemical structures of these materials are presented in Figure 1.

The nano- $\mathrm{SiO}_{2}$ used in this study is non-porous silica (Aerosil $200 \mathrm{~F}$, Antwerp, Belgium). Their average particle size and surface area are $15 \mathrm{~nm}$ and $200 \mathrm{~m}^{2} / \mathrm{g}$, respectively.

The toluene and butyl acetate solvents which were used were the Chinese P-type.

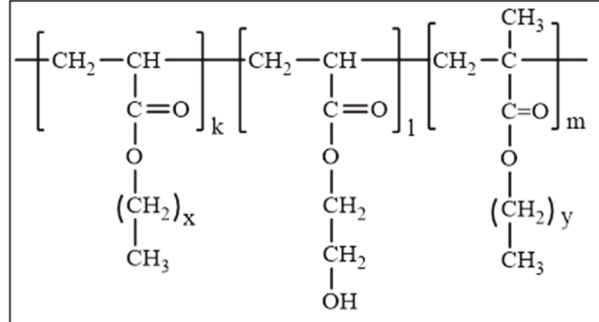

$\mathrm{k}, 1, \mathrm{~m}: 0,1,2, \ldots ; \mathrm{x}, \mathrm{y}: 0,1,2,3$.

HSU 1168

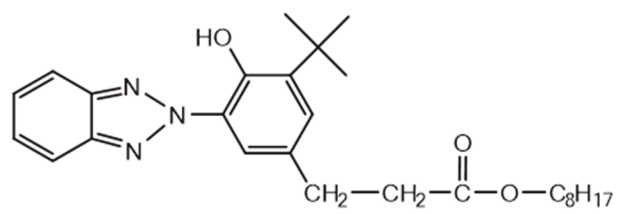

T 384<smiles>CCCCCNC(=O)N(CCN=C=O)C(=O)NCCCCCC=O</smiles>

N.75

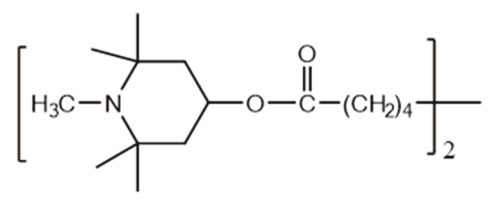

T 292

Figure 1. Chemical structures of used compounds. 


\subsection{Preparation of Coatings}

For fabrication of coating, 2 wt \% T384, 1 wt \% T292, and 2 wt \% $\mathrm{SiO}_{2}$ nanoparticles (by the total solid resin) were selected at the optimal values in our previously published works [5,27]. Weight ratios of materials in coating formulations are presented in Table 1.

At the first step, the nanoparticles were dispersed in the solvent using ultrasonic bath TP 25 for $1 \mathrm{~h}$, then this as-prepared solution was mixed with acrylic polyol resin solution, T384, and T292 by stirring for $15 \mathrm{~min}$. The obtained mixtures were continuously homogenized by ultrasonic bath for $3 \mathrm{~h}$ to ensure that the nanoparticles were well dispersed.

The coating samples (with quasi-constant thickness of $\sim 25 \mu \mathrm{m}$ ) were prepared by using a Quadruple Film Applicator (Erichsen model 360, Hemer, Germany). For infrared (IR), ultraviolet-visible (UV-Vis), and field emission scanning electron microscopy (FESEM) analysis, coating samples were prepared on the Teflon sheets, then after 6 days of curing at room temperature separated and attached to aluminum windows. The coating samples for monitoring the weight loss were prepared on glass sheets $(100 \times 70$ $\times 2 \mathrm{~mm}$ ) whereas for measuring the gloss and the abrasion resistance, coating samples were prepared on CT3 steel sheets $(100 \times 100 \times 2 \mathrm{~mm})$.

Table 1. Weight ratios of components in coating formulations.

\begin{tabular}{ccccc}
\hline \multirow{2}{*}{ No } & \multirow{2}{*}{ Materials } & \multicolumn{3}{c}{ Coating Samples } \\
\cline { 3 - 5 } & & ACPU & ACPU/SiO $_{2}$ & ACPU/SiO $_{2}$ - T \\
\hline 1 & HSU 1168 & 60.40 & 60.40 & 60.40 \\
2 & $\mathrm{SiO}_{2}$ & 0 & 1.33 & 1.33 \\
3 & $\mathrm{~T} 384$ & 0 & 0 & 1.33 \\
4 & $\mathrm{~T} \mathrm{292}$ & 0 & 0 & 0.66 \\
5 & Toluene & 18.10 & 18.76 & 18.76 \\
6 & Butyl acetate & 18.10 & 18.76 & 18.76 \\
7 & N-75 & 36.20 & 36.20 & 36.20 \\
\hline
\end{tabular}

Note: The contents of nano-SiO $2, \mathrm{~T} 384$, and $\mathrm{T} 292$ were $2 \%, 1.5 \%$, and $1.0 \%$ by weight of the total solid resin, respectively.

\subsection{Accelerated Weathering Test}

The accelerated weathering test was carried out in the Atlas UV/CON chamber (model UC-327-2, Chicago, IL, USA), under UV-A 340 fluorescent lamp, according to ASTM D 4587-05 standard (every testing cycle consists of $8 \mathrm{~h}$ for UV exposure at $60^{\circ} \mathrm{C}$ and further $4 \mathrm{~h}$ for condensate water at $50{ }^{\circ} \mathrm{C}$ ).

\subsection{Characterizations}

2.4.1. Field Emission Scanning Electron Microscopy (FESEM) and Transmission Electron Microscopy (TEM) Analysis

The morphology and size of nano-SiO ${ }_{2}$ were observed by FESEM S 4800 (Hitachi, Tokyo, Japan) and TEM-JEM 2100 (JEOL, Tokyo, Japan). FE-SEM technique was also used to assess the aging of the coatings under impact of accelerated weathering factors.

\subsubsection{Infrared (IR) Analysis}

The variations in chemical structures of the coating during the test were monitored by IR spectra on FT-IR spectroscopy (NEXUS 670, Nicolet Instrument Corporation, Madison, WI, USA). The quantitative analysis of the structural groups was calculated based on the changes in optical density of their characteristic absorption by the method we reported previously [3,5,7].

\subsubsection{Ultraviolet-Visible (UV-Vis) Analysis}

The UV-Vis absorption spectra of the coatings were analyzed on UV-Vis spectrophotometer (GBC, CINTRA 40, Austin, TX, USA) and performed on the samples which were examined by IR analysis. 


\subsubsection{Weight Loss Measurements}

The remaining weight of the coatings was calculated as follows:

$$
\text { Remaining weight }(\%)=\left(\mathrm{m}_{\mathrm{t}} / \mathrm{m}_{0}\right) \times 100
$$

where $\mathrm{m}_{0}$ and $\mathrm{m}_{\mathrm{t}}$ are weights of the coating (dried at $60{ }^{\circ} \mathrm{C}$ in vacuum oven until the constant weight) before and after the aging test, respectively.

\subsubsection{Gloss Loss Measurements}

The gloss of the coatings was measured on the Erichsen Picogloss model 503 equipment at $60^{\circ}$ angle. The remaining gloss of the coating was determined by the following expression:

$$
\text { Remaining gloss }(\%)=\left(G_{t} / G_{0}\right) \times 100
$$

where $G_{0}$ and $G_{t}$ are gloss of the coating (dried at $60{ }^{\circ} \mathrm{C}$ in vacuum oven until the constant weight) before and after the aging test, respectively.

\subsubsection{Determination of Abrasion Resistance}

The abrasion resistance of the coatings was determined by falling sand abrasion method according to ASTM D968 standard [27]. The obtained data were the average values from three measurements of each sample.

\section{Results and Discussion}

\subsection{Morphology Study of Coating}

Figure 2 presents the FESEM and TEM images of the as-received nano- $\mathrm{SiO}_{2}$. As can be seen in this figure, the average size of these nanoparticles ranges from 15 to $20 \mathrm{~nm}$. It was a challenge to disperse homogenously these small nanoparticles in polymer matrix. In this study, a $25 \mathrm{KHz}$ supersonic bath was used to prepare the formulations of the nanocomposite coatings.

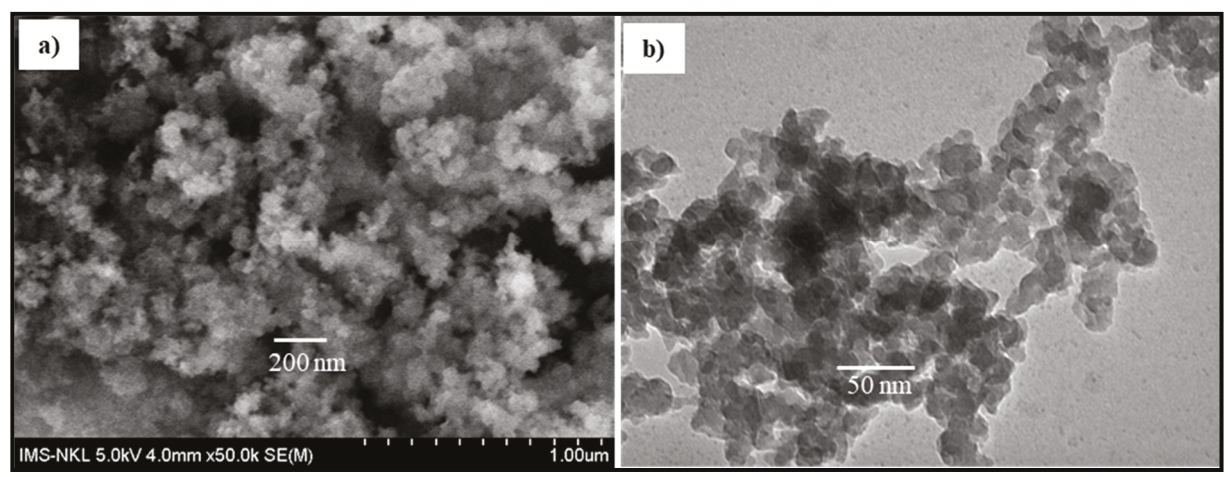

Figure 2. Field emission scanning electron microscopy (FESEM) (a) and transmission electron microscopy (TEM) (b) images of used $\mathrm{SiO}_{2}$ nanoparticles.

Figure 3 presents the FESEM images of the neat coating $\left(0 \%\right.$ nano- $\left.\mathrm{SiO}_{2}\right)$, nanocomposite coating without organic photostabilizers ( $2 \mathrm{wt} \%$ nano- $\left.\mathrm{SiO}_{2}\right)$, nanocomposite coating with the photostabilizers ( 2 wt \% nano-SiO 2,2 wt \% T384, and 1 wt \% T292), before and after 36 aging cycles. 


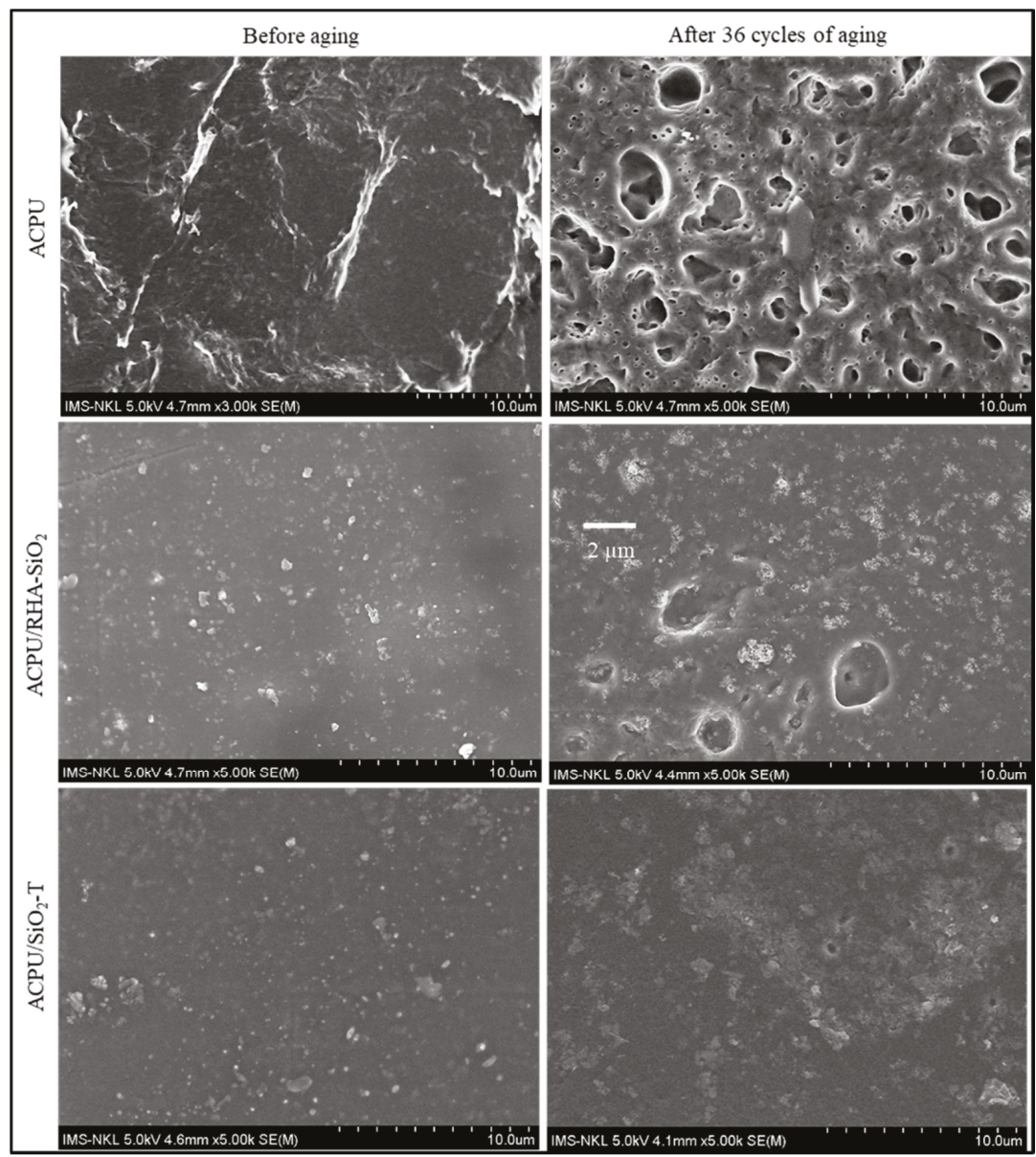

Figure 3. FESEM images of the coatings before (left) and 36 cycles of aging (right).

Before aging test, as shown in Figure 3, nanoparticles were dispersed evenly inside the coatings, providing a tight structure. Thus, incorporation of nano- $\mathrm{SiO}_{2}$ in polymer matrix should enhance the abrasion resistance of coating [27]. Besides, the light stabilizer, as viscous liquid—plasticizer [3]—might cause the softening effect to the coating. Thus, the abrasion resistance of coating containing stabilizer should decrease as compared to that of the one without stabilizer.

After 36 testing cycles (right side on Figure 3), the neat coating was destroyed seriously with the presence of many pits and pores (ranging in size from $100 \mathrm{~nm}$ to $\mu \mathrm{m}$ ) appearing on both surface and inside the coating. Whereas, by the presence of $2 \mathrm{wt} \%$ nano- $\mathrm{SiO}_{2}$, only few pits (size of a few micrometers) could be observed on the nanocomposite surface. The size of these pits was reduced (up to a few hundred nanometers) when $2 \mathrm{wt} \% \mathrm{~T} 384$ and $1 \mathrm{wt} \% \mathrm{~T} 292$ were added into the coating formulation.

\subsection{IR Spectra Study}

The changes in chemical structures of coatings (under weathering test) can be evaluated by using IR spectra measurement. Under impacts of the weathering factors, chemical bonds in the polymer chain can be broken, leading to the loss of bonds or the formation of new bonds. Therefore, the investigation of these chemical variations can clarify the degradation mechanism of organic coatings during the 
aging process. In this study, the variations in chemical structures of the coatings were evaluated by IR method. The IR spectra of the coatings before and after 36 testing cycles are presented in the Figure 4. Figure 5 presents the changes of alkane $\mathrm{CH}$ groups and $\mathrm{CNH}$ groups in the coating samples, which were deducted from the quantitative IR spectra analysis. Three coating samples were tested, such as (i) neat coating (ACPU), (ii) nanocomposite coating with 2 wt $\%$ nano- $\mathrm{SiO}_{2}\left(\mathrm{ACPU} / \mathrm{SiO}_{2}\right)$, (iii) nanocomposite coating with $2 \mathrm{wt} \% \mathrm{SiO}_{2}, 2 \mathrm{wt} \% \mathrm{~T} 384$, and $1 \mathrm{wt} \% \mathrm{~T} 292$. In addition, as the reference, we added the changes of alkane $\mathrm{CH}$ groups and $\mathrm{CNH}$ groups in the coating contained only 2 organic stabilizers (i.e., 2 wt \% T384 and 1 wt \% T292 -ACPU-T) [3], shown in Figure 5.

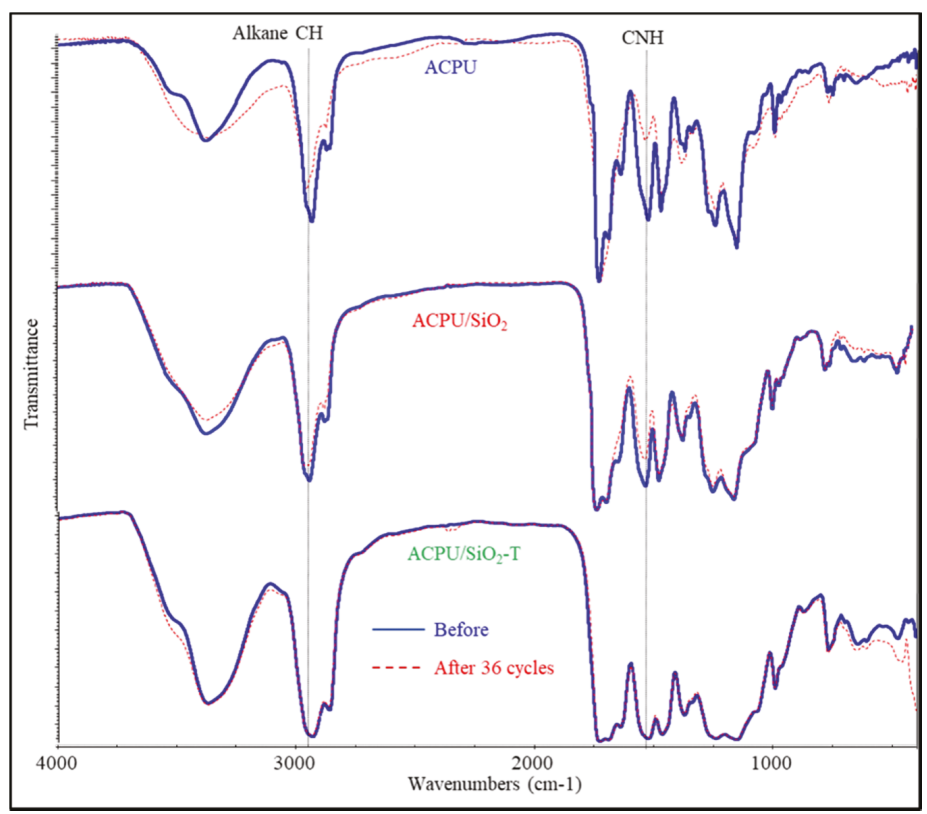

Figure 4. Infrared (IR) spectra of neat coating (ACPU), nanocomposite coating containing 2 wt \% nano- $\mathrm{SiO}_{2}\left(\mathrm{ACPU} / \mathrm{SiO}_{2}\right)$, and nanocomposite coating containing $2 \mathrm{wt} \%$ nano- $\mathrm{SiO}_{2}, 2 \mathrm{wt} \% \mathrm{~T} 384$, and $1 \mathrm{wt} \% \mathrm{~T} 292\left(\mathrm{ACPU} / \mathrm{SiO}_{2}-\mathrm{T}\right)$, before and after 36 aging cycles.

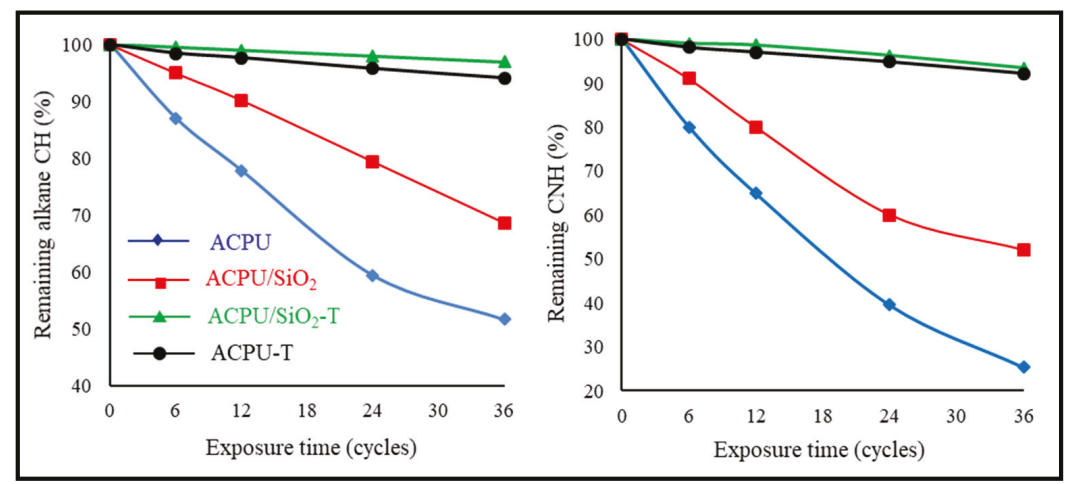

Figure 5. Chemical changes of the alkane $\mathrm{CH}$ (left) and $\mathrm{CNH}$ (right) groups in the various coatings under accelerated weathering condition. 
As can be seen in Figures 4 and 5, during the testing process, the peaks at 2950 and $1527 \mathrm{~cm}^{-1}$ characterizing the alkane $\mathrm{CH}$ groups and $\mathrm{CNH}$ groups in the coatings both decreased. Their intensity reduced the most strongly in the neat coating, but least in the coating containing the nanoparticles and organic light stabilizers. After 36 testing cycles, the remaining content of alkane $\mathrm{CH}$ groups were $51.6 \%$, $68.6 \%$, and $97.1 \%$, in the neat coating (ACPU), the nanocomposite coating with $2 \mathrm{wt} \%$ nano- $\mathrm{SiO}_{2}$ $\left(\mathrm{ACPU} / \mathrm{SiO}_{2}\right)$, and the nanocomposite coating with $2 \mathrm{wt} \%$ nano- $-\mathrm{SiO}_{2}, 2 \mathrm{wt} \% \mathrm{~T} 384$, and $1 \mathrm{wt} \% \mathrm{~T} 292$ $\left(\mathrm{ACPU} / \mathrm{SiO}_{2}-\mathrm{T}\right)$, respectively. In the case of $\mathrm{CNH}$ groups, their remaining content was $25.4 \%, 52.1 \%$, 93.5\% in $\mathrm{ACPU}, \mathrm{ACPU} / \mathrm{SiO}_{2}$, and $\mathrm{ACPU} / \mathrm{SiO}_{2}-\mathrm{T}$ coatings, respectively.

For comparative study, the chemical changes in the $\mathrm{ACPU} / \mathrm{SiO}_{2}-\mathrm{T}$ coating were lower than that in the ACPU-T coating.

\subsection{Weight Loss Study}

The variations in weight of the $\mathrm{ACPU}, \mathrm{ACPU} / \mathrm{SiO}_{2}$, and $\mathrm{ACPU} / \mathrm{SiO}_{2}-\mathrm{T}$ coatings during the aging test are shown in Figure 6. Besides, as the reference, we added the weight changes of ACPU-T coating [3] into Figure 6.

As shown in Figure 6, the weight loss of all coatings increased by testing time. It reached the highest value for the neat coating and the coating containing light stabilizer had the smallest value of weight loss. Quantitatively, after 36 cycles, the remaining weights of the ACPU, ACPU/SiO and $\mathrm{ACPU} / \mathrm{SiO}_{2}-\mathrm{T}$ coatings were $87.26 \%, 90.26 \%$, and $97.8 \%$, respectively. For comparative study, the weight loss in $\mathrm{ACPU} / \mathrm{SiO}_{2}-\mathrm{T}$ coating was lower than that in ACPU-T coating.

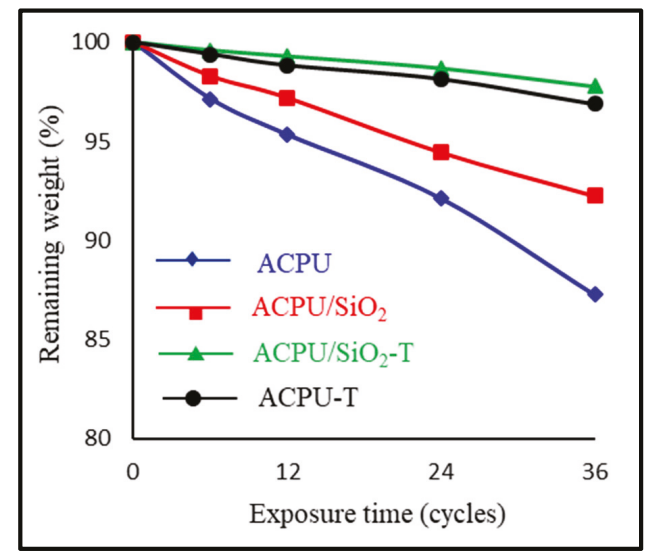

Figure 6. Changes in weight of the coatings under accelerated weathering aging condition.

\subsection{Coating Gloss Loss Study}

The weathering aging causes the degradation in properties of the coating. Hence, the degradation of the coating under the weathering factors can be evaluated by monitoring the variations in their properties. Figure 7 demonstrates the variations in gloss of the $\mathrm{ACPU}, \mathrm{ACPU} / \mathrm{SiO}_{2}$, and $\mathrm{ACPU} / \mathrm{SiO}_{2}-\mathrm{T}$ coatings during aging process. Besides, as the reference, we added the gloss changes of ACPU-T coating [3] into Figure 7.

From Figure 7, it can be seen that the gloss of the coatings decreased by aging time. The gloss of the neat coating was lost significantly. The gloss of the nanocomposite coating containing light stabilizer, by contrast, was lost slightly. After 36 aging cycles, the gloss value of the ACPU, ACPU/SiO and $\mathrm{ACPU} / \mathrm{SiO}_{2}$-T coatings, remained at $83.3 \%, 92.5 \%$, and $98.5 \%$, respectively. For comparative study, the gloss change in $\mathrm{ACPU} / \mathrm{SiO}_{2}-\mathrm{T}$ coating was lower than that in ACPU-T coating. 


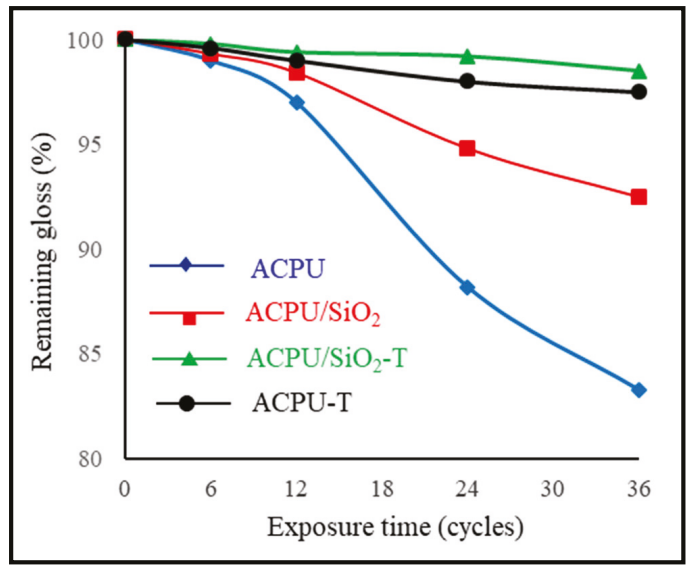

Figure 7. Changes in gloss of the coatings under accelerated weathering aging condition.

\subsection{Coating Abrasion Study}

Figure 8 presents the abrasion resistance of the $\mathrm{ACPU}, \mathrm{ACPU} / \mathrm{SiO}_{2}$, and $\mathrm{ACPU} / \mathrm{SiO}_{2}-\mathrm{T}$ coatings, before and after 36 aging cycles.

As seen in Figure 8, adding $2 \mathrm{wt} \%$ nano- $\mathrm{SiO}_{2}$ to the paint formulation increased significantly the abrasion resistance of coating from 130 to 240 lite/mil. When added $2 \mathrm{wt} \% \mathrm{~T} 384$ and $1 \mathrm{wt} \% \mathrm{~T} 292$, the abrasion resistance of coating slightly decreased from 240 to 235 lite/mil. After 36 aging cycles, the abrasion resistance of the neat coating reduced strongly (down to $38.46 \%$ ), from 130 to 80 lite $/ \mathrm{mil}$. However, the abrasion resistance of coating containing $2 \mathrm{wt} \%$ nano- $\mathrm{SiO}_{2}$ reduced slightly from 240 to 220 lite/mil (8.33\%). Whereas in the case of $\mathrm{ACPU} / \mathrm{SiO}_{2}-\mathrm{T}$ coating, reduction was only $2.12 \%$ (235 to 230 lite/mil) after aging test.

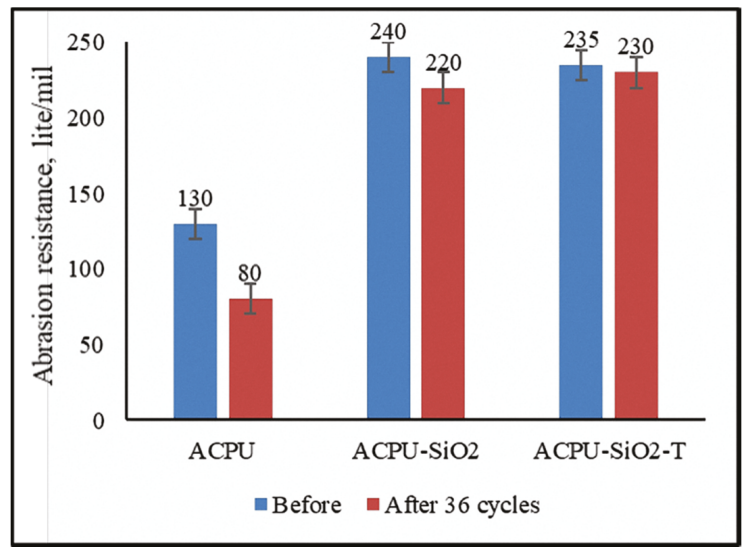

Figure 8. Values of abrasion resistance for coatings, before and after 36 cycles of aging.

As can be seen in Figure 8, addition of nano-SiO 2 , UV absorber T384, and light stabilizer HALS T292 into coating matrix significantly improved the weathering durability of the coating. As a complement data, Figure 9 presents the UV-Vis spectra of aqueous solution containing nano- $\mathrm{SiO}_{2}$ (0.5 wt \% dispersion), $\mathrm{ACPU}, \mathrm{ACPU} / \mathrm{SiO}_{2}$, and $\mathrm{ACPU} / \mathrm{SiO}_{2}-\mathrm{T}$ coatings. 


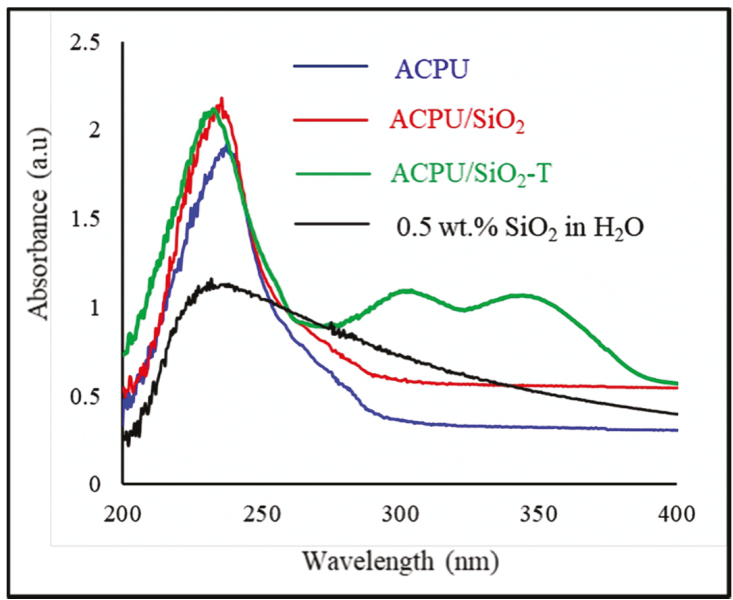

Figure 9. Ultraviolet-visible (UV-Vis) spectra of the various coating samples and the aqueous solution of nano- $\mathrm{SiO}_{2}$.

As shown in Figure 9, the absorption of UV radiation was much lower (less effective) for the ACPU coating, as compared to the $\mathrm{ACPU} / \mathrm{SiO}_{2}-\mathrm{T}$ coating. In particular, the $\mathrm{UV}$ absorption of $\mathrm{ACPU} / \mathrm{SiO}_{2}-\mathrm{T}$ coating was the strongest among these coating samples. As expected, due to the UV absorption of nano- $\mathrm{SiO}_{2}$, the polymer coating was protected under UV irradiation. Thus, the nanocomposite coating containing $2 \mathrm{wt} \% \mathrm{SiO}_{2}$ exhibited a smaller value in chemical change, leading lower loss in weight, higher gloss, and better abrasion resistance than that of the ACPU coating.

These findings are consistent with the data reported by Yari et al. [18] for the photo-protective effect of nano- $\mathrm{SiO}_{2}$ on acrylic melamine coating. Moreover, nano- $\mathrm{SiO}_{2}$ could also react with isocyanate groups [28] to form a tight organic-inorganic hybrid structure, which contributes to preventing the invasion of external environmental factors [29], leading the coating to reduce its degradation effectively. By the presence of $2 \mathrm{wt} \% \mathrm{~T} 384$ and $1 \mathrm{wt} \% \mathrm{~T} 292$, the polymer coating is double-protected by the combination of T 384 (as UV absorber) and T 292 (as free radical cleaner). In our previous paper [3], we discussed their photo-protection mechanism. Consequently, $\mathrm{ACPU} / \mathrm{SiO}_{2}-\mathrm{T}$ coating exhibited an excellent weathering resistance after 36 testing cycles.

The obtained data indicate that incorporation of nanoparticles into the acrylic polyurethane coating (with the presence of photostabilizers) enhances its weathering resistance.

\section{Conclusions}

The synergistic effects of nano- $\mathrm{SiO}_{2}$ and organic light stabilizers on enhancing the weathering resistance of acrylic polyurethane coating have been investigated and discussed.

The main findings of this study are:

- The obtained data indicated that incorporation of nano- $\mathrm{SiO}_{2}$ in the acrylic polyurethane matrix not only improved its mechanical property but also enhanced its weathering resistance.

- After 36 testing cycles, the remaining content of alkane $\mathrm{CH}$ groups was $51.6 \%, 68.6 \%$, and $97.1 \%$, in the ACPU, ACPU/SiO ${ }_{2}$, and $\mathrm{ACPU} / \mathrm{SiO}_{2}-\mathrm{T}$ coatings, respectively. In case of $\mathrm{CNH}$ groups, their remained content was $25.4 \%, 52.1 \%, 93.5 \%$ in the ACPU, $\mathrm{ACPU} / \mathrm{SiO}_{2}$, and $\mathrm{ACPU} / \mathrm{SiO}_{2}-\mathrm{T}$ coatings, respectively.

- After 36 aging cycles, the gloss remaining values of ACPU, ACPU/SiO2, and ACPU/SiO2-T coatings, were $83.3 \%, 92.5 \%$, and $98.5 \%$, respectively.

- After 36 aging cycles, the abrasion resistance of the ACPU coating reduced strongly (down to $38.46 \%$ ), from 130 to 80 lite/mil. However, for $\mathrm{ACPU} / \mathrm{SiO}_{2}$ coating, it reduced slightly from 240 to 
220 lite/mil (8.33\%). In the case of $\mathrm{ACPU} / \mathrm{SiO}_{2}-\mathrm{T}$ coating its reduction was only $2.12 \%$ (from 235 to 230 lite/mil) after aging test.

These enhancements could be explained by two possible reasons: (i) UV absorption of nanofillers (nano-SiO 2 ), could photo-protect the polymer coating, and (ii) a tight organic-inorganic hybrid structure was formed under curing reactions. Besides, addition of organic light stabilizer into paint formulation has provided excellent weathering resistance for the nanocomposite coating. These findings indicated the promising application of this nanocomposite coating as a multi-functional durable material.

Author Contributions: Conceptualization and writing-the original draft: T.V.N.; Experimentals and data analysis: T.H.N.; Writing-review and editing: T.A.N. All authors have read and agreed to the published version of the manuscript.

Funding: This work was financially supported by the Vietnam National Foundation for Science and Technology Development (NAFOSTED, Grant \# 104.02-2018.19).

Conflicts of Interest: The authors declare no conflict of interest.

\section{References}

1. Nguyen, T.N.L.; Do, T.V.; Nguyen, T.V.; Hung, D.P.; Trinh, V.T.; Mac, V.P.; Nguyen, A.H.; Le, T.L.; Nguyen, T.A.; Vo, T.K.A.; et al. Antimicrobial activity of acrylic polyurethane/ $\mathrm{Fe}_{3} \mathrm{O}_{4}$ - $\mathrm{Ag}$ nanocomposite coating. Prog. Org. Coat. 2019, 132, 15-20. [CrossRef]

2. Maganty, S.; Roma, M.P.C.; Meschter, S.J.; Starkey, D.; Gomez, M.; Edwards, D.G.; Elsken, A.E.K.; Cho, J. Enhanced mechanical properties of polyurethane composite coatings through nanosilica addition. Prog. Org. Coat. 2016, 90, 243-251. [CrossRef]

3. Nguyen, T.V.; Le, X.H.; Dao, P.H.; Decker, C.; Nguyen, T.P. Stability of acrylic polyurethane coatings under accelerated aging tests and natural outdoor exposure: The critical role of the used photo-stabilizers. Prog. Org. Coat. 2018, 124, 137-146. [CrossRef]

4. Chen, X.D.; Wang, Z.; Liao, Z.F.; Mai, Y.L.; Zhang, M.Q. Roles of anatase and rutile $\mathrm{TiO}_{2}$ nanoparticles in photooxidation of polyurethane. Polym. Test. 2007, 26, 202-208. [CrossRef]

5. Nguyen, T.V.; Nguyen, T.P.; Nguyen, T.D.; Aidani, R.; Trinh, V.T.; Decker, C. Accelerated degradation of water borne acrylic nanocomposites used outdoor protective coatings. Polym. Degrad. Stab. 2016, 128, 65-76. [CrossRef]

6. Nguyen, T.V.; Dao, P.H.; Duong, K.L.; Duong, Q.H.; Vu, Q.T.; Nguyen, A.H.; Mac, V.P.; Le, T.L. Effect of $\mathrm{R}_{-} \mathrm{TiO}_{2}$ and $\mathrm{ZnO}$ nanoparticles on the UV-shielding efficiency of water-borne acrylic coating. Prog. Org. Coat. 2017, 110, 114-121. [CrossRef]

7. Nguyen, T.V.; Nguyen, T.A.; Dao, P.H.; Mac, V.P.; Nguyen, A.H.; Do, M.T.; Nguyen, T.H. Effect of rutile titania dioxide nanoparticles on the mechanical property, thermal stability, weathering resistance and antibacterial property of styrene acrylic polyurethane coating. Adv. Nat. Sci. Nanosci. Nanotechnol. 2016, 7, 045015-045024. [CrossRef]

8. Seentrakoon, B.; Junhasavasdikul, B.; Chavasiri, W. Enhanced UV-protection and antibacterial properties of natural rubber/rutile- $\mathrm{TiO}_{2}$ nanocomposites. Polym. Degrad. Stab. 2013, 98, 566-578. [CrossRef]

9. Nguyen, T.V.; Tri, P.N.; Azizi, S.; Dang, T.C.; Hoang, D.M.; Hoang, T.H.; Nguyen, T.L.; Bui, T.T.L.; Dang, V.H.; Nguyen, N.L.; et al. The role of organic and inorganic UV-absorbents on photopolymerization and mechanical properties of acrylate-urethane coating. J. Mater. Today Commun. 2020, 22, 100780. [CrossRef]

10. Tri, P.N.; Nguyen, T.A.; Nguyen, T.H.; Carriere, P. Antibacterial behavior of hybrid nanoparticles—Chapter 7. In Noble Metal-Metal Oxide Hybrid Nanoparticles: Fundamentals and Applications; Mohapatra, S., Nguyen, T.A., Nguyen-Tri, P., Eds.; Elsevier: Amsterdam, The Netherlands, 2019; pp. 141-155. [CrossRef]

11. Ngo, T.D.; Le, T.M.H.; Nguyen, T.H.; Nguyen, T.V.; Nguyen, T.A.; Le, T.L.; Nguyen, T.T.; Tran, T.T.V.; Le, T.B.T. Antibacterial nanocomposites based on $\mathrm{Fe}_{3} \mathrm{O}_{4}$ - $\mathrm{Ag}$ hybrid nanoparticles and natural rubber-polyethylene blends. Int. J. Polym. Sci. 2016, 2016. [CrossRef]

12. Nguyen, T.V.; Do, T.V.; Ha, M.H.; Le, H.K.; Le, T.T.; Nguyen, T.N.L.; Dam, X.T.; Lu, L.T.; Tran, D.L.; Vu, Q.T.; et al. Crosslinking process, mechanical and antibacterial properties of UV-curable acrylate/ $\mathrm{Fe}_{3} \mathrm{O}_{4}-\mathrm{Ag}$ nanocomposite coating. J. Prog. Org. Coat. 2020, 139, 105325. [CrossRef] 
13. Nguyen, T.H.; Nguyen, T.A.; Nguyen, T.V.; Le, V.K.; Dinh, T.M.T.; Thai, H.; Shi, X. Effect of Electrochemical Injection of Corrosion Inhibitor (EICI) on the corrosion of steel rebar in chloride contanminated mortar. Int. J. Corros. 2015, 2015. [CrossRef]

14. Nguyen, T.V.; Dao, P.H.; Nguyen, T.A.; Dang, V.H.; Ha, M.N.; Nguyen, T.T.T.; Vu, Q.T.; Nguyen, N.L.; Dang, C.T.; Tri, P.N.; et al. Photocatalytic degradation and heat reflectance recovery of water-borne acrylic polymer/ZnO nanocomposite coating. J. Compos. Sci. 2020. [CrossRef]

15. Wu, G.; Liu, D.; Chen, J.; Liu, G.; Kong, Z. Preparation and properties of super hydrophobic films from siloxane-modified two-component waterborne polyurethane and hydrophobic nano $\mathrm{SiO}_{2}$. Prog. Org. Coat. 2019, 127, 80-87. [CrossRef]

16. Jouyandeh, M.; Rahmati, N.; Movahedifar, E.; Hadavand, B.S.; Karami, Z.; Ghaffari, M.; Taheri, P.; Bakhshandeh, E.; Vahabi, H.; Ganjali, M.R.; et al. Properties of nano- $\mathrm{Fe}_{3} \mathrm{O}_{4}$ incorporated epoxy coatings from cure index perspective. Prog. Org. Coat. 2019, 133, 220-228. [CrossRef]

17. Allahverdi, A.; Ehsani, M.; Janpour, H.; Ahmadi, S. The effect of nanosilica on mechanical, thermal and morphological properties of epoxy coating. Prog. Org. Coat. 2012, 75, 543-548. [CrossRef]

18. Yari, H.; Moradian, S.; Tahmasebi, N. The weathering performance of acrylic melamine automotive clearcoats containing hydrophobic nanosilica. J. Coat. Technol. Res. 2013, 11, 351-360. [CrossRef]

19. Dao, P.H.; Nguyen, T.V.; Dang, M.H.; Nguyen, T.L.; Trinh, V.T.; Mac, V.P.; Nguyen, A.H.; Duong, T.M. Effect of silica nanoparticles on properties of coatings based on acrylic emulsion resin. Vietnam J. Sci. Technol. 2018, 56, 117-125.

20. Nguyen, T.A.; Nguyen, T.H.; Nguyen, T.V.; Thai, H.; Shi, X. Effect of nanoparticles on the thermal and mechanical properties of epoxy coatings. J. Nanosci. Nanotechnol. 2016, 16, 9874-9881. [CrossRef]

21. Shi, X.; Nguyen, T.A.; Suo, Z.; Liu, Y.; Avci, R. Effect of nanoparticles on the anticorrosion and mechanical properties of epoxy coating. Surf. Coat. Technol. 2009, 204, 237-245. [CrossRef]

22. Junaidi, M.U.M.; Azaman, S.A.H.; Ahmad, N.N.R.; Leo, C.P.; Lim, G.W.; Chan, D.J.C.; Yee, H.M. Superhydrophobic coating of silica with photoluminescence properties synthesized from rice husk ash. Prog. Org. Coat. 2017, 111, 29-37. [CrossRef]

23. Kumar, A.M.; Latthe, S.S.; Sudhagar, P.; Obot, I.B.; Gasem, Z.M. In-situ synthesis of hydrophobic $\mathrm{SiO}_{2}-\mathrm{PMMA}$ composite for surface protective coatings: Experimental and quantum chemical analysis. Polymer 2015, 77, 79-86. [CrossRef]

24. Ammar, S.; Ramesh, K.; Ma, I.A.W.; Farah, Z.; Arof, A.K. Studies on $\mathrm{SiO}_{2}$-hybrid polymeric nanocomposite coatings with superior corrosion protection and hydrophobicity. Surf. Coat. Technol. 2017, 324, 536-545. [CrossRef]

25. Chen, H.; Zhang, X.; Zhang, P.; Zhang, Z. Facile approach in fabricating superhydrophobic $\mathrm{SiO}_{2} /$ polymer nanocomposite coating. Appl. Surf. Sci. 2012, 261, 628-632. [CrossRef]

26. Lin, B.; Zhou, S. Poly(ethylene glycol)-grafted silica nanoparticles for highly hydrophilic acrylic-based polyurethane coatings. Prog. Org. Coat. 2017, 106, 145-154. [CrossRef]

27. Le, T.T.; Nguyen, T.V.; Nguyen, T.A.; Nguyen, T.H.; Hoang, T.; Tran, D.L.; Dinh, D.A.; Nguyen, T.M.; Lu, T. Thermal, mechanical and antibacterial properties of water-based acrylic polymer $/ \mathrm{SiO}_{2}-\mathrm{Ag}$ nanocomposite coating. J. Mater. Chem. Phys. 2019, 232, 362-366. [CrossRef]

28. Mekuria, T.D.; Zhang, C.; Liu, Y.; Diaa, E.D.F.; Zhou, Y. Surface modification of nano-silica by diisocyanates and their application in polyimide matrix for enhanced mechanical, thermal and water proof properties. Mater. Chem. Phys. 2019, 225, 358-364. [CrossRef]

29. Bui, T.M.A.; Nguyen, T.V.; Nguyen, T.M.; Hoang, H.; Nguyen, T.T.; Lai, T.H.; Tran, T.N.; Nguyen, V.H.; Hoang, V.H.; Le, T.L.; et al. Investigation of crosslinking, mechanical properties and weathering stability of acrylic polyurethane nanocomposite coating reinforced by $\mathrm{SiO}_{2}$ nanoparticles issued from rice husk ash. J. Mater. Chem. Phys. 2020, 241, 122445. [CrossRef] 



\title{
The Synergic Effects of FDM 3D Printing Parameters on Mechanical Behaviors of Bronze Poly Lactic Acid Composites
}

\author{
Mahmoud Moradi ${ }^{1, *}$, Mojtaba Karami Moghadam ${ }^{1}$, Mahmoud Shamsborhan ${ }^{2,3}$ and \\ Mahdi Bodaghi ${ }^{4, *}$ \\ 1 Department of Mechanical Engineering, Faculty of Engineering, Malayer University, \\ P.O. Box 65719-95863 Malayer, Iran; mojtaba.kmoghadam1991@gmail.com \\ 2 Department of Engineering, Mahabad Branch, Islamic Azad University, P.O. Box 59135-433 Mahabad, Iran; \\ m.shamsborhan@gmail.com \\ 3 Department of Mechanical Engineering, University of Zakho, Kurdistan Region, P.O. Box 12 Zakho, Iraq \\ 4 Department of Engineering, School of Science and Technology, Nottingham Trent University, \\ Nottingham NG11 8NS, UK \\ * Correspondence: moradi@malayeru.ac.ir (M.M.); mahdi.bodaghi@ntu.ac.uk (M.B.)
}

Received: 11 January 2020; Accepted: 29 January 2020; Published: 3 February 2020

\begin{abstract}
In this paper, the influence of layer thickness (LT), infill percentage (IP), and extruder temperature (ET) on the maximum failure load, thickness, and build time of bronze polylactic acid (Br-PLA) composites 3D printed by the fused deposition modeling (FDM) was investigated via an optimization method. PLA is a thermoplastic aliphatic polyester obtained from renewable sources, such as fermented plant starch, especially made by corn starch. The design of experiment (DOE) approach was used for optimization parameters, and 3D printings were optimized according to the applied statistical analyses to reach the best features. The maximum value of failure load and minimum value of the build time were considered as optimization criteria. Analysis of variance results identified the layer thickness as the main controlled variable for all responses. Optimum solutions were examined by experimental preparation to assess the efficiency of the optimization method. There was a superb compromise among experimental outcomes and predictions of the response surface method, confirming the reliability of predictive models. The optimum setting for fulfilling the first criterion could result in a sample with more than $1021 \mathrm{~N}$ maximum failure load. Finally, a comparison of maximum failure from PLA with Br-PLA was studied.
\end{abstract}

Keywords: 3D printing; FDM method; bronze polylactic acid composite; response surface method

\section{Introduction}

Always, time and accuracy are the most important factors for engineering appliances [1-4]. Recently, novel manufacturing methods are enabled to solve many long-term processes, such as molding and casting [5]. Additive manufacturing (AM) has been introduced for tackling this problem with many applications for creating samples with high accuracy [6]. One of the most significant approaches of AM methods is fused deposition modeling (FDM), which can create samples by 3D printing technology (Figure 1) [7]. In this technology, a layer is generated by melting the polymer with the printer head at a specific temperature [8-10]. In nature, many materials are renewable, and polylactic acid (PLA) is one of them, which is normally produced from corn starch. Also, PLA is a thermoplastic aliphatic polyester and is obtained from the sources of energy that aren't evacuated by consuming [11-13]. By combining PLA with flexible metal, such as bronze, the mechanical properties of the composite may be improved [14]. The FDM method has also been served by many researchers [15-17]. 


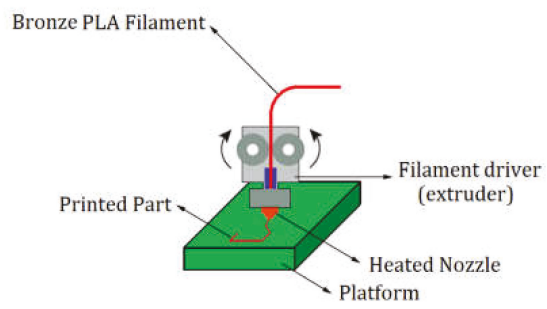

Figure 1. Schematic of 3D printing by the fused deposition modeling [18].

For instance, the influence of layer thickness on ABSP 400 samples was investigated by Padhi et al. [19]. Improving the quality of the parts made by two different methods was carried out by Gardan et al. [20]. The agents of the layer thickness, filling speed, extrusion speed, and line width on the built time and dimensions were investigated by Peng et al. [21]. Three responses were converted by a fuzzy inference system to a single output. The response surface methodology (RSM) was used to determine the relationship between four input parameters and comprehensive output. MATLAB software was also used to implement fitness function in the genetic algorithm. The results indicated that the proposed approach could effectively improve accuracy and efficiency in the FDM process. Sajan et al. carried out a study to improve the surface quality made with acrylonitrile butadiene styrene (ABS) filaments [22]. In this experiment, five parameters of the 3D printer were considered as input parameters, such as the printing speed, layer thickness, and infill percentage. Also, for the optimization of this experiment, they used the Taguchi method to reach the high quality of the surface. Results showed that the quality of the surface was improved in the $\mathrm{XY}$ and $\mathrm{XZ}$ planes. Gautam et al. [23] studied the compressive effect of ABS Kagome truss unit cell manufactured by the FDM. The properties of carbon-fiber-reinforced plastic (CFRP) manufactured composite parts were studied by Ning et al. [24]. They used the FDM method for fabricating CFRP composites, and the carbon fiber was added to composites filaments. In most traditional manufacturing methods, such as plastic molding [25-27], the tensile strength is acceptable due to the cohesion of materials. However, as one of the major disadvantages of additive manufacturing, they may result in weaker mechanical properties (electrical and thermal conductivity, optical transparency, and strength of printed parts). This paper attempted to improve the mechanical properties of FDM components by modifying the input parameters as well as using the design of experiment (DOE) method.

In the current research, the composite samples were produced by FDM 3D printing bronze polylactic acid (Br-PLA). Br-PLA tensile test sample was used to investigate the effects of the layer thickness, infill percentage, extruder temperature, and their interactions on mechanical properties, maximum failure load, thickness, build time of parts based on the DOE method. The main objective of this study was to fine-tune controlled variables to produce tough Br-PLA specimens, reduce part thickness, and shorten the build time of the printed parts. The build time data were recorded after printing the specimens by a digital timer. The tensile strength test determined the maximum failure load and elongation at break. Design-Expert V8 software was utilized for the statistical analysis of experimental data via the response surface method (RSM). The research objective was achieved by RSM and validated by experimental tests. Validation of the statistical model was confirmed by comparing the similar results with experimental data. Finally, the comparison of maximum failure from PLA with Br-PLA was investigated.

\section{Experimental Design and Methodology}

\subsection{Response Surface Method}

In the AM, the response surface methodology (RSM) is a superb opportunity for recognizing a connection between the input and output parameters. In this study, based on three input parameters 
(layer thickness, infill percentage, extruder temperature) and three output parameters (maximum failure load, thickness, and build time of parts), an experimental investigation was carried out to create some 3D samples by using the RSM with least structure defects. Also, the statistical analysis was carried out on experimental data using the Design-Expert V8 software. The statistical analysis was designed based on the central composite design (CCD) full replication with three factors on five levels. Table 1 illustrates the levels of controlled factors. The designed experiments and results of tests are shown in Table 2.

Table 1. Levels of independent variables.

\begin{tabular}{cccccccc}
\hline \multirow{2}{*}{ Variable } & \multirow{2}{*}{ Symbol } & \multirow{2}{*}{ Unit } & \multicolumn{7}{c}{ Levels } \\
\cline { 4 - 8 } & & & $\mathbf{- 2}$ & $\mathbf{- 1}$ & $\mathbf{0}$ & $\mathbf{1}$ & $\mathbf{2}$ \\
\hline Layer thickness (LT) & LT & mm & 0.15 & 0.25 & 0.35 & 0.45 & 0.55 \\
Infill percentage (IP) & IP & $\%$ & 15 & 25 & 35 & 45 & 55 \\
Extruder temperature (ET) & ET & C & 190 & 205 & 220 & 235 & 250 \\
\hline
\end{tabular}

Table 2. Design matrix and experiments results.

\begin{tabular}{|c|c|c|c|c|c|c|c|c|}
\hline \multirow[b]{2}{*}{$\Xi$} & \multicolumn{3}{|c|}{ Input Variables } & \multicolumn{5}{|c|}{ Output Responses } \\
\hline & $\begin{array}{c}\text { Layer } \\
\text { Thickness } \\
\text { (mm) }\end{array}$ & $\begin{array}{c}\text { Infill } \\
\text { Percentage } \\
(\%)\end{array}$ & $\begin{array}{c}\text { Extruder } \\
\text { Temperature } \\
\left({ }^{\circ} \mathrm{C}\right)\end{array}$ & $\begin{array}{l}\text { Maximum } \\
\text { Failure Load } \\
\text { (N) }\end{array}$ & $\begin{array}{c}\text { Thickness } \\
\text { ( } \mu \mathrm{m})\end{array}$ & $\begin{array}{l}\text { Build Time } \\
\text { (min) }\end{array}$ & $\begin{array}{c}\text { Elongation } \\
\text { at Break } \\
(\mathrm{mm})\end{array}$ & $\begin{array}{l}\text { Type of } \\
\text { Fracture }\end{array}$ \\
\hline 1 & 0.25 & 45.00 & 235.00 & 1015 & 1249 & 36 & 2.24 & Brittle \\
\hline 2 & 0.35 & 35.00 & 220.00 & 1025 & 1255 & 36 & 2.48 & Tough \\
\hline 3 & 0.45 & 45.00 & 235.00 & 1022 & 1258 & 37 & 2.35 & Brittle \\
\hline 4 & 0.35 & 15.00 & 220.00 & 1018 & 1252 & 36 & 2.26 & Brittle \\
\hline 5 & 0.15 & 35.00 & 220.00 & 805.8 & 521 & 25 & 1.50 & Brittle \\
\hline 6 & 0.35 & 35.00 & 220.00 & 1020 & 1256 & 35 & 2.25 & Brittle \\
\hline 7 & 0.35 & 35.00 & 220.00 & 1018 & 1255 & 36 & 2.20 & Brittle \\
\hline 8 & 0.45 & 25.00 & 235.00 & 1026 & 1258 & 36 & 2.64 & Brittle \\
\hline 9 & 0.35 & 55.00 & 220.00 & 1017 & 1247 & 36 & 3.45 & Tough \\
\hline 10 & 0.35 & 35.00 & 220.00 & 1019 & 1256 & 35 & 2.13 & Brittle \\
\hline 11 & 0.25 & 45.00 & 205.00 & 875 & 860 & 29 & 1.65 & Brittle \\
\hline 12 & 0.35 & 35.00 & 220.00 & 1014 & 1247 & 34 & 2.53 & Tough \\
\hline 13 & 0.45 & 25.00 & 205.00 & 862 & 905 & 30 & 1.40 & Brittle \\
\hline 14 & 0.45 & 45.00 & 205.00 & 882 & 910 & 31 & 1.52 & Brittle \\
\hline 15 & 0.25 & 25.00 & 235.00 & 895 & 917 & 32 & 1.89 & Brittle \\
\hline 16 & 0.35 & 35.00 & 220.00 & 1024 & 1257 & 36 & 2.75 & Brittle \\
\hline 17 & 0.25 & 25.00 & 205.00 & 981 & 923 & 33 & 2.26 & Brittle \\
\hline 18 & 0.35 & 35.00 & 250.00 & 1030 & 1270 & 39 & 2.55 & Tough \\
\hline 19 & 0.35 & 35.00 & 190.00 & 1017 & 1254 & 36 & 2.40 & Tough \\
\hline 20 & 0.55 & 35.00 & 220.00 & 1025 & 1272 & 38 & 2.25 & Brittle \\
\hline
\end{tabular}

\subsection{Experimental Work}

The mixture of two proper materials in the production of many composites has widely been used [28-35]. Mixed material has been detected to be effective in the 3D printing by a known approach, such as FDM. PLA is made from natural content with renewable features and also has good mechanical properties, which is noticed by many people who are environmental activists and persist in preventing many plastic products.

Simplify3D software was used to adapt the build parameters of samples. Simplify3D consists of an incredibly realistic pre-print simulation that allows checking the correct performance of the 3D printer before starting the printing process. The simulation contains information relating to the exact speeds, sequences, and settings, which are utilized for the printing. The tensile test sample was designed based on international standard ISO 527-2 by Solidworks software and imported in Simplify3D. Table 3 indicates definitions of FDM build parameters and shows fixed parameters that were kept constant for all experiments. The geometrical dimensions and internal pattern of the sample are represented in Figure 2. The machine used to print the samples was Sizan 3 (made in Sizan Pardazesh Kavir Company, 
Isfahan, Iran). Br-PLA filament (Kexcelled made in Hatchbox, Pomona, LA, USA) was installed on a specific part of the printer, and the filament was placed between two rollers and nozzle. By setting three input parameters on the printer, two rollers conducted the filament, and heating elements melted the materials. Then, the pressure was created by the rollers to push the half-melted material and deposit the first layer. The platform moved down and allowed the nozzle to print the next layers freely on the plane.

Table 3. FDM fixed parameters of the research.

\begin{tabular}{|c|c|c|c|c|}
\hline No & Build Parameters & Definition & Unit & Value \\
\hline 1 & Nozzle diameter & The diameter of the extruder nozzle. & $\mathrm{mm}$ & 0.45 \\
\hline 2 & Extrusion width & The desired single-outline width of the plastic extrusion. & $\mathrm{mm}$ & 0.45 \\
\hline 3 & Build orientation & $\begin{array}{l}\text { The angle between the central axis of the part and the } \\
\text { horizontal direction. }\end{array}$ & Degree & 45 \\
\hline 4 & Top solid layer & Number of solid layers required at the top of the part. & - & 6 \\
\hline 5 & Bottom solid layers & Required number of solid layers at the bottom of the part. & - & 6 \\
\hline 6 & $\begin{array}{l}\text { Default printing } \\
\text { speed }\end{array}$ & $\begin{array}{l}\text { Initial speed used for all printing movements } \\
\text { (modification may be added for cooling or } \\
\text { outline underspeed). }\end{array}$ & $\mathrm{mm} / \mathrm{min}$ & 3600 \\
\hline 7 & Retraction speed & $\begin{array}{l}\text { Extruder speed for the retraction movements typically } \\
\text { uses the highest speed the extruder can support. }\end{array}$ & $\mathrm{mm} / \mathrm{min}$ & 1800 \\
\hline 8 & Outline overlap & $\begin{array}{l}\text { Percentage of extrusion width that will overlap with } \\
\text { outline perimeters (ensures infill bonds to outline). }\end{array}$ & $\%$ & 15 \\
\hline
\end{tabular}
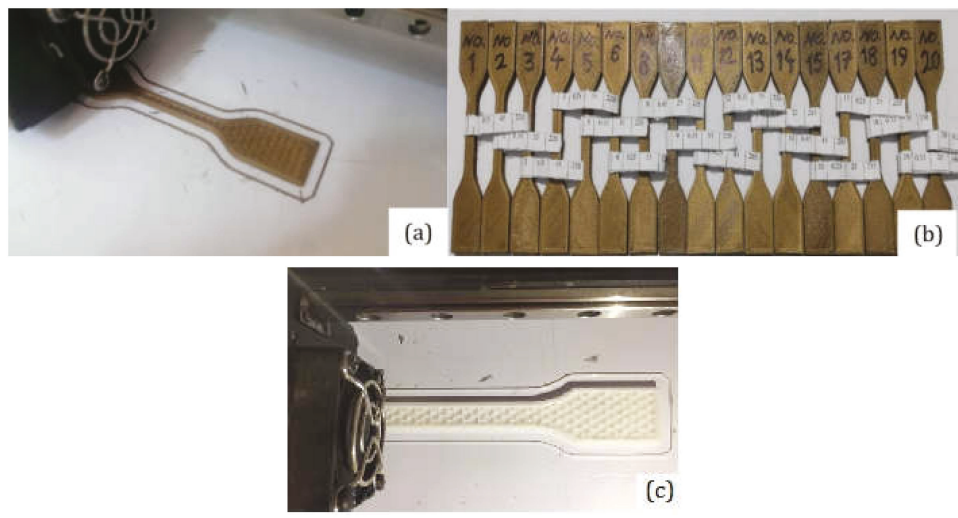

Figure 2. Cont. 


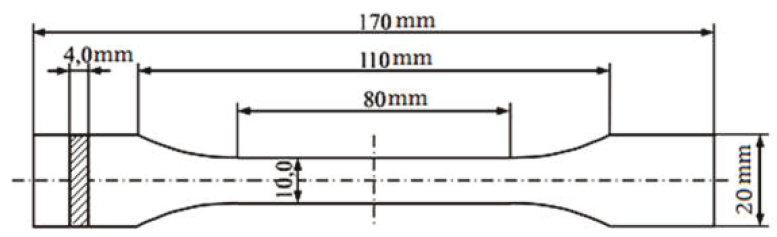

(d)

Figure 2. Geometrical dimensions and internal features of the sample. (a) 3D printing of bronze polylactic acid (Br-PLA) samples, (b) 3D printed samples, (c) 3D printing of polylactic acid (PLA) samples [18], (d) dimensions of the tensile test sample according to ISO 527-2.

The build time was measured by a digital timer after the printing of each sample; the maximum failure load was determined by the tensile strength test. The tensile strength tests were carried out with a universal testing machine based on ASTM D638 (ASTM International, Conshohocken. PA, USA). The brittle fracture of the samples (PLA and Br-PLA) on the universal testing machine is represented in Figure 3. Figure 4 also shows extension-force diagrams of samples \#2 and \#5. The results showed that the behavior of samples under load could be classified as a brittle and tough fracture. Almost $80 \%$ of the results in the design matrix had brittle fracture because PLA is relatively brittle under tensile loading. The fracture of brittle samples occurred at the elastic limit, while tough specimens showed the ability to undergo a low degree of plastic deformation before fracture. Therefore, samples with higher maximum failure load and elongation at the break had a tough fracture. However, a sudden brittle fracture is usually observed in samples at the elastic limit and in a lower failure load. Also, in the previous study [18], extruder temperature $\left(230{ }^{\circ} \mathrm{C}\right)$, infill percentage $(16.86 \%)$, and layer thickness $(0.23 \mathrm{~mm})$ were selected as controlled parameters by optimum settings for PLA printed parts, and, in this study, the failure load was compared with Br-PLA.
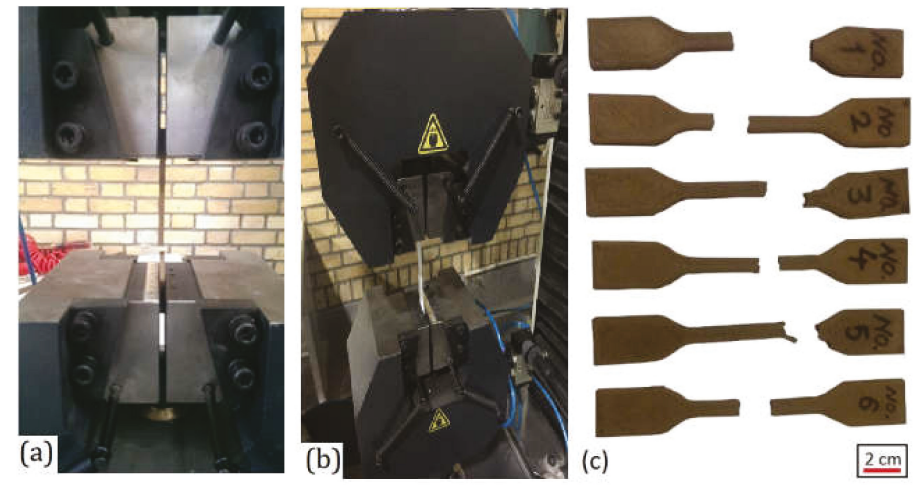

Figure 3. (a) Brittle fracture of the specimen (sample \#12 Br-PLA), (b) Brittle fracture of the optimum PLA specimen, (c) fracture of \#1 to \#6 samples. 


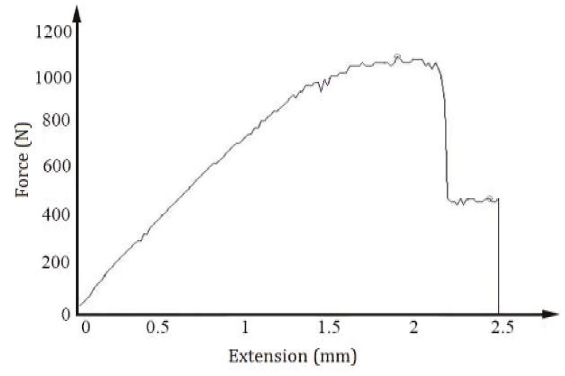

(a)

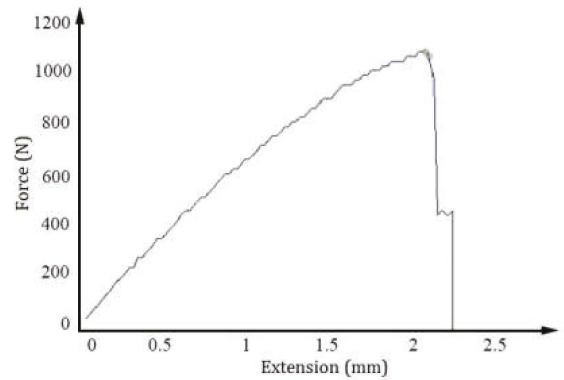

(b)

Figure 4. Extension-force diagrams of (a) sample \#2 and (b) sample \#4.

\section{Results and Discussion}

For improving the quality of the experiments and reducing the tests, the DOE approach was utilized. This method could be a link between input and output parameters with a logical and physical condition resulting from the primary experiment. For each of 20 samples in the first level of the experiment, the maximum failure load, thickness, and build time were measured. Design Expert V08 software, based on the regression equations and ANOVA table, sorted parameters for each output. In this stage of the experimental study, the results of the output parameters were analyzed. This composite was more flexible than the 3D printed PLA materials, but the failure load in the Br-PLA was less than PLA.

\subsection{Maximum Failure Load}

The ANOVA table showed that the layer thickness was the dominant controlled variable for the maximum failure load. Extruder temperature and infill percentage were also significant. Table 4 demonstrates the ANOVA results of the maximum failure load.

Table 4. Analysis of variance (ANOVA).

\begin{tabular}{|c|c|c|c|c|c|}
\hline Source & Sum of Squares & Degrees of Freedom (DF) & Mean Square & F Value & $p$-Value \\
\hline Model & $4.22 \times 10^{13}$ & 7 & $6.02 \times 10^{12}$ & 5.972742 & 0.0155 \\
\hline LT & $8.95 \times 10^{11}$ & 1 & $8.95 \times 10^{11}$ & 0.887652 & 0.3775 \\
\hline IP & $1.16 \times 10^{12}$ & 1 & $1.16 \times 10^{12}$ & 1.150847 & 0.3190 \\
\hline ET & $7.56 \times 10^{11}$ & 1 & $7.56 \times 10^{11}$ & 0.750007 & 0.4152 \\
\hline $\mathrm{LT} \times \mathrm{IP}$ & $9.67 \times 10^{12}$ & 1 & $9.67 \times 10^{12}$ & 9.593505 & 0.0174 \\
\hline $\mathrm{LT} \times \mathrm{ET}$ & $7.71 \times 10^{12}$ & 1 & $7.71 \times 10^{12}$ & 7.643659 & 0.0279 \\
\hline $\mathrm{LT}^{2}$ & $1.41 \times 10^{13}$ & 1 & $1.41 \times 10^{13}$ & 13.96848 & 0.0073 \\
\hline $\mathrm{ET}^{2}$ & $1.65 \times 10^{13}$ & 1 & $1.65 \times 10^{13}$ & 16.36513 & 0.0049 \\
\hline Residual & $7.06 \times 10^{12}$ & 7 & $1.01 \times 10^{12}$ & & \\
\hline \multirow[t]{2}{*}{ Cor Total } & $4.92 \times 10^{13}$ & 14 & & & \\
\hline & Adj $R$ & quared $=0.7131$ & R-Squared & 0.8565 & \\
\hline
\end{tabular}

Equation (1) is a predictive model of maximum failure load in terms of coded factors. Also, Equation (2) shows a predictive model of maximum failure load with respect to the actual values.

$$
\begin{gathered}
(\text { Maximum Failure Load })^{2.32}=9250115+473024.5 \mathrm{LT}-538606 \mathrm{IP}+434805.5 \mathrm{ET} \\
+4398413 \mathrm{LT} \times \mathrm{IP}+3926069 \mathrm{LT} \times \mathrm{ET}-3412710 \mathrm{LT}^{2}-3693896 \mathrm{ET}^{2} \\
\\
\left(\text { Maximum Failure Load) }{ }^{2.32}=-1.4 \times 10^{8}-1.2 \times 10^{8} \mathrm{LT}-411791 \mathrm{IP}+1591377 \mathrm{ET}\right. \\
+1099603 \mathrm{LT} \times \mathrm{IP}+654344.9 \mathrm{LT} \times \mathrm{ET}-8.5 \times 10^{7} \mathrm{LT}^{2}-4104.33 \mathrm{ET}^{2}
\end{gathered}
$$


The developed equation was useful to determine the relative significance of factors by comparing the factor coefficients. Also, Figure 5 shows the perturbation plot of the maximum failure load. The perturbation plot helped to compare the effect of all factors in the central point in the design space, as illustrated in Figure 5. The maximum failure load was plotted by changing only a factor over its range, while other factors were kept constant. Lines A, B, and C showed the sensitivity of maximum failure load to layer thickness, infill percentage, and extruder temperature, respectively. The perturbation plot disclosed increasing layer thickness and extruder temperature parameters that resulted in an increase in the mechanical strength of specimens. In addition, the plot showed that the maximum failure load depended almost equally on the extruder temperature. Figure 6a demonstrates the effects of the layer thickness and infill percentage on the maximum failure load. The IP had a very specific role in flexibility and tensile strength because by increasing the IP, the structure of 3D parts went to denser structure with lower porosity. Therefore, samples printed by high IP could resist the great tensile load, even though these samples did not have good flexibility properties. A 3D surface plot of maximum failure load with respect to the layer thickness and extruder temperature is shown in Figure 6b. It is clear that thinner samples under dramatic forces could not resist much. Figure 7 indicates the normal probability plot of the residuals to check for normality of residuals. The normal probability plot indicated whether residuals followed a normal distribution; in this case, the points followed a straight line. Some moderate scattering was also expected even with normal data.

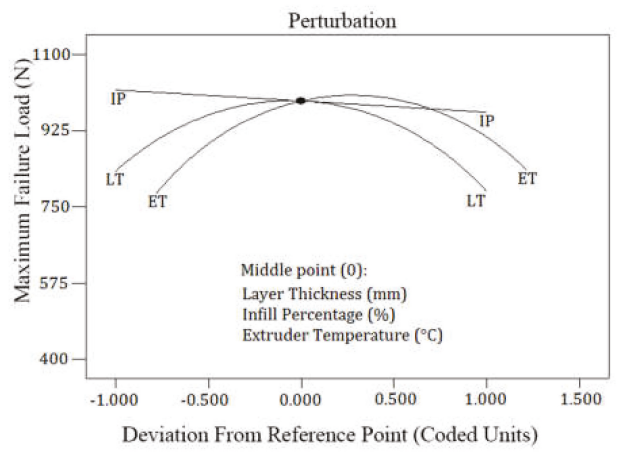

Figure 5. Perturbation plot of the maximum failure load.

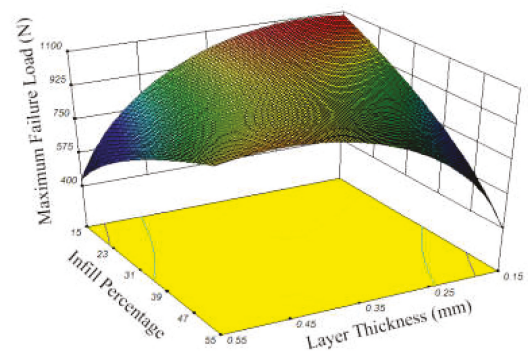

(a)

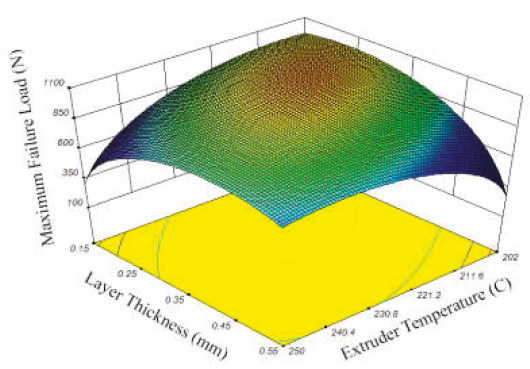

(b)

Figure 6. Cont. 


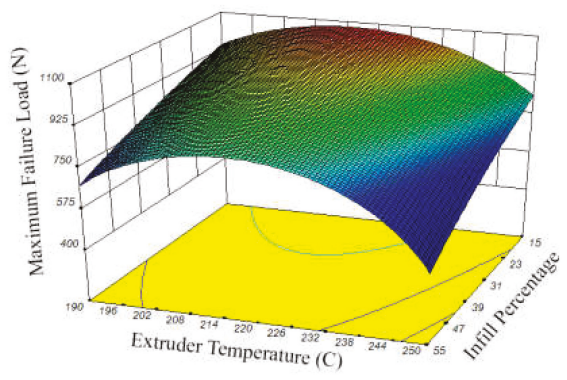

(c)

Figure 6. 3D surface plot of the maximum failure load with (a) infill percentage and layer thickness; (b) extruder temperature and layer thickness; (c) infill percentage and extruder temperature.

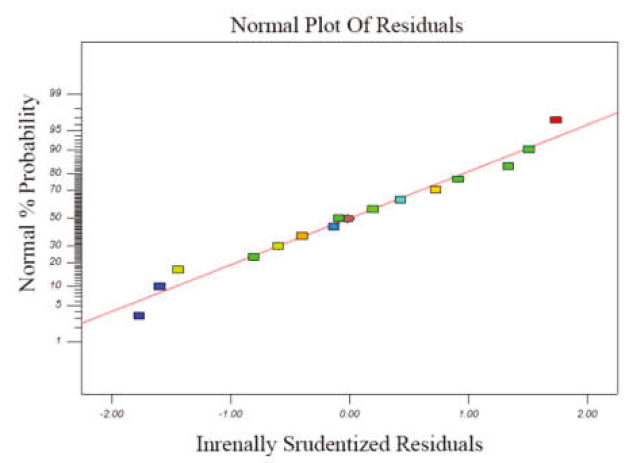

Figure 7. The normal plot of residuals of the maximum failure load.

\subsection{Build Time}

The ANOVA table revealed that Infill IP and IP2 of the printer were the most significant controlled variables for the build time. Table 5 demonstrates the ANOVA analysis for the build time. Equations (3) and (4) represent the final regression equation based on the coded values and actual values for the build time:

$$
\begin{aligned}
{\text { (Build Time })^{-3}} & =2.24976 \times 10^{-5}-1.20444 \times 10^{-5} \mathrm{IP}-2.51081 \times 10^{-7} \mathrm{ET} \\
& +3.00044 \times 10^{-5} \mathrm{IP}^{2}-1.27876 \times 10^{-5} \mathrm{ET}^{2} \\
\text { (Build Time) }^{-3} & =-0.000548983-5.85298 \times 10^{-6} \mathrm{IP}+6.24335 \times 10^{-6} \mathrm{ET} \\
& +7.50109 \times 10^{-8} \mathrm{IP}^{2}-1.42085 \times 10^{-8} \mathrm{ET}^{2}
\end{aligned}
$$

Regression equations' terms had superb advantages in this study because many reasons, such as coded equation, could provide a suitable perception to physical parameters. Here, in the build time, LT, LP, and ET had a significant effect on the 3D printed samples. Due to Table 5, it was clear that LT was not very effective than either parameter and had a steady change. Results showed that when the IP rose, the built time increased. Also, when the ET rose, the built time reduced (Figure $8 \mathrm{c}$ ) too. The probability plot in Figure 9 showed the residuals to illustrate the normality of residuals. In this diagram, the trend of the normal distribution in some particular samples was applied in a direct line. When the normal distribution became stable, the model was suitable for the build time, and it was clear that the normal distribution was close to the direct line. 
Table 5. Analysis of variance (ANOVA).

\begin{tabular}{cccccc}
\hline Source & Sum of Squares & Df & Mean Square & F Value & $p$-Value \\
\hline Model & $2.54 \times 10^{-9}$ & 5 & $5.09 \times 10^{-10}$ & 10.81049 & 0.0013 \\
IP & $5.8 \times 10^{-10}$ & 1 & $5.8 \times 10^{-10}$ & 12.33532 & 0.0066 \\
ET & $2.52 \times 10^{-13}$ & 1 & $2.52 \times 10^{-13}$ & 0.005361 & 0.9432 \\
IP $^{2}$ & $1.09 \times 10^{-9}$ & 1 & $1.09 \times 10^{-9}$ & 23.14339 & 0.0010 \\
ET $^{2}$ & $1.98 \times 10^{-10}$ & 1 & $1.98 \times 10^{-10}$ & 4.203745 & 0.0706 \\
Residual & $4.23 \times 10^{-10}$ & 9 & $4.7 \times 10^{-11}$ & & \\
Cor Total & $2.97 \times 10^{-9}$ & 14 & & \\
\hline \multicolumn{7}{c}{ R-Squared $=0.7779$} & Adj R-Squared $=0.8572$ & \\
\hline
\end{tabular}

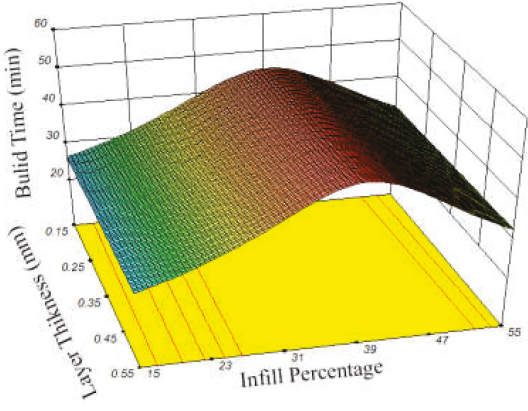

(a)

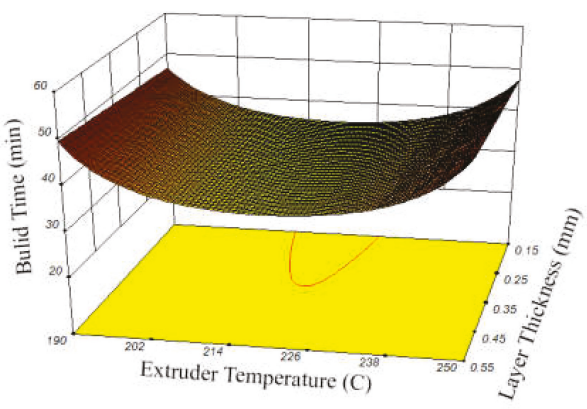

(b)

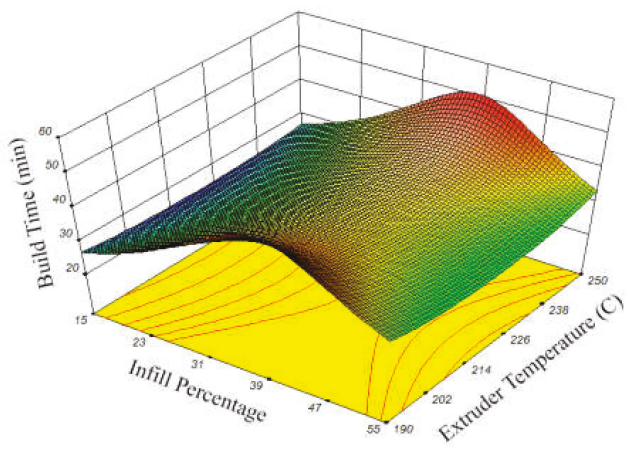

(c)

Figure 8. 3D surface plot of the build time with (a) infill percentage and layer thickness; (b) extruder temperature and layer thickness; (c) infill percentage and extruder temperature. 


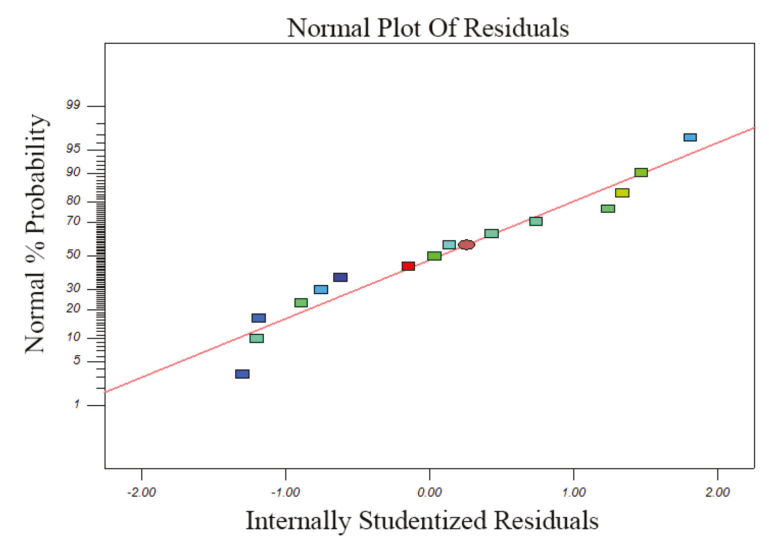

Figure 9. The normal plot of residuals of the build time.

\subsection{Thickness}

Table 6 depicts the ANOVA output and input parameters outcome for one of the important and significant features of samples. It could be found that LT and ET were the most effective variables. Part thickness' predictive model in terms of coded factors and actual amounts are represented in Equations (5) and (6), respectively.

$$
\begin{gathered}
(\text { Thickness })^{0.86}=340.4628+97.46882 \mathrm{LT}-5.40253 \mathrm{IP}-58.3206 \mathrm{ET}-210.432 \mathrm{IP} \times \mathrm{ET} \\
(\text { Thickness) })^{0.86}=-3285.51+4990.265 \mathrm{LT}+64.80622 \mathrm{IP}+15.92595 \mathrm{ET}-0.35072 \mathrm{IP} \times \mathrm{ET}
\end{gathered}
$$

Table 6. Analysis of variance (ANOVA).

\begin{tabular}{cccccc}
\hline Source & Sum of Squares & Df & Mean Square & F Value & $p$-Value \\
\hline Model & $94,256.12$ & 7 & $13,465.16$ & 4.82262 & 0.0274 \\
LT & $38,000.68$ & 1 & $38,000.68$ & 13.61015 & 0.0078 \\
IP & 116.7494 & 1 & 116.7494 & 0.041814 & 0.8438 \\
ET & $13,605.18$ & 1 & $13,605.18$ & 4.872769 & 0.0630 \\
IP $\times$ ET & $22,140.75$ & 1 & $22,140.75$ & 7.929828 & 0.0259 \\
Residual & $19,544.59$ & 7 & 2792.084 & & \\
Cor Total & $113,800.7$ & 14 & & \\
\hline \multicolumn{7}{c}{ Adj R-Squared $=0.6565$} & R-Squared $=0.8282$ \\
\hline
\end{tabular}

The excellent R-squared and adjusted R-squared of the predictive model confirmed that the model was immensely reliable. As shown in Figure 10a, by raising the infill percentage, the amount of the thickness increased. Figure $10 \mathrm{~b}$ revealed that with raising the layer thickness and the extruder temperature, the thickness increased. The reason for this phenomenon was that when ET and LT grew up, the material printed rose. That is because the LT always equated with more material injection. Therefore, the amount of thickness increased. Figures 11 and 12 show the perturbation plot and normal plot of residuals of the thickness, respectively. 


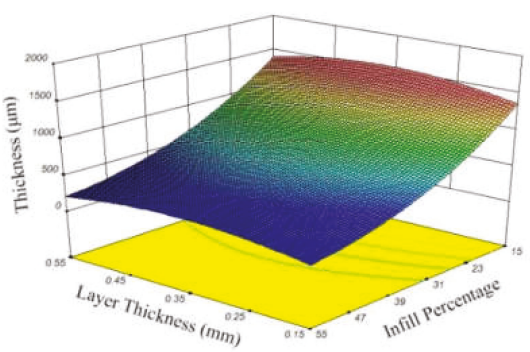

(a)

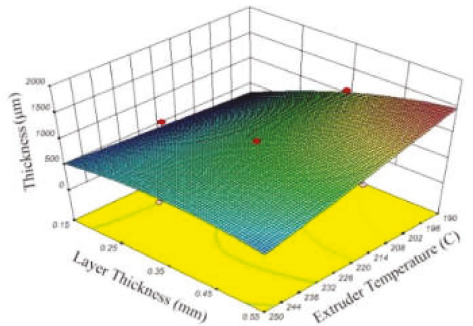

(b)

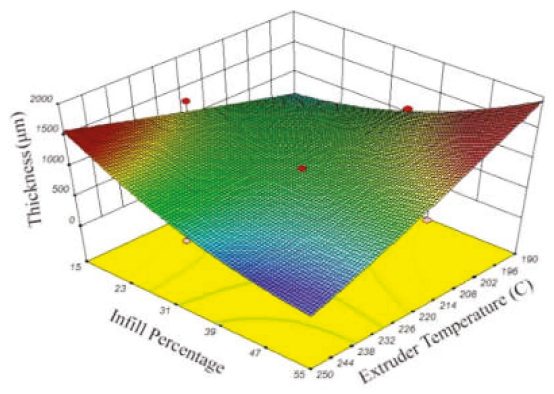

(c)

Figure 10. 3D surface plot of the maximum width with (a) infill percentage and layer thickness; (b) extruder temperature and layer thickness; (c) infill percentage and extruder temperature.

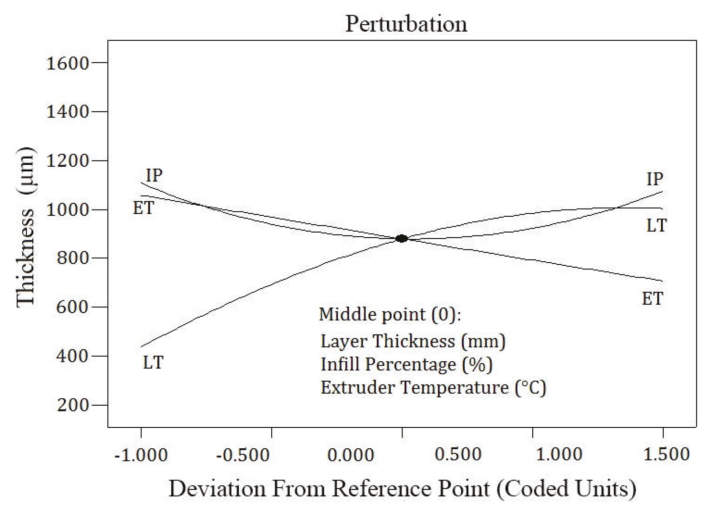

Figure 11. Perturbation plot of the maximum width. 


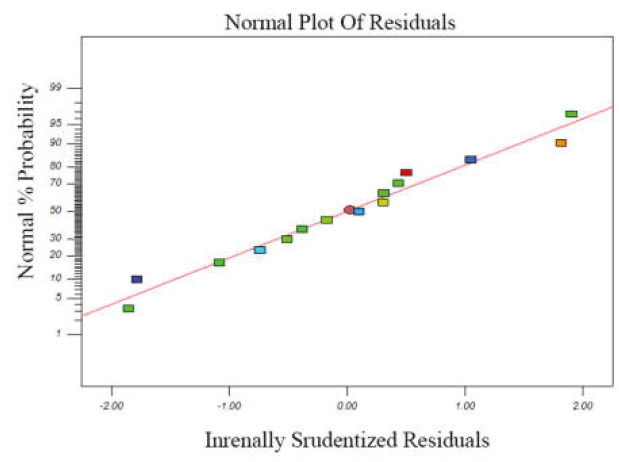

Figure 12. The normal plot of residuals of thickness.

\section{Numerical Optimization}

In this study, for the sake of numerical optimization, three criteria were evaluated. Three criteria of these experiments are shown in Table 7 . Table 8 shows the predicted optimum results and experimental validation for Br-PLA 3D printing samples. Some parameters of physical and mechanical properties were considered as output parameters because it is essential for manufacturing samples with good conditions, such as proper resist from tensile strengths and adequate thickness. The optimization method provided an efficient condition to produce these samples. As a matter of fact, the suitable portion of each material was very important in the composite structure. Br-PLA consisted of two phases with a ratio of $35 \%$ to $65 \%$, wherein the variation of the 3D printing input parameters played an important role in producing samples without any defects. The strong samples with the least deformation were the main goal of this article. Based on Table 8 , the predicted optimum results and experimental validation were very close together and showed slight errors between them. Overly diagram in Figure 13 illustrates two parts of optimization in which substantial region in input parameters was relevant by output parameters. It means that the variation of each parameter had a significant role in output results. Also, in Figure 14, the results for the higher tensile strength in optimum samples are shown. In a previous study [18], in the PLA 3D printing samples, the maximum failure load was reported more than Br-PLA samples because the composite structure had the more particle's space, while, in Br-PLA, the metal component took up more space than PLA structure. Therefore, the PLA parts had more resistance in the tensile strength test.

Table 7. Constraints and criteria of input parameters and responses.

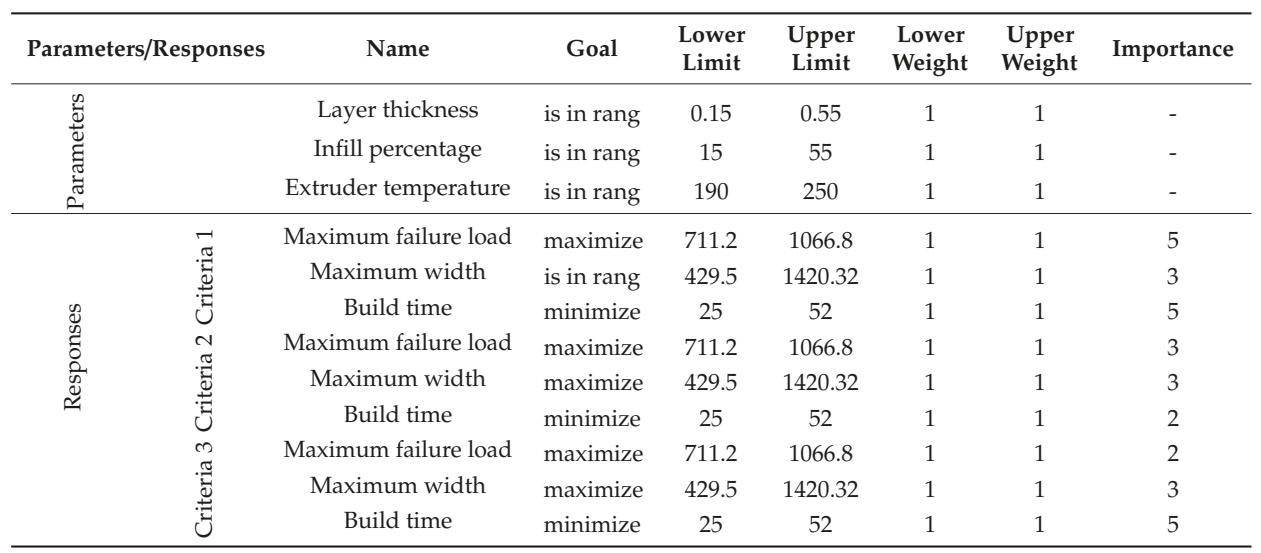


Table 8. Predicted optimum results and experimental validation.

\begin{tabular}{|c|c|c|c|c|c|c|c|c|}
\hline Solution & \multicolumn{3}{|c|}{ Optimum Input Parameters } & Desirability & & \multicolumn{3}{|c|}{ Output Responses } \\
\hline \multirow[t]{2}{*}{1} & \multirow[t]{2}{*}{0.23} & \multirow[t]{2}{*}{15.15} & \multirow[t]{2}{*}{222.73} & \multirow[t]{2}{*}{0.97} & Predicted & 950 & 1110 & 34 \\
\hline & & & & & Error\% & 6.49 & 10.98 & 5.55 \\
\hline 2 & 0.2 & 15.15 & 219.13 & 0.85 & Error\% & 6.25 & 10.94 & 2.94 \\
\hline \multirow{3}{*}{3} & \multirow{3}{*}{0.25} & \multirow{3}{*}{15.20} & \multirow{3}{*}{222.82} & \multirow{3}{*}{0.78} & Actual & 1021 & 1257 & 36 \\
\hline & & & & & Predicted & 1013 & 1237 & 35 \\
\hline & & & & & Error\% & 0.78 & 1.59 & 2.77 \\
\hline
\end{tabular}

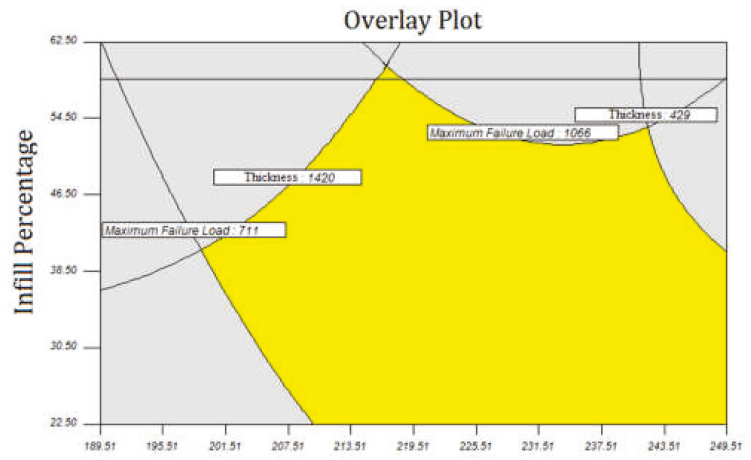

Extruder Temperature

(a)

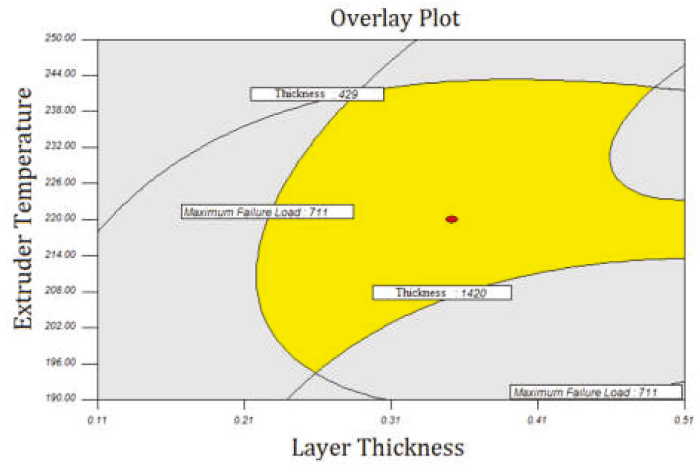

(b)

Figure 13. Overlay plot of 3D printing optimization with (a) infill percentage and extruder temperature; (b) extruder temperature and layer thickness. 


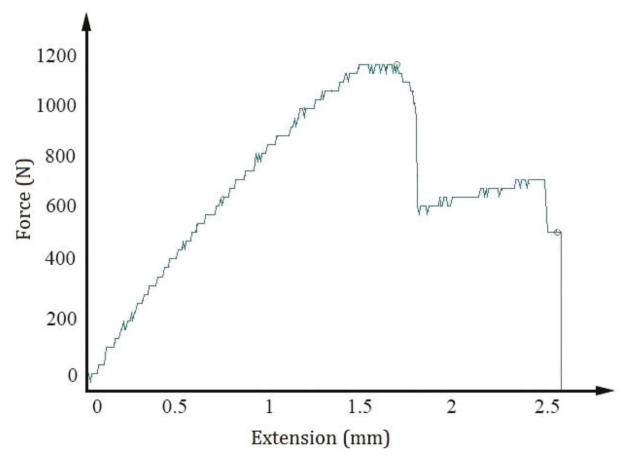

Figure 14. Extension-force diagram of the specimen for solution 3.

\section{Comparison of PLA and Br-PLA 3D Printed Samples}

In this part, the comparison of PLA and Br-PLA 3D printed samples were investigated. From Section 4, which is related to the extension-force result of the specimen for solution 3 of Br-PLA composite and also PLA optimum sample in the previous study [18], respectively, it was clear that the tensile strength of PLA was higher than the Br-PLA composite. This phenomenon happened because of two reasons. Firstly, when the Br-PLA composite parts were printed, the infill percentage was less than PLA printed parts in the constant situation and input parameters. The second reason was that PLA is a single material and has the good connection between its particles, whereas, in the Br-PLA sample, because two materials are used, the connection of particles are weaker than PLA sample, but the flexibility of the Br-PLA part is higher than the PLA part [36].

\section{Conclusions}

FDM 3D printing method for producing the Br-PLA samples was improved by the DOE approach and considering the significant input parameters (infill percentage, extruder temperature, and layer thickness) for each output parameter (maximum failure load, build time, and sample thickness). In the continuation of the article, some of the conclusions are mentioned:

(1) The results showed that the mechanical properties (maximum failure load) of the samples improved as the layer thickness increased because the higher layer thickness could resist a more tensile load.

(2) Results indicated that when the infill percentage increased, the mechanical properties of pieces improved because of the increase in the adhesion of components.

(3) The optimized printed Br-PLA specimen with a layer thickness of $0.25 \mathrm{~mm}, 15.20$ infill percentage, and $222.82{ }^{\circ} \mathrm{C}$ extruder temperature could resist more than $1000 \mathrm{~N}$.

(4) For producing a suitable sample with good mechanical and economical features, middle extruder temperatures and low infill percentages must be considered. Because in the Br-PLA 3D samples, the heavy and rough samples might not be used very much, and the heavier samples are costly.

(5) In the PLA 3D printing samples, the maximum failure load was reported more than Br-PLA samples, and that is because the composite structure has the more particle's space, and in Br-PLA, the metal component takes up more space than PLA structure.

Author Contributions: Conceptualization, M.M.; methodology, M.M. and M.K.M.; software, M.K.M. and M.S.; validation, M.M., M.K.M., and M.B.; investigation, M.M., M.K.M., and M.B.; resources, M.M.; writing—original draft preparation, M.M., M.K.M., and M.B.; writing-review and editing, M.M., M.K.M., M.S., and M.B.; supervision, M.M.; project administration, M.M. All authors have read and agreed to the published version of the manuscript.

Funding: This research received no external funding. 
Conflicts of Interest: The authors declare no conflict of interest.

\section{References}

1. Groover, M.P. Fundamentals of Modern Manufacturing: Materials, Processes, and Systems, 4th ed.; John Wiley \& Sons, Inc.: Hoboken, NJ, USA, 2010.

2. Casalino, G.; Moradi, M.; Moghadam, M.K.; Khorram, A.; Perulli, P. Experimental and Numerical Study of AISI 4130 Steel Surface Hardening by Pulsed Nd: YAG Laser. Materials 2019, 12, 3136. [CrossRef] [PubMed]

3. Moradi, M.; KaramiMoghadam, M. High power diode laser surface hardening of AISI 4130; statistical modelling and optimization. Opt. Laser Technol. 2019, 111, 554-570. [CrossRef]

4. Gibson, I.; Rosen, D.; Stucker, B. Additive Manufacturing Technologies: 3D Printing, Rapid Prototyping, and Direct Digital Manufacturing, 2nd ed.; Springer: Berlin, Germany, 2015.

5. Ahn, S.; Montero, M.; Odell, D.; Roundy, S.; Wright, P.K. Anisotropic material properties of fused deposition modeling ABS. Rapid Prototyp. J. 2002, 8, 248-257. [CrossRef]

6. Liu, X.; Zhang, M.; Li, S.; Si, L.; Peng, J.; Hu, Y. Mechanical property parametric appraisal of fused deposition modeling parts based on the gray Taguchi method. Int. J. Adv. Manuf. Technol. 2017, 89, $2387-2397$. [CrossRef]

7. Dong, G.; Wijaya, G.; Tang, Y.; Zhao, Y.F. Optimizing process parameters of fused deposition modeling by Taguchi method for the fabrication of lattice structures. Add. Manuf. 2018, 19, 62-72. [CrossRef]

8. Mahmood, S.; Qureshi, A.J.; Talamona, D. Taguchi based process optimization for dimension and tolerance control for fused deposition modelling. Add. Manuf. 2018, 21, 183-190. [CrossRef]

9. Milosevic, M.; Stoof, D.; Pickering, K.L. Characterizing the Mechanical Properties of Fused Deposition Modelling Natural Fiber Recycled Polypropylene Composites. J. Compos. Sci. 2017, 1, 7. [CrossRef]

10. Pandey, P.M.; Thrimurthulu, K.; Reddy, N.V. Optimal part deposition orientation in FDM by using a multicriteria genetic algorithm. Int. J. Prod. Res. 2004, 42, 4069-4089. [CrossRef]

11. El Magri, A.; El Mabrouk, K.; Vaudreuil, S.; Ebn Touhami, M. Mechanical properties of CF-reinforced PLA parts manufactured by fused deposition modeling. J. Thermopl. Compos. Mater. 2019. [CrossRef]

12. Moura, N.K.; Siqueira, I.A.W.B.; Machado, J.P.B.; Kido, H.W.; Avanzi, I.R.; Rennó, A.C.M.; Trichês, E.S.; Passador, F.R. Production and Characterization of Porous Polymeric Membranes of PLA/PCL Blends with the Addition of Hydroxyapatite. J. Compos. Sci. 2019, 3, 45. [CrossRef]

13. Backes, E.H.; Pires, L.N.; Costa, L.C.; Passador, F.R.; Pessan, L.A. Analysis of the Degradation During Melt Processing of PLA/Biosilicate ${ }^{\circledR}$ Composites. J. Compos. Sci. 2019, 3, 52. [CrossRef]

14. Galantucci, L.M.; Lavecchia, F.; Percoco, G. Quantitative analysis of a chemical treatment to reduce roughness of parts fabricated using fused deposition modelling. CIRP Ann. Manuf. Technol. 2010, 59, 247-250. [CrossRef]

15. Sood, A.K.; Ohdar, R.K.; Mahapatra, S.S. Experimental investigation and empirical modelling of FDM process for compressive strength improvement. J. Adv. Res. 2012, 3, 81-90. [CrossRef]

16. Rao, V.; Rai, D.P. Optimization of fused deposition modelling process using teaching-learning based optimization algorithm. Eng. Sci. Technol. Int. J. 2016, 19, 587-603. [CrossRef]

17. Austin, P.; Robert, M.; Alexander, G.D.; Jack, G. Graphene and Carbon Nanotube PLA Composite Feedstock Development for Fused Deposition Modeling; University of Tennessee Honors Thesis Projects: Knoxville, TN, USA, 2016.

18. Moradi, M.; Meiabadi, S.; Kaplan, A. 3D Printed Parts with Honeycomb Internal Pattern by Fused Deposition Modelling; Experimental Characterization and Production Optimization. Met. Mater. Int. 2019, 25, 1312-1325. [CrossRef]

19. Padhi, S.K.; Sahu, R.K.; Mahapatra, S.S.; Das, H.C.; Sood, A.K.; Patro, B.; Mondal, A.K. Optimization of fused deposition modeling process parameters using a fuzzy inference system coupled with Taguchi philosophy. Adv. Manuf. 2017, 5, 231-242. [CrossRef]

20. Gardan, J.; Makke, A.; Recho, N. Improving the fracture toughness of 3D printed thermoplastic polymers by fused deposition modeling. Int. J. Fract. 2018, 210, 1-15. [CrossRef]

21. Peng, A.; Xiao, X.; Yue, R. Process parameter optimization for fused deposition modeling using response surface methodology combined with fuzzy inference system. Int. J. Adv. Manuf. Technol. 2014, 73, 87-100. [CrossRef] 
22. Sajan, N.; John, T.D.; Singh, N.K. An investigation on circularity error of components processed on Fused Deposition Modeling (FDM). Mater. Today Proc. 2018, 5, 1327-1334. [CrossRef]

23. Gautam, R.; Idapalapati, S.; Feih, S. Printing and characterisation of Kagome lattice structures by fused deposition modelling. Mater. Des. 2018, 137, 266-275. [CrossRef]

24. Ning, F.; Cong, W.; Wei, J.; Wang, S. Additive Manufacturing of CFRP Composites Using Fused Deposition Modeling: Effects of Carbon Fiber Content and Length. In Proceedings of the ASME 2015 International Manufacturing Science and Engineering Conference, Charlotte, NC, USA, 8-12 June 2015.

25. Ghennai, W.; Boussaid, O.; Bendjama, H.; Haddag, B.; Nouari, M. Experimental and numerical study of DC04 sheet metal behaviour-plastic anisotropy identification and application to deep drawing. Int. J. Adv. Manuf. Technol. 2019, 100, 361-371. [CrossRef]

26. Taherzadehboroujeni, M.; Kalhor, R.; Fahs, G.B.; Moore, R.B.; Case, S.W. Accelerated testing method to estimate the long-term hydrostatic strength of semi-crystalline plastic pipes. Poly. Eng. Sci. 2019. [CrossRef]

27. Komarasamy, M.; Wang, T.; Liu, K.; Reza-Nieto, L.; Mishra, R.S. Hierarchical multi-phase microstructural architecture for exceptional strength-ductility combination in a complex concentrated alloy via high-temperature severe plastic deformation. Scr. Mater. 2019, 162, 38-43. [CrossRef]

28. Yuan, S.; Shen, F.; Chua, C.K.; Zhou, K. Polymeric composites for powder-based additive manufacturing. Mater. Appl. Progr. Polym. Sci. 2019, 91, 141-168. [CrossRef]

29. Naranjo-Lozada, J.; Ahuett-Garza, H.; Orta-Castañón, P.; Verbeeten, W.M.; Sáiz-González, D. Tensile properties and failure behavior of chopped and continuous carbon fiber composites produced by additive manufacturing. Add. Manuf. 2019, 26, 227-241. [CrossRef]

30. Griffiths, R.J.; Perry, M.E.; Sietins, J.M.; Zhu, Y.; Hardwick, N.; Cox, C.D.; Rauch, H.A.; Hang, Z.Y. A Perspective on Solid-State Additive Manufacturing of Aluminum Matrix Composites Using MELD. J. Mater. Eng. Perform. 2019, 28, 648-656. [CrossRef]

31. Dickson, A.N.; Dowling, D.P. Enhancing the bearing strength of woven carbon fibre thermoplastic composites through additive manufacturing. Compos. Struct. 2019, 212, 381-388. [CrossRef]

32. Singh, N.; Singh, R.; Ahuja, I.P.S.; Farina, I.; Fraternali, F. Metal matrix composite from recycled materials by using additive manufacturing assisted investment casting. Compos. Struct. 2019, 207, 129-135. [CrossRef]

33. Sekar, V.; Fouladi, M.H.; Namasivayam, S.N.; Sivanesan, S. Additive Manufacturing: A Novel Method for Developing an Acoustic Panel Made of Natural Fiber-Reinforced Composites with Enhanced Mechanical and Acoustical Properties. J. Eng. 2019, 2019, 4546863. [CrossRef]

34. Feng, Y.C.; Bodaghi, M.; Liao, W.H. Numerical/experimental assessment of 3D-printed shape-memory polymeric beams. J. Appl. Polym. Sci. 2019, 136, 47422. [CrossRef]

35. Bodaghi, M.; Damanpack, A.R.; Hu, G.F.; Liao, W.H. Large deformations of soft metamaterials fabricated by 3D printing. Mater. Des. 2017, 131, 81-91. [CrossRef]

36. Kuznetsov, V.E.; Solonin, A.N.; Urzhumtsev, O.D.; Schilling, R.; Tavitov, A.G. Strength of PLA Components Fabricated with Fused Deposition Technology Using a Desktop 3D Printer as a Function of Geometrical Parameters of the Process. Polymers 2018, 10, 313. [CrossRef] [PubMed]

(C) 2020 by the authors. Licensee MDPI, Basel, Switzerland. This article is an open access article distributed under the terms and conditions of the Creative Commons Attribution (CC BY) license (http://creativecommons.org/licenses/by/4.0/). 
Article

\title{
Free Vibration Analysis of Laminated Functionally Graded Carbon Nanotube-Reinforced Composite Doubly Curved Shallow Shell Panels Using a New Four-Variable Refined Theory
}

\author{
Vu Van Tham, Tran Huu Quoc* and Tran Minh Tu \\ Faculty of Industrial and Civil Engineering, National University of Civil Engineering, Hanoi 100000, Vietnam; \\ thamvv@nuce.edu.vn (V.V.T.); tutm@nuce.edu.vn (T.M.T.) \\ * Correspondence: thquoc@gmail.com; Tel.: +84-916-600-081
}

Received: 31 October 2019; Accepted: 28 November 2019; Published: 1 December 2019

\begin{abstract}
In this paper, a new four-variable refined shell theory is developed for free vibration analysis of multi-layered functionally graded carbon nanotube-reinforced composite (FG-CNTRC) doubly curved shallow shell panels. The theory has only four unknowns and satisfies zero stress conditions at the free surfaces without correction factor. Five different types of carbon nanotube (CNTs) distribution through the thickness of each FG-CNT layer are considered. Governing equations of simply supported doubly curved FG-CNTRC panels are derived from Hamilton's principle. The resultant eigenvalue system is solved to obtain the frequencies and mode shapes of the anti-symmetric cross-ply laminated panels by using the Navier solution. The numerical results in the comparison examples have proved the accuracy and efficiency of the developed model. Detailed parametric studies have been carried out to reveal the influences of CNTs volume fraction, CNTs distribution, CNTs orientation, dimension ratios and curvature on the free vibration responses of the doubly curved laminated FG-CNTRC panels.
\end{abstract}

Keywords: free vibration analysis; doubly-curved shell and panel; nano-composites; functionally graded carbon nanotube-reinforced composite (FG-CNTRC); four-variable refined shell theory

\section{Introduction}

Functionally graded carbon nanotube-reinforced composites were first proposed by Shen [1] and have been widely accepted as a new advanced material. In functionally graded carbon nanotube-reinforced composite (FG-CNTRC) structures, the CNTs are assumed to be distributed and functionally graded with certain rules along the desired direction to improve the mechanical properties of the structures. Due to the curvature effect, doubly curved shell structures possess increased structural stiffness as compared to flat ones. Therefore, doubly curved shells are often employed to fabricate structural elements of modern constructions made of advanced materials in various engineering disciplines such as aerospace, civil, marine and mechanical engineering. It is thus significant and very meaningful to explore the mechanical response of doubly curved shells made of laminated FG-CNTRC.

Due to its simplicity and effectiveness, the equivalent single-layer model is used for multi-layer composite materials. Among the equivalent single layer models, the model based on the classical theory (CPT) [2] only provides accurate results for the thin shell because it completely neglects the effect of shear deformation. To overcome the limitations of CPT, the model based on the first-order shear deformation theory (FSDT) [3] takes into account the shear deformation effects and provides relatively accurate results for both thin and moderately thick shells, but it has to use shear correction 
factor. Therefore, the model based on the higher-order shear deformation theory (HSDT) [4-6] is often desirable. However, it is not convenient to use HSDT because the equations of motions based on HSDT are complicated and difficult to solve. Therefore, the development of simple HSDT is needed. In addition to these, a four-variable deformation theory [7-11] has been developed and applied recently. In this theory model, the transverse shear stresses are satisfied to be parabolic and to be zero on free surfaces. Furthermore, it has only four unknowns, thus the governing equations can be reduced to four.

Based on the above-mentioned theories, various studies have been done to investigate the bending, buckling and vibration responses of FG-CNTRC shells and panels. Using the third-order shear deformation theory, Mehrabadi and Aragh [12] investigated static behavior of FG-CNTRC cylindrical shells. Aragh et al. [13] and Yas et al. [14] studied free vibration of FG-CNTRC cylindrical panels. Alibeigloo [15] analyzed the free vibration behavior of the FG-CNTRC cylindrical panel embedded in piezoelectric layers based on the three-dimensional theory of elasticity and the state-space technique. Lei et al. [16] presented the first-known dynamic stability of FG-CNTRC cylindrical panels under static and periodic axial force. Rasool el al. [17] analyzed the stress wave propagation of FG-CNTRC cylinders subjected to an impact load by using an element-free method. In [18], Shen and Zhang investigated thermal post-buckling of FG-CNTRC cylindrical shells subjected to a uniform temperature rise. Based on a HSDT with a von Kármán-type of kinematic nonlinearity, Shen [19] presented the thermal post-buckling and torsional post-buckling of FG-CNTRC cylindrical shells. Furthermore, Shen and Xiang also performed research on nonlinear vibration [20], and post-buckling [21] behavior of FG-CNTRC cylindrical shells in the thermal environment. A post-buckling analysis of FG-CNTRC cylindrical panels subjected to axial compression was also presented by Liew et al. [22]. In this study, Liew et al. used a meshless approach and arc-length method combined with the modified Newton-Raphson method to trace the post-buckling path. Using the element-free kp-Ritz method, Lei et al. [23] investigated free vibration of FG-CNTRC rotating cylindrical panels. Based on the generalized differential quadrature method (GDQM)and the finite element (FE) method, Tornabene et al. [24] and Thomas et al. [25], respectively, investigated free vibration of FG-CNT-reinforced laminated composite doubly curved shells.

The purpose of this paper is to develop a new four-variable refined shell theory for free vibration analysis of multi-layered functionally graded carbon nanotube-reinforced composite doubly curved panels. The present theory has only four unknowns but it satisfies the stress-free boundary conditions on the top and bottom surface without using shear correction factors. The distribution of the carbon nanotube (CNT) through the thickness of each layer may be functionally graded or uniformly distributed. The resultant eigenvalue system is solved to obtain the frequencies and mode shapes of the anti-symmetric, cross-ply laminated panels by Navier solution. The accuracy of the presented formulation is investigated by comparing the obtained natural frequencies with existing results in the literature. Also, a novelty parameter study of the laminated FG-CNTRC doubly-curved panels of which the geometrical parameters, CNTs distributions, the volume fraction of CNTs, as well as the number of layers are also reported in detail.

\section{Theoretical Formulations}

\subsection{Description of the Model}

As shown in Figure 1, a doubly curved FG-CNTRC shell panel in the orthogonal curvilinear coordinate system $(x, y, z)$ is considered as the modal analysis. The panel has curvilinear length $a$ in the $x$-direction, curvilinear width $b$ in the $y$-direction, thickness $h$ in the $z$-direction. In the middle surface of the panel, the principal radii of curvature, denoted by $R_{x}$ and $R_{y}$, are assumed as constants. This results in unit Lamé parameters. Here, four special kinds of the doubly curved shell panels are investigated such as plate (PLA, $R_{x}=R_{y}=\infty$ ), cylindrical (CYL) panel $\left(R_{x}=R\right.$ and $\left.R_{y}=\infty\right)$, spherical (SPH) panel $\left(R_{x}=R_{y}\right)$, and hyperbolic paraboloid (HPR) panel $\left(R_{x}=-R_{y}\right)$. 


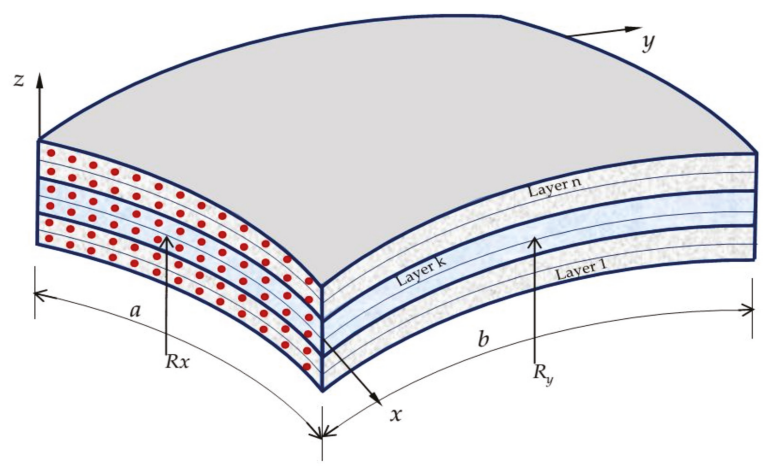

Figure 1. Schematic of the laminated functionally graded carbon nanotube-reinforced composite (FG-CNTRC) doubly curved panel.

\subsection{Material Properties of Functionally Graded Carbon Nanotube-Reinforced Composite}

In the present study, the lamina is assumed to be perfectly bonded at layer interfaces. As shown in Figure 2, five types of functionally graded distributions of CNTs in each layer are taken into consideration, named as UD, FG-A, FG-V, FG-X and FG-O.

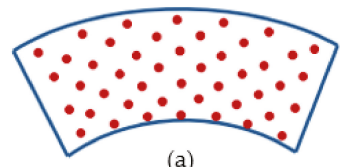

(a)

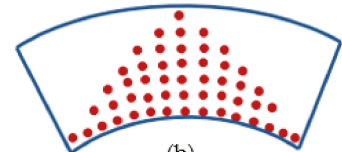

(b)

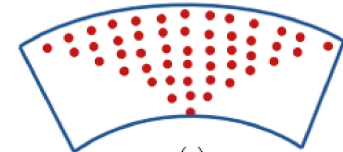

(c)

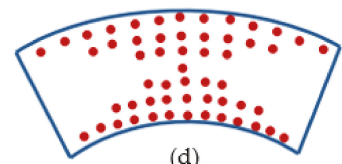

(d)

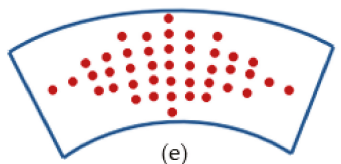

(e)

Figure 2. Configurations of the FG-CNTRC panels: (a) UD; (b) FG-A; (c) FG-V; (d) FG-X; (e) FG-O.

For these cases, the CNT volume fractions are given as [26]:

$$
\begin{aligned}
& U D: V_{C N T}(z)=V_{C N T}^{*} ; \\
& F G-V: V_{C N T}(z)=2 V_{C N T}^{*} \frac{z-z_{k}}{z_{k+1}-z_{k}} ; \\
& F G-A: V_{C N T}(z)=2 V_{C N T}^{*} \frac{z_{k+1}-z}{z_{k+1}-z_{k}} ; \\
& F G-O: V_{C N T}(z)=2 V_{C N T}^{*}\left(1-\frac{\left|2 z-z_{k}-z_{k+1}\right|}{z_{k+1}-z_{k}}\right) ; \\
& F G-X: V_{C N T}(z)=2 V_{C N T}^{*}\left(\frac{\left|2 z-z_{k}-z_{k+1}\right|}{z_{k+1}-z_{k}}\right)
\end{aligned}
$$

where $z_{k}$ and $z_{k+1}$ are the coordinates of the $k$-th layer to the reference plane $(z=0)$. $V_{C N T}^{*}$ is the given volume fraction of CNTs and can be calculated as:

$$
V_{C N T}^{*}=\frac{w_{C N T}}{w_{C N T}+\left(\rho^{C N T} / \rho^{m}\right)-\left(\rho^{C N T} / \rho^{m}\right) w_{C N T}}
$$


in which, $w_{C N T}$ is the mass fraction of the carbon nanotube, $\rho^{m}$ and $\rho^{\mathrm{CNT}}$ are mass densities of the matrix and the CNT, respectively. The effective material properties of FG-CNTRC of each layer can be expressed by the extended rule of the mixture as follows [27]:

$$
\begin{aligned}
& E_{11}(z)=\eta_{1} V_{C N T}(z) E_{11}^{C N T}+V_{m}(z) E^{m} \\
& \frac{\eta_{2}}{E_{22}(z)}=\frac{V_{C N T}(z)}{E_{22}^{C N T}}+\frac{V_{m}(z)}{E^{m}} ; \\
& \frac{\eta_{3}}{G_{12}(z)}=\frac{V_{C N T}(z)}{G_{12}^{C N T}}+\frac{V_{m}(z)}{G^{m}} ; \\
& \rho(z)=V_{C N T}(z) \rho^{C N T}+V_{m}(z) \rho^{m} ; \\
& v_{12}=V_{C N T}^{*} v_{12}^{C N T}+V_{m}(z) v^{m}
\end{aligned}
$$

where $E_{11}^{C N T}, E_{22}^{C N T}, E^{m}$ and $G_{12}^{C N T}, G^{m}$ are the Young's moduli and shear modulus of CNT and matrix; $\eta_{1}, \eta_{2}$ and $\eta_{3}$ are CNT/matrix efficiency parameters; $V_{C N T}(z)$ and $V_{m}(z)$ are volume fractions of CNT and matrix, and are related by $V_{C N T}(z)+V_{m}(z)=1 ; v_{12}^{C N T}$ and $v^{m}$ are Poisson's ratio of CNT and matrix.

\subsection{Kinematic Relations}

This work aims to establish a new shear deformation shell theory. The main idea of the present theory comes from the four-variable refined theory $[8,9,11,28,29]$. According to assumptions of various four-variable refined theories, the transverse displacement $w$ is partitioned into the bending component $w_{b}$ and shear component $w_{s}$, the in-plane displacements $u$ and $v$ are also partitioned into the extension component $u_{0}, v_{0}$, the bending component $u_{b}, v_{b}$, and shear component $u_{s}, v_{s}$. Therefore, the displacement field in the doubly curved shell space can be expressed as follows:

$$
\begin{aligned}
& u(x, y, z, t)=\left(1+\frac{z}{R_{x}}\right) u_{0}(x, y, t)-z \frac{\partial w_{b}(x, y, t)}{\partial x}-f(z) \frac{\partial w_{s}(x, y, t)}{\partial x} \\
& v(x, y, z, t)=\left(1+\frac{z}{R_{y}}\right) v_{0}(x, y, t)-z \frac{\partial w_{b}(x, y, t)}{\partial y}-f(z) \frac{\partial w_{s}(x, y, t)}{\partial y} \\
& w(x, y, z, t)=w_{b}(x, y, t)+w_{s}(x, y, t)
\end{aligned}
$$

where $u_{0}, v_{0}$ denote the displacements along $x$ and $y$ coordinate directions of the corresponding point on the reference surface; $w_{b}$ and $w_{s}$ are the bending and shear components of the transverse displacement, respectively; $f(z)$ represents shape function determining the distribution of the transverse shear strains and stresses along the thickness. By the same methodology, in the previous study [29], we proposed a new shape function $f(z)$ as follows:

$$
f(z)=z\left[-\frac{1}{8}+\frac{3}{2}\left(\frac{z}{h}\right)^{2}\right]
$$

Detail steps to construct this shape function for shell panels are listed in Appendix A.

The strains associated with the displacement field in Equation (4) are:

$$
\begin{aligned}
\varepsilon_{x x} & =\frac{1}{1+z / R_{x}}\left[\varepsilon_{x}^{0}+z \kappa_{x}^{b}+f(z) \kappa_{x}^{s}\right] ; \\
\varepsilon_{y y} & =\frac{1}{1+z / R_{y}}\left[\varepsilon_{y}^{0}+z \kappa_{y}^{b}+f(z) \kappa_{y}^{s}\right] ; \\
\gamma_{x y} & =\frac{1}{1+z / R_{x}}\left[\gamma_{x y}^{0}+z \kappa_{x y}^{b}+f(z) \kappa_{x y}^{s}\right]+\frac{1}{1+z / R_{y}}\left[\gamma_{y x}^{0}+z \kappa_{y x}^{b}+f(z) \kappa_{y x}^{s}\right] \\
\gamma_{x z} & =\frac{1}{1+z / R_{x}} g(z) \gamma_{x z}^{s} ; \\
\gamma_{y z} & =\frac{1}{1+z / R_{y}} g(z) \gamma_{y z}^{s}
\end{aligned}
$$


where:

$$
\begin{aligned}
& \varepsilon_{x}^{0}=\left(\frac{\partial u_{0}}{\partial x}+\frac{w_{b}}{R_{x}}+\frac{w_{s}}{R_{x}}\right) ; \gamma_{x y}^{0}=\frac{\partial v_{0}}{\partial x} ; \\
& \varepsilon_{y}^{0}=\left(\frac{\partial v_{0}}{\partial y}+\frac{w_{b}}{R_{y}}+\frac{w_{s}}{R_{y}}\right) ; \gamma_{y x}^{0}=\frac{\partial u_{0}}{\partial y} ; \\
& k_{x}^{b}=\left(\frac{1}{R_{x}} \frac{\partial u_{0}}{\partial x}-\frac{\partial w_{b}^{2}}{\partial x^{2}}\right) ; \kappa_{y}^{b}=\left(\frac{1}{R_{y}} \frac{\partial v_{0}}{\partial y}-\frac{\partial w_{b}^{2}}{\partial y^{2}}\right) ; \\
& \kappa_{x y}^{b}=\left(\frac{1}{R_{y}} \frac{\partial v_{0}}{\partial x}-\frac{\partial w_{b}^{2}}{\partial x \partial y}\right) ; \kappa_{y x}^{b}=\left(\frac{1}{R_{x}} \frac{\partial u_{0}}{\partial y}-\frac{\partial w_{b}^{2}}{\partial x \partial y}\right) ; \\
& k_{x}^{s}=-\frac{\partial^{2} w_{s}}{\partial x^{2}} ; k_{y}^{s}=-\frac{\partial^{2} w_{s}}{\partial y^{2}} ; \kappa_{x y}^{s}=\frac{\partial^{2} w_{s}}{\partial x \partial y} ; \kappa_{y x}^{s}=-\frac{\partial^{2} w_{s}}{\partial x \partial y} ; \\
& \gamma_{y z}=\frac{1}{1+z / R_{x}} g(z) \frac{\partial w_{s}}{\partial x} ; g(z)=\left(1-f^{\prime}(z)\right) ;
\end{aligned}
$$

The constitutive relation for an individual layer can be determined by the generalized Hooke's law, namely [30,31]:

$$
\left\{\begin{array}{c}
\sigma_{x x}^{k} \\
\sigma_{y y}^{k} \\
\tau_{y z}^{k} \\
\tau_{x z}^{k} \\
\tau_{x y}^{k}
\end{array}\right\}=\left[\begin{array}{ccccc}
\bar{Q}_{11}^{k} & \bar{Q}_{11}^{k} & 0 & 0 & \bar{Q}_{16}^{k} \\
\bar{Q}_{12}^{k} & \bar{Q}_{22}^{k} & 0 & 0 & \bar{Q}_{26}^{k} \\
0 & 0 & \bar{Q}_{44}^{k} & \bar{Q}_{45}^{k} & 0 \\
0 & 0 & \bar{Q}_{45}^{k} & \bar{Q}_{55}^{k} & 0 \\
\bar{Q}_{16}^{k} & \bar{Q}_{26}^{k} & 0 & 0 & \bar{Q}_{66}^{k}
\end{array}\right]\left\{\begin{array}{c}
\varepsilon_{x x} \\
\varepsilon_{y y} \\
\gamma_{y z} \\
\gamma_{x z} \\
\gamma_{x y}
\end{array}\right\}
$$

where $\bar{Q}_{i j}^{k}$ are the transformed material constraints expressed in terms of material constants:

$$
\begin{aligned}
& \bar{Q}_{11}^{k}=Q_{11} \cos ^{4} \theta^{k}+2\left(Q_{12}+2 Q_{66}\right) \sin ^{2} \theta^{k} \cos ^{2} \theta^{k}+Q_{22} \sin ^{4} \theta^{k} ; \\
& \bar{Q}_{12}^{k}=\left(Q_{11}+Q_{22}-4 Q_{66}\right) \sin ^{2} \theta^{k} \cos ^{2} \theta^{k}+Q_{12}\left(\sin ^{4} \theta^{k}+\cos ^{4} \theta^{k}\right) ; \\
& \bar{Q}_{22}^{k}=Q_{11} \sin ^{4} \theta^{k}+2\left(Q_{12}+2 Q_{66}\right) \sin ^{2} \theta^{k} \cos ^{2} \theta^{k}+Q_{22} \cos ^{4} \theta^{k} ; \\
& \bar{Q}_{16}^{k}=\left(Q_{11}-Q_{12}-2 Q_{66}\right) \sin \theta^{k} \cos ^{3} \theta^{k}+\left(Q_{12}-Q_{22}+2 Q_{66}\right) \sin ^{3} \theta^{k} \cos \theta^{k} ; \\
& \bar{Q}_{26}^{k}=\left(Q_{11}-Q_{12}-2 Q_{66}\right) \sin ^{3} \theta^{k} \cos \theta^{k}+\left(Q_{12}-Q_{22}+2 Q_{66}\right) \sin \theta^{k} \cos ^{3} \theta^{k} ; \\
& \bar{Q}_{66}^{k}=\left(Q_{11}+Q_{22}-2 Q_{12}-2 Q_{66}\right) \sin ^{2} \theta^{k} \cos ^{2} \theta^{k}+Q_{66}\left(\sin ^{4} \theta^{k}+\cos ^{4} \theta^{k}\right) ; \\
& \bar{Q}_{44}^{k}=Q_{44} \cos ^{2} \theta^{k}+Q_{55} \sin ^{2} \theta^{k} ; \\
& \bar{Q}_{45}^{k}=\left(Q_{55}-Q_{44}\right) \cos \theta^{k} \sin \theta^{k} ; \\
& \bar{Q}_{55}^{k}=Q_{55} \cos ^{2} \theta^{k}+Q_{44} \sin ^{2} \theta^{k} .
\end{aligned}
$$

in which, $Q_{i j}$ are the plane stress-reduced stiffnesses defined in terms of the engineering constants in the material axes of the layer. For each CNT layer:

$$
\begin{aligned}
& Q_{11}=\frac{E_{11}(z)}{1-v_{12} v_{21}} ; Q_{12}=\frac{v_{12} E_{22}(z)}{1-v_{12} v_{21}} ; Q_{22}=\frac{E_{22}(z)}{1-v_{12} v_{21}} ; \\
& Q_{44}=G_{23}(z) ; Q_{55}=G_{13}(z) ; Q_{66}=G_{12}(z)
\end{aligned}
$$




\subsection{Governing Equations}

Hamilton's principle is used herein to derive the equations of motion. In the absence of external forces, the principle can be stated in the analytical form as [32]:

$$
\int_{t_{1}}^{t_{2}}(\delta U-\delta K) d t=0
$$

where $\delta U$ is the variation of the strain energy, $\delta K$ is the variation of the kinetic energy, $t_{1}$ and $t_{2}$ are arbitrary time variables. The strain energy of the plate can be calculated as:

$$
\begin{aligned}
U= & \frac{1}{2} \int_{0}^{a} \int_{0}^{b} \int_{h / 2}^{h / 2}\left(\sigma_{x x} \varepsilon_{x x}+\sigma_{y y} \varepsilon_{y y}+\tau_{x y} \gamma_{x y}+\tau_{x z} \gamma_{x z}+\tau_{y z} \gamma_{y z}\right)\left(1+\frac{z}{R_{x}}\right)\left(1+\frac{z}{R_{y}}\right) d z d y d x \\
= & \frac{1}{2} \int_{0}^{a} \int_{0}^{b}\left(N_{x x} \varepsilon_{x x}^{0}+N_{y y} \varepsilon_{y y}^{0}+N_{x y} \gamma_{x y}^{0}+N_{y x} \gamma_{y x}^{0}+M_{x x}^{b} \kappa_{x x}^{b}+M_{y y}^{b} \kappa_{y y}^{b}+M_{x y}^{b} \kappa_{x y}^{b}+M_{y x}^{b} \kappa_{y x}^{b}+\right. \\
& \left.M_{x x}^{s} \kappa_{x x}^{s}+M_{y y}^{s} \kappa_{y y}^{s}+M_{x y}^{s} \kappa_{x y}^{s}+M_{y x}^{s} \kappa_{y x}^{s}+Q_{y s} \gamma_{y z}^{s}+Q_{x s} \gamma_{x z}^{s}\right) d x d y
\end{aligned}
$$

where stress resultants $(N, M$ and $Q)$ are defined by:

$$
\begin{aligned}
& \left\{\begin{array}{l}
N_{x x} \\
N_{x y} \\
Q_{x s}
\end{array}\right\}=\sum_{k=1}^{n} \int_{z_{k}}^{z_{k+1}}\left(1+\frac{z}{R_{y}}\right)\left\{\begin{array}{c}
\sigma_{x x}^{k} \\
\sigma_{x y}^{k} \\
\tau_{x z}^{k}
\end{array}\right\} d z ;\left\{\begin{array}{c}
N_{y y} \\
N_{y x} \\
Q_{y s}
\end{array}\right\}=\sum_{k=1}^{n} \int_{z_{k}}^{z_{k+1}}\left(1+\frac{z}{R_{x}}\right)\left\{\begin{array}{c}
\sigma_{y y}^{k} \\
\sigma_{y x}^{k} \\
\tau_{y z}^{k}
\end{array}\right\} d z ; \\
& \left\{\begin{array}{c}
M_{x x}^{b} \\
M_{x y}^{b}
\end{array}\right\}=\sum_{k=1}^{n} \int_{z_{k}}^{z_{k+1}}\left(1+\frac{z}{R_{y}}\right)\left\{\begin{array}{c}
\sigma_{x x}^{k} \\
\sigma_{x y}^{k}
\end{array}\right\} z d z ;\left\{\begin{array}{c}
M_{y y}^{b} \\
M_{y x}^{b}
\end{array}\right\}=\sum_{k=1}^{n} \int_{z_{k}}^{z_{k+1}}\left(1+\frac{z}{R_{x}}\right)\left\{\begin{array}{c}
\sigma_{y y}^{k} \\
\sigma_{y x}^{k}
\end{array}\right\} z d z ; \\
& \left\{\begin{array}{c}
M_{x x}^{s} \\
M_{x y}^{s}
\end{array}\right\}=\sum_{k=1}^{n} \int_{z_{k}}^{z_{k+1}}\left(1+\frac{z}{R_{y}}\right)\left\{\begin{array}{c}
\sigma_{x x}^{k} \\
\sigma_{x y}^{k}
\end{array}\right\} f(z) d z ;\left\{\begin{array}{c}
M_{y y}^{s} \\
M_{y x}^{s}
\end{array}\right\}=\sum_{k=1}^{n} \int_{z_{k}}^{z_{k+1}}\left(1+\frac{z}{R_{x}}\right)\left\{\begin{array}{c}
\sigma_{y y}^{k} \\
\sigma_{y x}^{k}
\end{array}\right\} f(z) d z .
\end{aligned}
$$

Based on the constitutive relations (8), strain-displacement relation (6) and displacement field (4), the force and moment resultants can be rewritten in terms of displacement components as:

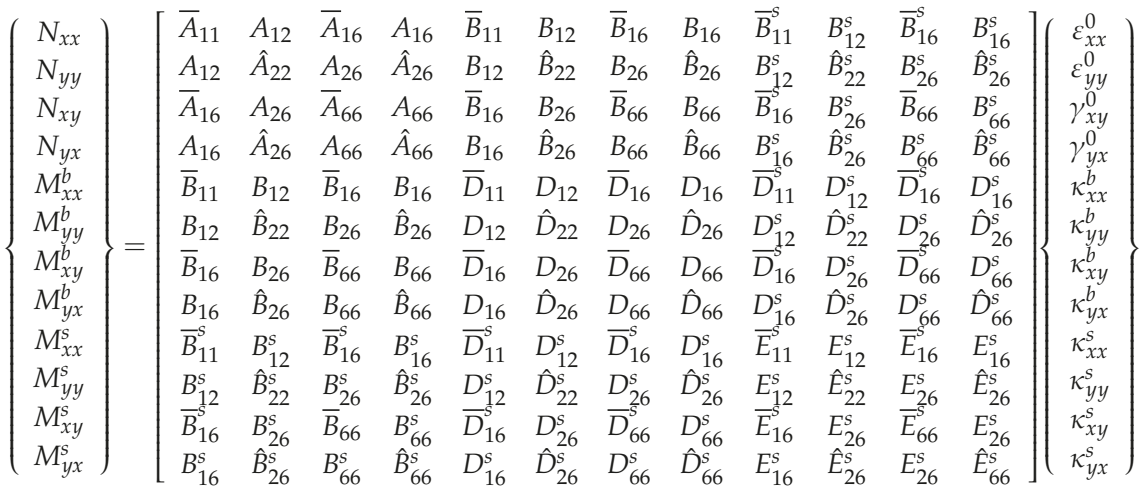

$$
\begin{aligned}
& \left\{\begin{array}{l}
Q_{y s} \\
Q_{x s}
\end{array}\right\}=\left[\begin{array}{cc}
\hat{A}_{44}^{s} & A_{45}^{s} \\
A_{45}^{s} & \bar{A}_{55}^{s}
\end{array}\right]\left\{\begin{array}{c}
\gamma_{y z}^{s} \\
\gamma_{x z}^{s}
\end{array}\right\}
\end{aligned}
$$


in which:

$$
\begin{aligned}
& \left\{A_{i j}, B_{i j}, D_{i j}, B_{i j}^{s}, D_{i j}^{s}, A_{i j}^{s}\right\}=\sum_{1}^{N} \int_{z_{k}}^{z_{+1}} \bar{Q}_{i j}^{(k)}\left\{1, z, z^{2}, f(z), z f(z), g^{2}(z)\right\} d z \\
& \left\{\bar{A}_{i j}, \bar{B}_{i j}, \bar{D}_{i j}, \bar{B}_{i j}^{s}, \bar{D}_{i j}^{s}, \bar{A}_{i j}^{s}\right\}=\left\{A_{i j x}, B_{i j x}, D_{i j x}, B_{i j x^{\prime}}^{s} D_{i j x^{\prime}}^{s}, A_{i j x}^{s}\right\}+\frac{\left\{B_{i j x}, D_{i j x}, E_{i j x}, D_{i j x^{\prime}}^{s} E_{i j x^{\prime}}^{s} A A_{i j x}^{s}\right\}}{R_{y}} ; \\
& \left\{A_{i j x}, B_{i j x}, D_{i j x}, E_{i j x}, B_{i j x^{\prime}}^{s} D_{i j x^{\prime}}^{s} E_{i j x^{\prime}}^{s} A_{i j x^{\prime}}^{s} A A_{i j x}^{s}\right\}= \\
& \sum_{1}^{N} \int_{z_{k}}^{z_{+1}} \bar{Q}_{i j}^{(k)} \frac{\left\{1, z, z^{2}, z^{3}, f(z), z f(z), z^{2} f(z), g(z), z g(z)\right\}}{1+z / R_{x}} d z \\
& \left\{\hat{A}_{i j}, \hat{B}_{i j}, \hat{D}_{i j}, \hat{B}_{i j}^{s}, \hat{D}_{i j}^{s}, \hat{A}_{i j}^{s}\right\}=\left\{A_{i j y}, B_{i j y}, D_{i j y}, B_{i j y^{\prime}}^{s} D_{i j y^{\prime}}^{s} A_{i j y}^{s}\right\}+\frac{\left\{B_{i j y}, D_{i j y}, E_{i j y}, D_{i j y,}^{s}, E_{i j y}^{s}, A A_{i j y}^{s}\right\}}{R_{x}} \\
& \left\{A_{i j y}, B_{i j y}, D_{i j y}, E_{i j y}, B_{i j y^{\prime}}^{s} D_{i j y^{\prime}}^{s} E_{i j y^{\prime}}^{s} A_{i j y^{\prime}}^{s} A A_{i j y}^{s}\right\} \\
& =\sum_{1}^{N} \int_{z_{k}}^{z+1} \bar{Q}_{i j}^{(k)} \frac{\left\{1, z, z^{2}, z^{3}, f(z), z f(z), z^{2} f(z), g(z), z g(z)\right\}}{1+z / R_{y}} d z
\end{aligned}
$$

The variation of the kinetic energy of the panel can be written as:

$$
\begin{aligned}
K= & \frac{1}{2} \int_{0}^{a} \int_{0}^{b} \int_{-h / 2}^{h / 2} \rho(z)\left(\dot{u}^{2}+\dot{v}^{2}+\dot{w}^{2}\right)\left(1+\frac{z}{R_{x}}\right)\left(1+\frac{z}{R_{y}}\right) d z d y d x \\
= & \frac{1}{2} \int_{0}^{a} \int_{0}^{b}\left(\left(\bar{I}_{0} \dot{u}_{0}+\bar{I}_{2} \dot{\phi}_{x b}^{2}+\bar{K}_{1} \dot{\phi}_{x \mathrm{~s}}^{2}+2 \bar{I}_{1} \dot{u}_{0} \dot{\phi}_{x b}+2 \bar{J}_{1} \dot{u}_{0} \dot{\phi}_{x \mathrm{~s}}+2 \bar{J}_{2} \dot{\phi}_{x b} \dot{\phi}_{x \mathrm{~s}}+\bar{I}_{0} \dot{v}_{0}^{2}+\bar{I}_{2} \dot{\phi}_{y b}^{2}\right.\right. \\
& \left.+\bar{K}_{1} \dot{\phi}_{y s}^{2}+2 \bar{I}_{1} \dot{v}_{0} \dot{\phi}_{y b}+2 \bar{J}_{1} \dot{v}_{0} \dot{\phi}_{y s}+2 \bar{J}_{2} \dot{\phi}_{y b} \dot{\phi}_{y s}+\bar{I}_{0}\left(\dot{w}_{b}^{2}+\dot{w}_{2}^{s}+2 \dot{w}_{b} \dot{w}_{s}\right)\right) d y d x
\end{aligned}
$$

where:

$$
\phi_{x b}=\left(\frac{u_{0}}{R_{x}}-\frac{\partial w_{b}}{\partial x}\right) ; \phi_{x s}=-\frac{\partial w_{s}}{\partial x} ; \phi_{y b}=\left(\frac{v_{0}}{R_{y}}-\frac{\partial w_{b}}{\partial y}\right) ; \phi_{y s}=-\frac{\partial w_{s}}{\partial y}
$$

and $\rho(z)$ is the mass density, and the mass moments of inertia $\bar{I}_{i}(\mathbf{i}=0,1,2)$ are defined as $[30,33]$ :

$$
\begin{aligned}
& \bar{I}_{i}=I_{i}+I_{i+1}\left(\frac{1}{R_{x}}+\frac{1}{R_{y}}\right)+\frac{I_{i+2}}{R_{x} R_{y}} ; \\
& \left\{I_{0}, I_{1}, I_{2}, I_{3}\right\}=\sum_{k=1}^{N} \int_{z_{k}}^{z_{+}} \rho(z)\left\{1, z, z^{2}, z^{3}\right\} d z ; \\
& \bar{J}_{i}=f(z) \bar{I}_{i-1} ; \bar{K}_{1}=f^{2}(z) \bar{I}_{0}
\end{aligned}
$$

Substituting the expressions of $U$ and $K$ from Equation (12) and Equation (17) into Equation (11), and by performing some mathematical manipulations, the equations of motion of the shell panel are obtained as follows:

$$
\begin{aligned}
& 0=-\int_{A}\left[\begin{array}{c}
{\left[\begin{array}{l}
\frac{\partial N_{x x}}{\partial x}+\frac{\partial N_{y x}}{\partial y}+\frac{Q_{x b}}{R_{x}}-\bar{I}_{0} \ddot{u}_{0}-\bar{I}_{1}\left(\frac{\ddot{u}_{0}}{R_{x}}-\frac{\partial \ddot{w}_{b}}{\partial x}\right)+\bar{J}_{1} \frac{\partial \ddot{w}_{s}}{\partial x} \\
\frac{\partial N_{y y}}{\partial y}+\frac{\partial N_{y x}}{\partial x}+\frac{Q_{y b}}{R_{y}}-\bar{I}_{0} \ddot{v}_{0}-\bar{I}_{1}\left(\frac{\ddot{v}_{0}}{R_{y}}-\frac{\partial \ddot{w}_{b}}{\partial y}\right)+\bar{J}_{1} \frac{\partial \ddot{w}_{s}}{\partial y}
\end{array}\right] \delta u_{0}} \\
{\left[-\frac{\partial N_{x x}}{R_{x}}-\frac{\partial N_{y y}}{R_{y}}+\frac{\partial Q_{x b}}{\partial x}+\frac{\partial Q_{y b}}{\partial y}-\bar{I}_{0}\left(\ddot{w}_{b}+\ddot{w}_{s}\right)\right] \delta w_{b}} \\
\left.-\frac{\partial N_{x x}}{R_{x}}-\frac{\partial N_{y y}}{R_{y}}+\frac{\partial Q_{x s}}{\partial x}+\frac{\partial Q_{y s}}{\partial y}-\bar{I}_{0}\left(\ddot{w}_{b}+\ddot{w}_{s}\right)\right] \delta w_{s}
\end{array}\right] d A \\
& +\int_{0}^{b}\left[\Gamma_{x}\right]_{0}^{a} d y+\int_{0}^{a}\left[\Gamma_{y}\right]_{0}^{b} d x
\end{aligned}
$$


where:

$$
\begin{aligned}
& Q_{x b}=\frac{\partial M_{x x}^{b}}{\partial x}+\frac{\partial M_{y x}^{b}}{\partial y}-\left(\bar{I}_{1}+\frac{\bar{I}_{2}}{R_{x}}\right) \ddot{u}_{0}+\bar{I}_{2} \frac{\partial \ddot{w}_{b}}{\partial x}+\bar{J}_{2} \frac{\partial \ddot{w}_{s}}{\partial x} \\
& Q_{y b}=\frac{\partial M_{y y}^{b}}{\partial y}+\frac{\partial M_{x y}^{b}}{\partial x}-\left(\bar{I}_{1}+\frac{\bar{I}_{2}}{R_{y}}\right) \ddot{v}_{0}+\bar{I}_{2} \frac{\partial \ddot{w}_{b}}{\partial y}+\bar{J}_{2} \frac{\partial \ddot{w}_{s}}{\partial_{y}} \\
& \bar{Q}_{x s}=\frac{\partial M_{x x}^{s}}{\partial x}+\frac{\partial M_{y x}^{s}}{\partial y}+Q_{x s}-\left(\bar{J}_{1}+\frac{\bar{J}_{2}}{R_{x}}\right) \ddot{u}_{0}+\bar{J}_{2} \frac{\partial \ddot{w}_{b}}{\partial x}+\bar{K}_{1} \frac{\partial \ddot{w}_{s}}{\partial_{x}} \\
& \bar{Q}_{y s}=\frac{\partial M_{y y}^{s}}{\partial y}+\frac{\partial M_{x y}^{s}}{\partial x}+Q_{y s}-\left(\bar{J}_{1}+\frac{\bar{J}_{2}}{R_{y}}\right) \ddot{v}_{0}+\bar{J}_{2} \frac{\partial \ddot{w}_{b}}{\partial x}+\bar{K}_{1} \frac{\partial \ddot{w}_{s}}{\partial y}
\end{aligned}
$$

and $\Gamma_{x}, \Gamma_{y}$ are boundary expressions:

$$
\begin{aligned}
& \Gamma_{x}=\bar{N}_{x x} \delta u_{0}+\bar{N}_{x y} \delta v_{0}+Q_{x b} \delta w_{b}+\bar{Q}_{x s} \delta w_{s}+M_{x x}^{b} \delta \widetilde{\phi}_{x b}+M_{x y}^{b} \delta \widetilde{\phi}_{y b}+M_{x x}^{s} \delta \phi_{x s}+M_{x y}^{s} \delta \phi_{y s} \\
& \Gamma_{y}=\bar{N}_{y y} \delta v_{0}+\bar{N}_{y x} \delta u_{0}+Q_{y b} \delta w_{b}+\bar{Q}_{y s} \delta w_{s}+M_{y y}^{b} \delta \widetilde{\phi}_{y b}+M_{y x}^{b} \delta \widetilde{\phi}_{x b}+M_{y y}^{s} \delta \phi_{y s}+M_{y x}^{s} \delta \phi_{x s}
\end{aligned}
$$

in which:

$$
\begin{aligned}
& \bar{N}_{x x}=\left(N_{x x}-\frac{M_{x x}^{b}}{R_{x}}\right) ; \bar{N}_{x y}=\left(N_{x y}-\frac{M_{x y}^{b}}{R_{y}}\right) ; \bar{N}_{y y}=\left(N_{y y}-\frac{M_{y y}^{b}}{R_{y}}\right) ; \bar{N}_{y x}=\left(N_{y x}-\frac{M_{y x}^{b}}{R_{x}}\right) ; \\
& \widetilde{\phi}_{x b}=-\frac{\partial w_{b}}{\partial x} ; \phi_{x s}=-\frac{\partial w_{s}}{\partial x} ; \widetilde{\phi}_{y b}=-\frac{\partial w_{b}}{\partial y} ; \phi_{y s}=-\frac{\partial w_{s}}{\partial y}
\end{aligned}
$$

By setting the coefficients of the virtual displacements $\delta u_{0}, \delta v_{0}, \delta w_{b}, \delta w_{s}$ to zeros, the governing equations are obtained as follows:

$$
\begin{aligned}
& \delta u_{0}: \frac{\partial N_{x x}}{\partial x}+\frac{\partial N_{y x}}{\partial y}+\frac{Q_{x b}}{R_{x}}=\bar{I}_{0} \ddot{u}_{0}+\bar{I}_{1}\left(\frac{\ddot{u}_{0}}{R_{x}}-\frac{\partial \ddot{w}_{b}}{\partial y}\right)-\bar{J}_{1} \frac{\partial \ddot{w}_{s}}{\partial x} \\
& \delta v_{0}: \frac{\partial N_{y y}}{\partial y}+\frac{\partial N_{y x}}{\partial x}+\frac{Q_{y b}}{R_{y}}=\bar{I}_{0} \ddot{v}_{0}+\bar{I}_{1}\left(\frac{\ddot{w}_{0}}{R_{y}}-\frac{\partial \ddot{w}_{b}}{\partial y}\right)-\bar{J}_{1} \frac{\partial \ddot{w}_{s}}{\partial y} \\
& \delta w_{b}: \frac{\partial N_{x x}}{R_{x}}+\frac{\partial N_{y y}}{R_{y}}-\frac{\partial Q_{x b}}{\partial x}-\frac{\partial Q_{y b}}{\partial y}=-\bar{I}_{0}\left(\ddot{w}_{b}+\ddot{w}_{s}\right) \\
& \delta w_{s}: \frac{\partial N_{x x}}{R_{x}}+\frac{\partial N_{y y}}{R_{y}}-\frac{\partial Q_{x s}}{\partial x}-\frac{\partial Q_{y s}}{\partial y}=-\bar{I}_{0}\left(\ddot{w}_{b}+\ddot{w}_{s}\right)
\end{aligned}
$$

\subsection{Solution Procedure}

The Navier method is employed to formulate the closed-form solution for vibration problems of simply supported anti-symmetric cross-ply laminated FG-CNTRC panels. The simply supported boundary conditions on all four edges can be considered as:

$$
\begin{aligned}
& v_{0}=w_{b}=w_{s}=w_{b, y}=w_{s, y}=N_{x x}=M_{x x}^{b}=M_{x x}^{s}=0 \text { at } x=0 \text { and } x=a \\
& u_{0}=w_{b}=w_{s}=w_{b, x}=w_{s, x}=N_{y y}=M_{y y}^{b}=M_{y y}^{s}=0 \text { at } y=0 \text { and } y=b
\end{aligned}
$$


These boundary conditions are exactly satisfied by the following double Fourier series forms:

$$
\begin{aligned}
& u(x, y, t)=\sum_{m=1}^{\infty} \sum_{n=1}^{\infty} U_{m n} e^{i \omega t} \cos \alpha_{m} x \sin \beta_{n} y ; \\
& v(x, y, t)=\sum_{m=1}^{\infty} \sum_{n=1}^{\infty} \mathrm{V}_{m n} e^{i \omega t} \sin \alpha_{m} x \cos \beta_{n} y ; \\
& w_{b}(x, y, t)=\sum_{m=1}^{\infty} \sum_{n=1}^{\infty} W_{b m n} e^{i \omega t} \sin \alpha_{m} x \sin \beta_{n} y ; \\
& w_{s}(x, y, t)=\sum_{m=1}^{\infty} \sum_{n=1}^{\infty} W_{s m n} e^{i \omega t} \sin \alpha_{m} x \sin \beta_{n} y .
\end{aligned}
$$

where $\left(U_{m n}, V_{m n}, W_{b m n}, W_{s m n}\right)$ are unknown coefficients to be determined, $\omega$ is the circular frequency of vibration, and $i=\sqrt{-1}, \alpha_{m}=m \pi / a, \beta_{n}=n \pi / b$ and $m, n$ denote the number of haft-waves in the $x$ and $y$ directions, respectively.

Substituting the admissible displacement functions of Equation (27) into the equation of motion, Equation (20), one obtains the analytical solution in the following matrix form:

$$
\left(\left[\begin{array}{llll}
s_{11} & s_{12} & s_{13} & s_{14} \\
s_{12} & s_{22} & s_{23} & s_{24} \\
s_{13} & s_{23} & s_{33} & s_{34} \\
s_{14} & s_{24} & s_{34} & s_{44}
\end{array}\right]-\omega^{2}\left[\begin{array}{llll}
m_{11} & m_{12} & m_{13} & m_{14} \\
m_{12} & m_{22} & m_{23} & m_{24} \\
m_{13} & m_{23} & m_{33} & m_{34} \\
m_{14} & m_{24} & m_{34} & m_{44}
\end{array}\right]\right)\left\{\begin{array}{c}
U_{m n} \\
V_{m n} \\
W_{b m n} \\
W_{s m n}
\end{array}\right\}=\left\{\begin{array}{l}
0 \\
0 \\
0 \\
0
\end{array}\right\}
$$

where the matrix elements of Equation (28) are given in the Appendix B.

\section{Numerical Results and Discussions}

In this section, several examples are presented and discussed to verify the accuracy and efficiency of the proposed theory in free vibration analysis of simply supported FG-CNTRC doubly-curved panels. Furthermore, the effects of volume fraction of CNTs, distribution type of CNTs, number of layers, CNT fiber orientation and geometrical parameters on the natural frequencies of panels are also investigated in detail. The material properties for the matrix and CNT are given in Table 1 [34,35]. Also, the CNT efficiency parameters $\eta_{j}(j=1,2,3)$ associated with a given volume fraction $V_{C N T}^{*}$ are: $\eta_{1}=0.149$ and $\eta_{2}=\eta_{3}=0.934$ for the case of $V_{C N T}^{*}=0.11 ; \eta_{1}=0.150$ and $\eta_{2}=\eta_{3}=0.941$ for the case of $V_{C N T}^{*}=0.14 ; \eta_{1}=0.149$ and $\eta_{2}=\eta_{3}=1.381$ for the case of $V_{C N T}^{*}=0.17$.

Table 1. Material properties of carbon nanotube (CNT) and matrix materials.

\begin{tabular}{cc}
\hline CNT & Matrix \\
\hline$E_{11}^{C N T}=5.6466 \mathrm{TPa}$ & $E^{m}=2.1 \mathrm{GPa}$ \\
$E_{22}^{C N T}=7.0800 \mathrm{TPa}$ & $v^{m}=0.34$ \\
$G_{12}^{C N T}=1.9445 \mathrm{TPa}$ & $\rho^{m}=1150 \mathrm{~kg} / \mathrm{m}^{3}$ \\
$v_{12}^{C N T}=0.175$ & - \\
$\rho^{C N T}=1400 \mathrm{~kg} / \mathrm{m}^{3}$ & - \\
\hline
\end{tabular}

\subsection{Comparison Studies}

To verify the reliability and accuracy of the present model, several comparison studies were carried out with the results of the previous literature [34,35].

Example 1: Free Vibration of the Simply Supported Doubly Curved FG-CNTRC Panels

Free vibration of the simply supported doubly curved single-layered FG-CNTRC panels is further analyzed for the comparison of the results obtained from the present formulation with the existing results developed by Pouresmaeeli and Fazelzadeh [34] based on FSDT formulations. The geometrical dimensions of the panels are taken as $a / b=1$ and $a / h=20$. Values of material parameters are listed 
in Table 1. From the results presented in Table 2, it is observed that the values of the fundamental frequency for plates, spherical, cylindrical, and hyperbolic paraboloid panels have excellent agreement with the available data.

Table 2. Comparison of the non-dimensional frequencies $\bar{\omega}=\omega\left(a^{2} / h\right) \sqrt{\rho^{m} / E^{m}}$ of the simply supported doubly curved FG-CNTRC panels.

\begin{tabular}{|c|c|c|c|c|c|c|c|c|c|c|}
\hline \multirow{2}{*}{$a / R_{x}$} & \multirow{2}{*}{$b / R_{y}$} & \multirow{2}{*}{$V^{*} C N T$} & \multicolumn{2}{|c|}{ UD } & \multicolumn{2}{|c|}{ FG-V } & \multicolumn{2}{|c|}{ FG-X } & \multicolumn{2}{|c|}{ FG-O } \\
\hline & & & [34] & Present & [34] & Present & [34] & Present & [34] & Present \\
\hline \multirow{3}{*}{0.5} & \multirow{3}{*}{0.5} & 0.11 & 20.238 & 20.087 & 18.543 & 17.917 & 22.432 & 22.752 & 17.140 & 16.653 \\
\hline & & 0.14 & 21.655 & 21.700 & 19.779 & 19.184 & 23.997 & 24.642 & 18.267 & 17.790 \\
\hline & & 0.17 & 25.051 & 24.691 & 22.951 & 21.848 & 27.883 & 28.023 & 21.212 & 20.419 \\
\hline \multirow{3}{*}{0.5} & \multirow{3}{*}{-0.5} & 0.11 & 17.106 & 17.282 & 14.809 & 14.617 & 19.588 & 20.253 & 13.364 & 13.202 \\
\hline & & 0.14 & 18.626 & 19.005 & 16.181 & 16.065 & 21.225 & 22.203 & 14.610 & 14.493 \\
\hline & & 0.17 & 21.095 & 21.214 & 18.225 & 17.875 & 24.274 & 24.879 & 16.389 & 16.149 \\
\hline \multirow{3}{*}{0.5} & \multirow{3}{*}{0} & 0.11 & 18.126 & 18.210 & 16.060 & 15.698 & 20.548 & 21.120 & 14.553 & 14.297 \\
\hline & & 0.14 & 19.628 & 19.890 & 17.391 & 17.065 & 22.179 & 23.044 & 15.766 & 15.525 \\
\hline & & 0.17 & 22.380 & 22.328 & 19.799 & 19.111 & 25.488 & 25.925 & 17.903 & 17.472 \\
\hline \multirow{3}{*}{0} & \multirow{3}{*}{0} & 0.11 & 18.008 & 18.201 & 15.701 & 15.55 & 20.624 & 21.332 & 14.068 & 13.907 \\
\hline & & 0.14 & 19.608 & 20.016 & 17.147 & 17.089 & 22.349 & 23.391 & 15.378 & 15.265 \\
\hline & & 0.17 & 22.207 & 22.343 & 19.315 & 19.021 & 25.557 & 26.208 & 17.252 & 17.012 \\
\hline
\end{tabular}

\subsection{Parametric Studies}

In this section, some new results for free vibration of the anti-symmetric cross-ply laminated FG-CNTRC doubly curved shell panels are investigated with respect to FG-CNTRC parameters, curvature, $R_{x} / R_{y}$ ratio, aspect $a / b$ ratio, and number of layers. The material properties for the matrix and CNT are shown in Table 1.

\subsubsection{Effect of FG-CNTRC Parameters}

To understand the effect of FG-CNTRC parameters on the free vibration response of different shell panels, non-dimensional frequencies $\bar{\omega}$ of anti-symmetric cross-ply laminated FG-CNTRC doubly curved shell panels with different CNT distribution, CNT volume fraction, and number of CNT layers are examined.

It is observed from Table 3, that the FG-X panels have the highest value of frequency, whereas, the FG-O panels have the lowest one. Therefore, it can be concluded that the type of CNT distribution has a remarkable influence on the stiffness of the FG-CNTRC shell panels. In detail, the CNTs distributed close to the top and bottom surfaces of each FG-CNTRC layer are more efficient than those distributed near the mid-plane of each FG-CNTRC layer in increasing the stiffness of the laminated FG-CNTRC shell panels. This is compatible with conclusions in previous studies in the literature. According to the detailed results, the values of $\bar{\omega}$ can be increased by more than $24 \%$ with only $6 \%$ increasing CNT volume fraction $V_{C N T}^{*}$ for any other parameters. Thus, by adjusting a small amount of CNT volume, the desired stiffness of the FG-CNTRC panels can be achieved. Table 3 also reveals that the SHP panel has the highest value of $\bar{\omega}$ while the HPR panel has the lowest one. This is because HPR has both sagging and hogging curvature along the two directions, neutralizing the effect of each other, while SHP does not. Table 3, once again confirms the accuracy of the present model by comparing the non-dimensional frequencies of the FG-CNTRC plates with the results of Wang [35]. 
Table 3. Non-dimensional frequencies $\bar{\omega}$ of the simply supported FG-CNTRC doubly curved shell panels $(a / b=1 ; R / a=5, a / h=50)$.

\begin{tabular}{|c|c|c|c|c|c|c|c|c|c|c|c|}
\hline \multirow{3}{*}{\multicolumn{2}{|c|}{ Shape }} & \multirow{3}{*}{ CNT Distribution } & \multicolumn{3}{|c|}{$(0 / 90)$} & \multicolumn{3}{|c|}{$(0 / 90)_{2}$} & \multicolumn{3}{|c|}{$(0 / 90)_{4}$} \\
\hline & & & \multicolumn{3}{|c|}{$V_{C N T}^{*}$} & \multicolumn{3}{|c|}{$V_{C N T}^{*}$} & \multicolumn{3}{|c|}{$V_{C N T}^{*}$} \\
\hline & & & 0.11 & 0.14 & 0.17 & 0.11 & 0.14 & 0.17 & 0.11 & 0.14 & 0.17 \\
\hline \multirow{5}{*}{\multicolumn{2}{|c|}{ CYL }} & UD & 12.854 & 13.841 & 15.937 & 18.658 & 20.596 & 23.032 & 19.829 & 21.941 & 24.467 \\
\hline & & FG-A & 11.383 & 12.181 & 14.177 & 18.367 & 20.295 & 22.700 & 19.739 & 21.856 & 24.378 \\
\hline & & FG-V & 12.216 & 12.969 & 15.137 & 18.624 & 20.528 & 22.998 & 19.858 & 21.963 & 24.516 \\
\hline & & FG-X & 14.442 & 15.713 & 17.937 & 19.084 & 21.089 & 23.582 & 20.062 & 22.212 & 24.776 \\
\hline & & FG-O & 11.067 & 11.720 & 13.753 & 18.241 & 20.121 & 22.528 & 19.610 & 21.694 & 24.207 \\
\hline \multirow{5}{*}{\multicolumn{2}{|c|}{ SPH }} & UD & 16.540 & 17.442 & 20.579 & 21.334 & 23.132 & 26.419 & 22.364 & 24.335 & 27.677 \\
\hline & & FG-A & 15.143 & 15.902 & 18.967 & 20.984 & 22.786 & 26.050 & 22.245 & 24.232 & 27.583 \\
\hline & & FG-V & 16.366 & 17.080 & 20.371 & 21.426 & 23.193 & 26.560 & 22.453 & 24.423 & 27.823 \\
\hline & & FG-X & 17.812 & 18.980 & 22.214 & 21.722 & 23.595 & 26.951 & 22.587 & 24.604 & 28.002 \\
\hline & & FG-O & 15.214 & 15.845 & 18.990 & 20.977 & 22.723 & 26.008 & 22.175 & 24.123 & 27.472 \\
\hline \multirow{5}{*}{\multicolumn{2}{|c|}{ HPR }} & UD & 11.295 & 12.340 & 13.969 & 17.583 & 19.576 & 21.671 & 18.806 & 20.969 & 23.171 \\
\hline & & FG-A & 10.085 & 10.900 & 12.474 & 17.407 & 19.374 & 21.459 & 18.768 & 20.928 & 23.133 \\
\hline & & FG-V & 10.085 & 10.900 & 12.474 & 17.407 & 19.374 & 21.459 & 18.768 & 20.928 & 23.133 \\
\hline & & FG-X & 13.057 & 14.384 & 16.174 & 18.023 & 20.080 & 22.229 & 19.042 & 21.240 & 23.474 \\
\hline & & FG-O & 9.219 & 9.907 & 11.409 & 17.141 & 19.075 & 21.128 & 18.574 & 20.708 & 22.889 \\
\hline \multirow{8}{*}{ PLATE } & Present & UD & 11.353 & 12.401 & 14.040 & 17.696 & 19.701 & 21.810 & 18.943 & 21.122 & 23.340 \\
\hline & [35] & & 11.348 & 12.395 & 14.035 & 17.714 & 19.726 & 21.831 & 18.958 & 21.142 & 23.358 \\
\hline & Present & FG-V & 10.138 & 10.956 & 12.541 & 17.519 & 19.498 & 21.597 & 18.906 & 21.081 & 23.302 \\
\hline & [35] & & 10.056 & 10.876 & 12.435 & 17.495 & 19.484 & 21.565 & 18.883 & 21.065 & 23.271 \\
\hline & Present & FG-X & 13.120 & 14.453 & 16.253 & 18.139 & 20.208 & 22.372 & 19.181 & 21.395 & 23.646 \\
\hline & [35] & & 13.064 & 14.396 & 16.180 & 17.975 & 20.032 & 22.165 & 18.995 & 21.193 & 23.411 \\
\hline & Present & FG-O & 9.270 & 9.960 & 11.472 & 17.251 & 19.197 & 21.264 & 18.710 & 20.859 & 23.057 \\
\hline & [35] & & 9.182 & 9.874 & 11.367 & 17.378 & 19.354 & 21.421 & 18.856 & 21.036 & 23.238 \\
\hline
\end{tabular}

\subsubsection{Effect of Curvature}

Two forms of doubly curved shell panels (SPH and HPR) with $a / b=1, a / h=20, R_{x}=R_{y}=R,(0 / 90)_{5}$, $V_{C N T}^{*}=0.17$ were considered, to study the effect of curvature on the non-dimensional frequencies $\bar{\omega}$. The results are shown in the Figure $3 a, b$. These figures indicate that at the small value of $R / a$, the SHP panels have a much higher non-dimensional frequency than HPR panels. The non-dimensional frequencies of the SHP panels decrease, while those of HPR panels increase with the increase of $R / a$ ratio from one to a specific value. After this value, the non-dimensional frequencies of both SHP and HPR panels have approximate values and seem to be unchanged.

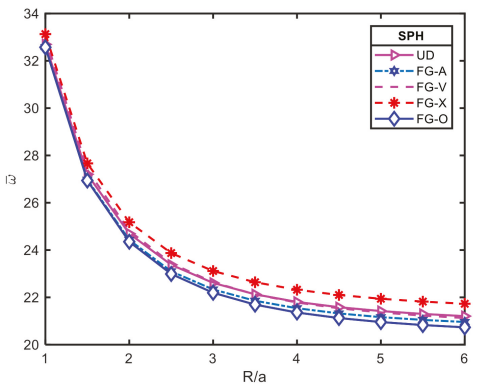

(a)

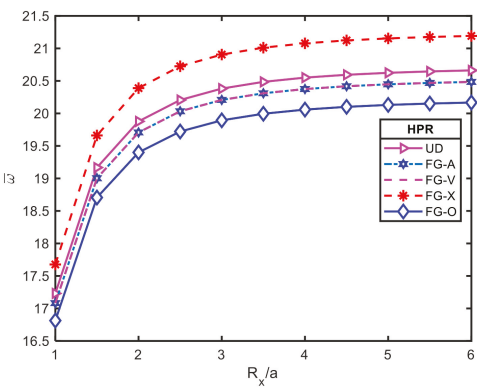

(b)

Figure 3. Effect of $R / a$ ratio on the frequency parameter $\bar{\omega}$ of FG-CNTRC shell panels. $(a / b=1, a / h=$ 20, $\left.R_{x}=R_{y}=R,(0 / 90)_{5}, V_{C N T}^{*}=0.17\right):(a)$ SPH panel; (b) HPR panel. 


\subsubsection{Effect of Curvature Ratio}

The effect of curvature ratio $R_{x} / R_{y}$ on non-dimension frequency of the panels is investigated in this subsection. The geometrical dimensions of the panels are taken as $a / b=1, a / h=20, R_{x} / a=5$. It can be seen from Figure $4 a, b$, that the non-dimension frequencies of panels decrease with the increase of curvature ratio from -3 to -1 , and increase with the value of curvature ratio bigger than -1 for different numbers of layers and different CNT volume fractions. Moreover, the values of $\bar{\omega}$ are at minimum when $R_{x} / R_{y}=-1$ shows that the curvature effect can be suppressed if the shell panels have both negative and positive curvature.

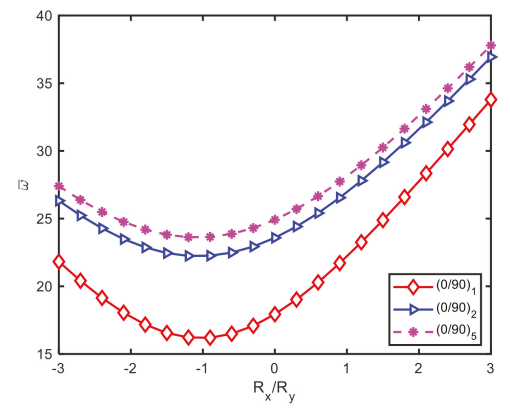

(a)

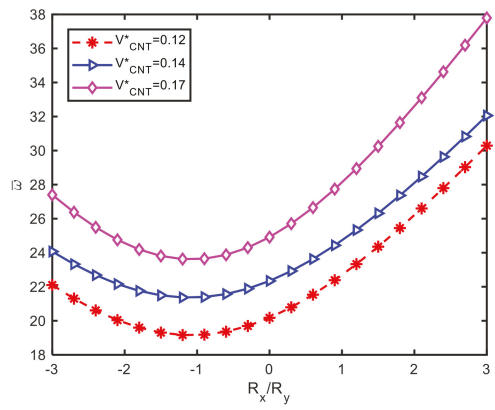

(b)

Figure 4. Effect of $R_{x} / R_{y}$ of FG-CNTRC shell panels $\left(a / b=1, a / h=20, R_{x} / a=5\right.$, FG-X): (a) For different number of layers, $V_{C N T}^{*}=0.17 ;(\mathbf{b})$ for different $C N T$ volume fractions.

\subsubsection{Effect of Thickness Ratio}

The SPH shell panel was chosen to study the effect of thickness on the free vibration response of the FG-CNTRC doubly curved shell panel. For this purpose, another non-dimensional frequency is defined as [34]:

$$
\begin{gathered}
\hat{\omega}=\omega a \sqrt{\frac{\rho^{m}}{E^{m}}} \\
P C F=\left(\frac{\hat{\omega}_{F G}-\hat{\omega}_{U D}}{\hat{\omega}_{U D}}\right) \times 100
\end{gathered}
$$

The effect of thickness ratio, $h / a$, on the non-dimensional frequency of the FG-CNTRC panels is shown in Figure 5. This figure indicates that with all types of CNT distribution, the panels become stiffer with the increase of the thickness ratio, as a result, the non-dimensional frequency of the FG-CNTRC panels increase. Besides, the influence of the thickness ratio, $h / a$, on the percentage change of frequency (PCF) of the SHP panel is depicted in Figure 5b. It is observed that FG-X panels show positive effectiveness while other FG-CNTRC panels show the negative effects concerning uniformly distribution (UD) panels. The highest percentage change of frequency of an FG-X panel and FG-O panel are about $14.5 \%$ and $-15.2 \%$, respectively. 


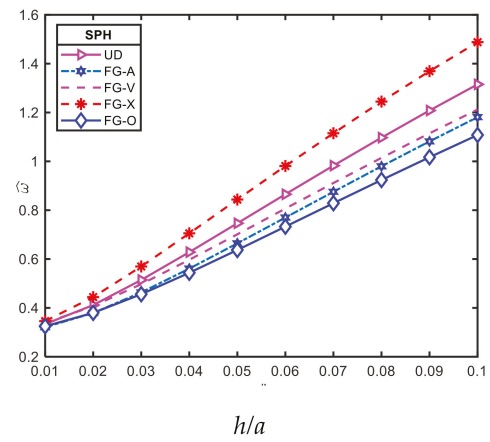

(a)

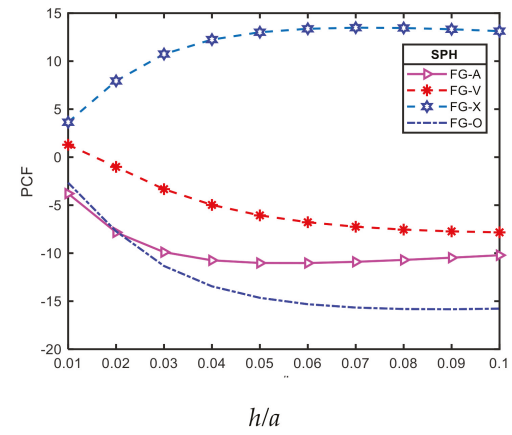

(b)

Figure 5. Effect of $h / a$ ratio on free vibration of FG-CNTRC shell panels $\left(\left(\mathrm{a} / \mathrm{b}=1 ; R_{x}=R_{y}=R\right.\right.$; $\left.V_{C N T}^{*}=0.17 ;(0 / 90)\right)$ : (a) For the frequency parameter $\hat{\omega}=\omega a \sqrt{\frac{\rho^{m}}{E^{m}}} ;(\mathbf{b})$ for the $(P C F)$.

\subsubsection{Effect of Aspect Ratio}

Figure $6 \mathrm{a}, \mathrm{b}$ show the effects of the aspect ratio $(a / b)$ on the vibration of FG-CNTRC. Here, we take $a / b=1 ; R_{x}=R_{y}=R ; R / a=5 ; V_{C N T}^{*}=0.17$ and $(0 / 90)$.

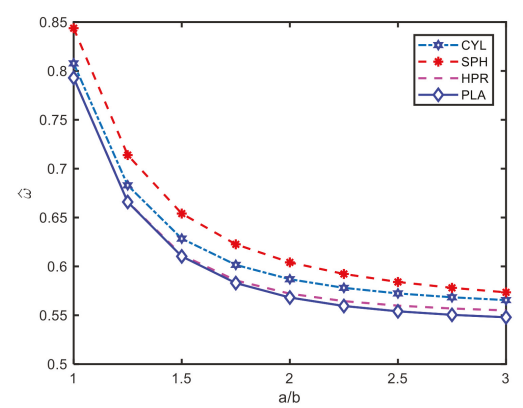

(a)

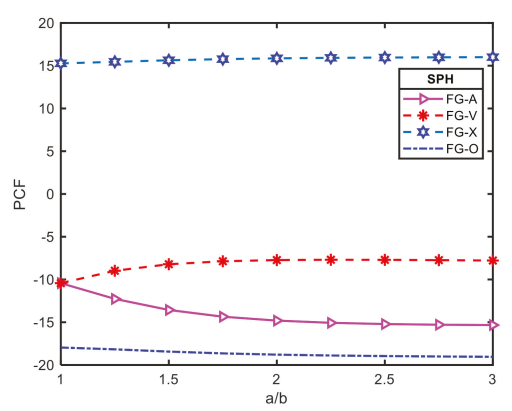

(b)

Figure 6. Effect of aspect ratio $(a / b)$ on free vibration of FG-CNTRC shell panels $\left(a / b=1 ; R_{x}=R_{y}=R\right.$; $\left.V_{C N T}^{*}=0.17 ;(0 / 90)\right)$ : (a) For the frequency parameter $\hat{\omega}=\omega a \sqrt{\frac{\rho^{m}}{E^{m}}} ;(\mathbf{b})$ For the percentage change of frequency $(\mathrm{PCF})$.

Figure 6a reveals that the non-dimensional frequencies of all four types of doubly curved panels decrease uniformly by increasing aspect ratio. In other words, the stiffness of doubly curved panels will be reduced as the aspect ratio increases. Figure 6 a states that the PCF of the FG-CNTRC panels remains unchanged with the increase of aspect ratio.

\subsubsection{Effect of Number of Layers}

The influence of number of layers ( $n$ is a couple of layers (0/90)) on $\hat{\omega}$, and PCF are depicted in Figure 7a,b, respectively. Here, the geometrical dimensions of the panels are taken as $a / b=1, a / h=20$, $R_{x}=R_{y}=R$, and $V_{C N T}^{*}=0.17, \mathrm{FG}-\mathrm{X},(0 / 90)_{\mathrm{n}}$. As the Figures show, with a fixed value of total thickness, the non-dimensional frequencies and the percentage change of frequency of laminated FG-CNTRC panels are strongly affected by the number of layers, changing from one layer to two layers. However, these two dimensionless parameters vary very slightly for the number of layers greater than three. This is compatible with the investigations of Reddy [31], for conventional fiber reinforced composites. 


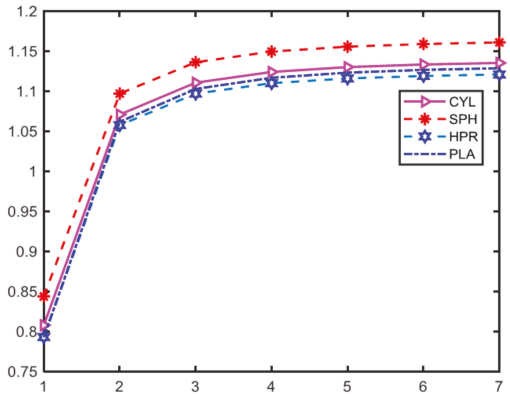

(a)

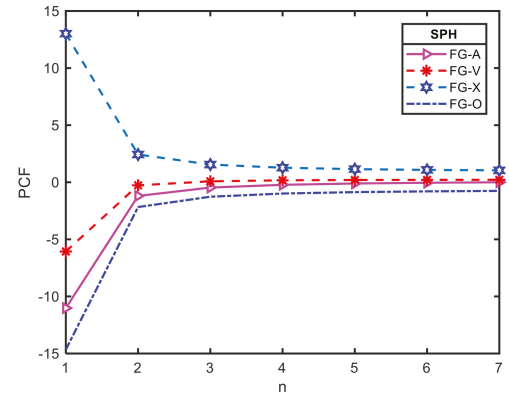

(b)

Figure 7. Effect of number of layers (n) on free vibration of FG-CNTRC shell panels $\left(a / b=1, R_{x}=R_{y}=R\right.$; $V_{C N T}^{*}=0.17,(0 / 90)_{n}:(\mathbf{a})$ For the frequency parameter $\hat{\omega}=\omega a \sqrt{\frac{\rho^{m}}{E^{m}}} ;(\mathbf{b})$ for the percentage change of frequency $P C F$.

\subsubsection{Effect of Different Wave Numbers}

Table 4 listed non-dimensional frequencies for two-layered (0/90) FG-CNTRC doubly curved shell panels $\left(a / b=1 ; R / a=5, a / h=50, \mathrm{FG}-\mathrm{X}, V_{C N T}^{*}=0.17\right)$ for different wave numbers. It can be seen that at the small value of wave numbers $(n, m)$ the SPH panels have highest non-dimensional frequencies while the HPR panels have lowest ones. However, it also can be seen that the non-dimensional frequencies of all three types of doubly curved panels will approximately have more wave numbers.

Table 4. Non-dimensional frequencies $\bar{\omega}$ for two-layered (0/90) FG-CNTRC doubly curved shell panels for different wave numbers $\left(a / b=1 ; R / a=5, a / h=50\right.$, FG-X, $\left.V_{C N T}^{*}=0.17\right)$.

\begin{tabular}{|c|c|c|c|c|c|c|c|}
\hline Shape & $\mathbf{n}$ & $m=1$ & $m=2$ & $m=3$ & $m=4$ & $m=5$ & $m=6$ \\
\hline \multirow{6}{*}{ CYL } & 1 & 17.937 & 48.140 & 99.846 & 169.706 & 254.950 & 352.930 \\
\hline & 2 & 46.027 & 64.594 & 109.402 & 176.466 & 260.683 & 358.380 \\
\hline & 3 & 97.820 & 109.032 & 141.357 & 198.901 & 277.607 & 372.340 \\
\hline & 4 & 168.004 & 176.095 & 198.835 & 243.742 & 311.861 & 399.381 \\
\hline & 5 & 253.606 & 260.401 & 277.580 & 311.892 & 367.569 & 444.182 \\
\hline & 6 & 351.923 & 358.209 & 372.384 & 399.478 & 444.253 & 508.835 \\
\hline \multirow{6}{*}{$\mathrm{SPH}$} & 1 & 22.214 & 49.271 & 100.122 & 169.593 & 254.585 & 352.371 \\
\hline & 2 & 49.472 & 65.771 & 109.763 & 176.410 & 260.356 & 357.845 \\
\hline & 3 & 100.573 & 109.960 & 141.685 & 198.853 & 277.285 & 371.804 \\
\hline & 4 & 170.323 & 176.802 & 199.065 & 243.665 & 311.532 & 398.838 \\
\hline & 5 & 255.596 & 260.940 & 277.698 & 311.759 & 367.219 & 443.632 \\
\hline & 6 & 353.644 & 358.612 & 372.397 & 399.275 & 443.867 & 508.271 \\
\hline \multirow{6}{*}{ HPR } & 1 & 16.174 & 47.141 & 99.497 & 169.711 & 255.202 & 353.378 \\
\hline & 2 & 47.141 & 64.179 & 109.145 & 176.475 & 260.924 & 358.816 \\
\hline & 3 & 99.497 & 109.145 & 141.314 & 198.990 & 277.883 & 372.799 \\
\hline & 4 & 169.711 & 176.475 & 198.990 & 243.935 & 312.190 & 399.872 \\
\hline & 5 & 255.202 & 260.924 & 277.883 & 312.190 & 367.960 & 444.710 \\
\hline & 6 & 353.378 & 358.816 & 372.799 & 399.872 & 444.710 & 509.403 \\
\hline
\end{tabular}

Figures 8-10 depict the first six mode shapes of the simply supported laminated FG-CNTRC CYL, SPH and HPR shell panels, respectively. Geometric characteristics of the panels are $a / b=1, R / a=5$ and $a / h=50$. Type of CNT distribution is FG-X and volume faction of CNT is $V_{C N T}^{*}=0.17$. It can be noticed from these Figures, that in CYL panels, mode $(m=2, n=1)$ is higher than mode $(m=1, n=2)$, while in SPH and HPR panels, mode $(m=1, n=2)$ and mode $(m=2, n=1)$ are the same order. This is because the CYL panel only has the curvature in $x$ direction while SPH and HPR panels have the curvature 
in both $x$ and $y$ directions. These mode shapes can help to understand vibration characteristics of laminated FG-CNTRC doubly curved shell panels.

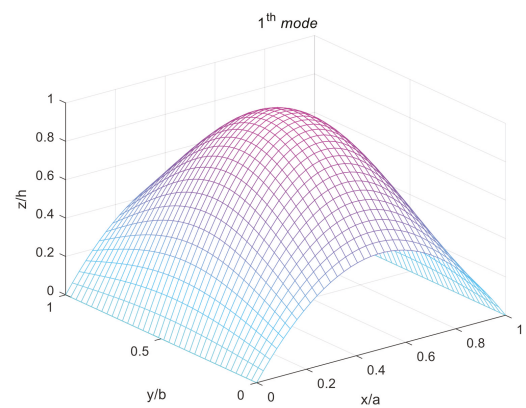

Mode $1(m=1 ; n=1)$

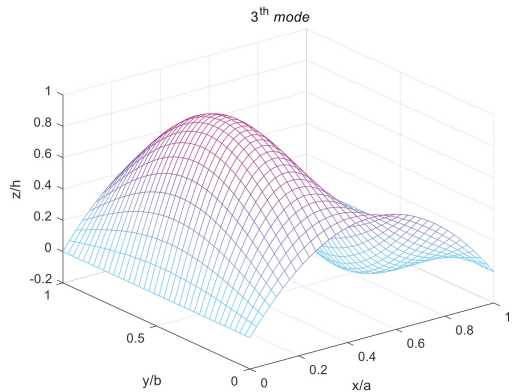

Mode $3(m=2 ; n=1)$

$5^{\text {th }}$ mode

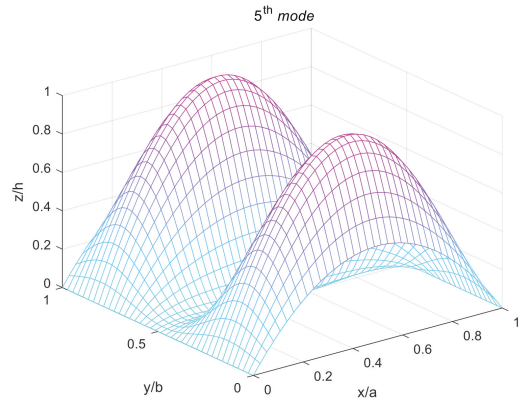

Mode $5(m=1 ; n=3)$

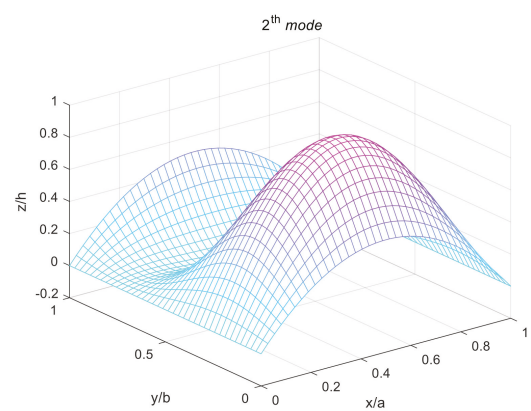

Mode $2(m=1 ; n=2)$

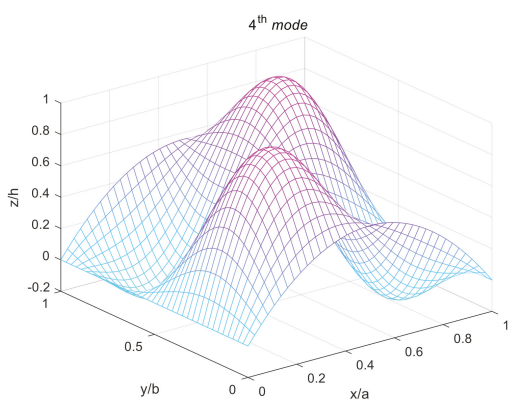

Mode $4(m=2 ; n=2)$

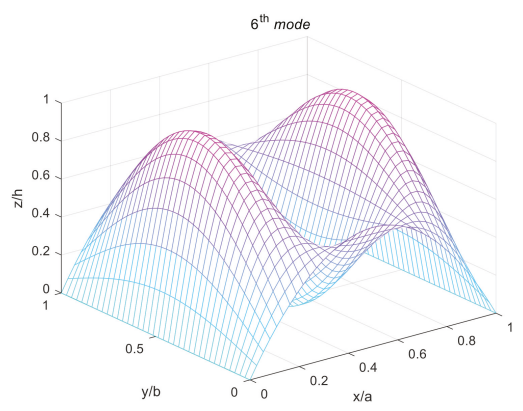

Mode $6(m=3 ; n=1)$

Figure 8. The first six mode shapes of simply supported laminated FG-CNTRC CYL panels. 


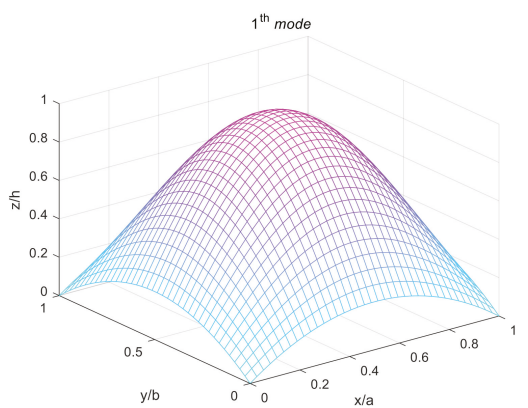

Mode $1(m=1 ; n=1)$

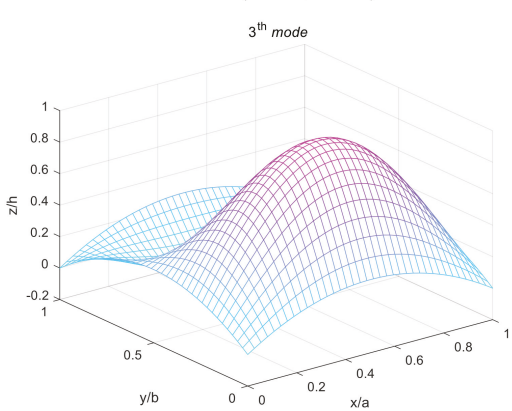

Mode $3(m=1 ; n=2)$

$5^{\text {th }}$ mode

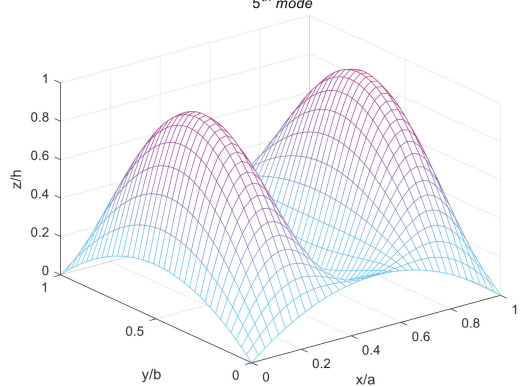

Mode $5(m=3 ; n=1)$

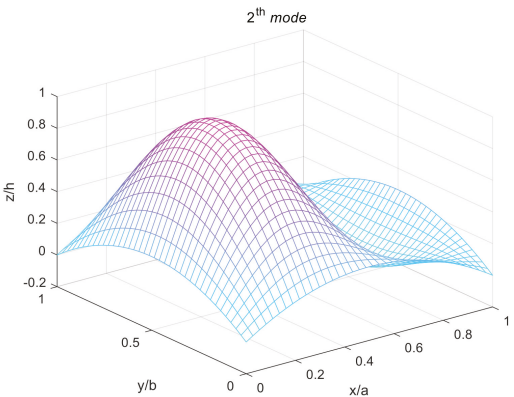

Mode $2(m=2 ; n=1)$

$4^{\text {th }}$ mode

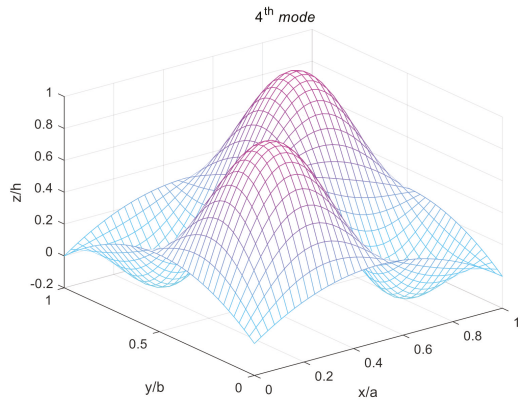

Mode $4(m=2 ; n=2)$

$6^{\text {th }}$ mode

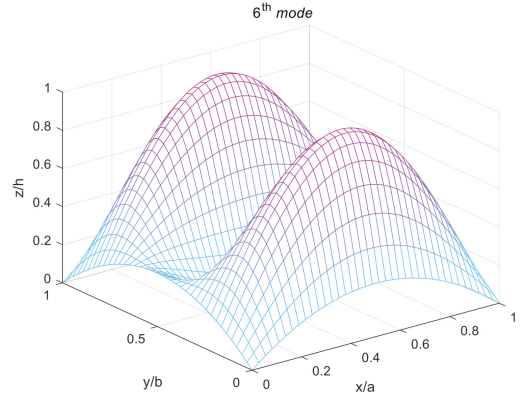

Mode $6(m=1 ; n=3)$

Figure 9. The first six mode shapes of simply supported laminated FG-CNTRC SPH panels. 


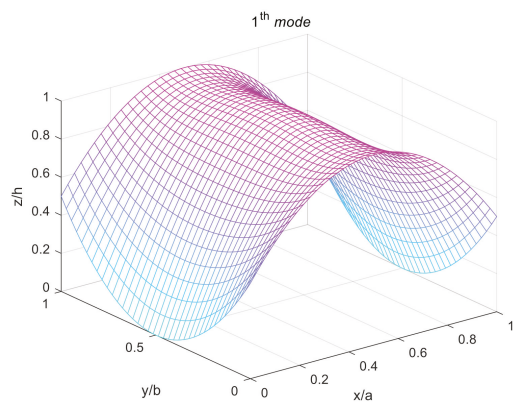

Mode $1(m=1 ; n=1)$

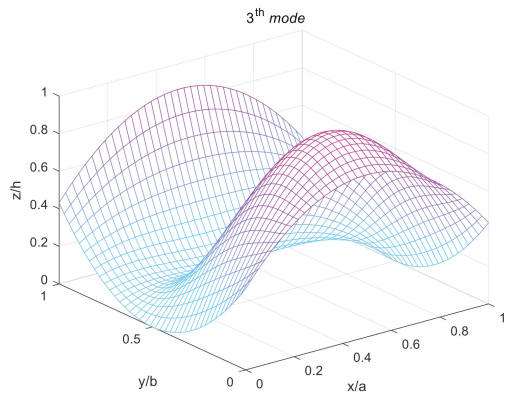

Mode $3(m=1 ; n=2)$

$$
5^{\text {th }} \text { mode }
$$

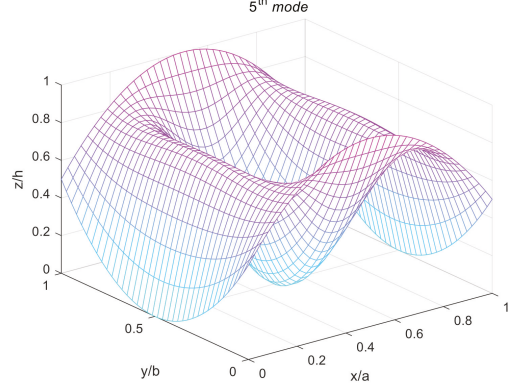

Mode $5(m=3 ; n=1)$

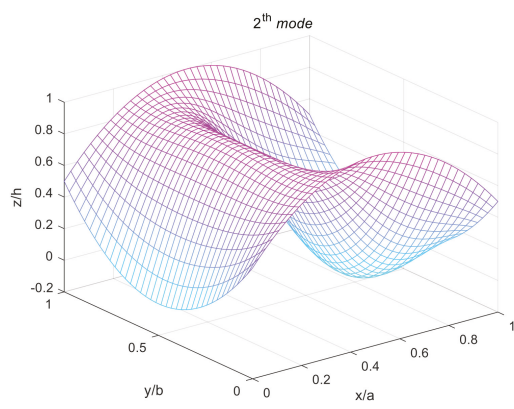

Mode $2(m=2 ; n=1)$

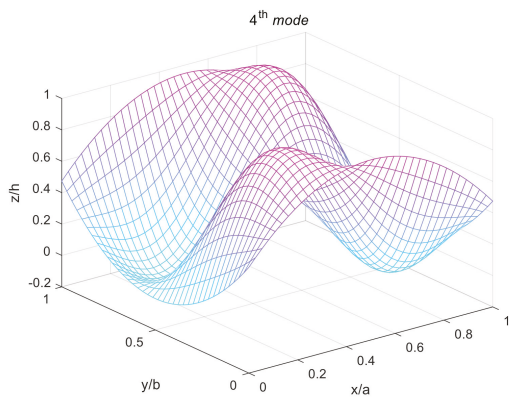

Mode $4(m=2 ; n=2)$ $6^{\text {th }}$ mode

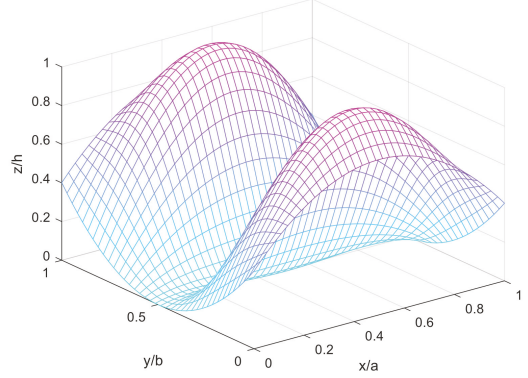

Mode $6(m=1 ; n=3)$

Figure 10. The first six mode shapes of simply supported laminated FG-CNTRC HPR panels.

\section{Conclusions}

In this paper, an analytical solution based on a new four-variable refined shell theory for free vibration analysis of the laminated FG-CNTRC doubly curved shell panels was developed. The accuracy and efficiency of the present model are validated through a review of comparison studies. The influences of several parameters such as FG-CNTRC parameters, curvature, curvature ratio, thickness ratio, aspect ratio and the number of layers on free vibration responses of the panels are explored. The results revealed that the shell panels become stiffer with increasing curvature, conversely, the stiffness of the panels is reduced as the aspect ratio increases. FG-X CNTRC panels have the highest frequency, while FG-O CNTRC panels have the smallest frequency regarding all inlet studied parameters. 
The present theory is accurate and efficient in solving free vibration behaviours of doubly curved laminated FG-CNT reinforced composite panels and may be useful in the study of similar composite structures.

Author Contributions: Formal analysis, Software, V.V.T.; Writing-original draft, Investigation, T.H.Q.; Supervision-editing, T.M.T.

Funding: This research received no external funding.

Conflicts of Interest: The authors declared no potential conflicts of interest with respect to the research, authorship, and/or publication of this article.

\section{Appendix A}

Detailed steps to construct the new shape function:

The transverse strains associated with the displacement field in Equation (1) are:

$$
\begin{aligned}
\gamma_{x z} & =\frac{1}{1+z / R_{x}}\left[\frac{\partial w}{\partial x}+\frac{\partial u}{\partial z}-\frac{u_{0}}{R_{x}}\right]=\frac{1}{1+z / R_{x}}\left[\frac{\partial w_{b}}{\partial x}+\frac{\partial w_{s}}{\partial x}+\frac{u_{0}}{R_{x}}-\frac{\partial w_{b}}{\partial x}-f^{\prime}(z) \frac{\partial w_{s}}{\partial x}-\frac{u_{0}}{R_{x}}\right] \\
& \left.=\frac{1}{1+z / R_{x}}\left(1-f^{\prime}(z)\right) \frac{\partial w_{s}}{\partial x}\right] \\
\gamma_{y z} & =\frac{1}{1+z / R_{y}}\left[\frac{\partial w}{\partial y}+\frac{\partial v}{\partial z}-\frac{v_{0}}{R_{y}}\right]=\frac{1}{1+z / R_{y}}\left[\frac{\partial w_{b}}{\partial y}+\frac{\partial w_{s}}{\partial y}+\frac{v_{0}}{R_{y}}-\frac{\partial w_{b}}{\partial y}-f^{\prime}(z) \frac{\partial w_{s}}{\partial y}-\frac{v_{0}}{R_{y}}\right] \\
& =\frac{1}{1+z / R_{y}}\left[\left(1-f^{\prime}(z)\right) \frac{\partial w_{s}}{\partial y}\right]
\end{aligned}
$$

For shells under bending, the transverse shear stresses $\sigma_{x z}, \sigma_{y z}$ must be vanished at the top and bottom surfaces. These conditions lead to the requirement that the corresponding transverse strains on these surfaces have to be zero. From $\gamma_{x z}\left(x, y, \pm \frac{h}{2}\right)=\gamma_{y z}\left(x, y, \pm \frac{h}{2}\right)=0$, we obtain:

$$
\begin{aligned}
& \gamma_{x z}=\frac{1}{1+z / R_{x}}\left[\left(1-f^{\prime}(z)\right) \frac{\partial w_{s}}{\partial x}\right]=0 \text { at } z= \pm \frac{h}{2} \\
& \gamma_{y z}=\frac{1}{1+z / R_{y}}\left[\left(1-f^{\prime}(z)\right) \frac{\partial w_{s}}{\partial y}\right]=0 \text { at } z= \pm \frac{h}{2}
\end{aligned}
$$

From Equations (A2) and (A3), we have:

$$
f^{\prime}(z)=1 \text { at } z= \pm \frac{h}{2}
$$

Function $f(z)$ satisfies the condition (5) can be selected as a polynomial, trigonometric, and exponential, ... function. In our study, we chose $f(z)$ as a cubic polynomial: $f(z)=a z+\frac{b}{h^{2}} z^{3}$, thus:

$$
f^{\prime}(z)=a+\frac{3 b}{h^{2}} z^{2}=1
$$

Some authors have chosen the value of the pair $\mathrm{a}, \mathrm{b}$ to satisfy Equation (A5). In this study, we chose: $a=-1 / 8, b=3 / 2$. Thus:

$$
f(z)=-\frac{1}{8} z+\frac{3}{2} \frac{z^{3}}{h^{2}}, f^{\prime}(z)=\left.\left(-\frac{1}{8}+\frac{3.3}{2} \frac{z^{2}}{h^{2}}\right)\right|_{z= \pm \frac{h}{2}}=1
$$

\section{Appendix B}

Matrix elements of Equation (25):

$$
s_{11}=-\left(\bar{A}_{11}+2 \frac{\bar{B}_{11}}{R_{x}}+\frac{\bar{D}_{11}}{R_{x}^{2}}\right) \alpha_{m}^{2}-\left(\hat{A}_{66}+2 \frac{\hat{B}_{66}}{R_{x}}+\frac{\hat{D}_{66}}{R_{x}^{2}}\right) \beta_{n}{ }^{2}
$$




$$
\begin{aligned}
& s_{12}=-\left(A_{12}+A_{66}+\left(B_{12}+B_{66}\right)\left(\frac{1}{R_{x}}+\frac{1}{R_{y}}\right)+\frac{1}{R_{x} R_{y}}\left(D_{12}+D_{66}\right)\right) \beta_{n} \alpha_{m} \\
& s_{14}=\left(\bar{B}_{11}^{s}+\frac{\bar{D}_{11}^{s}}{R_{x}}\right) \alpha_{m}{ }^{3}+\left(\left(B_{12}^{s}+B_{66}^{s}+\hat{B}_{66}^{s}+\frac{D_{66}^{s}}{R_{x}}+\frac{\hat{D}_{66}^{s}}{R_{x}}+\frac{D_{12}^{s}}{R_{x}}\right) \beta_{n}{ }^{2}+\frac{\bar{A}_{11}}{R_{x}}+\frac{A_{12}}{R_{y}}+\frac{\bar{B}_{11}}{R_{x}^{2}}+\frac{B_{12}}{R_{x} R_{y}}\right) \alpha_{m} \\
& s_{22}=-\left(\bar{A}_{66}+2 \frac{\bar{B}_{66}}{R_{y}}+\frac{\bar{D}_{66}}{R_{y}^{2}}\right) \alpha_{m}{ }^{2}-\left(\hat{A}_{22}+2 \frac{\hat{B}_{22}}{R_{y}}+\frac{\hat{D}_{22}}{R_{y}^{2}}\right) \beta_{n}{ }^{2} \\
& s_{23}=\left(\frac{A_{12}}{R_{x}}+\frac{\hat{A}_{22}}{R_{y}}+\frac{1}{R_{y}}\left(\frac{B_{12}}{R_{x}}+\frac{\hat{B}_{22}}{R_{y}}\right)\right) \beta_{n}+\left(\hat{B}_{22}+\frac{\hat{D}_{22}}{R_{y}}\right) \beta_{n}{ }^{3}+ \\
& \left(B_{12}+B_{66}+\bar{B}_{66}+\frac{1}{R_{y}}\left(D_{12}+D_{66}+\bar{D}_{66}\right)\right) \beta_{n} \alpha_{m}^{2} \\
& s_{24}=\left(\frac{A_{12}}{R_{x}}+\frac{\hat{A}_{22}}{R_{y}}+\frac{1}{R_{y}}\left(\frac{B_{12}}{R_{x}}+\frac{\hat{B}_{22}}{R_{y}}\right)\right) \beta_{n}+\left(\hat{B}_{22}^{s}+\frac{\hat{D}_{22}^{s}}{R_{y}}\right) \beta_{n}{ }^{3}+ \\
& \left(B_{12}^{s}+B_{66}^{s}+\bar{B}_{66}^{s}+\frac{1}{R_{y}}\left(D_{12}^{s}+D_{66}^{s}+\bar{D}_{66}^{s}\right)\right) \beta_{n} \alpha_{m}^{2} \\
& s_{33}=-\frac{\bar{A}_{11}}{R_{x}^{2}}-2 \frac{A_{12}}{R_{x} R_{y}}-\frac{\hat{A}_{22}}{R_{y}^{2}}-2\left(\frac{B_{12}}{R_{x}}+\frac{\hat{B}_{22}}{R_{y}}\right) \beta_{n}{ }^{2}-2\left(\frac{\bar{B}_{11}}{R_{x}}+\frac{B_{12}}{R_{y}}\right) \alpha_{m}{ }^{2}- \\
& \bar{D}_{11} \alpha_{m}{ }^{4}-\left(2 D_{12}+2 D_{66}+\bar{D}_{66}+\hat{D}_{66}\right) \alpha_{m}{ }^{2} \beta_{n}{ }^{2}-\hat{D}_{22} \beta_{n}{ }^{4} \\
& s_{34}=-\frac{\bar{A}_{11}}{R_{x}^{2}}-2 \frac{A_{12}}{R_{x} R_{y}}-\frac{\hat{A}_{22}}{R_{y}^{2}}-\left(\frac{\bar{B}_{11}}{R_{x}}+\frac{\bar{B}_{11}^{s}}{R_{x}}+\frac{B_{12}}{R_{y}}+\frac{B_{12}^{s}}{R_{y}}\right) \alpha_{m}{ }^{2}-\left(\frac{B_{12}}{R_{x}}+\frac{B_{12}^{s}}{R_{x}}+\frac{\hat{B}_{22}}{R_{y}}+\frac{\hat{B}_{22}^{s}}{R_{y}}\right) \beta_{n}{ }^{2}- \\
& \left(2 D_{12}^{s}+2 D_{66}^{s}+\bar{D}_{66}^{s}+\hat{D}_{66}^{s}\right) \alpha_{m}^{2} \beta_{n}{ }^{2}-\bar{D}_{11}^{s} \alpha_{m}{ }^{4}-\hat{D}_{22}^{s} \beta_{n}{ }^{4} \\
& s_{13}=\left(\frac{\bar{A}_{11}}{R_{x}}+\frac{A_{12}}{R_{y}}+\frac{1}{R_{x}}\left(\frac{\bar{B}_{11}}{R_{x}}+\frac{B_{12}}{R_{y}}\right)\left(B_{12}+B_{66}+\hat{B}_{66}+\frac{1}{R_{x}}\left(D_{12}+D_{66}+\hat{D}_{66}\right)\right) \beta_{n}{ }^{2}\right) \alpha_{m}+ \\
& \left(\bar{B}_{11}+\frac{\bar{D}_{11}}{R_{x}}\right) \alpha_{m}{ }^{3} \\
& s_{44}=-\frac{\bar{A}_{11}}{R_{x}^{2}}-2 \frac{A_{12}}{R_{x} R_{y}}-\frac{\hat{A}_{22}}{R_{y}^{2}}-\left(\hat{A}_{44}^{s}+2 \frac{B_{12}^{s}}{R_{x}}+2 \frac{\hat{B}_{22}^{s}}{R_{y}}\right) \beta_{n}{ }^{2}-\left(\bar{A}_{55}^{s}+2 \frac{\bar{B}_{11}^{s}}{R_{x}}+2 \frac{B_{12}^{s}}{R_{y}}\right) \alpha_{m}{ }^{2}- \\
& \left(2 E_{12}^{s}+2 E_{66}^{s}+\bar{E}_{66}^{s}+\hat{E}_{66}^{s}\right) \alpha_{m}{ }^{2} \beta_{n}{ }^{2}-\bar{E}_{11}^{s} \alpha_{m}{ }^{4}-\hat{E}_{22}^{s} \beta_{n}{ }^{4} \\
& m_{11}=-\left(\bar{I}_{0}+2 \frac{\bar{I}_{1}}{R_{x}}+\frac{\bar{I}_{2}}{R_{x}^{2}}\right) ; m_{12}=0 ; m_{13}=\left(\bar{I}_{1}+\frac{\bar{I}_{2}}{R_{x}}\right) \alpha_{m} ; m_{14}=\left(\bar{J}_{1}+\frac{\bar{I}_{2}}{R_{x}}\right) \alpha_{m} ; \\
& m_{11}=-\left(\bar{I}_{0}+2 \frac{\bar{I}_{1}}{R_{y}}+\frac{\bar{I}_{2}}{R_{y}^{2}}\right) ; m_{23}=\left(\bar{I}_{1}+\frac{\bar{I}_{2}}{R_{y}}\right) \beta_{n} ; m_{24}=\left(\bar{J}_{1}+\frac{\bar{I}_{2}}{R_{y}}\right) \beta_{n} ; \\
& m_{33}=-\bar{I}_{0}-\bar{I}_{2}\left(\alpha_{m}{ }^{2} \beta_{n}{ }^{2}\right) ; m_{34}=-\bar{I}_{0}-\bar{I}_{2}\left(\alpha_{m}{ }^{2} \beta_{n}{ }^{2}\right) ; m_{44}=-\bar{I}_{0}-\bar{K}_{1}\left(\alpha_{m}{ }^{2} \beta_{n}{ }^{2}\right) \text {; }
\end{aligned}
$$

\section{References}

1. Shen, H.-S. Nonlinear bending of functionally graded carbon nanotube-reinforced composite plates in thermal environments. Compos. Struct. 2009, 91, 9-19. [CrossRef]

2. Qatu, M.S. Theory and vibration analysis of laminated barrel thin shells. J. Vib. Control 1999, 5, 851-889. [CrossRef]

3. Reissner, E. A new derivation of the equations for the deformation of elastic shells. Am. J. Math. 1941, 63, 177-184. [CrossRef]

4. Bhimaraddi, A.; Stevens, L. A higher order theory for free vibration of orthotropic, homogeneous, and laminated rectangular plates. J. Appl. Mech. 1984, 51, 195. [CrossRef]

5. Eslami, M.; Shariyat, M. A high-order theory for dynamic buckling and postbuckling analysis of laminated cylindrical shells. J. Press. Vessel. Technol. 1999, 12, 94-102. [CrossRef]

6. Rahmani, O.; Khalili, S.; Thomsen, O.T. A high-order theory for the analysis of circular cylindrical composite sandwich shells with transversely compliant core subjected to external loads. Compos. Struct. 2012, 94, 2129-2142. [CrossRef]

7. Shimpi, R.; Patel, H. Free vibrations of plate using two variable refined plate theory. J. Sound Vib. 2006, 296, 979-999. [CrossRef] 
8. El Meiche, N.; Tounsi, A.; Ziane, N.; Mechab, I. A new hyperbolic shear deformation theory for buckling and vibration of functionally graded sandwich plate. Int. J. Mech. Sci. 2011, 53, 237-247. [CrossRef]

9. Thai, H.-T.; Vo, T.P. A new sinusoidal shear deformation theory for bending, buckling, and vibration of functionally graded plates. Appl. Math. Model. 2013, 37, 3269-3281. [CrossRef]

10. Thai, H.T.; Kim, S.E. A simple quasi-3D sinusoidal shear deformation theory for functionally graded plates. Compos. Struct. 2013, 99, 172-180. [CrossRef]

11. Daouadji, T.H.; Tounsi, A. A new higher order shear deformation model for static behavior of functionally graded plates. Adv. Appl. Math. Mech. 2013, 5, 351-364. [CrossRef]

12. Mehrabadi, S.J.; Aragh, B.S. Stress analysis of functionally graded open cylindrical shell reinforced by agglomerated carbon nanotubes. Thin Walled Struct. 2014, 80, 130-141. [CrossRef]

13. Aragh, B.S.; Barati, A.N.; Hedayati, H. Eshelby-Mori-Tanaka approach for vibrational behavior of continuously graded carbon nanotube-reinforced cylindrical panels. Compos. Part B Eng. 2012, 43, 1943-1954. [CrossRef]

14. Yas, M.; Pourasghar, A.; Kamarian, S.; Heshmati, M. Three-dimensional free vibration analysis of functionally graded nanocomposite cylindrical panels reinforced by carbon nanotube. Mater. Des. 2013, 49, 583-590. [CrossRef]

15. Alibeigloo, A. Free vibration analysis of functionally graded carbon nanotube-reinforced composite cylindrical panel embedded in piezoelectric layers by using theory of elasticity. Eur. J. Mech. A/Solids 2014, 44, 104-115. [CrossRef]

16. Lei, Z.; Zhang, L.; Liew, K.; Yu, J. Dynamic stability analysis of carbon nanotube-reinforced functionally graded cylindrical panels using the element-free kp-Ritz method. Compos. Struct. 2014, 113, 328-338. [CrossRef]

17. Moradi-Dastjerdi, R.; Foroutan, M.; Pourasghar, A. Dynamic analysis of functionally graded nanocomposite cylinders reinforced by carbon nanotube by a mesh-free method. Mater. Des. 2013, 44, 256-266. [CrossRef]

18. Shen, H.S.; Xiang, Y. Nonlinear vibration of nanotube-reinforced composite cylindrical panels resting on elastic foundations in thermal environments. Compos. Struct. 2014, 111, 291-300. [CrossRef]

19. Shen, H.S.; Xiang, Y. Postbuckling of nanotube-reinforced composite cylindrical shells under combined axial and radial mechanical loads in thermal environment. Compos. Part B Eng. 2013, 52, 311-322. [CrossRef]

20. Shen, H.-S. Thermal buckling and postbuckling behavior of functionally graded carbon nanotube-reinforced composite cylindrical shells. Compos. Part B Eng. 2012, 43, 1030-1038. [CrossRef]

21. Shen, H.-S. Torsional postbuckling of nanotube-reinforced composite cylindrical shells in thermal environments. Compos. Struct. 2014, 116, 477-488. [CrossRef]

22. Liew, K.; Lei, Z.; Yu, J.; Zhang, L. Postbuckling of carbon nanotube-reinforced functionally graded cylindrical panels under axial compression using a meshless approach. Comput. Methods Appl. Mech. Eng. 2014, 268, 1-17. [CrossRef]

23. Lei, Z.; Zhang, L.; Liew, K. Parametric analysis of frequency of rotating laminated CNT reinforced functionally graded cylindrical panels. Compos. Part B Eng. 2016, 90, 251-266. [CrossRef]

24. Tornabene, F.; Fantuzzi, N.; Bacciocchi, M.; Viola, E. Effect of agglomeration on the natural frequencies of functionally graded carbon nanotube-reinforced laminated composite doubly-curved shells. Compos. Part B Eng. 2016, 89, 187-218. [CrossRef]

25. Thomas, B.; Roy, T. Vibration and damping analysis of functionally graded carbon nanotubes reinforced hybrid composite shell structures. J. Vib. Control 2017, 23, 1711-1738. [CrossRef]

26. Arani, A.G.; Kiani, F.; Afshari, H. Free and forced vibration analysis of laminated functionally graded CNT-reinforced composite cylindrical panels. J. Sandw. Struct. Mater. 2019, 1099636219830787. [CrossRef]

27. Lei, Z.; Zhang, L.; Liew, K. Analysis of laminated CNT reinforced functionally graded plates using the element-free kp-Ritz method. Compos. Part B Eng. 2016, 84, 211-221. [CrossRef]

28. Thai, H.T.; Kim, S.E. A simple higher-order shear deformation theory for bending and free vibration analysis of functionally graded plates. Compos. Struct. 2013, 96, 165-173. [CrossRef]

29. Huu Quoc, T.; Minh Tu, T.; Van Tham, V. Free vibration analysis of smart laminated functionally graded CNT reinforced composite plates via new four-variable refined plate theory. Materials 2019, 12, 3675. [CrossRef]

30. Qatu, M.S. Vibration of Laminated Shells and Plates; Elsevier: Amsterdam, The Netherlands, 2004.

31. Reddy, J.N. Mechanics of Laminated Composite Plates and Shells: Theory and Analysis; CRC Press: Boka Raton, FL, USA, 2003 
32. Reddy, J.N. Energy Principles and Variational Methods in Applied Mechanics; John Wiley \& Sons: Hoboken, NJ, USA, 2017.

33. Wang, Q.; Shao, D.; Qin, B. A simple first-order shear deformation shell theory for vibration analysis of composite laminated open cylindrical shells with general boundary conditions. Compos. Struct. 2018, 184, 211-232. [CrossRef]

34. Pouresmaeeli, S.; Fazelzadeh, S. Frequency analysis of doubly curved functionally graded carbon nanotube-reinforced composite panels. Acta Mech. 2016, 227, 2765-2794. [CrossRef]

35. Huang, B.; Guo, Y.; Wang, J.; Du, J.; Qian, Z.; Ma, T.; Yi, L. Bending and free vibration analyses of antisymmetrically laminated carbon nanotube-reinforced functionally graded plates. J. Compos. Mater. 2017, 51, 3111-3125. [CrossRef]

(C) 2019 by the authors. Licensee MDPI, Basel, Switzerland. This article is an open access article distributed under the terms and conditions of the Creative Commons Attribution (CC BY) license (http://creativecommons.org/licenses/by/4.0/). 

Article

\title{
Synthesis, Characterization and Photocatalytic Activity of $\mathrm{N}$-doped $\mathrm{Cu}_{2} \mathrm{O} / \mathrm{ZnO}$ Nanocomposite on Degradation of Methyl Red
}

\author{
Yohannes Teklemariam Gaim *, Gebrekidan Mebrahtu Tesfamariam, \\ Gebretinsae Yeabyo Nigussie and Mengstu Etay Ashebir \\ Department of Chemistry, College of Natural and Computational Sciences, Mekelle University, Mekelle P.O.Box: \\ 231, Ethiopia; gebrekidanmebrahtu11102007@gmail.com (G.M.T.); g.tinsae21@gmail.com (G.Y.N.); \\ mengstu.etay@mu.edu.et (M.E.A.) \\ * Correspondence: yohannesteklemariam1@gmail.com; Tel.: +25-19-3203-4081
}

Received: 19 September 2019; Accepted: 14 October 2019; Published: 16 October 2019

\begin{abstract}
In this study, a $\mathrm{N}$-doped $\mathrm{Cu}_{2} \mathrm{O} / \mathrm{ZnO}$ nanocomposite was prepared by a co-precipitation and thermal decomposition technique from $\mathrm{CuCl}_{2}, 2 \mathrm{H}_{2} \mathrm{O}, \mathrm{ZnSO}_{4}, 7 \mathrm{H}_{2} \mathrm{O}$ and $\mathrm{CO}\left(\mathrm{NH}_{2}\right)_{2}$ as precursors. The as-synthesized nanocomposites were characterized using X-ray diffraction (XRD), scanning electron microscopy (SEM), Fourier transform infrared analysis (FT-IR) and an ultraviolet-visible (UV-Vis) reflectance spectrometer. From the XRD diffractogram of $\mathrm{N}$-doped $\mathrm{Cu}_{2} \mathrm{O} / \mathrm{ZnO}$ nanocomposite, cubic and hexagonal wurtzite crystal structures of $\mathrm{Cu}_{2} \mathrm{O}$, and $\mathrm{ZnO}$, respectively were identified. The UV-vis reflectance spectra illustrated that the absorption edge of $\mathrm{N}$-doped $\mathrm{Cu}_{2} \mathrm{O} / \mathrm{ZnO}$ nanocomposite is more extended to the longer wavelength than $\mathrm{ZnO}, \mathrm{Cu}_{2} \mathrm{O}$ and $\mathrm{Cu}_{2} \mathrm{O} / \mathrm{ZnO}$ nanomaterials. FT-IR bands confirmed the presence of $\mathrm{ZnO}, \mathrm{Cu}_{2} \mathrm{O}$, and nitrogen in the $\mathrm{N}$-doped $\mathrm{Cu}_{2} \mathrm{O} / \mathrm{ZnO}$ nanocomposite. Photocatalytic activity of the as-synthesized nanocomposite was tested for methyl red degradation using sunlight as an energy source by optimizing the concentration of the dye and amount of the catalyst loaded. The degradation efficiency was greater in $\mathrm{N}$-doped $\mathrm{Cu}_{2} \mathrm{O} / \mathrm{ZnO}$ nanocomposite as compared to $\mathrm{ZnO}, \mathrm{Cu}_{2} \mathrm{O}$ and $\mathrm{Cu}_{2} \mathrm{O} / \mathrm{ZnO}$ nanomaterials. This is due to the coupling of the semiconductors which increases the absorption and exploitation capability of solar light and increases the charge separation as well. Besides that, nitrogen doping can extend absorption of light to the visible region by decreasing the energy gap. Therefore, $\mathrm{N}$-doped $\mathrm{Cu}_{2} \mathrm{O} / \mathrm{ZnO}$ nanocomposite is a solar light-active photocatalyst which can be used in the degradation of organic pollutants.
\end{abstract}

Keywords: photocatalyst; nanocomposite; dye degradation; co-precipitation

\section{Introduction}

Population growth and rapid urbanization/industrialization are among the greatest causes of environmental pollution and consumption of a large amount of energy [1]. Synthetic organic dyes that are used in various industries such as pharmaceuticals, textiles, cosmetics, paper, and plastic factories have led to severe environmental pollution as a result of their discharging contaminated and colored wastewater into the water stream [2]. They adversely affect the quality of water, prevent light penetration and diminish photosynthetic reactions. Moreover, some dyes are both poisonous and cancer-causing [3]. To address the above issues, several treatment methods have been commonly used. The treatment techniques including adsorption, chemical precipitation and coagulation show reduced efficiency and generate other pollutants like toxic gases and slurry that require additional purification $[4,5]$. Therefore, advanced technology-based treatments have been suggested for the removal of these pollutants. 
Advanced oxidation processes (AOPs) have attracted much attention as a substitute for traditional treatment routes for the removal of toxic organic pollutants into harmless products. AOPs have benefits such as degradation of organic pollutants to green products and capability of operating at normal temperature and pressure [6]. Among AOPs, heterogeneous photocatalysis is an emerging technique, which is valuable for environmental and energy applications. It is a photochemical reaction which takes place on the surface of the solid catalyst and encompasses oxidation from photogenerated holes and reduction from photogenerated electrons at the same time [7]. $\mathrm{TiO}_{2}, \mathrm{ZnO}, \mathrm{CdS}, \mathrm{ZnS}$ and $\mathrm{Fe}_{2} \mathrm{O}_{3}$ are some of the outstanding semiconductors used as photocatalysts [8]. Among these, $\mathrm{TiO}_{2}$ and $\mathrm{ZnO}$ are the top applicable as photocatalysts $[9,10]$. The energy levels of these semiconductors are nearly comparable. However, $\mathrm{ZnO}$ is easily obtainable; it absorbs a large portion of solar light and has great photocatalytic performance than $\mathrm{TiO}_{2}[11,12]$.

Zinc oxide-based materials are used in the area of multifunctional electrode for both energy conversion and storage applications, like lithium-ion batteries and Dye-sensitized Solar Cells [13], gas sensors, monitoring air quality and optical devices due to its exceptional properties, for example, being inexpensive, photoconductive response, pyroelectricity and surface functionalization [14], high binding energy and electron mobility [15]. This metal oxide based semiconductor also has great application in the field of optoelectronic devices such as light-emitting diodes, flat panel displays, transparent semiconductors and conductive oxides, due to its good optical properties [16]. Different research investigated sensing and photovoltaic applications of $\mathrm{ZnO}$-based materials such as ammonia gas sensing using $\mathrm{Ag} / \mathrm{ZnO}$ flower and $\mathrm{Cu}$-doped $\mathrm{ZnO}$ nanostructures $[15,17]$, tin-doped $\mathrm{ZnO}$ thin films as a $\mathrm{NO}_{2}$ gas sensor [18], $\mathrm{ZnO} @ \mathrm{In}_{2} \mathrm{O}_{3}$ coreshell nanofibers for ethanol vapor sensing [19], $\mathrm{ZnO}$-based quaternary transparent conductive oxide materials for solar cells [16], and $\mathrm{CdO}-\mathrm{ZnO}$ nanocones for efficient electrode materials [18]. The application of lithium ion batteries has been a major success in small electronic devices. However, the shortage of lithium resources challenges its application in large-scale electrical energy storage systems [20]. The Layered Sodium Transition-Metal Oxides are promising materials that can minimize the challenges of lithium batteries due to excellent cyclic stability and rate performance which significantly contribute to the development of large-scale electrical energy storage systems [21].

However, $\mathrm{ZnO}$ absorbs only in the ultraviolet section of electromagnetic radiation for the reason that its bandgap energy is large. As a result, its photocatalytic activity is low under solar radiation as the ultraviolet (UV) constituent of solar energy that touches the Earth is only $3-5 \%[22,23]$. Nowadays, the existing photocatalysts such as $\mathrm{ZnO}$ are modified by doping or co-doping with metals and non-metals to enrich their photocatalytic activity $[24,25]$. Moreover, compositing of dissimilar nanostructured semiconductors develops their photocatalytic performance by sharing of their charge carriers to each other [26].

Cuprous oxide $\left(\mathrm{Cu}_{2} \mathrm{O}\right)$ is a narrow bandgap semiconductor which has been thought of as a possible visible light photocatalyst. Electrons of $\mathrm{Cu}_{2} \mathrm{O}$ can undergo a transition from the valence band to the conduction band using visible light as a source of energy. However, the photo-induced electrons and holes recombine within microseconds after their generation, which can influence its photocatalytic action negatively. $\mathrm{Up}$ to the present time, graphene and selected metals were coupled with $\mathrm{Cu}_{2} \mathrm{O}$ to delay the recombination of the photoinduced electrons and holes. $\mathrm{Cu}_{2} \mathrm{O}$ joined with large bandgap metal oxides such as $\mathrm{ZnO}$ is expected as an operational means to control the problem of recombining the charge carriers [27]. In this work, we synthesized a $\mathrm{N}$-doped $\mathrm{Cu}_{2} \mathrm{O} / \mathrm{ZnO}$ nanocomposite via co-precipitation and thermal decomposition methods and tested its photocatalytic activity in the degradation of methyl red (Scheme 1), which is considered as model dye pollutant. 


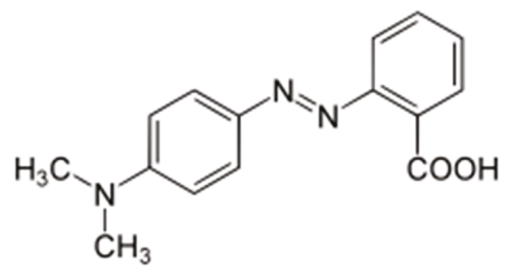

Scheme 1. Structure of methyl red.

\section{Experimental}

\subsection{Chemicals}

The chemicals used were: cupric chloride dihydrate, zinc sulfate heptahydrate, sodium hydroxide, ascorbic acid, urea, $\mathrm{C}_{2} \mathrm{H}_{6} \mathrm{O}$, methyl red, and distilled water. The chemicals were analytical grade and used throughout without further purification. Distilled water was used in all the experiments.

\subsection{Synthesis of Photocatalysts}

The undoped $\mathrm{Cu}_{2} \mathrm{O}$ nanoparticles were prepared from $\mathrm{CuCl}_{2} \cdot 2 \mathrm{H}_{2} \mathrm{O}$ as a precursor via precipitation and reduction techniques. 0.01 moles of $\mathrm{CuCl}_{2} \cdot 2 \mathrm{H}_{2} \mathrm{O}$ was dissolved in $100 \mathrm{~mL}$ deionized water. The solution was adjusted in its $\mathrm{pH}$ level by adding $30 \mathrm{~mL}$ of $2 \mathrm{M} \mathrm{NaOH}$ drop by drop with continuous stirring until 12.2. During the addition of the $\mathrm{NaOH}$ aqueous solution, a deep blue precipitate was formed quickly. After being stirred for $30 \mathrm{~min}, 2.2 \mathrm{~g}$ of $\mathrm{C}_{6} \mathrm{H}_{8} \mathrm{O}_{6}$ was added into the above solution to reduce $\mathrm{Cu}^{2+}$ into $\mathrm{Cu}^{+}$and stirred for an extra $30 \mathrm{~min}$. The color of the precipitate then changed to brick red indicating the formation of $\mathrm{Cu}_{2} \mathrm{O}$. The brick-red precipitate was filtered and washed four times using deionized water and dried at $100{ }^{\circ} \mathrm{C}$ in an oven [27]. To show high crystallinity and remove organic impurities, the powders were calcined at $500{ }^{\circ} \mathrm{C}$ in a furnace for $2 \mathrm{~h}$.

$\mathrm{ZnO}$ nanoparticles were prepared using $\mathrm{ZnSO}_{4} \cdot 7 \mathrm{H}_{2} \mathrm{O}$ as a precursor through a precipitation method [27]. To prepare $\mathrm{ZnO}$ nanoparticles, 0.01 moles of $\mathrm{ZnSO}_{4} \cdot 7 \mathrm{H}_{2} \mathrm{O}$ dissolved in $100 \mathrm{~mL}$ deionized water. While stirring, $30 \mathrm{~mL}$ of $2 \mathrm{M} \mathrm{NaOH}$ was dropped carefully into the aqueous solution of zinc sulfate until the $\mathrm{pH}$ of the solution reached 12.4. Upon addition of $\mathrm{NaOH}$ aqueous solution, a white precipitate was formed and stirred for $30 \mathrm{~min}$. The white product was separated by filtration and washed using deionized water repeatedly to remove impurities and dried at $100^{\circ} \mathrm{C}$ in an oven. Finally, the powders were calcined at $500{ }^{\circ} \mathrm{C}$ in a furnace for $2 \mathrm{~h}$.

The $\mathrm{Cu}_{2} \mathrm{O} / \mathrm{ZnO}$ nanocomposite was synthesized from $\mathrm{CuCl}_{2} \cdot 2 \mathrm{H}_{2} \mathrm{O}$ and $\mathrm{ZnSO}_{4} \cdot 7 \mathrm{H}_{2} \mathrm{O}$ via the co-precipitation method followed by reduction using ascorbic acid; 0.01 moles of $\mathrm{CuCl}_{2} \cdot 2 \mathrm{H}_{2} \mathrm{O}$ and 0.01 moles of $\mathrm{ZnSO}_{4} \cdot 7 \mathrm{H}_{2} \mathrm{O}$ were dissolved in $100 \mathrm{~mL}$ deionized water and stirred using a magnetic stirrer; $30 \mathrm{~mL}$ of $2 \mathrm{M} \mathrm{NaOH}$ dropped slowly into the mixture of cupric chloride and zinc sulfate aqueous solutions with continuous stirring and the $\mathrm{pH}$ of the solution became 11.8. A light blue precipitate was formed and stirred for $30 \mathrm{~min}$. Once the solution has been stirred for half an hour, the copper reduced from +2 to +1 oxidation states after $2.2 \mathrm{~g}$ of $\mathrm{C}_{6} \mathrm{H}_{8} \mathrm{O}_{6}$ added while stirring for an additional $30 \mathrm{~min}$. The color of the precipitate changed from light blue into yellow as soon as the ascorbic acid was added as a reducing agent. Lastly, the yellow precipitate was filtered, washed, repeatedly, using deionized water and ethanol, and dried at $100{ }^{\circ} \mathrm{C}$ in the oven [27]. The nanocomposite was then calcined at $500{ }^{\circ} \mathrm{C}$ in a furnace for $2 \mathrm{~h}$.

To prepare the $\mathrm{N}-\mathrm{Cu}_{2} \mathrm{O} / \mathrm{ZnO}$ nanocomposite, $2.681 \mathrm{~g}$ of $\mathrm{CO}\left(\mathrm{NH}_{2}\right)_{2}$ dissolved in ethanol and $25 \mathrm{~g}$ of uncalcined $\mathrm{Cu}_{2} \mathrm{O} / \mathrm{ZnO}$ nanocomposites was added to the solution. The mixture was stirred up to mix well and then dried. Finally, the powder was calcined at $500{ }^{\circ} \mathrm{C}$ for $2 \mathrm{~h}$ and the nitrogen-doped $\mathrm{Cu}_{2} \mathrm{O} / \mathrm{ZnO}$ nanocomposite was obtained [25]. 


\subsection{Characterization Techniques}

The following were used as characterization techniques: X-ray diffraction (XRD) analysis was conducted using X-ray diffractometer (Shimadzu XRD-7000, Shimadzu Corp., Kyoto, Japan) with a Cu-K $\alpha$ radiation $(\lambda=0.15406 \mathrm{~nm})$, step scan mode with step time and degree $(2 \theta)$ of $0.4 \mathrm{~s}$ and $0.02^{\circ}$, respectively, for the range of $10^{\circ}$ to $80^{\circ}$ ), to know crystal structures and average crystallite size of the samples. The surface morphology of the materials was examined using a scanning electron microscope (SEM), a JEOL JSM-5610 (JEOL, Ltd., Akishima, Tokyo) equipped with an Everhart-Thornley detector. The chemical compositions of the prepared samples were characterized using Spectrum 65 Fourier transform infrared (FT-IR) (PerkinElmer, Waltham, MA, USA) in the range 4000-400 $\mathrm{cm}^{-1} \mathrm{using}$ $\mathrm{KBr}$ pellets. The optical property of the nanocomposites was recorded using a PerkinElmer Lamda 35 spectrometer which is operated at a wavelength range of $200-800 \mathrm{~nm}$ and the absorption spectra have been obtained from reflectance data using the Kubelka-Munk algorithm [28].

\subsection{Photocatalytic Activities}

The photocatalytic activities of the as-synthesized nanomaterials were tested on the degradation of methyl red dye (Scheme 1) as a model pollutant under sunlight as an energy source at ambient temperature. The degradation experiments were performed as follows: $500 \mathrm{~L}$ glass vessels containing $60 \mathrm{mg} / \mathrm{L}$ solution of methyl red and appropriate amount of nanomaterials (18 mg/L) were stirred under a dark for $1 \mathrm{~h}$ to attain absorption-desorption equilibrium before irradiating. All experiments were carried out under direct solar irradiation explicitly sunny days in between 10 AM and 2 PM when the solar intensity variations were insignificant [29]. Thereafter, the mixed solution was exposed to sunlight and $8 \mathrm{~mL}$ of the heterogeneous mixture was withdrawn within 20 min intervals of irradiating to sunlight, centrifuged at $3000 \mathrm{rpm}$ for $6 \mathrm{~min}$ and filtered using filter paper to separate the catalyst before conducting the absorption measurement. The pure supernatant liquid was evaluated for methyl red dye concentration after measuring the absorbance at $410 \mathrm{~nm}$ using an ultraviolet-visible (UV-Vis) spectrophotometer and the percentage degradation of methyl red solution was calculated according to the following equation:

$$
\% \text { degradation }=\frac{\mathrm{A}_{0}-\mathrm{A}_{\mathrm{t}}}{\mathrm{A}_{0}} \times 100 \%
$$

where $A_{0}$ is initial absorbance of methyl red dye and $A_{t}$ is absorbance of methyl red at each time interval " $\mathrm{t}$ ".

\section{Results and Discussion}

\subsection{X-ray Diffraction (XRD) Patterns of the Nanomaterials}

The diffraction patterns of $\mathrm{Cu}_{2} \mathrm{O}, \mathrm{ZnO}, \mathrm{Cu}_{2} \mathrm{O} / \mathrm{ZnO}$, and $\mathrm{N}$-doped $\mathrm{Cu}_{2} \mathrm{O} / \mathrm{ZnO}$ nanoparticles are shown in Figure 1. In the XRD patterns of $\mathrm{ZnO}, \mathrm{Cu}_{2} \mathrm{O} / \mathrm{ZnO}$ and $\mathrm{N}-\mathrm{Cu}_{2} \mathrm{O} / \mathrm{ZnO}$ nanomaterials, diffraction peaks appeared at $2 \theta=31.76^{\circ}, 34.40^{\circ}, 36.24^{\circ}, 47.53^{\circ}, 56.59^{\circ}, 62.85^{\circ}, 66.37^{\circ}, 67.90^{\circ}, 69.07^{\circ}$ which correspond to (100), (002), (101), (102), (110), (103), (200), (112), and (201) planes of the hexagonal wurtzite structure of zinc oxide. Similar results were reported in [30]. The diffraction peaks in the XRD patterns of $\mathrm{Cu}_{2} \mathrm{O}, \mathrm{Cu}_{2} \mathrm{O} / \mathrm{ZnO}$ and $\mathrm{N}-\mathrm{Cu}_{2} \mathrm{O} / \mathrm{ZnO}$ at $2 \theta$ value of $29.57^{\circ}, 36.40^{\circ}, 42.32^{\circ}, 61.43^{\circ}, 73.55^{\circ}$ and $77.40^{\circ}$ correspond to the reflection from (110), (111), (200), (220), (311) and (222) crystal planes of the cubic structure of cuprous oxide which is in agreement with [31]. There is no other diffraction peak displayed from impurities such as $\mathrm{CuO}, \mathrm{Cu}(\mathrm{OH})_{2}$ and $\mathrm{Zn}(\mathrm{OH})_{2}$, indicating the purity of the nanostructured materials. As shown in Figure 1d, no additional peak was displayed due to nitrogen doping which might be nitrogen introduced into the $\mathrm{ZnO}$ [32] and $\mathrm{Cu}_{2} \mathrm{O}$ lattices without changing their crystal structures. The insignificant shift in the diffraction peaks of $\mathrm{N}-\mathrm{Cu}_{2} \mathrm{O} / \mathrm{ZnO}$ nanocomposite corresponds to the possibility of substituting oxygen by nitrogen. This can be mainly attributed to the highest resemblance among nitrogen and oxygen atoms in terms of electronegativity and atomic radius. 


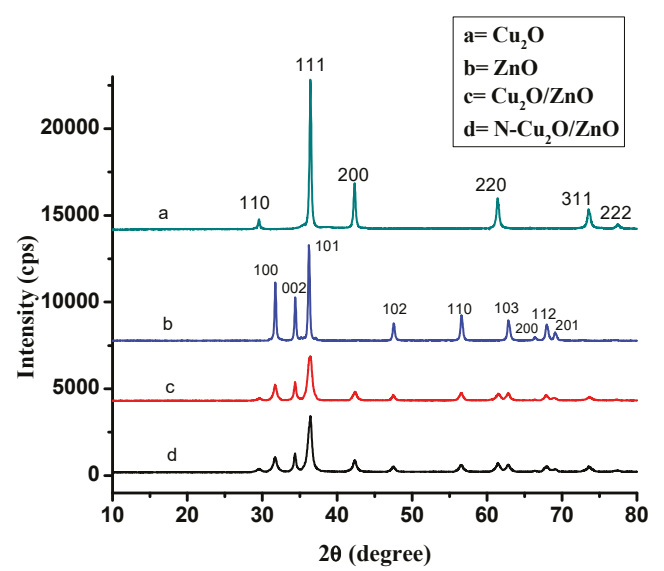

Figure 1. X-ray diffractogram of (a) $\mathrm{Cu}_{2} \mathrm{O}$, (b) $\mathrm{ZnO}$, (c) $\mathrm{Cu}_{2} \mathrm{O} / \mathrm{ZnO}$ and (d) N-doped $\mathrm{Cu}_{2} \mathrm{O} / \mathrm{ZnO}$ nanomaterials.

The average crystallite sizes of the nanomaterials were calculated from the intensive peak using the Scherer equation:

$$
\mathrm{D}=\frac{0.9 \lambda}{\beta \cos \theta}
$$

where $D$ is the crystallite size, $\lambda$ is the wavelength, $\theta$ is the Bragg angle and $\beta$ is the full width at half maximum in radian. The average crystallite sizes of $\mathrm{ZnO}, \mathrm{Cu}_{2} \mathrm{O}, \mathrm{Cu}_{2} \mathrm{O} / \mathrm{ZnO}$ and $\mathrm{N}-\mathrm{Cu}_{2} \mathrm{O} / \mathrm{ZnO}$ were found at $33.72 \mathrm{~nm}, 32.33 \mathrm{~nm}, 14.15 \mathrm{~nm}$, and $13.57 \mathrm{~nm}$, respectively. Based on these results, the size of the crystallites is decreased in $\mathrm{N}$-doped $\mathrm{Cu}_{2} \mathrm{O} / \mathrm{ZnO}$ nanocomposite compared to the $\mathrm{Cu}_{2} \mathrm{O}$ and $\mathrm{ZnO}$. The effect of decreasing the crystallite size may be ascribed to the insertion of nitrogen (incorporation of dopant) in $\mathrm{Cu}_{2} \mathrm{O}$ and $\mathrm{ZnO}$ lattices [32,33] and this was also confirmed in the photocatalytic degradation experiment. This insertion of nitrogen into the $\mathrm{Cu}_{2} \mathrm{O}$ and $\mathrm{ZnO}$ lattices can disturb the growth process of the particles, which might be the reason for the reduction of crystallite size in $\mathrm{N}-\mathrm{Cu}_{2} \mathrm{O} / \mathrm{ZnO}$ nanocomposite compared to $\mathrm{Cu}_{2} \mathrm{O}$ and $\mathrm{ZnO}$ nano-level particles.

\subsection{Scanning Electron Microscopy (SEM) Analysis}

Surface morphology of $\mathrm{ZnO}, \mathrm{Cu}_{2} \mathrm{O}, \mathrm{Cu}_{2} \mathrm{O} / \mathrm{ZnO}$ and $\mathrm{N}-\mathrm{Cu}_{2} \mathrm{O} / \mathrm{ZnO}$ nanomaterials was determined by SEM as shown in Figure $2 \mathrm{a}-\mathrm{d}$, respectively. From SEM micrographs, it was evident that the morphology of $\mathrm{ZnO}$ showed some agglomerated nanoparticles with irregular morphology, which is in line with [30]. However, $\mathrm{SEM}$ micrographs of $\mathrm{Cu}_{2} \mathrm{O}, \mathrm{Cu}_{2} \mathrm{O} / \mathrm{ZnO}$ and $\mathrm{N}-\mathrm{Cu}_{2} \mathrm{O} / \mathrm{ZnO}$ samples were relatively ordered and showed that the agglomerations of particles were much less (Figure $2 b$,d) than in $\mathrm{ZnO} N P s$ with the nanocrystals, which had a truncated octahedron shape; this might be due to the presence of $\mathrm{Cu}_{2} \mathrm{O}[34,35]$. 

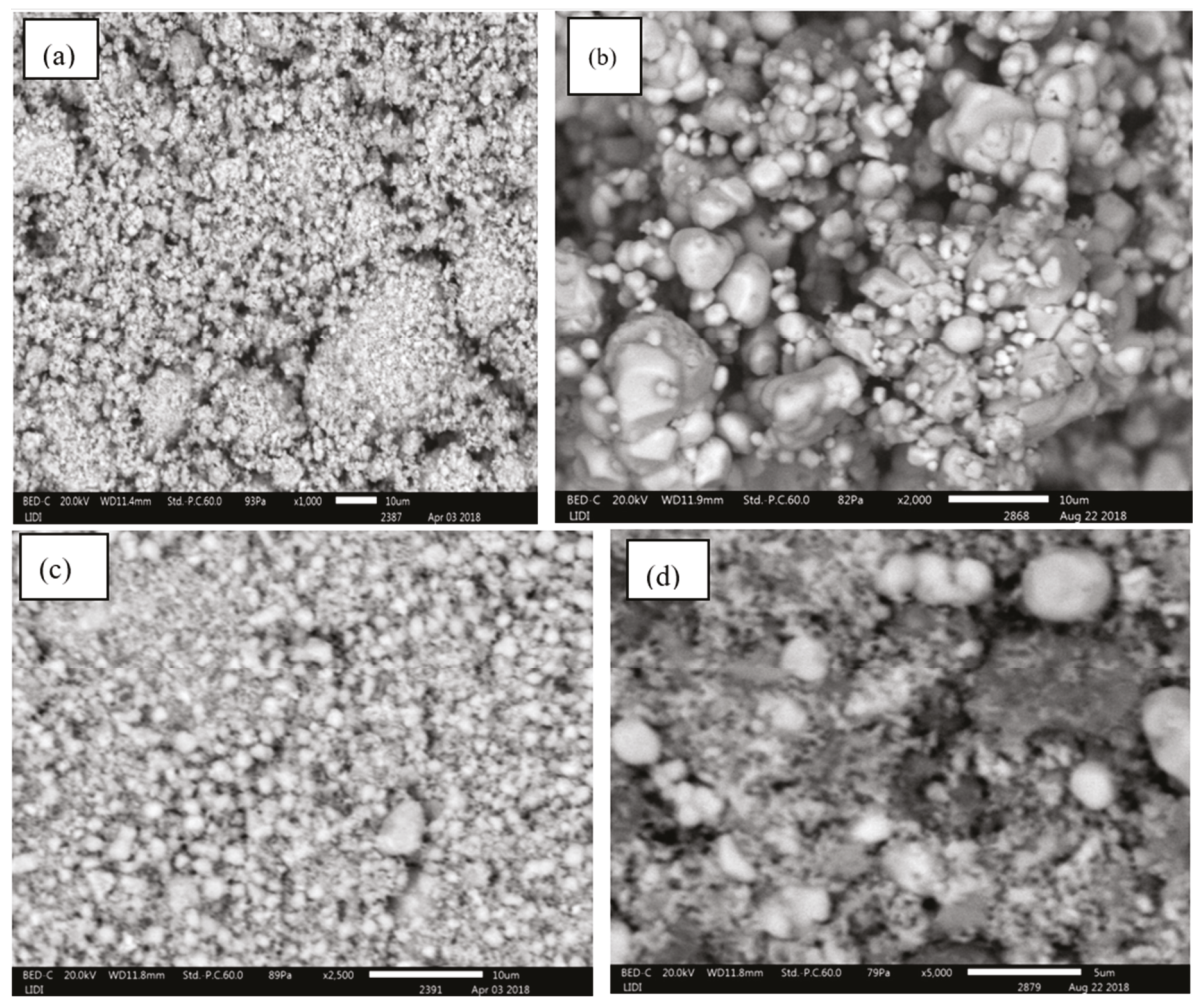

Figure 2. Scanning electron microscopy (SEM) morphology of (a) $\mathrm{ZnO},(\mathbf{b}) \mathrm{Cu}_{2} \mathrm{O}$, (c) $\mathrm{Cu}_{2} \mathrm{O} / \mathrm{ZnO}$ and (d) $\mathrm{N}$-doped $\mathrm{Cu}_{2} \mathrm{O} / \mathrm{ZnO}$ nanomaterials.

\subsection{Fourier Transform Infrared (FT-IR) Analysis}

The FT-IR bands of $\mathrm{ZnO}, \mathrm{Cu}_{2} \mathrm{O}, \mathrm{Cu}_{2} \mathrm{O} / \mathrm{ZnO}$ and $\mathrm{N}$-doped $\mathrm{Cu}_{2} \mathrm{O} / \mathrm{ZnO}$ nanomaterials are given in Figure 3. The peaks appeared in the range of $490-505 \mathrm{~cm}^{-1}$ in all the samples except in $\mathrm{Cu}_{2} \mathrm{O}$ and correspond to the stretching vibration of $\mathrm{ZnO}$, which agreed with the findings of previous studies [36,37]. In the FT-IR spectra of $\mathrm{Cu}_{2} \mathrm{O}, \mathrm{Cu}_{2} \mathrm{O} / \mathrm{ZnO}$ and $\mathrm{N}$-doped $\mathrm{Cu}_{2} \mathrm{O} / \mathrm{ZnO}$ nanoparticles, there were peaks in the range of $610-630 \mathrm{~cm}^{-1}$, which corresponds to the stretching vibration of $\mathrm{Cu}_{2} \mathrm{O}$; a similar result was reported by [34]. The peak that appeared at $3169 \mathrm{~cm}^{-1}$ in the FT-IR spectrum of the $\mathrm{N}$-doped $\mathrm{Cu}_{2} \mathrm{O} / \mathrm{ZnO}$ nanocomposite might be due to $\mathrm{N}-\mathrm{H}$ stretching vibration mode. The band located at $1441 \mathrm{~cm}^{-1}$ might be due to N-H bending vibration mode [38]. Besides the above absorption bands, there was an additional peak located at $431 \mathrm{~cm}^{-1}$ in the FT-IR spectrum of the $\mathrm{N}$-doped $\mathrm{Cu}_{2} \mathrm{O} / \mathrm{ZnO}$ nanocomposite, which might be attributed to the metal-nitrogen $(\mathrm{M}-\mathrm{N})$ stretching vibration similar results have been reported [32]. Therefore, the bands indicated the presence of $\mathrm{ZnO}, \mathrm{Cu}_{2} \mathrm{O}$ and nitrogen in the $\mathrm{N}$-doped $\mathrm{Cu}_{2} \mathrm{O} / \mathrm{ZnO}$ nanocomposite. 


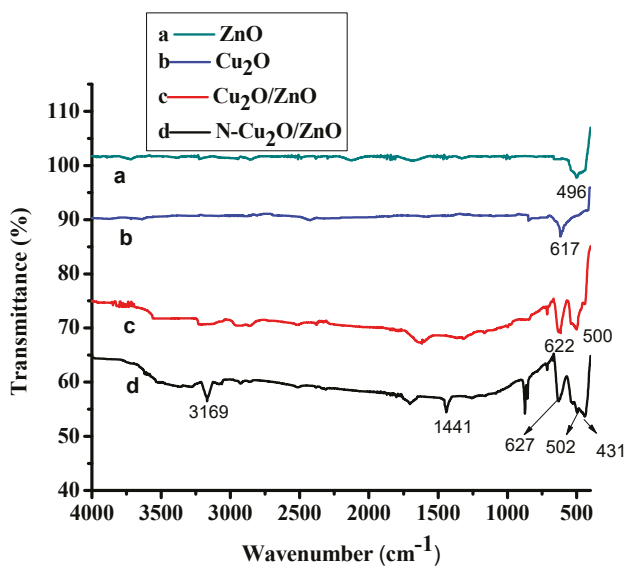

Figure 3. Fourier transform infrared (FT-IR) spectrums of (a) $\mathrm{ZnO}$, (b) $\mathrm{Cu}_{2} \mathrm{O}$, (c) $\mathrm{Cu}_{2} \mathrm{O} / \mathrm{ZnO}$ and (d) $\mathrm{N}-\mathrm{Cu}_{2} \mathrm{O} / \mathrm{ZnO}$ nanomaterials.

\subsection{Optical Property Analysis}

The region of absorption of electromagnetic radiation of the prepared nanomaterials was studied using UV-Vis diffuse reflectance spectroscopy. The spectra for the absorption of light by $\mathrm{ZnO}_{2} \mathrm{Cu}_{2} \mathrm{O}$, $\mathrm{Cu}_{2} \mathrm{O} / \mathrm{ZnO}$ and $\mathrm{N}-\mathrm{Cu}_{2} \mathrm{O} / \mathrm{ZnO}$ are given in Figure 4. $\mathrm{ZnO}, \mathrm{Cu}_{2} \mathrm{O}, \mathrm{Cu}_{2} \mathrm{O} / \mathrm{ZnO}$ and $\mathrm{N}-\mathrm{Cu}{ }_{2} \mathrm{O} / \mathrm{ZnO}$ absorbed at $360,440,470$ and $500 \mathrm{~nm}$, respectively. For $\mathrm{ZnO}$, the absorption edge was in the ultraviolet region. The $\mathrm{Cu}_{2} \mathrm{O} / \mathrm{ZnO}$ composite nanoparticles absorbed light in the visible region because of the presence of $\mathrm{Cu}_{2} \mathrm{O}$ [27]. The absorption edges were extended into $470 \mathrm{~nm}$ by coupling $\mathrm{ZnO}$ with $\mathrm{Cu}_{2} \mathrm{O}$ and then further to $500 \mathrm{~nm}$ by doping with nitrogen.

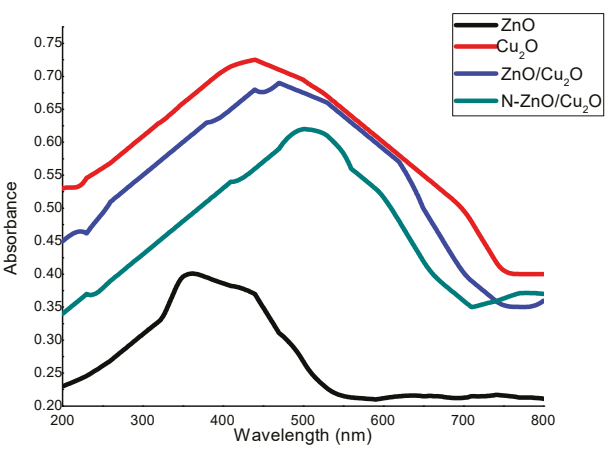

(a)

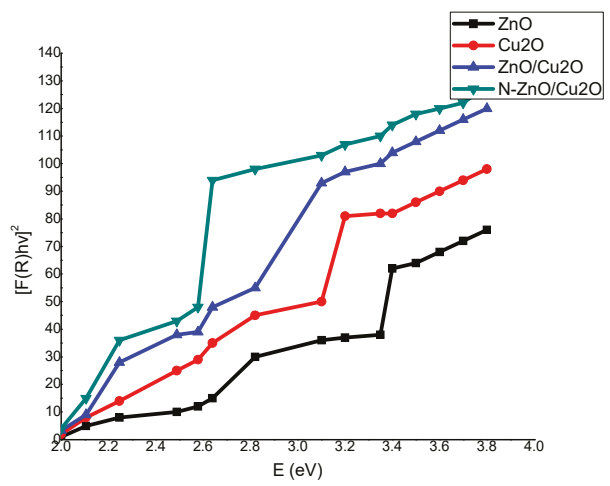

(b)

Figure 4. (a) Spectra for the optical property of $\mathrm{ZnO}, \mathrm{Cu}_{2} \mathrm{O}, \mathrm{Cu}_{2} \mathrm{O} / \mathrm{ZnO}$ and $\mathrm{N}-\mathrm{Cu}_{2} \mathrm{O} / \mathrm{ZnO}$ nanomaterials. (b) Kubelka-Munk function versus energy plots of $\mathrm{ZnO}, \mathrm{Cu}_{2} \mathrm{O}, \mathrm{ZnO} / \mathrm{Cu}_{2} \mathrm{O}$, and $\mathrm{N}-\mathrm{ZnO} / \mathrm{Cu}_{2} \mathrm{O}$ nanoparticles.

The bandgap energy of the nanocomposites can be inferred by extrapolation of the linear portion of the graph between the modified Kubelka-Munk function $[\mathrm{F}(\mathrm{R}) \mathrm{h} v]^{2}$ versus photon energy(hv) [39]; as shown in Figure 4b. The bandgap energy of $\mathrm{ZnO}$ and $\mathrm{Cu}_{2} \mathrm{O}$ is $3.4 \mathrm{eV}$ and $2.81 \mathrm{eV}$, respectively; however, there is decrement for $\mathrm{ZnO} / \mathrm{Cu}_{2} \mathrm{O}(2.64 \mathrm{eV})$ and $\mathrm{N}-\mathrm{ZnO} / \mathrm{Cu}_{2} \mathrm{O}(2.48 \mathrm{eV})$. The greatly extended absorption of light by $\mathrm{N}-\mathrm{Cu}_{2} \mathrm{O} / \mathrm{ZnO}$ to the visible region may be ascribed to the creation of a new energy level above the valence band of $\mathrm{Cu}_{2} \mathrm{O}$ and $\mathrm{ZnO}$ as a result of nitrogen doping, leading to 
narrowing of the bandgap to the visible region for harvesting more photons in the sunlight, which is in agreement with previous findings [40].

\subsection{Photocatalytic Activity}

\subsubsection{Optimization of $\mathrm{N}-\mathrm{Cu}_{2} \mathrm{O} / \mathrm{ZnO}$ Loading}

To know the optimal value of catalyst dosage, a series of photocatalytic degradation experiments were conducted by varying the amount of the $\mathrm{N}-\mathrm{Cu}_{2} \mathrm{O} / \mathrm{ZnO}$ nanocomposite from 120 to $240 \mathrm{mg} / \mathrm{L}$ as optimized by [27]. The photocatalytic degradation of methyl red under sunlight irradiation using a different amount of $\mathrm{N}$-doped $\mathrm{Cu}_{2} \mathrm{O} / \mathrm{ZnO}$ nanocomposite is shown in Figure 5. The figure shows that, as the amount of catalyst loading increases from $120 \mathrm{mg} / \mathrm{L}$ to $180 \mathrm{mg} / \mathrm{L}$, the degradation efficiency also increased. The reason is that increasing the catalyst loading increases the surface area and quantity of reaction sites on the surface of the photocatalyst. Consequently, the amount of hydroxyl radical formation increases too, which enables the photocatalytic degradation of the dye. However, the degradation efficiency was decreased when the amount of the catalyst dosage was beyond $180 \mathrm{mg} / \mathrm{L}$. This might be due to light-scattering and screening effects [41,42]. Besides, agglomeration also occurs when the concentration of catalyst is high; which results in the decreasing of catalyst surface area and causes diminishing of degradation efficiency $[42,43]$. Therefore, the degradation efficiency was greatest when the amount of the catalyst used was $180 \mathrm{mg} / \mathrm{L}$ and was the optimal value in the experiment.

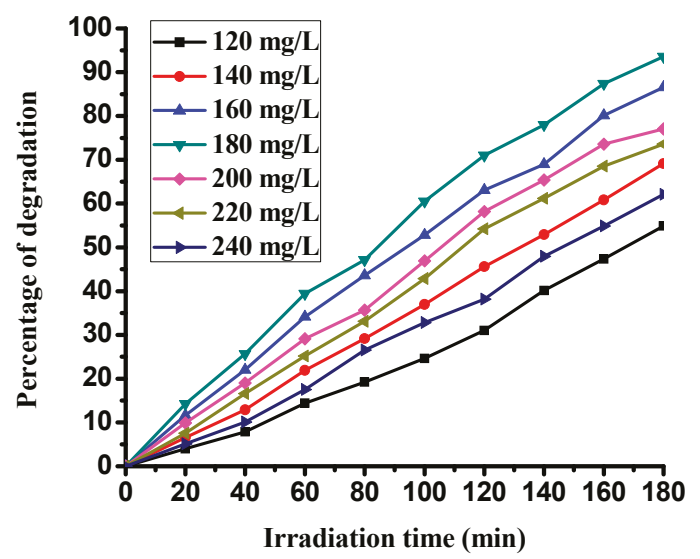

Figure 5. Optimization of $\mathrm{N}-\mathrm{Cu}_{2} \mathrm{O} / \mathrm{ZnO}$ nanocomposite loading for the degradation of methyl red under sunlight.

\subsubsection{Optimization of Methyl Red Concentration}

Once the amount of the catalyst was optimized at $180 \mathrm{mg} / \mathrm{L}$, a series of photocatalytic degradation experiments were conducted by varying the concentration of methyl red from 40 to $100 \mathrm{mg} / \mathrm{L}$ as adjusted by [27] to know the proper amount of the dye. As shown in Figure 6, as the concentration of the dye was enlarged from $40 \mathrm{mg} / \mathrm{L}$ to $60 \mathrm{mg} / \mathrm{L}$, the degradation efficiency was likewise enhanced. However, as the concentration of the dye goes above $60 \mathrm{mg} / \mathrm{L}$, the degradation efficiency sharply decreased. The reason for the decreasing of photocatalytic degradation efficiency with increasing concentration of the dye is that the higher dye concentration could affect the transmission of light which leads to a decrease in hydroxyl radical formation. The total amount of active sites on the surface of the catalyst was limited by the amount of catalyst loaded. Therefore, in the solution having fixed catalyst dosage, an inadequate amount of hydroxyl radicals that can attack the methyl red can form, hence leading to the diminishing of degradation capability [43]. 


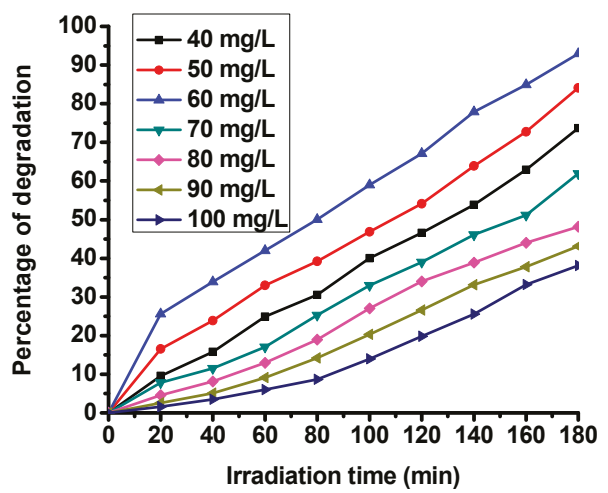

Figure 6. Optimization of the initial concentration of methyl red on the photocatalytic degradation using $\mathrm{N}-\mathrm{Cu}_{2} \mathrm{O} / \mathrm{ZnO}$ nanocomposite under sunlight.

3.5.3. Evaluation of the Photocatalytic Activities of $\mathrm{Cu}_{2} \mathrm{O}, \mathrm{ZnO}, \mathrm{Cu}_{2} \mathrm{O} / \mathrm{ZnO}$ and $\mathrm{N}-\mathrm{Cu}_{2} \mathrm{O} / \mathrm{ZnO}$ under the Optimized Catalyst Amount and Dye Concentration

The photocatalytic performance of $\mathrm{Cu}_{2} \mathrm{O}, \mathrm{ZnO}, \mathrm{Cu}_{2} \mathrm{O} / \mathrm{ZnO}$, and $\mathrm{N}-\mathrm{Cu}_{2} \mathrm{O} / \mathrm{ZnO}$ nanomaterials were evaluated in the degradation of methyl red dye, as shown in Figure 7. The photocatalytic degradation efficiency of methyl red reached $45.5 \%, 54 \%, 84.5 \%$ and $93.5 \%$ using $\mathrm{Cu}_{2} \mathrm{O}, \mathrm{ZnO}$, $\mathrm{Cu}_{2} \mathrm{O} / \mathrm{ZnO}$, and $\mathrm{N}$-doped $\mathrm{Cu}_{2} \mathrm{O} / \mathrm{ZnO}$, respectively, within 180 min irradiation time. Among these nanomaterials, the $\mathrm{N}$-doped $\mathrm{Cu}_{2} \mathrm{O} / \mathrm{ZnO}$ nanocomposite displayed better photocatalytic activity than the others under the optimized conditions. The activity of $\mathrm{N}$-doped $\mathrm{Cu}_{2} \mathrm{O} / \mathrm{ZnO}$ nanocomposite is enhanced because of the formation of a heterojunction [35]. The $\mathrm{p}-\mathrm{Cu}_{2} \mathrm{O} / \mathrm{n}-\mathrm{ZnO}$ heterojunction might significantly increase the absorption and exploitation capability of solar light; the electrons transfer from the one semiconductor to the other encourages the charge separation and construct significant synergistic effect in the degradation of the dye [35]. In addition to the effect of the coupling of the two semiconductors, the improved photocatalytic efficiency of $\mathrm{N}-\mathrm{Cu}_{2} \mathrm{O} / \mathrm{ZnO}$ nanocomposite is due to doping with nitrogen. Incorporating non-metals, for example nitrogen, can diminish the energy gap and extend absorption of light to the visible region of electromagnetic radiation [44]. In other words, nitrogen can modify the energy levels of both $\mathrm{Cu}_{2} \mathrm{O}$ and $\mathrm{ZnO}$ nanoparticles. Besides the above reasons, the enhanced photocatalytic activity of $\mathrm{N}$-doped $\mathrm{Cu}_{2} \mathrm{O} / \mathrm{ZnO}$ composite nanoparticles may be due to the reduction in particle size and creation of defect sites.

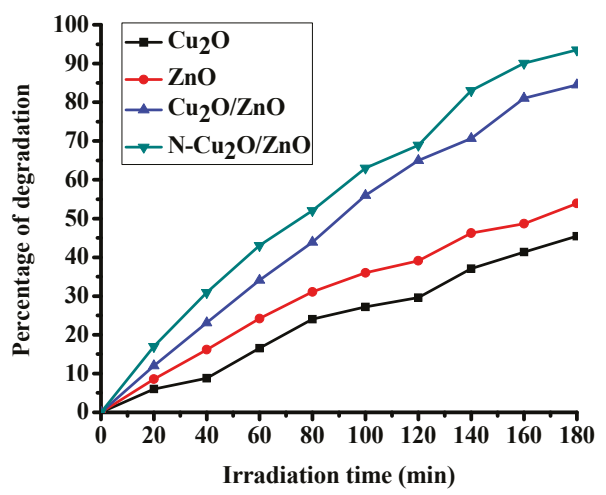

Figure 7. Evaluation of photocatalytic properties of $\mathrm{ZnO}, \mathrm{Cu}_{2} \mathrm{O}, \mathrm{Cu}_{2} \mathrm{O} / \mathrm{ZnO}$ and $\mathrm{N}$-doped $\mathrm{Cu}_{2} \mathrm{O} / \mathrm{ZnO}$ on the degradation of methyl red under solar light. 


\subsubsection{Proposed Mechanism}

Scheme 2 demonstrates the photocatalytic degradation mechanism of methyl red by N-doped $\mathrm{Cu}_{2} \mathrm{O} / \mathrm{ZnO}$ composite nanoparticles under sunlight irradiation. When the semiconductors are exposed to sunlight, a transition of electrons from the valence band to the conduction band and formation of holes in the valence band (Equations (3) and (4)) can take place. The conduction band of cuprous oxide is at higher position compared to zinc oxide (Jiang et al., 2013), the photo-induced electrons in the $\mathrm{Cu}_{2} \mathrm{O}$ conduction band can simply transfer to the $\mathrm{ZnO}$ conduction band Equation (5), which can successfully prevent the recombination of charge carriers. The electrons at the conduction band of $\mathrm{Cu}_{2} \mathrm{O}$ and $\mathrm{ZnO}$ undergo a reaction with adsorbed oxygen to give a peroxide radical anion Equation (6). It is impossible to oxidize the $\mathrm{OH}^{-}$by holes of $\mathrm{Cu}_{2} \mathrm{O}$ because the valence band edge of $\mathrm{Cu}_{2} \mathrm{O}$ is higher in a position [45]. However, the holes of $\mathrm{ZnO}$ oxidize the hydroxyl ion to yield a hydroxyl radical Equation (8), a strong oxidizing agent that can break down the organic dye. Besides, the peroxide radical anion undergoes a reaction with the hydrogen ion to produce $\mathrm{HO}_{2}$ and $\mathrm{H}_{2} \mathrm{O}_{2}$ Equation (9). The hydrogen peroxide is then reacted with the peroxide radical anion to create the powerful hydroxyl radicals Equation (11). Eventually, the hydroxyl radical oxidizes the dye into photocatalytic degradation products Equation (12) [35,43]. The reaction steps are described below.

$$
\begin{gathered}
\mathrm{Cu}_{2} \mathrm{O}+\mathrm{hv} \rightarrow \mathrm{Cu}_{2} \mathrm{O}\left(\mathrm{h}^{+}\right)+\mathrm{Cu}_{2} \mathrm{O}\left(\mathrm{e}^{-}\right) \\
\mathrm{ZnO}+\mathrm{hv} \rightarrow \mathrm{ZnO}\left(\mathrm{h}^{+}\right)+\mathrm{ZnO}\left(\mathrm{e}^{-}\right) \\
\mathrm{Cu}_{2} \mathrm{O}\left(\mathrm{e}^{-}\right)+\mathrm{ZnO} \rightarrow \mathrm{Cu}_{2} \mathrm{O}+\mathrm{ZnO}\left(\mathrm{e}^{-}\right) \\
\mathrm{Cu}_{2} \mathrm{O}\left(\mathrm{e}^{-}\right) / \mathrm{ZnO}\left(\mathrm{e}^{-}\right)+\mathrm{O}_{2-} \\
\mathrm{H}_{2} \mathrm{O} \rightarrow \mathrm{H}^{+}+\mathrm{OH}^{-} \\
\mathrm{ZnO}\left(\mathrm{h}^{+}\right)+\mathrm{OH}^{-} \rightarrow \mathrm{OH} \\
\mathrm{O}_{2-}+\mathrm{H}^{+} \rightarrow \mathrm{HO}_{2} \\
\mathrm{HO}_{2}+\mathrm{HO}_{2} \rightarrow \mathrm{O}_{2}+\mathrm{H}_{2} \mathrm{O}_{2} \\
\mathrm{H}_{2} \mathrm{O}_{2}+\mathrm{O}_{2-} \rightarrow \mathrm{OH}^{-}+\mathrm{OH}_{+} \mathrm{O}_{2} \\
\mathrm{OH}_{+} \mathrm{Dye}^{\rightarrow} \mathrm{H}_{2} \mathrm{O}+\mathrm{CO}_{2}
\end{gathered}
$$

The schematic illustration for the photocatalytic degradation mechanism of methyl red under sunlight is summarized below. 


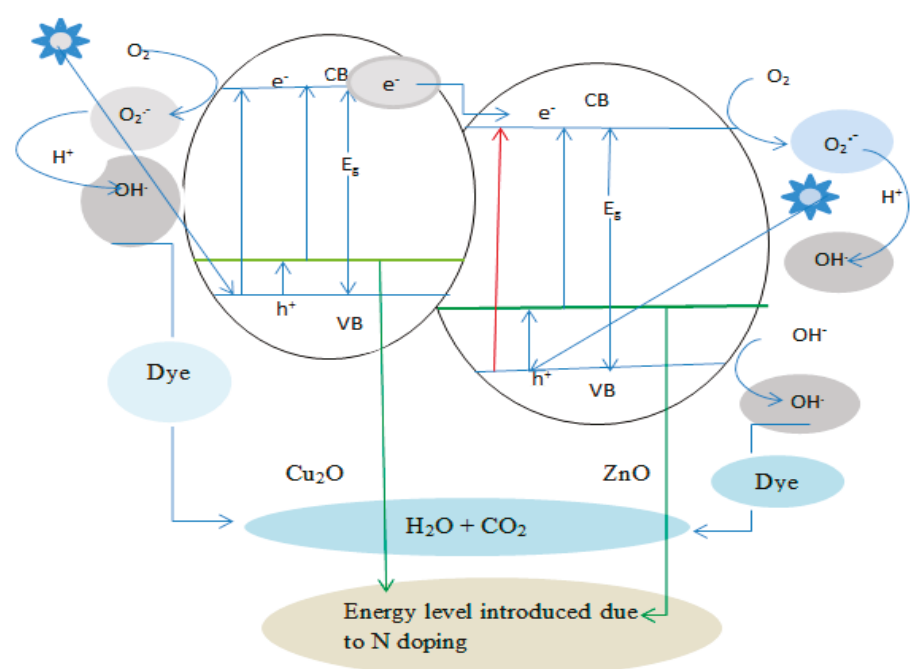

Scheme 2. Schematic illustration of the photocatalytic degradation of methyl red using $\mathrm{N}-\mathrm{Cu}_{2} \mathrm{O} / \mathrm{ZnO}$ nanocomposite under sunlight illumination.

\subsection{Kinetic Study of the Photocatalytic Decolorization}

The kinetics of the photocatalytic degradation of methyl red over $\mathrm{ZnO}, \mathrm{Cu}_{2} \mathrm{O}, \mathrm{Cu}_{2} \mathrm{O} / \mathrm{ZnO}$ and $\mathrm{N}$-doped $\mathrm{Cu}_{2} \mathrm{O} / \mathrm{ZnO}$ is shown in Figure 8. The plots of $\ln \left(\mathrm{C}_{0} / \mathrm{C}_{\mathrm{t}}\right)$ versus irradiation time indicated linear curves. The linearity of the kinetic curve shows that the photocatalytic degradation of methyl red follows pseudo-first-order kinetics. A fairly good correlation coefficient value to the pseudo-first-order kinetics of $R^{2}>0.96$ was obtained, which is in agreement with other reports [46]. The rate constants (reaction rate) were predicted from the slope of the graph. The rate constants are found to be 0.00338 , $0.00423,0.01005$ and $0.01088 \mathrm{~min}^{-1}$ for $\mathrm{Cu}_{2} \mathrm{O}, \mathrm{ZnO}, \mathrm{Cu}_{2} \mathrm{O} / \mathrm{ZnO}$, and $\mathrm{N}-\mathrm{Cu}_{2} \mathrm{O} / \mathrm{ZnO}$ nanomaterials, respectively. The rate constants of the photocatalytic degradation of methyl red using $\mathrm{N}-\mathrm{Cu}_{2} \mathrm{O} / \mathrm{ZnO}$ and $\mathrm{Cu}_{2} \mathrm{O} / \mathrm{ZnO}$ nanocomposites are larger than pure $\mathrm{Cu}_{2} \mathrm{O}$ and $\mathrm{ZnO}$ nanoparticles. Therefore, the photocatalytic activities of $\mathrm{N}-\mathrm{Cu}_{2} \mathrm{O} / \mathrm{ZnO}$ and $\mathrm{Cu}_{2} \mathrm{O} / \mathrm{ZnO}$ nanocomposites based on the rate constants are found to be greater than $\mathrm{Cu}_{2} \mathrm{O}$ and $\mathrm{ZnO}$ nanoparticles [5,47].

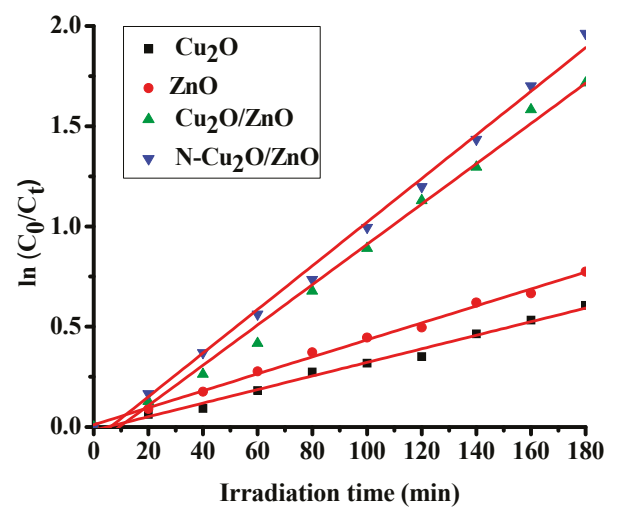

Figure 8. Reaction kinetics curve. 


\section{Conclusions}

$\mathrm{N}$-doped $\mathrm{Cu}_{2} \mathrm{O} / \mathrm{ZnO}$ nanocomposite was synthesized by co-precipitation and thermal decomposition methods. The absorption edge of the nanocomposite was more extended to the visible region of electromagnetic radiation compared to $\mathrm{ZnO}, \mathrm{Cu}_{2} \mathrm{O}$ and $\mathrm{Cu}_{2} \mathrm{O} / \mathrm{ZnO}$ nanomaterials. The photocatalytic activity of $\mathrm{N}$-doped $\mathrm{Cu}_{2} \mathrm{O} / \mathrm{ZnO}$ nanocomposite has enhanced efficiency than $\mathrm{ZnO}$, $\mathrm{Cu}_{2} \mathrm{O}$ and $\mathrm{Cu}_{2} \mathrm{O} / \mathrm{ZnO}$ nanomaterials. The enhancement is due to the coupling of $\mathrm{Cu}_{2} \mathrm{O}$ and $\mathrm{ZnO}$ semiconductors, which can drop the recombination rate of the charge carriers, and improve the absorption and utilization ability to sunlight. In addition to that, doping the nanocomposite with nitrogen can outspread the photoabsorption to longer wavelengths. Based on the findings, N-doped $\mathrm{Cu}_{2} \mathrm{O} / \mathrm{ZnO}$ nanocomposite is an effective solar light active photocatalyst that can be used for the removal of organic dyes from wastewater.

Author Contributions: All the authors participated in conceptualizing, executing, analyzing, editing, and reviewing this article.

Funding: This research received no external funding.

Conflicts of Interest: The authors declared no conflict interest.

\section{References}

1. Lin, B.; Ouyang, X. Energy demand in China: Comparison of characteristics between the US and China in rapid urbanization stage. Energy Convers. Manag. 2014, 79, 128-139. [CrossRef]

2. Pekakis, P.A.; Xekoukoulotakis, N.P.; Mantzavinos, D. Treatment of textile dyehouse wastewater by TiO2 photocatalysis. Water Res. 2006, 40, 1276-1286. [CrossRef] [PubMed]

3. Wainwright, M. Dyes in the development of drugs and pharmaceuticals. Dye. Pigment. 2008, 76, 582-589. [CrossRef]

4. Gupta, V.K.; Ali, I.; Saleh, T.A.; Nayak, A.; Agarwal, S. Chemical treatment technologies for waste-water recycling-an overview. Rsc Adv. 2012, 2, 6380-6388. [CrossRef]

5. Balcha, A.; Yadav, O.P.; Dey, T. Photocatalytic degradation of methylene blue dye by zinc oxide nanoparticles obtained from precipitation and sol-gel methods. Environ. Sci. Pollut. Res. 2016, 23, 25485-25493. [CrossRef] [PubMed]

6. Ong, C.B.; Ng, L.Y.; Mohammad, A.W. A review of $\mathrm{ZnO}$ nanoparticles as solar photocatalysts: Synthesis, mechanisms and applications. Renew. Sustain. Energy Rev. 2018, 81, 536-551. [CrossRef]

7. Emeline, A.; Ryabchuk, V.; Serpone, N. Photoreactions Occurring on Metal-oxide Surfaces are not all Photocatalytic: Description of Criteria and Conditions for Processes to be Photocatalytic. Catal. Today 2007, 122, 91-100. [CrossRef]

8. Benedix, R.; Dehn, F.; Quaas, J.; Orgass, M. Application of titanium dioxide photocatalysis to create self-cleaning building materials. Lacer 2000, 5, 157-168.

9. Gupta, S.M.; Tripathi, M. An overview of commonly used semiconductor nanoparticles in photocatalysis. High Energy Chem. 2012, 46, 1-9. [CrossRef]

10. Samadi, M.; Zirak, M.; Naseri, A.; Khorashadizade, E.; Moshfegh, A.Z. Recent progress on doped ZnO nanostructures for visible-light photocatalysis. Thin Solid Films 2016, 605, 2-19. [CrossRef]

11. Sakthivel, S.; Neppolian, B.; Shankar, M.; Arabindoo, B.; Palanichamy, M.; Murugesan, V. Solar photocatalytic degradation of azo dye: Comparison of photocatalytic efficiency of $\mathrm{ZnO}$ and TiO2. Sol. Energy Mater. Sol. Cells 2003, 77, 65-82. [CrossRef]

12. Behnajady, M.; Modirshahla, N.; Hamzavi, R. Kinetic study on photocatalytic degradation of CI Acid Yellow 23 by ZnO photocatalyst. J. Hazard. Mater. 2006, 133, 226-232. [CrossRef] [PubMed]

13. Cauda, V.; Pugliese, D.; Garino, N.; Sacco, A.; Bianco, S.; Bella, F.; Lamberti, A.; Gerbaldi, C. Multi-functional energy conversion and storage electrodes using flower-like Zinc oxide nanostructures. Energy 2014, 65, 639-646. [CrossRef]

14. Miccoli, B.; Cauda, V.; Bonanno, A.; Sanginario, A.; Bejtka, K.; Bella, F.; Fontana, M.; Demarchi, D. One-dimensional $\mathrm{ZnO} /$ gold junction for simultaneous and versatile multisensing measurements. Sci. Rep. 2016, 6, 29763. [CrossRef] [PubMed] 
15. Navaneethan, M.; Patil, V.; Ponnusamy, S.; Muthamizhchelvan, C.; Kawasaki, S.; Patil, P.; Hayakawa, Y. Sensitivity enhancement of ammonia gas sensor based on $\mathrm{Ag} / \mathrm{ZnO}$ flower and nanoellipsoids at low temperature. Sens. Actuators B Chem. 2018, 255, 672-683.

16. Jang, J.S.; Kim, J.; Ghorpade, U.; Shin, H.H.; Gang, M.G.; Park, S.D.; Kim, H.-J.; Lee, D.S.; Kim, J.H. Comparison study of ZnO-based quaternary TCO materials for photovoltaic application. J. Alloy. Compd. 2019, 793, 499-504. [CrossRef]

17. Shishiyanu, S.T.; Shishiyanu, T.S.; Lupan, O.I. Sensing characteristics of tin-doped ZnO thin films as NO2 gas sensor. Sens. Actuators B Chem. 2005, 107, 379-386. [CrossRef]

18. Umar, A.; Akhtar, M.; Al-Assiri, M.; Al-Salami, A.; Kim, S. Composite CdO-ZnO hexagonal nanocones: Efficient materials for photovoltaic and sensing applications. Ceram. Int. 2018, 44, 5017-5024. [CrossRef]

19. Huang, B.; Zhang, Z.; Zhao, C.; Cairang, L.; Bai, J.; Zhang, Y.; Mu, X.; Du, J.; Wang, H.; Pan, X. Enhanced gas-sensing performance of $\mathrm{ZnO@} \mathrm{In2O3} \mathrm{core@} \mathrm{shell} \mathrm{nanofibers} \mathrm{prepared} \mathrm{by} \mathrm{coaxial} \mathrm{electrospinning.} \mathrm{Sens.}$ Actuators B Chem. 2018, 255, 2248-2257. [CrossRef]

20. Li, Y.; Liang, Y.; Hernandez, F.C.R.; Yoo, H.D.; An, Q.; Yao, Y. Enhancing sodium-ion battery performance with interlayer-expanded $\mathrm{MoS}_{2}$-PEO nanocomposites. Nano Energy 2015, 15, 453-461. [CrossRef]

21. Chen, T.; Liu, W.; Zhuo, Y.; Hu, H.; Zhu, M.; Cai, R.; Chen, X.; Yan, J.; Liu, K. Single-phase P2-type layered oxide with Cu-substitution for sodium ion batteries. J. Energy Chem. 2020, 43, 148-154. [CrossRef]

22. Li, Y.; Xie, C.; Peng, S.; Lu, G.; Li, S. Eosin Y-sensitized nitrogen-doped TiO2 for efficient visible light photocatalytic hydrogen evolution. J. Mol. Catal. A Chem. 2008, 282, 117-123. [CrossRef]

23. Bora, L.V.; Mewada, R.K. Visible/solar light active photocatalysts for organic effluent treatment: Fundamentals, mechanisms and parametric review. Renew. Sustain. Energy Rev. 2017, 76, 1393-1421. [CrossRef]

24. Anandan, S.; Vinu, A.; Lovely, K.S.; Gokulakrishnan, N.; Srinivasu, P.; Mori, T.; Murugesan, V.; Sivamurugan, V.; Ariga, K. Photocatalytic activity of La-doped $\mathrm{ZnO}$ for the degradation of monocrotophos in aqueous suspension. J. Mol. Catal. A Chem. 2007, 266, 149-157. [CrossRef]

25. Welderfael, T.; Yadav, O.; Taddesse, A.M.; Kaushal, J. Synthesis, characterization and photocatalytic activities of Ag-N-codoped $\mathrm{ZnO}$ nanoparticles for degradation of methyl red. Bull. Chem. Soc. Ethiop. 2013, 27, 221-232. [CrossRef]

26. Wang, Y.; Tao, J.; Wang, X.; Wang, Z.; Zhang, M.; He, G.; Sun, Z. A unique Cu2O/TiO2 nanocomposite with enhanced photocatalytic performance under visible light irradiation. Ceram. Int. 2017, 43, 4866-4872. [CrossRef]

27. Ma, J.; Wang, K.; Li, L.; Zhang, T.; Kong, Y.; Komarneni, S. Visible-light photocatalytic decolorization of Orange II on Cu2O/ZnO nanocomposites. Ceram. Int. 2015, 41, 2050-2056. [CrossRef]

28. Ahmad, M.; Ahmed, E.; Hong, Z.; Khalid, N.; Ahmed, W.; Elhissi, A. Graphene-Ag/ZnO nanocomposites as high performance photocatalysts under visible light irradiation. J. Alloy. Compd. 2013, 577, 717-727. [CrossRef]

29. Jiang, Y.; Sun, Y.; Liu, H.; Zhu, F.; Yin, H. Solar photocatalytic decolorization of CI Basic Blue 41 in an aqueous suspension of TiO2-ZnO. Dye. Pigment. 2008, 78, 77-83. [CrossRef]

30. Essawy, A.A. Silver imprinted zinc oxide nanoparticles: Green synthetic approach, characterization and efficient sunlight-induced photocatalytic water detoxification. J. Clean. Prod. 2018, 183, 1011-1020. [CrossRef]

31. Jiang, D.; Xing, C.; Liang, X.; Shao, L.; Chen, M. Synthesis of cuprous oxide with morphological evolution from truncated octahedral to spherical structures and their size and shape-dependent photocatalytic activities. J. Colloid Interface Sci. 2016, 461, 25-31. [CrossRef] [PubMed]

32. Rajbongshi, B.M.; Ramchiary, A.; Samdarshi, S. Influence of N-doping on photocatalytic activity of ZnO nanoparticles under visible light irradiation. Mater. Lett. 2014, 134, 111-114. [CrossRef]

33. Gionco, C.; Fabbri, D.; Calza, P.; Paganini, M.C. Synthesis, characterization, and photocatalytic tests of N-doped zinc oxide: A new interesting photocatalyst. J. Nanomater. 2016, 2016. [CrossRef]

34. Kerour, A.; Boudjadar, S.; Bourzami, R.; Allouche, B. Eco-friendly synthesis of cuprous oxide (Cu2O) nanoparticles and improvement of their solar photocatalytic activities. J. Solid State Chem. 2018, 263, 79-83. [CrossRef]

35. He, Z.; Xia, Y.; Tang, B.; Jiang, X.; Su, J. Fabrication and photocatalytic property of ZnO/Cu2O core-shell nanocomposites. Mater. Lett. 2016, 184, 148-151. [CrossRef] 
36. Abraham, N.; Rufus, A.; Unni, C.; Philip, D. Dye sensitized solar cells using catalytically active CuO-ZnO nanocomposite synthesized by single step method. Spectrochim. Acta Part A Mol. Biomol. Spectrosc. 2018, 200, 116-126. [CrossRef]

37. Alizadeh, E.; Baseri, H. Catalytic degradation of Amlodipine Besylate using $\mathrm{ZnO}, \mathrm{Cu}$ doped $\mathrm{ZnO}$, and Fe doped $\mathrm{ZnO}$ nanoparticles from an aqueous solution: Investigating the effect of different parameters on degradation efficiency. Solid State Sci. 2018, 78, 86-94. [CrossRef]

38. Sanchez-Martinez, A.; Ceballos-Sanchez, O.; Koop-Santa, C.; López-Mena, E.R.; Orozco-Guareño, E.; García-Guaderrama, M. N-doped TiO2 nanoparticles obtained by a facile coprecipitation method at low temperature. Ceram. Int. 2018, 44, 5273-5283. [CrossRef]

39. Jeyasubramanian, K.; Hikku, G.; Sivashakthi, M. Synthesis, characterization and photo-catalytic studies of mixed metal oxides of nano $\mathrm{ZnO}$ and SnOx. Mater. Sci. Semicond. Process. 2016, 51, 25-32. [CrossRef]

40. Yu, W.; Zhang, J.; Peng, T. New insight into the enhanced photocatalytic activity of N-, C-and S-doped ZnO photocatalysts. Appl. Catal. B Environ. 2016, 181, 220-227. [CrossRef]

41. Elhalil, A.; Elmoubarki, R.; Farnane, M.; Machrouhi, A.; Mahjoubi, F.; Sadiq, M.; Qourzal, S.; Barka, N. Synthesis, characterization and efficient photocatalytic activity of novel Ca/ZnO-Al2O3 nanomaterial. Mater. Today Commun. 2018, 16, 194-203. [CrossRef]

42. Ashebir, M.E.; Tesfamariam, G.M.; Nigussie, G.Y.; Gebreab, T.W. Structural, Optical, and Photocatalytic Activities of Ag-Doped and Mn-Doped ZnO Nanoparticles. J. Nanomater. 2018, 2018. [CrossRef]

43. Lee, K.M.; Lai, C.W.; Ngai, K.S.; Juan, J.C. Recent developments of zinc oxide based photocatalyst in water treatment technology: A review. Water Res. 2016, 88, 428-448. [CrossRef] [PubMed]

44. Yu, Z.; Yin, L.-C.; Xie, Y.; Liu, G.; Ma, X.; Cheng, H.-M. Crystallinity-dependent substitutional nitrogen doping in $\mathrm{ZnO}$ and its improved visible light photocatalytic activity. J. Colloid Interface Sci. 2013, 400, 18-23. [CrossRef]

45. Shi, J.; Li, J.; Huang, X.; Tan, Y. Synthesis and enhanced photocatalytic activity of regularly shaped Cu $2 \mathrm{O}$ nanowire polyhedra. Nano Res. 2011, 4, 448-459. [CrossRef]

46. Patil, A.B.; Patil, K.R.; Pardeshi, S.K. Ecofriendly synthesis and solar photocatalytic activity of S-doped ZnO. J. Hazard. Mater. 2010, 183, 315-323. [CrossRef]

47. Rajaboopathi, S.; Thambidurai, S. Enhanced photocatalytic activity of Ag-ZnO nanoparticles synthesized by using Padina gymnospora seaweed extract. J. Mol. Liq. 2018, 262, 148-160. [CrossRef]

(C) 2019 by the authors. Licensee MDPI, Basel, Switzerland. This article is an open access article distributed under the terms and conditions of the Creative Commons Attribution (CC BY) license (http://creativecommons.org/licenses/by/4.0/). 
Article

\title{
Synthesis of $\mathrm{CuO} / \mathrm{ZnO}$ Nanocomposites and Their Application in Photodegradation of Toxic Textile Dye
}

\author{
Abdullah Al Mamun Sakib ${ }^{1}$, Shah Md. Masum ${ }^{1}$, Jan Hoinkis ${ }^{2}$, Rafiqul Islam ${ }^{1}$ and \\ Md. Ashraful Islam Molla ${ }^{1, *}$ \\ 1 Department of Applied Chemistry \& Chemical Engineering, Faculty of Engineering \& Technology, \\ University of Dhaka, Dhaka 1000, Bangladesh; abdullahsakib33@gmail.com (A.A.M.S.); \\ masumdhk@yahoo.com (S.M.M.); professorrafiqulislam@yahoo.co.uk (R.I.) \\ 2 Centre of Applied Research (CAR), Karlsruhe University of Applied Sciences, 76133 Karlsruhe, Germany; \\ jan.hoinkis@hs-karlsruhe.de \\ * Correspondence: ashraful.acce@du.ac.bd
}

Received: 23 August 2019; Accepted: 13 September 2019; Published: 17 September 2019

\begin{abstract}
CuO} / \mathrm{ZnO}$ composites are synthesized using a simple mechanochemical combustion method. $X$-ray diffraction (XRD), scanning electron microscopy (SEM), energy-dispersive X-ray spectroscopy (EDX), and Fourier transform infrared (FTIR) are used to characterize the prepared oxides. X-ray diffraction reveals that the prepared $\mathrm{CuO} / \mathrm{ZnO}$ exhibit a wurtzite $\mathrm{ZnO}$ crystal structure and the composites are composed of $\mathrm{CuO}$ and $\mathrm{ZnO}$. The strong peaks of the $\mathrm{Cu}, \mathrm{Zn}$, and $\mathrm{O}$ elements are exhibited in the EDX spectrum. The FTIR spectra appear at around $3385 \mathrm{~cm}^{-1}$ and $1637 \mathrm{~cm}^{-1}$, caused by $\mathrm{O}-\mathrm{H}$ stretching, and $400 \mathrm{~cm}^{-1}$ to $590 \mathrm{~cm}^{-1}$, ascribable to $\mathrm{Zn}-\mathrm{O}$ stretching. The photocatalytic performances of $\mathrm{CuO} / \mathrm{ZnO}$ nanocomposites are investigated for the degradation of methylene blue (MB) aqueous solution in direct solar irradiation. The degradation value of $\mathrm{MB}$ with $5 \mathrm{wt} \% \mathrm{CuO} / \mathrm{ZnO}$ is measured to be $98 \%$, after $2 \mathrm{~h}$ of solar irradiation. The reactive ${ }^{\bullet} \mathrm{O}_{2}{ }^{-}$and ${ }^{\bullet} \mathrm{OH}$ radicals play important roles in the photodegradation of MB. Mineralization of MB is around $91 \%$ under sunlight irradiation within $7 \mathrm{~h}$. The photodegradation treatment for the textile wastewater using sunlight is an easy technique-simply handled, and economical. Therefore, the solar photodegradation technique may be a very effective method for the treatment of wastewater instead of photodegradation with the artificial and expensive Hg-Xe lamp.
\end{abstract}

Keywords: $\mathrm{CuO} / \mathrm{ZnO}$; photodegradation; nanocomposite; methylene blue; sunlight

\section{Introduction}

It is evident that water pollution is a global environmental problem now due to the presence of different types of hazardous pollutants in it [1]. Textile wastewater, which contains huge amounts of pollutants that are very harmful to the environment, is of special research interest. The release of textile wastewater to the environment causes aesthetic problems due to the changed color of the water bodies [2]. Nanocomposites, containing oxides of metal, are of great research interest at the moment due to their high photocatalytic degradation efficiency, sustainable development characteristics, and lack of secondary pollution for water pollution treatment $[3,4]$. Recently, different types of metal oxide nanocomposites have been synthesized, such as $\mathrm{ZnO}-\mathrm{Mg}$ [5], $\mathrm{CuO} / \mathrm{ZnO}$ [6], $\mathrm{ZnO}-\mathrm{NiO}$ [7], $\mathrm{Co}_{3} \mathrm{O}_{4}-\mathrm{ZnO}$ [8], and $\mathrm{CeO}_{2}-\mathrm{ZnO}$ [9]. Saravanan et al. prepared $\mathrm{CuO} / \mathrm{ZnO}, \mathrm{V}_{2} \mathrm{O}_{5} / \mathrm{ZnO}$, and $\mathrm{ZnO} / \gamma-\mathrm{Mn}_{2} \mathrm{O}_{3}$ nanocomposites using the thermal decomposition method [10-12]. They also studied the photocatalytic degradation of rhodamine $\mathrm{B}$ under sunlight irradiation using $\mathrm{CuO} / \mathrm{ZnO}$ nanocomposite. Li et al. [13] synthesized $\mathrm{CuO} / \mathrm{ZnO}$ nanocomposites using the thermal decomposition method and investigated the visible light-driven photocatalytic degradation of methylene blue and methyl orange. Kuriakose et al. [14] prepared $\mathrm{CuO} / \mathrm{ZnO}$ nanocomposites using the carbothermal 
evaporation method and evaluated the photocatalytic degradation of methylene blue and methyl orange dyes under sunlight irradiation. Wang el al. [15] prepared MnO@MnOx microspheres through the solvothermal process and reported the degradation of levofloxacin under simulated sunlight irradiation. Nanocomposite photocatalytic technology can be considered a green technology and provides the advantages of abundance, including postpone electron-hole recombination, higher photocatalytic activity, and the ability to convert solar energy to chemical energy, which eventually realizes the solution of energy and environmental issues [16-21].

$\mathrm{ZnO}$ is an n-type semiconductor, having a conductivity of about $10^{-7}-10^{-3} \mathrm{~S} / \mathrm{cm}$. It has a relatively large binding energy of $60 \mathrm{meV}$. However, the main disadvantages of $\mathrm{ZnO}$ are its fast electron-hole recombination rate and inefficient utilization of sunlight that lead to a reduction in photodegradation efficiency. The photodegradation performance of $\mathrm{ZnO}$ can be increased by modifying $\mathrm{ZnO}$ with transition metals [22]. Among the various transition metals, $\mathrm{Cu}$-doped $\mathrm{ZnO}$ nanomaterials are of special interest due to the photocatalytic efficiency enhancement that creates defects in the lattice and reduces the recombination of photogenerated charge carriers [23]. $\mathrm{Cu}$ also provides plenty of advantages, such as low cost, more electronegativity than zinc, and a similar atomic size to that of zinc, and leads to better doping efficiency [24]. $\mathrm{CuO}$ is a natural p-type semiconductor with a narrow band gap, having a conductivity of $10^{-4} \mathrm{~S} / \mathrm{cm}$, and it can be applied in photodegradation reactions [25]. Among the various metal oxide nanocomposites, researchers are paying more attention to $\mathrm{CuO} / \mathrm{ZnO}$ because of its non-toxicity, economical benefits, and availability. It possesses high energy density and good electrical and piezoelectric properties [26,27]. $\mathrm{CuO} / \mathrm{ZnO}$ nanocomposites improve physicochemical properties, compared to pure $\mathrm{ZnO}$ and $\mathrm{CuO}$ nanostructures [14]. The formation of a $\mathrm{CuO} / \mathrm{ZnO}$ heterojunction also enhances the optical and electronic properties, which are considered to be promising applications in photocatalysis [10].

Herein, the various proportions of $\mathrm{CuO} / \mathrm{ZnO}$ nanocomposites are prepared using the mechanochemical combustion method. The synthesized composites are characterized by X-ray diffraction (XRD), scanning electron microscopy (SEM), energy-dispersive X-ray spectroscopy (EDX), and Fourier transform infrared (FTIR). Methylene blue (MB) is a non-biodegradable and hazardous organic compound intensively used in textile industries and, so, it is selected as the degradation target to evaluate the photocatalytic performances of the composites using sunlight. The results show that $\mathrm{CuO} / \mathrm{ZnO}$ exhibit increased photocatalytic activities, compared with $\mathrm{ZnO}$. The degradation mechanism and mineralization of the improved photocatalytic performance are also discussed.

\section{Materials and Methods}

\subsection{Chemicals}

The samples were synthesized using zinc acetate dihydrate $\left(\mathrm{Zn}\left(\mathrm{CH}_{3} \mathrm{COO}\right)_{2} \cdot 2 \mathrm{H}_{2} \mathrm{O}\right)$, oxalic acid dihydrate $\left.(\mathrm{COOH})_{2} \cdot 2 \mathrm{H}_{2} \mathrm{O}\right)$, and copper acetate $\left(\mathrm{Cu}\left(\mathrm{CH}_{3} \mathrm{COO}\right)_{2}\right)$. Methylene blue $\left(\mathrm{C}_{16} \mathrm{H}_{18} \mathrm{ClN}_{3} \mathrm{~S}\right)$ was employed in the photodegradation experiment. Three scavengers were selected: Ascorbic acid $\left(\mathrm{C}_{6} \mathrm{H}_{8} \mathrm{O}_{6}\right)$, 2-propanol $\left.\left(\mathrm{CH}_{3}\right)_{2} \mathrm{CHOH}\right)$, and di-ammonium oxalate monohydrate $\left.\left(\mathrm{NH}_{4}\right)_{2} \mathrm{C}_{2} \mathrm{O}_{4} \cdot \mathrm{H}_{2} \mathrm{O}\right)$. All of the analytical grade chemicals were used without any purification.

\subsection{Fabrication of $\mathrm{CuO} / \mathrm{ZnO}$}

The mechanochemical combustion method was used to prepare $\mathrm{CuO} / \mathrm{ZnO}$. In agitate mortar, $2.195 \mathrm{~g}$ of zinc oxalate dihydrate and $2.521 \mathrm{~g}$ of acetic acid were taken. Then, the mixture was ground for 10 min to produce $\mathrm{Zn}\left(\mathrm{CH}_{3} \mathrm{COO}\right)_{2} \cdot 2 \mathrm{H}_{2} \mathrm{O}$ and $(\mathrm{COOH})_{2} \cdot 2 \mathrm{H}_{2} \mathrm{O}$ paste. In the above paste, $\mathrm{Cu}\left(\mathrm{CH}_{3} \mathrm{COO}\right)_{2}$ was added as a source of $\mathrm{Cu}$, and then the grinding process was continued for the next $10 \mathrm{~min}$ to produce a precursor of zinc oxalate-copper oxalate. The precursor powders were calcined at $500{ }^{\circ} \mathrm{C}$ for $3 \mathrm{~h}$ in the presence of air atmosphere to obtain the $\mathrm{CuO} / \mathrm{ZnO}$ composite [28]. For comparison, un-doped $\mathrm{ZnO}$ was prepared from the zinc oxalate and acetic acid paste. 


\subsection{Characterization}

The X-ray diffractometer (XRD, Ultima IV, Rigaku Corporation, Akishima, Japan) was selected to collect the diffraction patterns of materials using $\mathrm{Cu} \mathrm{K} \alpha$ radiation $(\lambda=0.15406 \mathrm{~nm}, 40 \mathrm{KV}, 1.64 \mathrm{~mA})$ in the ranges of $10^{\circ}$ to $80^{\circ}$ of 2-theta angle. The morphologies of oxides were recorded with a scanning electron microscope (SEM, JSM-6010 PLUS/LA, JEOL Ltd., Tokyo, Japan). Elemental analysis of $\mathrm{CuO} / \mathrm{ZnO}$ was examined using a JSM-7900F SEM attached with EDX. The chemical structures of $\mathrm{CuO} / \mathrm{ZnO}$ were studied with a Fourier transform infrared (FTIR) spectrophotometer (IR Prestige-21, SHIMADZU, Kyoto, Japan).

\subsection{Evaluation of Photocatalytic Activity}

The photocatalytic experimental conditions are presented in Table 1. Briefly, the photocatalytic performance of $\mathrm{CuO} / \mathrm{ZnO}$ composites was investigated in aqueous $\mathrm{MB}$ solution using sunlight. Experiments were conducted under similar conditions on a sunny day between 11:00 and 14:00. In photodegradation, $20 \mathrm{mg}$ of photocatalyst was added into $30 \mathrm{~mL}$ aqueous $\mathrm{MB}$ of $10 \mathrm{mg} / \mathrm{L}$ in the beakers. To equilibrate the suspension, a magnetic stirrer was used in the dark for $30 \mathrm{~min}$. Then, the suspensions in the beakers were kept in sunlight for different time intervals. About $3 \mathrm{~mL}$ MB solution was withdrawn and separated with an Advantec membrane filter $0.45 \mu \mathrm{m}$. The MB concentration was calculated using a UV-visible spectrometry (UV-1700 Pharma Spec, SHIMADZU, Kyoto, Japan). The relative $\mathrm{MB}$ concentration $\left(\mathrm{C} / \mathrm{C}_{0}\right)$ was determined at the relative absorbance $\left(\mathrm{A} / \mathrm{A}_{0}\right)$ of $\lambda=662 \mathrm{~nm}$, according to the Beer-Lambert law, where $\mathrm{A}_{0}$ and A were the absorbance of aqueous $\mathrm{MB}$ at a starting time $\left(t_{0}\right)$ of photodegradation and at any time $t$, respectively.

The total organic carbon (TOC) was studied using Shimadzu TOC analyzer (TOC-VCPH, Kyoto, Japan). The oxidation and titration with potassium permanganate method was applied for the measurement of chemical oxygen demand (COD).

Table 1. Experimental conditions.

\begin{tabular}{cc}
\hline Methylene blue & $30 \mathrm{~mL}, 5-20 \mathrm{mg} / \mathrm{L}$ \\
Photocatalyst & $20 \mathrm{mg}$ \\
Temperature & $\sim 30^{\circ} \mathrm{C}$ \\
pH & Natural \\
Light source & Sunlight \\
Irradiation time & $0-150 \mathrm{~min}$ \\
\hline
\end{tabular}

\subsection{Detection of Active Species}

To scrutinize the reactive species that was responsible for photocatalytic degradation of MB, three scavenger tests were done in the same procedure as discussed in the photodegradation experiment. In the scavenger tests, di-ammonium oxalate monohydrate, 2-propanol, and ascorbic acid were stipulated as $\mathrm{h}^{+}, \bullet \mathrm{OH}$, and $\bullet^{\bullet} \mathrm{O}_{2}{ }^{-}$reactive species, respectively $[29,30]$.

\section{Results and Discussion}

\subsection{XRD Patterns Study}

The crystal structure of the nanomaterials was confirmed by $\mathrm{X}$-ray diffraction. Figure 1 displays the XRD patterns of the $\mathrm{ZnO}$ and with different copper contents $\mathrm{CuO} / \mathrm{ZnO}$ nanocomposites. Major peaks were observed at around $31.82^{\circ}(100), 34.50^{\circ}(002)$, and $36.32^{\circ}(101)$ of the undoped $\mathrm{ZnO}$ (JCPDS no.36-1451) [31]. $\mathrm{CuO} / \mathrm{ZnO}$ nanocomposites displayed a very minor peak at $38.8^{\circ}$, which was indexed to the (111) of $\mathrm{CuO}$ [24]. With the addition of $\mathrm{Cu}$ in $\mathrm{ZnO}$, the diffraction intensities and angles changed remarkably. The diffraction peak of $\mathrm{CuO}(111)$ was found with 5 and 7 wt \% of copper content. In addition, with increased amounts of copper, no other peaks or appreciable shifts were observed and no solid solution was formed in between $\mathrm{ZnO}$ and $\mathrm{CuO}$. The Scherrer equation was used to obtain the 
grain size of the $\mathrm{ZnO}$ and $\mathrm{CuO} / \mathrm{ZnO}$ nanocomposites. The estimated grains were found as $\sim 32.16$ and $\sim 32.13 \mathrm{~nm}$ for $\mathrm{ZnO}$ and $5 \mathrm{wt} \% \mathrm{CuO} / \mathrm{ZnO}$, respectively.

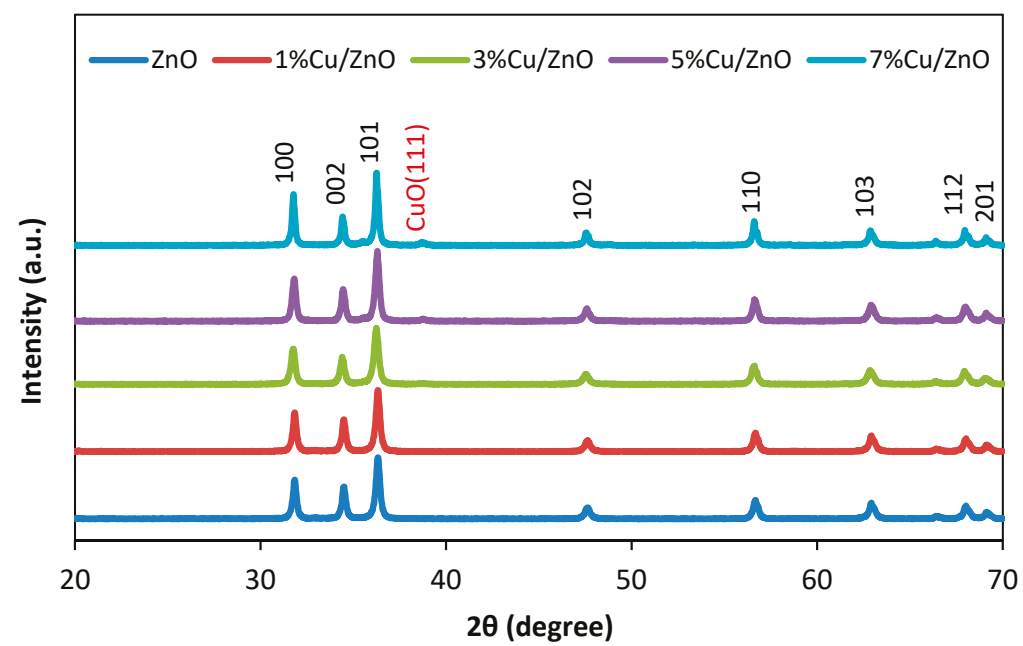

Figure 1. X-ray diffraction (XRD) patterns of $\mathrm{ZnO}$ and $\mathrm{CuO} / \mathrm{ZnO}$.

\subsection{SEM and EDX Study}

Crystal morphologies of the $\mathrm{ZnO}$ and $\mathrm{CuO} / \mathrm{ZnO}$ were evaluated through SEM. Figure 2a shows that the synthesized $\mathrm{ZnO}$ was heterogeneous with rod-shaped branches of building blocks. On the other hand, Figure $2 \mathrm{~b}$ shows that the shape of the $\mathrm{CuO} / \mathrm{ZnO}$ composite changed from rod-like to spheroid. The particle sizes of synthesized composites were in the nanometer range, which was similar to the data of XRD. Figure $2 \mathrm{c}$ shows the EDX line-scanning values of $\mathrm{CuO} / \mathrm{ZnO}$ heterojunction. The presences of copper, zinc, and oxygen atoms were exhibited by the EDX spectra analysis. Sharp peaks of $\mathrm{Zn}, \mathrm{Cu}$, and $\mathrm{O}$ were obtained; no other peak related to any other element was detected in the spectrum within the detection limit, which confirmed that synthesized materials were composed of $\mathrm{Zn}$, $\mathrm{Cu}$, and $\mathrm{O}$ only. The spectrum confirmed that $\mathrm{Cu}$ exists in the heterostructure, representing that the copper nanoparticles were successfully deposited on zinc oxide. 

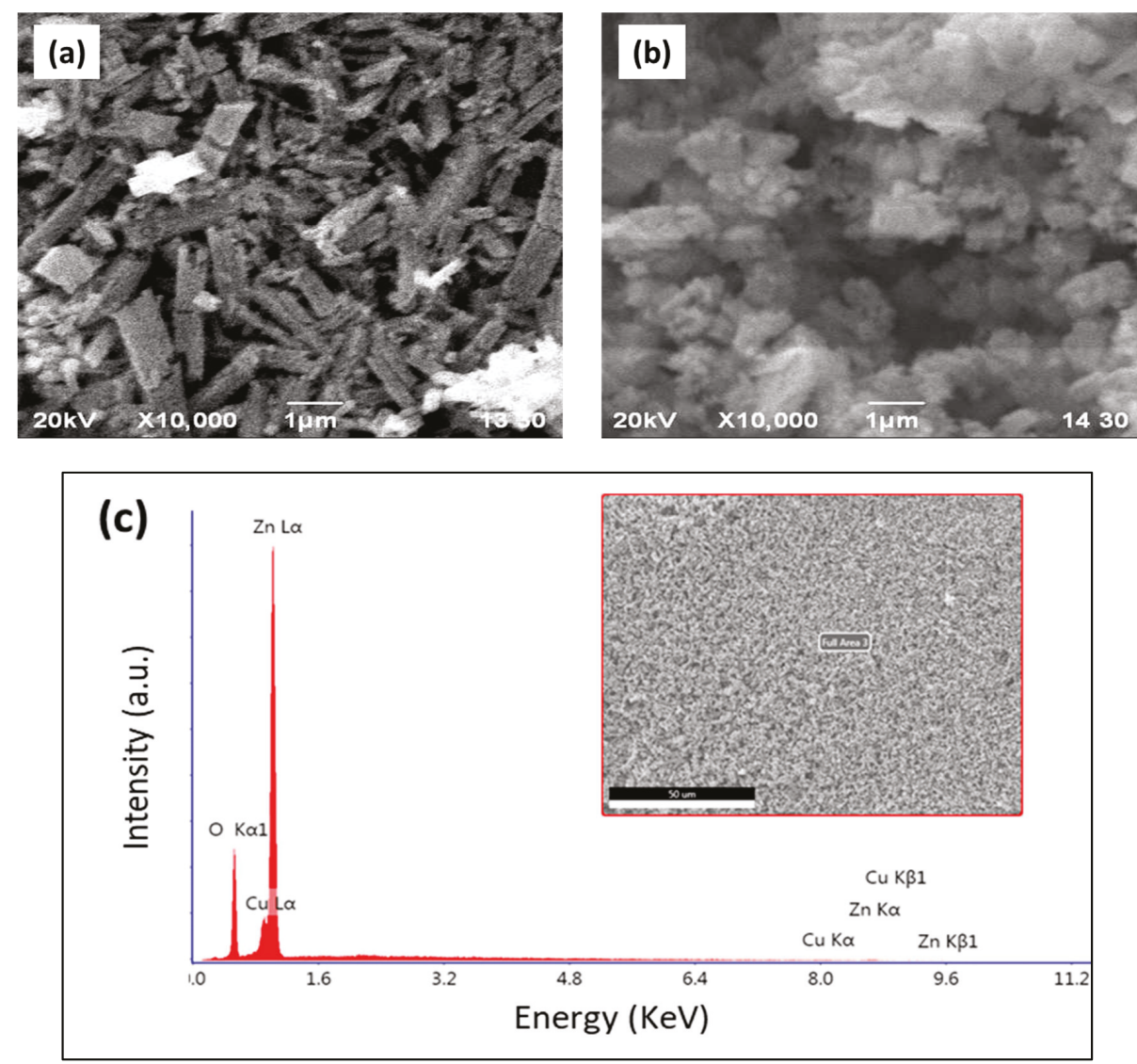

Figure 2. Scanning electron microscopy (SEM) images of (a) $\mathrm{ZnO}$ and (b) $\mathrm{CuO} / \mathrm{ZnO}$, and (c) energydispersive X-ray spectroscopy (EDX) pattern of $\mathrm{CuO} / \mathrm{ZnO}$.

\subsection{FTIR Spectral Study}

The FTIR spectra of $\mathrm{ZnO}$ and $\mathrm{CuO} / \mathrm{ZnO}$ nanocomposites are depicted in Figure 3. Generally, the absorption bands of metal oxides were below $1000 \mathrm{~cm}^{-1}$, due to inter-atomic vibrations. From Figure 3, it is seen that the absorption band of zinc oxide (stretching of $\mathrm{Zn}-\mathrm{O}$ ) was between $400 \mathrm{~cm}^{-1}$ and $590 \mathrm{~cm}^{-1}$, which confirmed the wurtzite structure of $\mathrm{ZnO}$ [32]. The vibration around $3385 \mathrm{~cm}^{-1}$ and $1637 \mathrm{~cm}^{-1}$ was attributed to asymmetric and symmetric stretching $\mathrm{H}-\mathrm{O}-\mathrm{H}$ vibration, which was due to chemisorbed water. The very weak peak at $2320 \mathrm{~cm}^{-1}$ corresponded to the symmetric $\mathrm{C}-\mathrm{H}$ bond vibrations, which may have been present due to the environmental conditions. Stretching modes of $\mathrm{C}-\mathrm{O}$ appeared at $1110 \mathrm{~cm}^{-1}$, because of the acetate group improper decomposition [33]. The bands of $3000-3650 \mathrm{~cm}^{-1}$ were attributed to reversible dissociative absorption of hydrogen on $\mathrm{Zn}$ and O [34]. 


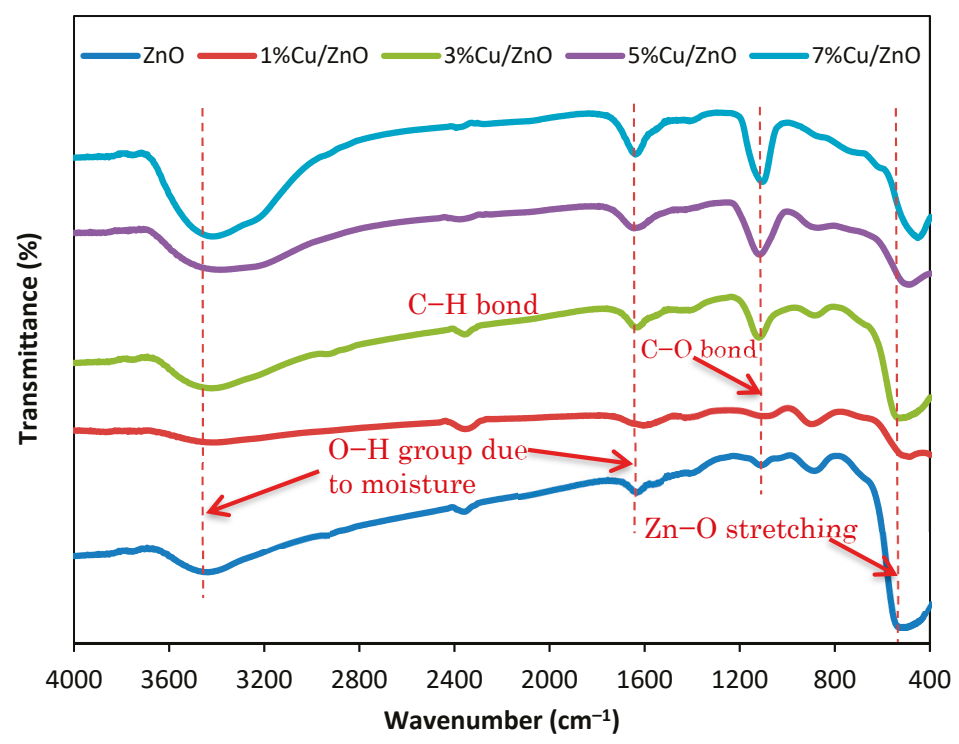

Figure 3. Fourier transform infrared (FTIR) spectra of $\mathrm{ZnO}$ and $\mathrm{CuO} / \mathrm{ZnO}$.

\subsection{UV-VIS Spectral Changes}

The absorption spectra of $\mathrm{MB}$ solution with $\mathrm{CuO} / \mathrm{ZnO}$ under sunlight irradiation are shown in Figure 4. During photolysis, pure MB was exposed $150 \mathrm{~min}$ under sunlight and it was seen that the change of the absorption spectrum was negligible. The absorption spectrum at $662 \mathrm{~nm}$ slightly decreased under dark after $150 \mathrm{~min}$ with $\mathrm{CuO} / \mathrm{ZnO}$, indicating the $\mathrm{MB}$ dye adsorption on the composite. The well-defined absorption band disappeared after $150 \mathrm{~min}$, which confirmed the MB degradation with $\mathrm{CuO} / \mathrm{ZnO}$ in the presence of sunlight.

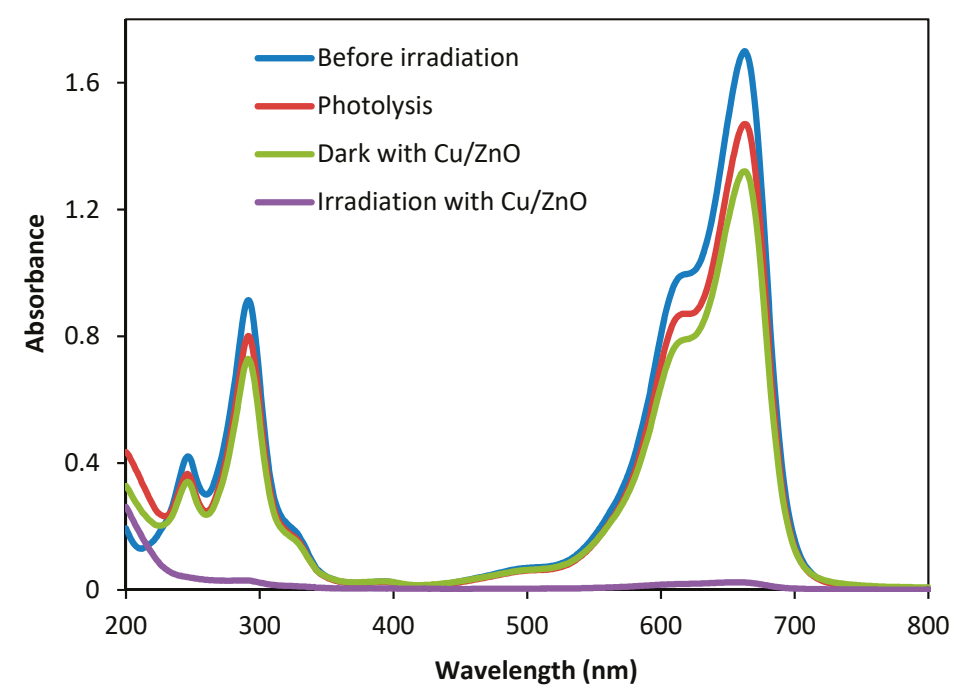

Figure 4. UV-visible spectral changes of methylene blue (MB) in water for before irradiation, photolysis, under dark, and sunlight irradiation. 


\subsection{Photocatalytic Dye Degradation}

$\mathrm{ZnO}$ and $\mathrm{CuO} / \mathrm{ZnO}$ were used in the presence of sunlight for the photodegradation of $\mathrm{MB}$ to evaluate the photocatalytic performance. The effect of the doping amounts of copper in the photodegradation of MB is depicted in Figure 5. The degradation rate increased with increasing copper amounts up to $5 \mathrm{wt} \%$ of the composite. More than $5 \mathrm{wt} \%$ of copper decreased the photocatalytic activity. This was because the $\mathrm{ZnO}$ surface was covered by the higher percentage of copper and reduced the sunlight absorption [35]. Due to efficient charge separation and higher electron transfer, 5 wt \% CuO/ZnO composite showed better photocatalytic activity for MB degradation.

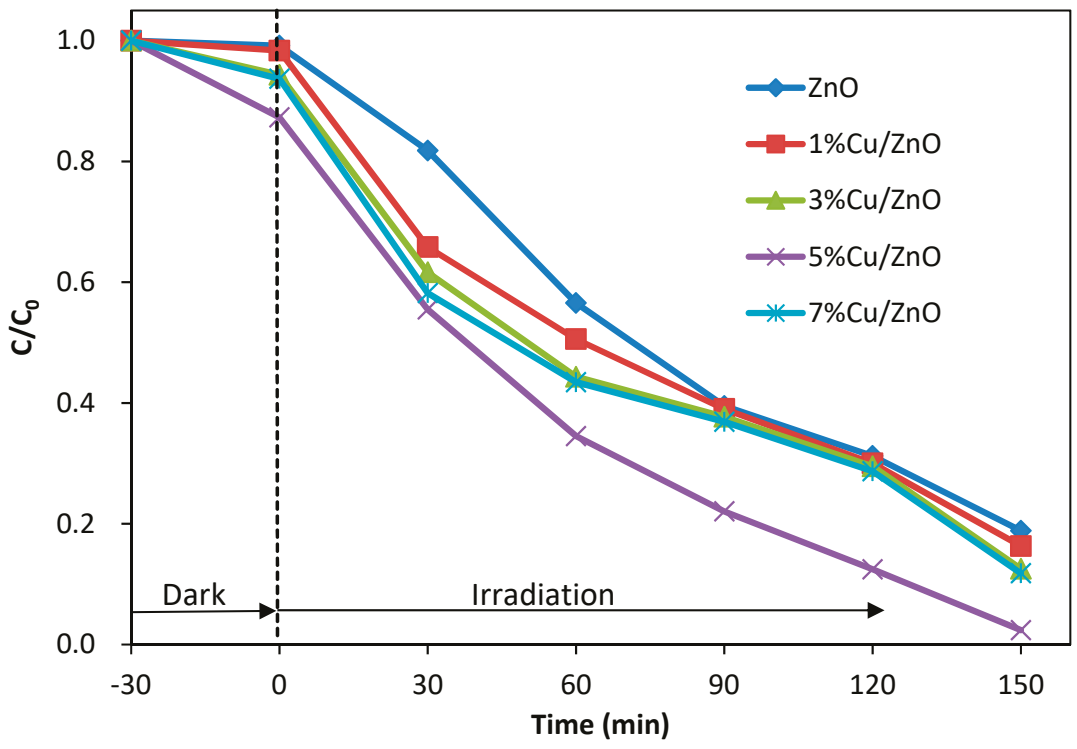

Figure 5. Photodegradation of $\mathrm{MB}$ by $\mathrm{ZnO}$ and $\mathrm{CuO} / \mathrm{ZnO}$ using sunlight.

\subsection{Effect of Initial Dye Concentration}

The photocatalytic degradation of dye depended on its initial concentration, and it was necessary to investigate the effect of dye concentrations in view of their practical application. The solar photocatalytic degradation with different initial $\mathrm{MB}$ dye concentrations in the presence of $\mathrm{CuO} / \mathrm{ZnO}$ was studied, as shown in Figure 6. It was observed that as initial MB dye concentrations increased from $5 \mathrm{mg} / \mathrm{L}$ to $20 \mathrm{mg} / \mathrm{L}$, the dye degradation efficiency gradually decreased [36,37]. In this study, methylene blue of $10 \mathrm{mg} / \mathrm{L}$ solution was selected to evaluate the photodegradation of dye under sunlight, because of the high concentration of real wastewater. 


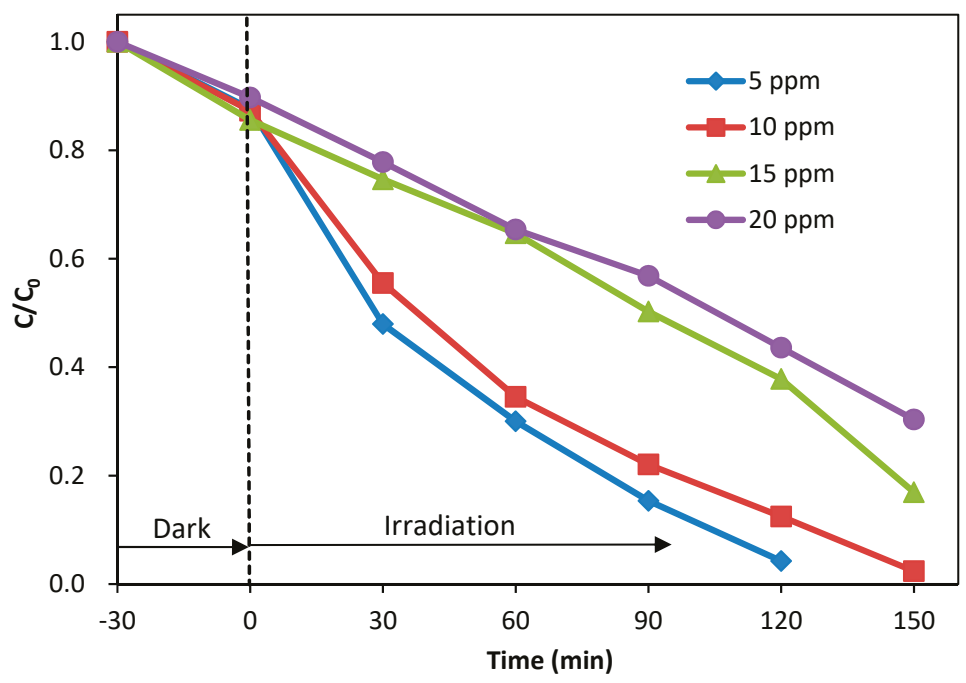

Figure 6. Effect of initial dye concentration on the photodegradation of $\mathrm{MB}$ with $\mathrm{CuO} / \mathrm{ZnO}$.

\subsection{Role of Reactive Species}

The scavengers of $d i$-ammonium oxalate monohydrate (AO), 2-propanol, and ascorbic acid (AA) were used to identify the reactive species for MB photodegradation. The three scavengers' effect on the $\mathrm{MB}$ photodegradation with $\mathrm{CuO} / \mathrm{ZnO}$ is displayed in Figure 7. From the results (Figure 7), it was observed that with the addition of 2-propanol, $\mathrm{AO}$, and $\mathrm{AA}$ as a scavenger, photocatalytic degradation dropped from $66 \%$ (without scavenger) to $23 \%\left({ }^{\circ} \mathrm{O}_{2}{ }^{-}\right), 13 \%\left({ }^{\bullet} \mathrm{OH}\right)$, and $53 \%\left(\mathrm{~h}^{+}\right)$for $1 \mathrm{~h}$, while the photocatalytic activity significantly decreased from $88 \%$ (without scavenger) to $29 \%\left({ }^{\bullet} \mathrm{O}_{2}{ }^{-}\right), 37 \%\left({ }^{\bullet} \mathrm{OH}\right.$ ), and $79 \%\left(\mathrm{~h}^{+}\right)$for $2 \mathrm{~h}$ irradiation, respectively. It can be surmised that the important roles played for the photodegradation of $\mathrm{MB}$ were by ${ }^{\bullet} \mathrm{O}_{2}{ }^{-}$and ${ }^{\bullet} \mathrm{OH}$ radicals, while a minor role was played by the $\mathrm{h}^{+}$ radical in the degradation process under sunlight [38].

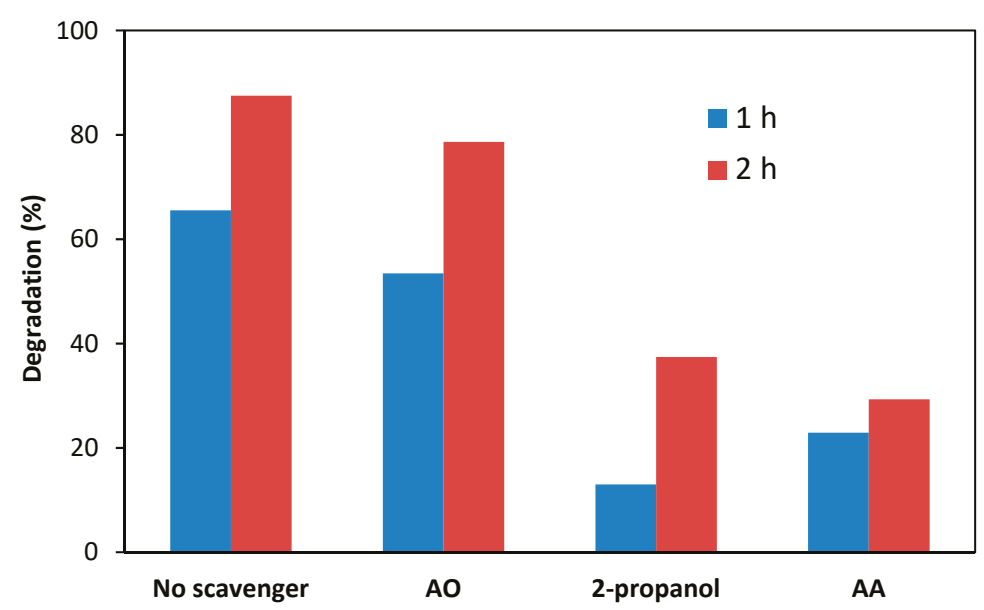

Figure 7. Effects of scavengers on the photodegradation of $\mathrm{MB}$ with $\mathrm{CuO} / \mathrm{ZnO}$ using sunlight. 


\subsection{Degradation Mechanism}

The schematic diagram (Figure 8) shows the photodegradation mechanism of MB with $\mathrm{CuO} / \mathrm{ZnO}$ nanocomposite. $\mathrm{CuO}$ and $\mathrm{ZnO}$ formed a heterojunction, which assisted the separation of photogenerated carriers [39]. The conduction band (CB) potentials were $-0.43 \mathrm{eV}$ for $\mathrm{CuO}$ and $-0.15 \mathrm{eV}$ for $\mathrm{ZnO}$ vs Normal Hydrogen Electrode (NHE) [40]. The band gaps of $\mathrm{CuO}$ and $\mathrm{ZnO}$ were 1.4 and $3.23 \mathrm{eV}$, respectively [41,42]. During sunlight irradiation, $\mathrm{CuO}$ and $\mathrm{ZnO}$ were excited to generate electrons and holes at the $\mathrm{CB}$ and the valence band (VB), respectively, as displayed in Figure 8 , since the band positions of $\mathrm{ZnO}$ were below the $\mathrm{CB}$ and $\mathrm{VB}$ of $\mathrm{CuO}$. The photoexcited electrons transferred from $\mathrm{CuO}$ to $\mathrm{ZnO}$, whereas the holes migrated from $\mathrm{ZnO}$ to $\mathrm{CuO}$. [43]. Then, oxygen molecules in dye solution reacted with electrons to generate superoxide radical $\left({ }^{\bullet} \mathrm{O}_{2}{ }^{-}\right)$and the holes combined with $\mathrm{H}_{2} \mathrm{O}$ to produce hydroxyl radical $\left({ }^{\bullet} \mathrm{OH}\right)$. Moreover, $\mathrm{MB}$ was directly oxidized by the holes at the $\mathrm{VB}$ of $\mathrm{CuO}[44,45]$. The strong oxidant radicals of ${ }^{\bullet} \mathrm{OH}$ and ${ }^{\bullet} \mathrm{O}_{2}{ }^{-}$readily oxidized the MB molecule. We proposed the following possible degradation mechanism of $\mathrm{MB}$ with $\mathrm{CuO} / \mathrm{ZnO}$ in the presence of sunlight.

$$
\begin{gathered}
\mathrm{ZnO}+h v \rightarrow \mathrm{ZnO}\left(\mathrm{e}_{\mathrm{CB}}{ }^{-}+\mathrm{h}_{\mathrm{VB}}{ }^{+}\right) \\
\mathrm{e}^{-}(\mathrm{CB})+\mathrm{O}_{2} \rightarrow{ }^{\bullet} \mathrm{O}_{2}{ }^{-} \\
\mathrm{h}^{+}(\mathrm{VB})+\mathrm{OH}^{-} \rightarrow{ }^{\bullet} \mathrm{OH} \\
\mathrm{O}_{2}{ }^{-}+\mathrm{MB} \rightarrow \text { degraded products } \\
\bullet \mathrm{OH}+\mathrm{MB} \rightarrow \text { degraded products } \\
\mathrm{h}^{+}(\mathrm{VB})+\mathrm{MB} \rightarrow \text { degraded products }
\end{gathered}
$$

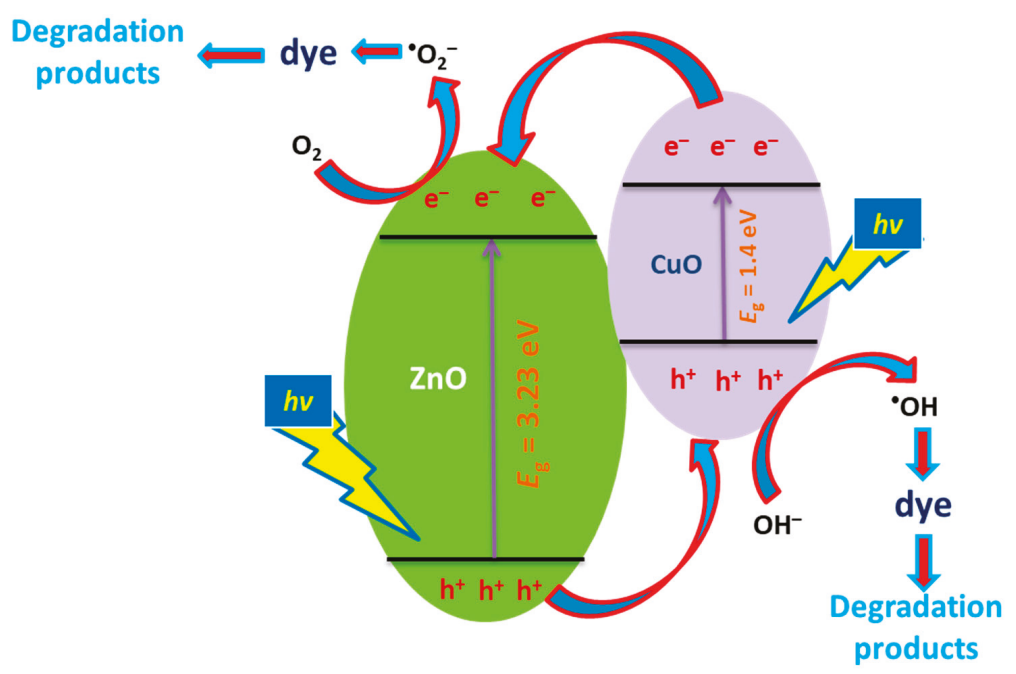

Figure 8. The possible degradation mechanism of $\mathrm{CuO} / \mathrm{ZnO}$ photocatalyst using sunlight.

\subsection{Mineralization of Dye}

The evaluation of mineralization of MB was investigated by measuring the total organic carbon (TOC). The TOC removal is presented in Figure 9a, showing the degradation of MB under sunlight irradiation. The TOC rapidly decreased with increased solar irradiation time up to $2 \mathrm{~h}$. After $7 \mathrm{~h}$ irradiation using $\mathrm{CuO} / \mathrm{ZnO}$, the mineralization of $\mathrm{MB}$ was observed at about $91 \%$ of $\mathrm{TOC}$ reduction. The chemical oxygen demand (COD) was an effective method, widely used for the measurement of 
photodegradation of organic dye [46]. The test was used to measure the total amount of oxygen needed for the oxidation of dye to produce carbon dioxide and water [47]. The COD value of MB of aqueous solution using $\mathrm{CuO} / \mathrm{ZnO}$ is described in Figure 9b. With increased solar irradiation time, COD values sharply decreased up to $3 \mathrm{~h}$, and COD reduction was about $84 \%$ after $7 \mathrm{~h}$. The reduction of COD and TOC values after the solar irradiation of MB indicated that methylene blue molecule was mineralized.
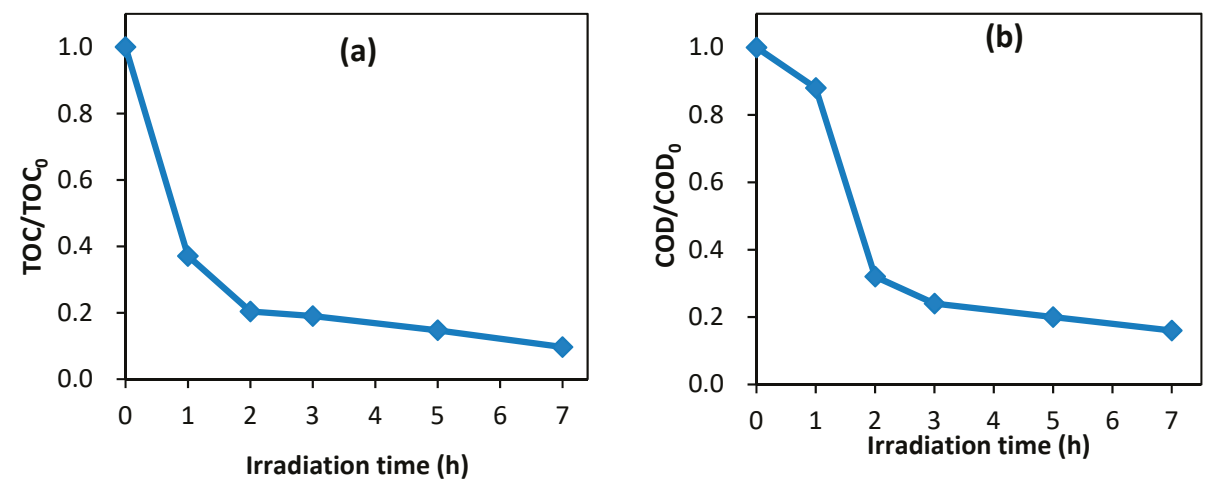

Figure 9. Mineralization of $\mathrm{MB}$ during the photodegradation with $\mathrm{CuO} / \mathrm{ZnO}$ using sunlight. (a) total organic carbon (TOC) and (b) chemical oxygen demand (COD).

\section{Conclusions}

The low-cost mechanochemical combustion method was used to synthesize $\mathrm{CuO} / \mathrm{ZnO}$ nanocomposites with various $\mathrm{Cu}$ contents. The best photodegradation efficiency was obtained with 5 wt $\% \mathrm{CuO} / \mathrm{ZnO}$. The values of $\mathrm{MB}$ degrading with un-doped $\mathrm{ZnO}$ and $\mathrm{CuO} / \mathrm{ZnO}$ were measured to be $81 \%$ and $98 \%$ respectively, after $2 \mathrm{~h}$ of solar irradiation. $\mathrm{MB}$ photodegradation with $\mathrm{CuO} / \mathrm{ZnO}$ under sunlight occurred mainly with ${ }^{\bullet} \mathrm{O}_{2}{ }^{-}$and ${ }^{\bullet} \mathrm{OH}$ radicals, while the $\mathrm{h}^{+}$radical showed a minor role in the process. The decrease of TOC values of $\mathrm{MB}$ indicated the mineralization in the photocatalytic process. Therefore, sunlight photodegradation technology may be a more effective technique for textile wastewater treatment than photodegradation with artificial and expensive $\mathrm{Hg}$-Xe lamp.

Author Contributions: M.A.I.M. conceived and designed the experiments and wrote the paper. A.A.M.S. performed the experiments. S.M.M., J.H., and R.I. analyzed the results.

Funding: This research was funded by the University Grants Commission of Bangladesh, grant number 6(76)UGC/S\&T/Chemistry-02/2018/3577.

Acknowledgments: The authors are grateful to the Centre for Advanced Research in Sciences (CARS), University of Dhaka, Bangladesh for providing partial analytical support.

Conflicts of Interest: The authors declare no conflict of interest.

\section{References}

1. Mu, J.; Shao, C.; Guo, Z.; Zhang, Z.; Zhang, M.; Zhang, P.; Chen, B.; Liu, Y.C. High photocatalytic activity of $\mathrm{ZnO}-$ carbon nanofiber heteroarchitectures. ACS Appl. Mater. Interfaces 2011, 3, 590-596. [CrossRef] [PubMed]

2. Molla, M.A.I. Development of Advanced Technology for Photocatalytic Degradation of Organic Pollutants in Wastewater. Ph.D. Thesis, Mie University, Tsu, Japan, 2018.

3. Zangeneh, H.; Zinatizadeh, A.A.L.; Habibi, M.; Akia, M.; Isa, M.H. Photocatalytic oxidation of organic dyes and pollutants in wastewater using different modified titanium dioxides: A comparative review. J. Ind. Eng. Chem. 2015, 26, 1-36. [CrossRef]

4. Yulizar, Y.; Bakri, R.; Apriandanu, D.O.B.; Hidayat, T. ZnO/CuO nanocomposite prepared in one-pot green synthesis using seed bark extract of Theobroma cacao. Nano Struct. Nano Objects 2018, 16, 300-305. [CrossRef] 
5. Vidic, J.; Stankic, S.; Haque, F.; Ciric, D.; Le Goffic, R.; Vidy, A.; Jupille, J.; Delmas, B. Selective antibacterial effects of mixed ZnMgO nanoparticles. J. Nanopart. Res. 2013, 15, 1595-1605. [CrossRef] [PubMed]

6. Lu, P.; Zhou, W.; Li, Y.; Wang, J.; Wu, P. Abnormal room temperature ferromagnetism in $\mathrm{CuO} / \mathrm{ZnO}$ nanocomposites via hydrothermal method. Appl. Surf. Sci. 2017, 399, 396-402. [CrossRef]

7. Dorneanu, P.P.; Airinei, A.; Olaru, N.; Homocianu, M.; Nica, V.; Doroftei, F. Preparation and characterization of $\mathrm{NiO}, \mathrm{ZnO}$ and $\mathrm{NiO}-\mathrm{ZnO}$ composite nanofibers by electrospinning method. Mater. Chem. Phys. 2014, 148, 1029-1035. [CrossRef]

8. Hassanpour, M.; Hojaghan, H.S.; Niasari, M.S. Degradation of methylene blue and Rhodamine B as water pollutants via green synthesized $\mathrm{Co}_{3} \mathrm{O}_{4} / \mathrm{ZnO}$ nanocomposite. J. Mol. Liq. 2017, 229, 293-299. [CrossRef]

9. Hassanpour, M.; Salavati-Niasari, M.; Mousavi, S.A.; Safardoust-Hojaghan, H.; Hamadanian, M. CeO $2 / Z n O$ Ceramic nanocomposites, synthesized via microwave method and used for decolorization of dye. J. Nanostruct. 2018, 8, 97-106.

10. Saravanan, R.; Karthikeyan, S.; Gupta, V.K.; Sekaran, G.; Narayanan, V.; Stephen, A. Enhanced photocatalytic activity of $\mathrm{ZnO} / \mathrm{CuO}$ nanocomposite for the degradation of textile dye on visible light illumination. Mater. Sci. Eng. C 2013, 33, 91-98. [CrossRef]

11. Saravanan, R.; Gupta, V.K.; Mosquera, E.; Gracia, F. Preparation and characterization of $\mathrm{V}_{2} \mathrm{O}_{5} / \mathrm{ZnO}$ nanocomposite system for photocatalytic application. J. Mol. Liq. 2014, 198, 409-412. [CrossRef]

12. Saravanan, R.; Gupta, V.K.; Narayanan, V.; Stephen, A. Visible light degradation of textile effluent using novel catalyst $\mathrm{ZnO} / \gamma-\mathrm{Mn}_{2} \mathrm{O}_{3}$. J. Taiwan Inst. Chem. Eng. 2014, 45, 1910-1917. [CrossRef]

13. Li, B.; Wang, Y. Facile synthesis and photocatalytic activity of $\mathrm{ZnO}-\mathrm{CuO}$ nanocomposite. Superlattice Microst. 2010, 47, 615-623. [CrossRef]

14. Kuriakose, S.; Avasthi, D.K.; Mohapatra, S. Effects of swift heavy ion irradiation on structural, optical and photocatalytic properties of $\mathrm{ZnO}-\mathrm{CuO}$ nanocomposites prepared by carbothermal evaporation method. Beilstein J. Nanotechnol. 2015, 6, 928-937. [CrossRef]

15. Wang, A.; Chen, Z.; Zheng, Z.; Xu, H.; Wang, H.; Hu, K.; Yan, K. Remarkably enhanced sulfate radical-based photo-Fenton-like degradation of levofloxacin using the reduced mesoporous MnO@MnOx microspheres. Chem. Eng. J. 2019, 379, 122340. [CrossRef]

16. Gnanasekaran, L.; Hemamalini, R.; Saravanan, R.; Qin, J.; Yola, M.L.; Atar, N.; Gracia, F. Nanosized $\mathrm{Fe}_{3} \mathrm{O}_{4}$ incorporated on a $\mathrm{TiO}_{2}$ surface for the enhanced photocatalytic degradation of organic pollutants. J. Mol. Liq. 2019, 287, 110967. [CrossRef]

17. Saravanan, R.; Agarwal, S.; Gupta, V.K.; Khan, M.M.; Gracia, F.; Mosquera, E.; Narayanan, V.; Stephen, A. Line defect $\mathrm{Ce}^{3+}$ induced $\mathrm{Ag} / \mathrm{CeO}_{2} / \mathrm{ZnO}$ nanostructure for visible-light photocatalytic activity. J. Photochem. Photobiol. A Chem. 2018, 353, 499-506. [CrossRef]

18. Jebaranjitham, J.N.; Mageshwari, C.; Saravanan, R.; Mu, N. Fabrication of amine functionalized graphene oxide-AgNPs nanocomposite with improved dispersibility for reduction of 4-nitrophenol. Compos. Part B 2019, 171, 302-309. [CrossRef]

19. Qin, J.; Yang, C.; Cao, M.; Zhang, X.; Saravanan, R.; Limpanart, S.; Ma, M.; Liu, R. Two dimensional porous sheet-like carbon-doped $\mathrm{ZnO} / \mathrm{g}-\mathrm{C}_{3} \mathrm{~N}_{4}$ nanocomposite with high visible-light photocatalytic performance. Mater. Lett. 2017, 189, 156-159. [CrossRef]

20. Saravanan, R.; Khan, M.M.; Gracia, F.; Qin, J.; Gupta, V.K.; Arumainathan, S. Ce ${ }^{3+}$-ion-induced visible-light photocatalytic degradation and electrochemical activity of $\mathrm{ZnO} / \mathrm{CeO}_{2}$ nanocomposite. Sci. Rep. 2016, 6, 31641. [CrossRef]

21. Yang, C.; Xue, Z.; Qin, J.; Sawangphruk, M.; Saravanan, R.; Zhang, X.; Liu, R. Visible-light Driven Photocatalytic $\mathrm{H}_{2}$ Generation and Mechanism Insights on $\mathrm{Bi}_{2} \mathrm{O}_{2} \mathrm{CO}_{3} / \mathrm{G}-\mathrm{C}_{3} \mathrm{~N}_{4}$ Z-scheme Photocatalyst. Phys. Chem. C 2019, 123, 4795-4804. [CrossRef]

22. Kanade, K.G.; Kale, B.B.; Baeg, J.O.; Lee, S.M.; Lee, C.W.; Moon, S.J.; Chang, H. Self-assembled aligned $\mathrm{Cu}$ doped $\mathrm{ZnO}$ nanoparticles for photocatalytic hydrogen production under visible light irradiation. Mater. Chem. Phys. 2007, 102, 98-104. [CrossRef]

23. Rooydell, R.; Brahma, S.; Wang, R.C.; Modaberi, M.R.; Ebrahimzadeh, F.; Liu, C.P. Cu doped ZnO nanorods with controllable $\mathrm{Cu}$ content by using single metal organicprecursors and their photocatalytic and luminescence properties. J. Alloys Compd. 2017, 691, 936-945. [CrossRef]

24. Hsieh, S.-H.; Ting, J.-M. Characterization and photocatalytic performance of ternary Cu-doped ZnO/Graphene materials. Appl. Surf. Sci. 2018, 427, 465-475. [CrossRef] 
25. Phiwdang, K.; Suphankij, S.; Mekprasart, W.; Pecharapa, W. Synthesis of CuO nanoparticles by precipitation method using different precursors. Energy Procedia 2013, 34, 740-745. [CrossRef]

26. Jun, S.T.; Choi, G.M. Composition dependence of the electrical conductivity of $\mathrm{ZnO}(\mathrm{n})-\mathrm{CuO}(\mathrm{p})$ ceramic composite. J. Am. Ceram. Soc. 1998, 81, 695-699. [CrossRef]

27. Zhang, D. Synthesis and characterization of ZnO-doped cupric oxides and evaluation of their photocatalytic performance under visible light. Transit. Met. Chem. 2010, 35, 689-694. [CrossRef]

28. Molla, M.A.I.; Furukawa, M.; Tateishi, I.; Katsumata, H.; Kaneco, S. Studies of effects of calcination temperature on the crystallinity and optical properties of Ag-doped ZnO nanocomposites. J. Compos. Sci. 2019, 3, 18. [CrossRef]

29. Benavente, E.; Duran, F.; Sotomayor-Torres, C.; Gonzalez, G. Heterostructured layered hybrid ZnO/MoS 2 nanosheets with enhanced visible light photocatalytic activity. J. Phys. Chem. Solids 2018, 113, 119-124. [CrossRef]

30. Su, J.; Zhu, L.; Geng, P.; Chen, G. Self-assembly graphitic carbon nitride quantum dots anchored on $\mathrm{TiO}_{2}$ nanotube arrays: An efficient heterojunction for pollutants degradation under solar light. J. Hazard. Mater. 2016, 316, 159-168. [CrossRef] [PubMed]

31. Lamba, R.; Umar, A.; Mehta, S.K.; Kansal, S.K. $\mathrm{Sb}_{2} \mathrm{O}_{3}-\mathrm{ZnO}$ nanospindles: A potential material for photocatalytic and sensing applications. Ceram. Int. 2015, 41, 5429-5438. [CrossRef]

32. Khana, S.A.; Noreen, F.; Kanwal, S.; Iqbal, A.; Hussain, G. Green synthesis of ZnO and Cu-doped ZnO nanoparticles from leaf extracts of Abutilon indicum, Clerodendrum infortunatum, Clerodendrum inerme and investigation of their biological and photocatalytic activities. Mater. Sci. Eng. C 2018, 82, 46-59. [CrossRef] [PubMed]

33. Saravanakkumar, D.; Sivaranjani, S.; Kaviyarasu, K.; Ayeshamariam, A.; Ravikumar, B.; Pandiarajan, S.; Veeralakshmi, C.; Jayachandran, M.; Maaza, M. Synthesis and characterization of ZnO-CuO nanocomposites powder by modified perfume spray pyrolysis method and its antimicrobial investigation. J. Semicond. 2018, 39, 033001. [CrossRef]

34. Ma, G.; Liang, X.; Li, L.; Qiao, R.; Jiang, D.; Ding, Y.; Chen, H. Cu-doped zinc oxide and its polythiophene composites: Preparation and antibacterial properties. Chemosphere 2014, 100, 146-151. [CrossRef] [PubMed]

35. Molla, M.A.I.; Furukawa, M.; Tateishi, I.; Katsumata, H.; Kaneco, S. Fabrication of Ag-doped ZnO by mechanochemical combustion method and their application into photocatalytic Famotidine degradation. J. Environ. Sci. Health Part A 2019, 54, 914-923. [CrossRef] [PubMed]

36. Kaneco, S.; Li, N.; Itoh, K.-K.; Katsumata, H.; Suzuki, T.; Ohta, K. Titanium dioxide mediated solar photocatalytic degradation of thiram in aqueous solution: Kinetics and mineralization. Chem. Eng. J. 2009, 148, 50-56. [CrossRef]

37. Molla, M.A.I.; Ahsan, S.; Tateishi, I.; Furukawa, M.; Katsumata, H.; Suzuki, T.; Kaneco, S. Degradation, Kinetics, and Mineralization in the solar photocatalytic treatment of aqueous amitrole solution with titanium dioxide. Environ. Eng. Sci. 2018, 35, 401-407. [CrossRef]

38. Wang, A.; Wang, H.; Deng, H.; Wang, S.; Shi, W.; Yi, Z.; Qiu, R.; Yan, K. Controllable synthesis of mesoporous manganese oxide microsphere efficient for photo-Fenton-like removal of fluoroquinolone antibiotics. Appl. Catal. B Environ. 2019, 248, 298-308. [CrossRef]

39. Chabri, S.; Dhara, A.; Show, B.; Adak, D.; Sinha, A.; Mukherjee, N. Mesoporous CuO-ZnO p-n heterojunction based nanocomposites with high specific surface area for enhanced photocatalysis and electrochemical sensing. Catal. Sci. Technol. 2016, 6, 3238-3252. [CrossRef]

40. Yang, L.; Xie, C.S.; Zhang, G.Z.; Zhao, J.W.; Yu, X.L.; Zeng, D.W.; Zhang, S.P. Enhanced response to $\mathrm{NO}_{2}$ with $\mathrm{CuO} / \mathrm{ZnO}$ laminated heterostructured configuration. Sens. Actuator B 2014, 195, 500-508. [CrossRef]

41. Alsabahi, J.; Bora, T.; Alabri, M.; Dutta, J. Efficient visible light photocatalysis of benzene, toluene, ethylbenzene and xylene (BTEX) in aqueous solutions using supported zinc oxide nanorods. PLoS ONE 2017, 12, e0189276.

42. Hansen, B.J.; Kouklin, N.; Lu, G.H.; Lin, I.; Chen, J.H.; Zhang, X. Transport, analyte detection, and opto-electronic response of p-Type CuO nanowires. J. Phys. Chem. C 2010, 114, 2440-2447. [CrossRef]

43. Zhang, J.N.; Chen, T.H.; Yu, J.H.; Liu, C.; Yang, Z.B.; Lu, H.B.; Yin, F.; Gao, J.Z.; Liu, Q.R.; Zhang, X.W.; et al. Enhanced photocatalytic activity of flowerlike $\mathrm{CuO}-\mathrm{ZnO}$ nanocomposites synthesized by one-step hydrothermal method. J. Mater. Sci. 2016, 27, 10667-10672. [CrossRef] 
44. Harish, S.; Archana, J.; Sabarinathan, M.; Navaneethan, M.; Nisha, K.D.; Ponnusamy, S.; Muthamizhchelvan, C.; Ikeda, H.; Aswal, D.K.; Hayakawa, Y. Controlled structural and compositional characteristic of visible light active $\mathrm{ZnO} / \mathrm{CuO}$ photocatalyst for the degradation of organic pollutant. Appl. Surf. Sci. 2017, 418, 103-112. [CrossRef]

45. Wu, F.S.; Wang, X.H.; Hu, S.Z.; Hao, C.; Gao, H.W.; Zhou, S.S. Solid-state preparation of CuO/ZnO nanocomposites for functional supercapacitor electrodes and photocatalysts with enhanced photocatalytic properties. Int. J. Hydrogen Energy 2017, 42, 30098-30108. [CrossRef]

46. Li, J.; Chen, C.; Zhao, J.; Zhu, H.; Orthman, J. Photodegradation of dye pollutants on $\mathrm{TiO}_{2}$ nanoparticles dispersed in silicat;e UV-Vis irradiation. Appl. Catal. B Environ. 2002, 37, 331-338. [CrossRef]

47. Jain, R.; Shirkarwar, S. Removal of hazardous dye Congo-red removal from waste material. J. Hazard. Mater. 2008, 152, 942-948. [CrossRef]

(C) 2019 by the authors. Licensee MDPI, Basel, Switzerland. This article is an open access article distributed under the terms and conditions of the Creative Commons Attribution (CC BY) license (http://creativecommons.org/licenses/by/4.0/). 

MDPI

St. Alban-Anlage 66

4052 Basel

Switzerland

Tel. +41616837734

Fax +41 613028918

www.mdpi.com

Journal of Composites Science Editorial Office

E-mail: jcs@mdpi.com

www.mdpi.com/journal/jcs

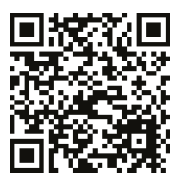



MDPI

St. Alban-Anlage 66

4052 Basel

Switzerland

Tel: +41 616837734

Fax: +41 613028918

www.mdpi.com 